\title{
Technology Evaluations Related to Mercury, Technetium, and Chloride in Treatment of Wastes at the Idaho Nuclear Technology and Engineering Center of the Idaho National Engineering and Environmental Laboratory
}

\author{
C. M. Barnes \\ D. D. Taylor \\ S. C. Ashworth \\ J. B. Bosley \\ D. R. Haefner
}

Published October 1999
Idaho National Engineering and Environmental Laboratory High-Level Waste Program
Idaho Falls, Idaho 83415




\section{DISCLAIMER}

This report was prepared as an account of work sponsored by an agency of the United States Government. Neither the United States Government nor any agency thereof, nor any of their employees, make any warranty, express or implied, or assumes any legal liability or responsibility for the accuracy, completeness, or usefulness of any information, apparatus, product, or process disclosed, or represents that its use would not infringe privately owned rights. Reference herein to any specific commercial product, process, or service by trade name, trademark, manufacturer, or otherwise does not necessarily constitute or imply its endorsement, recommendation, or favoring by the United States Government or any agency thereof. The views and opinions of authors expressed herein do not necessarily state or reflect those of the United States Government or any agency thereof. 


\section{DISCLAIMER}

Portions of this document may be illegible in electronic image products. Images are produced from the best available original document. 


\title{
AECEIVED \\ NOV 012080 \\ OSTI
}

\begin{abstract}
The Idaho High-Level Waste and Facility Disposition Environmental Impact Statement defines alternatives for treating and disposing of wastes'stored at the Idaho Nuclear Technology and Engineering Center. Development is required for several technologies under consideration for treatment of these wastes. This report contains evaluations of whether specific treatment is needed and if so, by what methods, to remove mercury, technetium, and chlorides in proposed Environmental Impact Statement treatment processes. The evaluations of mercury include a review of regulatory requirements that would apply to. mercury wastes in separations processes, an evaluation of the sensitivity of mercury flowrates and concentrations to changes in separations processing schemes and conditions, test results from laboratory-scale experiments of precipitation of mercury by sulfide precipitation agents from the TRUEX carbonate wash effluent, and evaluations of methods to remove mercury from New Waste Calcining Facility liquid and gaseous streams. The evaluation of technetium relates to the need for technetjum removal and alternative methods to remove technetium from streams in separations processes. The need for removal of chlorides from New Waste Calcining Facility scrub solution is also evaluated.
\end{abstract}




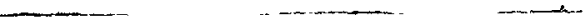$$
\therefore .3^{3}
$$ 


\section{SUMMARY}

\section{Mercury Removal in Separations Options}

Mercury removal will be required in the Full Separations for processing high-mercury calcine feeds, either alumina calcine or alumina calcine blends. Mercury removal from offgas will be required to meet the Maximum Achievable Control Technology (MACT) emission limit for mercury. Mercury removal will also be required from a low activity waste (LAW) effluent. Mercury removal is recommended for these high-mercury feed cases from the Transuranic Radionuclide Solvent Extraction Process (TRUEX) carbonate wash effluent by sulfide precipitation. Based on laboratory-scale tests, precipitation by calcium sulfide removes $>99.9 \%$ of the mercury in the wash effluent, produces a precipitate that could easily be separated, does not precipitate technetium that would contaminate the resulting mercury waste, and produces a waste that will meet the Toxicity Characteristic Leaching Procedure (TCLP) mercury concentration limit.

Development activities are recommended to demonstrate sulfide precipitation from the TRUEX carbonate wash in larger equipment, obtain TRUEX and Strontium Extraction Process (SREX) distribution coefficient data for calcine containing the highest mercury concentration, determine the effect of mercury concentration on the SREX solvent performance, and demonstrate removal of mercury from expected offgases to within the MACT emission limit.

\section{Mercury Removal from NWCF Streams}

Modifications are required to the New Waste Calcining Facility (NWCF) to.meet MACT emission limits, including the emission limit for mercury. Removal of mercury by electrochemical reduction is the preferred technology, and could be applied to the NWCF feed or the offgas scrub solution. Other technologies were identified that initially looked promising, including precipitation with trimercaptotriazine (TMT), photocatalysis with $\mathrm{TiO}_{2}$, and displacement of $\mathrm{Hg}^{+2}$ by copper or aluminum. However, small-scale tests of each of these methods showed that they were ineffective or posed serious safety issues. Galvanic reduction using zinc or the proprietary $\mathrm{KDF} 55$ as a sacrificial anode may also be feasible, and testing this method is recommended. Testing is also recommended to characterize the oxidation of mercury in offgas by $\mathrm{NO}_{2}$ and to determine the scrubbing efficiency of silica gel for $\mathrm{Hg}$ that has been oxidized with $\mathrm{NO}_{2}$. Data from these proposed tests, along with the recently obtained qualified gaseous emission data from NWCF, could then be used to design and evaluate NWCF modifications to meet MACT emission limits.

\section{Technetium Removal in Separations Options}

Technetium removal will not be required when processing SodiumBearing Waste (SBW), but will be required when processing alumina calcine or calcine blends, because of the relatively high concentration of technetium in alumina calcine. Numerous technologies have been developed at other sites for technetium removal. Possible schemes to remove technetium in a Separations 
Process include separate stripping of technetium from the TRUEX or SREX solvent, removal from the TRUEX carbonate wash, removal from calcine dissolver vapor, and removal from LAW concentrate or LAW offgas scrub solution. Data from FY-99 TRUEX and SREX tests, as well as additional extraction tests for calcine feeds, are needed to better determine the streams from which to remove technetium. Following this determination, testing is recommended to demonstrate feasibility of technetium removal schemes.

\section{Chloride Buildup in the NWCF Scrub Solution}

Chlorides volatilized as $\mathrm{HCl}$ in the calciner or carried over into the calciner offgas as salt particles are in part scrubbed out of the offgas into the scrub solution. The potential for unacceptable buildup of chlorides in NWCF scrub solution and offgas was evaluated using: (1) data from FY-98 runs in the 10-cm and 15-cm calciners, (2) data from the NWCF H-4 campaign, (3) a spreadsheet material balance model, and (4) results from ASPEN PLUS simulations of the NWCF scrub and offgas treatment system. Based on these data, it is expected that scrub solution chloride concentrations can be maintained below a concentration of $5,000 \mathrm{mg} / \mathrm{L}$ when processing SBW in the NWCF for either the baseline $\left(500^{\circ} \mathrm{C}\right)$ or high temperature $\left(600^{\circ} \mathrm{C}\right)$ flowsheet; minimal recycle of scrub solution to the tank farm will be required during processing of SBW in the NWCF due to chloride buildup; and chloride emissions will be below the MACT limit during processing of SBW in the NWCF. 


\section{CONTENTS}

ABSTRACT.

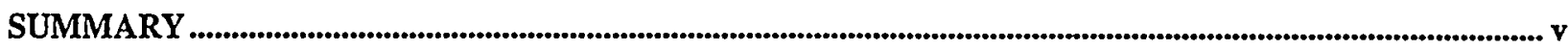

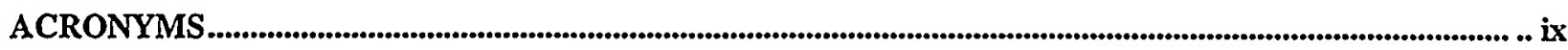

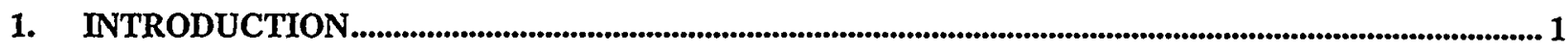

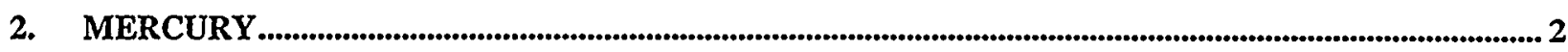

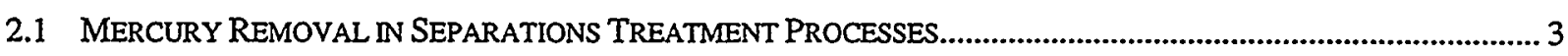

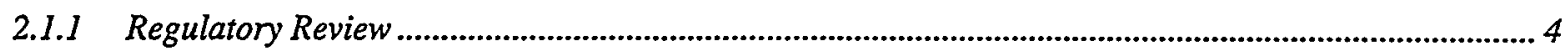

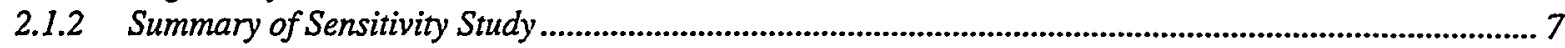

2.1.3 Summary of Sulfide Precipitation Study for Removal of Mercury from TRUEX Carbonate Wash

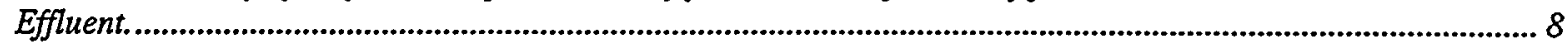

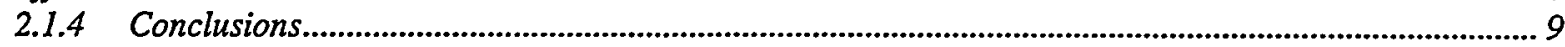

2.2 EVALUATION OF TECHNOLOGIES FOR REMOVAL OF MERCURY FROM ACDIC WASTES .............................. 10

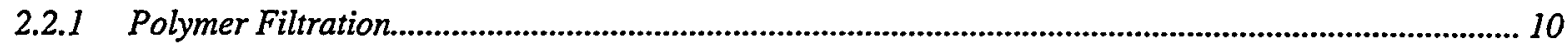

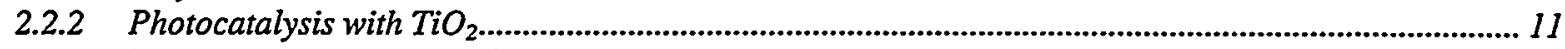

2.2.3 Hg-specific Polymer Pendant Crown Thioethers.................................................................................... 12

2.2.4 Self-Assembled Monolayers on Mesoporous Silica (SAMMS)............................................................. 13

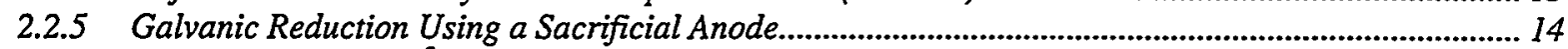

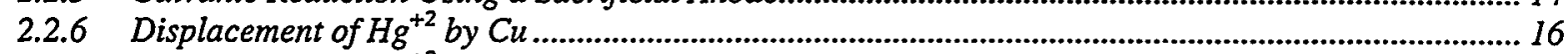

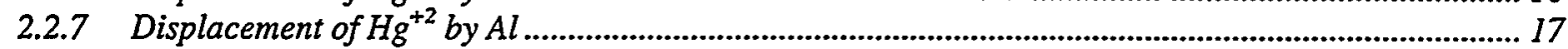

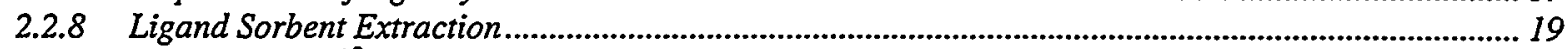

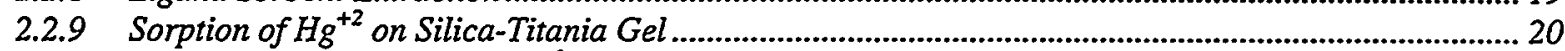

2.2.10 Adsorption of Gaseous $\mathrm{Hg}^{+2}$ With Silica Gel..............................................................................2 21

2.2.11 Precipitation of $\mathrm{Hg}$ From Acid Scrub With TMT.......................................................................... 22

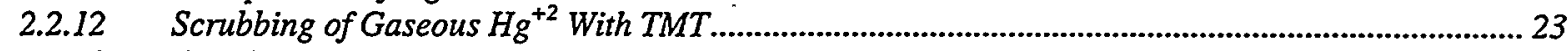

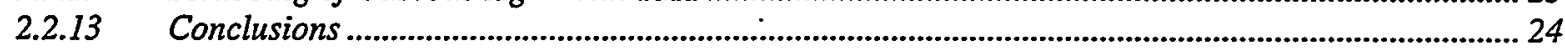

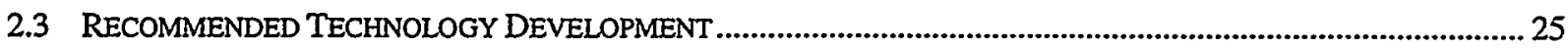

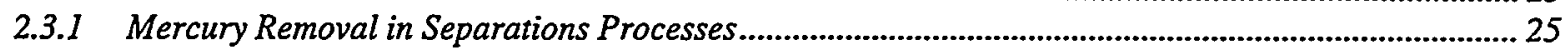

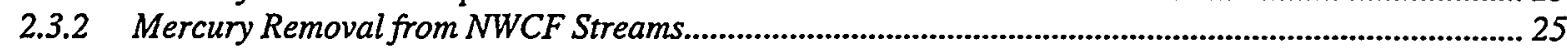

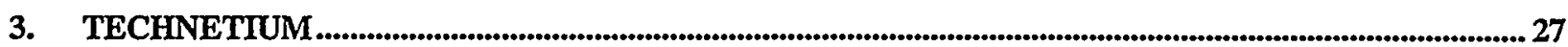

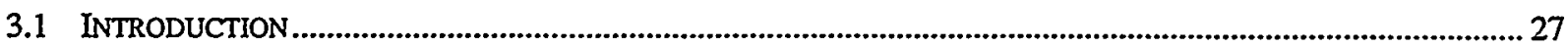

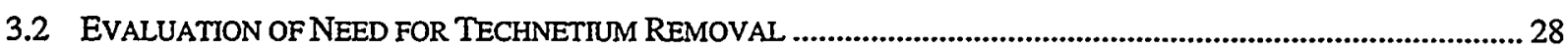

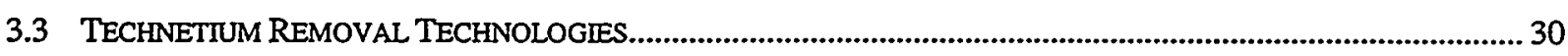

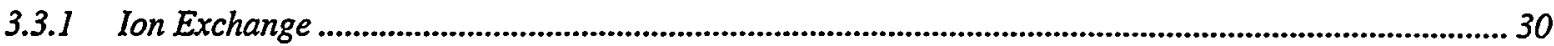

3.3.2 Sorption on Metal Particles or Sulfides ........................................................................................... 31

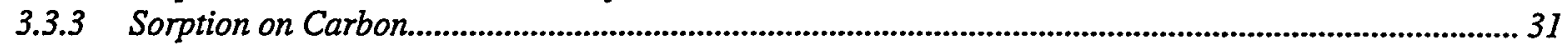

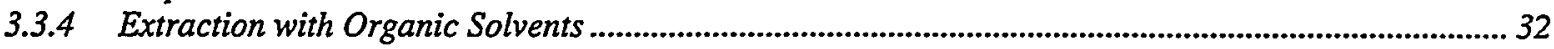

3.3.5 Aqueous Biphasic Extraction and Capture on Immobilized PEG......................................................... 32

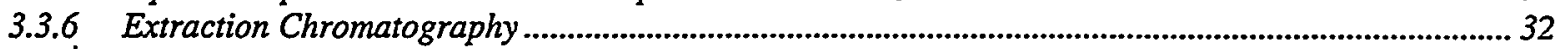

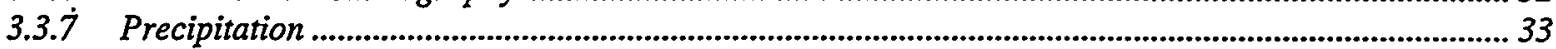

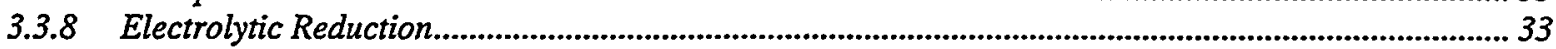




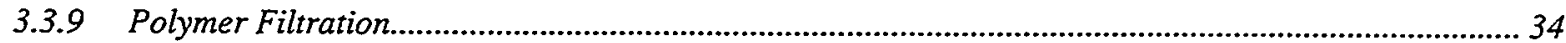

3.3.10 Reverse Osmosis, Liquid Membrane, and Nanofiltration Process ................................................ 34

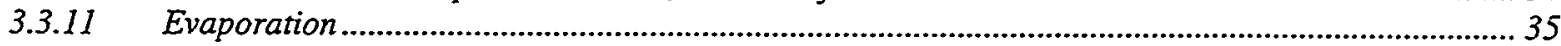

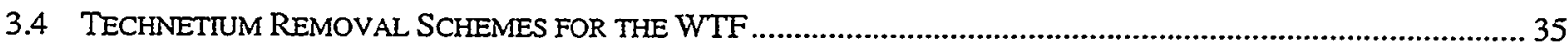

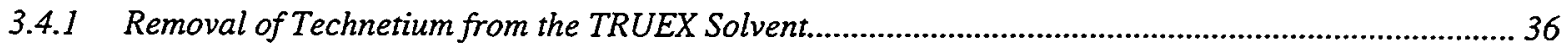

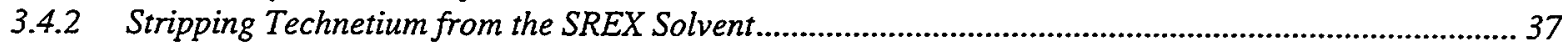

3.4.3 Removal of Technetium from TRUEX Carbonate Wash Effluent .........................................................37

3.4.4 Removal of Technetium from Calcine Dissolver Vapor ......................................................................... 39

3.4.5 Removal of Technetium from LAW Concentrate, Denitrator Offgas, or LAW Offgas Scrub Solution.. 40

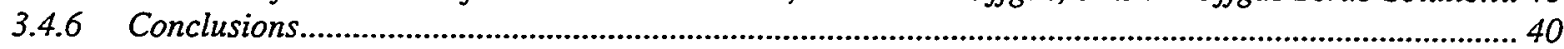

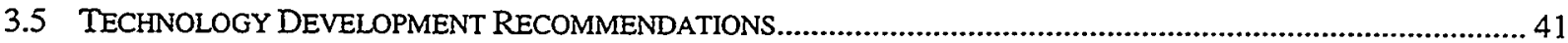

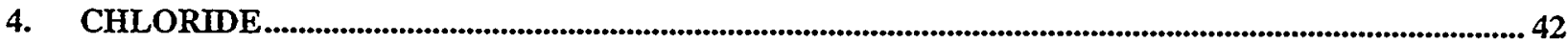

4.1 SUMMary OF EVALUATION OF CHLORDE BULdUP IN NWCF SCRUB SOLUTION..................................... 42

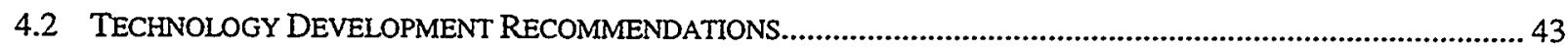

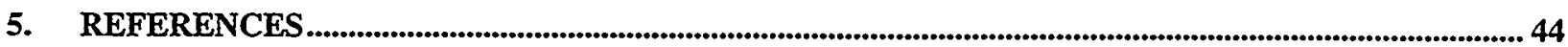

APPENDIX A, PROCESS ENGINEERING BASIS, NWCF MERCURY TREATMENT

APPENDIX B, LABORATORY TESTS OF HG REMOVAL SCHEMES FROM LIQUID/GAS PHASE

APPENDIX C, REGULATORY CONSIDERATIONS IN EVALUATION OF NEED FOR AND METHOD OF MERCURY REMOVAL IN FULL SEPARATIONS FACILITIES

APPENDIX D, MERCURY PRECIPITATION SCOPING STUDY

APPENDIX E, MERCURY SENSITIVITY STUDY

APPENDIX F, UPDATED EVALUATION OF CHLORIDE BUILD-UP IN NWCF SCRUB SOLUTION

FIGURES

FIGURE 1. GENERAL APPROACH FOR MERCURY TREATMENT STANDARDS RELATED TO SEPARATIONS PROCESS WASTE.

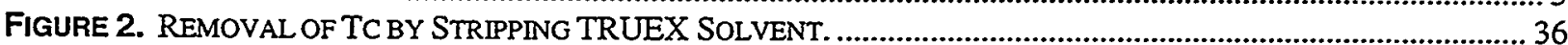

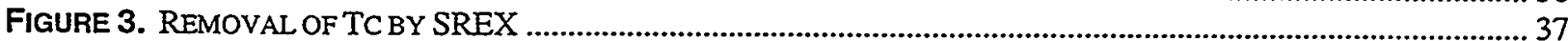

FIGURE 4. REMOVAL OF TC FROM TRUEX CARBONATE WASH BY ION EXCHANGE. ............................................. 38

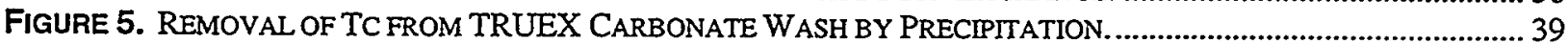

FIGURE 6. REMOVAL OF TC FROM CALCINER DISSOLVER VAPOR..................................................................... 40

\section{TABLES}

TABLE 1. TEChNETIUM IN CALCINE

TABLE 2. PARTITIONING OF TC IN CALCINE FULI SEPARATIONS MATERIAL BALANCES ........................................... 29 


\section{ACRONYMS}

$\mathrm{ABE} \quad$ Aqueous Biphasic Extraction

BDAT Best Demonstrated Available Technology

CERCLA Comprehensive Environmental Response, Compensation, and Liability Act

CT Coupled Transport

DF decontamination factor

DOE U.S. Department of Energy

DSSF Double Shell Slurry Feed

DVB Divinyl Benzene

EPA U.S. Environmental Protection Agency

FS Feasibility Study

HAW High Activity Waste

HEPA high-efficiency particulate air

HLW High Level Waste

INEEL Idaho National Engineering and Environmental Laboratory

INTEC Idaho Nuclear Technology and Engineering Center

LANL Los Alamos National Laboratory

LAW Low Activity Waste

LAWT Low Activity Waste Treatment (Facility)

LDR Land Disposal Restriction

LMTCOC Lockheed Martin Idaho Technologies Company

MACT Maximum Achievable Control Technology

MWG/MWFA Mercury Working Group/Mixed Waste Focus Area

NGLW Newly Generated Liquid Waste

NRC Nuclear Regulatory Agency 


$\begin{array}{ll}\text { NWCF } & \text { New Waste Calcining Facility } \\ \text { ORNL } & \text { Oak Ridge National Laboratory } \\ \text { PEG } & \text { Polyethylene Glycol } \\ \text { PNNL } & \text { Pacific Northwest National Laboratory } \\ \text { PPG } & \text { Polypropylene Glycol } \\ \text { RCRA } & \text { Resource Conservation and Recovery Act } \\ \text { RO } & \text { Reverse Osmosis } \\ \text { SAMMS } & \text { Self-Assembled Monolayers on Mesoporous Silica } \\ \text { SBW } & \text { Sodium-Bearing Waste } \\ \text { SREX } & \text { Strontium Solvent Extraction Process } \\ \text { TCLP } & \text { Toxicity Characteristic Leaching Procedure } \\ \text { TMT } & \text { Trisodium Trimercapto-S-Triazine } \\ \text { TRA } & \text { Test Reactor Area at the INEEL } \\ \text { TRU } & \text { Transuranic } \\ \text { TRUEX } & \text { Transuranic Radionuclide Solvent Extraction Process } \\ \text { WS } & \text { Waste Separations (Facility) } \\ \text { WSCP } & \text { water soluble chelating polymer } \\ \text { WTF } & \text { Waste Treatment Facilities } \\ \end{array}$




\section{Technology Evaluations Related to Mercury, Technetium, and Chloride in Treatment of Wastes at the Idaho Nuclear Technology and Engineering Center of the Idaho National Engineering and Environmental Laboratory}

\section{INTRODUCTION}

Wastes stored at the Idaho Nuclear Engineering and Technology Center (INTEC) of the Idaho National and Environmental Laboratory (INEEL) include approximately 1.3 million gallons of liquid waste in the tank farm ${ }^{1}$ and $4,287 \mathrm{~m}^{3}$ of calcine. ${ }^{2}$ An Environmental Impact Statement, presently in draft form, identifies numerous alternatives for the treatment and disposal of these wastes. The treatment alternatives fall into two categories, referred to as "nonseparations" and "separations" alternatives. In the nonseparations alternatives, the New Waste Calcining Facility (NWCF) is used to convert the liquid waste into calcine before additional treatment of the calcine into a final waste form. In the separations alternatives, transuranic and in some cases other radionuclides are separated from the waste and further processed to produce a high activity waste (HAW) glass and a low activity waste (LAW) grout.

The evaluations presented in this report were performed to determine whether certain chemical or radionuclide species present in the waste need to be removed, and, if so, to identify feasible technologies for their removal. These species include mercury, technetium, and chloride.

Mercury is an issue for both nonseparations and separations alternatives. Mercury in the feed to the NWCF volatilizes in the calciner, and a high percentage is captured by scrub solution in the Quench Tower and venturi scrubber. The scrub solution is either purged to the tank farm, resulting in a buildup of mercury in the tank farm, or recycled to the NWCF feed, resulting in an even higher concentration in the scrub solution. Thus, removal of mercury is needed from the NWCF feed, the scrub solution, or ultimately from the residual tank farm liquid. In addition, in order to meet the proposed Maximum Achievable Control Technology (MACT) concentration limit for gaseous emissions from the NWCF, removal of mercury will be required from the offgas.

Likewise in the separations alternatives, unless removed, mercury will build up in the process. The high temperatures of the melter and the LAW denitrator effectively limit concentrations of mercury in the glass and grout to negligible values, and MACT regulations limit the allowable concentration of mercury in the stack gases. Removal of mercury from both liquid and gaseous streams may be required.

Technetium is an issue only for separations alternatives. The nonseparations alternatives produce a high level waste, for which there is no limit on the technetium concentration. However, for the separations alternatives, the grout must meet either Class A or Class C concentrations limits, one of which is ${ }^{99} \mathrm{Tc}$.

Chlorides are primarily an issue for NWCF operation. Depending on the fraction of chlorides that volatilize in the calciner and are captured in the scrub solution, chlorides could build up in the scrub system beyond limits set by corrosion considerations, or build up at a rate that would require frequent purges of scrub back to the tank farm. The same issue could apply to the LAW denitrator of a separations process. However, unlike the existing calciner, the separations denitrator could be designed for a higher chloride concentration. 


\section{MERCURY}

The need for mercury removal in both future NWCF operations and in any future separations facility has been recognized for some time. In a feasibility study (FS) performed in 1994, formic acid was used to both reduce mercury and nitrates in HAW and LAW effluent streams in a process treating INTEC wastes. ${ }^{3}$ Elemental mercury was then collected in traps and amalgamated. A later feasibility study ${ }^{4}$ for a separations facility [the "Waste Treatment Facilities" (WTF)] for treating INTEC wastes included removal of mercury by chemical reduction from two other liquid streams, and identified the removal and processing of the mercury waste as the "only significant technical concern" of their proposed design. Pending further development of mercury removal processes, the WTF FS identified "a potential problem with the low-activity grout product passing EPA TCLP" for mercury. The WTF FS recommended development activities to: (1) optimize the extraction of mercury in the TRUEX process, (2) demonstrate their proposed chemical reduction method for removal of mercury from the TRUEX wash effluent, (3) demonstrate methods for removal of mercury from offgas treatment scrub solutions, (4) develop a method for back-extracting mercury from the SREX solvent, and (5) establish mercury removal criteria based on leach testing of simulated grout products.

A follow-on study ${ }^{5}$ to the WTF FS identified alternative processes that could be used to remove mercury from separations effluents, and recommended testing sulfide precipitation of mercury from the TRUEX carbonate wash effluent, as well as testing other technologies for mercury removal from liquid streams and demonstrating technologies for removal of mercury from offgas streams.

In regards to the NWCF, a feasibility study that identified modifications that would be required to the calciner to meet MACT emissions limits included an evaluation of mercury removal technologies from both liquid and gaseous streams. ${ }^{6}$ A Value Engineering Session was held to select a technology for mercury removal for the NWCF MACT FS design from among those detailed in the evaluation. Performance uncertainties were identified for both liquid and gaseous removal technologies; however, the first decision of the VE session relative to mercury was to select removal from the gaseous effluent over liquid treatment technologies, primarily because of larger uncertainties with liquid treatment technologies. Of the gaseous removal alternatives, a sulfur-impregnated activated carbon sorption system was selected as representative of cost, schedule, and effectiveness.

Scoping studies were performed in 1998 to evaluate the feasibility of separating mercury from NWCF scrub solutions by electrochemical reduction. ${ }^{7}$ The studies concluded that electrochemical reduction using a graphite felt cathode for removing mercury was infeasible, however, using a mercury pool cathode was feasible. Continued development of the mercury pool electrode is being performed in FY-99. Testing of sorption of mercury from simulated NWCF offgas streams is also being tested in FY99 , using activated carbon and possibly other sorbents. ${ }^{8}$

A process engineering analysis and evaluation of mercury removal methods applicable to NWCF streams has also been performed, and is attached as Appendix A. Methods of removing mercury from the calciner feed, offgas, and a scrub solution side stream were evaluated. The report recommended that preliminary designs and cost estimates be prepared for three alternatives:

No NO idizer Alternative In this alternative a new packed column scrubber is installed in the NWCF downstream of the venturi scrubber to remove additional mercury from the calciner offgas. Mercury is removed from the acidic scrubber liquid effluent and from a side stream from the existing Scrub Collection Tank. The preferred method of mercury removal from these acidic liquids is by electrochemical reduction to metallic mercury using a mercury pool electrode. The reduced mercury is then amalgamated and stabilized, if needed, for disposal. This system would meet the MACT emission limit for mercury but is not expected to meet limits for CO or VOCs. 
$\mathrm{NO}_{x}$ idizer Alternative In this alternative a $\mathrm{NO}_{x}$ idizer is installed downstream of existing offgas treatment equipment. A new tank would be installed to collect scrub solution from the Venturi Knock-Out Drum. Side streams from the new scrub tank and the existing Scrub Collection Tank are processed by the same electrochemical reduction system as for the No Noxidizer Alternative. In this alternative, all MACT emission limits would be met.

Feed Pretreatment Alternative Electrochemical reduction using a mercury pool electrode would also be used in this alternative to remove mercury from the calciner feed. Because the mercury concentration in the feed is lower than in the scrub solution, a lower efficiency would be expected. This system would be expected to meet the MACT emission limit for mercury but not for $\mathrm{CO}$ or VOCs.

Small-scale scoping tests have also been performed this year to:

Determine the effect of silica gel in adsorbing mercury from simulated NWCF offgas

Determine whether mercury in NWCF scrub solutions can be precipitated with trimercaptotriazine (TMT)

Determine the extent to which elemental $\mathrm{Hg}$ can be oxidized in a typical denitration offgas, and the extent to which the oxidized $\mathrm{Hg}$ can be removed by scrubbing.

The results of these tests are contained in Appendix B.

The solvent extraction process used in separations to remove strontium, called SREX, is highly effective in extracting mercury as well as strontium. Testing performed in 1997 failed to find a stripping agent to back-extract mercury from the SREX solvent. ${ }^{9}$ Additional reagents tested in FY-99 have also been shown to be ineffective in stripping mercury from the SREX solvent.

Results from the above FY -99 studies on electrochemical reduction of mercury using a mercury pool electrode, removal of mercury from offgas, and stripping mercury from the SREX solvent will be contained in separate reports. Relative to mercury, this report contains: a review of regulations applicable to mercury in waste treatment processes (Section 2.1.1 and Appendix C); test results from scoping studies for sulfide precipitation of mercury from simulated TRUEX carbonate wash effluent (Section 2.1.3 and Appendix D), an evaluation of the sensitivity of mercury rates and concentrations in separations streams to changes in process schemes and operating parameters (Section 2.1.2 and Appendix E), an evaluation of technologies for mercury removal from NWCF streams other than the electrochemical reduction method (Section 2.2 and Appendix B), and an overall process evaluation of schemes to remove mercury from NWCF streams (Appendix A).

\subsection{Mercury Removal in Separations Treatment Processes}

The "Full Separations" treatment process includes either filtration of SBW or dissolution of calcine, followed by cesium removal by ion exchange, actinide removal by solvent extraction using the TRUEX process, and strontium removal by solvent extraction using the SREX process. The solvents for both extraction processes are highly effective for removal of mercury. High activity waste (HAW) effluents are combined and fed to a melter, while LAW effluents are combined, evaporated, denitrated, and grouted. An alternative separations process, the "TRU/Class A" scheme, does not include the stripped actinides in the melter feed, but instead processes them to produce a dry granular TRU waste. A third alternative separations process, the "TRU/Class C" scheme, produces the same TRU waste as in the 
TRU/Class A scheme, but deletes the cesium and strontium separation systems, and as a result, does not have a glass melter.

\subsubsection{Regulatory Review}

Mercury could be present in several primary and secondary waste products from a separations treatment facility. A decision chart, prepared specifically for INTEC wastes for determining land disposal restriction (LDR) treatment standards is shown in Figure 1. The chart has 10 questions which, when asked for a specific feed case, will lead to the required treatment standard. Additional information regarding regulatory treatment requirements for processing INTEC wastes is given in Appendix C.

The first question is "Is the waste HLW/SBW?" The feed to the separations facility will either be SBW or calcine. Most calcine is high-level waste resulting from reprocessing of naval reactor fuel. A relatively small portion of the total calcine, such as nonradioactive calcine from startup beds or calcine from SBW, may not fit into the high-level waste category. However, these non-HLW calcines are mixed in the Bin Sets with other calcines, and thus all calcine will need to be considered as HLW. The LDR treatment standard for HLW is vitrification. Following the decision chart for HLW/SBW, the separations process will result in two streams that could contain mercury: LAW waste streams and offgas scrub from the HAW melter. Both of these streams lead to Question 2, "Is waste rad-contaminated elemental mercury?"

A small quantity of newly generated liquid waste (NGLW) will also be treated in the separations facility. These NGLW streams may or may not be mixed with SBW in the tank farm. If not, the answer to the first question is "no" and leads to Question 2 as well.

Secondary wastes that will be generated in the separations facility include spent solvent and spent activated carbon that has been used to remove mercury from offgas streams.

Four of the wastes at this point, LAW, HAW offgas scrub, NGLW, and spent solvent, are not radcontaminated elemental mercury," and are liquid streams. Hence, at Question 3, we proceed on the "liquid" path for these wastes to Question 4, "Is waste High-Hg?" The spent carbon follows the solid path to Question 6.

From this point, paths diverge depending on a stream's mercury concentration and other characteristics.

Spent Solvent The spent SREX solvent will very likely contain more than $260 \mathrm{mg} / \mathrm{kg}$ $(\sim 0.0012$ moles/L) of mercury. Hence, the solvent is "high mercury" and is classified as a nonwastewater. An affirmative answer to the next question, "Is the waste organic?" leads to incineration as the required treatment. The products of incineration are an offgas scrub solution and an ash. If the ash contains less $260 \mathrm{mg} / \mathrm{kg}$ of mercury and a TCLP test of the ash shows less than $0.2 \mathrm{mg} / \mathrm{L}$ mercury, the ash is not a hazardous waste and can be land disposed. Otherwise, the ash must be stabilized to meet a TCLP limit of $0.025 \mathrm{mg} / \mathrm{L}$. The mercury concentration in spent TRUEX solvent wash is unknown, and may depend on the waste being processed. For a high-mercury waste like alumina calcine or SBW, the mercury concentration may be greater than $260 \mathrm{mg} / \mathrm{kg}$. For zirconia calcines, the mercury concentration will likely be less than $260 \mathrm{mg} / \mathrm{kg}$; however, since the spent solvent will be incinerated regardless of the mercury content, the same path will be followed in regards to mercury processing requirements. 


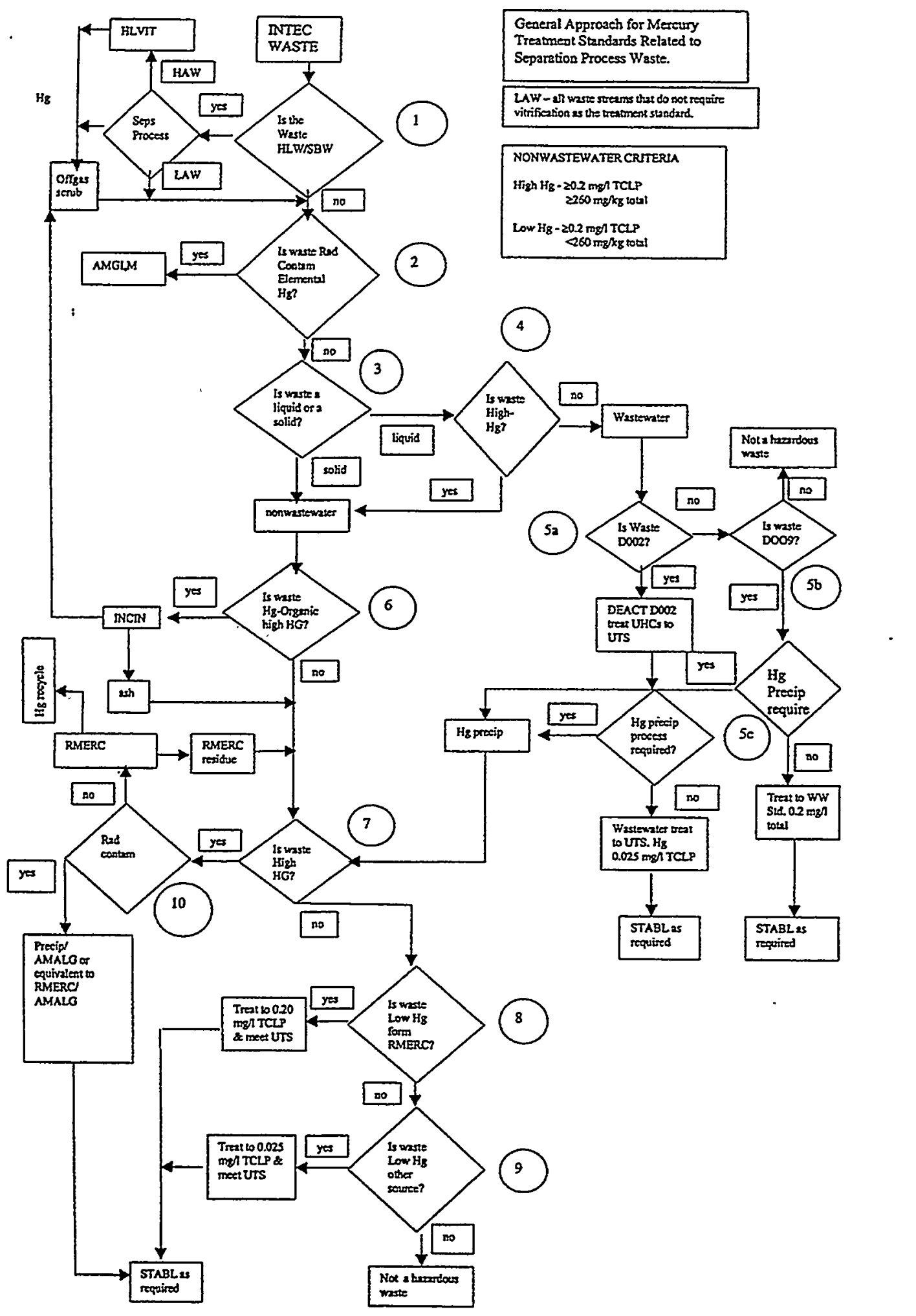

Figure 1. General Approach for Mercury Treatment Standards Related to Separations Process Waste. 
Offgas Treatment Scrub Solutions Based on present material balances, ${ }^{10}$ offgas scrub liquid from the HAW melter will contain less than $260 \mathrm{mg} / \mathrm{kg}$ of mercury for SBW, zirconia calcine, and a total mixed calcine case, but higher than $260 \mathrm{mg} / \mathrm{kg}$ mercury for alumina calcine. If generated as a waste, the alumina calcine HAW scrub would need to be treated by precipitation followed by amalgamation of the mercury, following the path nonwastewater, nonorganic, high-mercury waste contaminated with radionuclides. HAW offgas scrub for the other cases would follow the wastewater, D002 path to deactivation (acid neutralization), followed by treatment of the aqueous stream to $0.025 \mathrm{mg} / \mathrm{L}$ mercury. However, the HAW scrub solution is recycled in the WTF to the SBW Feed Tank or the Calcine Dissolver. Thus, the stream is effectively treated for mercury by the separations steps of the WTF. Offgas scrub from incineration of the spent TRUEX and SREX solvents could also be processed through the separations steps to avoid multiple mercury removal and stabilization systems.

LAW Waste Streams The LAW streams in the WTF are evaporated, denitrated, and the denitrator solids are grouted. Most of the mercury in the LAW will volatilize in the denitrator; the small amount of mercury that remains in the denitrator solids will be stabilized in the LAW grout by sulfur contained in blast furnace slag. The grouted waste is expected to be below the $0.2 \mathrm{mg} / \mathrm{L}$ TCLP mercury concentration limit, $^{2}$ and hence no additional mercury treatment is required. Mercury will build up in the LAW offgas scrub solution, requiring removal either from individual LAW streams upstream of the LAW evaporator or LAW scrub solution.

TRUEX Carbonate Wash The TRUEX solvent is highly efficient for extracting mercury, and mercury extracted into the solvent is extracted out of the solvent by the sodium carbonate wash. Because a high percentage of feed mercury is present in this stream and because the stream has a high $\mathrm{pH}$ that is conducive to removal by precipitation, the present flowsheets shows mercury removal by sulfide precipitation from the carbonate wash. Small-scale tests have shown that sulfide precipitation meets the treatment standard of $0.2 \mathrm{mg} / \mathrm{L}$ mercury in the filtrate (See Appendix D). Also based on these tests, the mercury concentration in the filtrate from a TCLP test on the sulfide precipitant is expected to be less than the $0.025 \mathrm{mg} / \mathrm{L}$ treatment standard. ${ }^{b}$

LAW Offgas Scrub Solution. The LAW scrub purge is recycled to the LAW evaporator. Mercury will build up in the scrub until the rate of mercury in the LAW offgas downstream of the demister is equal to the rate of mercury into the LAW evaporator, excluding the LAW scrub purge. The present material balances show a mercury concentration in the scrub purge of less than $260 \mathrm{mg} / \mathrm{kg}$ for all feed cases except alumina calcine. Thus, for feed cases other than alumina calcine, the scrub purge will be low mercury wastewater, and no treatment other than the planned recycle is required. For the alumina calcine feed case, the scrub purge is a high mercury waste. The flowsheet shows this stream recycled to the LAW evaporator like the other feed cases. Because the rate of the scrub purge is small $(<2 \%)$ compared to the total LAW feed, the mercury content of the scrub purge has little influence on the ultimate LAW waste product-the LAW grout. The concentration of mercury in the LAW offgas will be higher for this feed case, requiring a greater consumption rate activated carbon (or other sorbent) than the other feed cases. If the LAW scrub purge for alumina calcine was not recycled to the LAW evaporator, but grouted either directly or in combination with the denitrator solids, the resulting grout would need to meet a TCLP concentration of $0.025 \mathrm{mg} / \mathrm{L}$.

\footnotetext{
a The grouted waste, being solid, is a nonwastewater. Thus proceed on Figure 1 from question 3 to 6 to 7 to 8 to 9 . Since the TCLP concentration is $<0.2 \mathrm{mg} / \mathrm{L}$, the waste is not low $\mathrm{Hg}$ and the waste is not hazardous in regard to mercury.

${ }^{b}$ TCLP tests on the aggregated sulfide precipitant showed $0.004 \mathrm{mg} / \mathrm{L}$ mercury.
} 
Spent Carbon The present separations flowsheets show that mercury is removed from both HAW and LAW offgas streams by activated carbon in order to meet the MACT emission limit for mercury. Testing is needed to demonstrate this removal for the range of offgas compositions and conditions expected. However, assuming these demonstration tests are successful, spent carbon loaded with mercury will be a waste from the full separations process. The waste will be classified as a nonwastewater and have no or low organics. The treatment standard for high mercury nonwastewaters is retorting, and if the waste has radionuclides, the resulting elemental mercury will need to be amalgamated. Use of sulfurimpregnated activated carbon may result in a waste equivalent to amalgamated mercury. The costs of these mercury treatment steps provides incentive to achieve high mercury removal in upstream processes, including offgas treatment trains.

\subsubsection{Summary of Sensitivity Study}

Appendix E contains an evaluation of the sensitivity of mercury distribution among streams and wastes in the Full Separation process to process scheme configurations and process operating parameters. The study was performed in order to better evaluate the need for mercury removal, evaluate alternative schemes of mercury removal, and help define development activities for the Full Separations process.

The present inventoryc of SBW contains approximately $2,300 \mathrm{~kg}$ of mercury and calcine ${ }^{d}$ contains approximately $3,650 \mathrm{~kg}$. The concentration of mercury in SBW varies from about $100 \mathrm{mg} / \mathrm{L}$ to over 2000 $\mathrm{mg} / \mathrm{L}$, and in calcine from 15 to $19,000 \mathrm{ppm}$. Based on present estimates, $94 \%$ of the mercury in calcine is contained in Bin Set 1.

The MACT regulations limit mercury releases from the stack to $45 \mu \mathrm{g} / \mathrm{dry}$ standard cubic meter, and the mercury concentrations in the final solid waste streams from Full Separations are limited because of upstream high temperature processes. Thus, either a process step is needed to specifically remove mercury in the Full Separations process, which would result in a separate mercury waste, or offgas scrub solutions containing mercury will require grouting, either in combination with the denitration solids or as a separate waste. If not removed as a separate waste, mercury concentrations in the LAW grout will be approximately $2 \mathrm{ppm}$ when processing zirconia calcine, about $60 \mathrm{ppm}$ for a well-blended calcine, 170 ppm when processing an "average" SBW, and up to $2,000 \mathrm{ppm}$ when alumina calcine is processed.

Five schemes for removal or processing of mercury were evaluated in the sensitivity study:

1. Grouting LAW scrub purge in combination with LAW denitration solids

2. Grouting LAW scrub purge to form a separate Hg-containing grouted waste

3. Removal of mercury from the TRUEX carbonate wash

4. Removal of mercury from the LAW scrub purge

5. Recycle of the LAW scrub purge to the LAW evaporator without treatment.

\footnotetext{
'Approximately 1.3 million gallons contained in tanks WM-180, WM-181, WM-185, WM-186 and WM-189.

${ }^{d} 4136 \mathrm{~m}^{3}$ present as of December, 1998.

${ }^{c}$ for a new facility
} 
The evaluation showed:

1. Mercury removal will be required from LAW and HAW offgas streams to meet the MACT limit for mercury emissions.

2. Mercury removal from an aqueous stream in the Waste Separations (WS) or Low Activity Waste Treatment (LAWT) Facility will be required when processing alumina calcine, whether by itself or blended with other calcine.

Mercury concentrations in streams throughout the Waste Treatment Facilities processes are highly sensitive to the feed type and to the processing scheme, but generally insensitive to changes in process parameters of a given scheme.

Removal of mercury from the carbonate wash is recommended because it will result in minimal processing steps and will be applicable to all feed cases.

Development activities are recommended to demonstrate methods to remove mercury from the carbonate wash, determine the upper limit of mercury that will be present in dissolved calcine, obtain distribution coefficient data for TRUEX and SREX for the calcine composition that has the highest concentration of mercury, and test systems to remove mercury from expected LAW and HAW offgas. These recommendations are expanded in Section 2.3.1.

\subsubsection{Summary of Sulfide Precipitation Study for Removal of Mercury from TRUEX Carbonate Wash Effluent}

For wastewaters, RCRA regulations identifies chemical precipitation as the Best Demonstrated Available Technology (BDAT). Also, an evaluation of processes to remove mercury from Full Separations process streams recommended testing sulfide precipitation to remove mercury from the TRUEX carbonate wash effluent. ${ }^{5}$ Small-scale tests were thus performed to evaluate different sulfide precipitating agents, to determine the achievable mercury removal efficiency, and to determine characteristics of the resulting mercury sulfide precipitant. The results of these tests are contained in Appendix D.

The first series of tests used a surrogate waste of 0.25 molar sodium carbonate to which $\mathrm{HgCl}_{2}$ had been added to a concentration of $94 \mathrm{mg} / \mathrm{L}$ mercury. Three precipitating agents were tested: sodium sulfide, calcium sulfide, and TMT-15, which is a commercial product containing $15 \mathrm{wt} \%$ trisodium trimercapto-s-triazine. Both sodium and calcium sulfide produced a black $\mathrm{HgS}$ precipitate of relatively large, easily separated particles. The precipitate formed during the first 5 minutes after adding the precipitation agent, and was separated from the supernate by decanting after about 15 minutes. TMT-15 produced a relatively nondense, cream-colored precipitant that required several hours to settle. Analyses of the supernate solutions showed mercury concentrations of $0.74 \mathrm{mg} / \mathrm{L}$ for $46 \%$ excess sodium sulfide, $0.054 \mathrm{mg} / \mathrm{L}$ for $50 \%$ excess calcium sulfide, $0.51 \mathrm{mg} / \mathrm{L}$ for $128 \%$ excess calcium sulfide, and $0.12 \mathrm{mg} / \mathrm{L}$ for TMT.

Particle size analysis was performed on precipitant samples from the first series of tests. The mean particle size for the sodium and calcium sulfide tests was $13-20 \mu \mathrm{m}$, and for TMT it was $6.5-13 \mu \mathrm{m}$. Based on the average of the data for four calcium sulfide precipitates, $10 \%$ of the particles were greater than $56 \mu \mathrm{m}, 25 \%$ greater than $34 \mu \mathrm{m}, 50 \%$ greater than $18 \mu \mathrm{m}, 75 \%$ greater than $9 \mu \mathrm{m}$, and $90 \%$ greater than $4 \mu \mathrm{m}$. 
A carbonate wash effluent from the FY-99 integrated TRUEX tests was used in the second series of tests. The solution contained about $400 \mathrm{mg} / \mathrm{L}$ of mercury, which is considerably higher than could be obtained in dissolving mercuric chloride in 0.25 molar sodium carbonate. Six tests were performed at different ratios of calcium sulfide to waste feed solution, equivalent to $-7.6 \%$ to $125 \%$ excess sulfide. The results showed that the optimum calcium sulfide excess was $\sim 20 \%$ and that up to $99.975 \%$ of the mercury in the waste feed could be removed. The concentration of mercury in the supernate was $0.10 \mathrm{mg} / \mathrm{L}$ for $17 \%$ excess calcium sulfide and $0.16 \mathrm{mg} / \mathrm{L}$ for $25 \%$ excess calcium sulfide.

Additional analytical results were obtained subsequent to the report given in Appendix D which measured mercury in the filtrate from a TCLP test of the aggregated precipitate from Series 2 , and also the rhenium concentration in the feed and supernate solutions from Series 2 . The concentration of mercury in the TCLP filtrate from the aggregated precipitate was $4.05 \mu \mathrm{g} / \mathrm{L}$, which is well below the RCRA wastewater standard of $25 \mu \mathrm{g} / \mathrm{L}$.

Rhenium was used as a surrogate for technetium in the TRUEX integrated test. Thus, the analysis of rhenium in the sulfide supernate solutions was important in determining whether technetium would precipitate along with mercury, contaminating the mercury waste with the long-lived radionuclide technetium. Analysis showed $142.7 \mu \mathrm{g} / \mathrm{mL}$ of rhenium in the waste feed, an average $142.3 \mu \mathrm{g} / \mathrm{mL}$ of rhenium in the supernates from the $17 \mathrm{wt} \%$ excess calcium sulfide test, and $144.8 \mu \mathrm{g} / \mathrm{mL}$ of rhenium in the supernate from the $25 \mathrm{wt} \%$ excess calcium sulfide test. Within analytical error, the feed and supernate concentrations are equal, and hence rhenium did not precipitate with mercury. If rhenium adequately mimics technetium behavior, the mercury waste would not be contaminated by technetium.

\subsubsection{Conclusions}

Mercury removal will be required in the Full Separations process if all INTEC wastes are to be processed or if all calcine is to be processed. Mercury removal from offgas will be required to meet the MACT emission limit for mercury. For feeds high in mercury such as alumina calcine, mercury removal will also be required from a LAW effluent. Mercury removal is recommended for these high-mercury feed cases from the TRUEX carbonate wash effluent. Mercury removal from the carbonate wash is recommended because: (1) it has been demonstrated at laboratory scale, (2) it requires minimal equipment, (3) the feed stream is of less volume either upstream or downstream of mercury-containing streams, and (4) the mercury concentration is greater in the carbonate wash effluent than in downstream LAW streams.

The recommended process for mercury removal from the carbonate wash is by precipitation using calcium sulfide. Based on the laboratory-scale tests reported above, precipitation by calcium sulfide removes $>99.9 \%$ of the mercury in the wash effluent, produces a precipitate that could easily be separated, does not precipitate technetium that would contaminate the resulting mercury waste, and produces a waste that will meet the TCLP mercury concentration limit, and hence can be disposed with minimal additional treatment. ${ }^{\mathrm{f}}$

\footnotetext{
'Additional processing could include drying or grouting, and would be determined by waste handling and economic considerations rather than regulatory requirements.
} 


\subsection{Evaluation of Technologies for Removal of Mercury from Acidic Wastes}

As part of the Feasibility Study for NWCF MACT Compliance, ${ }^{6}$ an evaluation of mercury control technologies for the NWCF was performed. In the following sections, updates of the status of alternative technologies in that evaluation as well as additional technologies are briefly described and evaluated. Following the format of the previous study, for each technology references are provided followed by a process description, a summary of the current development status, a discussion of the technology's application to the NWCF, and a recommendation regarding that technology.

\subsubsection{Polymer Filtration}

\subsubsection{Reference.}

Draft 2, LAUR-95-5709, "Polyelectrolyte Enhanced Removal of Mercury from Mixed Waste Debris", Smith, B.F., Robision, T.W., Rogers, Y.C., Lubeck, C., Los Alamos National Laboratory (paper presented at WM'99).

\subsubsection{Process Description}

- Water soluble chelating polymer (WSCP) and oxidizing agent $\left(\mathrm{H}_{2} \mathrm{O}_{2}\right.$ or $\left.\mathrm{Fe}^{+3}\right)$ dissolved in mild acid solution

- Above solution used to leach mercury from contaminated debris

- Mercury is oxidized to the +2 state and bound by the proprietary WSCP

- Mercury-laden polymer is separated from solution using ultrafiltration

- Resulting concentrate ( $\mathrm{Hg}+\mathrm{WSCP})$ is acid stripped of the mercury at pH 0

- $\quad$ Polymer is $\mathrm{pH}$ adjusted and recycled

- The mercury in the strip permeate is precipitated and stabilized with sodium sulfide

Studies to date show a nonoptimized process can leach $86 \%$ of the mercury on contaminated stainless steel pipes, roughly the same as a $6 \underline{\mathrm{M}} \mathrm{HNO}_{3}$ leaching process.

2.2.1.3 Development Status. Bench-scale studies with reagent grade chemicals have been performed. Laboratory-scale leaching of $\mathrm{Hg}$ from stainless steel coupons simulating contaminated pipes has also been conducted. DOE Mixed Waste Focus Area funding was terminated in the middle of the technology demonstration that was in progress at LANL. However, the process has apparently been commercialized to some degree, and there is a company licensed to manufacture and sell the polymer.

2.2.1.4 Applicability to NWCF. The process was designed to leach elemental mercury from contaminated debris, and then separate this mercury from solution for stabilization and disposal. The polymer chelating agent obviously does not bind the mercury in strong acid solution (bound mercury is released when stripped with $1 \mathrm{M}$ acid, presumably $\mathrm{HNO}_{3}$ ). Thus, the process is not directly applicable to NWCF scrub solutions or waste feeds, unless the chelating polymer can be tailored to retain the mercury at a higher acid concentration. According to Barbara Smith, this has not been done, as the target application for the process is cleanup of debris and polishing of $\mathrm{Hg}$-contaminated wastewasters. 
2.2.1.5 Recommendation. This technology does not appear to be sufficiently developed or applicable to the NWCF scrub or feed solutions to warrant testing on NWCF waste streams at this time.

\subsubsection{Photocatalysis with $\mathrm{TiO}_{2}$}

\subsubsection{References}

1. ADA Technologies, Inc. White Paper: "Photocatalytic Treatment of Dissolved Metals", Turchi, C.S, (fax to Sam Ashworth)

2. ADA Technologies, Inc. White Paper: "A Novel Photosorbent for Removal of Mercury from Aqueous Waste Streams, Phase II Progress Report" (e-mailed to D.D. Taylor).

3. "Mercury Precipitation from Carbonate Wash Solution", D.R. Haefner, EDF-HG-003 (INEEL Project File Number SPR-Hg-001), 4/19/99 (Attached as Appendix D).

\subsubsection{Process Description}

- Aqueous Hg-laden stream is passed through a "photoreactor" containing microspheresupported sorbent of $\mathrm{TiO}_{2}$ irradiated with $\mathrm{UV}$ light

- UV excitation moves electrons in photocatalyst to higher energy levels, resulting in the formation of two types of reactive sites:

- Electron vacancies ("holes") with elevated oxidation potential

- Excited electrons with elevated reducing potential.

- Organic species present are oxidized at holes

- Oxidized $\mathrm{Hg}$ species are reduced by interaction of excited electrons with molecular $\mathrm{O}_{2}$

- Elemental $\mathrm{Hg}$ is sorbed to the $\mathrm{TiO}_{2}$ catalyst

- $\quad \mathrm{Hg}$-laden $\mathrm{TiO}_{2}$ catalyst may be disposed after stabilization (ADA patented process)

\section{Alternative process}

- Noble metal is dispersed on TiO2 photosorbent surface before extraction of $\mathrm{Hg}$

- After $\mathrm{Hg}$ extraction, saturated photosorbent is thermally regenerated and reused

- Mercury is condensed from regeneration step, stabilized (e.g., by amalgamation with sulfur), and disposed

2.2.2.3 Development Status. Phase I laboratory studies showed:

- $99.6 \%$ recovery of mercury from solutions of $\mathrm{HgCl}_{2}$ and $\mathrm{HgI}_{2}$

- $\mathrm{TiO}_{2}$ sorbs $160 \%$ of its weight in $\mathrm{Hg}$ (without noble metal) 
- $\mathrm{TiO}_{2}$ sorbs $230 \%$ of its weight in $\mathrm{Hg}$ (with noble metal)

- Sorbent may be regenerated without loss of performance.

With input from INEEL, ADA completed Phase II laboratory tests in mid-1999. They were performed using a surrogate for NWCF scrub solution consisting of $6 \underline{\mathrm{M} \mathrm{NO}_{3}}, 4 \underline{\mathrm{M}} \mathrm{HNO}_{3}, 30 \mathrm{gm} / \mathrm{L} \mathrm{Hg}^{+2}$ (added as $\mathrm{Hg}\left(\mathrm{NO}_{3}\right)_{2}$, and $0.15 \mathrm{M} \mathrm{Cl}$. The remaining charge balance was supplied with $\mathrm{Na}^{+1}$. In Reference 2 it was reported that $\mathrm{Hg}$ loadings as high as $400-700 \mathrm{wt} \%$ on the $\mathrm{TiO}_{2}$ catalyst were achieved. However, only about $15-25 \%$ of the mercury in solution was removed in these tests, even when the $\mathrm{TiO}_{2}$ concentration was increased by a factor of three. Moreover, high $\mathrm{Hg}$ loadings in the $\mathrm{TiO}_{2}$ were only achieved when $500 \%$ of the stoichiometric requirement of glucose was added as a reducing agent. When INEEL personnel indicated that addition of organics to the scrub is considered an unacceptable safety risk due to potential nitration of organics in the tank farm, ADA suggested that EDTA, sodium citrate, or sodium acetate could possibly be used as alternative reducing agents. This possibility was not explored because these additives are also organic in nature.

A second series of tests done under the phase II ADA tests was directed at removal of $\mathrm{Hg}$ from carbonate wash solutions that could be generated by TRUEX/SREX processing of INTEC calcines. In these tests a surrogate carbonate wash solution was used consisting of $0.5 \mathrm{M} \mathrm{Na}{ }^{+}, 0.25 \mathrm{M} \mathrm{CO}^{-2}, 0.01 \mathrm{M}$ $\mathrm{NO}_{3}{ }^{-}, 0.0002 \mathrm{M} \mathrm{PO}_{4}^{-3}, 100 \mathrm{mg} / \mathrm{L} \mathrm{Hg}$, and $75 \mathrm{mg} / \mathrm{L} \mathrm{Re}$ (as $\mathrm{ReO}_{4}^{-}$, used as a surrogate for $\mathrm{TcO}_{4}{ }^{-}$). In these tests about $97 \%$ of the $\mathrm{Hg}$ was removed from solution by the $\mathrm{TiO}_{2} / \mathrm{UV}$ process with about $12 \mathrm{wt} \%$ loading of $\mathrm{Hg}$ on the catalyst. This high removal efficiency was achieved without use of an organic additive (however, the precipitation of the $\mathrm{Hg}$ was faster when organic was used).

2.2.2.4 Applicability to NWCF. The process appears applicable to NWCF scrub solutions. However, because of the safety concern associated with the use organic reducing agents, it appears unlikely that the process would be implemented.

2.2.2.5 Recommendation. Further testing of the $\mathrm{TiO}_{2} / \mathrm{UV}$ process on NWCF scrubs is not warranted based on the data that $\mathrm{ADA}$ has provided. However, the favorable results attained with the carbonate wash surrogate suggests the process may have application if TRUEX/SREX separations are used. For this process, even if the organic additive were used, the safety concerns associated with the tank farm are not applicable, since the treated streams would not be recycled. This process could provide an alternative precipitation method to direct precipitation with $\mathrm{CaS}$ (as recommended by Haefner in Reference 3) in case the latter proves infeasible. If such an alternative is desirable then onsite testing of the $\mathrm{TiO}_{2}$ process (with involvement and oversight by INEEL personnel) is recommended.

\subsubsection{Hg-specific Polymer Pendant Crown Thioethers}

\subsubsection{Reference.}

"Polymer Pendant Crown Thioether for Removal of Mercury from Acidic Wastes," Baumann, T.F., Reynolds, J.G., Fox, G.A., Lawrence Livermore National Laboratory, University of California (paper presented at WM'99).

\subsubsection{Process Description}

- A cross-linked, acid-resistant thiacrown polymer is prepared by copolymerization of a C-substituted thiacrown [N,N-(4-vinylbenzylmethyl)-2-aminomethy]-1,4,8,11,14pentathiocycloheptadecane] with DVB ( $80 \%$ divinylbenzene) using a radical initiator. 
- The polymer is mixed with the Hg-laden aqueous solution for approximately 30 minutes, during which time the polymer selectively extracts the $\mathrm{Hg}^{+2}$ ion from the solution

- The Hg-laden polymer is filtered from the solution

- The Hg-laden, solid polymer residue is washed with acetone and dried

- The $\mathrm{Hg}$-laden polymer is treated with $\mathrm{H}_{2}$-diphenylthiocarbazone $\left(\mathrm{H}_{2}\right.$-dithizone or $\left.\mathrm{H}_{2} \mathrm{dtz}\right)$ in choroform $\left(\mathrm{CHCl}_{3}\right)$ which complexes the mercury as $\mathrm{Hg}(\mathrm{dtz})_{2}$

- The treated polymer is washed with $\mathrm{CHCl}_{3}$ to remove the $\mathrm{Hg}(\mathrm{dtz})_{2}$

- The stripped polymer is now reused with a slight loss in loading capacity

- The $\mathrm{Hg}(\mathrm{dtz})_{2}-\mathrm{CHCl}_{3}$ solution is disposed in an unspecified manner (perhaps by incineration with subsequent condensation of $\mathrm{Hg}$ vapor and amalgamation of elemental $\mathrm{Hg}$ )

2.2.3.3 Development Status. Laboratory studies have been completed at test-tube scale ( $20 \mathrm{mg}$ of polymer in $5 \mathrm{~mL}$ of $\mathrm{Hg}(\mathrm{NO} 3)_{2}$ solution. One recycle of the polymer has been demonstrated at this scale.

2.2.3.4 Applicability to NWCF. The process may be applicable to NWCF, since the polymer was engineered specifically for compatibility with strongly acidic solutions. However, testing to date has been done only in the $\mathrm{pH}$ range of 1.5-6.2.

2.2.3.5 Recommendation. This process appears to be at the early developmental stage. Little process optimization appears to have been done, and the required processing of the polymer for recycle appears to be complex and potentially problematic. Disposal of the acetone wash solution and the final $\mathrm{Hg}$-laden organic waste stream could also be problematic. This technology does not appear to be sufficiently developed or to offer a sufficient advantage to warrant testing on NWCF waste streams at this time.

\subsubsection{Self-Assembled Monolayers on Mesoporous Silica (SAMMS)}

\subsubsection{References}

1. Pacific Northwest National Laboratory (PNNL) White Paper: "Self-Assembled Monolayers on Mesoporous Supports (SAMMS) for RCRA Metal Removal," Feng, X., Liu, J., Fryxell, G.E.

2. Discussion with G.A. Hulet [Mercury Working Group/Mixed Waste Focus Area (MWG/MWFA)] on 2/1/99.

3. Telecon with J. Liu (PNNL) on 3/12/99.

4. Telecon with G.A. Hulet on 3/15/99.

5. Rawlins, J.K., "Feasibility Study Report for NWCF MACT Compliance Facility," IMITCO Internal Report, INEEL/INT-97-00992, Appendix F. 


\subsubsection{Process Description}

[This process has been reviewed previously in Reference 5 above]

- $\quad$ SAMMS material is installed in filtration columns

- Hg-containing liquid is pumped through the column with mercury being adsorbed by the functional monolayers in the SAMMS material

- Once the SAMMS material is saturated, it is washed (to stop acid degradation), flushed from the column, and replaced with virgin SAMMS material

- Spent SAMMS material is directly disposed as nonhazardous low-level waste, or as LDRcompliant, treated RCRA waste

2.2.4.3 Development Status. Sorption tests of SAMMS documented in Reference 1 were limited to a $\mathrm{pH}$ range of 3-9. The developers of the $\mathrm{Hg}$-specific SAMMS material were optimistic that further development testing of the material might show it to be effective in higher acid concentrations. However, DOE funding for this development was terminated, precluding any such testing.

An effort to provide an engineering demonstration of the SAMMS material was sponsored by the MWG/MWFA at Oak Ridge National Laboratory (ORNL). This effort entailed the manufacture by ORNL of an engineered form (i.e., 0.5-mm beads) of the SAMMS material (manufactured and used as a powder in the earlier laboratory tests at PNNL). This demonstration failed, however, because the beads manufactured from the SAMMS material had dramatically reduced surface area from the native SAMMS powder. The capacity of the material for mercury sorption was thus very low. done.

No additional development of the SAMMS material for application to mercury removal has been

2.2.4.4 Applicability to NWCF. The SAMMS process, as currently constituted, is not applicable to NWCF solutions for two reasons. First, it has not been shown that the SAMMS material will function in highly acidic solutions, and second, an engineered form of the material, suitable for use in a contacting column, has not been produced and demonstrated.

2.2.4.5 Recommendation. This process probably requires significant additional technology development before it is ready for testing on NWCF mercury-contaminated streams. Testing on NWCF waste streams at this time is therefore not recommended.

\subsubsection{Galvanic Reduction Using a Sacrificial Anode}

\subsubsection{References}

1. Mellor's Modem Inorganic Chemistry, edited by Parkes, G.D., Longmans, Green and Co., London, 1951.

2. Encyclopedia of Chemical Reactions, edited by Jacobson, C.A., Reinhold Publishing Corp., New York, 1951. 
3. Massachusetts Water Resources Authority: Mercury Bench Scale Testing Project, "Technology Identification Subgroup Report," Appendix F (Vendor Bench-Scale Feasibility Test Reports).

4. Telecon with KDF Fluid Treatment, Inc. 3/12/99.

2.2.5.2 Process Description. A proprietary medium (KDF 55) made from copper and zinc metals is installed in a filtration column.

- An aqueous solution containing mercury is pumped through the column with ionic mercury being reduced to elemental mercury by the galvanic action of the water on the dissimilar metals $(\mathrm{Zn}$ and $\mathrm{Cu}$ ).

- Reduced, elemental mercury amalgamates with the copper anode and is thus removed from solution. The ionic mercury from solution is replaced with ionic $\operatorname{zinc}\left(\mathrm{Zn}^{+2}\right)$.

- When the $\mathrm{Zn}$ has been fully consumed, the $\mathrm{Cu}-\mathrm{Hg}$ amalgam is removed and directly disposed as nonhazardous low-level waste, or as LDR-compliant, treated RCRA waste

- Additional KDF 55 is installed in the filtration column

2.2.5.3 Development Status. Bench scale feasibility testing has been done on hospital wastewater with mercury concentrations of $11-90 \mu \mathrm{g} / \mathrm{L}(\mathrm{ppb})$. The method is apparently effective for removing ionic mercury but ineffective in removing organically bound mercury.

2.2.5.4 Applicability to NWCF. The commercial mercury extraction medium (KDF 55) was developed by treating potable wastewater at small mercury concentrations. The KDF representative indicated that at $\mathrm{pH}$ below 6.5, both the zinc and copper metals are digested by acid. He indicated that the commercial process would probably not work at the high acid concentrations present in NWCF, but offered to send enough of the product to allow testing to be done.

Notwithstanding the above comments, there may be some merit in the concept of replacing ionic mercury with another oxidized metal. Reference 1 states "mercury is displaced from solutions of its salts, whether mercurous or mercuric, by all metals except gold and the platinum metals". Reference 1 lists the following reaction of mercuric chloride with $\mathrm{Zn}$ :

\section{Eq 1: $\mathrm{HgCl}_{2}+\mathrm{Zn} \rightarrow \mathrm{Hg}+\mathrm{ZnCl}_{2}$}

In the high acid, high nitrate environments typical of NWCF aqueous streams it is likely that the high oxidizing potential will result in eventual digestion of both zinc and copper metals. However, based on the standard reduction potentials for $\mathrm{Hg}^{+2}$ and for NO3-, it is at least conceivable that a portion of the mercuric ion may be reduced before total consumption of the zinc. If this were to occur, and elemental mercury could be decanted from the bottom of the reaction vessel before it is ultimately digested, this method would provide a comparatively simple way to extract mercury from the acidic NWCF solutions.

2.2.5.5 Recommendation. This process may merit some exploratory laboratory-scale testing to determine: (a) whether the mercury in solution would be reduced at a high enough rate that it could be feasibly extracted, and if so, (b) whether the resultant reduced mercury would settle out at a rate that would make it feasible to decant it. 
Alternatively, the concept of a sacrificial zinc anode may merit testing in the electrowinning cell currently under feasibility testing by INTEC Technology Development personnel (J. Del Debbio) as an optimization approach.

\subsubsection{Displacement of $\mathrm{Hg}^{+2}$ by $\mathrm{Cu}$}

\subsubsection{References}

1. Maude, B.M., Wilkinson, K.L., "The Separation of Small Quantities of Mercury from Gross Amounts of Silver in Nitric Acid Solution," United Kingdom Atomic Energy Authority Research Group Memorandum, AERE-M 2008, 1968.

2. Tyson, D.R., Schwendiman, G.L., "Results of Bench-Scale Treatability Studies of Problematic Mercury Waste Types," Technology: Journal of the Franklin Institute, Vol. 334A, pp. 159$169,1997$.

3. Telecon with D.D. Siemer, 3/23/99.

4. Telecon with Barbara F. Smith (LANL) on 3/25/99.

5. Lotus Notes Memo from D.D. Siemer to D.D. Taylor on $4 / 6 / 99$.

\subsubsection{Process Description}

- Acidic solution containing mercury is processed batchwise in an appropriately-sized tank

- Copper filings are added to the tank and reduce oxidized mercury to elemental mercury

- Elemental mercury plates on the surface of the copper and amalgamates with it

- The $\mathrm{Cu}-\mathrm{Hg}$ amalgam is filtered from the solution as the tank is drained, with filtrate being recycled to the process

- Recovered amalgam is treated as required for disposal (either by washing and further amalgamation with sulfur, or by retorting followed by amalgamation with sulfur).

2.2.6.3 Development Status. This method was successfully demonstrated as described in Reference 1. Copper filings were added to the $\mathrm{Hg}$-containing acidic solution until subsequent additions of $\mathrm{Cu}$ remained bright. Percent recovery for the four tests report ranged from $95.9 \%$ in dilute $\mathrm{HNO}_{3}$ to

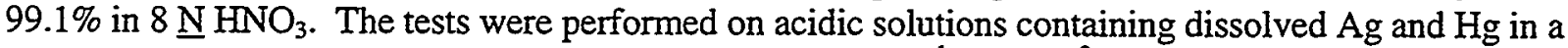
ratio of 100:1 (Ag: $\mathrm{Hg})$, and resulted in codisplacement of $\mathrm{Ag}^{+1}$ and $\mathrm{Hg}^{+2}$ from solution. Following filtration of the resulting $\mathrm{Ag} / \mathrm{Hg} / \mathrm{Cu}$ alloy from the solution it was heated to $700^{\circ} \mathrm{C}$ to recover elemental mercury.

In addition to the tests described in Reference 1, a number of tests were performed at the INEEL in the 1995-1997 timeframe that applied the subject method, as described in Reference 1. Though the focus of the testing was amalgamation of mercury, one series of tests involved the use of $\mathrm{Cu}$ metal to reduce and displace $\mathrm{Hg}^{+2}$ from nitric acid solution. These tests showed that most of the mercury could be removed from solution and amalgamated with the copper, provided the solution was vigorously mixed (steel balls were added to the $\mathrm{Cu}-\mathrm{Hg}-\mathrm{HNO}_{3}$ mixture and the container was sealed and shaken for several minutes). 
To explore the feasibility of using this approach in NWCF, a limited set of exploratory tests were performed this year by D.D. Siemer at TRA on three tank farm simulants having $\mathrm{HNO}_{3}$ concentrations between 1.5 and $2.0 \underline{\mathrm{M}}$ (Reference 4). Small ribbons of copper foil were cut and placed in a 3-in $\times 0.3$-in I.D. column. Simulant samples were pumped through this tube and the extraction efficiency of the copper was determined by comparing the inlet and outlet concentrations of $\mathrm{Cu}$ and $\mathrm{Hg}$. The tests indicated (a) that copper was rapidly digested into solution by the acid, and (b) that most of the copper did not reduce mercury from the solution. However, the same copper foil was used for all three simulants, and it was noted that the third test showed much better utilization $(-20 \%)$ of the copper. This may have been due to the fact that after the first two tests the copper surface was partially coated with mercury, and under this condition the kinetics of the $\mathrm{Hg}^{+2}$ reduction became relatively more favorable than the direct acid oxidation of the $\mathrm{Cu}$. (This was suggested by D. D. Siemer ${ }^{2}$ as a possible explanation for the apparent success of the tests described in Reference 1. Alternatively, it may have been due to the lower concentration of $\mathrm{HNO}_{3}(1.5 \underline{\mathrm{M}})$ in the third test than was present in the first two $(2.0 \underline{\mathrm{M}})$.

2.2.6.4 Applicability to NWCF. The method appears to be applicable to acidic, mercurycontaining solutions in NWCF. The presence of the silver in the solutions described in Reference 1 is clearly nonrepresentative of the NWCF streams. However, the Ag present in the test solutions was a consequence of the manner in which the $\mathrm{Hg}$ had been used in the process that generated the waste, and was not added to facilitate the $\mathrm{Hg}$ recovery. However, in light of the amalgamation tests of Tyson, and the scoping tests by Siemer it appears that the efficiency of the process is highly dependent on:

(a) peculiarities of the aqueous solution being treated, (b) the state of the copper employed to reduce the $\mathrm{Hg}^{+2}$, and/or (c) the intimacy of contact between reduced (elemental) mercury and the remaining metallic copper in the reactor vessel.

In addition to the issues of efficiency of $\mathrm{Cu}-\mathrm{Hg}$ replacement in solution there are additional issues of concern for this process. First, it is clear that in order to extract most of the mercury from the solution a significant quantity of copper must be placed back into the solution. While copper is nonhazardous from a RCRA standpoint, it may present problems for solutions that eventually would be processed through the calciner. At a minimum, a new flowsheet would require testing in the cold pilot plants for NWCF. A second concern is the handling of the precipitated $\mathrm{Cu}-\mathrm{Hg}$ amalgam. In the tests described in Reference 1, this amalgam often failed to pass TCLP testing to comply with LDRs. Therefore, it is likely that the mixture would require further treatment before it could be properly disposed.

2.2.6.5 Recommendation. The primary motivations for considering this method are the conceptual simplicity and the supposed robustness of the process. However, the foregoing discussion regarding variability of the mercury removal efficiency, and the likelihood that additional treatment of the $\mathrm{Cu}-\mathrm{Hg}$ residue would likely be needed, largely negate the presumed advantages of the method. For this reason, further testing is not recommended at this time.

\subsubsection{Displacement of $\mathrm{Hg}^{+2}$ by $\mathrm{Al}$}

\subsubsection{References}

1. Greenhalgh, W.O., "Recovery Of Mercury From Acid Waste Residues", United States Statutory Invention Registration (U.S. Patent Application), Registration Number H715, December 5, 1989.

2. Lotus Notes Memo from D.D. Siemer to D.D. Taylor on $4 / 14 / 99$ (see attachments to this report) 


\subsubsection{Process Description}

- Acidic solution containing mercury is processed batchwise in an appropriately-sized tank

- Aluminum filings or powder are added stoichiometrically to the tank and reduce (nearquantitatively) oxidized mercury to elemental mercury

- Elemental mercury precipitates out of solution and collects on bottom of tank

- Mercury metal is decanted from bottom of tank before it is attacked by acidic nitrate solution and reoxidized

- Aqueous solution is slightly enriched in $\mathrm{Al}^{+3}$ (due to partial direct oxidation of $\mathrm{Al}$ by acid/nitrate) and is recycled to calciner

- $\quad$ Recovered $\mathrm{Hg}$ metal is washed and amalgamated with sulfur for disposal as LDR-compliant low-level waste.

2.2.7.3 Development Status. This method was demonstrated as described in Reference 1 in $1 \underline{\mathrm{M}}$ nitric acid solutions containing $0.2-0.4 \underline{\mathrm{M}}$ mercuric nitrate without chloride present. Sufficient powdered aluminum was added to create a $0.37-0.74 \underline{\mathrm{M}}$ solution if all the aluminum was dissolved. The mixtures were heated to $60-70^{\circ} \mathrm{C}$ and allowed to react for $10-15$ minutes. After a sizeable ball of elemental mercury was observed in the bottom of the reactor vessel the reaction was quenched by the addition of cold water. The mercury was decanted and monitored for several days during which no deterioration was observed.

To explore the feasibility of using this approach in NWCF, a limited set of exploratory tests were performed this year by D. D. Siemer at TRA on scrub simulant having $\mathrm{HNO}_{3}$ concentrations of $0.1,1.0$, and $3.0 \underline{\mathrm{M}}, \mathrm{Hg}^{+2}$ concentration of $0.15 \underline{\mathrm{M}}$, and $\mathrm{Cl}^{-}$concentration of $0.14 \underline{\mathrm{M}}$ (Reference 2). The balancing cation was $\mathrm{Al}^{+3}$. Sufficient aluminum powder was added to these solutions to reduce $80 \%$ of the mercury if the reduction were $100 \%$ efficient. The $3 \mathrm{M}$ acid solution was duplicated and one of the solutions was placed in a boiling water bath with a small amount of aluminum foil added (in addition to the aluminum powder). The solutions were observed for a period of 14-18 hours, during which time a small amount of calomel $\left(\mathrm{Hg}_{2} \mathrm{Cl}_{2}\right)$ was observed to form in each solution. Significantly more calomel was formed in the $0.1 \mathrm{M}$ acid solutions than in the others. From a gravimetric measurement, the calomel in this solution contained roughly $19 \%$ of the mercury that had originally been added. No elemental mercury was observed to collect in any of the solutions.

2.2.7.4 Applicability to NWCF. The method described in Reference 1 appeared to be directly applicable to scrub solutions in NWCF, based on mercury and acid concentrations. However, the absence of chloride in the tests described in Reference 1 appears to be a significant factor in the apparent success of these tests. The presence of chloride appears to cause the principal reaction product to become calomel rather than elemental mercury. Calomel is sufficiently insoluble in the acid solution that it could possibly be separated by filtration, though not as easily as elemental mercury. However, in order to prepare the recovered calomel for disposal it would likely have to be retorted to recover elemental mercury, and then amalgamated.

This procedure might be feasible if mercury was quantitatively recovered from the reduction by aluminum. The scoping tests, however, indicated that this is probably not possible. The highest mercury recovery was only $19 \%$ in $0.1 \mathrm{M} \mathrm{HNO}_{3}$, and appears to have been much lower at the higher acid concentrations. 
2.2.7.5 Recommendation. As in the case of mercury reduction with copper, the primary motivations for considering this method are simplicity and robustness of the process. However, the fact that calomel was recovered (and not elemental mercury), and that retorting of the calomel would likely be necessary for RCRA disposal, makes the method less attractive. This, together with the fact that a relatively small fraction of the mercury in solution is recoverable by this method, prompts the recommendation that further testing of this method not be pursued.

\subsubsection{Ligand Sorbent Extraction}

\subsubsection{Reference}

Taylor, P.A., Klasson, K.T., Corder, S.L., Carlson, T.R., and McCandless, K.R., "Mercury Separation from Mixed Wastes, Annual Report," Oak Ridge National Laboratory (ORNL) Chemical Technology Division, ORNL/TM-13121, November 1995.

\subsubsection{Process Description}

- Adsorbent material (SuperLig 618, consisting of a ligand material bonded to a silica gel support) is installed in one or more filtration columns

- Hg-containing liquid is pumped through the column with mercury being adsorbed by the adsorbent material

- Once saturated, the adsorbent is regenerated with $6 \underline{\mathrm{M}} \mathrm{HCl}$ with $0.5 \underline{\mathrm{M}} \mathrm{HBr}$ or a strong complexing agent (ethylenedinitrilotetraacetic [EDTA], citrate, or thiourea)

- Regenerated resin is reused to process additional Hg-containing liquid

- Hg-laden regenerating fluid is treated to remove mercury and disposed (e.g., the fluid might be neutralized with $\mathrm{NaOH}$ and precipitated with sulfide. Mercury precipitate could then be retorted and amalgamated or direct grouted. The supernatant liquid could be direct disposed or treated per LDR requirements and then disposed.)

- $\quad$ Spent resin would be replaced with new resin (as required), treated (e.g., by incineration with suitable mercury emission control), and disposed.

2.2.8.3 Development Status. The resin is manufactured by IBC Advanced Technology (American Fork, Utah), is commercially available, and has been successfully tested in laboratory-scale column tests at $\mathrm{ORNL}$ using simulated INEEL SBW at $\left[\mathrm{HNO}_{3}\right]=1.6 \mathrm{M}$. The column tests showed the resin to be fully effective for about three cycles (two regenerations), capturing $50-60 \mathrm{mg} \mathrm{Hg}$ per loading cycle in a column containing $1.62 \mathrm{gm}$ of resin $(-34 \mathrm{mg} \mathrm{Hg} / 1,000 \mathrm{mg}$ resin, or $3.4 \mathrm{wt} \%$ loading). Mercury recovery during column regeneration was significantly degraded during the fourth and fifth regenerations, and mercury uptake was degraded after four loading cycles.

2.2.8.4 Applicability to NWCF. The process could be applied directly to NWCF tank farm waste, and probably also to NWCF scrub liquor (though the latter has an acid concentration 2-4 times that of the tank farm waste). Treatment and disposal of both spent resin and regenerating fluids would have to be devised and tested, however.

2.2.8.5 Recommendation. The nominal cost of the resin quoted in the above reference is $\$ 30 / \mathrm{gm}$, with some discount for production quantities. If we assume the resin may be purchased for $\$ 15 / \mathrm{gm}$, and 
that five resin loading cycles are achievable at $3.4 \mathrm{wt} \% \mathrm{Hg}$ loading per cycle, the resin cost per gram of $\mathrm{Hg}$ removed is $\$ 88.24 / \mathrm{gram} \mathrm{Hg}$. Based on roughly $1.5 \times 10^{6}$ gal of remaining tank farm waste at an average mercury concentration of $1.13 \times 10^{-3} \mathrm{M}$, the total mercury to be removed is about $2,800 \mathrm{lbm}$. The corresponding resin cost would thus be about $\$ 112$ Million.

The above cost does not account for any costs associated with treatment and disposal of the secondary mercury wastes discussed above. In addition, there are no demonstrated treatment methods for handling these secondary wastes. Based on these considerations, testing of this process on NWCF waste streams is not recommended.

\subsubsection{Sorption of $\mathrm{Hg}^{+2}$ on Silica-Titania Gel}

\subsubsection{Reference}

Thomas, R., Anirudhan, T.S., "Equilibrium Studies for the Sorption of $\mathrm{Hg}(\mathrm{II})$ on Silica-titania

Mixed-oxide Gel," Journal of Scientific \& Industrial Research, Vol. 57, September 1998, pp. 529535.

\subsubsection{Process Description}

- Sorbent material (silica-titania gel precipitated from solution by addition of $\mathrm{NaOH}$ ) is installed in one or more filtration columns.

- Hg-containing liquid is pumped through the column with mercury being adsorbed by the adsorbent material

- Once saturated, $\mathrm{Hg}$ is eluted from the sorbent with $0.2 \mathrm{M} \mathrm{HCl}$

- Regenerated sorbent is reused to process additional Hg-containing liquid

- Hg-laden regenerating fluid is treated to remove mercury and disposed (e.g., fluid might be neutralized with $\mathrm{NaOH}$ and precipitated with sulfide. Mercury precipitate could then be retorted and amalgamated or direct grouted. The supernatant liquid could be direct disposed or treated per LDR requirements and then disposed.)

- Spent resin would be replaced with new resin (as required), treated, and disposed.

2.2.9.3 Development Status. Only laboratory-scale experiments were reported with no mention of commercialization of the process. Up to $90 \%$ of the mercury in test solutions (0.001 $\mathrm{M}$ total ionic

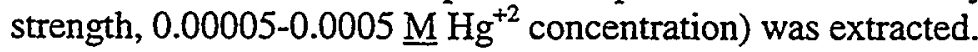

2.2.9.4 Applicability to NWCF. Test results indicate a fairly strong dependence of mercury extraction on $\mathrm{pH}$ over a test range of $\mathrm{pH} 2$ to 10 . Optimal results were at $\mathrm{pH} 6$, with $\sim 50 \%$ extraction at $\mathrm{pH} 2$ and 10 . Elution with $0.2 \mathrm{M} \mathrm{HCl}$ indicates that the sorbent probably would not be effective in strong acid solutions typical of NWCF feeds and scrubs.

2.2.9.5 Recommendation. Based on probable ineffectiveness in strong acid solution testing of this process on NWCF waste streams is not recommended. 


\subsubsection{Adsorption of Gaseous $\mathrm{Hg}^{+2}$ With Silica Gel}

\subsubsection{References}

1. LMITCO Interdepartmental Communication from R.E. Schindler to B.H. O'Brien, "MERCURY BEHAVIOR DURING NWCF RUN H-4" dated January 25, 1999, Schi-03-99

2. Appendix B (this report).

\subsubsection{Process Description}

- Offgas from NWCF Ru adsorbers is routed through a set of scrubbing columns packed with silica gel

- $\quad \mathrm{Hg}$ is adsorbed from offgas onto silica gel

- An HNO3 solution is trickled through the silica gel to remove $\mathrm{Hg}$

- Hg-laden acid scrub is neutralized and mercury is precipitated with $\mathrm{CaS}$ to $\mathrm{HgS}$, which passes TCLP and may be land-disposed

- Supernate from above precipitation is recycled to tank farm.

- Alternatively, buildup of $\mathrm{Hg}$ in the tank farm could be avoided by removing it from the scrub solution by electrodeposition. The mercury could then be amalgamated for disposal.

2.2.10.3 Development Status. R. E. Schindler performed a mass balance on mercury for the H-4 calcination campaign and concluded that about $10 \%$ of the mercury input is unaccounted for in recycled scrub solutions and gaseous emissions (Reference 1). He suggests that one possible explanation for the discrepancy is adsorption of $\mathrm{Hg}$ by silica gel in the Ru adsorbers. If this is the case, it suggests the above scheme as a relatively inexpensive and robust method to "polish" the NWCF offgas by removing residual $\mathrm{Hg}$ after the venturi scrubber.

For this reason, tests were performed at the INEEL (see Appendix B) during FY 1999 to investigate the effectiveness of silica gel as a scrubbing agent for mercury. The tests indicated that silica gel will not efficiently scrub elemental mercury whether or not it is washed with $4 \mathrm{M} \mathrm{HNO}_{3}$. Silica gel does appear to scrub oxidized mercury. However, the scrubbing efficiency attained in the tests was not consistent, varying from very to very high values. The testing suggests that silica gel washed with $4 \mathrm{M}$ $\mathrm{HNO}_{3}$ is more effective than either dry or water-washed silica gel.

The testing as documented in Appendix B also showed that elemental, gas phase mercury can be efficiently oxidized by contact with $\mathrm{NO}_{2}$ at concentrations of 15,000-20,000 ppm, typical of NWCF offgas. Mercury and $\mathrm{NO}_{2}$ at high concentrations are also likely to be present in offgases from other waste denitration processes contemplated for use in treatment of INEEL calcines. The test results strongly suggest that $\mathrm{NO}_{2}$ could be exploited to oxidize $\mathrm{Hg}$ in these offgases so that it could be efficiently scrubbed downstream by $\mathrm{HNO}_{3}$-washed silica gel. Alternatively, further testing may indicate how the current offgas system in NWCF might be modified to achieve the same result.

2.2.10.4 Applicability to NWCF. The proposed process could be applied to NWCF with modifications. Schindler indicates in Reference 1 that about $3 \%$ of the $\mathrm{Hg}$ fed to the calciner is emitted to the stack. This quantity of mercury would not be acceptable based on the MACT requirement of 
$120 \mu \mathrm{g} / \mathrm{dsm}^{3} @ 7 \% \mathrm{O}_{2}$ the MACT limit for existing facilities. Therefore, the present ruthenium adsorbers would have to be augmented with suitably designed secondary silica gel scrubbing columns, to achieve the MACT standard. This would require a retrofit to the existing offgas system in NWCF. However, it could conceivably be done downstream of the high-efficiency particulate air (HEPA) filters in a noncontaminated area, reducing the cost of the retrofit. Assuming the collected $\mathrm{Hg}$ would be nonradioactive, the treatment of the secondary waste stream could also be done in a nonshielded facility.

2.2.10.5 Recommendation. It is recommended that the testing described in Appendix B be extended to quantify the impacts of key process parameters (e.g., water content of offgas, residence time upstream of scrubber, etc.) on mercury oxidation efficiency. The testing should include scrubber testing at various gas/liquid contact ratios and residence times to (a) determine whether efficient scrubbing of oxidized $\mathrm{Hg}$ can be reliably and repeatably obtained, and (b) determine design conditions required to obtain efficiency scrubbing.

\subsubsection{Precipitation of Hg From Acid Scrub With TMT}

\subsubsection{References}

1. Personal communication from Ernest W. Haug (Degussa Corp.) to D. D. Taylor (LMTCO), "Addendum to TMT-99-14" (white paper report describing scoping tests of TMT-15 on 1000 $\mathrm{ppm} \mathrm{HgSO}_{4}$ in $3.5 \underline{\mathrm{M}} \mathrm{HNO}_{3}$ ).

2. Appendix B (this report).

\subsubsection{Process Description}

- Liquid TMT chelating agent is added to a batch reactor tank in an amount that is substoichiometric to the expected amount of $\mathrm{Hg}+2$ in the stream to be treated

- $\mathrm{Hg}^{+2}$-laden stream is introduced into the tank and sparged continuously with air to maintain TMT in suspension

- TMT continually dissolves and immediately chelates with $\mathrm{Hg}+2$ in solution, precipitating from the solution

- Following a prescribed batch reaction time, sufficient to complex all the TMT, the air sparge is discontinued and the precipitated Hg-TMT complex settles out

- Supernatant liquor is decanted, filtered (or centrifuged), and recycled

- $\quad$ Residual solid Hg-TMT complex is washed to remove residual acid. Solid Hg-TMT passes TCLP and may disposed as a treated, LDR-compliant mixed waste.

2.2.11.3 Development Status. Scoping tests were performed by Degussa Corporation, on a $3.5 \underline{\mathrm{M}}$ $\mathrm{HNO}_{3}$ solution containing $962 \mathrm{ppm} \mathrm{Hg}^{+2}$ (added as $\mathrm{HgSO}_{4}$ ). The resulting $\mathrm{Hg}^{+2}$ concentration was roughly $0.005 \mathrm{M}$. This solution was treated with TMT, agitated for a period of 25-30 minutes. The solution was then filtered, sampled, and analyzed for mercury using atomic absorption. Results indicated $>99 \%$ removal of the mercury from solution by the TMT. (see Reference 1)

As a result of the above favorable results tests were performed during FY 1999 (see Ref. 2) at the INEEL on an acidic, sodium bearing waste (SBW) simulant to determine whether TMT would perform 
equally well with a more realistic waste simulant than was used by Degussa in their scoping tests. The results of these tests were unfavorable. In the raw SBW simulant the TMT failed to remove a measurable fraction of the dissolved $\mathrm{Hg}^{+2}$. With addition of sulfamic acid (to suppress nitrogen oxidation) it removed about $13 \%$ of the mercury. Subsequently, tests were performed in partially neutralized SBW simulant and in fully neutralized simulant ( $\mathrm{pH}-13$ ). The TMT removed about $12 \%$ and $66 \%$, respectively in these tests. However, a large quantity of caustic addition was needed to accomplish this which also resulted in precipitation of a significant quantity of $\mathrm{Al}(\mathrm{OH})_{3}$.

The poor performance of TMT in the SBW simulant tests was attributed to the high chloride content (relative to mercury) of the simulant.

2.2.11.4 Applicability to NWCF. The proposed process could be applied to NWCF with retrofitting. At a minimum, a suitably-sized reactor tank would be needed. One of the blend and hold tanks may possibly be used for this purpose, provided the tank was replumbed to allow decanting of the supernatant liquid to another tank following precipitation and sluicing of the solid precipitate to another location with a wash tank and filtering setup. Liquids from the filtering/washing operation would be sent back to the NWCF feed tank and the residual solid Hg-TMT complex would be dried and packaged for disposal.

An altemative application is to remove $\mathrm{Hg}^{+2}$ directly from liquid SBW before calcination. This might also be accomplished using one of the blend and hold tanks as described above. This approach has the advantage of lower acid concentration in the feed stream, which increases the effectiveness of the TMT in precipitating the $\mathrm{Hg}^{+2}$ from solution and reduces the likelihood of degrading the TMT.

2.2.11.5 Recommendation. Based on the testing at INEEL, it is recommended that TMT not be considered further for removal of $\mathrm{Hg}^{+2}$ from acidic INEEL liquid wastes containing chloride in concentrations which approach or exceed those of mercury.

\subsubsection{Scrubbing of Gaseous $\mathrm{Hg}^{+2}$ With TMT}

\subsubsection{References}

1. Telecon between Elfriede Sextl (Degussa-Hüls) and D. D. Taylor (LMITCO) on 5/18/99, regarding the application of Degussa's "Wessalith-DAY" and "TMT" products for removal of elemental and oxidized mercury, respectively from offgas streams.

2. Appendix B (this report).

\subsubsection{Process Description}

- Liquid TMT chelating agent is blended with water in a new, secondary scrubbing system for NWCF offgas, between NWCF and the INTEC Atmospheric Protection System (APS; i.e., the main INTEC stack)

- Offgas from the existing NWCF offgas system, downstream of the HEPA filters, is heated to the required temperature to prevent condensation of water in the secondary scrubber

- Heated NWCF offgas is scrubbed with the TMT-water scrubbing solution using either a second venturi scrubber or a packed bed to effect the required liquid/gas contact

- Treated NWCF offgas is routed to the APS and thence to the INTEC stack 
- TMT-water scrubbing solution is routed to a settling tank (or other suitable liquid/solid separation operation) to remove precipitated Hg-TMT complex. Additionally, the $\mathrm{pH}$ of the scrubbing solution is adjusted with $\mathrm{CaO}$, lime, or caustic to maintain optimal scrubbing capacity of the TMT

- Sludge, containing the precipitated Hg-TMT complex and dried for disposal

2.2.12.3 Development Status. From Reference 1 it was inferred that the Degussa product, TMT, is currently being used in industrial scrubbers in Europe to reduce gaseous emissions of mercury. European emission standards for mercury are assumed to be comparable to U.S. MACT standards. Thus, it appears likely that there is a significant experience base for this technology. For this reason, laboratory scrubber testing with TMT in water to remove $\mathrm{Hg}^{+2}$ from the gas phase was recommended. Such testing was attempted at the INEEL during FY 1999 (see Appendix B). However, it was found that gaseous $\mathrm{HgCl}_{2}$ is unstable and a suitable test gas could not be generated. Evaluation of the TMT for this application was therefore not completed.

2.2.12.4 Applicability to NWCF. The proposed process might be applied to NWCF offgas with the addition of a new secondary scrubbing system outside NWCF. Since the NWCF offgas downstream of the HEPA filters contains only minute quantities of radionuclides, it is assumed that such a scrubbing system could be built and operated as a nonradioactive facility. This would greatly reduce the cost of construction and operation, as well as the risk of radioactive contamination of workers. If the Hg-TMT complex passes TCLP then it is likely that it could be disposed in a subtitle C RCRA facility for mixed waste, such as Envirocare of Utah.

2.2.12.5 Recommendation. From the testing described in Ref. 2 it was tentatively concluded that (a) wet scrubbing of pure $\mathrm{HgCl}_{2}$ from the gas phase would likely be very effective, with or without TMT addition to the scrubbing solution, and (b) wet scrubbing of other oxidized forms of $\mathrm{Hg}$ may not be as easy as $\mathrm{HgCl}_{2}$. The effectiveness of TMT added to a scrubbing solution should therefore still be tested but with other divalent forms of $\mathrm{Hg}$ (i.e., besides $\mathrm{HgCl}_{2}$ ).

\subsubsection{Conclusions}

Technologies have been briefly evaluated in this section in an effort to determine if there are proven methods to remove mercury from acidic NWCF streams apart from the electrochemical reduction method being developed separately at the INEEL. Based on a literature review, several technologies appeared to have potential application to NWCF feed or scrub solution. However, small-scale tests of most of these methods with NWCF surrogates demonstrated the methods ineffective or problematic:

Precipitation of mercury with TMT is not recommended because of test results (see Appendix B) that showed low removal efficiencies.

Photocatalysis with $\mathrm{TiO}_{2}$ is not recommended because of test results that showed the need to use an organic and the resulting safety issues related to adding organics to NWCF streams.

Displacement of $\mathrm{Hg}^{+2}$ by copper or aluminum is not recommended because of test results that showed dissolution of copper by acid and low mercury removal efficiencies.

Oxidation of gaseous elemental $\mathrm{Hg}$ using $\mathrm{NO}_{2}$ present in offgases from present or proposed denitration processes may allow efficient wet scrubbing of $\mathrm{Hg}$ with silica gel. Further testing is suggested to determine whether this process is viable. 
Ashworth (Appendix A) recommended two of the above technologies, precipitation with TMT and photocatalysis with TiO2, as backup methods for electrochemical reduction. However, based on the test results (Appendix B) for these technologies, these do not appear feasible.

\subsection{Recommended Technology Development}

Development activities related to mercury removal are summarized below.

\subsubsection{Mercury Removal in Separations Processes}

The following development activities are recommended:

1. Perform pilot-scale demonstration tests for removal of mercury from the TRUEX carbonate wash effluent by precipitation with calcium sulfide. These tests would include: (a) a demonstration of - separation of the mercury precipitate from the supernate, (b) TCLP analyses of the mercury precipitate to confirm that it would meet RCRA requirements for land disposal, and (c) determining what, if any, additional processing of the precipitate would be required before packaging for disposal.

2. Determine the upper limit of mercury that will be present in the feed to the WS facility. This will involve evaluating the compositional variations in calcine Bin Set strata and defining a calcine blend strategy.

3. Obtain distribution data from TRUEX and SREX for the calcine composition, determined in Recommendation \#2, that has the highest proportion of alumina calcine. Use the analysis of the TRUEX carbonate wash effluent from these tests to define the feed for the pilot-scale mercury removal tests of Recommendation \#1.

4. Determine the effect of mercury concentration in the SREX solvent on its performance by extended SREX runs with a high mercury feed, and based on these effects as well as optimizing mercury removal by TRUEX, determine if mercury removal from the SREX solvent is required. If mercury removal from the SREX solvent is found to be required, develop and test removal methods.

5. Test systems to remove mercury from expected LAW and HAW offgas compositions to: (1) demonstrate that the MACT emission limit can be met, (2) determine the effect of offgas temperature on mercury removal (3) determine the effect of gas inlet mercury concentration on mercury removal

(4) determine the required residence time and its relation to feed temperature and composition, and

(5) determine the quantity and characteristics of the resulting mercury-waste. A precursor to this effort is to accurately detemine mercury speciation in offgas streams and optimize upstream scrub steps for mercury removal.

\subsubsection{Mercury Removal from NWCF Streams}

Recommendations regarding removal of mercury from the scrub solution or feed by electrochemical reduction and from the NWCF offgas will be found in separate reports to be issued in FY-99. As a backup for the electrochemical reduction process, scoping tests of galvanic reduction are recommended. These tests could include both using zinc or KDF 55 as a sacrificial anode in an acidic waste, as recommended in Section 2.2.5.5, and tests of reduction of mercury by copper or zinc in a neutral solution, as described by Ashworth (Appendix A, Section 6.10.2). In order to better select a system for mercury removal from NWCF streams, Ashworth (see Appendix A) also recommends preparing preliminary design and rough order of magnitude cost estimates for three processing schemes - (a) installation of a new scrubber plus electrochemical reduction of scrub solution, (b) installation of a new 
scrub collection tank for the venturi scrubber plus electrochemical reduction of scrub solution, and (c) electrochemical reduction of mercury from the calciner feed.

Taylor (Appendix B) recommends:

1. Additional tests should be conducted to characterize the oxidation of $\mathrm{Hg}$ by $\mathrm{NO}_{2}$. This testing should be done in a carefully-designed test bed, capable of maintaining $\pm 1^{\circ} \mathrm{C}$ temperature variation. Testing should be done with all glass tubing and reaction vessels, with provision for insertion of stainless steel (and other materials) to determine its effect on the oxidation of $\mathrm{Hg}$. Provision should also be made to control the concentration of water vapor in the gas phase and the residence time after injection of $\mathrm{NO}_{2}$. A real time monitor for $\mathrm{NO}_{\mathrm{x}}$ should be used to measure the actual concentration. Real time monitoring of elemental and total $\mathrm{Hg}$ would also be desirable, if possible.

2. Additional tests should be conducted to determine the scrubbing efficiency of silica gel for $\mathrm{Hg}$ that has been oxidized with $\mathrm{NO}_{2}$. This testing should be done with stable inlet and outlet concentrations of oxidized $\mathrm{Hg}$ in the scrubber, and with accurate determination of gas and scrubbing solution flow rates. Test should be done with water, $4 \mathrm{M} \mathrm{HNO}$, and TMT- 15 in water as the scrubbing agents. If possible testing should be done with both $\mathrm{HgCl}_{2}$ and with whatever oxidized form of $\mathrm{Hg}$ is produced by contact with $\mathrm{NO}_{2}$.

3. The offgas system and recently obtained qualified gaseous emission data from NWCF should be analyzed in light of data from the above advanced testing program to determine how the system could be modified to remove $\mathrm{Hg}$ to MACT-compliant levels. 


\section{TECHNETIUM}

\subsection{Introduction}

${ }^{99}$ Technetium is a long-lived fission product present in small concentrations in SBW and calcine. Based on present material balances for the Full Separations process, a large percentage $(-60-70 \%)$ of the technetium in the feed is captured by the TRUEX solvent and then is washed from the solvent into the carbonate wash effluent. More recent data from the FY-99 integrated TRUEX tests, which used rhenium as a surrogate for $\mathrm{Tc}$, show only $19.4 \%$ of the rhenium in the carbonate wash effluent, $36.3 \%$ in the TRUEX strip effluent, and $44.3 \%$ remaining in the TRUEX raffinate. A portion of the technetium present in HAW streams will volatilize in the melter, and through recycle of the HAW offgas scrub liquid, also end up in LAW streams. If not removed from LAW effluents, ${ }^{99} \mathrm{Tc}$ will end up in the LAW grout. Depending on the feed concentration of ${ }^{99} \mathrm{Tc}$, the concentration of ${ }^{99} \mathrm{Tc}$ in the grout may exceed the NRC ${ }^{99} \mathrm{Tc}$ limit for Class A grout. Even if the ${ }^{99} \mathrm{Tc}$ concentration does not exceed the NRC Class A limit, it may contribute sufficiently to the "sum of the fractions" of Class A limits to require removal.

Additional regulatory drivers that may come into play for requiring technetium separation are DOE Order 435.1, "Radioactive Waste Management," and Comprehensive Environmental Response, Compensation, and Liability Act (CERCLA) regulations. In reference to incidental waste, DOE Order 435.1 states that "key radionuclides," which include ${ }^{99} \mathrm{Tc}$, must be removed to "the maximum extent that is technically and economically practical."

DOE Order 435.1 states in Section II.B.(2)(a) that waste incidental to reprocessing will be managed as low-level waste and:

1. Will be managed to meet safety requirements comparable to the performance objectives set out in 10 CFR Part 61, Subpart C, Performance Objectives.

2. Are to managed, pursuant to DOE's authority under the Atomic Energy Act of 1954, as amended, and in accordance with the provisions of Chapter IV (LLW) of this Manual, provided the waste will be incorporated in a solid physical form at a concentration that does not exceed the applicable concentration limits for Class Clow-level waste as set out in 10 CFR 61.55, Waste Classification; or will meet alternative requirement for waste classification and characterization as DOE may authorize.

DOE Order 435.1 guidance, pages $\Pi 1-22$ and 23 , states:

Processing to remove the key radionuclides to the extent technically practical could be a chemical treatment process or a physical removal process. The examination of such processes should include a range of alternatives - from processes that have been demonstrated by plantscale experience to be practical to those that have been demonstrated to be impractical due to their technological immaturity, uncertainty, or risk. Selection of the chosen "technically practical process" must be evaluated to a sufficient degree through a formal, documented assessment of such factors as technical risk, incompatible physical or chemical requirements with the waste, and potential impacts to the public, the worker and the environment.

The economically practical part of this requirement is determined by the development of total life-cycle costs for an alternative, or unit costs, e.g.; costs per curie removed. Some subjectivity will be present in determining whether these costs are economically practical; however in general, the goal should be to determine a relationship between costs and removal of the key radionuclides and identify the point in this relationship at which removal costs increase 
significantly and thus become impractical. An economic assessment may not be considered necessary if a technology option is not first considered to be technically practical.

Under CERCLA, a radiological performance assessment must show that performance objectives of the disposal site for the LAW must be met. Because of ${ }^{99}$ technetium's high solubility, long half-life and high mobility, ${ }^{99} \mathrm{Tc}$ often poses a high health hazard in performance assessments. The high risks associated with ${ }^{99} \mathrm{TC}$ transport resulted in changing the LAW waste form at Hanford from grout to glass.

\subsection{Evaluation of Need for Technetium Removal}

Wenzel ${ }^{11}$ estimated the concentration of ${ }^{99} \mathrm{Tc}$ in SBW to be $1.2 \times 10^{-5} \mathrm{Ci} / \mathrm{L}$, based on a decay date of 2016. For on a present inventory of 1.1 million gallons of waste, 8 SBW thus contains about $50 \mathrm{Ci}$ or 3 $\mathrm{kg}$ of technetium. TRUEX:

The Full Separations material balance ${ }^{10}$ for SBW shows the following partitioning of ${ }^{99} \mathrm{Tc}$ in

$\begin{array}{lr}\text { Raffinate } & 13.8 \% \\ \text { HAW Strip } & 25.3 \% \\ \text { Carbonate Wash } & 60.7 \% \\ \text { Acid Rinse } & 0.2 \%\end{array}$

In lieu of Tc data for SREX, default distribution coefficients were used in the SBW material balance and hence all Tc in the SREX feed is shown contained in the SREX raffinate. However, the SREX solvent is known to extract technetium. ${ }^{12,13}$ Much of the technetium in TRUEX and SREX HAW strip solutions will also end up in LAW streams, either being vaporized in the HAW evaporator or via recycle of melter offgas liquids.

The amount of technetium retained in glass can vary between 0 and $60 \%$ depending on the chemical form of technetium in the feed and the melt conditions. ${ }^{14}$ The chemical form of Tc in the TRUEX strip is suspected to be pertechnetate, $\mathrm{TcO}_{4}^{-}$, but is not known. For processing SBW in the WTF, without separating technetium and using the range of $0-60 \%$ retention of $\mathrm{Tc}$ in glass, the concentration in the LAW grout ${ }^{\mathrm{h}}$ would be $0.023-0.027 \mathrm{Ci} / \mathrm{m}^{3}$. These concentrations are $8-9 \%$ of the NRC Class A grout limit. Hence for SBW, technetium does not need to be removed to meet the NRC Class A grout limit.

Table 1 shows the estimated concentration of technetium in calcine.

\footnotetext{
s The combined volume of WM-180, WM-181, WM-184 and WM-186 on December 31, 1998 as per http://wcb08/nicht/jm/tankdata/Tankmap.htm.

${ }^{\mathrm{b}}$ Based on a grout volume of 1822 cubic meters.
} 
Table 1. Technetium in Calcine ${ }^{i}$

\begin{tabular}{lcc}
\hline & $\mathrm{Tc}, \mathrm{mg} / \mathrm{kg}$ & $\mathrm{Tc}, \mathrm{kg}$ \\
\hline Bin Set 1 & 140 & 25.6 \\
Bin Set 2 & 26 & 28.1 \\
Bin Set 3 & 32 & 44.6 \\
Bin Set 4 & 38 & 24.8 \\
Bin Set 5 & 38 & 54.3 \\
Bin Set 6 & 20 & 12.9 \\
Total & & 190.3 \\
\hline
\end{tabular}

Table 2 shows the partitioning of technetium in TRUEX and SREX for alumina and zirconia calcine feeds.

Table 2. Partitioning of Tc in Calcine Full Separations Material Balances. ${ }^{10}$

\begin{tabular}{|l|c|c|c|c|}
\hline \multirow{2}{*}{$\begin{array}{l}\text { Values shown are the } \\
\text { percentage of Tc in the }\end{array}$} & \multicolumn{2}{|c|}{ Zirconia calcine } & \multicolumn{2}{c|}{ Alumina calcine } \\
\cline { 2 - 5 } $\begin{array}{l}\text { TRUEX or SREX feed } \\
\text { that partitions to the: }\end{array}$ & TRUEX & SREX & TRUEX & SREX \\
\cline { 2 - 5 } & & & & \\
\hline Raffinate & 25.2 & 13.3 & 25.2 & 12.2 \\
\hline HAW Strip & 3.3 & 85.7 & 3.3 & 87.6 \\
\hline Carbonate Wash & 71.5 & 0.7 & 71.5 & 0.2 \\
\hline Acid Rinse & - & 0.3 & - & 0.1 \\
\hline
\end{tabular}

Based on the above TRUEX and SREX distributions of $\mathrm{Tc}$ and a $0-60 \%$ retention of $\mathrm{Tc}$ in the melter, the concentration of ${ }^{99} \mathrm{Tc}$ in LAW grout for alumina calcine is $0.48-0.57 \mathrm{Ci} / \mathrm{m}^{3}$, and for zirconia calcine, $0.22-0.26 \mathrm{Ci} / \mathrm{m}^{3}$. These concentrations are $160-190 \%$ and $72-85 \%$ of the NRC limit for Class A grout, respectively. For zirconia calcine, the sum of the fractions would be 1.3-1.5, exceeding the NRC limit of 1.0 .

If calcine from all bins could be evenly blended, as reflected in the "Total Calcine" material balance, the ${ }^{99} \mathrm{Tc}$ concentration in the grout would be about 70-80\% of the NRC limit for Class A grout. In this case, the low Tc-concentration calcine from Bin Set 6 more than offsets the high Tc-concentration from Bin Set 1. The sum of the fractions of NRC limited radionuclides would be about 1.4. In order to reduce the sum of the fractions to less than 1.0 , removal of technetium would likely be much less costly than increasing the removal efficiencies of both cesium and strontium.

\footnotetext{
'Based on Excel file received from Dan Staiger, Jan. 28, 1999. Analysis of H-3 Calcine (B. A. Staples, "Radioassay of Calcines form H3 Campaign of the NWCF," BAS-1-95, Jan. 16, 1995) showed $32.65-35.75 \mathrm{mg} / \mathrm{kg}^{99} \mathrm{Tc}$.
} 
There is considerable uncertainty in many of the above values, both in estimates of the amount of technetium in SBW and calcine and its distribution in SREX and TRUEX. Past analytical methods used for technetium may have produced questionable results. Some actual data are available for the behavior of Tc in TRUEX for both SBW ${ }^{15}$ and zirconia calcine, ${ }^{16}$ but not for alumina calcine or for SREX. As previously mentioned, the form of technetium in the melter feed is not known, nor the fraction in the melter feed that will be retained in the glass. However, based on the present flowsheets for all calcine feeds, ${ }^{10}$ a high percentage of technetium in the feed will end up in the LAW grout, and the concentration of Tc in the grout will either exceed the NRC limit for Class A grout or cause the sum of the fractions of all NRC regulated radionuclides to exceed the limiting value of 1.0 .

\subsection{Technetium Removal Technologies}

Technologies for removal of technetium from liquid wastes include:

Ion exchange

Sorption on metal particles

Sorption on carbon

Extraction with organic solvents

Aqueous biphasic extraction

Extraction chromatography

Precipitation

Electrolytic reduction

Polymer filtration

Concentration using reverse osmosis followed by liquid membrane filtration and nanofiltration

Evaporation.

\subsubsection{Ion Exchange}

Ion exchange is a well-established process for technetium removal, ${ }^{12,17-32}$ and has been shown to be effective for removing technetium from:

Alkaline wastes

ORNL Newly Generated Liquid Wastes ${ }^{18,27}$

Hanford tank wastes ${ }^{17,19,20,24,28}$

ORNL Underground Storage Tank supernatant liquids ${ }^{23}$

West Valley PUREX waste ${ }^{26}$

$\mathrm{pH}$ adjusted Portsmouth raffinate ${ }^{32}$ 


\section{Neutral wastes}

Hanford groundwater 22

Paducah groundwater ${ }^{32}$

environmental waters in Pakistan ${ }^{31}$

unspecified radioactive wastes in Germany ${ }^{33}$

\section{Acidic wastes}

Portsmouth decontamination solutions ${ }^{21}$

unspecified acidic solutions. ${ }^{29}$

The above wastes cover the $\mathrm{pH}$ range of 0.5 to 13 , and vary considerably in concentration of nitrates, salts, and other species. Ion exchange is thus applicable to a broad spectrum of wastes containing technetium. However, nearly all technetium ion exchange resins remove technetium as the pertechnetate anion, $\mathrm{TcO}_{4}{ }^{-}$. If technetium is complexed with organics or in a different chemical form in the waste, ion exchange may not achieve the required separation and an alternative method or additional treatment steps may be required.

Ion exchange resins used to remove technetium are typically organic strong base anionic resins. Numerous resins are effective for technetium removal, but differ in their selectivity, tolerance for nitrate, high salts or other species, whether technetium can be desorbed from the resin, and for resins that can be desorbed, the nature of the elution solution. A few inorganic ion exchange materials have also been shown to be reasonable effective for removing technetium. ${ }^{33,34}$

\subsubsection{Sorption on Metal Particles or Sulfides}

Iron sulfides, ${ }^{35}$ metallic zinc, ${ }^{35-37}$ metallic iron dust, ${ }^{35,38}$ lead-tin alloys, ${ }^{37}$ steel wool ${ }^{18,27}$ bronze wool ${ }^{18,27}$ and aluminum metal ${ }^{39}$ have been shown to remove technetium. Chromium and tin have also been tested for technetium removal, with mixed results. ${ }^{37}$

Removal of technetium by this sorption on metal particles is limited to wastes of mildly acidic to alkaline solutions, as strong acid waste solutions will dissolve the metal or sulfide particles. Adsorption of technetium by metals in highly alkaline wastes ( $\mathrm{pH}>\sim 10)$ is also not effective, as has been shown by tests using zinc ${ }^{36}$ and steel wool. ${ }^{38}$ If oxidizing species such as nitrite ions are present in the waste, removal of technetium will be ineffective because of oxidization of the metal, coating the metal particles with an oxide film or causing plugging of the bed. If complexing agents are present in the waste, technetium removal efficiency can be drastically reduced. ${ }^{36}$

Metals potentially can reduce $\mathrm{TcO}_{4}{ }^{-}$to the insoluble $\mathrm{TcO}_{2}$ or a $\mathrm{Tc}(\mathrm{IV})$ oxyhydroxide form. Other metal ions in the waste, such as $\mathrm{Pb}, \mathrm{Hg}, \mathrm{Cr}$, and $\mathrm{Cd}$ may be similarly reduced and absorbed. Sorption on $\mathrm{Tc}$ by zinc dust has been shown to be unaffected by the concentration of anions as $\mathrm{Cl}^{-}, \mathrm{NO}_{3}^{-}$, and $\mathrm{SO}_{4}{ }^{-36}$ However, the form of the metal plays a key role in its effectiveness for technetium removal. High surface area is generally required. Also, highly purified iron was shown to be relatively ineffective..$^{35}$ Desorption of technetium from the metal may be possible, or incorporation of the Tc-loaded metal into a waste form.

\subsubsection{Sorption on Carbon}

Activated carbon has been proposed as a method for removal of technetium from contaminated groundwater that is more efficient and cost-effective than ion exchange or extraction primarily because of better kinetics than ion exchange and less secondary waste than extraction. ${ }^{40}$ Small-scale testing has been reported for removal of technetium from groundwater ${ }^{40}$ and from nitric acid ${ }^{41,42}$ solutions, both with and without other metal species present. These tests show that: 
1. There is minimal change in the effectiveness ${ }^{j}$ of carbon to remove technetium over the $\mathrm{pH}$ range of $4.5-9.5$

2. Sorption of $\mathrm{Tc}$ on carbon is nearly instantaneous

3. The removal effectiveness is significantly lowered by nitrate

4. Tc adsorbed on carbon can be effectively eluted with a $0.5 \mathrm{M}$ solution of sodium salicylate or sodium nitrate

5. The effectiveness of removal of Tc from nitric acid solutions drops off steeply with an acid concentration greater than about $2 \mathrm{M}$

6. The removal effectiveness decreases with increasing temperature

7. $\mathrm{Ba}, \mathrm{Cs}, \mathrm{Cr}, \mathrm{Fe}, \mathrm{Na}, \mathrm{Ni}, \mathrm{Rb}, \mathrm{Sr}$, and $\mathrm{Rb}$ in the waste solution are not adsorbed by carbon, and

8. $\mathrm{Ru}, \mathrm{Rh}$, and $\mathrm{Pd}$ in the waste solution are adsorbed by carbon.

\subsubsection{Extraction with Organic Solvents}

Solvent extraction can be used to remove technetium from both acid and alkaline wastes, ${ }^{12,37,41}$, ${ }^{43-53}$ removing technetium as the pertechnetate ion. Organic solvents for pertechnetate include tributyl phosphate (TBP), ${ }^{48,52,53}$ the TRUEX solvent, ${ }^{47,49,52}$ the crown ethers such as the SREX solvent, ${ }^{44-46,53}$ ketones including cyclohexanone, methylethylketone and acetone, ${ }^{37,50,52,53}$ nitrogen-containing compounds such as pyridines and amines, ${ }^{37,51-53}$ Aliquat- $336,{ }^{46}$ and others. ${ }^{46,53}$ Recent development for extraction of technetium from the Hanford tank waste and Melton Valley tank liquid has focused primarily on crown ethers. ${ }^{446}$ Technetium can be stripped from either the TRUEX or SREX solvent using dilute sodium or ammonium carbonate. Deionized water or dilute acid will also strip technetium from the SREX solvent.

\subsubsection{Aqueous Biphasic Extraction and Capture on Immobilized PEG}

Addition of polyethylene (PEG) or polypropylene glycol (PPG) to certain salt-containing wastes can result in the formation of two aqueous phases. This technique, called Aqueous Biphasic Extraction $(\mathrm{ABE})$ had been shown to remove pertechnetate in simulants of several Hanford tank wastes. ${ }^{54,55}$ Backextraction of $\mathrm{Tc}$ from the loaded PPG-rich phase can be achieved with $1 \mathrm{M} \mathrm{NaNO}_{3}{ }^{54}$

\subsubsection{Extraction Chromatography}

Extraction chromatography has been proposed for removal of $\mathrm{Tc}$ and other radionuclides from INTEC wastes, ${ }^{12}$ and testing of the technique has been done on wastes in Japan. ${ }^{56}$ Extraction chromatography resins are usually prepared by sorbing a known extractant on a nonporous polymeric support. The resin is loaded into a column that operates similarly to an ion exchange column, in that the contaminant is sorbed onto the resin during processing, followed by regeneration of the resin with an appropriate back-extractant. Tests have shown that a resin available from EIChroM Industries, TEVA

\footnotetext{
jMeasured in the tests as "partitioning coefficient" or "Kd" values, equivalent to the ratio of the difference of Tc concentrations before and after absorption times the ratio of waste volume divided by the activated carbon mass.
} 
Spec $^{\mathrm{TM}}$ removed technetium from ${ }^{95 \mathrm{~m}} \mathrm{Tc}$-spiked groundwater, and that $97-99 \%$ of the feed Tc could be recovered from the resin using $12 \mathrm{M}$ nitric acid. ${ }^{56}$

\subsubsection{Precipitation}

Technetium forms insoluble compounds in acidic or neutral media, including $\mathrm{Tc}_{2} \mathrm{~S}_{7},\left(\mathrm{C}_{6} \mathrm{H}_{5}\right)_{4} \mathrm{PTcO}_{4}$, and $\left(\mathrm{C}_{4} \mathrm{H}_{9}\right)_{4} \mathrm{NTcO}_{4}{ }^{37}$ A process for removal technetium by precipitation with the tetraphenylphosphonium cation has been patented, ${ }^{57}$ and in tests using an alkaline Savannah River waste and tetraphenylphosphonium chloride, $90 \%$ removal of Tc was achieved. ${ }^{17}$

The solubility of $\mathrm{TcO}_{2} \mathrm{nH}_{2} \mathrm{O}$ in $\mathrm{pH} 7-10$ solutions in the absence of oxidants and complexing agents is $10^{-8}-10^{-9} \mathrm{M}$, however, in 4-10 $\underline{\mathrm{M} \mathrm{NaOH}} \mathrm{Tc}$ reported forms $\mathrm{Tc}(\mathrm{OH})_{6}^{-}$complexes. $^{37}$

Literature data for sulfide precipitation of technetium contain mixed results. Seven tests of sulfide precipitation of Savannah River waste.solutions showed 92.6-99.3\% removal of $\mathrm{Tc}^{39}$ The tests covered a range of solution $\mathrm{pH}$ of $0-8$, either $5 \%$ excess $\mathrm{Na}_{2} \mathrm{~S}$ or thioacetamide was used as the precipitating agent, and the initial $\mathrm{TcO}_{4}^{-}$concentration varied from $1.37 \times 10^{4}$ to $4.0 \times 10^{6} \mathrm{dpm} / \mathrm{mL}(0.36-1.1 \mathrm{mg} / \mathrm{L})$.

Two separate tests with Hanford tank waste showed removal of $40 \%$ and $0.03 \%$ using sodium sulfide. ${ }^{17}$ A comparison of the two tests is shown below:

$\begin{array}{lcc}\text { Test date } & 1994 & 1988 \\ \% \text { Tc Removal } & 40 & 0.03 \\ \text { Waste } & \text { actual tank waste } & \text { simulated tank waste } \\ \text { Waste } \mathrm{pH} & \text { alkaline } & \text { alkaline } \\ \mathrm{Na}, \underline{\mathrm{M}} & 5 & 7 \\ \text { Sulfide, } \underline{\mathrm{M}} & 9.09 \times 10^{-2} & 10^{-4}, 10^{-5} \\ \text { Tc, } \underline{\mathrm{M}} & 4.4 \times 10^{-5} & 7 \times 10^{-7}, 6.8 \times 10^{-5}\end{array}$

Tests have shown that greater than $99 \%$ of the Tc in alkaline solutions and Hanford tank simulants can be precipitated using reductive coprecipitation with iron(III) hydroxide. ${ }^{37}$ In these tests $1 \underline{\mathrm{M}}$ $\left(\mathrm{NH}_{4}\right)_{2} \mathrm{Fe}\left(\mathrm{SO}_{4}\right)_{2}$ was added to 0.5 to $4 \mathrm{M} \mathrm{NaOH}$ solutions to a final concentration of 0.1 to $0.15 \mathrm{M}$. Similar results were obtained by reduction of $\mathrm{Tc}(\mathrm{VII})$ with hydrazine and subsequent addition of $\mathrm{FeCl}_{3}$. If $\mathrm{CrO}_{4}^{-2}$ was included in the test solution, an excess of $\mathrm{Fe}^{+2}$ was needed to oxidize chromate and avoid a drastic reduction in technetium removal.

\subsubsection{Electrolytic Reduction}

Electrochemical reduction of $\mathrm{TcO}_{4}^{-}$has been demonstrated for both Savannah River nitric acid wastes $^{58}$ and Hanford Tank wastes. ${ }^{59}$ In a nitric acid waste solution, nitrates would be reduced to $\mathrm{NO}_{\mathrm{x}}$ and technetium to $\mathrm{TcO}_{2}$ or $\mathrm{Tc}$ metal at the cathode, while hydroxide ions are oxidized to oxygen and water at the anode. Other metal ions in solution would also be reduced, including mercury, ruthenium, and chromates. Organics, if present, would be oxidized to $\mathrm{CO}_{2}$ and water. Technetium deposited on the cathode could be removed by reversing the cell polarity to reoxidize $\mathrm{TcO}_{2}$ to $\mathrm{TcO}_{4}{ }^{-58}$. 
Technetium removals of 80-95\% were achieved from high-salt, high-Tc Hanford supernate liquids $\left(-3 \mathrm{M} \mathrm{NO}_{3}, 9-10 \underline{\mathrm{M} \mathrm{Na}}{ }^{+}, \sim 470-530 \mathrm{~g} / \mathrm{L}\right.$ total solids, 6-7 $\left.\mathrm{g} / \mathrm{L} \mathrm{Tc}\right)$ in a two step process that included electrochemical oxidation followed by electrochemical reduction. ${ }^{59}$ For one waste similar results were obtained for the actual and simulated waste; however, for a second waste the removal from the actual waste was five times lower than that from the simulated waste. During the oxidation step, $40-75 \%$ of the nonpertechnetate Tc was oxidized to pertechnetate, and the total organic content of the waste was reduced by more than $90 \%$.

\subsubsection{Polymer Filtration}

Polymer filtration, which has been developed at Los Alamos National Laboratory, uses watersoluble metal-binding polymers and ultrafiltration membranes. ${ }^{60-62}$ Technetium-bearing waste is treated in a reaction reservoir, where the polymer binds with the pertechnetate ions. The reservoir fluid is then pumped through the ultrafiltration system, which is a cartridge packed with ultrafiltration membranes consisting of hollow fibers. As the fluid travels inside the fiber, water and other small molecules, salts such as calcium and sodium, for example, pass through the porous membrane walls of the fibers and are discharged through the outlet as permeate. The polymer-bound metal, which is too large to pass through the pores, is both purified and concentrated inside the hollow fibers and is recycled to the fluid reservoir.

Tests have been performed of polymer filtration to remove technetium from simulated contaminated groundwater from the Paducah Gaseous Diffusion Plant, from Hanford Double Shell Slurry Feed (DSSF), and other high nitrate solutions.

\subsubsection{Reverse Osmosis, Liquid Membrane, and Nanofiltration Process}

A process conceived and tested for removal of $T c, U$, and nitrates from groundwater in the 200 West area of the Hanford site involved a combination of three treatment steps: reverse osmosis, "coupled transport," and nanofiltration. ${ }^{63}$ Groundwater is first adjusted to a pH of 3 with nitric acid and then fed through two stages of reverse osmosis (RO) units. The permeate from the RO units is reinjected into the ground, while the retentate is fed to two coupled transport (CT) units: one to remove uranium and one for technetium. The RO retentate contains not only the groundwater contaminants, but also other ions such as calcium, magnesium, and silicon.

The CT units are columns of hollow fiber membranes containing a liquid ion exchange agent. For technetium, the ion exchange agent was $0.2 \mathrm{M}$ trilaurylamine in dodecane. The effluent from the $C T$ units passes through a nanofiltration unit. The filtrate from nanofiltration unit goes to the groundwater reinjection tank, while the retentate is recycled to the $\mathrm{RO}$ unit feed tank. The nanofiltration unit removes the larger radionuclide ions while allowing the smaller ions to pass through. The CT-membranes are stripped of Tc using $0.1 \mathrm{M} \mathrm{NaOH}$.

Initial tests of this process with contaminated groundwater showed a $76 \%$ removal of $\mathrm{Tc}$ in the first RO stage and an $84 \%$ removal in the second RO stage. About $60 \%$ of the Tc in the CT unit feed was removed by the Tc strip and another $12 \%$ was found in the U strip solution. The remainder was speculated to be retained in the CT fiber pores. The nanofiltration unit showed only $24-69 \% \mathrm{Tc}$ removal over a corresponding range of $90-50 \%$ volume reduction. 


\subsubsection{Evaporation}

Technetium has a high volatility, as $\mathrm{HTcO}_{4}, \mathrm{Tc}_{2} \mathrm{O}_{7}$ and other technetium compounds. The vapor pressure over a saturated solution of $\mathrm{HTCO}_{4}$ has been reported to be: ${ }^{14}$

7 torr at $50^{\circ} \mathrm{C}$

68 torr at $100^{\circ} \mathrm{C}$

144 torr at $120^{\circ} \mathrm{C}$.

$\mathrm{Tc}_{2} \mathrm{O}_{7}$ has a melting temperature of $119^{\circ} \mathrm{C}$ and a boiling temperature of $311^{\circ} \mathrm{C}$. Technetium halides and oxyhalides are also very volatile, some with boiling points below $100^{\circ} \mathrm{C}$.

The high volatility of technetium compounds gives rise to its possible separation by evaporation and subsequent recovery from either the vapor phase or from condensate. One proposal for using this method is to evaporate a waste solution to dryness and recover technetium from the vapor phase using silica gel. ${ }^{64}$ Tests of this method were made using nitric acid solutions containing different complexing, reductive and other additives. ${ }^{64}$ The silica gel was added directly in the "reaction vessel" or evaporator. When $\mathrm{Fe}^{+3}, \mathrm{NH}_{4}^{+}, \mathrm{Fe}^{+3}$ plus $\mathrm{SO}_{4}^{-2}$, or $\mathrm{Fe}^{+3}$ plus $\mathrm{SO}_{4}^{-2}$ plus $\mathrm{NH}_{4}^{+}$were added to the simulated waste, only $1.8-3.3 \%$ of the technetium was contained in the condensate. When only $\mathrm{SO}_{4}{ }^{-2}$ was added to the waste simulant, $21-32 \%$ of the technetium was found in the condensate. Tests with an actual waste, PUREX raffinate, showed less than $1 \%$ of the $\mathrm{Tc}$ in the condensate. In some of these tests, a significant amount of Tc remained as residue on the reaction vessel.

An evaluation of flowsheet options for removal of technetium from Hanford tank waste recommended the "volatilization" option, in which quench liquid from LAW melter offgas treatment was treated. ${ }^{17}$ Technetium was to be removed from the quench liquid by either sulfide precipitation or ion exchange.

\subsection{Technetium Removal Schemes for the WTF}

For this study, it will be assumed that technetium is incorporated into the high activity waste glass. Other waste forms proposed for technetium disposal include grout, ${ }^{18,65,66}$ chemically bonded phosphate ceramics, ${ }^{67}$ and polymers. ${ }^{18,27,68}$ However, the lack of permanent disposal sites for the long-lived and highly mobile ${ }^{99} \mathrm{Tc}$ in these forms precludes them from further consideration.

Also, the removal schemes will assume no treatment of melter feed to reduce volatilization of technetium in the melter. Reductive additives can convert pertechnetate to less volatile forms, ${ }^{14}$ however, reduced forms are reported to form metallic Tc inclusions in glass. ${ }^{69}$

Test data are needed to establish a reasonable value for Tc volatility in the HAW melter. A review of data for various melters and wastes showed Tc volatility ranging from 6 to $75 \%{ }^{70}$ Decontamination factors (DFs) for Tc of 1.2-2.8 in the melter and 5.2-23 in the dust scrubber were seen for the PAMELA plant operations in 1985-1986. ${ }^{71}$ Using a DF of 2 for the melter and 14 for the dust scrubber, about $87 \%$ of the technetium in the HAW would be incorporated into the glass. For the Full Separations melter, Stegen $^{71}$ recommends DF values for Tc of 2 for the melter and 2 for the dust scrubber, which is equivalent to $67 \%$ retention of $\mathrm{Tc}$ in the glass, based on recycle of the dust scrubber solids to the melter.

Data are also needed to determine what fraction of technetium will volatilize in the HAW evaporator, and the distribution of technetium in TRUEX and SREX effluents. 
Some of the removal processes that have been proposed or tested for technetium removal have been shown or could be expected to also remove mercury. Technetium present in a mercury waste could limit the disposal options for the waste. Thus, any scheme proposed for technetium removal should also consider how mercury behaves in the technetium removal process.

Potential schemes to remove technetium in the Full Separations process include:

1. Separate stripping of Tc from the TRUEX solvent

2. Recombining the TRUEX carbonate wash with the raffinate, and stripping technetium from the SREX solvent

3. Removal from TRUEX carbonate wash effluent

4. Removal from Calcine Dissolver vapor

5. Removal from LAW evaporator bottoms, denitrator offgas, or LAW offgas scrub solution.

\subsubsection{Removal of Technetium from the TRUEX Solvent}

Testing would be needed to determine whether a stripping agent could be found to remove technetium from the TRUEX solvent that would not also strip mercury. If such a stripping agent could be found, the technetium strip would be sent to the HAW evaporator. Use of a separate stripping agent for Tc would result in minimal changes to the overall separations processes, although it would add to the volume of liquids processed in all three facilities of WTS - the Waste Separations Facility, Low Activity Waste Treatment Facility, and High Activity Waste Treatment Facility. However, this alternative may require significant development of, or significant changes to, the TRUEX process. A sketch of this scheme is shown in Figure 2.

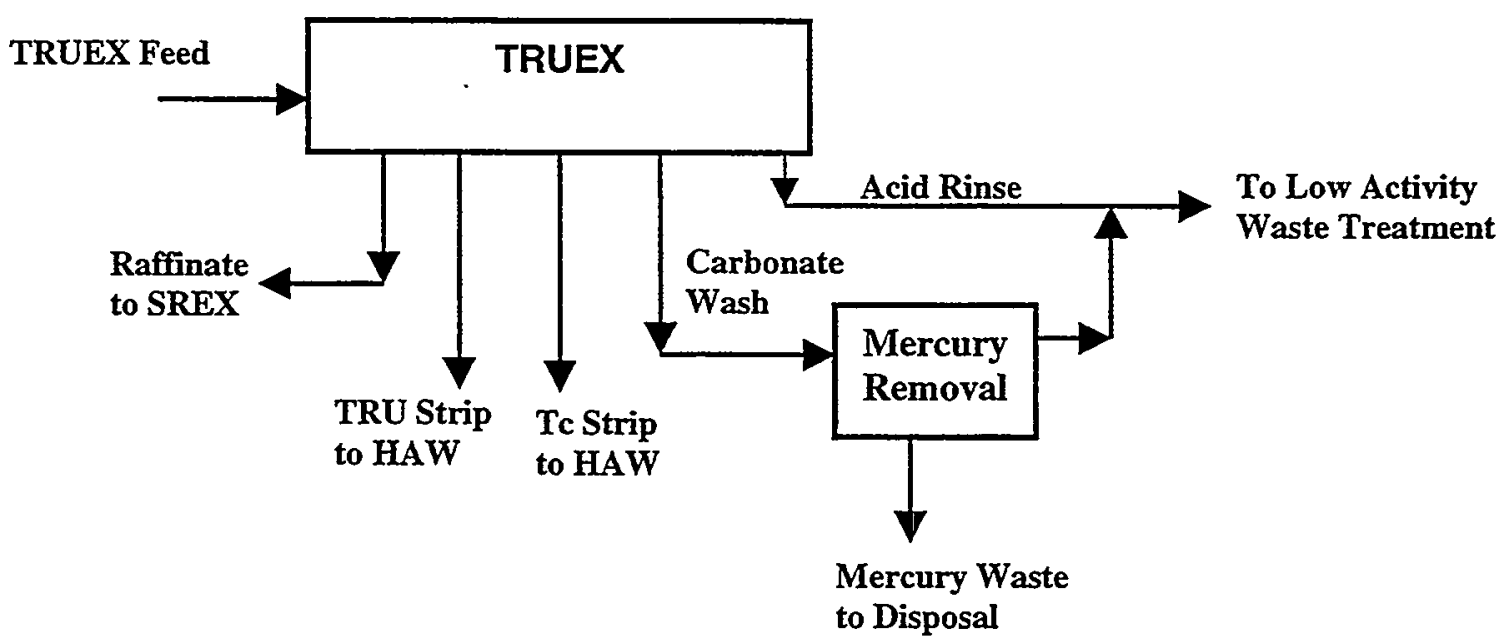

Figure 2. Removal of Tc by Stripping TRUEX Solvent.

The TRUEX process would also need to be optimized for Tc removal. The present limited data for Tc behavior in TRUEX show $\sim 25-44 \%$ of the technetium in the TRUEX feed remains in the raffinate. A fairly low Tc removal efficiency may be adequate for zirconia or mixed calcine feeds, but not for aluminum calcine. 


\subsubsection{Stripping Technetium from the SREX Solvent}

The SREX solvent is also effective for removing both mercury and technetium. Literature data suggest that stripping technetium from the SREX solvent can be done by deionized water, dilute acids or dilute carbonate solutions. At present, no effective stripping agent has been found to remove mercury from the SREX solvent. If a stripping agent for mercury is found, a scheme could be developed in which the TRUEX carbonate wash effluent is recombined with the TRUEX raffinate, and processed by SREX. The SREX solvent would extract both technetium and mercury (as well as strontium), and each of these extracted species would be separately stripped from the solvent. As shown in present separations material balances for calcine feeds, a high percentage of technetium in SREX feed is contained in the strontium strip effluent; hence, a separate technetium strip may not be required. However, test data are needed to determine the partitioning of $\mathrm{Tc}$ in the SREX process, and demonstrate mercury removal. A sketch of this scheme is shown in Figure 3.

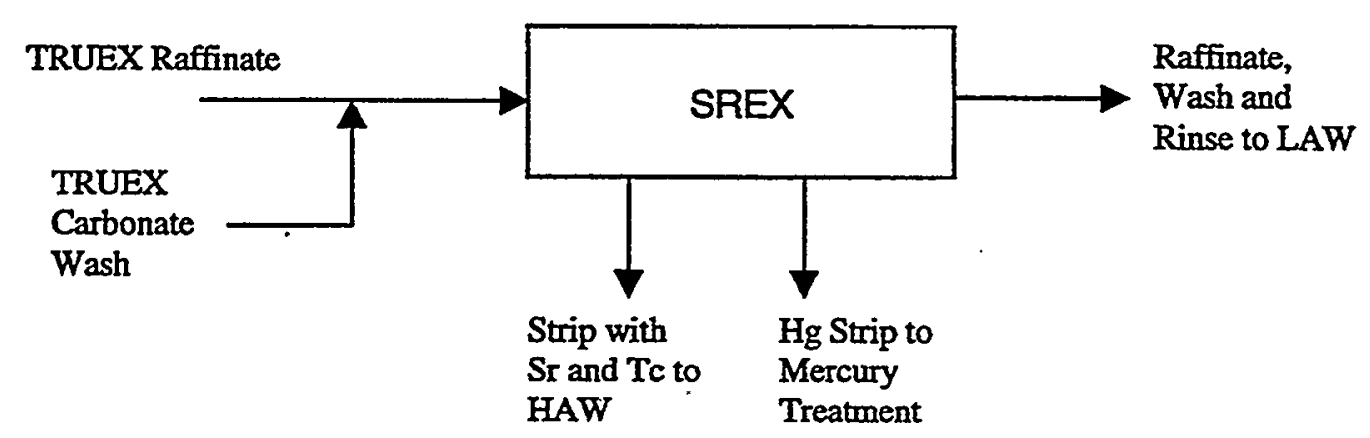

Figure 3. Removal of Tc by SREX

Alternatively, the mercury could be removed from the TRUEX carbonate wash effluent before recombining it with raffinate. Then the combined TRUEX raffinate/wash effluent would be fed to SREX. Mercury removal from the SREX solvent may not be required if the mercury removal by TRUEX was sufficiently high, and the SREX solvent was purged to prevent mercury buildup to unacceptable concentrations. However, test data are needed to determine what level of mercury can be tolerated in the SREX solvent.

\subsubsection{Removal of Technetium from TRUEX Carbonate Wash Effluent}

As discussed above, the TRUEX solvent is reasonably efficient for removing technetium from dissolved calcine, and a sodium carbonate solution strips the technetium from the solvent. Numerous methods could be used for removal of technetium from the carbonate wash. However, testing will be needed to develop a scheme that selectively removes technetium without also removing mercury from the carbonate wash. The technetium removal methods that could be applied to the high-pH carbonate wash may also remove mercury. Likewise, many of the mercury removal methods that have been proposed for the TRUEX carbonate wash may remove technetium.

The chemical forms of both technetium and mercury in the carbonate wash are not known with certainty. If technetium is present as the anion pertechnetate, and if mercury is present as the zero charge dissolved species $\mathrm{HgCl}_{2}$, it may be possible to remove technetium by an anion exchange resin that will allow the noncharged mercury to pass through. If this is the case, technetium could be removed first from the carbonate wash by ion exchange and then mercury by precipitation or another method. This scheme is shown in Figure 4. However, it has been reported that ion exchange resins commonly used for technetium, as well as metal sorbents, also remove mercury. ${ }^{65}$ 


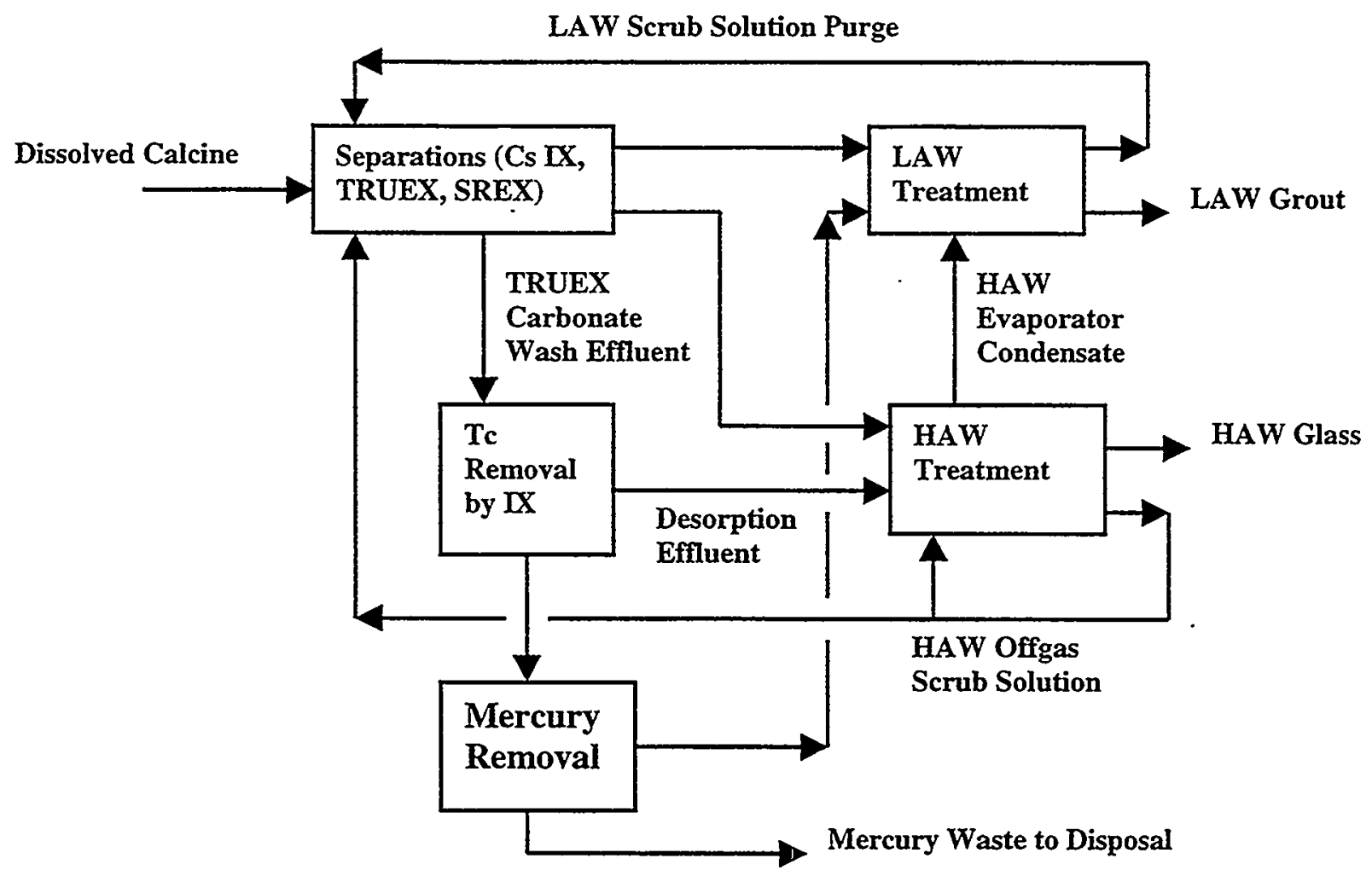

Figure 4. Removal of Tc from TRUEX Carbonate Wash by Ion Exchange.

Researchers at ORNL have tested several ion exchange resins for removal of technetium from their NGLW, using a surrogate very similar in $\mathrm{pH},{ }^{99} \mathrm{Tc}$, carbonate, sodium, nitrate, and chloride to the expected composition of the TRUEX carbonate wash effluent. ${ }^{18,27}$ A strongly basic anion exchange resin such as Dowex 1-X8 was recommended based on these tests. The Dowex resin showed a loading of $12 \mathrm{mg}{ }^{99} \mathrm{Tc} / \mathrm{cm}^{3}$, and it was recommended not to elute the sorbed technetium, but dispose of the resin in a grouted or a polymer waste form. ${ }^{18,27}$ Based on the above loading, about $3 \mathrm{~m}^{3}$ of spent resin would result from processing Bin Set 1 calcine, and $16 \mathrm{~m}^{3}$ from processing all of the Bin Sets.

A second possibility is that mercury could be removed from the carbonate wash by precipitation without contamination of the mercury waste by technetium. Data from the sulfide precipitation tests, discussed in Section 2.1.3, indicated that rhenium, a common surrogate for technetium, was not removed by sulfide precipitation. Mercury could thus be removed from the carbonate wash first; then technetium could be removed in a second step. Unlike mercury sulfide precipitation that is highly efficient from highly alkaline wastes, it is reported that technetium forms a sulfide precipitate in highly acid solutions. ${ }^{72}$ This scheme is shown in Figure 5. 


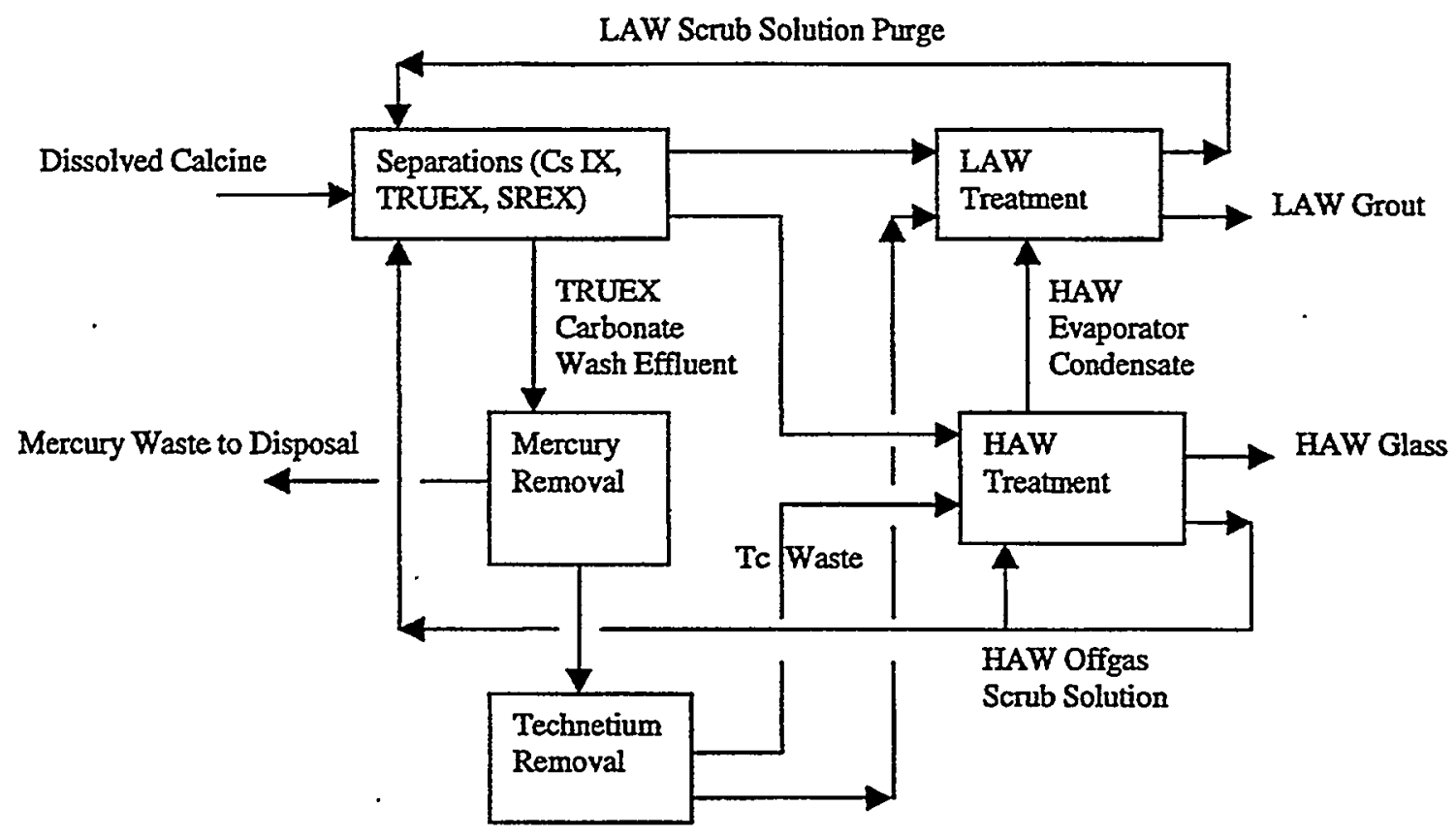

Figure 5. Removal of 'Tc from TRUEX Carbonate Wash by Precipitation.

A third alternative is to find or develop an ion exchange resin that would remove both mercury and technetium, but that would allow selective stripping of the sorbed species. In this scheme, the carbonate wash would pass through an ion exchange column that removes both mercury and technetium.

Technetium would be stripped off the resin and sent to the HAW evaporator. Depending on the nature of the resin, either mercury would then be stripped of the resin or the mercury-laden resin would be grouted.

If technetium does precipitate with mercury in a sulfide precipitation treatment, it may be possible to redissolve technetium from the precipitate. A scheme of sulfide precipitation followed by redissolution has been proposed (although without mercury in the feed) has been proposed for recovery of ${ }^{99 \mathrm{~m}} \mathrm{Tc} .{ }^{73}$

\subsubsection{Removal of Technetium from Calcine Dissolver Vapor}

The relatively high vapor pressure of $\mathrm{HTcO}_{4}$ and $\mathrm{Tc}_{2} \mathrm{O}_{7}$ may allow separation of technetium by removal from calcine dissolver vapor. A sketch of this concept is shown in Figure 6. Technetium could be removed from the vapor by sorption on silica gel, ${ }^{64} \mathrm{MgF}_{2}$ pellets, ${ }^{21}$ activated carbon or another sorbent. 


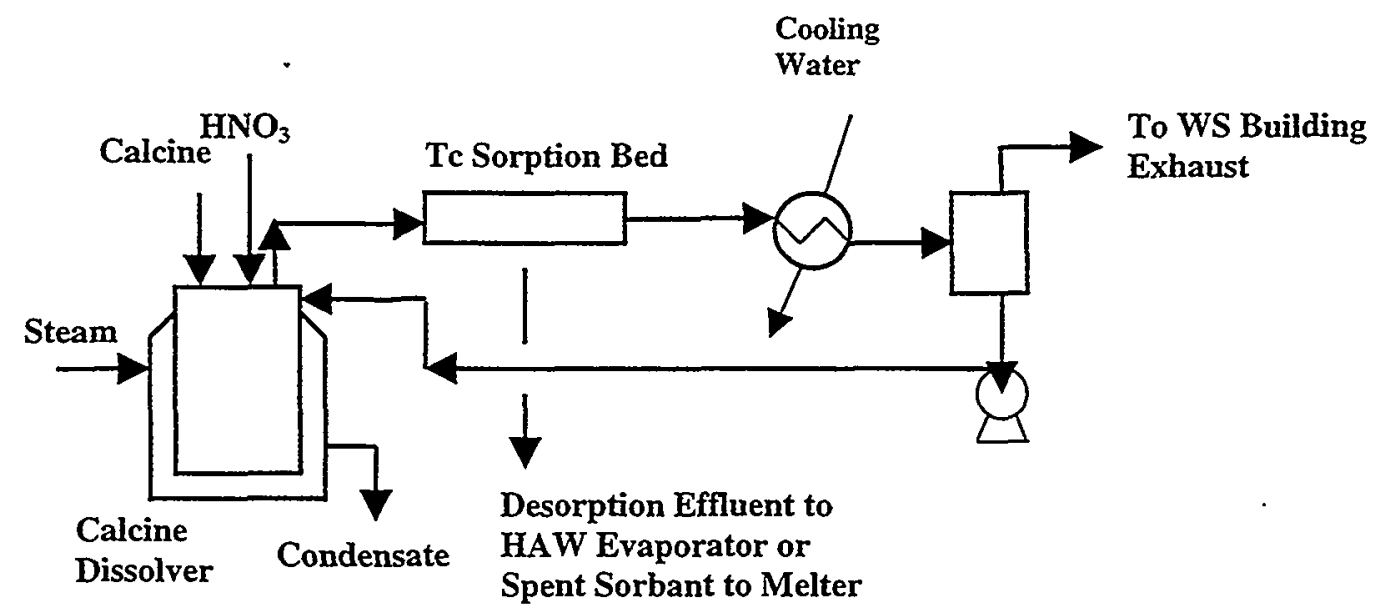

Figure 6. Removal of Tc from Calciner Dissolver Vapor.

Test data would be needed to verify the feasibility of this scheme, and determine that the volatility of ' $T c$ is sufficiently high to remove the required fraction of technetium.

\subsubsection{Removal of Technetium from LAW Concentrate, Denitrator Offgas, or LAW Offgas Scrub Solution}

Development would be needed of any technetium removal scheme of Tc from the LAW concentrate, offgas or scrub solution. For removal from offgas, ion exchange resins or sorbents would need to withstand the high temperature and acid gases of the denitrator offgas. For removal from the offgas scrub solution, ion exchange, chemical reduction or electrolytic reduction are possible removal methods.

The rates of the LAW liquid streams, whether the combined LAW evaporator feed, the LAW evaporator bottoms, or the total LAW scrub are all large relative to other possible feeds to a technetium removal unit. With high flowrates, the technetium concentration is lower than in streams of alternate removal processes, and the removal equipment would likely be larger. Also the streams will contain nearly all species present in the feed waste, some of which could interfere with technetium removal or require additional treatment steps. For example, removal by chemical or electrolytic reduction would generate a high $\mathrm{NO}_{\mathrm{x}}$ offgas that would need to be treated. Thus, development of technetium removal schemes for LAW streams is only recommended if future TRUEX tests show a higher fraction of technetium in LAW streams other than the carbonate wash and if initial tests of other schemes discussed above, such as stripping from the TRUEX or SREX solvents, are not successful in removing technetium.

\subsubsection{Conclusions}

Technetium removal will not be required when processing SBW. If alumina calcine is processed without blending in the Waste Treatment Facilities, technetium will need to be removed in order to meet the NRC Class A grout limit for ${ }^{99} \mathrm{Tc}$. To process zirconia calcine or various calcine blends and result in a NRC Class A grout, technetium removal will likely be more economic than increasing the efficiencies of cesium and strontium removal.

Technologies have been developed for technetium removal. However, no testing of these technologies has been performed with INTEC wastes. 


\subsection{Technology Development Recommendations}

It is recommended that ${ }^{99} \mathrm{Tc}$ analyses be performed in radioassays of calcine from Bin Sets $1-5$ in order to more accurately determine the need for technetium removal for zirconia and blended calcine feed cases.

Because alumina calcine contains the highest concentration of both technetium and mercury, it will be the limiting feed case for both mercury and technetium removal. An evaluation is recommended that would determine the maximum concentration of these species in the feed, or equivalently, the maximum proportion of alumina calcine that the WTF will be designed for.

Better distribution coefficients for technetium partitioning in TRUEX and SREX are needed. Test results from FY-99 TRUEX and SREX tests, which utilized a simulated SBW feed containing $R e$ as a surrogate for technetium, were not available in time to be incorporated into this evaluation. Also, minimal testing of the separations processes have been performed for alumina calcine and calcine blends high in alumina calcine. It is recommended that technetium removal studies be considered and integrated into any future testing and development of TRUEX and SREX for alumina calcine or blended calcine feeds. These studies should include obtaining distribution coefficients for Tc for both TRUEX and SREX, evaluation of a separate TRUEX strip for technetium, optimization of TRUEX for mercury removal, and determination of the effect of mercury concentration in the SREX solvent on SREX performance.

Better data is also needed to determine the fraction of technetium incorporated into denitrator solids and HAW glass, and the technetium decontamination factors for the denitrator, meiter, and offgas treatment equipment.

After obtaining technetium analyses for calcines, better TRUEX and SREX distribution coefficients for technetium, and better offgas decontamination factors, the feed streams and processes for technetium removal can be better identified and evaluated. Following this reevaluation, testing of one or more removal schemes is recommended. 


\section{CHLORIDE}

An evaluation of chloride buildup in the NWCF scrub solution was performed in 1997 as part of the Conceptual Design for the NWCF Process Modification for Sodium-Bearing Waste Project. ${ }^{74}$ The conclusions of that study were primarily based on data from a single $10-\mathrm{cm}$ pilot calciner run. The study recommended obtaining additional data on chloride volatility and scrub solution buildup. Some of these data were generated in FY-98, and evaluated in an Engineering Design File, attached as Appendix F.

\subsection{Summary of Evaluation of Chloride Buildup in NWCF Scrub Solution}

Several options being evaluated in the Environmental Impact Statement for INEEL High Level Waste include calcination in the NWCF of liquid waste presently stored in tanks at the INTEC. Chloride present in the feed to the calciner partially volatilizes as $\mathrm{HCl}$ in the calciner and chloride salt particles formed in the calciner are in part carried over into the offgas. These chlorides in the offgas are captured in part in the NWCF scrub solution. The concern has been raised that chloride could build up in the scrub solution and cause increased corrosion in scrub system piping or components, $\mathrm{HCl}$ emissions exceeding the MACT limit, or an unworkable frequency of scrub solution recycle to the tank farm.

The potential for unacceptable buildup of chlorides in NWCF scrub solution and offgas was evaluated using: (1) data from FY-98 runs in the $10-\mathrm{cm}$ and $15-\mathrm{cm}$ calciners, (2) data from the NWCF H-4 campaign, (3) a spreadsheet material balance model, and (4) results from ASPEN PLUS simulations of the NWCF scrub and offgas treatment system.

Data from pilot calciner runs show that calcine solids retain a high percentage, 50-90\%, of the chlorides in the feed and that runs at higher temperatures do not show lower retention of chlorides in calcine. The average chloride carry-over factor, defined as the fraction of chloride in the calciner feed that is captured in the scrub solution, for five pilot runs at $600^{\circ} \mathrm{C}$ was 0.32 and the range $0.28-0.43$.

Data from three periods of the NWCF H-4 campaign show chloride carry-over factors in the range $0.15-0.34$. Because the mercury to chloride ratio is higher, and the sodium to chloride ratio the same or lower for the $\mathrm{H}-4$ feeds than remaining SBW, higher chloride carry-over factors are not expected when processing SBW in the NWCF. For the H-4 campaign, scrub solution was transferred to sump tanks upon reaching a chloride concentration of $5,000 \mathrm{mg} / \mathrm{L}$. Based on a chloride carry-over factor of 0.34 , chlorides are not expected to build up to concentrations above $5,000 \mathrm{mg} / \mathrm{L}$ and recycle of scrub solution to the tank farm will not be required. (Although recycle will not be required because of chloride, it will likely eventually be required because of the buildup of mercury.)

ASPEN PLUS vapor-liquid equilibrium calculations indicate that $\mathrm{HCl}$ emissions will be $<50 \%$ of the MACT limit.

Based on the results discussed in the Appendix F, the following conclusions are drawn:

1. Scrub solution chloride concentrations can be maintained below a concentration of $5,000 \mathrm{mg} / \mathrm{L}$ when processing SBW in the NWCF.

2. Chloride volatility at a calcination temperature of $600^{\circ} \mathrm{C}$ does not appear to be significantly greater than at $500^{\circ} \mathrm{C}$. 
3. Minimal, if any, recycle of scrub solution to the tank farm will be required during processing of SBW in the NWCF due to chloride buildup. (See EDF for a discussion of the potential recycle requirement due to mercury buildup).

4. Chloride emissions are expected to be below the MACT limit during processing of SBW in the NWCF.

5. Removal of chloride from the NWCF feed or scrub solution is not needed.

\subsection{Technology Development Recommendations}

No development activities are recommended relative to chloride removal from NWCF feed, scrub or offgas. However, it is recommended that for calciner campaigns in FY-99 and FY-2000:

1. Analyses be performed for chlorides in calcine product and fines for each campaign

2. Analyses be performed at least daily for chlorides and mercury in scrub solution.

3. This analytical data be reviewed following the campaign to determine chloride carry-over factors. 


\section{REFERENCES}

1. From http://challenger.inel.gov/nichtt/jm/tankdata/Tankmap.htm and as of June 30, 1999.

2. From http://challenger.inel.gov/nichtt/jm/Bins/Bininvt2.htm, and as of May 31, 1999.

3. Raytheon Engineers \& Constructors, Idaho Chemical Processing Plant Waste Treatment Facilities Feasibility Study Report, October 1994.

4. Fluor Daniel, Inc., Idaho Chemical Processing Plant Waste Treatment Facilities Feasibility Report, DOE/D/13206, December 1997.

5. C. M. Barnes, "Mercury Material Balance and Evaluation of Mercury Removal Processes" Engineering Design File WTFO-002, contained in W. H. Landman, Jr., et. al, Waste Treatment Facilities Optimization Report, INEEL/EXT-98-01064, November, 1998.

6. D. D. Taylor, C. M. Barnes, "Mercury Control Process Evaluation," Appendix F in J. K. Rawlins, Feasibility Study Report for NWCF MACT Compliance Facility, INEEL/INT-9700992, November 1997.

7. J. A. Del Debbio, L. G. Olson, S. D. Cauffman, "Report on Electrochemical Reduction for Removal of Mercury from Simulated NWCF Scrub Solutions," Lockheed Martin Idaho Technologies Company Interdepartmental Communication, JAD-03-98-LGO-02-98/SDC-0298, September 28, 1998.

8. J. A. Del Debbio, L. G. Olson, "Test Plan for the Removal of Mercury from Simulated NWCF Offgas," Lockheed Martin Idaho Technologies Company Interdepartmental Communication, JAD-01-99/LGO-01-99, May 11, 1999.

9. D. J. Wood, et. al, Development of the SREX Process for the Treatment of ICPP Liquid Wastes, INEEL/EXT-97-00831, December, 1997.

10. C. M. Barnes, "Transmittal of Full Separations Process Flow Diagrams and Material Balances," Lockheed Martin Idaho Technologies Company Interdepartmental Communication, CMB-05-99, September 14, 1999.

11. D. R. Wenzel, "Calculation of Radionuclide Inventories for Sodium Bearing Wastes," LMITCO Interdepartmental Communication, Wen-23-97, November 26, 1997.

12. A. L. Olson, W. W. Schulz, L. A. Burchfield, C. D. Carlson, J. L. Swanson, M. C. Thompson, Evaluation and Selection of Aqueous-Based Technology for Partitioning Radionuclides from ICPP Calcine, WINCO-1171, February, 1993.

13. B. A. Moyer, R. A. Sachleben, P. V. Bonnesen, Solvent Extraction of Technetium from Alkaline Waste Media Using Bis-4,4'(5')[tert-butyl)cyclyhexano]-18-crown-6, CONF-9603143, 1995. 
14. M. H. Langowski, J. G. Darab, P. A. Smith, Volatility Literature of Chlorine, Iodine, Cesium, Strontium, Technetium, and Rhenium; Technetium and Rhenium Volatility Testing, PNNL11052, March, 1996.

15. J. D. Law, K. N. Brewer, R. S. Herbst, T. A. Todd, Demonstration of the TRUEX Process for Partitioning of Actinides from Actual ICPP Tank Waste Using Centrifugal Contractors in a Shielded Cell Facility, INEL-96!/0353, September, 1996.

16. K. N. Brewer, R. S. Herbst, T. J. Tranter, J. D. Law, T. G. Garn, T. A. Todd, Actinide Partitioning from Actual Dissolved Zirconium Calcine Using the TRUEX Solvent, INEL95/0225, May, 1995.

17. K. M. Eager, Technetium Removal: Preliminary Flowsheet Options, WHC-SD-WM-TI-718, October 1995.

18. W. D. Bostick, P. E. Osborne, D. E. Beck, D. H. Bunch, R. L. Fellows, G. F. Sellers, J. L. Shoemaker, K. T. Bowser, D. T. Bostick, Removal of Technetium-99 from Simulated Oak Ridge National Laboratory Newly-Generated Liquid Low-Level Waste, K/TCD-1141, June, 1995.

19. D. L. Blanchard, Jr., G. N. Brown, S. D. Conradson, S. K. Fadeff, G. R. Golcar, N. J. Hess, G. S. Klinger, D. E. Kurath, Technetium in Alkaline, High-Salt, Radioactive Tank Waste Supernate: Preliminary Characterization and Removal, PNNL-11386, January, 1997.

20. D. L. Blanchard, Jr., D. E. Kurath, G. R. Golcar, S. D. Conradson, Technetium Removal Column Flow Testing with Alkaline, High-Salt, Radioactive Tank Waste, PNNL-11398, September 30, 1996.

21. A. J. Saraceno, The Control of Technetium at the Portsmouth Gaseous Diffusion Plant, CAT2010, November 13, 1981.

22. U.S. DOE 200-BP-5 Operable Unit Treatability Test Report, DOE/RL-96-59, April, 1996.

23. J. L. Collins, B. Z. Egan, K. K. Anderson, C. W. Chase, J. T. Bell, Batch Test Equilibration Studies Examining the Removal of $C s$, Sr and Tc from Supernatants from ORNL Underground Storage Tanks by Selected Ion Exchangers, $2^{\text {nd }}$ International Conference of Waste Management, Washington, DC, May 10-12, 1995.

24. S. F. Marsh, Z. V. Svitra, S. M. Bowen, Distributions of 15 Elements on 58 Absorbers from Simulated Hanford Double-Shell Slurry Feed (DSSF), LA-12863, 1995

25. B. Z. Egan, J, L. Collins, D. J. Davidson, K. K. Anderson, C. W. Chase, Comprehensive Supernate Treatment, CONF-970148-3, December 6, 1996. M97001739.pdf

26. L. A. Bray, L. K. Holton, T. R. Myers, G. M. Richardson, B. M. Wise, Experimental Data Developed to Support the Selection of a Treatment Process for West Valley Alkaline Supernatant, PNL-4969, January, 1984.

27. D. T. Bostick, W. D. Amold, M. W. Burgess, D. J. Davidson, J. H. Wilson, W. D. Bostick, T. A. Dillow, G, Abotsi, P. A. Taylor, D. R. McTaggart, S. C. Osborne, T. E. Kent, FY 1995 
Separation Studies for Liquid Low-Level Waste Treatment at Oak Ridge National Laboratory, ORNL/TM-13101, January, 1996.

28. K. R. Ashley, J. R. Ball, S. L. Cobb, J. M. Adams, D. A. Young, An Investigation of the Applicability of the New Reillex ${ }^{T M}$-HPQ Anion Exchange Resin System for Technetium/Rhenium and Uranium in the Hanford Waste Tanks, LA-SUB-95-28, September 30, 1994.

29. J. B. Laidler, R. H. Abrahams, "Process for Concentrating Technetium-99m," US Patent 4,176,158, November 27, 1979.

30. F. R. Knapp, Jr., A. L. Beets, S. Mirzadeh, Use of a New Tandem Cation/Anion Exchange System with Clinical-Scale Generators Provides High Specific Volume Solutions of Technetium-99m and Rhenium-188, ORNL/CP-96890, March, 1998.

31. Ihsanullah, "Optimization of Various Factors for the Separation of Technetium Using AnionExchange Resins," Separation Science and Technology 29, 1994, pp. 239-247.

32. G. D. Del Cul, W. D. Bostick, D. R. Trotter, P. E. Osborne, "Technetium-99 Removal From Process Solutions and Contaminated Groundwater," Separation Science and Technology 28, 1993, pp. 551-564.

33. M. J. Kang, S. W. Rhee, H. Moon, V. Neck, Th. Fanghänel, "Sorption of $\mathrm{MO}_{4}^{-}(\mathrm{M}=\mathrm{Tc}, \mathrm{Re})$ on Mg/Al Layered Double Hydroxide by Ion Exchange," Radiochemica Acta 75, 1996, pp. 169 173.

34. D. A. Palmer, R. E. Meyer, "Adsorption of Technetium on Selected Inorganic Ion-Exchange Materials and on a Range of Naturally Occurring Minerals Under Oxic Conditions," J. Inorg. Nuclear Chemistry 43, 1981, pp. 2979-2984.

35. G. D. Del Cul, W. D. Bostick, "Simple Method for Technetium Removal from Aqueous Solutions," Nuclear Technology 109, Jan., 1995

36. A. Mushtaq, "Sorption Behavior of Carrier-Free Technetium-99m on Zinc Dust," Separation Science and Technology 28, 1993, pp. 1743-1751.

37. V. F. Peretrukhin, V. P. Shilov, I. G. Tananaev, A. V. Kareta, V. E. Trushina, Decontamination of Alkaline Solutions from Technetium and Other Fission Products and from Some Actinides by Reductive Coprecipitation and Sorption on Metals, PNNL-11626, September, 1997.

38. T. E. Mallouk, J. G. Darab, S. M. Ponder, "Removal of Technetium, Carbon Tetrachloride and Metals from DOE Properties," Environmental Management Science Program Project ID 60017, Project Summary, June 1, 1998.

39. J. P. Bibler, R. M. Wallace, Precipitation Methods of Recovery of Tc-99 from Soluble Waste, DPST-84-707, August 23, 1984.

40. B. Gu, K. E. Dowlen, An Investigation of Groundwater Organics, Soil Minerals, and Activated Carbon on the Complexation, Adsorption, and Separation of Technetium-99, ORNL/TM13154, January, 1996. 
41. I. Yamagishi, M. Kubota, "Separation of Technetium with Active Carbon," J. of Nuclear Science and Technology 26, 1989, pp. 1038-1044.

42. I. Yamagishi, M. Kubota, "Recovery of Technetium with Active Carbon Column in Partitioning Process of High-Level Liquid Waste," J. of Nuclear Science and Technology 30, 1993, pp. 717-719.

43. P. V. Bonnesen, B. A. Moyer, D. J. Presley, V. S. Armstrong, T. J. Haverlock, R. M. Counce, R. A. Sachleben, Alkaline-Side Extraction of Technetium from Tank Waste Using Crown Ethers, ORNL/TM-13241, June, 1996.

44. B. A. Moyer, R. A. Sachleben, P. V. Bonnesen, Solvent Extraction of Technetium from Alkaline Waste Media Using Bis-4,4'(5')[(tert-butyl)cyclyhexano]-18-crown-6, CONF-960314-3, 1996.

45. P. V. Bonnesen, D. J. Presley, T. J. Haverlock, B. A. Moyer, Removal of Technetium from Alkaline Nuclear-Waste Media by a Solvent-Extraction Process Using Crown Ethers, CONF9505101-6, 1995.

46. S. H. Strauss, Separation of Technetium from Nuclear Waste Stream Simulants, LA-SUB-9530, September 30, 1994.

47. R. S. Herbst, K. N. Brewer, J. D. Law, T. J. Tranter, T. A. Todd, TRUEX Partitioning Studies Applied to ICPP Sodium-Bearing Waste, WINCO-1206, May, 1994.

48. D. J. Pruett, The Solvent Extraction of Heptavalent Technetium and Rhenium by Tributyl Phosphate, ORNL/TM-8668, December, 1984.

49. E. P. Horwitz, D. G. Kalina, H. Diamond, G. F. Vandergrift, W. W. Schultz, "The TRUEX Process - A Process for the Extraction of the Transuranic Elements from Nitric Acid Wastes Utilizing Modified Purex Solvent," Solvent Extraction and Ion Exchange 3, 1985, pp. 75-109.

50. W. W. Schultz, Cylcohexanone Solvent Extraction of ${ }^{99} \mathrm{TcO}_{4}$ From Alkaline Nuclear Waste Solutions, RHO-SA-123, 1980.

51. K. Ito, "Enhanced Recovery of Technetium (VI) by Primary Amine Extraction From Aqueous Fluoride Solutions and Aqueous Alkaline Solutions," Scientific Basis for Nuclear Waste Management VII, Materials Research Society Symposium Proceedings Volume 353, Kyoto, Japan, October 23-37, pp. 1307-1314.

52. Z. Kolarik, Separation of Actinides and Long-Lived Fission Products from High-Level Radioactive Wastes (A Review), KfK-4945, November, 1991.

53. V. F. Peretrukhin, V. P. Shilov, A. K. Pikaev, Alkaline Chemistry of Transuranium Elements and Technetium and the Treatment of Alkaline Radioactive Wastes, WHC-EP-0817, May, 1995.

54. D. J. Chaiko, C. J. Mertz, Y. Vojta, J. L. Henriksen, R. Neff, M. Takeuchi, Extraction of Longlived Radionuclides from Caustic Hanford Tank Waste Supernatants, ANL-95/39, July, 1995. 
55. R. D. Rogers, J. Zhang, S. T. Griffin, "The Effects of Halide Anions on the Partitioning Behavior of Pertechnetate in Polyethylene Glycol-Based Aqueous Biphasic Systems," Separation Science and Technology 32, 1997, pp. 699-707.

56. S. Uchida, K. Tagami, "Separation and Concentration of Technetium Using a Tc-Selective Extraction Chromatographic Resin," J. Radioanalytical \& Nuclear Chemistry 221, 1997, pp. 35-39.

57. D. D. Walker, M. A. Ebra, "Nuclear Waste Solutions," U.S. Patent 4,654,173, March 31, 1987.

58. D. T. Hobbs, Summary Technical Report on the Electrochemical Treatment of Alkaline Nuclear Wastes, WSRC-TR-94-0287, July 30, 1994.

59. W. E. Lawrence, D. L. Blanchard, Jr., D. E. Kuath, Electrochemical Reduction Removal of Technetium-99 from Hanford Tank Wastes, PNNL-11696, September, 1997

60. B.F Smith, T.W Robison, G.D. Jarvinen, Polymer Filtration Systems for Dilute Metal Ion Recovery, LA-UR--98-1716, December 31, 1998.

61. N. C. Schroeder, J. R. Ball, T. W. Robison, R. R. Gibson, B. F. Smith, "Technetium Separation from Aqueous Solutions Using Polymer Filtration," $213^{\text {th }}$ ACS National Meeting, San Francisco, April 13-17, 1997.

62. B. F. Smith, "Selective Removal/Recovery of RCRA Metals from Waste and Process Solutions Using Polymer Filtration Technology," Proceedings of the Efficient Separations and Processing Crosscutting Program 1997 Technical Exchange Meeting, Gaithersburg, Maryland, January 28-30, 1997, pp. 2.31-2.34.

63. K. M. Hodgson, T. R. Lunsford, G. Panjabi, Testing of a Benchscale Reverse Osmosis/Coupled Transport System for Treating Contaminated Groundwater, WHC-SA-2755-FP, January, 1995.

64. K. K. Korchenkin, A. N. Mashkin, A. K. Nardova, "High Temperature Adsorption Process for Solidification of Technetium," Spectrum '96, 1996, pp.107-109.

65. W. D. Bostick, J. L. Shoemaker, P. E. Osborne, B. Evens-Brown, "Treatment and Disposal Options for a Heavy Metals Waste Containing Soluble Technetium-99," ACS Symposium Series 422, Emerging Technologies in Hazardous Waste Management, Atlanta, May 1-4, 1989, D. W. Tedder and F. G. Pohland, editors, 1990, pp. 345-367.

66. G. D. Del Cul, I. L Morgan, W. D. Bostick, P. E. Osborne, Grout-Based Waste Forms for the Solidification of Anion-Exchange Resins, K/TCD-1004, December, 1991.

67. D. Singh, A. S. Wagh, M. Tlustochowicz, V. Mandalika, Immobilization of Fission Products in Low-Temperature Ceramic Waste Forms, ANL/ET/CP-90989, January, 1997.

68. D. F. McGinnes, A. Dyer, "Disposal of Organic Ion Exchange Resins Contaminated with Technetium-99," Waste Management '92...pp. 1557-1562.

69. W. L. Ebert, A. J. Bakel, D. L. Bowers, E. C. Buck, J. W. Emery, The Incorporation of Technetium in to a Representative Low-Activity Waste, ANL/CMT/CP-92096, May, 1997. 
70. J. Vida, "The Chemical Behavior of Technetium During the Treatment of High-Level Radioactive Waste, KfK-4642 (undated), translated by J. R. Jewett, PNL-TR-497, June 23, 1994.

71. G. E. Stegen, "Melter Offgas Technology Information," DSI97-GES-024, June 30, 1997.

72. S. Y. Lee and E. A. Bondietti, "Technetium Behavior in Sulfide and Ferrous Iron Solutions," Scientific Basis for Nuclear Waste Management VI, Materials Research Society Symposia Proceedings Volume 15, 1982, pp. 315-322.

73. M. Chatterjee, S. Bhattacharyya, A. Bhattacharyya, M. Banerjee, G. Muthukrishnan, S. N. Banerjee, "Recovery of Ammonium ${ }^{99}$ Tc-pertecnetate From Its Reaction Waste," J. Radioanalytical and Nuclear Chemistry Articles 198, 1995, pp. 135-141.

74. C.M. Barnes, "Evaluation of Chloride Build Up in Scrub Solution and Deep Recycle Tanks," NWCF Process Modification for Sodium-Bearing Waste Project Conceptual Design, Appendix B8, INEL/INT-97-00075, April 1997. 


\section{Appendix A}

\section{Process Engineering Basis, NWCF Mercury Treatment}




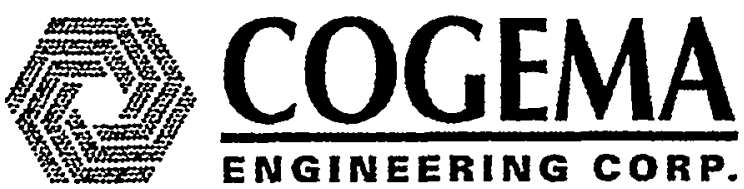

\section{Process Engineering Basis NWCF Mercury Treatment}

Prepared by:

COGEMA Engineering Corporation

Post Office Box 840

Richland, Washington 99352

Author:

S. C. Ashworth

Prepared for:

Lockheed Martin Idaho Technology Company

Idaho Falls, Idaho

Contract MOA-97-002.SESC, Release 99.08

Date Published:

September 1999 


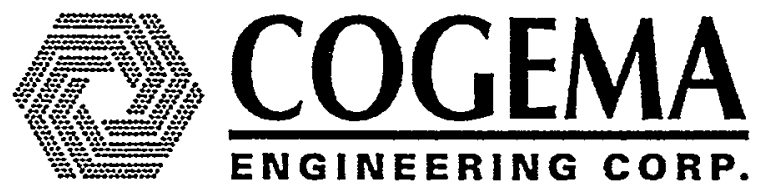

\section{Process Engineering Basis NWCF Mercury Treatment}

Signature. $\frac{1}{\text { S.C. Astworth, Author }}$

Signature:
2.W.MeClure L. W. McClure, Manager

Chemical Engineering
Date: $9 / 30 / 99$

Date: $\quad q / 30 / 99$ 


\section{EXECUTIVE SUMMARY}

A Process Engineering Evaluation has been completed for removing mercury compounds from the offgas and scrub liquor streams of the New Waste Calcining Facility (NWCF) At the Idaho National Engineering and Environmental Laboratory (INEEL). Mercury removal will likely be required to meet Enyironmental Protection Agency (EPA) Maximum Achievable Control Technology (MACT) rules for mercury emissions and to reduce the mercury content in the HighLevel Liquid Waste (HLW) Tank Farm. Several technologies were evaluated to determine potential process improvements.

The NWCF takes liquid waste from the HLW Tank Farm and converts it to a solid waste product. The existing pollution control system was developed primarily to reduce radioactive emissions from the offgas. The quench/venturi system was developed to reduce calciner gas to saturation and capture entrained particulates. Ruthenium filters, containing silica gel, were installed to remove radioactive ruthenium. HEPA filters provide a final barrier to releases. However, the pollution control system was not developed to reduce volatile mercury emissions. The INEEL estimates the mercury concentration in the NWCF offgas to be $1,000 \mu \mathrm{g} / \mathrm{m}^{3}$.

Mercuric chloride in the calciner feed is volatilized from the calciner. Some of it may react in the calciner forming oxide $(\mathrm{HgO})$ and metal $\left(\mathrm{Hg}^{0}\right)$. The high temperature of the scrubbing liquor, the concentration of mercury chloride in the recycled scrubber liquor, and the equipment configuration all limit absorption of mercury chloride vapor from the offgas. Any $\mathrm{HgO}$ would be in aerosol form and is removed via inertia (e.g., venturi scrubber and quench) except for some submicron particles. Little metallic mercury is removed via absorption, but oxidizes to $\mathrm{HgO}$ downstream in the presence of $\mathrm{NO}_{2}$ and cooler temperatures.

Mercury that is absorbed in the scrubber liquor is (eventually) recycled to the calciner, because it is not purged from the system. Spent scrubber liquor containing mercury chloride is recycled to the underground tanks and is eventually fed to the calciner system at a higher concentration. Because there is no purge from the existing process, mercury will continue to accumulate in the tank farm.

Reduction of mercury emission from the NWCF is a three-part process. Capture of mercury chloride vapor and $\mathrm{HgO}$ aerosol from the calciner offgas, removal of aqueous mercuric chloride from the scrubber liquor, and immobilization of recovered mercury chloride compounds. Process modeling of the calciner offgas system indicates that mercury chloride emissions can be reduced below EPA requirements by increasing vapor/liquid contacting in the pollution control system and continuously removing aqueous mercury chloride from the scrubber liquor.

Although nitrogen oxides $\left(\mathrm{NO}_{x}\right)$ emitted from the NWCF are currently within INEEL air emissions permit, there are several reasons that removal would be beneficial. NOx impacts sampling and monitoring of the gases emitted. The EPA methods and protocols require modification due to the $\mathrm{NO}_{x}$ presence. Studies by RADIAN concluded that the EPA protocols were not possible with $\mathrm{NO}_{\mathrm{x}}$ present. Gas phase mercury removal via activated carbon and other sorbents is also impacted by $\mathrm{NO}_{\mathbf{x}}$. Systems to remove $\mathrm{NO}_{\mathbf{x}}$ have been investigated. The John 
Zink, multi-chamber $\mathrm{NO}_{\mathrm{x}}$ idizer ${ }^{\circledR}$ was selected for further study. The $\mathrm{NO}_{\mathrm{x}}$ idizer ${ }^{\circledR}$ has a reduction section that reduces $\mathrm{NO}_{\mathrm{x}}$ to nitrogen and oxygen and a re-oxidation section that can oxidize $\mathrm{CO}$ and organic compounds.

The following unit processes for removal of aqueous and gas phase mercury are recommended for potential implementation:

\section{Gas Phase}

- Adsorption, including activated carbon, (plain and impregnated), noble metals, and other materials. No specific sorbent was determined as this is currently being evaluated. Activated carbon may be a fire hazard unless $\mathrm{NO}_{x}$ is removed. The presence of $\mathrm{NO}_{x}$ impacts the efficiency of most sorbents, including activated carbon.

- Installing a packed bed scrubber downstream of the venturi scrubber to remove $\mathrm{HgCl}_{2}$ more efficiently.

- Process modifications that provide a new scrub tank for the venturi scrubber. This is expected to remove $\mathrm{HgCl}_{2}$ by a factor of 20 greater than the current configuration.

- $\mathrm{NO}_{\mathrm{x}}$ idizer $\circledast$ installation to remove $\mathrm{NO}_{\mathrm{x}}, \mathrm{CO}$, and VOCs, simplifying the gas sampling/analysis protocols, and enabling gas phase sorption of mercury.

\section{Aqueous Phase}

- Electrochemical reduction

- UV/Ti photocatalytic reduction

- TMT 15 organic sulfide precipitation

- Copper/zinc reduction (requires a water scrub solution)

- Formic acid reduction (requires a water scrub solution)

\section{Alternatives}

Three alternatives emerged based on this evaluation.

1. No $\mathrm{NO}_{\mathbf{x}}$ Removal. This system would not include the $\mathrm{NO}_{\mathbf{x}}$ idizer or any gas-phase adsorption. The $\mathrm{HgCl}_{2}$ and aerosol $\mathrm{HgO}$ would be removed by the quench venturi scrubber and a new packed bed scrubber. The quench scrub collection tank has continuous sidestreams totaling $2-5 \mathrm{gpm}$. If successfully demonstrated, this stream could be treated via the electrochemical system. Filtered solids (if filtration is required) would go either to the tank farm or could be recycled to the calciner feed. The scrubber would have fresh acid scrub at approximately $2 \mathrm{gpm}$ or treated scrub that requires minimum DFs depending on the scrub rate to meet MACT for $\mathrm{Hg}$. The process modifications described in the "NO Alternative" below may also apply to this alternative. However, it may only require blending of materials from tanks with higher mercury concentration with tanks having lower concentrations. Elemental mercury would be collected from the mercury pool cathode. The 
aqueous phase treatment backups for this process are UV/Ti or TMT 15 precipitation unless a water scrub is used. The feasibility of a water scrub would need to be determined for $\mathrm{Cu} / \mathrm{Zn}$ or reduction, including filterability of non-dissolved suspended alumina and iron and other considerations. This alternative is not expected to meet MACT for CO and VOCs.

2. $\mathrm{NO}_{x}$ idizer. $\mathrm{A} \mathrm{NO}_{\mathrm{x}}$ idizer could be installed prior to the stack and a sorbent system installed for polishing. The quench/scrub system would be upgraded by installing a new, separate collection tank for the venturi system. This would allow the removal of more mercury, thus reducing the load on the downstream sorbent system. According to the analysis in Appendix $\mathrm{B}$, this modification should remove mercury approximately 20 times better than the current configuration does. The aqueous phase treatment is the same as the "No $\mathrm{NO}_{x}$ Removal" alternative above. This alternative is expected to meet all of the MACT requirements, but at considerable expense (mainly due to the $\mathrm{NO}_{x}$ idizer) over the "No NOxidizer" alternative (depending on scrubber costs versus $\mathrm{NO}_{\mathrm{x}}$ idizer costs, i.e., it may cost more to install a scrubber inside the NWCF than a $\mathrm{NO}_{x}$ idizer outside).

3. Feed Pretreatment. Feed pretreatment would consist of treatment of the calciner feed to remove mercury with one of the aqueous phase processes. The electrochemical system would be the preferred technology if successfully demonstrated. However, initial testing indicates that the mercury concentrations in the feed may be too low for the electrochemical system to be viable. The backup methods are UV/Ti and TMT 15 precipitation. This alternative is not expected to meet MACT for CO and VOCs.

\section{Recommendation}

Perform rough order of magnitude (ROM) cost estimates for the above three alternatives based on preliminary designs. The preliminary designs should include enough information to present to the EPA and determine the cost of fully meeting MACT. 


\section{CONTENTS}

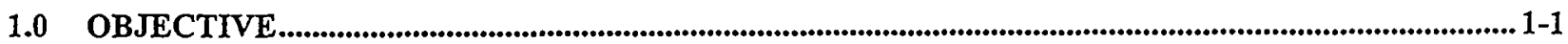

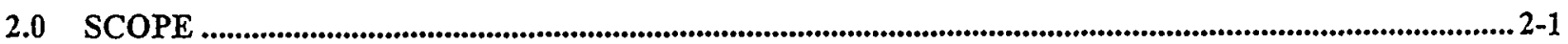

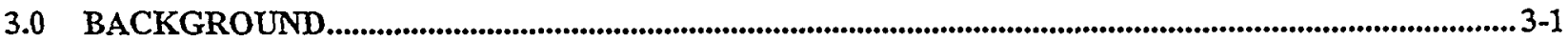

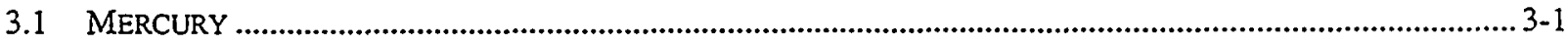

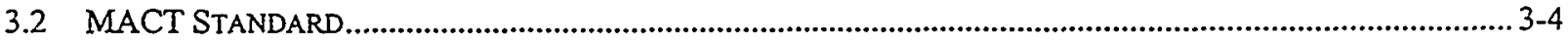

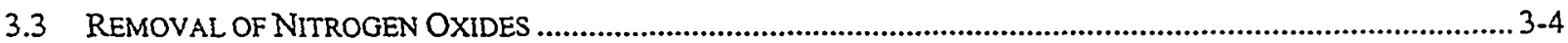

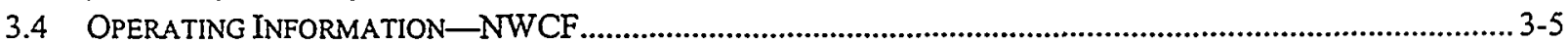

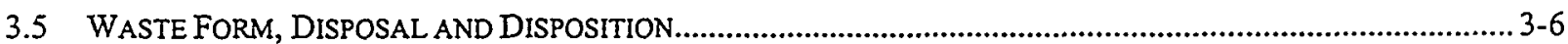

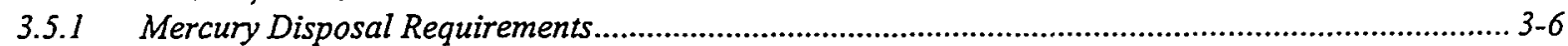

3.5.2 Potential Waste Forms .................................................................................................................. 3-7

3.6 MERCURY AMALGAMATION SOLIDIFICATION/STABILIZATION ................................................................ 3-7

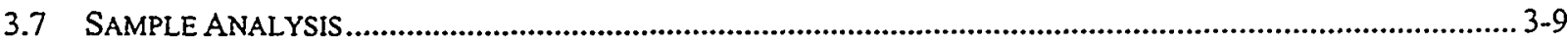

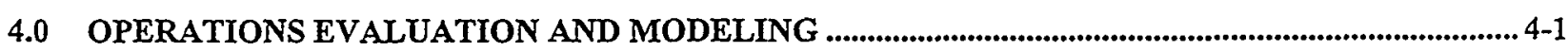

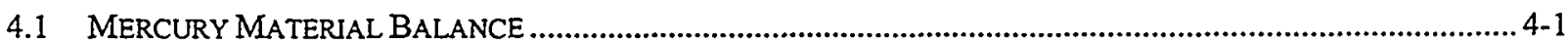

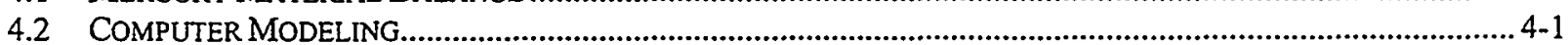

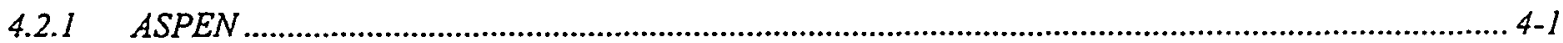

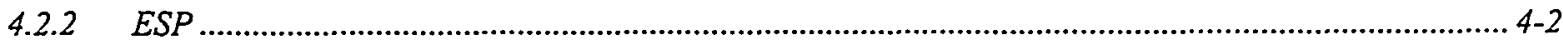

4.2.3 HSC Chemistry 3.0......................................................................................................................... 4-2

4.2.4 ROSA 4.10

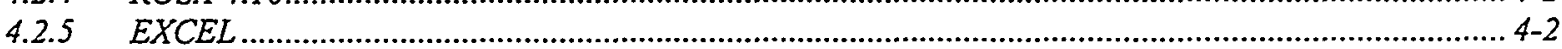

4.2.6 Analysis of Scrub Collection Sidestream ................................................................................. 4-5

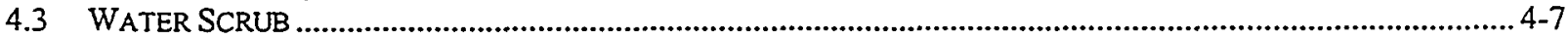

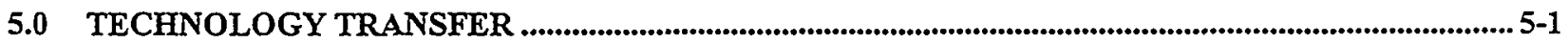

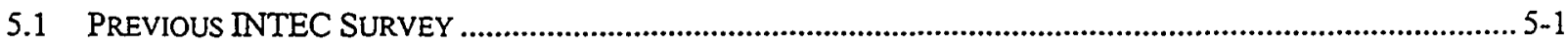

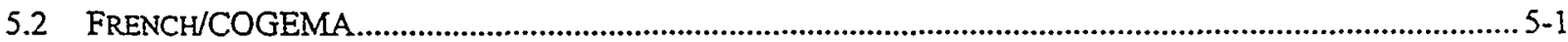

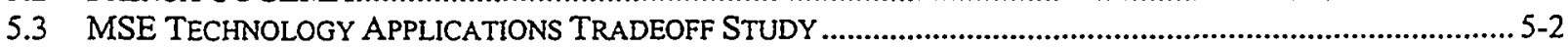

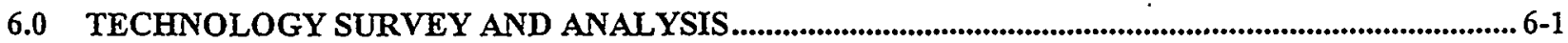

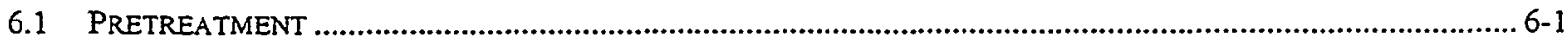

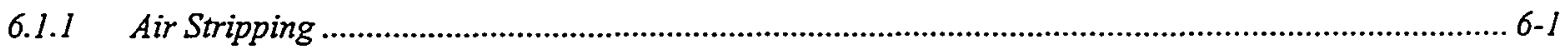

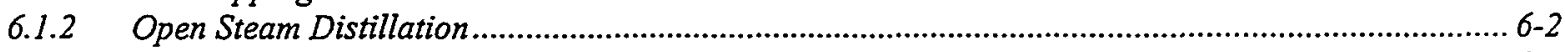

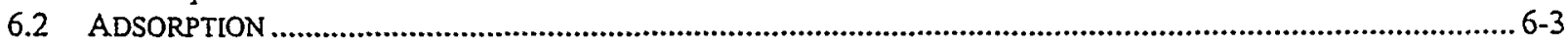

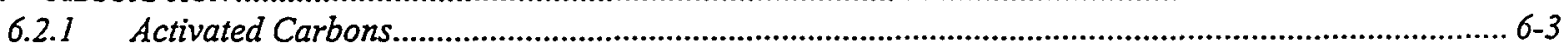

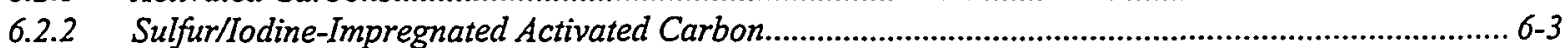

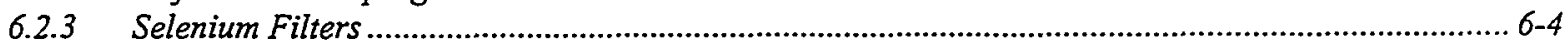

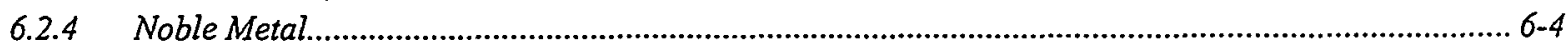

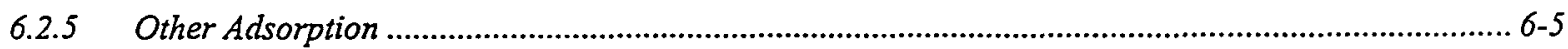

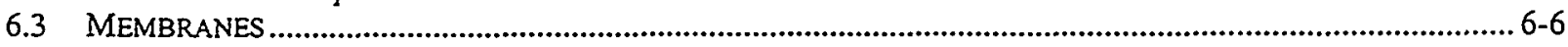

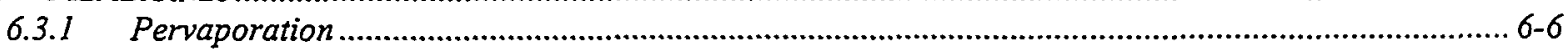

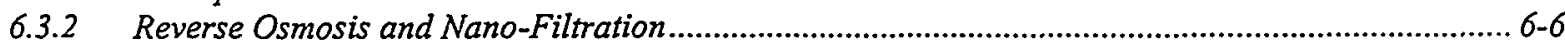

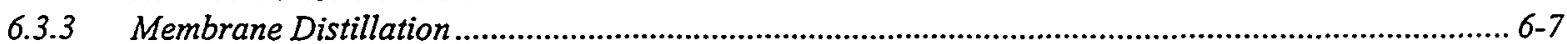

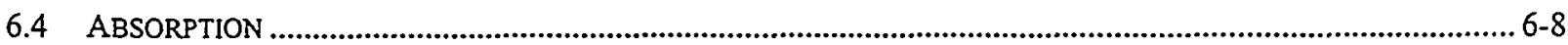

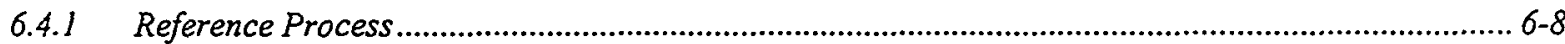

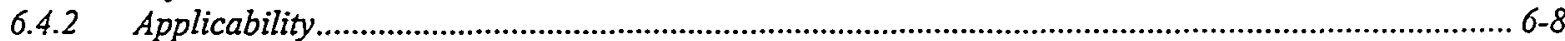

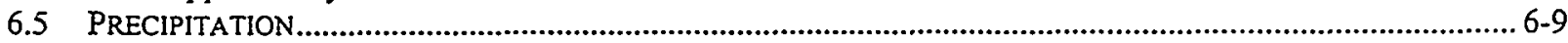

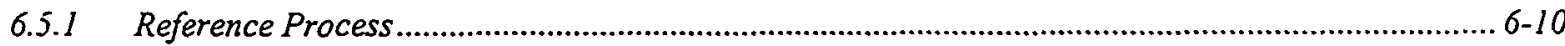

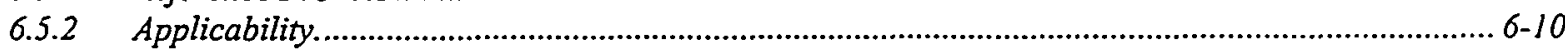

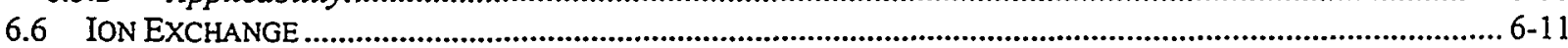




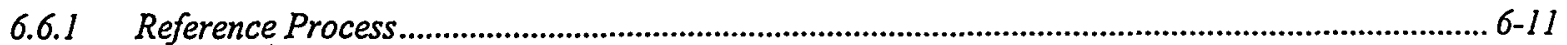

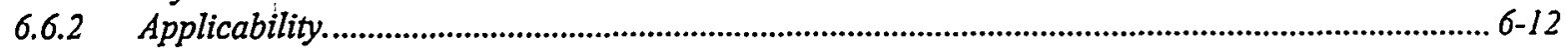

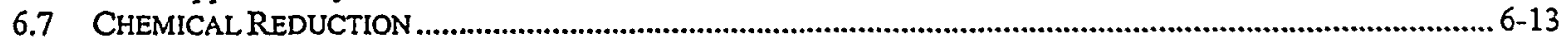

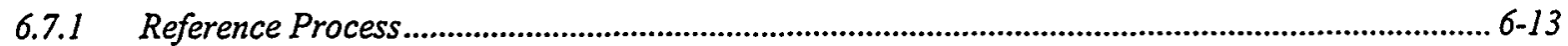

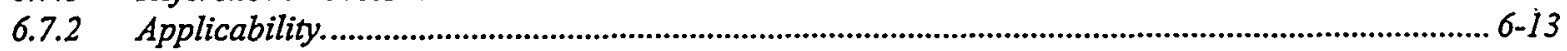

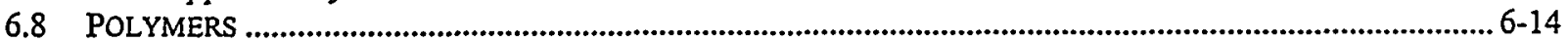

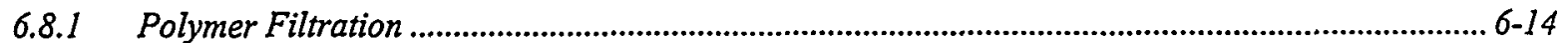

6.8.2 Polyelectrolyte Enhanced Removal ................................................................................................... 6-14

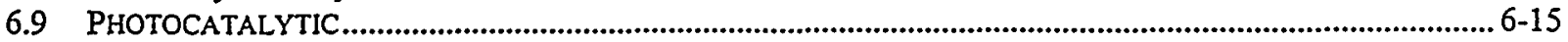

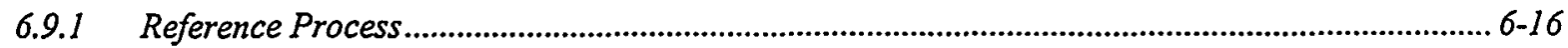

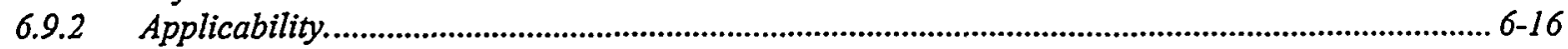

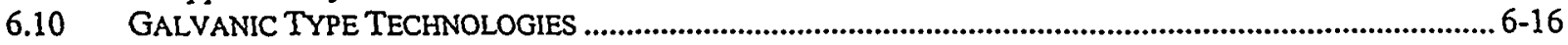

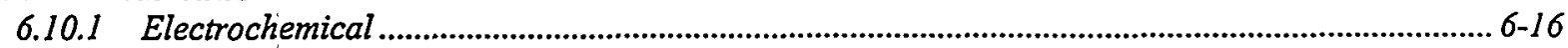

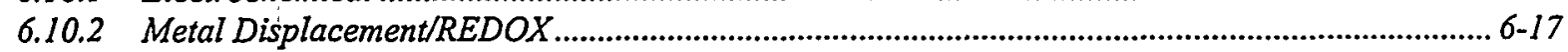

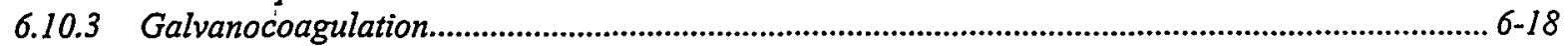

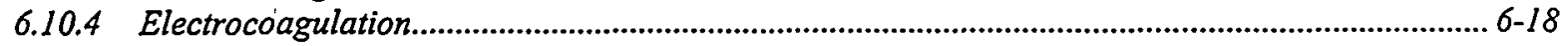

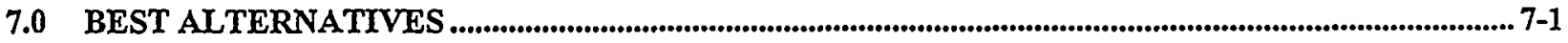

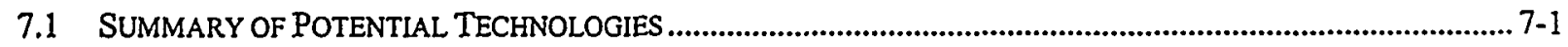

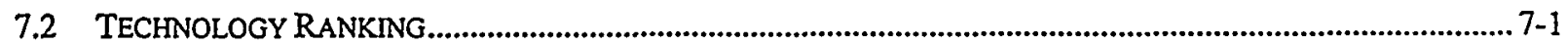

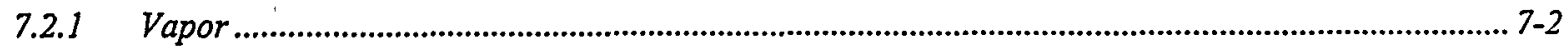

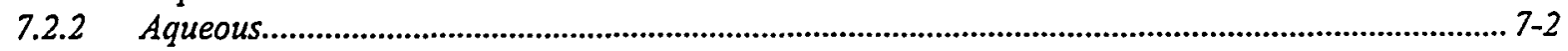

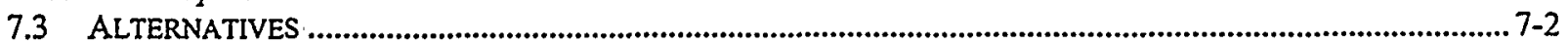

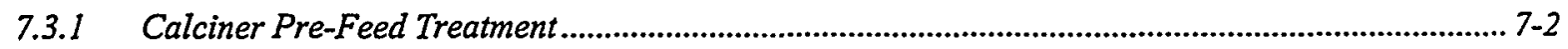

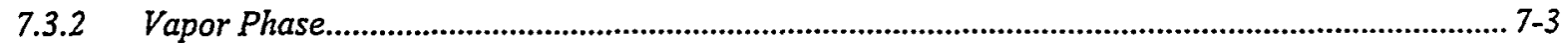

7.3.3 Aqueous/Acidic Phase Mercury Removal ............................................................................................ 7-4

7.3.4 Aqueous/Non-Acidic Phase Treatment ............................................................................................... 7-6

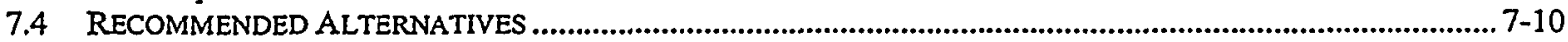

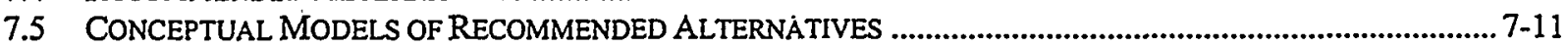

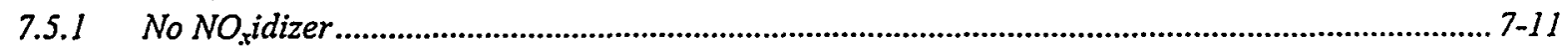

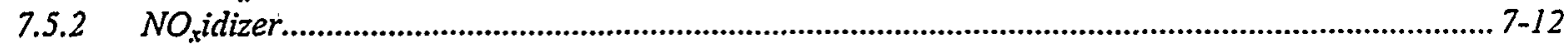

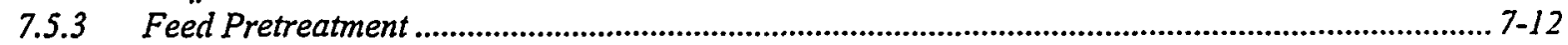

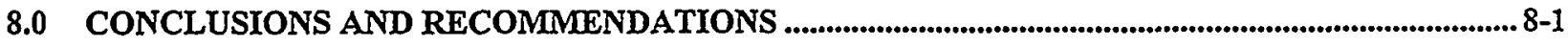

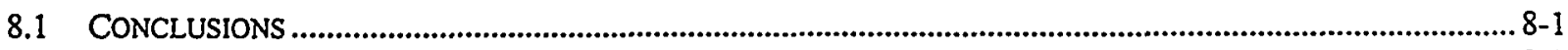

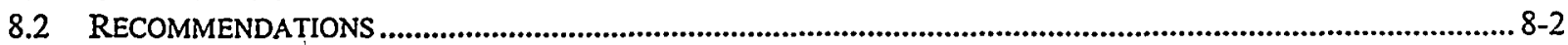

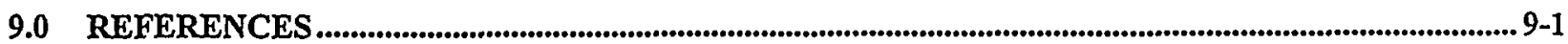

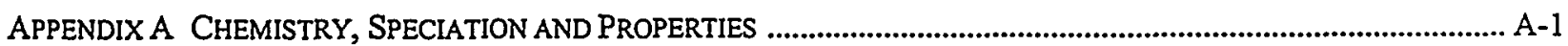

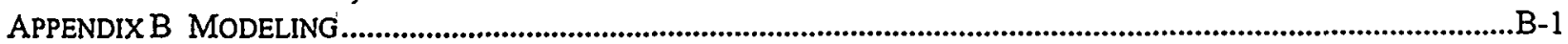

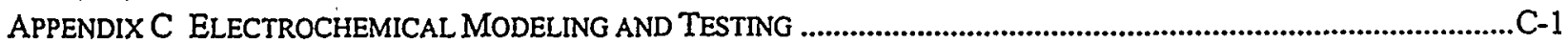




\section{FIGURES}

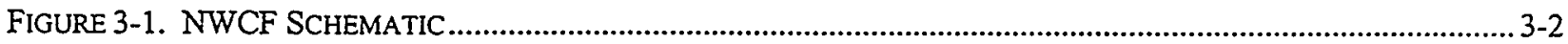

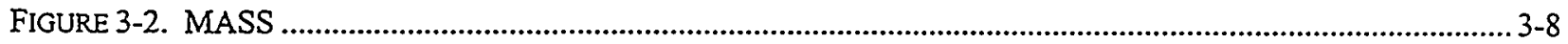

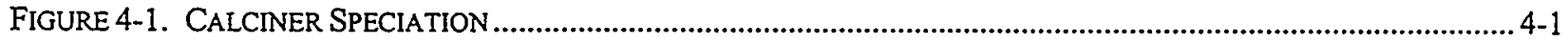

FIGURE 4-2. CURRENT SYSTEM, SIDESTREAM FLOW VS. VAPOR CONCENTRATION ................................................4-3

FIGURE 4-3. SIDESTREAM REMOVAL RATES, CURRENT CONFIGURATION.................................................................. 4-4

FIGURE 4-4. MODIFIED CONFIGURATION, FLOW RATE VS. VAPOR CONCENTRATION .......................................... 4-5

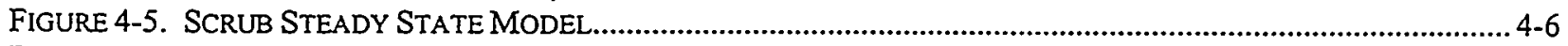

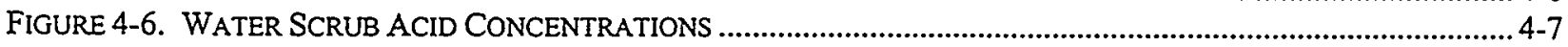

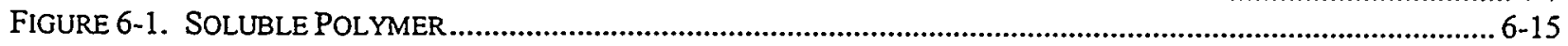

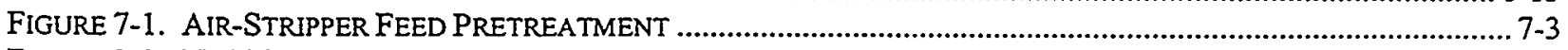

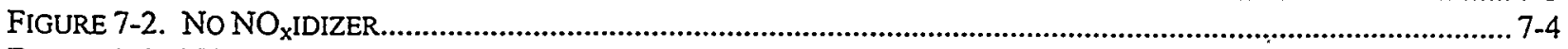

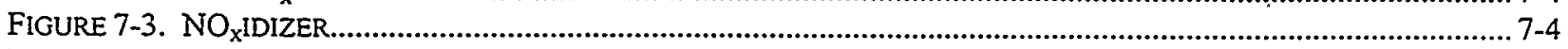

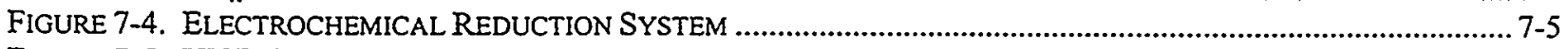

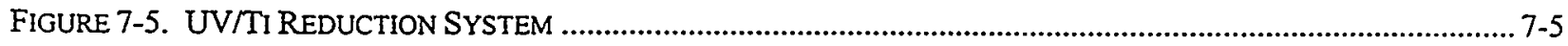

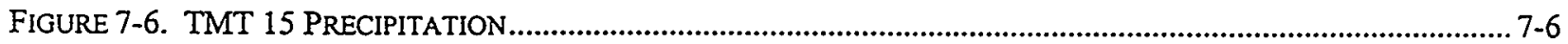

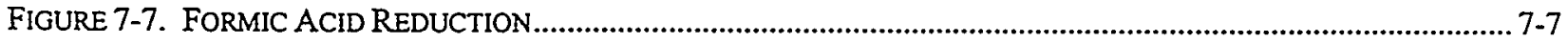

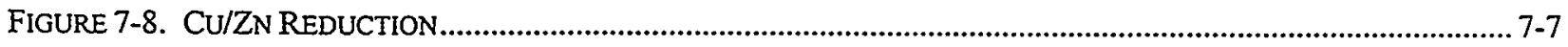

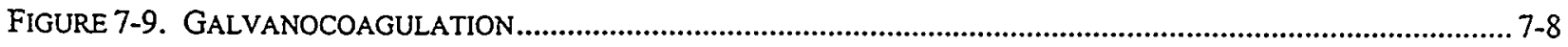

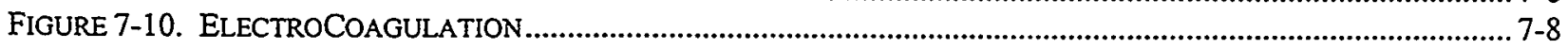

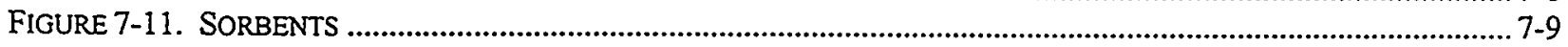

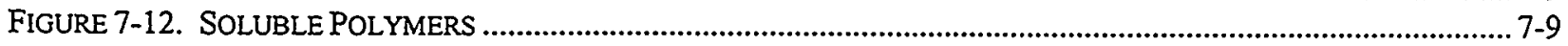

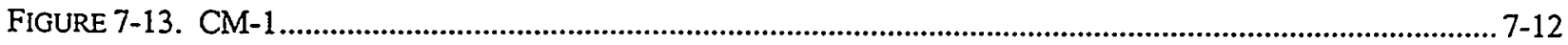

FIGURE 7-14. CM-2

\section{TABLES}

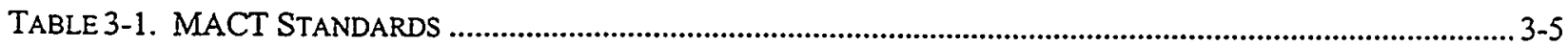

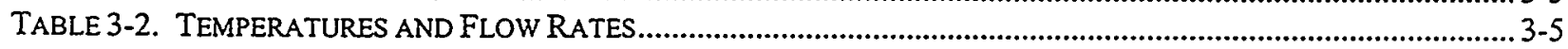

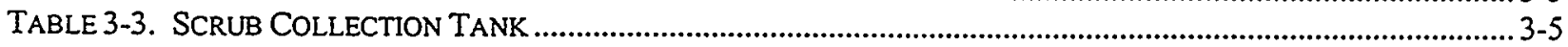

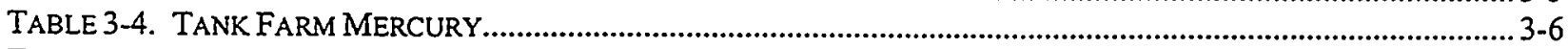

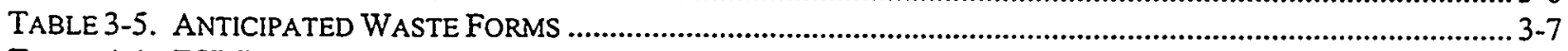

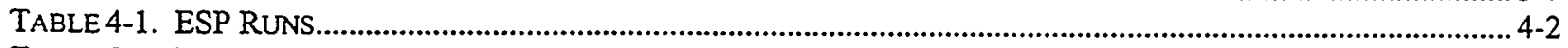

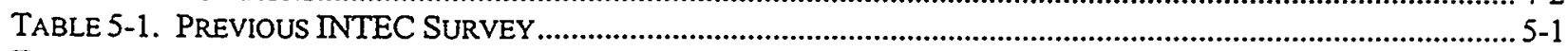

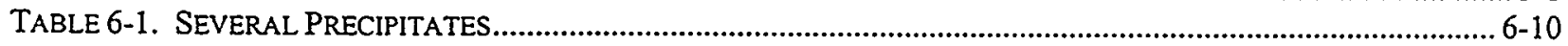

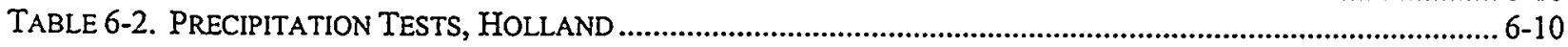

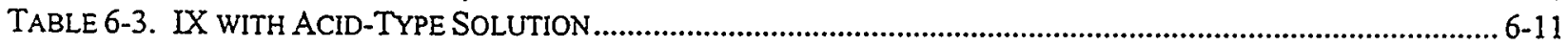

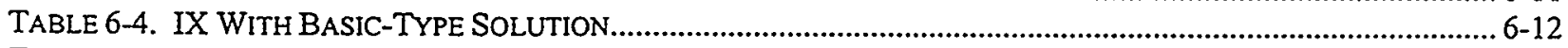

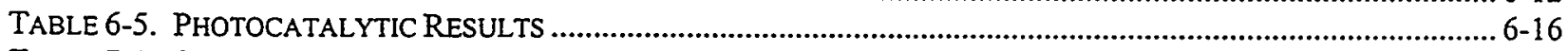

TABLE 7-1. SUMMARY OF POTENTIAL TECHNOLOGIES …................................................................................

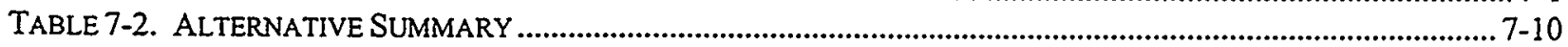

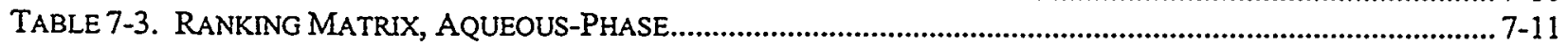




\section{GLOSSARY}

$\begin{array}{ll}\text { CAA } & \text { Clean Air Act } \\ \text { CEA } & \text { French Atomic Energy Commission } \\ \text { CEM } & \text { Continuous Emissions Monitor } \\ \text { CIF } & \text { Consolidated Incineration Facilities } \\ \text { D/F } & \text { Dioxins/Furans } \\ \text { DOE } & \text { U.S. Department of Energy } \\ \text { EIS } & \text { Environmental Impact Statement } \\ \text { GAC } & \text { Granulated Activated Carbon } \\ \text { HEPA } & \text { High-Efficiency Particulate Air } \\ \text { HLW } & \text { High-Level Waste } \\ \text { INEEL } & \text { Idaho National Engineering and Environmental Laboratory } \\ \text { INTEC } & \text { Idaho Nuclear Technology and Engineering Center } \\ \text { IX } & \text { Ion Exchange } \\ \text { LANL } & \text { Los Alamos National Laboratory } \\ \text { LLNL } & \text { Lawrence Livermore National Laboratory } \\ \text { LLW } & \text { Low-Level Radioactive Waste } \\ \text { MACT } & \text { Maximum Achievable Control Technology } \\ \text { MASS } & \text { Mercury Amalgamation Solidification/Stabilization } \\ \text { MWFA } & \text { Mixed Waste Focus Area } \\ \text { NF } & \text { Nano Filtration } \\ \text { NO } & \text { Mixture of NO }{ }_{2} \text { and NO (and possibly others) } \\ \text { NOxidizer }{ }^{\circ} & \text { John Zink Combustion Unit } \\ \text { NWCF } & \text { New Waste Calciner Facilities } \\ \text { ORNL } & \text { Oak Ridge National Laboratory } \\ \text { PAC } & \text { Powdered Activated Carbon } \\ \text { PIC } & \text { Product of Incomplete Combustion } \\ \text { RCRA } & \text { Resource Conservation and Recovery Act } \\ \text { RO } & \text { Reverse Osmosis } \\ \text { S-GAC } & \text { Sulfur-Impregnated GAC } \\ \text { SRS } & \text { Savannah River Site } \\ \text { TCLP } & \text { Toxic Characteristic Leaching Procedure } \\ & \end{array}$




\section{NOMENCLATURE}

\begin{tabular}{ll} 
A & Stripping Factor \\
$1 / A$ & Absorption Factor \\
$\mathrm{Ac}$ & Cathode area \\
$\mathrm{acfm}$ & Actual Cubic Feet per Minute \\
$\mathrm{D}$ & Diffusion coefficient \\
$\mathrm{DF}$ & Decontamination Factor (mass flow in/mass flow out) \\
$\mathrm{D}_{\mathrm{H}}$ & Hydraulic diameter \\
$\mathrm{dscm}$ & Dry Standard Cubic Meter \\
$\mathrm{F}$ & Faradays constant, 96,500 Coulomb/eq \\
$\mathrm{gpm}$ & Gallons per Minute \\
$\mathrm{H}$ & Henry's Law Constant \\
$\mathrm{K}_{\mathrm{i}}$ & Equilibrium Constants \\
$\mathrm{k}$ & Reaction Rate Constant \\
$\mathrm{K}_{\mathrm{L}} \mathrm{a}$ & Liquid Phase Mass Transfer Coefficient \\
$\mathrm{pH}$ & -logio $\left[\mathrm{H}^{+}\right]$ \\
$\mathrm{ppm}$ & Parts per Million based on mass \\
$\mathrm{ppm}$ & Parts per Million based on volume \\
$\mathrm{Q}$ & Flow rate \\
$\mathrm{Re}$ & Reynolds number $(\mathrm{Dvp} / \mu)$ \\
$\mathrm{Sc}$ & Schmidt number $(v / \mathrm{D})$ \\
$\mathrm{Sh}$ & Sherwood number $\left(\mathrm{K}_{\mathrm{L}} \mathrm{D}_{\mathrm{H}} / \mathrm{D}\right)$ \\
$\mathrm{V}$ & Volume \\
$\varphi$ & Fugacity coefficient \\
$\gamma$ & Activity coefficient \\
$\mu$ & micro $\left(10^{-6}\right)$ or viscosity \\
$\pi$ & Osmotic pressure \\
$v$ & Kinematic viscosity $(\mu / \rho)$ \\
$\mathrm{p}$ & Density \\
& \\
\hline
\end{tabular}




\subsection{OBJECTIVE}

The overall objective of this study was to provide a set of potential technologies and alternatives for meeting the Maximum Achievable Control Technology (MACT) gaseous emissions standard for mercury at the New Waste Calcining Facility (NWCF). MACT may govern future operations at the NWCF as well as other thermal processes at the Idaho National Engineering and Environmental Laboratory (INEEL). Efforts are in progress by several groups at the INEEL, other national laboratories, and private industry to determine the best mercury removal technologies for various processes and media. This document provides information to interested parties, including the Mixed Waste Focus Area (MWFA), NWCF personnel, INEEL Projects, and the INEEL High-Level Waste (HLW) Program, and for coordination purposes. This document can be used as a process design basis facilitating information flow between development and conceptual design. In addition, it is intended to provide technology and information transfer to other organizations, including other U.S. Department of Energy (DOE) facilities. A secondary objective is to determine potential processes for removing mercury from the NWCF scrub collection tank. This would ultimately decrease the mercury heel in the tank farm and reduce the amount in the vapor loading in the offgas. 


\subsection{SCOPE}

The scope of this effort included:

- Surveys of existing experience, including INEEL, other DOE sites, European sites, MWFA, and private industry

- Analysis of technologies for potential applicability to NWCF

- Narrowing the field of technologies for testing, design, and installation

- Providing data and status of testing efforts

- Providing physical and chemical properties of mercury and its relevant compounds

- Identifying issues and resolutions for waste forms and disposal (gas and aqueous treatment)

- Recommending best alternatives

- Providing justification for the preferred alternatives. 
COGEMA-DOC-001, Rev. 0

\subsection{BACKGROUND}

The DOE, in its past mission of reprocessing nuclear fuel at the INEEL has generated large quantities of HLW that have been in storage at the Idaho Nuclear Technology and Engineering Center (INTEC) for many years. The DOE must dispose of the stored wastes in accordance with regulations and to fulfill agreements with the State of Idaho. The DOE is preparing a HLW Environmental Impact Statement (EIS) to identify alternative management strategies for the HLW. If a decision is made to treat the stored wastes (i.e., calcine and stored liquid wastes) for off-site disposal, high temperature immobilization is the primary processes in consideration.

The sodium-bearing liquid waste stored at the INEEL's INTEC is DOE mixed waste. Mixed waste is defined as waste materials having hazardous contaminants regulated under the Resource Conservation and Recovery Act (RCRA) and radioactive contaminants regulated under the Atomic Energy Act. The sodium-bearing liquid waste will likely be converted to a more stable waste form (e.g., calcine) in the near future. The calcination process would be performed at the NWCF located at INTEC. The calcination process may generate an offgas stream containing MACT-regulated contaminants, including mercury and its compounds, acid gases $\left(\mathrm{HCl}^{-} \mathrm{Cl}_{2}\right)$, volatile organics (VOCs) and dioxins/furans (D/F).

\subsection{MERCURY}

At the NWCF, the calciner operates at $500-600^{\circ} \mathrm{C}$. A schematic is shown in Figure 3-1. The feed from the tank farm to the calciner has significant amounts of mercury present from past operations in which mercuric nitrate was used as a catalyst to help dissolve aluminum clad fuels. The offgas from the calciner is scrubbed/quenched in a spray tower using recirculated nitric acid. The nitric acid is used to dissolve solids entrained from the calciner. The quench tower operates at $73^{\circ} \mathrm{C}\left(164^{\circ} \mathrm{F}\right)$. The scrub liquid containing particulates, condensibles, and nitric acid enters a scrubber collection tank. Some entrainment occurs that carries small particles from the calciner to the scrub solution. Entrainment likely brings in actinides, aluminum, iron, chlorides, and others. The scrub liquid is subsequently recycled to the quench system, and a much smaller amount is intermittently recycled to the calciner feed. The scrub liquid is sent back to the tank farm when the chloride level increases to approximately 5,000 ppm. The quenched offgas is treated in a venturi scrubber for particle removal and then through a demister and a HEPA filter. There are ruthenium adsorbers downstream consisting of beds packed with silica gel that were installed to remove radioactive ruthenium. The mercury accumulates in the scrub tank to concentrations up to approximately $30 \mathrm{~g} / \mathrm{L}$. Volatile mercury components, likely $\mathrm{HgCl}_{2}$ and metallic $\mathrm{Hg}$, are emitted into the offgas. The mercury emission concentration from the stack is estimated at $1,000 \mu \mathrm{g} / \mathrm{m}^{3}$ (MSE 1998a). 
Figure 3-1. NWCF Schematic

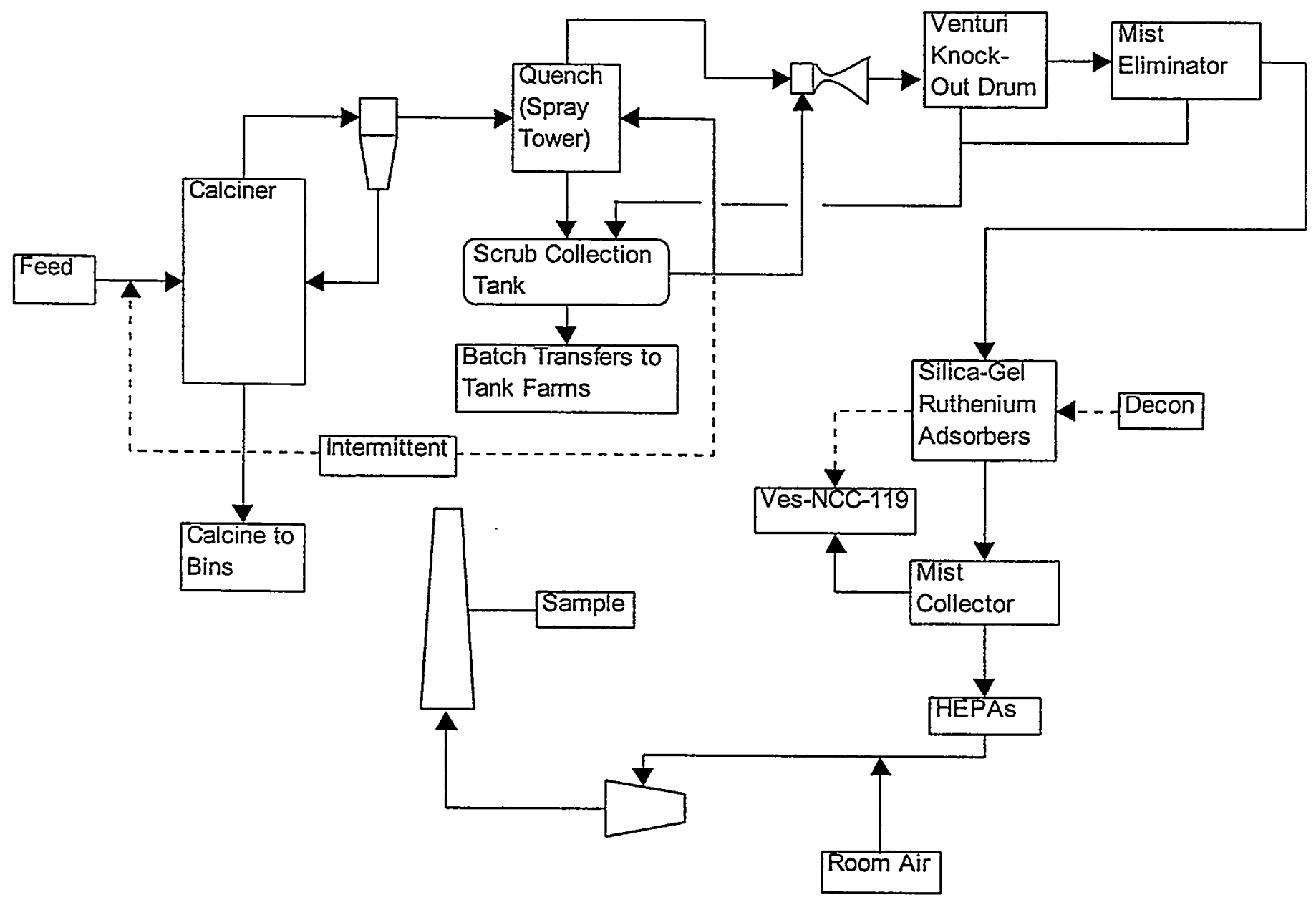


There are many uncertainties associated with determining processes for removing mercury from gaseous and liquid effluents at the NWCF. Some of the major ones include:

- It is not certain which species of mercury are being emitted from the calciner. Previous modeling using ASPEN predicts $\mathrm{Hg}$ metal and, to a lesser extent, $\mathrm{HgCl}_{2}$ and $\mathrm{HgO}$ at calciner conditions (Schindler 1998a). However, recent modeling and gas sample results indicate little or no metal. The ASPEN results are based only on thermodynamics, so it is likely that much higher levels of $\mathrm{HgCl}_{2}$ are emitted, as residence time is short.

- Speciation in the liquid phase is somewhat uncertain. The mercury concentration in the scrub collection tank increases to rather high levels (i.e., $\cong 30 \mathrm{~g} / \mathrm{L}$ ). $\mathrm{ESP}^{1}$ modeling and equilibrium calculations indicate the following major species in the scrub tank: $\mathrm{HgCl}_{2}$, $\mathrm{HgCl}^{+}$, and $\mathrm{Hg}^{+2}$. Hand calculations and HSC Chemistry ${ }^{\mathrm{TM}}$ predict similar results.

- $\mathrm{NO}_{\mathrm{x}}$ gases likely impact many of the gas-phase adsorption processes; it is not known how small quantities of $\mathrm{NO}_{\mathrm{x}}$ may impact adsorption.

- Chemical reactions in the gas phase are not quantified. $\mathrm{NO}_{2}$ appears to be oxidizing to mercury. Oxygen concentration and temperature impact the equilibria between oxide and metal. The installation of the $\mathrm{NO}_{x}$ idizer ${ }^{2}$ will impact the species requiring treatment.

- The amount of mercury sorbed onto the ruthenium silica gel adsorbers is not known. However, plant analysis indicates approximately 84 percent of the mercury fed to the calciner is removed in the scrub/quench system (Schindler 1998b). It is likely that the silica gel ruthenium adsorbers have a significant isotherm for mercury, but this is not known ${ }^{3}$.

- The nature (particle size, filterability, etc.) of fines carried over is not known. If small and plastic, they may be difficult to filter, especially if a water quench/scrub solution were used. The fines entrained from the calciner enter the scrub solution and are partially dissolved by nitric acid.

- The vapor-liquid equilibria of $\mathrm{HgCl}_{2}$ in water and/or acid solutions are not well known. Modeling was performed based on estimates using ESP.

- For the electrochemical system, the mercury mass transfer coefficient is uncertain leading to uncertainties in required cathode area and whether it is practical at the flow rates recommended in this document.

\footnotetext{
'Produced by OLI Systems, Inc., in Morris Plains, NJ. It is a chemical process simulator for aqueous based systems, and can handle highly concentrated electrolyte solutions. It solves for thermodynamic equilibrium by minimizing the chemical potential of the system being simulated. It uses the Helegeson-Kirkham-Flowers Equation of State for predicting thermodynamic properties, and the Bromely-Zemaitis equation for activity coefficients of electrolytes, and the Pitzer equation for non-electrolytes.

2 The NO $\mathrm{X}_{x}$ idizer is a multiple-chamber combustion unit being installed and tested at MSE using a reducing and re-oxidation chamber that converts $\mathrm{NO}_{\mathrm{x}}$ to nitrogen. It is uncertain if a unit like this one will be installed, but may be required to meet MACT for VOCs.

3 Recent testing was conducted by D. Siemer and D. Taylor of LMITCO. Metallic Hg vapor in almost-saturated $70^{\circ} \mathrm{C}$ air is instantaneously oxidized by the level of $\mathrm{NO}_{2}$ apt to be present downstream of NWCF's venturi scrubber $\left(-16,000 \mathrm{ppm} \mathrm{NO}_{2}\right)$, but is not oxidized by either gaseous $\mathrm{O}_{2}$ alone or $\mathrm{NO}_{x}$-free $4 \mathrm{M}$ nitric acid. Once so oxidized, it is efficiently scrubbed out by passing the gas through a packed bed of silica gel particles pre-wetted with $4 \mathrm{M}$ nitric acid. Dry silica gel didn't do a good job of scrubbing out $\mathrm{Hg}$.
} 


\subsection{MACT STANDARD}

The Environmental Protection Agency (EPA) is proposing this rule under the joint authority of the Clean Air Act (CAA) and RCRA. This proposal fulfills the EPA's commitment to upgrade the emission standards for hazardous waste-burning facilities, as stated in its 1993 Hazardous Waste Minimization and Combustion Strategy. The proposed standards would achieve significant reductions in some of the top priority pollutants for EPA: dioxins/furans (D/F) by 98 percent, mercury by 80 percent, cadmium and lead by 95 percent, and four other toxic metals by 87 percent. This proposal establishes a common-sense approach that provides for coordinated CAA and RCRA permitting of hazardous waste-burning facilities. In particular, the proposal ensures that facilities will be able to avoid two potentially different regulatory compliance schemes by integrating the monitoring, compliance testing, and record keeping requirements of the CAA and RCRA. It also significantly promotes regional, state, and local agency flexibility by enabling them to coordinate their resources for permitting, compliance, and enforcement efforts.

The proposed, revised technical standards would limit emissions of D/F, mercury, semi-volatile metals (cadmium and lead), low-volatile metals (arsenic, beryllium, chromium, and antimony), particulate matter, acid gas emissions (hydrochloric acid and chlorine), hydrocarbons, and carbon monoxide. The standards are based on MACTs, an approach required by the CAA. MACT reflects the maximum degree of hazardous air pollution reduction that can be achieved considering the availability, current use, costs, benefits, and impacts of emissions control technologies. Under this proposed rule, continuous emissions monitors (CEMs) would be required for particulate matter and mercury. Prior to this rule, CEMs were required to be installed at these facilities only for carbon monoxide, total hydrocarbons, and oxygen. Facilities that burn less than 27 gallons of hazardous waste per month will continue to be exempt from regulation. In the past, facilities that burned up to 2,000 gallons of hazardous waste per month were exempt.

This proposed rule would apply to hazardous waste incinerators, cement kilns, and lightweight aggregate kilns that burn hazardous waste as fuel. Hazardous waste incinerators are enclosed, controlled flame combustion devices used primarily to treat organic and/or aqueous wastes. Table 3-1 provides the proposed standards for existing incinerators (Federal Register 1996).

\subsection{REMOVAL OF NITROGEN OXIDES}

Although nitrogen oxides $\left(\mathrm{NO}_{\mathrm{x}}\right)$ emitted from the NWCF are currently within the INEEL air emissions permit, there are several reasons that removal would be beneficial. NOx impacts sampling and monitoring of the gases emitted. The EPA methods and protocols require modification due to the $\mathrm{NO}_{\mathrm{x}}$ presence. Studies by RADIAN concluded that the EPA protocols were not possible with $\mathrm{NO}_{x}$ present. Gas phase mercury removal via activated carbon and other sorbents is impacted by $\mathrm{NO}_{x}$. Systems to remove $\mathrm{NO}_{x}$ have been investigated. The John Zink, multi-chamber $\mathrm{NO}_{x}$ idizer ${ }^{\circledR}$ was selected for further study. The $\mathrm{NO}_{\mathrm{x}}$ idizer ${ }^{\circledR}$ has a reduction section that reduces $\mathrm{NO}_{\mathrm{x}}$ to nitrogen and oxygen and a re-oxidation section that can oxidize $\mathrm{CO}$ and organic compounds. This system is currently being installed for testing by MSE Technology Applications of Butte, Montana. 
Table 3-1. MACT Standards ${ }^{1}$

\begin{tabular}{|l|l|}
\hline \multicolumn{1}{|c|}{ Compound } & \multicolumn{1}{c|}{ Proposed Standards } \\
\hline D/F & $0.20 \mathrm{ng} / \mathrm{dscm}$ \\
\hline Particulate Matter (PM) & $69 \mathrm{mg} / \mathrm{dscm}$ \\
\hline Mercury & $50 \mu \mathrm{g} / \mathrm{dscm}$ \\
\hline $\mathrm{SVM}(\mathrm{Cd}, \mathrm{Pb})$ & $270 \mu \mathrm{g} / \mathrm{dscm}$ \\
\hline $\mathrm{LVM}(\mathrm{As}, \mathrm{Be}, \mathrm{Cr}, \mathrm{Sb})$ & $210 \mu \mathrm{d} / \mathrm{dscm}$ \\
\hline $\mathrm{HCl}+\mathrm{Cl}{ }_{2}$ & $280 \mathrm{ppm}_{\mathrm{v}}$ \\
\hline $\mathrm{CO}$ & $100 \mathrm{ppm}_{\mathrm{v}}$ \\
\hline $\mathrm{HC}$ & $12 \mathrm{ppm}_{\mathrm{v}}$ \\
\hline
\end{tabular}

\subsection{OPERATING INFORMATION-NWCF}

Table 3-2 includes some of the flow rates and temperatures of the NWCF system.

Table 3-2. Temperatures and Flow Rates

\begin{tabular}{|l|l|l|}
\hline \multicolumn{1}{|c|}{ Stream } & \multicolumn{1}{c|}{ Temperature } & \multicolumn{1}{c|}{ Rate } \\
\hline Raw Feed & Ambient & $3 \mathrm{gpm}$ \\
\hline Quench Acid & $106^{\circ} \mathrm{F}$ & $85 \mathrm{gpm}$ \\
\hline Venturi Acid & $106^{\circ} \mathrm{F}$ & $35 \mathrm{gpm}$ \\
\hline Total Calciner Offgas & $831^{\circ} \mathrm{F}$ & $5,195 \mathrm{acfm}$ \\
\hline Quench Tower Offgas & $162^{\circ} \mathrm{F}$ & $2,622 \mathrm{acfm}$ \\
\hline Venturi Offgas & $145^{\circ} \mathrm{F}$ & $3,288 \mathrm{acfm}$ \\
\hline Mist Eliminator Offgas & $145^{\circ} \mathrm{F}$ & $3,611 \mathrm{acfm}$ \\
\hline Mist Collector Offgas & $167^{\circ} \mathrm{F}$ & $6,129 \mathrm{acfm}$ \\
\hline Blower Inlet Gas & $194^{\circ} \mathrm{F}$ & $8,145 \mathrm{acfm}$ \\
\hline Blower Outlet Gas & $340^{\circ} \mathrm{F}$ & TBD acfm \\
\hline
\end{tabular}

\footnotetext{
${ }^{1}$ Modeling and analysis based on the MACT for $\mathrm{Hg}, 50 \mu \mathrm{g} / \mathrm{dscm}$. The results will change if a different value is used (e.g., $130 \mu \mathrm{g} / \mathrm{dscm}$ for existing facilities).
} 
Table 3-3 includes information on scrub collection tank to the tank farms.

Table 3-3. Scrub Collection Tank

\begin{tabular}{|l|l|}
\hline \multicolumn{2}{|c|}{ Scrub Collection Tank } \\
\hline Total Scrub Volume & 1200 gal \\
\hline Volume Recycle/Batch & 400 gal \\
\hline Average Recycle Flow, gpm & 0.28 \\
\hline Volume Recycle/60 Batches & 600 gal \\
\hline Batch/day & 1 \\
\hline Composition $\left(\mathrm{HNO}_{3}\right)$ & $1-5$ Molar \\
\hline$[\mathrm{Hg}] /[\mathrm{Cl}]$ ratio & $1-2$ \\
\hline
\end{tabular}

Table 3-4 includes information on tank farm mercury and $\mathrm{Hg} / \mathrm{Cl}$ ratios, vapor concentrations (assuming none removed and all vaporized from the feed), and the required DF to meet MACT.

Table 3-4. Tank Farm Mercury

\begin{tabular}{|l|l|l|r|r|}
\hline Waste tank & $\begin{array}{c}\text { Mercury, Molar } \\
(\mathrm{g} / \mathrm{L})\end{array}$ & $\begin{array}{c}\mathrm{Hg} / \mathrm{Cl} \text { Molar } \\
\text { Ratio }\end{array}$ & $\begin{array}{c}\text { Vapor Concentration, } \\
\mu \mathrm{g} / \mathrm{dscm}^{2}\end{array}$ & DF Required \\
\hline WM-180 & $0.00098(0.196)$ & 0.03 & $1.30 \mathrm{E}+04$ & $2.60 \mathrm{E}+02$ \\
\hline WM-181 & $0.0005(0.1)$ & 0.04 & $6.62 \mathrm{E}+03$ & $1.32 \mathrm{E}+02$ \\
\hline WM-184 & $0.0018(0.36)$ & 0.04 & $2.38 \mathrm{E}+04$ & $4.76 \mathrm{E}+02$ \\
\hline WM-185 & $0.004(0.8)$ & 0.13 & $5.30 \mathrm{E}+04$ & $1.06 \mathrm{E}+03$ \\
\hline WM-186 & $0.0013(0.26)$ & 0.06 & $1.72 \mathrm{E}+04$ & $3.44 \mathrm{E}+02$ \\
\hline WM-189 & $0.0051(1.02)$ & 0.21 & $6.76 \mathrm{E}+04$ & $1.35 \mathrm{E}+03$ \\
\hline WM-182 (heel) & $0.001(0.2)$ & 0.05 & $1.32 \mathrm{E}+04$ & $2.64 \mathrm{E}+02$ \\
\hline WM-183 (heel) & $0.0029(0.58)$ & 0.27 & $3.84 \mathrm{E}+04$ & $7.68 \mathrm{E}+02$ \\
\hline WM-187 (heel) & $0.0027(0.54)$ & 0.77 & $3.58 \mathrm{E}+04$ & $7.16 \mathrm{E}+02$ \\
\hline WM-188 (heel) & $0.0077(1.54)$ & 0.5 & $1.02 \mathrm{E}+05$ & $2.04 \mathrm{E}+03$ \\
\hline
\end{tabular}

\subsection{WASTE FORM, DISPOSAL AND DISPOSITION}

The following discusses final waste forms that require planning to manage. The implicit recommendation is to ship these wastes to off-site, private vendors, if possible.

\subsubsection{Mercury Disposal Requirements}

On May 26, 1998, EPA published a new final rule establishing new treatment standards for metal-bearing wastes, including toxicity characteristic (TC) metals with waste codes D004 D011 (that includes mercury, D009). One of the many things this rule includes are universal treatment standards for 12 metal constituents, which means that listed and characteristic wastes

\footnotetext{
${ }^{1} 600$ gal every 60 days reduces chlorides and undissolved solids

2 Calciner vapor concentration assumes all $\mathrm{Hg}$ fed to the calciner is vaporized.
} 
containing one or more of these constituents may have to meet new treatment standards. Prior to this rule, wastes that were characteristic according to the Toxicity Characteristic Leaching Procedure (TCLP) but did not fail the Extraction Procedure (EP) were not subject to the Land Disposal Restriction (LDR) requirements. Wastes that failed the TCLP and EP tests required treatment, but only to their TCLP levels. The new land disposal restrictions will require these toxic metal wastes to be treated to a lower level of leachable metals and evaluated and treated for all underlying hazardous constituents. EPA is applying Universal Treatment Standards (UTS) for the first time to eight TC metal wastes: arsenic, barium, cadmium, chromium, lead, mercury, selenium, and silver. Some subcategories of mercury and arsenic metal wastes have treatment methods requiring the use of a specified technology, and are not affected by the rule. The metalbearing land disposal restrictions portion of this rule was effective on August 24, 1998.

The UTS for mercury ( 40 CFR 268.48) is as follows:
Mercury, non-wastewater $(\mathrm{Hg}<260 \mathrm{mg} / \mathrm{kg})$ from retort Mercury, all others
$0.20 \mathrm{mg} / \mathrm{L}$ TCLP
$0.025 \mathrm{mg} / \mathrm{L}$ TCLP

\subsubsection{Potential Waste Forms}

3.5.2.1 Gas Phase Treatment Wastes. The waste forms requiring disposal/treatment depend on which processes are chosen for removal. In removing mercury from the vapor/gaseous phase, it is anticipated that the waste form will be sorbents containing mercury. These sorbents should be non-radioactive or low radioactive solids as they are anticipated being downstream of the current HEPAs and other particulate removing equipment. However, it is likely that they will be considered mixed low-level waste (LLW) based on the source. The noble metal sorbents have built-in regeneration, and can be coupled with an amalgamation process. The granulated activated carbon (GAC) will likely require further treatment as it probably will not pass the TCLP. The S-GAC and the selenium filters (see Section 6.2) may pass the TCLP due to the affinity of mercury for the sulfur family. However, the intent is to send carbon and other mercury waste products to a vendor for treatment and required handling.

3.5.2.2 Aqueous Phase Treatment Wastes. There is a large variability in the types of wastes that can be generated from the many different types of aqueous phase mercury removal processes. These range from relatively pure mercury to a TRU mixed waste containing all the metals, actinides, and radionuclides. However, even processes that generate relatively pure mercury (e.g., electrochemical) may be considered LLW. Table 3-5 indicates some of the waste forms anticipated.

Table 3-5. Anticipated Waste Forms

\begin{tabular}{|l|l|}
\hline \multicolumn{1}{|c|}{ Waste Form } & \multicolumn{1}{c|}{ Process(s) } \\
\hline Class A Mixed LLW (CH) & Electrochemical, Reduction, UV/ Ti, Cu/Zn (with retort) \\
\hline $\begin{array}{l}\text { Class C Mixed LLW } \\
\text { and/or TRU }\end{array}$ & Electrocoagulation, Galvanocoagulation, Precipitation \\
\hline
\end{tabular}




\subsection{MERCURY AMALGAMATION SOLIDIFICATION/STABILIZATION}

Treatment for the mercury in miscellaneous forms is required prior to disposal if not recovered or sent off-site. One possible stabilization method is the Mercury Amalgamation Solidification/Stabilization (MASS) technique or equivalent stabilization method. The MASS technique reduces leaching of mercury into the environment several hundred-fold compared with untreated waste (Spence 99). The risk from mercury exposure is thereby dramatically reduced.

Traditionally, mercury has been one of the most difficult contaminants to stabilize in hazardous or mixed waste. Cement does not directly stabilize either elemental mercury or mercury salts, and high-temperature techniques, such as incineration or vitrification, volatilize the mercury.

Even the lower temperatures used in sulfur polymer cement encapsulation can volatilize the mercury contaminants. MASS, developed by the Materials Technology Group of the Chemical Technology Division at DOE's Oak Ridge National Laboratory (ORNL), has been successful at stabilizing mercury and mercury compounds to meet the TCLP criteria of $0.20 \mathrm{mg} / \mathrm{L}$ in concentrations well above the $260-\mathrm{mg} / \mathrm{kg}$ ceiling established by RCRA for stabilization (Figure 3-2 used with permission of Roger Spence). In addition to relatively pure mercury contaminated with radioactivity, DOE sites have many mixed waste streams contaminated with significant amounts of mercury that may be treated with this technique.

Figure 3-2. MASS

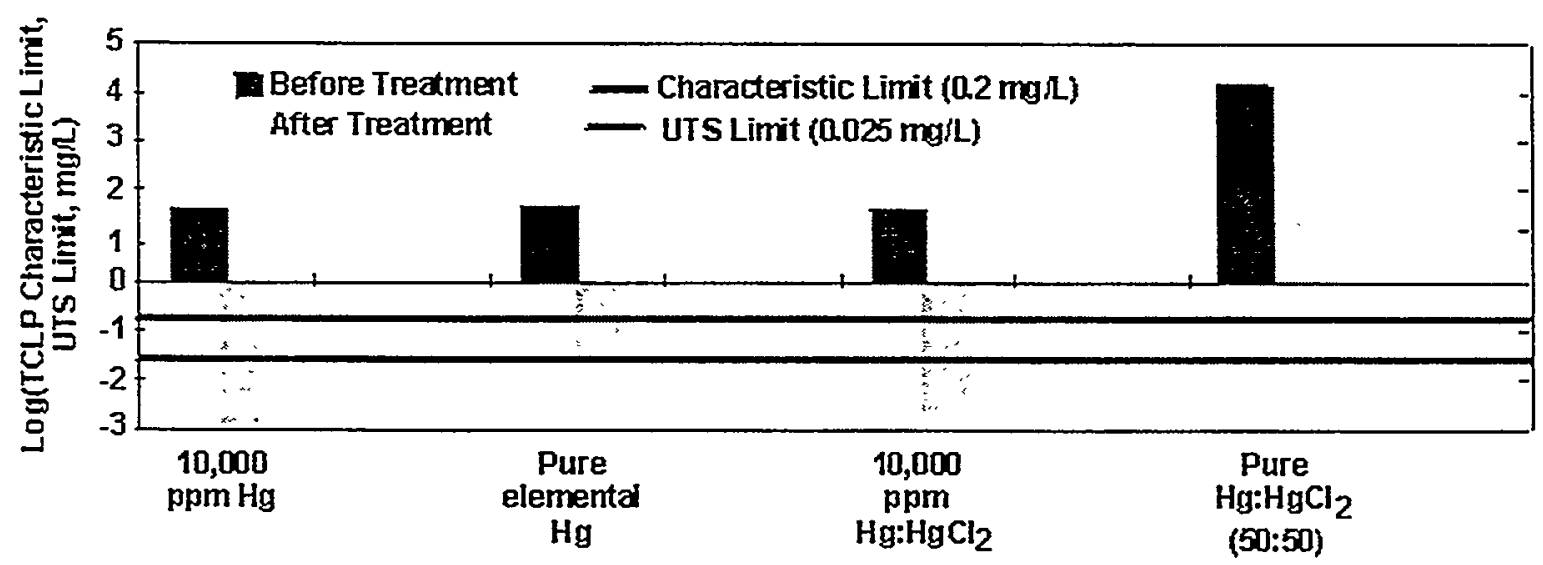

Some unique capabilities of MASS are as follows:

- Stabilizes both elemental mercury and soluble mercury compounds.

- Minimizes the mercury vapor pressure inside the waste form.

- Controls the oxygen potential inside the waste form to prevent oxidation of the amalgamating agents (e.g., sulfides). 
- Solidifies the stabilized mercury, other RCRA metals (e.g., lead), and radionuclides inside a cementitious waste form.

For further information, please contact:

\author{
Roger D. Spence \\ Oak Ridge National Laboratory \\ P.O. Box 2008 \\ Building 4500N, MS 6202 \\ Oak Ridge, TN 37831-6202 \\ Phone: (423) 574-6782 \\ Fax: (423) 574-7241 \\ E-mail: spencerd@,oml.gov
}

\title{
3.7 SAMPLE ANALYSIS
}

An extensive sampling and analysis program has been conducted at the NWCF. At the time of this document, no formal results were available. However, the preliminary data indicate that there may be a problem meeting MACT for VOC and carbon monoxide. These results will have a major impact on the conclusions of this evaluation. 


\subsection{OPERATIONS EVALUATION AND MODELING}

\subsection{MERCURY MATERIAL BALANCE}

A material balance during 1997 operations indicates that 84 percent of the mercury was collected in the scrub solution, $0.76 \%$ percent was discharged to the atmosphere, 0.05 percent was drained to NCC-122, and 15 percent was unaccounted for (Schindler 1997a). Based on this, the $\mathrm{HgO}$ plus $\mathrm{HgCl}_{2}$ is approximately 84 percent and the remaining 16 percent is metal and/or $\mathrm{HgCl}_{2}$. It is believed, based on thermodynamics and experience that metal remaining is oxidized to $\mathrm{HgO}$ in downstream equipment in the presence of high $\mathrm{NO}_{x}$ concentrations. The amount emitted to the atmosphere is likely $\mathrm{HgCl}_{2}$ that was not removed in the quench tower or venturi scrubber. It is likely that the silica gel ruthenium sorbents are removing significant mercury from the offgas.

\subsection{COMPUTER MODELING}

\subsubsection{ASPEN}

Schindler provided results from some ASPEN runs (Schindler 1997b). The results below in Figure 4-1 were digitized from the ASPEN runs for considering reaction with $\mathrm{CaO}$ and a $\mathrm{Hg}: \mathrm{Cl}$ ratio of 1:2 (mercury/chloride ratio). This is based on thermodynamics only (mass transport and reaction kinetics not considered). Without the $\mathrm{CaO}$ and $\mathrm{NaNO}_{3}$ considered, $\mathrm{HgCl}_{2}$ is about 65 percent, $\mathrm{Hg}$ is 32 percent, and $\mathrm{HgO}$ is three percent at $500^{\circ} \mathrm{C}$. These are only estimates and sampling during NWCF or pilot plant operation would be required to determine if these values are reliable.

Figure 4-1. Calciner Speciation

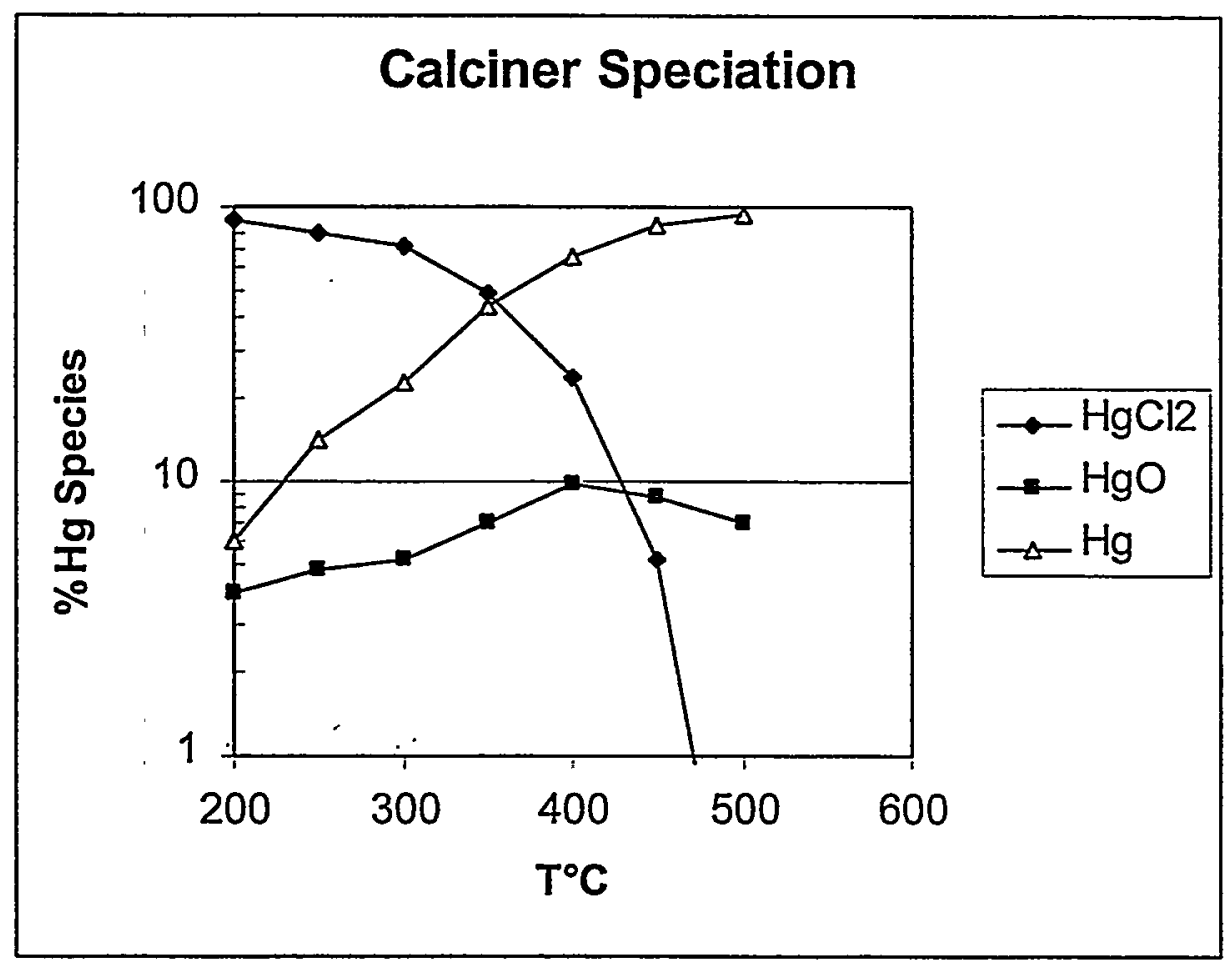




\subsubsection{ESP}

The ESP computer code was run to determine the vapor-liquid equilibria (activity coefficients). This run was performed at COGEMA Engineering Corporation's facility in Richland, Washington in August 1999. The activity coefficient for $\mathrm{HgCl}_{2}$ is calculated from the data in Appendix A.4.3. Table 4-1 includes this information and ESP results from Schindler's ESP runs (Schindler 1997c). Since activity coefficients are invariant in concentration, the $\mathrm{HgCl}_{2}$ follows Henry's Law (the scrub solution increases hydrogen by about 18 percent over plain water). ESP was also used to validate the modeling described in Sections 4.2.5.1, 4.2.5.2, and 4.2.5.3.

Table 4-1. ESP Runs

\begin{tabular}{|c|c|c|c|c|c|}
\hline $\begin{array}{c}\mathrm{HgCl}_{2}, \\
\text { Aqueous } \\
\text { mole fraction }\end{array}$ & $\begin{array}{c}\mathrm{HgCl}_{2}, \\
\text { Vapor } \\
\text { mole } \\
\text { fraction }\end{array}$ & $\begin{array}{c}\text { Temperature } \\
{ }^{\circ} \mathrm{C}\end{array}$ & $\begin{array}{c}\mathrm{HgCl}_{2} \\
\text { Vapor } \\
\text { Pressure, } \\
\text { atm }^{1}\end{array}$ & $\begin{array}{c}\text { Activity } \\
\text { Coefficient } \\
(\gamma)\end{array}$ & $\begin{array}{c}\text { Henry's } \\
\text { Constant, atm }\end{array}$ \\
\hline $6.31 \mathrm{E}-06$ & $8.97 \mathrm{E}-08$ & 70 & 0.000167 & 85 & 0.014 \\
\hline $6.60 \mathrm{E}-05$ & $9.38 \mathrm{E}-07$ & 70 & 0.000167 & 85 & 0.014 \\
\hline $7.16 \mathrm{E}-05$ & $1.40 \mathrm{E}-06$ & 100 & 0.000444 & 44 & 0.019 \\
\hline 7.27E-04 & $1.42 \mathrm{E}-05$ & 100 & 0.000444 & 44 & 0.020 \\
\hline$--^{2}$ & -- & 70 & 0.000167 & 42 & 0.007 \\
\hline-- & -- & 100 & 0.000444 & 36 & 0.016 \\
\hline
\end{tabular}

\subsubsection{HSC Chemistry 3.0}

HSC Chemistry $3.0^{3}$ was used to validate the speciation, interpret results from others (e.g., IX), determine tank farms speciation, and assist in determining the volatile fraction for modeling absorption scenarios.

\subsubsection{ROSA $4.10^{4}$}

ROSA was used to evaluate the potential of treating scrub or feed liquors via reverse osmosis (RO).

\subsubsection{EXCEL}

EXCEL was used to provide the graphics in this paper and to model three scenarios described below and in Appendix B. The procedure used for the models was to use the models developed in Appendix B coupled with HSC Chemistry to determine the correction factor for the Henry's Law constant for $\mathrm{HgCl}_{2}$.

4.2.5.1 Quench Model 1. This models the current system as described in Appendix B with a continuous sidestream. Figure 4-2 indicates the amount of $\mathrm{Hg}$ projected exiting the venturi scrubber versus the sidestream rate. This is assuming an 84 percent scrubbable fraction and that $\mathrm{Hg}: \mathrm{Cl}$ is $1: 1$. This model assumes the quench tower and the venturi scrubber are one equilibrium stage each and hence the exiting liquors are in equilibrium with the exiting vapors. This explains why this method doesn't do very well as the recirculating scrub liquor is virtually

\footnotetext{
1 Vapor pressures extrapolated downward using Antoines Equation.

${ }^{2}$ ESP runs from Schindler $1997 \mathrm{c}$

${ }^{3}$ HSC from Outokumpu Research Oy, P.O. Box 60, FIN-2819, PORI, Finland

${ }^{4}$ Reverse Osmosis System Analysis (ROSA) by DOW Liquid Separations.
} 
the same for both of the units. Therefore, the venturi gas actually strips a small amount of mercury out of the venturi scrubber liquor. This system was not designed to scrub mercury, but to reduce the temperature and remove particles.

Figure 4-2. Current System, Sidestream Flow vs. Vapor Concentration

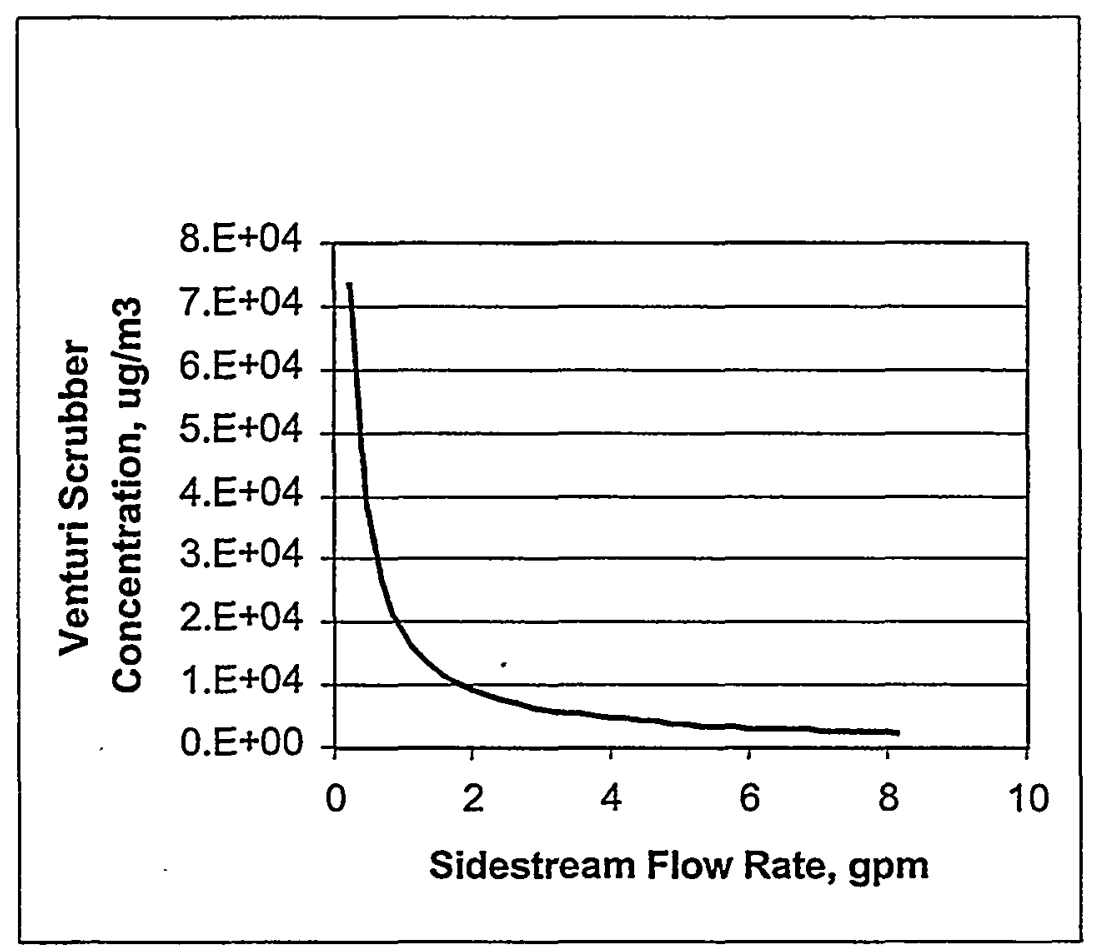

The concentration is reduced as a function of the side stream flow rate. This reduction and the mass treatment rate are shown in Figure 4-3. 
Figure 4-3. Sidestream Removal Rates, Current Configuration

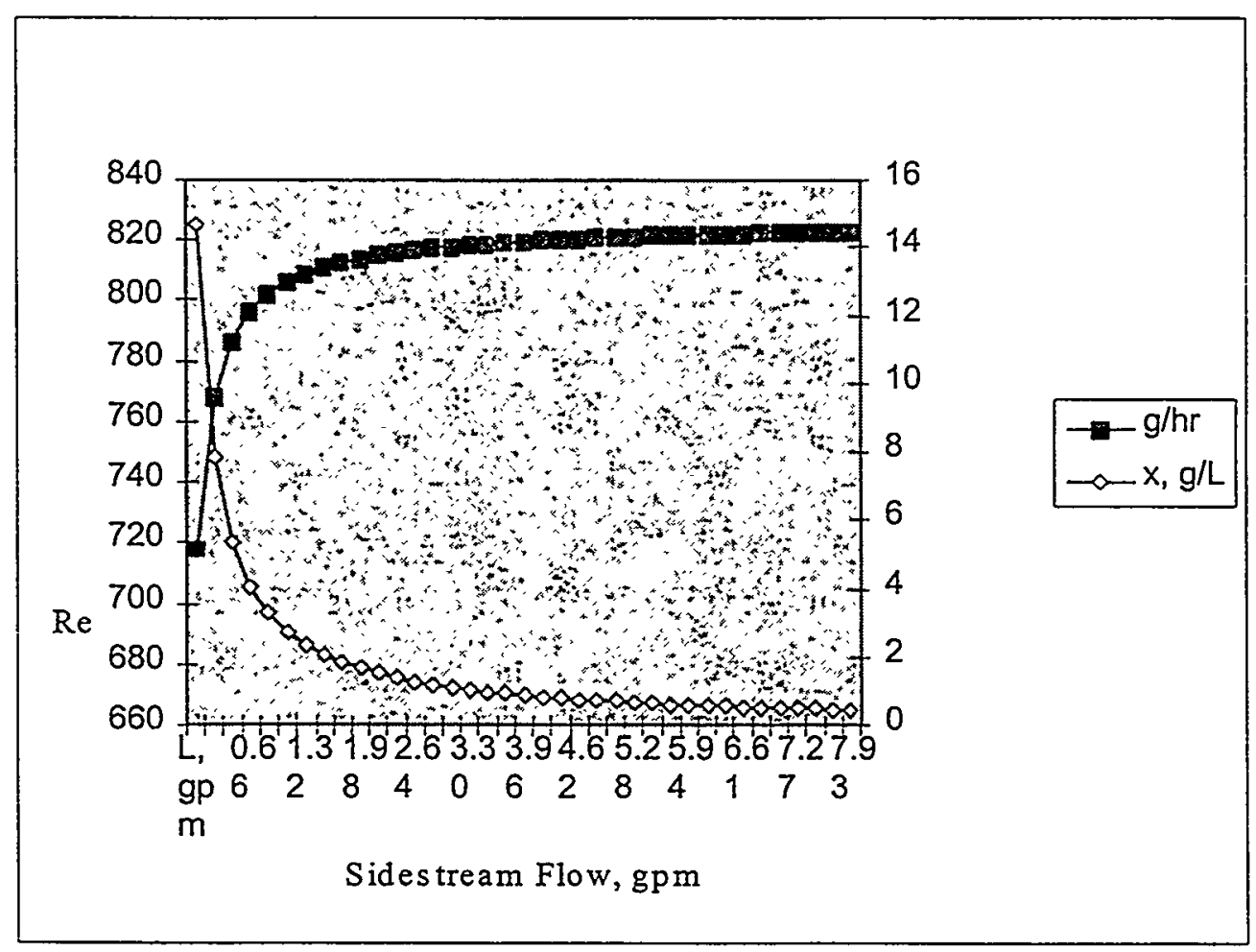

4.2.5.2 Quench Model 2. This models the current system with a change such that the quench and venturi systems have separate liquors as described in Appendix B. Each is treated with an independent recirculating scrub stream with the liquors mixed for aqueous phase mercury removal. Implementing this modification reduces scrubbable mercury in the venturi effluent by a factor of 20 at the same sidestream treatment rate as shown in Figure 4-4. With this modification and a continuous sidestream rate of $2-5 \mathrm{gpm}$, the effluent is about four times $\mathrm{MACT}$, at least for the fraction that is $\mathrm{HgCl}_{2}$. 


\section{Figure 4-4. Modified Configuration, Flow Rate vs. Vapor Concentration}

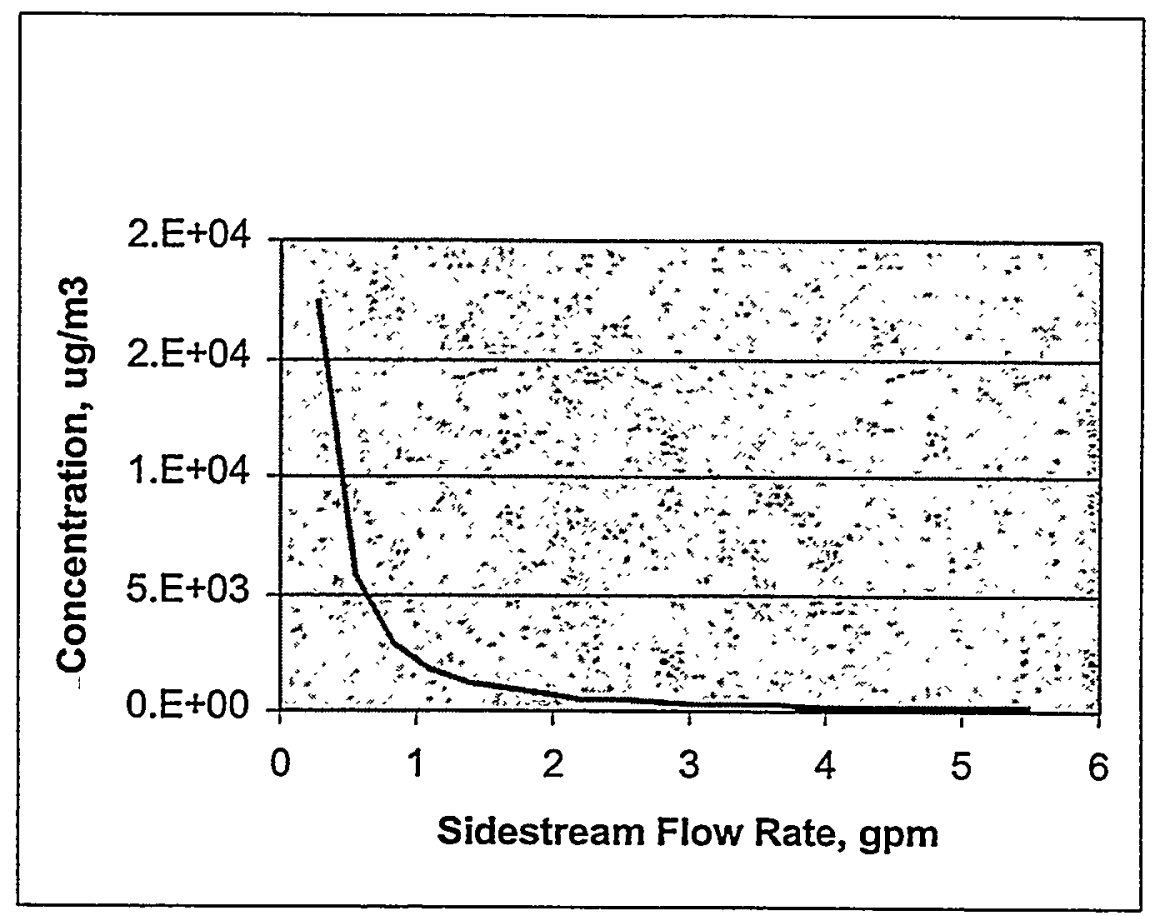

4.2.5.3 New Scrubber. A multi-stage absorber (scrubber) unit using plates or packing could be installed. Recirculation can be used only if most of the mercury is removed (DF varies depending on the scrub loop recirculation rate). This can reduce the scrubbable mercury to less than $50 \mu \mathrm{g} / \mathrm{scm}$ with $10-15$ theoretical transfer units.

\subsubsection{Analysis of Scrub Collection Sidestream}

The scrub collection tank recirculates nitric acid solution to the quench tower at $85 \mathrm{gpm}$ and the venturi scrubber at $35 \mathrm{gpm}$. Treatment of this entire stream for removing mercury is not considered practical. However, a sidestream treatment is. This would involve removing some of the liquid continuously or by batch, removing mercury, and returning the treated sidestream or wasting it. Obviously, the preferred method would be to return the treated sidestream for reuse. Reusing the treated scrub eliminates the creation of a waste stream. However, this severely limits the technologies that can be used. The other method is to partially neutralize (or use a water scrub) the sidestream, remove the mercury, and deal with the waste effluent by stabilizing and disposing or returning to the tank farms. If the latter were used, a small sidestream would be required. To provide perspective, the raw feed is approximately 2 gpm so a much smaller sidestream flow would be preferred. Depending on the sidestream rate, the removal may or may not significantly reduce the amount of mercury in the offgas.

Figure 4-5 compares the current method of partial blowdown of 400 gallons every 24 hours to a continuous sidestream of the average flow rate of the blowdown. The continuous model is a good representation of the maximum scrub tank concentration of a dissolved species. The model shown below used mercury (not including vapor phase effects) but applies to any species retained in the scrub. 


\section{Scrub Steady State Model}

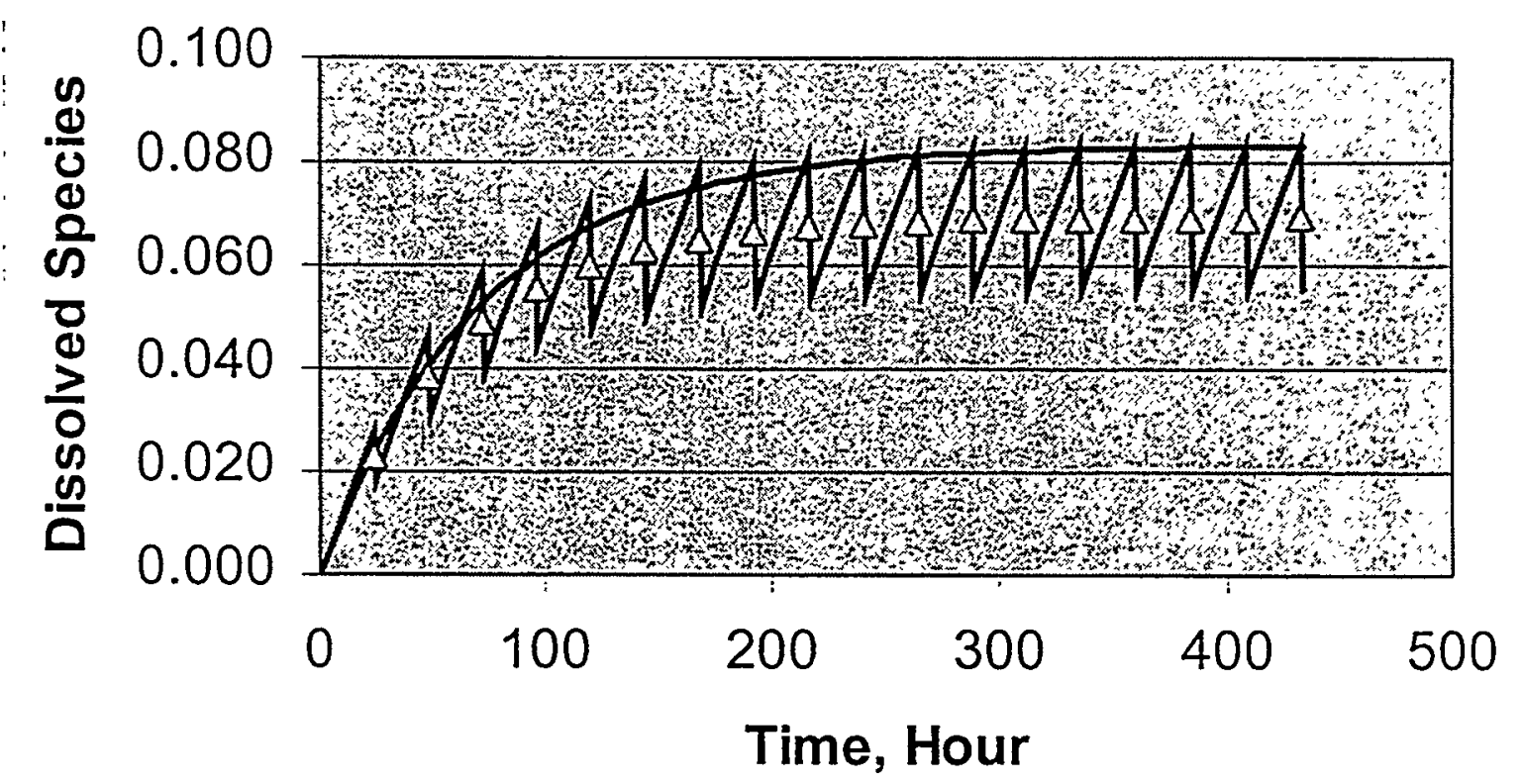

The continuous model is based on the material balance

$$
E-S x=V \frac{d x}{d t}
$$

Where $\mathrm{E}=$ emission rate, mole or gram $/ \mathrm{hr}$ (estimated rate from calciner into quench tower)

$\mathrm{S}=$ average blowdown, $(400 \mathrm{gal} / 24 \mathrm{hr} * 3.785 \mathrm{~L} / \mathrm{gal}=63 \mathrm{~L} / \mathrm{hr})$

$\mathrm{V}=$ scrub collection tank volume, $\mathrm{L}$

$\mathrm{x}=$ concentration $\mathrm{gm}, \mathrm{Ci}$ or mole/ $\mathrm{L}$

The integrated form is:

$$
x=\frac{E}{S}-\left(\frac{E}{S}-x_{0}\right) e^{\frac{-S}{V} t}
$$

It does not account for the 600 -gallon recycles that occur every 60 days. In the steady state, the maximum concentration is $\mathrm{x}=\mathrm{E} / \mathrm{S}$. The plot above also has a sawtooth line and some triangular points that are both models themselves. The sawtooth line represents the 
actual operation (i.e., 400 gallon batch every 24 hours). The triangular points are averages just prior and just after blowdown.

\subsection{WATER SCRUB}

This would be a process change that uses a water scrub instead of nitric acid. The consequences of this would be an increased accumulation rate of solids. However, the sidestream aqueousphase treatment process includes solids filtration that would eliminate any buildup of solids. Successful filtration depends upon the size and filterability of these solids that is uncertain at this time. Distilled water would scrub some $\mathrm{NO}_{\mathrm{x}}$ out. The formula representing this is given by Long (Long 1978).

$$
3 \mathrm{NO}_{2}+\mathrm{H}_{2} \mathrm{O}=2 \mathrm{HNO}_{3}+\mathrm{NO}
$$

The $\mathrm{NO}_{2}$ is limited by the acid concentration. The maximum nitric acid concentration was estimated at 0.138 molar $(\mathrm{pH}=0.86)$. The HSC Chemistry program was used to determine this at $70^{\circ} \mathrm{C}$. The plot of this is shown in Figure 4-6 and indicates a concentration of about 0.013 molar $(\mathrm{pH}=1.9)$.

Figure 4-6. Water Scrub Acid Concentrations

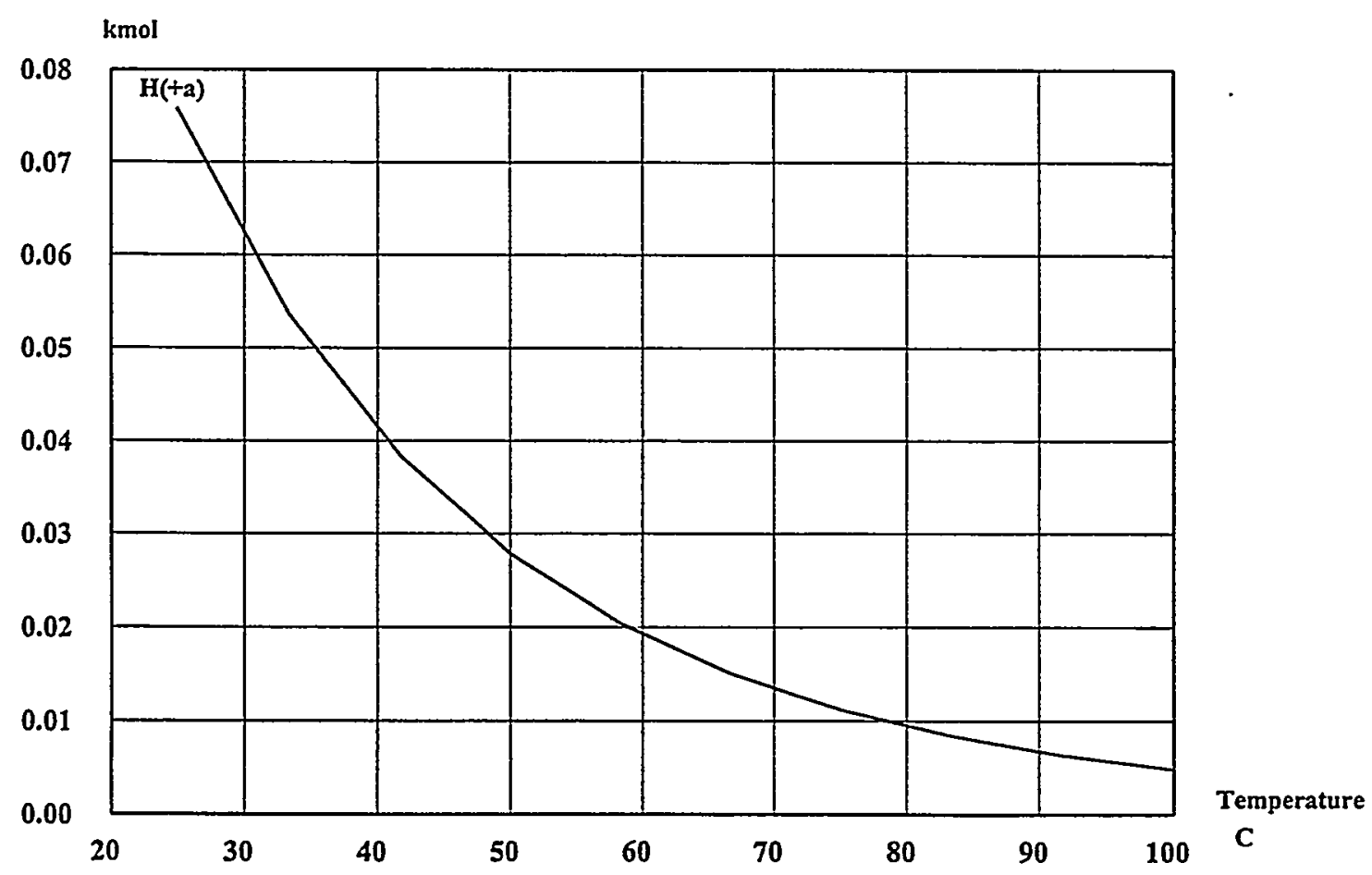




\subsection{TECHNOLOGY TRANSFER}

\subsection{PREVIOUS INTEC SURVEY}

A previous evaluation considered removing mercury from the gas, from raw feed, and from the scrub collection tank (Taylor et al, 1998). Raw feed aqueous phase mercury removal was not recommended. Gas phase treatment was recommended. The report also recommended removing mercury from the scrub collection tank to reduce tank farm inventories (not to provide MACT compliance). The following Table 5-1 summarizes the technologies from this report.

Table 5-1. Previous INTEC Survey

\begin{tabular}{|c|c|c|}
\hline Technology & Liquid & Gas \\
\hline Electrochemical & $\overline{\text { Recommended }}$ & \\
\hline S-Impregnated GAC & & Recommended \\
\hline Ion Exchange & & \\
\hline Precipitation & & \\
\hline Chemical Reduction & & \\
\hline Liquid Extraction & & \\
\hline $\begin{array}{l}\text { Mesoporous Silica (SAMMS), form of } \\
\text { IX/sorption }\end{array}$ & & \\
\hline Noble Metal Adsorption & & \\
\hline
\end{tabular}

\subsection{FRENCH/COGEMA}

The French have not encountered mercury in the presence of $\mathrm{NO}_{\mathrm{x}}$ in the gas phase and mercury under high nitric acid conditions in the liquid phase. CEA (Commissariat à l'Energie Atomique), the French Atomic Energy Commission, is currently contemplating the disposition of its mercury backlog. A distillation unit has been previously used at Saclay for processing contaminated mercury.

In the COGEMA spent nuclear fuel reprocessing facilities, mercury is not used in the dissolution process. Therefore, COGEMA has not been faced with any problems relating to mercury removal from the offgas of thermal processes used (i.e., calciner and vitrification).

CEA performed testing for mercury 25 years ago at the AVM vitrification pilot plant. More recently, CEA performed some calcination tests on a mercury solution at the ATALANTE vitrification pilot plant. Mercury removal testing, using zinc in nitric acid solution, was performed by a COGEMA laboratory at Bessines. COGEMA/SGN is currently studying how to use this past experience for the design of vitrification facilities for a customer who has to process liquid waste containing mercury. Corresponding tests at a CEA pilot plant in Marcoule are in progress.

Mercury releases from thermal systems, including incineration and vitrification, are regulated in France. The mercury emission limit value for hazardous waste incinerators is $50 \mu \mathrm{g} / \mathrm{dscm}$ (dscm 
$=$ standard $\mathrm{m}^{3}$ at $0^{\circ} \mathrm{C}, 101.3 \mathrm{kPa}$, dry gas at $11 \% \mathrm{O}_{2}$ ). To ensure that the emissions comply with the regulatory limit, incineration plants must sample for heavy metals at least twice per year. Representative samples from the offgas system are analyzed in the laboratory using normalized procedure NFX 43.308. There are no requirements for online, continuous measurement.

French sites do not experience the problem of competition between $\mathrm{NO}_{\mathrm{x}}$ and mercury when processing offgas. COGEMA's French specialists do not recommend using activated carbon when $\mathrm{NO}_{\mathrm{x}}$ is present based on previous problems at a pilot plant dedicated to uranyl nitrate calcination. The offgas from this plant condenser was being treated in an activated carbon unit. A fire occurred in the unit and it was taken off-line. COGEMA's French sites have no experience with the hindrance of mercury sorption processes by $\mathrm{NO}_{\mathrm{x}}$. Cold trapping, if practicable, may be one possibility. Another would be to use copper turnings. A Swedish company has developed a mercury specific filter using selenium (see Section 6.2.3).

Removal of mercury from acidic liquid waste is not practiced in COGEMA facilities. A possible method for removing mercury from the recirculation loop is to reduce $\mathrm{Hg}^{+2}$ to $\mathrm{Hg}$ metal, which precipitates. The large difference in phase densities leads to easy phase separation. Formic acid addition can be used for this purpose but only at less acidic conditions (see Section 6.6). COGEMA's laboratory at Bessines is in the process of evaluating stabilization and detoxification of sludge and wastes contaminated with mercury. They have developed specific expertise in this field and are able to perform studies and analyses in their facilities.

\subsection{MSE TECHNOLOGY APPLICATIONS TRADEOFF STUDY}

A trade study was conducted by MSE Technology Applications (MSE 1998b) for the Consolidated Incineration Facilities (CIF) at the Savannah River Site (SRS) of scrubber blowdown and recirculating liquors. MSE recommended Galvanocoagulation, a process combining sorption and cementation, precipitation via organo-sulfide compounds, and electrocoagulation for mercury removal at the CIF. The CIF stream is different than the NWCF scrubber liquors, but some of the information may apply. 


\subsection{TECHNOLOGY SURVEY AND ANALYSIS}

This section provides a brief analysis of technologies available to remove mercury from the gaseous and aqueous effluents. These technologies range from laboratory experiments to operating facilities. In the aqueous phase scrub liquor, removal is a serious challenge as mercury exists in several speciated forms as shown in Appendix A. Therefore, many of the potential technologies may not be effective (e.g., Ion Exchange and Adsorption). This is compounded by likely problems with gelatinous solids (presumed to be $\mathrm{Al}(\mathrm{OH})_{3}$ ) if the quench scrub liquors are partially neutralized, a requirement for most aqueous phase technologies. Likewise, in the gaseous phase, the presence of $\mathrm{NO}_{x}$ in large concentrations impacts gas-phase adsorption. Even if most of the $\mathrm{NO}_{x}$ is removed via a $\mathrm{NO}_{x}$ idizer, the remaining $\mathrm{NO}_{\mathrm{x}}$ may still impact adsorption.

\subsection{PRETREATMENT}

Several technologies for pretreatment were considered. Air stripping and steam distillation are discussed below. The nitric acid-compatible technologies evaluated for scrub liquors can also be considered for pretreatment. The other processes were not considered as they were eliminated for good reasons during previous investigations (Taylor et al., 1998).

\subsubsection{Air Stripping}

Air stripping uses an air stream countercurrent to the liquid feed and removes the more volatile components based on concentration difference driving force. Air strippers can be plate or packed columns. The resulting contaminant-laden air stream is scrubbed or treated via sorption or other processes to remove the contaminant.

6.1.1.1 Reference Process. No process was found that uses this technology to air strip $\mathrm{HgCl}_{2}$.

\subsubsection{Applicability.}

6.1.1.2.1 Aqueous Phase. This technology applies only to the aqueous phase (the reverse process, absorption, is covered later for scrub solutions). This technology was determined for use in feed pre-treatment only. Since the speciation analysis (see Appendix A) predicts tank farm mercury in the molecular $\mathrm{HgCl}_{2}$ form, this technology is feasible. However, this technology would require a significant amount of air as predicted by the Kremser Equation. The air required is approximately $3,000 \mathrm{~m}^{3} / \mathrm{min}$ for packed bed strippers even with pre-heating. This technology likely requires a separate air pollution treatment train.

$$
N_{\text {IOL }}=\frac{\ln \left[\frac{x_{2}-y_{1} / H}{x_{1}-y_{1} / H} *(1-A)+A\right]}{1-A}
$$


Where $\mathrm{A}=$ Stripping factor, $\mathrm{HV} / \mathrm{L}$

$\mathrm{H}=$ Henry's Law constant

$\mathrm{L}=$ Feed mole rate

$\mathrm{N}_{\mathrm{toL}}=$ The number of transfer units required to make a separation

$\mathrm{x}_{2}=$ the mole fraction of feed solution

$\mathrm{x}_{1}=$ the mole fraction of effluent solution

$\mathrm{y}_{1}=$ the mole fraction of stripping air

$\mathrm{V}=$ Vapor mole rate

\subsection{Vapor. Not applicable.}

\subsubsection{Open Steam Distillation}

This technology is similar to distillation used in the petrochemical industry. The distillation column has the feed directed towards the middle of the column with the upper portion for enriching and the bottom for exhaustion. The condensate from the overhead gas is partially recycled to the top for reflux. The use of open steam is common for aqueous systems containing a volatile component that eliminates the need for a reboiler. This technology is different than steam stripping as steam stripping is used to remove an immiscible compound from an aqueous or organic continuous phase.

6.1.2.1 Reference Process. No process was found using this technology to distill $\mathrm{HgCl}_{2}$. However, the Defense Waste Processing Facility (DWPF) at SRS uses steam stripping and boiling to remove elemental mercury as a pre-treatment step after chemical reduction.

\subsubsection{Applicability.}

6.1.2.2.1 Aqueous. This technology generally applies to an aqueous stream containing a volatile component. A general test to determine technical feasibility is to determine the relative volatility.

$$
\alpha=\frac{y^{*}(1-x)}{x\left(1-y^{*}\right)}
$$

Where $\alpha=$ Relative volatility

$\mathrm{y}^{*}=$ Equilibrium concentration in vapor

$\mathrm{x}=$ Liquid phase concentration

Based on the Henry's Law constants determined via ESP, the relative volatility of $\mathrm{HgCl}_{2}$ to water is less than one and this technology is therefore not feasible.

\subsection{Vapor. Not applicable.}




\subsection{ADSORPTION}

\subsubsection{Activated Carbons}

6.2.1.1 Plain Activated Carbon. Activated carbon adsorbs mercury and compounds using this technology. The activated carbon is normally in granular form (GAC) or powdered form (PAC). The activated carbon can be modified specifically for different compounds by manufacturing for different pore sizes. The activated carbons can be impregnated with sulfur, iodine, and iron chlorides to enhance removal efficiencies in mercury adsorption. Activated carbon is a porous material manufactured from carbonaceous raw materials. The activation process develops pores of molecular dimensions within the carbon particle. Typically, activated carbons contain surface areas in the range of $500-1,400 \mathrm{~m}^{2} / \mathrm{g}$. This large internal pore system creates the unique adsorptive properties. The main mechanism is physi-sorption that depends on Van der Waals or London forces between the mercury and the internal carbon surfaces.

6.2.1.1.1 Reference Process. Several municipal incinerators are using PAC systems to remove mercury from the offgas system. The PAC systems require baghouses and other major equipment. Mercury concentrations are usually much lower than at the NWCF for these types of facilities $(540-9,503 \mu \mathrm{g} / \mathrm{dscm})$ and removal efficiencies range from 78-98 percent. Three facilities that use this technology are Burnaby, British Columbia; Camden, New Jersey; and Stanislaus, California (EPA 1992).

\subsection{Applicability.}

6.2.1.1.2.1 Aqueous Phase. While being able to adsorb dissolved mercury, the GAC also adsorbs other metals and radionuclides. The limitation is a $\mathrm{pH}$ of about 4 so that treatment of the quench receiver tank via $\mathrm{GAC}$ requires $\mathrm{pH}$ adjustment. There is some evidence that the efficiency of mercury removal is increased at lower $\mathrm{pH}$, but nitric acid attack of the matrix also occurs. Based on the large expected ionic strength, the loading will require excessive changeout frequency of GAC media and is not a good application for scrub collection treatment (i.e., it is not specific enough).

6.2.1.1.2.2 Vapor Phase. Vapor phase adsorption of mercury using activated carbon is considered one of the best technology applications for removing gas phase mercury. Additional testing is required for adsorption as $\mathrm{NO}_{\mathrm{x}}$ gases appear to interfere with adsorption and breakthrough. It can also result in a fire hazard as discussed previously. The configuration would likely be a packed bed (GAC) as a powdered system may be too difficult to implement in the facility.

\subsubsection{Sulfur/Iodine-Impregnated Activated Carbon}

The impregnated carbons include chemical reactions (chemi-sorption) with the impregnated working best on metallic mercury $\left(\mathrm{Hg}^{\circ}\right)$ and the plain activated carbon working best for speciated mercury (via physi-sorption). Most of the impregnated carbons are being used and/or tested in Europe (Restor 1999). 
6.2.2.1 Reference Process. Testing of sulfur-impregnated activated carbons is ongoing in Europe and the United States. No known industrial application has been found. However, gas phase testing of PAC and GAC is also being conducted by MSE in Butte, Montana. Liquid phase testing has been conducted at ORNL using sulfur impregnated activated carbon pellets (see Section 6.6).

\subsubsection{Applicability.}

6.2.2.2.1 Aqueous. A system would be installed to treat a sidestream from the scrub collection tank continuously or in batches. This would likely be a packed bed system and require $\mathrm{pH}$ adjustment. This system would require additional testing to determine uptake of radionuclides and actinides.

\subsection{Vapor. See Section 6.2.1.1.2.2}

\subsubsection{Selenium Filters}

Selenium filters have been listed by the EPA as a potential method for metallic mercury removal in its report to congress (EPA 1997). The filters operate based on a strong affinity between mercury and metallic selenium. Standard sizes range from $535-53,500 \mathrm{~m}^{3} / \mathrm{hr}$. They are effective for inlet concentrations of $9,000 \mu \mathrm{g} / \mathrm{m}^{3}$ and are not effective at very low concentrations. A residence time of two seconds is required. With a residence time of four seconds, a temperature of $250^{\circ} \mathrm{C}$, and $9,000 \mu \mathrm{g} / \mathrm{m}^{3}$ feed, the selenium filters removed mercury to below $40 \mu \mathrm{g} / \mathrm{m}^{3}$ $(>99 \%)$.

6.2.3.1 Reference Process. Selenium filters were first developed in Sweden in the 1970s for use on smelter flue gas streams and others (EPA 1997). There are several selenium filters installed for mercury removal in Sweden. Vendors indicate they meet the MACT standard of $40 \mu \mathrm{g} / \mathrm{m}^{3}$. The EPA was contacted to obtain more information but have yet to respond.

\subsubsection{Applicability.}

\subsection{Aqueous. Not applicable.}

6.2.3.2.2 Vapor. Selenium filters are a potentially viable technology for NWCF vapors. However, it is not known how the $\mathrm{NO}_{\mathrm{x}}$ gases may impact the efficiency or breakthrough time. Also, they can not be regenerated and would require disposal. However, they may pass the TCLP due to the affinity of mercury for selenium (and other sulfur family elements).

\subsubsection{Noble Metal}

Sorbent-based processes are being developed to remove mercury from offgases produced during thermal treatment of wastes at DOE complexes (Roberts, et al 1998). These sorption processes use a noble metal, such as gold, that adsorbs mercury and forms an amalgam (chemi-sorption). The adsorbate is regenerated at a high temperature and the mercury is recovered. The noble metal sorbents apparently adsorb all species of mercury expected. 
6.2.4.1 Reference Process. No existing thermal unit is using a noble metal based process. However, $\mathrm{ADA}$ technologies have been testing one called Mercu-RE $\mathrm{E}^{\mathrm{TM}}$ at various facilities, including INTEC and MSE in Butte, Montana. Results using metallic mercury indicate interference from $\mathrm{NO}_{2}$ gases where the mercury is oxidized in the gas phase. Metallic $\mathrm{Hg}$ would not desorb in the presence of $\mathrm{NO}_{2}$. Other testing indicates $\mathrm{HgCl}_{2}$ is also removed but with reduced capacity (i.e., reduced sorption capacity before breakthrough) in the presence of $\mathrm{NO}_{2}$ (ADA 1998). This testing is far from complete and needs to be continued especially using NO (reducing gas) along with $\mathrm{NO}_{2}$. However, it appears that the technology has potential to remove 99 percent of the mercury. There has also been testing on the liquid phase. A pilot test unit at the Y-12 Plant in ORNL reduced mercury in an outfall from 800 to 1 ppt. Testing has also been successful at ADA's facilities for removing mercury in sulfuric acid solutions. Testing in nitric acid has not yet been conducted but is needed.

\subsubsection{Applicability.}

6.2.4.2.1 Aqueous. Although not as much testing has been conducted for aqueous phase adsorption, it is considered potentially viable for this application. However, ADA has recommended using a photocatalytic process (see Section 6.9) instead.

6.2.4.2.2 Vapor. This is considered very applicable to vapor mercury treatment if $\mathrm{NO}_{x}$ is removed. This technology would be a regenerable, packed bed unit particularly well suited to the needs at NWCF.

\subsubsection{Other Adsorption}

There are other sorbents being tested by various organizations. Mercsorbent and a chemically treated vermiculite were tested by Sorbent Technologies (Nelson et al 1997; Nelson and Wang 1996). There is also a zeolite that may work in high NOx streams; American Degussa indicated that the 'Wessalith-DAY' product (a zeolite made in Germany) may work for the NWCF's high $\mathrm{NO}_{x}$ offgas stream.

6.2.5.1 Reference Process. As a control (for Mercsorbent testing), regular GAC was used to test for elemental mercury sorption as a function of temperature and humidity (ranges: $280-400^{\circ} \mathrm{F}, 40$ $\mu \mathrm{g} / \mathrm{m}^{3}$, gas face velocity of $0.61 \mathrm{~m} / \mathrm{s}$ ). With dry air, the GAC could sorb 60 percent at $400^{\circ} \mathrm{F}$ (Nelson et al 1997). However, with moisture the sorption dropped to zero at this temperature. At reduced temperatures, the GAC would again sorb the mercury. Testing with the Mercsorbent indicated 95 percent removal at $230^{\circ} \mathrm{F}$ and 100 percent at $300^{\circ} \mathrm{F}$ indicating a good high temperature sorbent. Some $\mathrm{HgCl}_{2}$ is also removed but testing is still in progress. Exfoliated, chemically treated vermiculites were tested. The one treated with a proprietary chemical showed especially promising mercury-capture abilities (Nelson and Wang 1996). In a 70-hour run, 95 percent removal was observed with no diminution $\left(55-115^{\circ} \mathrm{C}\right.$ range). The vermiculite also passed the TCLP $(0.2 \mathrm{mg} \mathrm{Hg} / \mathrm{L})$ at $0.08 \mathrm{mg} \mathrm{Hg} / \mathrm{L}$. At $230^{\circ} \mathrm{C}$ approximately 85 percent removal was realized. In-plant slipstream testing was conducted at R.E. Burger Station near Shadyside, Ohio. The removal varied between 75-97 percent.

\subsubsection{Applicability.}


6.2.5.2.1 Aqueous. Not available.

6.2.5.2.2 Vapor. Applicable to elemental mercury sorption from the vapor. The vermiculite has an additional advantage of passing the TCLP.

\subsection{MEMBRANES}

\subsubsection{Pervaporation}

In the pervaporation process, a membrane is used to selectively separate solvents by reducing the vapor pressure on the permeate side of the membrane. Components in the stream being treated must permeate through the membrane by first dissolving into and then diffusing through the membrane (AWWA 1996). Evaporation occurs on the permeate side via vacuum. The driving force is the difference in chemical potentials or fugacity (i.e., vapor pressure) across the membrane similar to membrane distillation. The rate is also determined by a solvent's solubility and diffusivity in the membrane. It differs in this respect from membrane distillation.

6.3.1.1 Reference Process. Artisan Industries have standard units available for separating water from organics based on size difference. Artisan's membrane consists of a zeolite on a porous ceramic substrate. This material has apparently provided better stability than the organic polymer pervaporation membranes.

\subsubsection{Applicability.}

6.3.1.2.1 Aqueous. This technology would require that water and $\mathrm{NO}_{\mathrm{x}}$ be soluble and permeable while excluding mercury or vice versa. At present, there are no known membranes that can be used in pervaporation for this process (Giberti 1998). However, it is believed that one could be developed but it would require extensive research. The concentrate would require further treatment via an aqueous phase process.

6.3.1.2.2 Vapor. This is normally used for liquid phase but development potential exists.

\subsubsection{Reverse Osmosis and Nano-Filtration}

$\mathrm{RO}$ and Nano-Filtration (NF) are the most commonly used membrane processes for potable water treatment in the United States (AWWA 1996). RO is a membrane process wherein the membrane acts as a molecular filter to remove up to 99 percent of all dissolved minerals, bacteria, particles, and organics larger than 300 molecular weight. To purify water using RO membranes, the natural process of osmosis, where pure water flows through a membrane to dilute an impure solution, must be reversed. To reverse the process, a pump is used to pressurize the feedwater flow to the membrane. The membrane allows pure product water (permeate) to flow through it while rejecting the passage of impurities contained in the feedwater. To limit the buildup of impurities on the RO membrane, a portion of the feedwater containing the rejected impurities (concentrate or reject) is removed for treatment continuously. NF membranes are sometimes referred to as loose RO membranes. NF allows larger ions to transmit through the membrane (e.g., $\mathrm{Cl}^{\text {) }}$ ) while rejecting larger ones (e.g. divalent cations). This technology would require a testing program. 
6.3.2.1 Reference Process. There are no known RO/NF processes treating water for mercury removal or solutions similar to tank farm feed.

\subsubsection{Applicability.}

6.3.2.2.1 Aqueous. There is potential for treating the scrub solution using RO/NF. It would be required to cool this solution to approximately $60^{\circ} \mathrm{C}$, the membrane material limit (Koch 1999). Tests are required to determine the percentage of mercury compounds rejected and to determine if the material can maintain its properties under the 5 molar nitric acid concentration. The Koch membrane considered has been tested in 10 percent nitric acid. It is anticipated that an array/combination of $\mathrm{RO} / \mathrm{NF}$ would be required. It is also possible that $\mathrm{HgCl}_{2}$, if gas-like (i.e., no hydration water), will permeate through the membrane. The concentrate would require further treatment via an aqueous phase process.

The pressure required is on the order of the osmotic pressure of the solution, which is approximated by

$$
\pi=C R T
$$

Where $\mathrm{C}=\mathrm{TDS}$, molar

$\mathrm{R}=$ Gas constant, $0.082 \mathrm{~L}-\mathrm{atm} / \mathrm{gmole} /{ }^{\circ} \mathrm{K}$

$\mathrm{T}=$ Temperature, ${ }^{\circ} \mathrm{K}$

Applying this to feed that has a TDS of approximately $240,000 \mathrm{mg} / \mathrm{L}$ results in an osmotic pressure of approximately $3,000 \mathrm{psi}$, which is not considered practical for this application. Further, ROSA was used to try and establish an RO array for feeds with high TDS. The program would not converge under any configuration exceeding the manufacturers' membrane pressure limitations. Therefore, RO/NF are not considered for further analysis.

\subsection{Vapor. Not applicable.}

\subsubsection{Membrane Distillation}

Hot feedwater flows past a microporous, hydrophobic membrane. Surface tension prevents the feed, while in a liquid state, from penetrating the membrane. In the vapor phase, however, water molecules will pass through and condense on a cooling surface, while non-volatile matter remains completely withheld by water's surface tension. The driving force is the difference in vapor pressure, created by the temperature difference between the hot feed and the cooling surface. When it condenses, this vapor has substantial purity; in fact, only other volatile compounds may pass through at the same time as water. The technology and the theory for it were developed in several countries chiefly in the 1980s, and the term "membrane distillation" was adopted at a conference in the Netherlands in 1989.

6.3.3.1 Reference Process. Radzero is a member of the Scarab Group and develops MD technology under a license from Scarab Development AB. Other members are HVR Water Purification $A B$ (household water purifiers), Medea $A B$ (seawater desalinators), and Xzero $A B$ (semiconductor rinse water systems). The origin of Radzero is a set of tests conducted by the Radiation Physics Department of Lund University in 1992, where equipment from HVR was 
tested for its ability to separate radioactive plutonium, strontium, radium, and cesium from water. The convincing results came to the attention of the Swedish Radiation Protection Institute, which in the 1990s, has publicized alarm over reactor repair workers' exposure to radiation. The institute contacted HVR, and initial talks led to the design of a test and development project in cooperation with the nuclear industry and equipment designers. Radzero $A B$ was formed to administer the project. The original scope of the project was substantially reduced by its financing institutions, but in 1995 a test series was performed at a waste laboratory of the Vattenfall-Ringhals nuclear plant. These tests have further documented the separating ability of the technology, and they have raised pertinent questions regarding the choice of materials and design when dealing with radioactive nuclides, questions which Radzero is addressing in its current efforts to develop larger capacity and eventually pilot size equipment.

\subsubsection{Applicability.}

6.3.3.2.1 Aqueous. This is a viable technology for hot liquid streams with potential applicability to treating the scrub solution sidestream. The $\mathrm{HNO}_{3}$ chiefly stays with the concentrate, but small amounts transmit through the membrane. Further treatment of the reject stream, and possibly the permeate, are likely required. The process would concentrate the reject stream and require upstream filtration to remove particles. NWCF personnel evaluated this technology and do not think it is applicable. Therefore, based on their request, this will not be considered.

6.3.3.2.2 Vapor. Although membrane distillation is more suitable to hot aqueous-phase liquids, a unit may be adaptable to the gas phase. This would require the use of vacuum or low-humidity air down gradient. It would also require additional treatment of the reject stream. Also, the removal would be chiefly from a temperature decrease and would depend on almost complete condensation. The volatile mercury compounds could pass through the membrane (e.g., $\mathrm{HgCl}$, $\mathrm{HgCl}_{2}, \mathrm{Hg}$ ) unless chemical adjustment were made. Adjustment would cause mercury to either precipitate or form ions, neither of which can transmit through the membrane. However, it may not be necessary to perform an adjustment.

\subsection{ABSORPTION}

Multi-stage scrubbing is a potentially viable method particularly for oxides and $\mathrm{HgCl}_{2}$ that are highly soluble. The scrub stream effluent would require treatment expected to involve similar equipment as scrub recycle treatment processes. Absorption is an interphase mass transfer process using a liquid to absorb a species from the vapor phase. The driving force for mass transfer is the concentration (or more exactly, the fugacity) differences between the vapor and liquid.

\subsubsection{Reference Process}

The reference process is the existing NWCF quench and venturi system that is known to scrub most of the mercury from the calciner gas.

\subsubsection{Applicability}


6.4.2.1 Aqueous. Not applicable.

6.4.2.2 Vapor. Scrubbing is applicable to the vapor phase for $\mathrm{HgCl}_{2}$ but not for $\mathrm{Hg}^{\circ}$. However, a scrubber, at lower temperatures can act as a contact condenser. Low soluble candidates ${ }^{1}$ (i.e., $\mathrm{Hg}^{\circ}$ ) are poor candidates for this technology based on the mass transfer relations and material balance:

$$
\begin{aligned}
& V y_{i}-K_{L} a\left(x_{s}-x\right)=V y_{0} \\
& K_{L} a\left(x_{s}-x\right)-k x=0
\end{aligned}
$$

Where $\mathrm{k}=$ First order reaction coefficient (e.g., $2 \mathrm{Hg}+2 \mathrm{HNO}_{3}=\mathrm{Hg}\left(\mathrm{NO}_{3}\right)_{2}+\mathrm{H}_{2}$ )

$\mathrm{K}_{\mathrm{L}} \mathrm{a}=$ Liquid phase mass transfer coefficient

$\mathrm{x}=$ Liquid phase mercury concentration ( $\mathrm{x}_{\mathrm{s}}$ is solubility)

$y=$ gas phase mercury concentration

$\mathrm{V}=$ Rate of gas flow to quench

Combining the above two equations, the following significant prediction results:

$$
y_{0}=y_{i}-\frac{K_{L} a}{V} * x_{s}\left(1-\frac{K_{L} a}{K_{L} a+k}\right)
$$

This shows that scrubbing does little for $\mathrm{Hg}^{\circ}$ as $\mathrm{x}_{\mathrm{s}}$ is small $\left(\mathrm{x}_{\mathrm{s}}<1 \times 10^{-6}\right)^{2}$. Similar results can be determined using the Kremser equation (Treybal 1987), which shows that as Henry's constant increases (for scrubbing), exceedingly high scrub liquid flowrate is required. Henry's constant for $\mathrm{Hg}^{\circ}$ at the operating conditions is about 7,300 atm and decreases to $495 \mathrm{~atm}$ at $298^{\circ} \mathrm{K}$ (Clever, et al 1985), both too high for scrubbing mercury metal as a practical technology. However, if a fast oxidizing reagent were available that could be used in large quantities, the reaction would be concentrated at the interface. For this case, the gas phase is the controlling resistance and the metal could possibly be removed. Nitric acid is an oxidizing reagent but the reaction is not adequately fast (Smith et al 1999). $\mathrm{H}_{2} \mathrm{O}_{2}$ may provide the oxidizing power to do this but would require testing.

Analysis in Appendix B indicates a packed scrubber is feasible to remove the mercuric chloride. However, the entire recirculating scrub would need to be treated. Figure B-4 shows the treatment flow rate versus the required DF's that are quite large for reasonable treatment rates.

\subsection{PRECIPITATION}

Precipitation is a very common process for removing metals in aqueous effluents. There are many reagents suitable for precipitating mercury depending on $\mathrm{pH}$. In fact, standard wastewater analytical methods use iodine to form $\mathrm{HgI}_{2}$ precipitate (Dean 1995). An EDTA chelating agent has also been used for mercury titrations in analytical work. However, this description will focus

\footnotetext{
' Although references (Perry 1985) indicate solubility of $\mathrm{Hg}^{\circ}$ in nitric acid, this is believed to be as an ionic compound that requires significant time.

${ }^{2}$ Higher levels of metallic $\mathrm{Hg}$ are possible than predicted by this as $\mathrm{Hg}$ metal solubility is $\sim 700$ times higher in aerated waters (Bailar 1973 ).
} 
on the sulfur family (sulfides, selenides, and tellurides), chiefly sulfides. Appendix B has calculations that show the high effectiveness of precipitating mercury with sulfide even at high acid concentration (however, toxic $\mathrm{H}_{2} \mathrm{~S}$ gas will form in acidic conditions). Selenides and tellurides (Clever, et al 1985) are also highly effective as shown by the following solubility product constants in Table 6-1, a good indication of the degree of precipitation (i.e., the smaller $\mathrm{K}_{\mathrm{sp}}$, the more tightly bound).

Table 6-1. Several Precipitates

\begin{tabular}{|l|l|l|}
\hline Reagent & Precipitate & Ksp \\
\hline Iodate & $\mathrm{Hg}\left(\mathrm{IO}_{3}\right)_{2}$ & $3 \times 10^{-14}$ \\
\hline Selenide & $\mathrm{HgSe}$ & $\cong 10^{-57}$ \\
\hline Telluride & $\mathrm{HgTe}$ & $\cong 10^{-70}$ \\
\hline Sulfide & $\mathrm{HgS}(\mathrm{Red})$ & $\begin{array}{l}4 \times 10^{-55} \text { (Dean } \\
1985)\end{array}$ \\
& & $\begin{array}{l}1.6 \times 10^{-52} \\
1985)\end{array}$ \\
\hline Sulfide & $\mathrm{HgS}$ \\
& (Black) & 1 \\
\hline
\end{tabular}

\subsubsection{Reference Process}

Tests were performed in a pilot unit at Rotterdam, Holland using water from a gas scrubber. The analyses were performed by three independent laboratories using $\mathrm{Na}_{2} \mathrm{~S}$, trimercapto-S-triazine (T-S-T), and the polythiocarbonate (MP7). The results are provided below in Table 6-2 and indicate that any of these reagents are successful in meeting the proposed Dutch limit of $1 \mathrm{ppb}$. All of the testing used a flocculating agent.

Table 6-2. Precipitation Tests, Holland

\begin{tabular}{|l|l|l|l|l|}
\hline Metal & Average & \multicolumn{3}{|l|}{ Average Effluent (ppb) } \\
\cline { 3 - 5 } & Influent $(\mathrm{ppb})$ & $\mathrm{T}-\mathrm{S}-\mathrm{T}$ & $\mathrm{Na}_{2} \mathrm{~S}$ & $\mathrm{MP7}$ \\
\hline $\mathrm{Hg}$ & 230 & 0.2 & 0.2 & 0.2 \\
\hline
\end{tabular}

Degussa Corporation has tested the trimercapto-s-triazine (TMT 15) in high nitric acid concentration with good results. Degussa achieved 99.9 percent removal ( $\mathrm{DF}=1,000)$ during testing of TMT 15 starting with $1,000 \mathrm{ppm} \mathrm{Hg}$ and $3.5 \mathrm{M} \mathrm{HNO}_{3}$ initially simulated nitric acid scrubber solution with a 25 -minute stirred residence time.

\subsubsection{Applicability.}

6.5.2.1 Aqueous. A precipitation process would require installation of a sidestream process on the quench scrub collection tank. However, it may require $\mathrm{pH}$ adjustment as toxic $\mathrm{H}_{2} \mathrm{~S}$ gas is formed under the acidic conditions, at least when using sulfide. If using TMT 15 , no pH adjustment is required and it can be used directly in the acid. It would also require flocculation if based on the Dutch experience (alum may be beneficial in this respect). The precipitate will require filtration and the solid passes the TCLP. 
6.5.2.2 Vapor. Not applicable.

\subsection{ION EXCHANGE}

Ion exchangers are insoluble solid materials that carry exchangeable cations or anions (Helfferich 1995). In this way ion exchange (IX) differs from other sorption processes. During the ion exchange process, the rate limiting steps are mass transport of the solute from the liquid to the resin followed by sorption and transport through the resin. The ion exchange reaction is usually virtually instantaneous. IX is a well established technology with mercury-specific mercapto resins being available for some time. IX is a continuous flowthrough process using packed columns of IX resins.

\subsubsection{Reference Process}

The Treated Effluent Disposal Facility (TEDF) at Hanford uses mercury specific ion exchange as one of their unit processes. The water is high chloride so significant $\mathrm{HgCl}_{2}$ is likely present. The resin functional group is thiol. The columns are regenerated with $\mathrm{HCl}$. However, the water has been pre-treated at this point using precipitation at a $\mathrm{pH}$ of 10 and a $\mathrm{FeCl}_{3}$ flocculating agent and contains much less dissolved solids than the NWCF scrub solution. Also, the feed to the unit is non-acidic.

Several IX/sorption resins were tested on INEEL tank simulants at ORNL (Taylor et al 1995). The tank waste simulated was that of a high-sodium tank waste with $\mathrm{HNO}_{3}$ at $1.66 \mathrm{M}, 0.02 \mathrm{M}$ $\mathrm{HCl}, 0.002 \mathrm{M} \mathrm{Hg}\left(\mathrm{NO}_{3}\right)_{2}$ and various nitrates and other salts. The results of this testing indicate limited capacity (during sorbent tests, column testing was not conducted) likely due to high acid but was also impacted by chlorides as shown in Table 6-3 below. However, these were sorbent capacity tests and column testing indicates that most of the resins/sorbents will work. High acid concentration attacks some of these resins, which likely leads to early breakthrough.

Table 6-3. IX with Acid-Type Solution

\begin{tabular}{|l|l|l|l|}
\hline Resin & Functional Group & $\begin{array}{l}\text { Final Hg Conc., } \\
\mathrm{mg} / \mathrm{L}^{1}\end{array}$ & \% Removed \\
\hline Ionac SR-4 & Thiol & 205 & 25.6 \\
\hline $\begin{array}{l}\text { SuperLig } \\
618\end{array}$ & Proprietary & 213 & 25.2 \\
\hline Durasil 70 & Proprietary & 265 & 3.6 \\
\hline Ionac SR-3 & Isothiouronium & 267 & 3.0 \\
\hline Mersorb & Sulfur (S-GAC) & 273 & 0.5 \\
\hline Filtersorb & GAC & 274 & 0.4 \\
\hline IRC-718 & Iminodiacetate & 278 & 0.0 \\
\hline
\end{tabular}

\footnotetext{
${ }^{1}$ Initial $\mathrm{Hg}$ was $278 \mathrm{mg} / \mathrm{L}$

${ }^{2}$ Mersorb is a S-Impregnated GAC made by NUCON
} 
Testing at higher $\mathrm{pH}$ with chlorides present indicate better efficiency. The following results in Table 6-4 are for SRS simulant that had $1.33 \mathrm{M} \mathrm{NaOH}, 0.22 \mathrm{M} \mathrm{NaCl}, 0.002 \mathrm{HgCl}_{2}$, and various nitrates and other salts.

Table 6-4. IX With Basic-Type Solution

\begin{tabular}{|l|l|l|l|}
\hline Resin & $\begin{array}{l}\text { Functional } \\
\text { Group }\end{array}$ & $\begin{array}{l}\text { Final Hg Conc., } \\
\mathrm{mg}^{1} \mathrm{~L}^{1}\end{array}$ & \% Removed \\
\hline Mersorb & Sulfur (S-GAC) & 0.8 & 99.3 \\
\hline Durasil 70 & Proprietary & 21.9 & 79.7 \\
\hline Ionac SR-3 & Isothiouronium & 22.4 & 79.2 \\
\hline SuperLig 608 & Proprietary & 24.1 & 75.1 \\
\hline Filtersorb & GAC & 60.2 & 44.1 \\
\hline Ionac SR-4 & Thiol & 66.6 & 38.2 \\
\hline IRC-718 & Iminodiacetate & 68.4 & 36.5 \\
\hline
\end{tabular}

The HSC Chemistry speciation equilibrium program was used to understand the above results. The mercury in both of the simulants was virtually all as $\mathrm{HgCl}_{2}$ due to the high chloride. The acid interferes with Mersorb sorption of $\mathrm{HgCl}_{2}$ by oxidizing the sulfur on the granules, but the removal efficiency is excellent in the absence of acid indicating good affinity for $\mathrm{HgCl}_{2}$ and $\mathrm{S}$ $\mathrm{GAC}$ in aqueous solution (lower limit of $\mathrm{pH} \sim 4$ ).

There are also newer type IX/sorption resins that are specific to mercury. Mesoporous silica materials containing functionalized organic monolayers (thiol groups) have been developed to remove heavy metals from wastewater. The distribution coefficient for $\mathrm{Hg}$ ranges from 56,000 to 340,000 using SRS simulants (Fryxell 1997). Also known as self-assembled monolayers on mesoporous supports (SAMMS), the material has good potential but would require testing. Previous testing was conducted in the $\mathrm{pH}$ range of 3 to 9 .

\subsubsection{Applicability.}

6.6.2.1 Aqueous Phase. This technology has potential applicability to a scrub sidestream. However, IX resins are normally not designed for high acid conditions so $\mathrm{pH}$ adjustment (or water scrub) is likely required. Also, the presence of chloride in this stream complicates IX possibilities. Cation exchangers prefer other cations to $\mathrm{Hg}^{+2}$ if chloride is present (Helfferich 1995). This is also shown in Appendices A and B.3. The use of this technology would require the installation of IX columns and associated regeneration and/or replacement/removal equipment. Even with pH adjustment, it is questionable whether some of the resins can apply to this type of waste as the speciation indicates a significant amount of mercury bound up as $\mathrm{HgCl}_{2}$. While the Mersorb may sorb this, $\mathrm{Hg}^{+2}$ and $\mathrm{HgCl}^{+}$are also significant in the scrub at the $\mathrm{Hg}: \mathrm{Cl}$ ratios observed. Additional testing with partially neutralized solutions would be required.

\subsubsection{Vapor Phase. Not applicable.}

\footnotetext{
' Initial concentration of $108 \mathrm{mg} / \mathrm{L} \mathrm{Hg}$
} 


\subsection{CHEMICAL REDUCTION}

Chemical reduction can also be used to treat a hazardous waste constituent (Freeman 1989). The most prevalent use of reduction in current waste treatment is the reduction of $\mathrm{Cr}$ (VI) to $\mathrm{Cr}$ (III). Common reducing agents include $\mathrm{SO}_{2}$ and $\mathrm{NaBH}_{4}$. For mercury, as discussed in the French (COGEMA) experience, formic acid is used as a reducing agent. The mercury metal forms a separate, dense phase and is removed from solution.

\subsubsection{Reference Process}

SRS has developed a process that uses formic acid to chemically reduce mercury oxide (SRS has no $\mathrm{HgCl}_{2}$ ) in sludge feeds to the DWPF melter (Barnes 1997, Coleman et al 1994). Formic and nitric acids are added to sludges that result from treatment of SRS high-activity wastes that contain $0.2-2$ weight percent mercury. The mixture is heated to $95^{\circ} \mathrm{C}$ for six to 12 hours, then steam-stripped to remove the reduced mercury. The $\mathrm{pH}$ is limited to 4.5 to prevent reoxidation.

$$
\mathrm{Hg}^{+2}+\mathrm{HCOOH}=\mathrm{Hg}+\mathrm{CO}_{2}+2 \mathrm{H}^{+}
$$

Based on thermodynamics, the other expected mercury species can also be reduced.

$$
\begin{aligned}
& \mathrm{HgCl}_{2}+\mathrm{HCOOH}=\mathrm{Hg}+\mathrm{CO}_{2}+2 \mathrm{HCl} \\
& \mathrm{HgCl}^{+}+\mathrm{HCOOH}=\mathrm{Hg}+\mathrm{CO}_{2}+\mathrm{H}^{+}+\mathrm{HCl}
\end{aligned}
$$

SRS (Eibling 1983) indicates the second reaction, above, does not go to completion forming $\mathrm{HgCl}$. However, recent discussions (Eibling 1999) indicate that the reaction does go to completion in caustic solution and depends somewhat on the initial speciation.

\subsubsection{Applicability.}

6.7.2.1 Aqueous. The process is only applicable to the aqueous phase. If viable, this process would treat a sidestream from the scrub collection tank. It would require $\mathrm{pH}$ adjustment. It would also require a condenser and adsorbant for recovering the mercury if a steam stripper were used. The hydrochloric acid $(\mathrm{HCl})$ could cause some of the mercury to reform the chlorides in the recovery well. The recovered mercury would require further treatment (e.g., amalgamation, stabilization) or removal to an off-site mercury center. However, steam stripping is likely not required for the scrub liquor as it is not a sludge that entraps the Hg like at SRS. A decanting system might be sufficient. Also, there are potential energetic reactions when adjusting $\mathrm{pH}$ from the acidic direction then using formic acid as opposed to SRS that adjusts from the caustic side downward. Testing would be required to demonstrate this technology for current or projected scrub liquors to ensure all species can be removed.

6.7.2.2 Vapor. Not applicable. 


\subsection{POLYMERS}

\subsubsection{Polymer Filtration}

Specialized polymers are added to contaminated water where they create a bond with the targeted metals. This bonded complex forms a much larger compound that can then be separated from the waste stream. An acid-resistant thiacrown polymer has been developed as a costeffective mercury extractant (Baumann et al 1999).

6.8.1.1 Reference Process. Testing indicates mercury (as $\mathrm{Hg}^{+2}$ ) is removed ranging from $95-99$ percent depending on concentration and time (Baumann et al 1999). This process was selective even in the presence of competing cations. The bound $\mathrm{Hg}^{+2}$ can be stripped from the polymer allowing reuse. This technology has been shown to be effective for $\mathrm{Hg}^{+2}$ in the presence of lead and other competing cations. It is also possible to use this material in a column/sorption unit.

\subsubsection{Applicability.}

6.8.1.2.1 Aqueous. This process is applicable and designed for treating aqueous liquids. It will require testing for this particular application on a sidestream treatment of the scrub collection tank liquors. Testing has been conducted in the $\mathrm{pH}$ range of 1.5 to 6.2. Although it was designed for acidic conditions, it is not known how higher acid concentrations would impact material integrity and sorption efficiency. This would require further testing. Also, the fact that there are mercury chlorides may impact this technology negatively. Since NWCF scrub solution contains other species of mercury, this technology by itself may not remove all of the mercury. This would likely be a batch or semi-batch operation and require filtration to remove the polymer followed by a $\mathrm{Hg}$ recovery process. It would also require stripping of the polymer (so far only dithizone dispersed in $\mathrm{CHCl}_{3}$, a fairly complex process, has been used).

\subsection{Vapor. Not applicable.}

\subsubsection{Polyelectrolyte Enhanced Removal}

This technology uses water soluble chelating polymers (WSCP) that have been designed for mercury ion selectivity in the presence of dilute acid and mild oxidant (Smith et al 1999). The technology was developed to assist in the oxidation of elemental mercury to mercuric cation $\left(\mathrm{Hg}^{+2}\right)$ and remove the mercury via chelation. The solution is chemically adjusted removing the mercury while the polyelectrolyte and solution is recycled. The concentrated mercury is treated via sulfide precipitation.

6.8.2.1 Reference Process. The process was developed at Los Alamos National Laboratories (LANL) for treating debris that is chiefly metallic contaminated. A number of different WSCPs were evaluated for their ability to bind $\mathrm{Hg}(\mathrm{II})$ as a function of $\mathrm{pH}$. Figure 6-1 shows a plot of $\mathrm{pH}$ versus $\mathrm{Hg}$ (II) breakthrough. 
Figure 6-1. Soluble Polymer

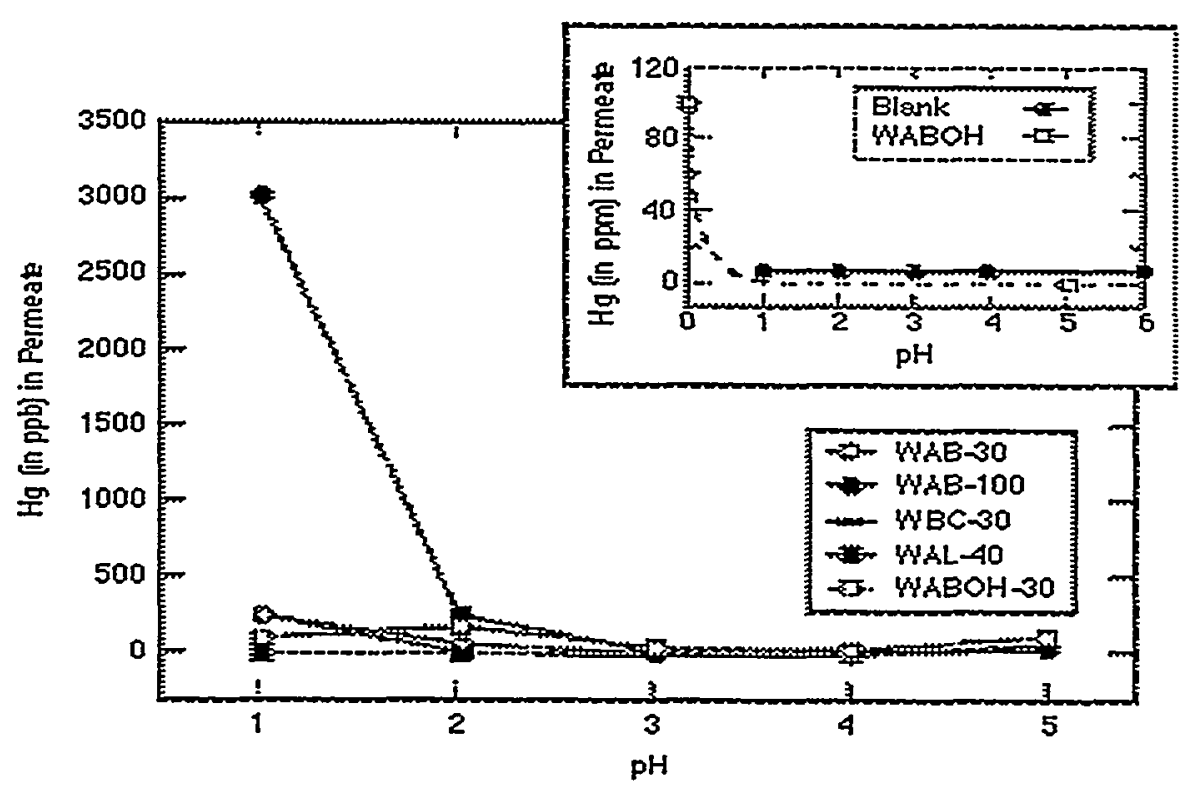

The plot shows that all of the polymers bound well in the $\mathrm{pH}$ range $>3$. Most of the polymers bound well even to $\mathrm{pH} 1$ with two polymers, WAB-100 and WABOH-30, showing some release starting to occur below $\mathrm{pH} 2$. This plot indicates that the $\mathrm{Hg}(\mathrm{II})$ can be stripped from the WSCP by using a diafiltration process (Cheryan 1992) at a lower $\mathrm{pH}$ range. Some of the polymers studied thus far have poor solubility in the $<\mathrm{pH} 0.2$ ranges. Only WABOH- 30 had reasonable solubility at low $\mathrm{pH}$ values. A number of the polymers were able to reach the target limit in the higher $\mathrm{pH}$ ranges (Smith 1999).

\subsubsection{Applicability.}

6.8.2.2.1 Aqueous. This process was developed for solubilizing and binding metallic mercury from waste debris. However, it may be possible to adapt the process for the scrub liquor but will require further testing to determine if the speciated mercury will bind to the polymer. This will also require ultra-filtration and a form of mercury recovery, presumably sulfide precipitation.

\subsection{Vapor. Not applicable.}

\subsection{PHOTOCATALYTIC}

Photocatalysis, an athermal process, uses ultraviolet (UV) light with a wavelength $<385 \mathrm{~nm}$ to excite an electron of solid particles of $\mathrm{TiO}_{2}$ to a higher energy level. This leaves holes in the semi-conductor that oxidize organic compounds. While most research has focused on the oxidation of organics, the free electrons generated reduce metals in solution. The technology has the potential of removing hazardous metals from solution, including mercury (Serpone 1987). 


\subsubsection{Reference Process}

$A D A$ Technologies has received funding from the DOE to perform treatability testing for mercury removal from selected surrogates using this technology. There has been previous research using this method (Prairie 1995, Aguado 1995, and Lau et al 1998). ADA has completed some Phase I testing that indicates that this is a good potential process for treating non-acidic liquid streams. Table 6-5 summarizes some of the recent testing using $\mathrm{TiO}_{2}$ with finely dispersed noble metal on the surface.

Table 6-5. Photocatalytic Results

\begin{tabular}{|l|l|l|l|}
\hline Mercury Species & $\begin{array}{l}\text { Organic } \\
\text { source }\end{array}$ & $\begin{array}{l}\text { Post-Treatment } \\
\text { Conc. }\end{array}$ & $\begin{array}{l}\text { Removal } \\
\text { Efficiency }\end{array}$ \\
\hline $\mathrm{HgCl}_{2}, 10 \mathrm{mg} / \mathrm{L}$ as Hg & Citric Acid & $13 \mu \mathrm{g} / \mathrm{L}$ & $99.9 \%$ \\
\hline $\mathrm{HgCl}_{2}, 10 \mathrm{mg} / \mathrm{L}$ as Hg & Na-EDTA & $46 \mu \mathrm{g} / \mathrm{L}$ & $99.6 \%$ \\
\hline $\mathrm{HgI}_{2}, 10 \mathrm{mg} / \mathrm{L}$ as Hg & Na-EDTA & $10 \mu \mathrm{g} / \mathrm{L}$ & $99.9 \%$ \\
\hline
\end{tabular}

The $\mathrm{TiO}_{2}$ with noble metal was found to adsorb 230 percent of its own weight while plain $\mathrm{TiO}_{2}$ is able to adsorb 160 percent of its own weight. Recent testing conducted by ADA on scrub surrogate indicates feasibility in nitric acid. Test results are forthcoming.

\subsubsection{Applicability.}

6.9.2.1 Aqueous. This process is applicable to treating scrub liquors. The process can reduce all of the potential species of mercury and operate in nitric acid. It will require a mixing/contact chamber, filtration, and an amalgamation process for the mercury. This technology requires addition of an organic compound to provide electrons that may be perceived as a safety issue. The $\mathrm{TiO}_{2}$ could be regenerated and recycled but it may not be cost-effective unless the noble metal form is used. This process also requires an organic additive that provides electrons. Testing is required to determine this feasibility in addition to overall testing in the nitric acid media. This testing is in progress at the time of issue.

6.9.2.2 Vapor. Although not developed or tested for the vapor phase, there is potential applicability. It would require a UV light source in a chamber with titanium packing. However, it may be difficult to transmit UV light in such an arrangement and this is still in the idea stage.

\subsection{GALVANIC TYPE TECHNOLOGIES}

\subsubsection{Electrochemical}

A method using a mercury pool cathode is potentially feasible (Del Debbio et al 1998) to remove dissolved mercury from acid solutions. The process can be batch or continuous. The process is more efficient at higher concentrations.

6.10.1.1 Reference Process. There are no known industrial processes using this technology for a similar application. However, testing has been conducted indicating the feasiblity (Del Debbio et al 1998). One method, using a graphite felt cathode proved infeasible, at least at nitrate concentrations greater than $2 \mathrm{M}$. The other uses a liquid pool of mercury metal for the cathode 
and a platinum foil anode. Removal rates ranged from 0.8 to $9.8 \mathrm{~g} / \mathrm{hr}$. The mercury pool cathode requires sparging or agitation to obtain significant reduction rates. Three tests with an average cell voltage of 3.7 volts averaged 99 percent $\mathrm{Hg}$ removal and average removal rate of 9.6 grams of $\mathrm{Hg} /$ hour. Also, future tests will focus on determining the effects of waste solution components on $\mathrm{Hg}$ removal rates.

\subsubsection{Applicability.}

6.10.1.2.1 Aqueous. This process was developed for and is applicable to the aqueous phase. In particular, the process is well suited for nitric acid, a distinct advantage. However, it may be difficult to implement from an engineering perspective and requires further testing and evaluation. Preliminary design was developed in Appendix $\mathrm{C}$ that indicates practical application of this technology but there is uncertainty in the mass transfer coefficient.

\subsection{Vapor. Not applicable.}

\subsubsection{Metal Displacement/REDOX}

REDOX media (copper and zinc) remove up to 98 percent of water soluble cations of lead, mercury, copper, nickel, chrome, and other metals.

$$
\mathrm{Zn}^{0}+\mathrm{Hg}^{+2} \rightarrow \mathrm{Zn}^{+2}+\mathrm{Hg}^{0}
$$

The zinc goes into solution while the mercury plates out on the copper. KDF Fluid Treatment, Inc. process media are high-purity copper-zinc granules used in a number of pretreatment, primary treatment, and wastewater treatment applications (KDF 1999).

6.10.2.1 Reference Process. KDF informed us that the reference process they have is the New Jersey Department of Environment, which recommends the KDF 55 media for reduction of mercury. It performed a two-year study in 1992 on treating the Kirkwood-Cohansey aquifer that has an average $\mathrm{pH}$ of 4.5 .

\subsubsection{Applicability.}

6.10.2.2.1 Aqueous. This process would require partial neutralization of the scrub sidestream. The adjusted liquors would flow through a column of the media for reduction of mercury. The media containing the plated mercury are then removed and treated further. Anything above zinc in the electromotive series (most transition metals/actinides) might be reduced as well in this process.

6.10.2.2.2 Vapor. It is possible that a form of this process might be possible in the vapor phase per the French suggestion on copper turnings. This would require sorption from the gas-phase onto the metal surface followed by gas-phase reduction of the oxidized species of mercury. However, this is still in the idea phase and would require proof testing. 


\subsubsection{Galvanocoagulation}

Hydrated iron oxides are generated from internal processes of galvanic couples. This process is the physi/chemi-sorption of metals on the ferrohydroxides. The following might represent the removal of the three main species of mercury:

$$
\begin{aligned}
& \mathrm{Fe}(\mathrm{OH})_{3}+\mathrm{HgCl}_{2} \rightarrow \mathrm{Fe}(\mathrm{OH}) \mathrm{O}_{2} \mathrm{Hg}+2 \mathrm{HCl} \\
& \mathrm{Fe}(\mathrm{OH})_{3}+\mathrm{Hg}^{+2} \rightarrow \mathrm{Fe}(\mathrm{OH}) \mathrm{O}_{2} \mathrm{Hg}+2 \mathrm{H}^{+} \\
& \mathrm{Fe}(\mathrm{OH})_{3}+\mathrm{HgCl}^{+} \rightarrow \mathrm{Fe}(\mathrm{OH}) \mathrm{O}_{2} \mathrm{Hg}+\mathrm{H}^{+}+\mathrm{HCl}
\end{aligned}
$$

This technology also removes some radionuclides and other metals. These are concentrated in the solid phase. The information provided (MSE 1998) indicates a $\mathrm{pH}$ range of 2-14 and high turbidity operation.

6.10.3.1 Reference Process. Borsekov Institute of Catalysis (Novosibirsk, Russia) has tested this at the Siberian Chemical complex in Seversk. No data were available for mercury but the process is very efficient for actinides.

\subsubsection{Applicability.}

6.10.3.2.1 Aqueous. Not very much is known about this process but it appears similar to coprecipitation. It is believed that partial neutralization would be required and it is not known what the Hg TCLP is in the final waste form, which could well be a TRU mixed waste. The sorbed mercury may require recovery and additional stabilization.

\subsection{Vapor. Not applicable.}

\subsubsection{Electrocoagulation}

This technology uses electric fields to coagulate metals, i.e. it facilitates chemical coagulation. Contaminant-laden water moves through an electric field where destabilization, ionization, and electrolysis influence treatment. The mechanism for electrocoagulation is based on reduction of the zeta potential, i.e. the repulsive charges between colloidal particles are reduced so that larger particles can form and drop out of solution.

6.10.4.1 Reference Process. This process was an EPA superfund project to stabilize oil reprocessing on acidic sludge. Mercury was non-detectable in bench-scale TCLP results. The influent mercury was $0.06 \mathrm{mg} / \mathrm{kg}$.

\subsubsection{Applicability.}

6.10.4.2.1 Aqueous. The use of this technology for scrub liquors will require that the solution be partially neutralized. Most metal cations, including actinides, can be flocculated with this technology so it is virtually non-specific. The waste form may require further treatment if 
COGEMA-DOC-001, Rev. 0

actinides are present in significant quantities. Additional chemical reagents may be required to ensure colloidal formation of mercury.

6.10.4.2.2 Vapor. Not available. 
COGEMA-DOC-001, Rev. 0

\subsection{BEST ALTERNATIVES}

\subsection{SUMMARY OF POTENTIAL TECHNOLOGIES}

Table 7-1. Summary of Potential Technologies

\begin{tabular}{|c|c|c|c|c|}
\hline \multicolumn{2}{|c|}{ Technology } & Feed Pretreatment & Gas Phase & Aqueous Phase \\
\hline \multicolumn{2}{|l|}{ Air Stripping } & Large air flow required & $\mathrm{N} / \mathrm{A}$ & $N / A$ \\
\hline \multicolumn{2}{|l|}{ Distillation } & Infeasible & $\mathrm{N} / \mathrm{A}$ & N/A \\
\hline \multirow[t]{5}{*}{ Adsorption } & $\overline{G A C}$ & $N / A, \cdots$ & Best For $\mathrm{HgCl}_{2}$ & Not Recommended \\
\hline & Impregnated GAC & N/A & Best For Hg Metal & Not Recommended \\
\hline & Selenium Filters & $N / A$ & For Hg Metal & NA \\
\hline & Noble Metal & N/A & Both & Not Recommended \\
\hline & Other Adsorption & $N / A$ & TBD & Not Recommended \\
\hline \multirow[t]{3}{*}{ Membranes } & Pervaporation & $\mathrm{N} / \mathrm{A}$ & Not Recommended & Not Recommended \\
\hline & RONE & Pressure exceeds linits & N/A & $\begin{array}{l}\text { Pressure exceeds } \\
\text { limits. }\end{array}$ \\
\hline & Membrane distillation & 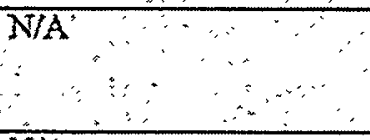 & Not Recommended & $\begin{array}{l}\text { Directed to be } \\
\text { elinuinated by } \\
\text { NWCF Personnel } \\
\end{array}$ \\
\hline Absorption & Multi-Stage Scrabbing & $N / A, \cdots$ & For $\mathrm{HgCl}_{2}$ & N/A \\
\hline Precipitation & TMT 15 or equivalent & Expected to be effective & N/A: & All species \\
\hline Ion Exchange & $\begin{array}{l}\text { Cation, anion, } \mathrm{Hg} \\
\text { specific, etc }\end{array}$ & N/A & N/A & $\begin{array}{l}\text { Cationic form, may } \\
\text { require complex } \\
\text { array for speciation }\end{array}$ \\
\hline $\begin{array}{l}\text { Chemical } \\
\text { Reduction }\end{array}$ & Formic Acid & 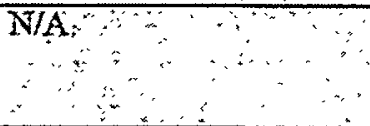 & $N / A$ & $\begin{array}{l}\text { All species } \\
\text { projected (needs } \\
\text { tests for } \mathrm{HgCl}_{2} \text { ) }\end{array}$ \\
\hline \multirow[t]{4}{*}{ Galvanic Type } & $\begin{array}{l}\text { Electrochemical, } \\
\text { Mercury Pool Cathode }\end{array}$ & $\begin{array}{l}\text { Hg concentration may be } \\
\text { too low }\end{array}$ & N/A" & All species \\
\hline & REDOX/Metal & $\bar{N} / \mathrm{A}$ & $\mathrm{N} / \mathrm{A}$ & $\begin{array}{l}\mathrm{Hg}^{2}, \text { other species } \\
\text { possible }\end{array}$ \\
\hline & Galvanocoagulation & $\mathrm{N} / \mathrm{A}$ & $\mathrm{N} / \mathrm{A}$ & $\begin{array}{l}\text { All species } \\
\text { speculated }\end{array}$ \\
\hline & Elcctrocoagulation & N/A & N/A & $\begin{array}{l}\text { All species } \\
\text { speculated }\end{array}$ \\
\hline Photocatalytic & $\mathrm{UV}_{\mathrm{TiO}}$ & Expected to be effective & Idea Stage Orily & All species \\
\hline \multirow[t]{2}{*}{$\begin{array}{l}\text { Polymer } \\
\text { Technologies }\end{array}$} & Thiocrown Hg specific & N/A & N/A & $\begin{array}{l}\text { Removes } \mathrm{Hg}^{+2} \text {, } \\
\text { testing needed for } \\
\text { others }\end{array}$ \\
\hline & $\begin{array}{l}\text { Polyelcctrolyte } \\
\text { Enhanced (soluble } \\
\text { polymers) }\end{array}$ & $\overline{N / A}$ & $\mathrm{~N} / \mathrm{A}^{\prime}$ & $\begin{array}{l}\text { Further testing } \\
\text { needed }\end{array}$ \\
\hline
\end{tabular}

1 Regular and impregnated $\mathrm{GAC}$ soro both species but the impregnated is better for metal and the regular is better for $\mathrm{HgCl}_{2}$. 


\subsection{TECHNOLOGY RANKING}

\subsubsection{Vapor}

7.2.1.1 Criteria. The following criteria were used to qualitatively rank the vapor-phase mercury removal technologies in Table 7-1:

- Minimization of secondary waste

- Simplicity of installation and operation

- Effectiveness in presence of $\mathrm{NO}_{\mathrm{x}}$

- Contact-handled waste form preferred

- Practical final waste form dispositioning and disposal

- Ability to remove all species of mercury present

- Technical maturity

- Minimal research and development (R\&D)

- Compatibility with current process (including $\mathrm{NO}_{\mathrm{x}}$ idizer upgrades)

- Negligible safety issues

7.2.1.2 Ranking. No gas-phase ranking is performed based on the limited data available. There is not enough known about selenium filters yet. Because of the uncertainty in speciation in the gas phase, the noble metal or a mixture of plain GAC and S-impregnated GAC might be prudent. However, it is believed that if the $\mathrm{NO}_{x}$ idizer is used, the sorption media can be sent out for bids with a performance specification. The use of GAC may be prohibited based on fire hazard if the $\mathrm{NO}_{x}$ is not removed.

\subsubsection{Aqueous.}

7.2.2.1 Criteria. The following criteria are used to qualitatively rank the aqueous-phase mercury removal technologies in Table 7-1:

- Minimization of secondary waste (i.e., recycle nitric acid if possible)

- Simplicity of installation and operation

- Contact-handled waste form preferred

- Practical final waste form dispositioning and disposal

- Ability to remove all species of mercury present

- Technical maturity

- Minimal R\&D

- Compatibility with current process

- Negligible safety issues 


\subsection{ALTERNATIVES}

\subsubsection{Calciner Pre-Feed Treatment}

7.3.1.1 Air-Stripper/Scrubber System, Alternative MT-1. This alternative consists of removing all (or most) mercury prior to the calciner. Since the HSC shows tank farm mercury to be $99+\% \mathrm{HgCl}_{2}$, it should be strippable from the feed using air. The $\mathrm{HgCl}_{2}$ is stripped, then scrubbed back out using water that is treated by an aqueous-phase process (must remove $\mathrm{Hg}$ down to $1 \times 10^{-7}$ mole fraction). This alternative requires a large amount of air $\left(\sim 3,000 \mathrm{~m}^{3} / \mathrm{min}\right)$ that may be too difficult to manage.

Figure 7-1. Air-Stripper Feed Pretreatment

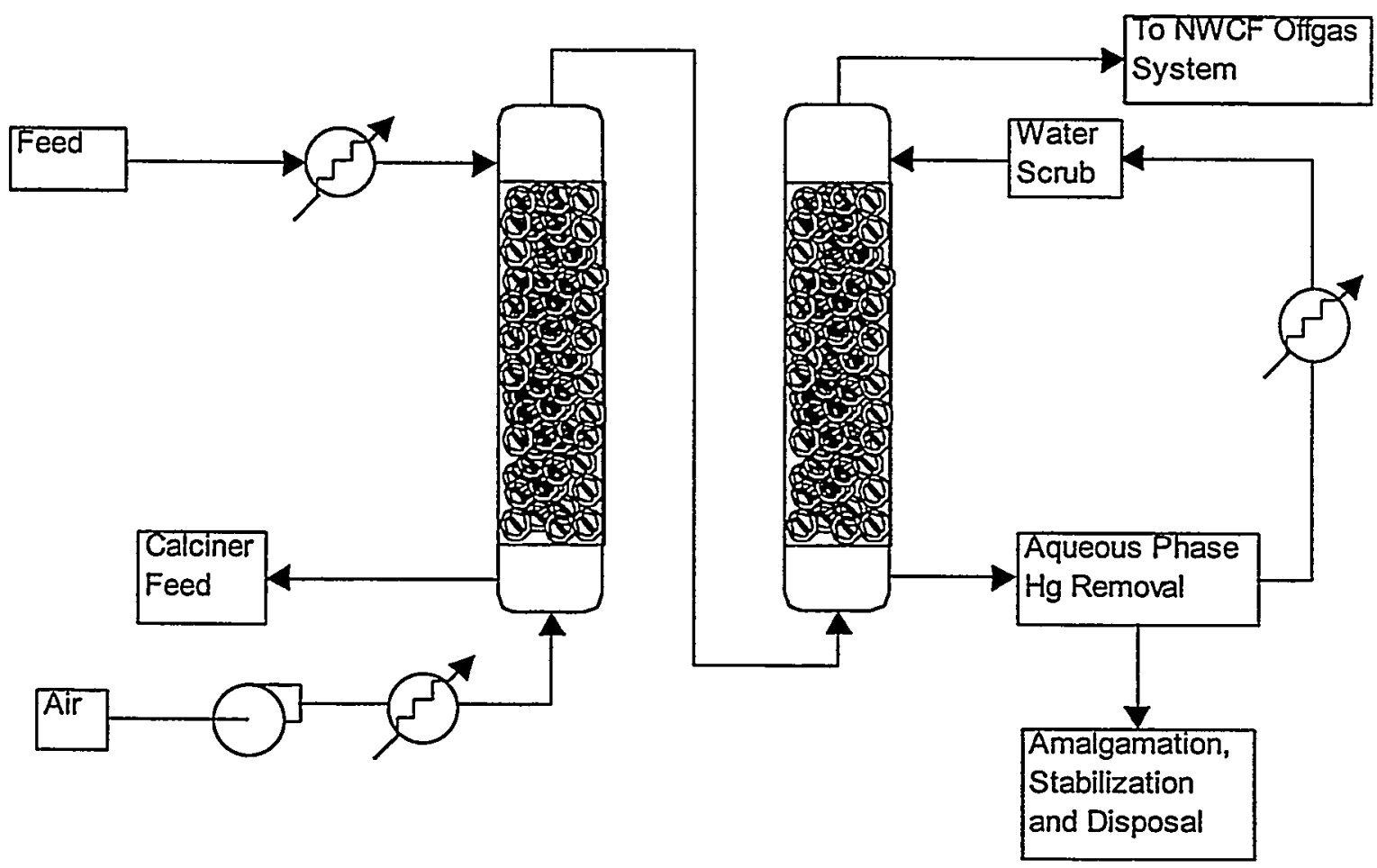

7.3.1.2 Phase Pretreatment. Other potential candidates for pretreatment, including electrochemical, UV/Ti, and precipitation via TMT 15, are discussed in the aqueous phase for scrub liquor sections below.

\subsubsection{Vapor Phase}

The following two alternatives are for vapor treatment and have a similar aqueous-phase treatment system identified as heel reduction.

7.3.2.1 Alternative $\mathrm{V}-1, \mathrm{No} \mathrm{NO}_{\mathrm{x}} \mathrm{idizer}$ (Figure 7-2). This alternative assumes that a $\mathrm{NO}_{\mathrm{x}}$ idizer is not used and hence, no NO $x$ is removed. This alternative likely requires extensive $R \& D$ to determine a gas-phase sorbent or other method to remove metallic mercury, if present. However, if the thermodynamics described in Appendix A.3 are a valid indicator (i.e., if gas-phase kinetics 
are fast), no method would be required to remove metallic $\mathrm{Hg}$ as it exists as oxide at downstream temperatures. Therefore, this alternative includes an upgrade or an additional liquid scrubber based on previous analysis. The water scrub option is also possible within this alternative. The heel reduction shown is an aqueous-phase mercury removal process. This alternative is not expected to meet MACT for some of the emissions (e.g., CO).

Figure 7-2. $\mathrm{No}_{\mathrm{NO}} \mathrm{idizer}$

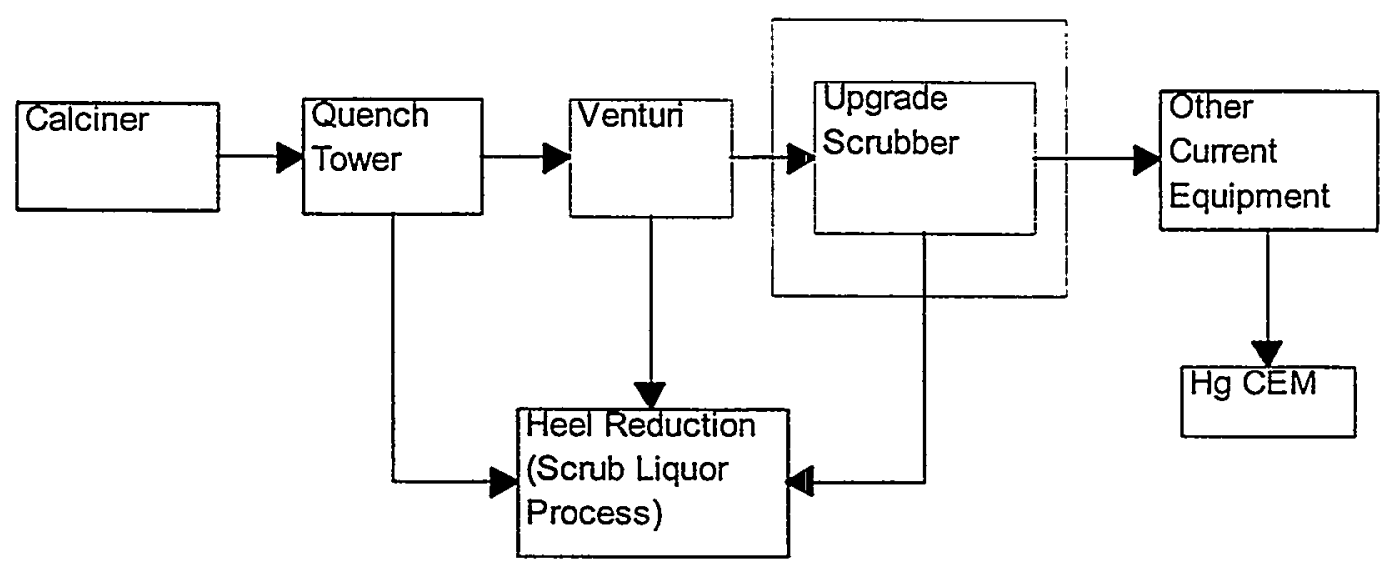

7.3.2.2 Alternative $\mathrm{V}-2, \mathrm{NO}_{\mathrm{x}}$ idizer (Figure 7-3). This alternative includes installation of a $\mathrm{NO}_{x}$ idizer, scrubber upgrades, and one or more of the gas-phase sorbents identified in the technology table. The sorbent is installed downstream of the $\mathrm{NO}_{\mathrm{x}}$ idizer and cooling systems. The heel reduction shown is an aqueous-phase mercury removal process. This alternative is expected to meet MACT for all expected emissions.

Figure 7-3. $\mathrm{NO}_{\mathbf{x}}$ idizer

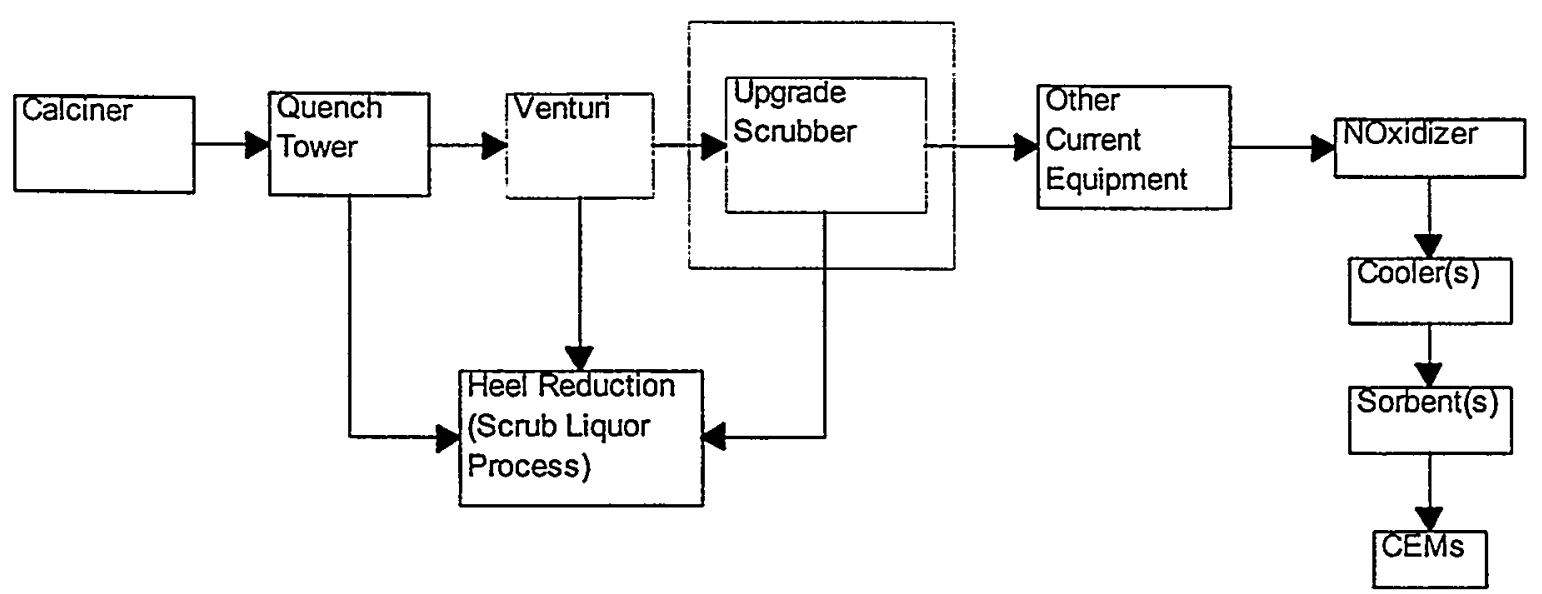




\subsubsection{Aqueous/Acidic Phase Mercury Removal}

The following three technologies represent the known field of available methods of mercury removal under nitric acid conditions and the specific chemistry of scrub liquors. All three have been tested.

7.3.3.1 Alternative AA-1, Electrochemical (Figure 7-4). This alternative would take a sidestream from the scrub collection tank and remove mercury via an electrochemical process. The clean acid is recycled to the scrub collection tank. The mercury is removed as liquid metal from the unit and treated further via amalgamation (e.g., MASS) and disposed as low-level mixed waste or sent offsite. The process requires nitrogen sparging of the cathode to realize reasonable removal rates. The mercury may need retorting if significant radionuclides and/or actinides are present.

Figure 7-4. Electrochemical Reduction System

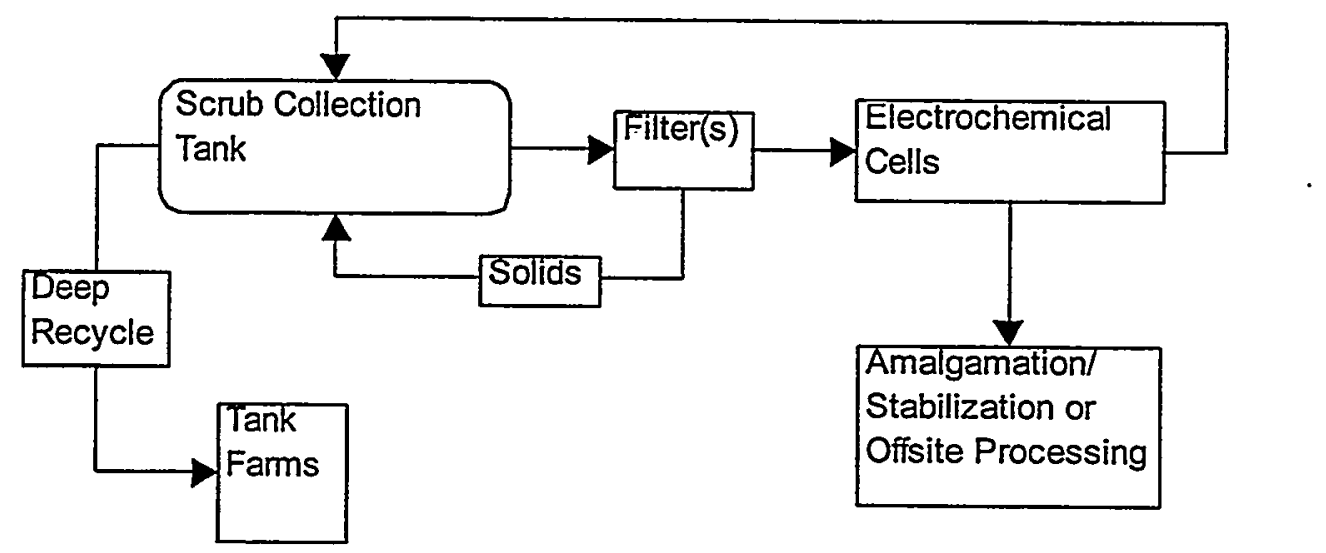

7.3.3.2 Alternative AA-2, Photocatalysis (Figure 7-5). This alternative uses photocatalysis technology to reduce and sorb mercury onto $\mathrm{TiO}_{2}$ semi-conductor. The preferred configuration would be a single pass of titanium through the system for stabilization and disposal. However, this depends on the actinides present, physi-sorbed on the solids. Mercury can be recovered, amalgamated, and disposed, and the titanium can be recycled. This would be preferred if the gold form of titania were used. 
Figure 7-5. UV/Ti Reduction System

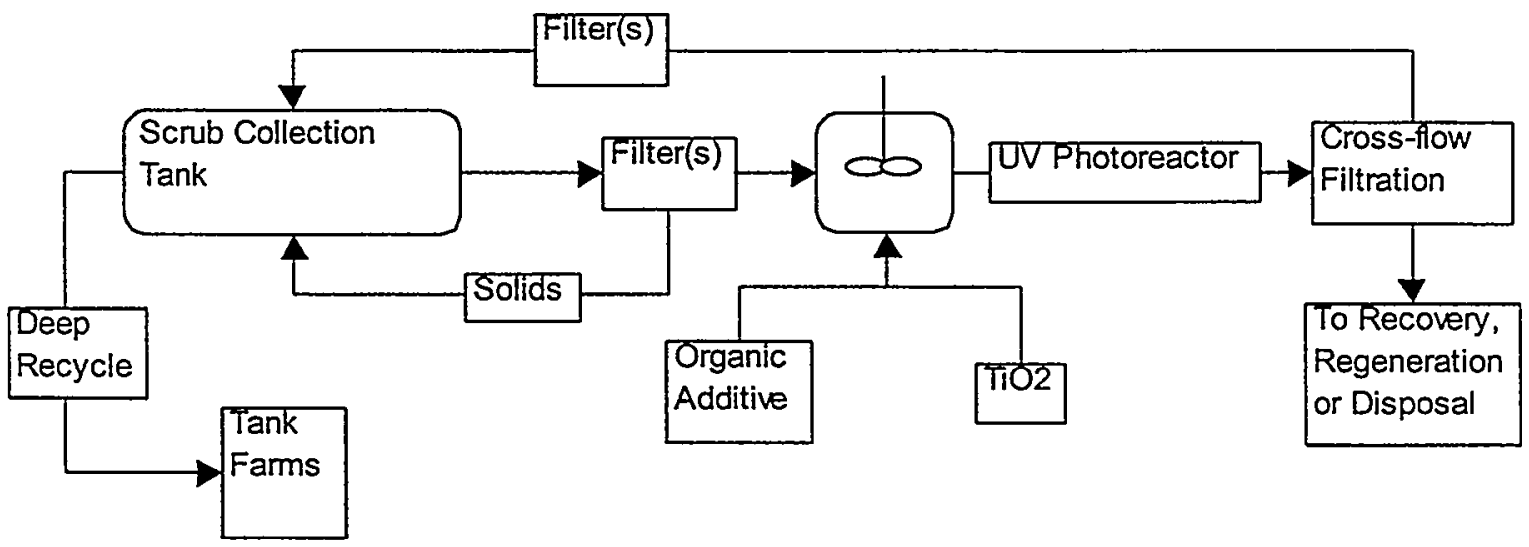

7.3.3.3 Alternative AA-3, Precipitation (Figure 7-6). This alternative uses TMT 15 to precipitate mercury. The solids are stabilized (e.g., MASS process or off-site vendor) and disposed as low-level mixed waste. If actinides are present, a retort may be required followed by amalgamation and stabilization prior to disposal.

Figure 7-6. TMT 15 Precipitation

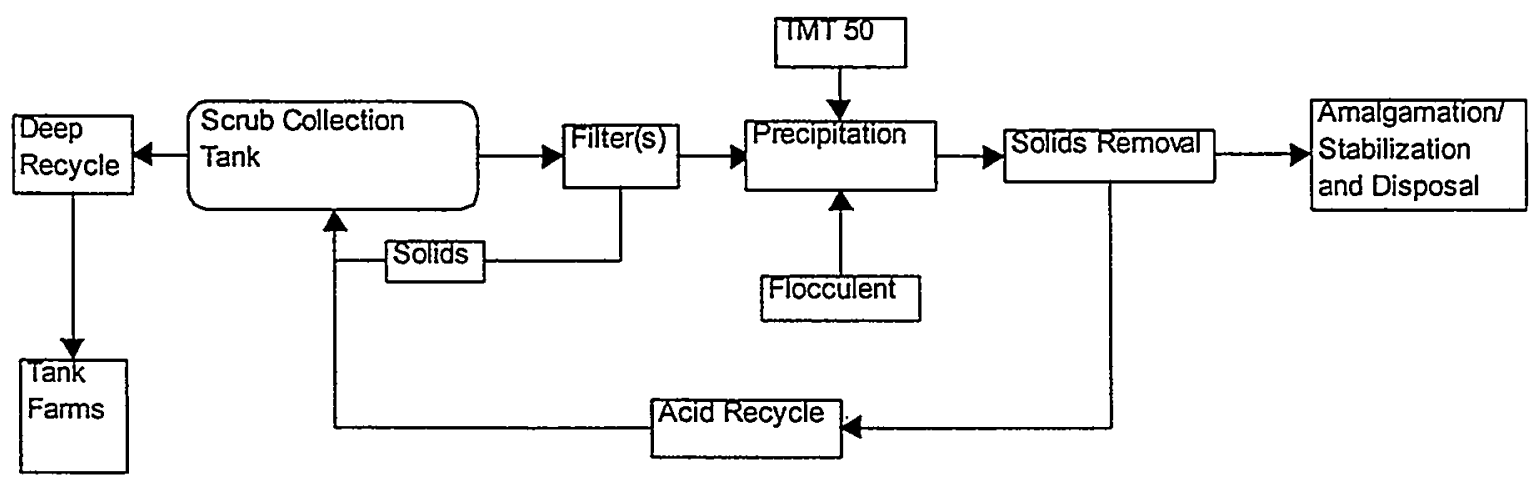

\subsubsection{Aqueous/Non-Acidic Phase Treatment}

The following processes require non-acidic (or acidic but much higher $\mathrm{pH}$ than current acid scrub liquor). The only method to achieve this is via replacing the scrub liquor with a water solution (neutralization is not believed to be practical). The technologies in Section 7.3.3 can also be used in a non-acidic media.

7.3.4.1 Alternative AW-1, Chemical Reduction (Figure 7-7). This alternative uses formic acid $(\mathrm{HCOOH})$ to reduce the mercury in a continuous or batch process. The reduced metallic mercury is separated in a decanter system (this may not be as "clean" of a process as described and may be difficult to implement). The reference process used steam stripping to remove $\mathrm{Hg}$ from the reduction vessel. This stream is condensed and separated. It is believed that a decanter system can be designed to do this based on the large density difference. The metallic mercury is then treated further via amalgamation/stabilization. Solids are blown down to a collection tank 
and nitric acid added. The digested solids are transferred to the tank farm or recycled to the calciner. $\mathrm{PH}$ is adjusted for optimal process conditions prior to recycling.

Figure 7-7. Formic Acid Reduction

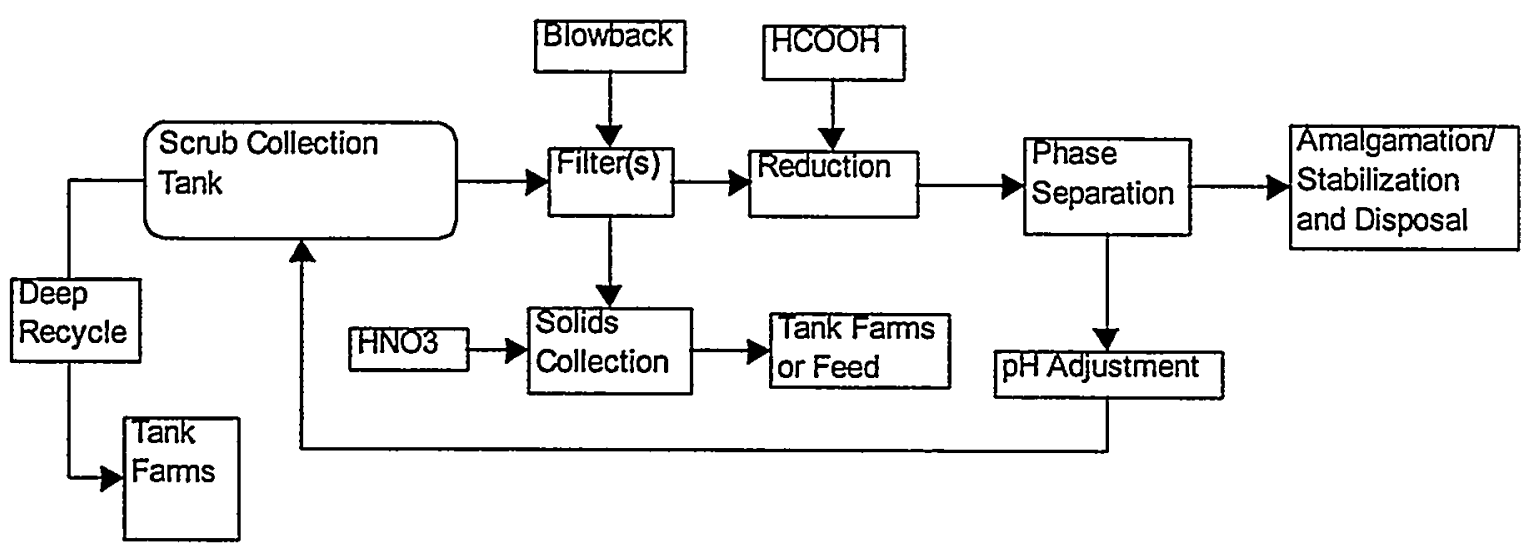

7.3.4.2 Alternative AW-2, REDOX/Metal Displacement (Figure 7-8). This system uses the . $\mathrm{KDF}$ or equivalent $\mathrm{Cu} / \mathrm{Zn}$ media that reduces mercury that then plates the copper. The system is $\mathrm{pH}$ adjusted as shown. Everything above zinc in the electromotive series, including actinides, might also be reduced. The metal media might require retorting to remove the mercury and subsequent amalgamation/stabilization.

Figure 7-8. $\mathrm{Cu} / \mathrm{Zn}$ Reduction

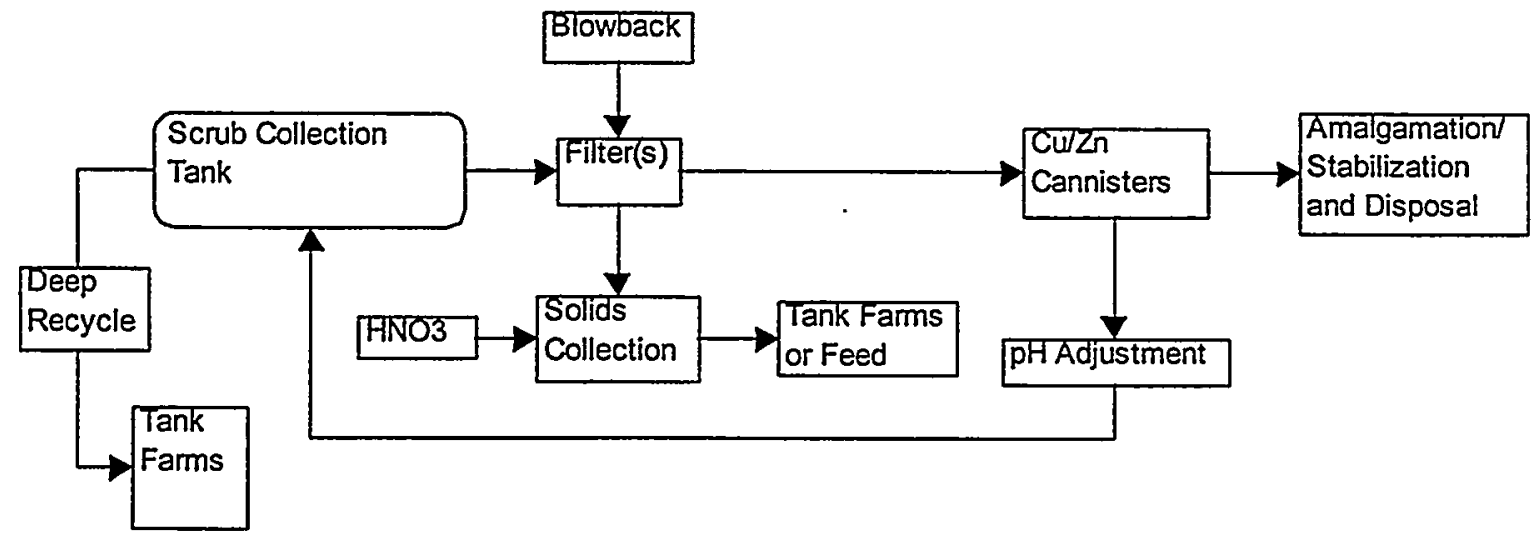

7.3.4.3 Alternative AW-3, Galvanocoagulation (Figure 7-9). Galvanocoagulation uses iron scraps or other forms of iron along with air to form the oxy-hydroxides previously described. The process also removes other metals, including actinides. The product waste is further stabilized (if required as it may pass the TCLP as is) and disposed. 


\section{Figure 7-9. Galvanocoagulation}

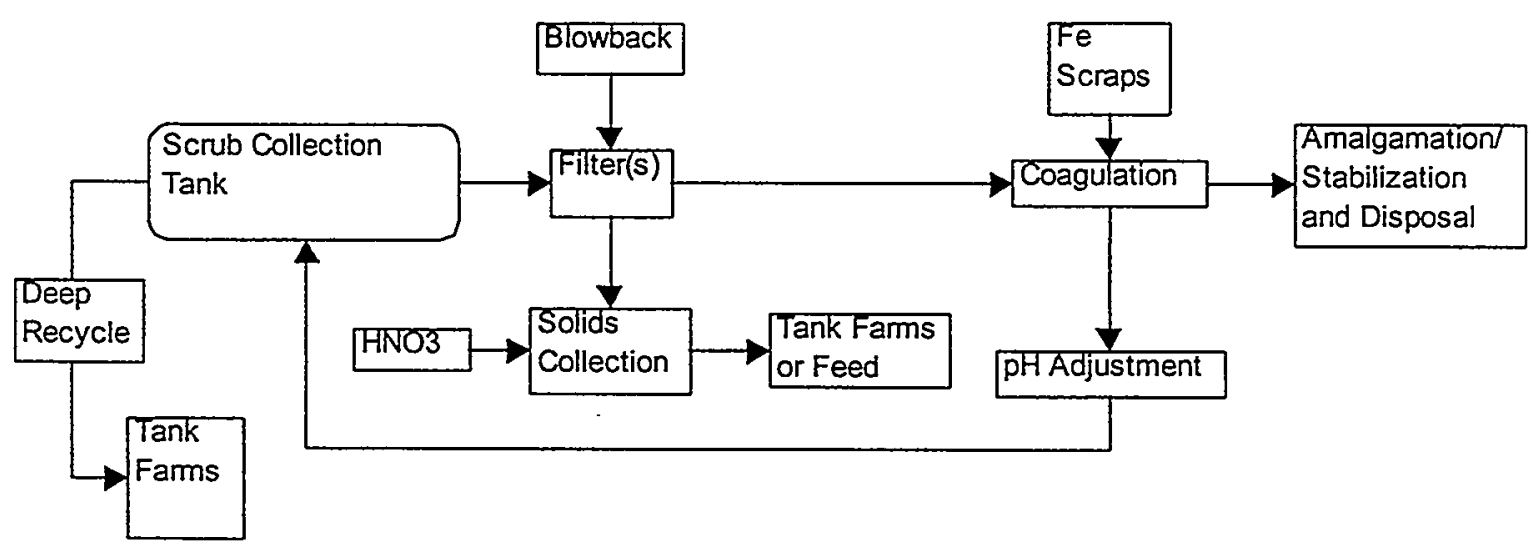

7.3.4.4 Alternative AW-4, Electrocoagulation (Figure 7-10). This process is similar to the other coagulation process but few, if any chemicals are added. AC power is used to produce the electro-floc for the process.

Figure 7-10. ElectroCoagulation

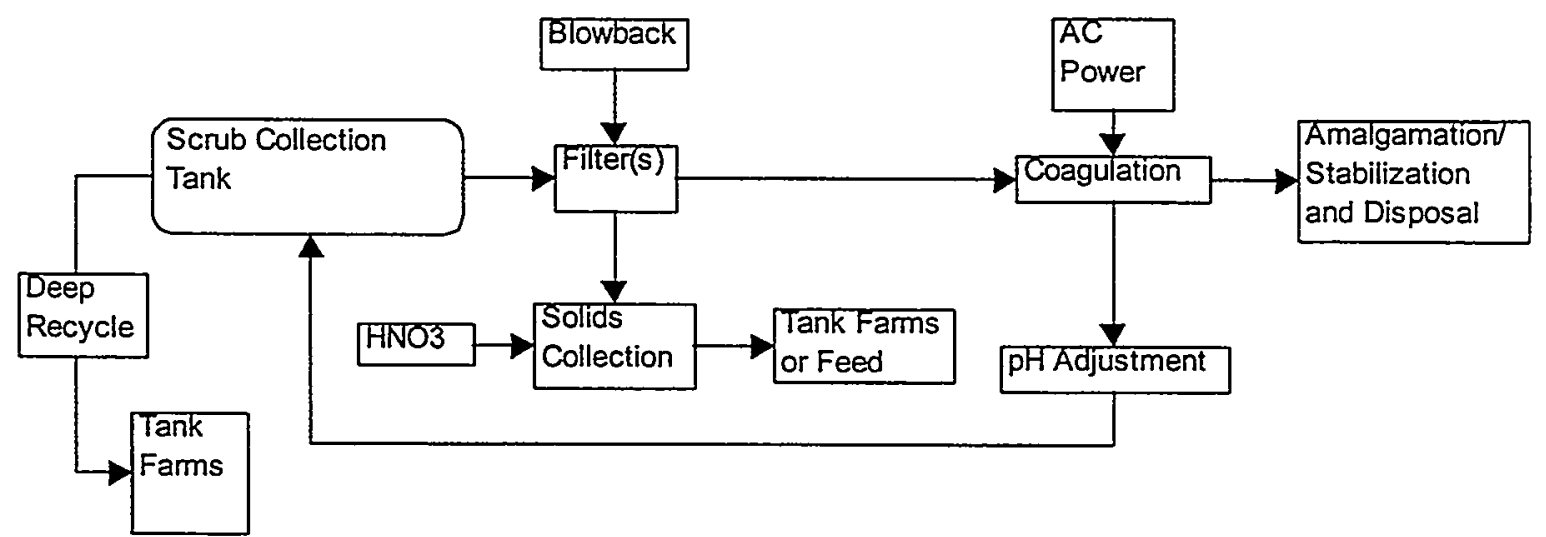

Alternative AW-5, IX Thiocrown Ethers, General Sorbents (Figure 7-11). This alternative uses an IX resin or sorbent to remove mercury from partially neutralized waste effluent. Either the sorbent is regenerated or the resins are wasted. As shown, the resins are regenerated with the waste solution being stabilized and disposed. 


\section{Figure 7-11. Sorbents}

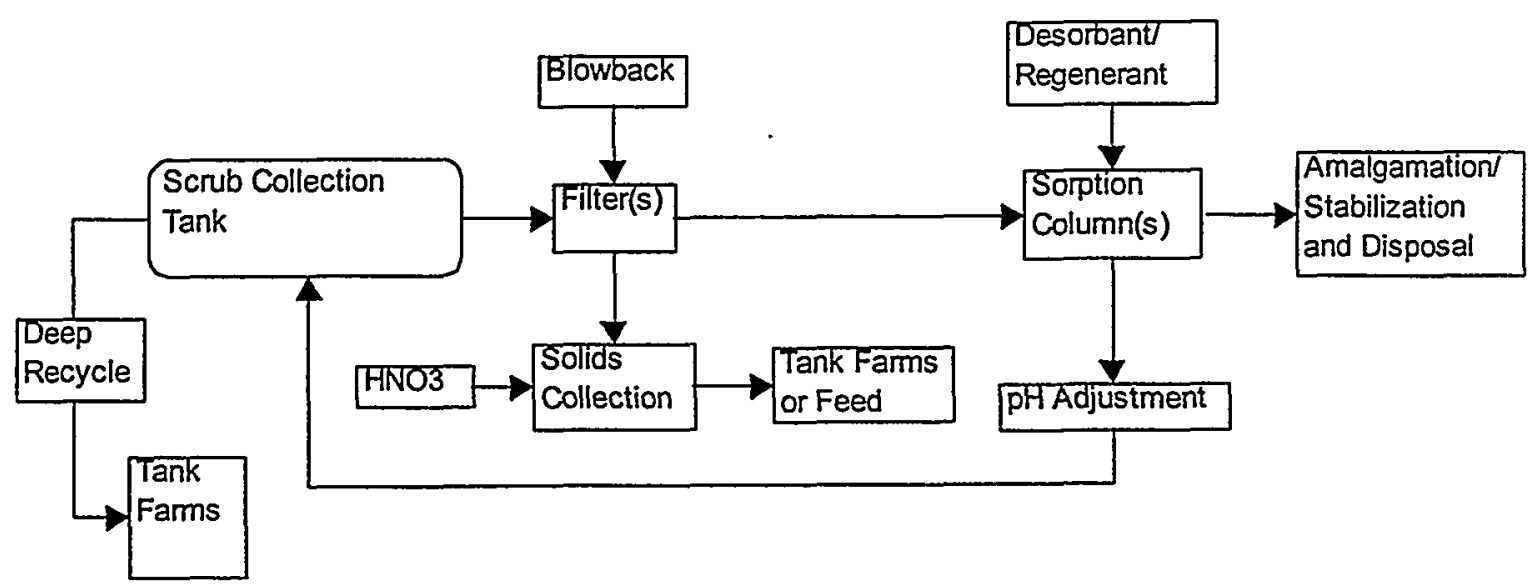

Alternative AW-6, Soluble Polymers (Figure 7-12). This requires an initial $\mathrm{pH}$ adjustment to enable the polymer $(\mathrm{pH} \sim 2)$. The soluble polymer is then used as a reagent in a batch or continuous mixed contactor. Ultra-filtration removes the polymer along with the sorbed mercury. The polymer is stripped with acid and adjusted prior to stabilization. The polymer is recycled.

Figure 7-12. Soluble Polymers

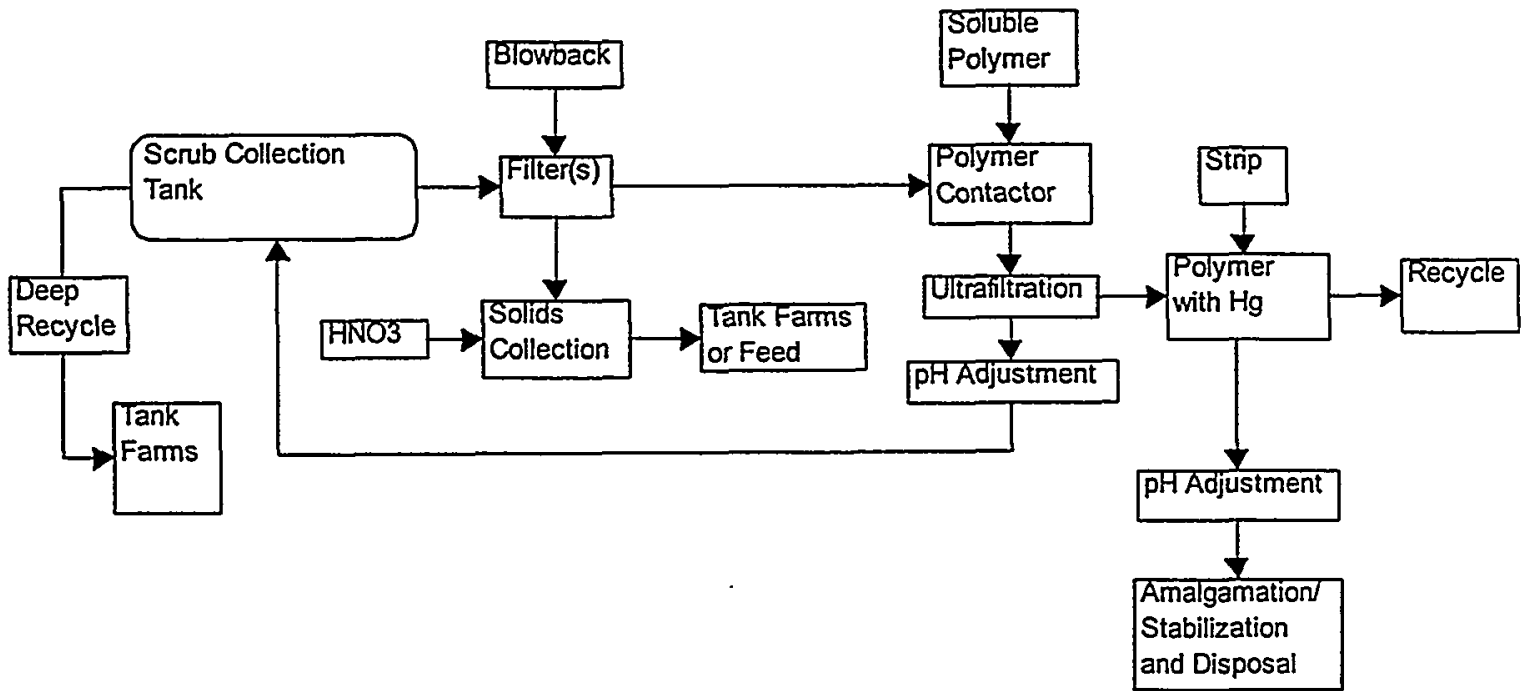


COGEMA-DOC-001, ReV. 0

\subsection{RECOMMENDED ALTERNATIVES}

Table 7-2 lists the recommended alternatives for further testing and/or consideration assuming that switching to a water scrub is infeasible.

Table 7-2. Alternative Summary

\begin{tabular}{|c|c|c|}
\hline Alternative & Phase or Step & Comments \\
\hline MT-1 A Strip/Scrub & Pre-Calciner Feed & $\begin{array}{l}\text { Requires Significantair } \\
\text { flow }\end{array}$ \\
\hline$V-1$ No NOxidizer & Vapor & \\
\hline $\mathrm{V}-2$, NOxidizer & Vapor & Testing Planned at MSE \\
\hline A-A-1 Electro-Chemical & $\begin{array}{l}\text { Aqueous-Phase Scrub } \\
\text { Sidestream }\end{array}$ & \\
\hline AA-2 UV/Titanium & $\begin{array}{l}\text { Aqueous-Phase Scrub } \\
\text { Sidestream }\end{array}$ & $\begin{array}{l}\text { Testing In Progress at } \\
\mathrm{ADA}\end{array}$ \\
\hline $\begin{array}{l}\text { AA-3 Precipitation (TMT } \\
15 \text { ) }\end{array}$ & $\begin{array}{l}\text { Aqueous-Phase Scrub } \\
\text { Sidestream }\end{array}$ & $\begin{array}{l}\text { Tested in Nitric Acid by } \\
\text { Degussa }\end{array}$ \\
\hline AW- Chemical Reduction & $\begin{array}{l}\text { Aqueous Phasescrub } \\
\text { Sidestream }\end{array}$ & \\
\hline$A W-2 \operatorname{Redox} C u / Z n$ & $\begin{array}{l}\text { Aqueous Phase Scrub } \\
\text { Sidestream }\end{array}$ & \\
\hline AW 3 Galyanocoagulation & $\begin{array}{l}\text { Aqueous Phase Scrub } \\
\text { Sidestream }\end{array}$ & \\
\hline AW-A Electro Coagulation & $\begin{array}{l}\text { Aqueoús Phase Scrub } \\
\text { Sidestream }\end{array}$ & Free Tests Offered \\
\hline$A W=5$ Sorbent/MX & $\begin{array}{l}\text { Aqueous Phase Sctub } \\
\text { Sidestream }\end{array}$ & Requires Proof Testing \\
\hline AW $6^{4}$ Soluble Polymer & $\begin{array}{l}\text { Aqueous Phase Scrub } \\
\text { Sidestream }\end{array}$ & Requires Poof Tésting \\
\hline
\end{tabular}

If the water scrub can be used, then the altematives in the shaded portion can also be considered.

A decision matrix was constructed to determine the top four aqueous phase processes assuming a water scrub is feasible. The rankings are indicated in Table $7-3$ by the top scores based qualitatively on the criteria stated previously. 
Table 7-3. Ranking Matrix, Aqueous-Phase

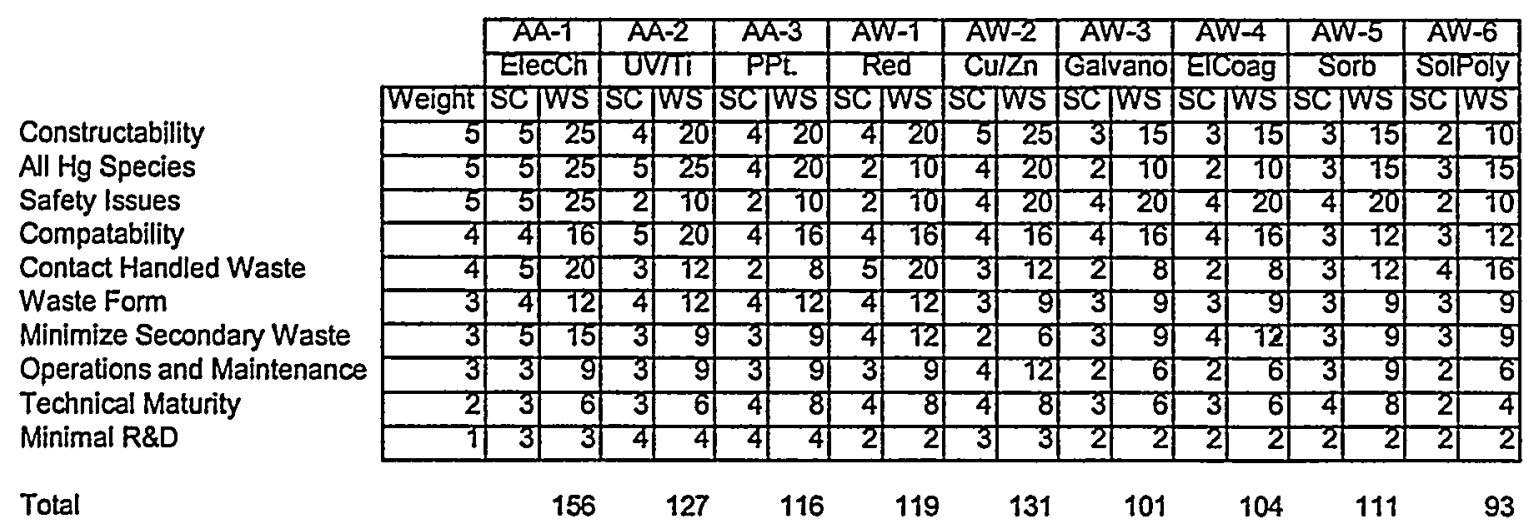

Based on Table 7-3, the electrochemical process, if demonstrated, is the top candidate for the current acidic scrub liquor and also if the scrub solution were switched to water. Based on this analysis, the following aqueous phase technologies as backups are recommended:

- UV/Ti

- TMT 15 precipitation

- $\mathrm{Cu} / \mathrm{Zn}$ (with switch to water scrub)

- Reduction (with switch to water scrub)

\subsection{CONCEPTUAL MODELS OF RECOMMENDED ALTERNATIVES}

\subsubsection{No $\mathrm{NO}_{\mathbf{x}}$ idizer}

This system does not include the $\mathrm{NO}_{\mathrm{x}}$ idizer or any gas-phase adsorption. The $\mathrm{HgCl}_{2}$ is removed by the quench and venturi scrubbers and by installing a packed column scrubber as shown in Figure 7-13. The quench scrub collection tank has a continuous sidestream totaling 1-5 gpm. This stream is treated via the electrochemical system. Filtered solids (if filtration is required) go either to the tank farm or are recycled to the calciner feed. The elemental mercury is collected from the mercury pool cathode. The scrubber has fresh acid scrub at approximately $2 \mathrm{gpm}$ or treated scrub that requires minimum DFs depending on the scrub rate to meet MACT for $\mathrm{Hg}$. Since the modeling was based on peak $\mathrm{HgCl}_{2}$, i.e., $[\mathrm{Hg}] /[\mathrm{Cl}]=1$, and the heel from WM-188, the process modification described in 7.5.2 may also apply to this alternative. However, it may require blending of tank heels with high mercury concentration with tanks of low concentration. The aqueous phase treatment backups for this process are UV/Ti or TMT 15 precipitation unless a water scrub is used. This alternative is not expected to meet MACT for CO and VOCs. However, due to the potential cost savings, it is recommended that this information be provided to the EPA for consideration. 
Figure 7-13. CM-1

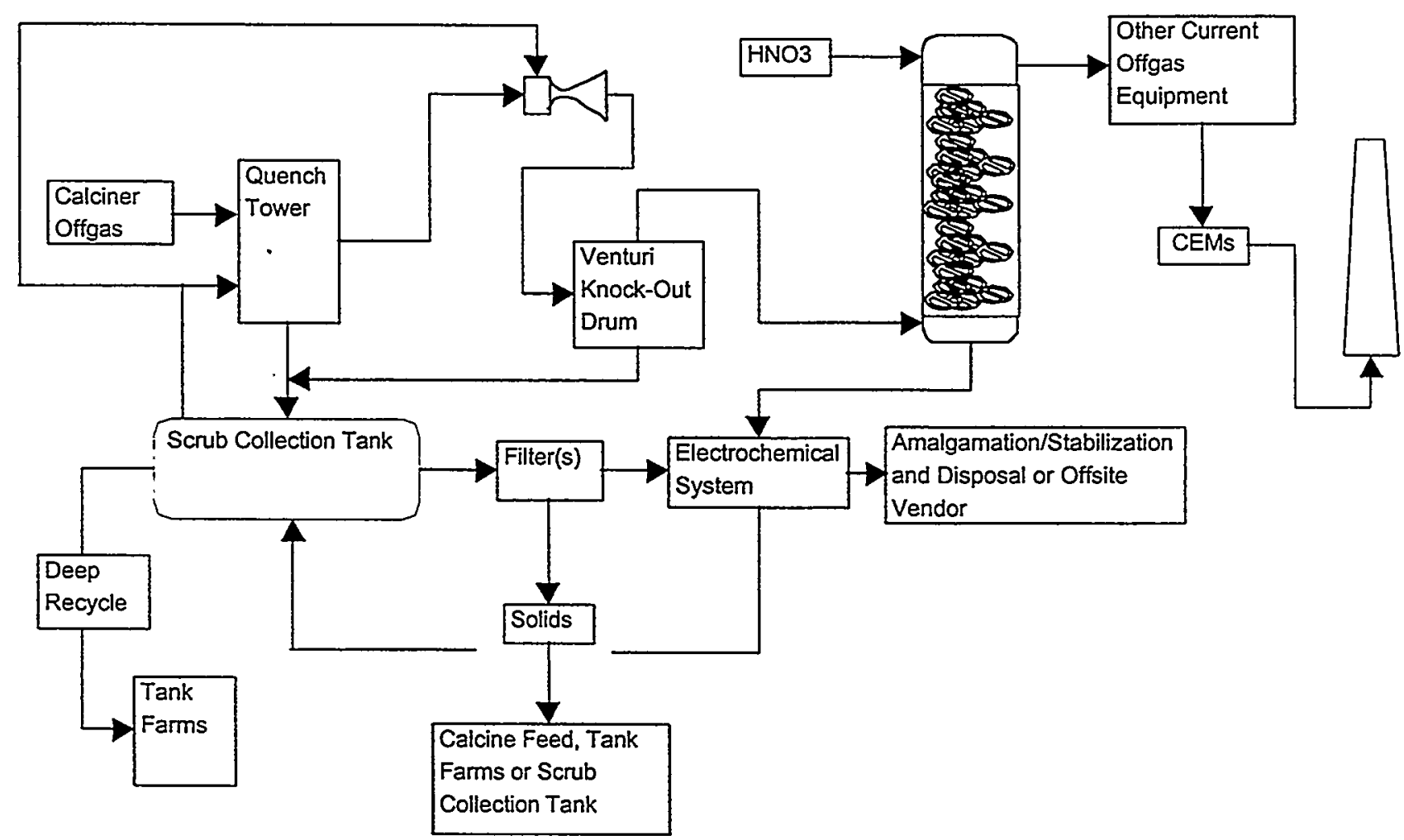

\subsection{2 $\mathrm{NO}_{\mathrm{x}}$ idizer}

A NO ${ }_{x}$ idizer could be installed prior to the stack and a sorbent system installed for polishing as shown in Figure CM-2. The quench/scrub system would be upgraded by installing a new, separate collection tank for the venturi system. This would allow the removal of more mercury, thus reducing the load on the downstream sorbent system. According to the analysis in Appendix B, this modification should remove mercury approximately 20 times better than the current configuration does. The aqueous phase treatment is the same as the "No $\mathrm{NO}_{\mathrm{x}}$ Removal" alternative above. This alternative is expected to meet all of the MACT requirements, but at considerable expense (mainly due to the $\mathrm{NO}_{x}$ idizer) over the "No NOxidizer" alternative (depending on scrubber costs versus $\mathrm{NO}_{x}$ idizer costs, i.e., it may cost more to install a scrubber inside the NWCF than a $\mathrm{NO}_{x}$ idizer outside).

\subsubsection{Feed Pretreatment}

Feed pretreatment would consist of one of the aqueous phase processes with the electrochemical system being the preferred technology if demonstrated. However, initial testing indicates that the mercury concentrations in the feed may be too low for the electrochemical system to be viable. The backup methods are UV/Ti and TMT 15 precipitation. As in Section 7.5.1, this alternative is not expected to meet all of the MACT standards. 
Figure 7-14. CM-2

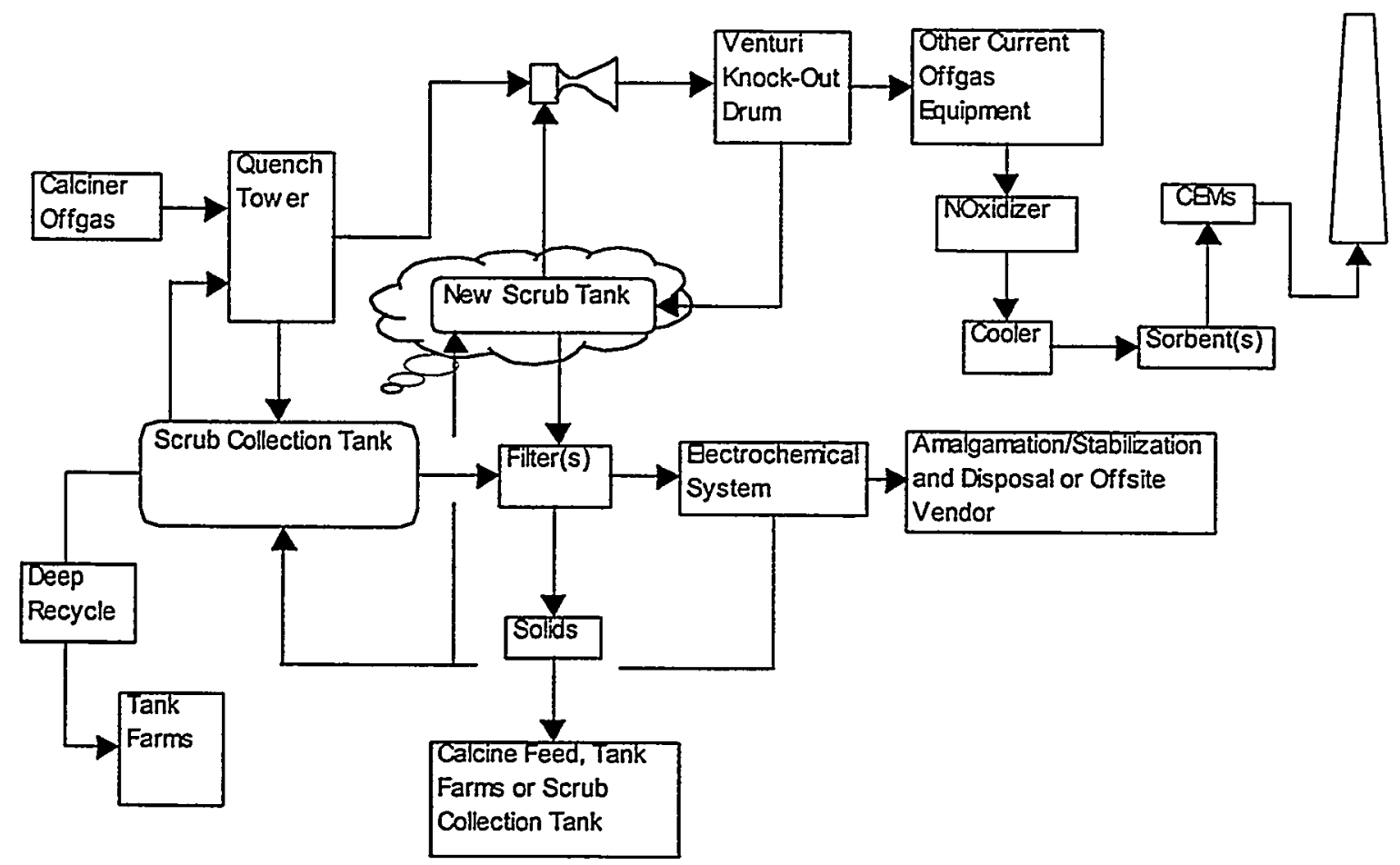


COGEMA-DOC-001, Rev. 0

\subsection{CONCLUSIONS AND RECOMMENDATIONS}

The characteristics of the aqueous phase and gaseous phase within the NWCF system present a challenge in determining appropriate technologies for removing mercury.

Mercury removal from the gas phase by sorbents is likely impacted by $\mathrm{NO}_{\mathrm{x}}$, possibly even if most of the $\mathrm{NO}_{\mathrm{x}}$ is removed. This research is ongoing and efforts should continue to try and determine a sorbent. Removal by absorption is feasible as the mercury is in the $\mathrm{HgCl}_{2}$ form (or $\mathrm{HgO}$, an aerosol of which the larger sizes are removed in scrubbing). There are too many uncertainties to determine a single alternative, but three potential systems were determined. Also, additional technologies were identified for testing.

\subsection{CONCLUSIONS}

- Mercury can be removed prior to calciner feed via air stripping as it is mainly in the $\mathrm{HgCl}_{2}$ form, but excessive air rates and pre-heating would be required. The high rates needed for air stripping would require major offgas system upgrades. This method of pre-treatment is not recommended for consideration.

- The aqueous phase, acid-compatible technologies identified (electrochemical, UV/Ti, and TMT-15) should be effective for feed pretreatment.

- The preferred aqueous phase process, electrochemical reduction, might not be able to process the rate determined in Section 4. The system is assumed to be mass transfer controlling and depending on this rate, the required cathode area may be too large to be practical in reactor design.

- The "no NO ${ }_{x}$ idizer alternative" and feed pretreatment will likely not meet MACT for all components (e.g., $\mathrm{CO}$ ).

- The $\mathrm{NO}_{x}$ idizer alternative is expected to meet MACT for all components, but possibly at much added expense to remove all of them.

- An in-plant modification can remove 20 times more $\mathrm{HgCl}_{2}$ than the current configuration. Elemental mercury in the gas phase soon converts to $\mathrm{HgO}$ (predicted by thermodynamics) and the larger aerosols are removed via inertial processes (e.g., venturi, quench, demisters). The modification requires an aqueous-phase mercury removal sidestream of 2-5 gpm to achieve this. Installation of a multistage scrubber system can achieve this with a much smaller sidestream flow rate, but requires a large DF.

- The array of aqueous-phase mercury removal processes is limited to the three acidcompatible technologies unless a water scrub is used. 
COGEMA-DOC-001, Rev. 0

- Gas-phase mercury removal by solid sorbents is impacted by $\mathrm{NO}_{\mathrm{x}}$. If $\mathrm{NO}_{\mathrm{x}}$ is removed by a $\mathrm{NO}_{x}$ idizer, several sorbents are available and can likely be procured via a performance specification.

- A water scrub coupled with solids filtration may be feasible, but requires testing to demonstrate. This testing would include filterability and particle size characterization.

- The UV/Ti technology has been tested on surrogate solution indicating feasibility. Recent testing in nitric acid indicated a good capacity. Field testing is required to determine complete feasibility.

\subsection{RECOMMENDATIONS}

- Validate/verify gas-phase speciation, including kinetics.

- Evaluate and concur with the criteria developed for use in gaseous and aqueous technology evaluations.

- Determine $\mathrm{HgCl}_{2}$ VLE experimentally for current and projected solutions.

- Constuct PFDs and ROM cost estimates for the three final alternatives, including mercury waste paths and forms.

- Continue testing other technologies determined applicable for aqueous phase backup processes.

- Determine calciner overheads solids characterization (e.g., size, filterability, etc.) and evaluate using a water scrub liquor as a replacement for the current nitric acid system.

- Continue with gas-phase sorbent evaluations, including evaluation of some of the other sorbents discussed in this document.

- Determine the isotherms for mercury compounds and metallic mercury on silica gel.

- If a water scrub is feasible, conduct further testing on ion exchange including the mercury specific thiol resin used at TEDF at Hanford. 


\subsection{REFERENCES}

$\mathrm{ADA} 1998$, Investigation on the Removal of Elemental mercury and Mercuric Chloride from a Highly Oxidizing Gas Stream, ADA Technologies, November, 30, 1998.

Aguado, M.A., et al, Continuous Photocatalytic Treatment of Mercury (II) on Titania Powders, Kinetics and Catalyst Activity, Chem. Eng. Sci., 50, 1561-1569, 1995.

ASME 1998, Assessment of Technologies Supported by the Office of Science and Technology Department of Energy, Results of the Peer Review for Fiscal Year 1998, CRTD-Vol. 50.

AWWA 1996, Mallevialle, J, et al, Water Treatment Membrane Processes, McGraw-Hill, 1996.

Bailar, J.C., Comprehensive Inorganic Chemistry, Pergamon Press, 1973.

Barnes, C. M., Mercury Material Balance and Evaluation of Mercury Removal Processes, INEEL/EXT-98-01064, June 17, 199.7.

Baumann, T.F., Reynolds, J.G., Fox, G.A., Polymer Pendant Crown Thioethers for Removal of Mercury from Acidic Wastes.

Buso, A., et al, New Electrochemical Reactor for Wastewater Treatment: Electrochemical Characterization, Chemical Engineering and Processing 36 (1997) 255-260.

Chase, M., National Institute of Standards, personal conversations (email), January 6, 1999.

Cheryan, M., Ultrafiltration Handbook, 1986, Technomic, Lancaster, United Kingdom, see also Winston, W. S. and Sirkar, K. K. Membrane Handbook, Van Nostrand Reinhold: N.Y., 1992.

Clever, L.H., Johnson, S.A., Derrick, M.E., Solubility of Mercury and Some Sparingly Soluble Mercury Salts in Water and Aqueous Electrolyte Solutions, J. Phys. Chem. Ref. Data, Vol. 14, No. 3, 1985.

Coleman, C.J., et al, Reaction of Formic Acid and Nitric Acid with Sanannah River Site Radioactive HLW Sludge in the DWPF Pretreatment Steps, WSRC-MS-93-563, 1994.

Dean, J.A., Lange's Handbook of Chemistry, McGraw-Hill 1985.

Dean, J.A., Analytical Chemistry Handbook, McGraw-Hill, 1995.

Del Debbio, J.A., Olson, L.G., Cauffman, S.D., Report on Electrochemical Reduction for Removal of Mercury from Simulated NWCF Scrub Solutions, LMICO Internal Report, JAD-0398, September 28, 1998. 
Eibling, R.E., Results of Mercury Reduction with Formic Acid, Savannah River Plant Internal Memo DPST-83-1047, December 1, 1983.

Eibling, R.E., Personal Communicationss with Russ Eibling, July 19, 1999.

EPA 1992, EPA Research and Development Report, EPA-600/R-92-192.

EPA 1997, Mercury Study Report to Congress (Vol. VIII), EPA-452/R-97-003, December 1997.

Federal Register/Vol. 61, No. 77/Friday, April 19, 1996/Proposed Rules.

Freeman, H. M., Standard Handbook of Hazardous Waste Treatment and Disposal, McGrawHill 1989.

Fryxell, G.E., et al, Functionalized Monolayers on Ordered Mesoporous Supports, Science Vol. 276, May 9, 1997.

Giberti, Richard, Personal Communications with Artisan Industries, December, 1998.

Helfferich, F., Ion Exchange (republication), Dover Publications, 1995.

ICT 1930, International Critical Tables of Numerical Data, Physics, Chemistry and Technology, National Research Council, McGraw-Hill 1930.

IUPAC 1983, Solubility Data Series, Vol 23, Pergamon Press.

Jiang, H.D., et al, Thermosolutal Transport Phenomena in Large Lewis Number Electrochemical Systems, Int. J. Heat Mass Transfer, Vol. 39, No. 4, pp. 841-850, 1996.

$\mathrm{KDF} 1999, \mathrm{http}: / / \mathrm{kdfft.com} / \mathrm{html} / \mathrm{metals} / . \mathrm{htm}$

Koch 1999, personal communications with Koch Membranes, January 4, 1999.

Lau, L.D., et al, Photoreduction of Mercuric Salt Solutions at High pH, Environ, Sci. Technol., 32, 670-675, 1998.

Lide, D.R., and Kehiaian, H.V., CRC Handbook of Thermophysical and Thermochemical Data, CRC 1994.

Long, J.T., Engineering For Nuclear Fuel Reprocessing, ANS 1978.

MSE 1998a, Controlled Emissions Demonstration Project Test Plan-Activated Carbon Mercury Removal, MSE Technology Applications, Inc., Butte, MT, August 1998.

MSE 1998b, Tradeoff Study: Air Pollution Control Scrubber Blowdown Mercury Removal System, MSE Technology Applications, Inc., Butte, MT, June 1998. 
Nelson, S. Jr., Wang, A, Recoverable-Mercury Sorbents, 96-WP64B.04, Air \& Waste Management Association, Nashville, Tennessee, June 8-13, 1997.

Nelson, S., Jr., Miller, J., Summanen, D., Innovative Mercury Emission Control, Air \& Waste Management Association, Toronto, Ontario, June 23-28, 1996.

Perry, R.H., and Green, D.W., Perry's Chemical Engineers' Handbook $6^{\text {th }}$ ed., McGraw-Hill, 1984.

Pontius, F.W., Water Quality and Treatment (pg 236), American Water Works Association, McGraw-Hill, $4^{\text {th }}$ ed 1990.

Prairie, M.R., Practical Aspects of Aqueous Photocatalysis, Photocatalytic Oxidation Research Review Meeting, NREL/CP-471-20577, Copper Mountain, Colorado, October 4-6, 1995.

Restor, D., Personal Converstion with Dennis Restor, Norit Americas, Inc., January 26, 1999.

Roberts, D.L., Broderick, T.E., Stewart, R.M., Removing and Recovering Mercury from OffGases of Thermal Treatment Processes, Air \& Waste Management, San Diego, California, June 14-18, 1998, ADA Pub No. 98005, Englewood, Colorado.

Schindler, R.E., 1997a, Mercury Behavior During NWCF Run H-4 Operation, LMITCO Internal Report, October 16, 1997.

Schindler, R.E., 1997b, Mercury Behavior During Calcination, LMITCO Internal Report, September 17, 1997.

Schindler, R.E., 1997c, Mercury Speciation in the NWCF ScrubSolution, LMITCO Internal Report, November 3, 1997.

Serpone, N., Heterogeneous Photocatalysis at Work, Selective Separations and Recovery of Metals from Industrial Waste Streams, AIChE Annual Meeting, New York, November, 1987.

Siemer, D., Personal Conversation (email), September 23, 1999.

Smith, B. F. et al, Polyelectrolyte Enhanced Removal of Mercury from Mixed Waste Debris, Waste Management 1999, Tucson, Arizona, 1999.

Spence, R., 1999, http://www.ornl.gov/divisions/ctd/Eng Dev/capabilities/MASS.htm

Taama, W.M., et al, Mass Transfer Rates in a DEM Electrochemical Cell, Electrochemica Acta, Vol. 41, pp. 543-548, 1996.

Taylor, D. D., Barnes, C.M., Mercury Control Process Evaluation, LMITCO Internal Report, 1998. 
Taylor, P.A., et al, Mercury Separation From Mixed Wastes: Annual Report, ORNL/TM-13121, November, 1995.

Treybal, R. E., Mass Transfer Operations, McGraw-Hill, 1987.

Venkateswarlu, P., Gopalakrishna, P., A Simplified Method for Correlating Mass Transfer Data in Electrochemical Cells, Int. Comm. Heat Mass Transfer, Vol. 25, No 1, pp. 59-65, 1998.

Wragg, A.A., Leontaritis, A.A., Local Mass Transfer and Current Distribution in Baffled and Unbaffled Parallel Plate Electrochemical Reactors, Chem. Eng. Jour. 66 (1977) 1-10. 
COGEMA-DOC-001, Rev. 0

Appendix A

Chemistry, Speciation, and Properties

A-1 


\section{Appendix A Chemistry, Speciation and Properties}

Mercury chemistry is complicated, and hence, so is speciation. However, some simplifications can be made. Considering gas removal, only the information concerning the volatile species present is required. $\mathrm{Hg}$ metal and $\mathrm{HgCl}_{2}$ have fairly well known properties. The oxide ( $\left.\mathrm{HgO}\right)$ does not have a measurable vapor pressure as it breaks down to $\mathrm{Hg}$ and oxygen upon heating (Chase 1999) but it does exist as an aerosol. The volatile dimer, $\mathrm{HgCl} / \mathrm{Hg}_{2} \mathrm{Cl}_{2}$, also breaks down upon heating and is normally a solid in solution (but does sublime). Therefore, there are only two gaseous chemical species to deal with in the vapor phase with large differences in properties. While their vapor pressures are similar, the solubilities are very different as well as other thermodynamic properties.

A.1 Tank Farms Species. In A-1 below, the speciation was determined by hand but this is more difficult for the $\mathrm{Hg}: \mathrm{Cl}$ ratio observed in the tank farms. Therefore, the HSC Chemistry equilibrium program was used to estimate the speciation. The results indicate most as $\mathrm{HgCl}_{2}$ with lesser amounts of $\mathrm{HgCl}_{3}{ }^{-}$and $\mathrm{HgCl}_{4}{ }^{-2}$ (see left-hand side of Figure A-2).

A.2 Scrub Collection Tank. For the scrub observed $\mathrm{Hg}: \mathrm{Cl}$ ratio of 1-2, there is a mixture of $\mathrm{HgCl}_{2}, \mathrm{HgCl}^{+}$, and $\mathrm{Hg}^{+2}$. The difference in the ratio and the ratio in the tank farms has been attributed to chloride retention in the calcine (Schindler 1997). The chloride observed in the scrub liquors is probably due to fines entrainment from the calciner and from the $\mathrm{HgCl}_{2}$.

\section{Scrub Tank Speciation}

The following equations (Clever et al 1985) are considered the most important, assuming that the vapor pressure of $\mathrm{HgCl}_{2}$ does not impact the equilibria and acid is high:

$$
\begin{array}{lc}
\mathrm{Hg}^{+2}+\mathrm{Cl}^{-}=\mathrm{HgCl}^{+} & K_{1}=5.8 \times 10^{6} \\
\mathrm{HgCl}^{+}+\mathrm{Cl}^{-}=\mathrm{HgCl}_{2} & K_{2}=2.5 \times 10^{6} \\
\mathrm{HgCl}_{2}+\mathrm{Cl}^{-}=\mathrm{HgCl}_{3}^{-} & K_{3}=6.7 \\
\mathrm{HgCl}_{3}^{-}+\mathrm{Cl}^{-}=\mathrm{HgCl}_{4}^{-2} & K_{4}=13
\end{array}
$$

The last two equations are ignored (for hand calculations) as the ESP runs did not indicate a significant presence of $\mathrm{HgCl}_{3}{ }^{-}$and beyond. Using the first two equations and two balances as follows:

The total chloride is the free and bound

$$
\left[\mathrm{Cl}^{-}\right]_{\mathrm{T}}=\left[\mathrm{Cl}^{-}\right]+\left[\mathrm{HgCl}^{+}\right]+2\left[\mathrm{HgCl}_{2}\right]
$$


Likewise with the mercury

$$
\left[\mathrm{Hg}_{T}=\left[\mathrm{Hg}^{+2}\right]+\left[\mathrm{HgCl}^{+}\right]+\left[\mathrm{HgCl}_{2}\right]\right.
$$

With the four equations and four unknowns, $\left[\mathrm{HgCl}^{+}\right]$is solved quadratically:

$$
\left[\mathrm{HgCl}^{+}\right]^{2}+\frac{1+K_{1}[\mathrm{Hg}]_{T}}{2 K_{2}-K_{1} / 2}\left[\mathrm{HgCl}^{+}\right]+\frac{K_{1}[\mathrm{Cl}]_{T}^{2} / 2-K_{1}[\mathrm{Hg}]_{T}[\mathrm{Cl}]_{T}}{2 K_{2}-K_{1} / 2}=0
$$

The others then fall out easily, e.g.,

$$
\left[\mathrm{Cl}^{-}\right]=\frac{[\mathrm{Cl}]_{T}-\left[\mathrm{HgCl}^{+}\right]}{2 \mathrm{~K}_{2}\left[\mathrm{HgCl}^{+}\right]+1}
$$

The results are shown below in Figure A-1.

Figure A-1

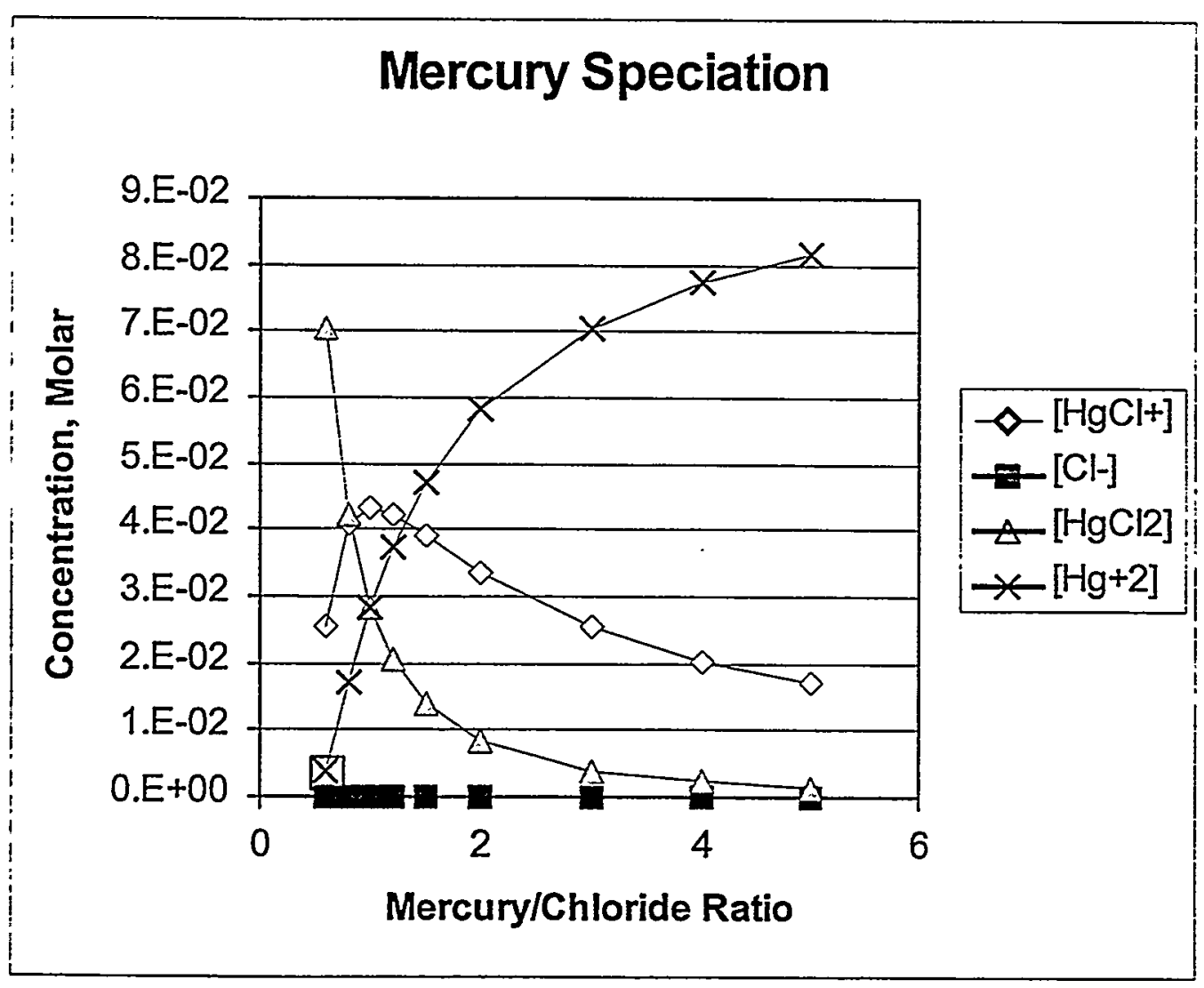


To determine speciation over the entire expected range, the HSC chemistry package was used. Figure A-2 indicates small amounts of $\mathrm{HgCl}_{3}{ }^{-}$and $\mathrm{HgCl}_{4}{ }^{-2}$ but with increasing $\mathrm{HgCl}^{+}$at higher $[\mathrm{Hg}] /[\mathrm{Cl}]$ ratios (notice the $\mathrm{HgCl}_{2}$ discontinuity that prevented examining this region by hand calculations. The HSC uses Gibbs free energy minimization). The [Cl] was held constant while the total $\mathrm{Hg}$ was varied through the domain. The maximum for $\mathrm{HgCl}_{2}$ occurs at $[\mathrm{Hg}] /[\mathrm{Cl}]=0.5$ while the scrub solution varies from 1-2 so worse case for modeling is at 1 .

Figure A-2

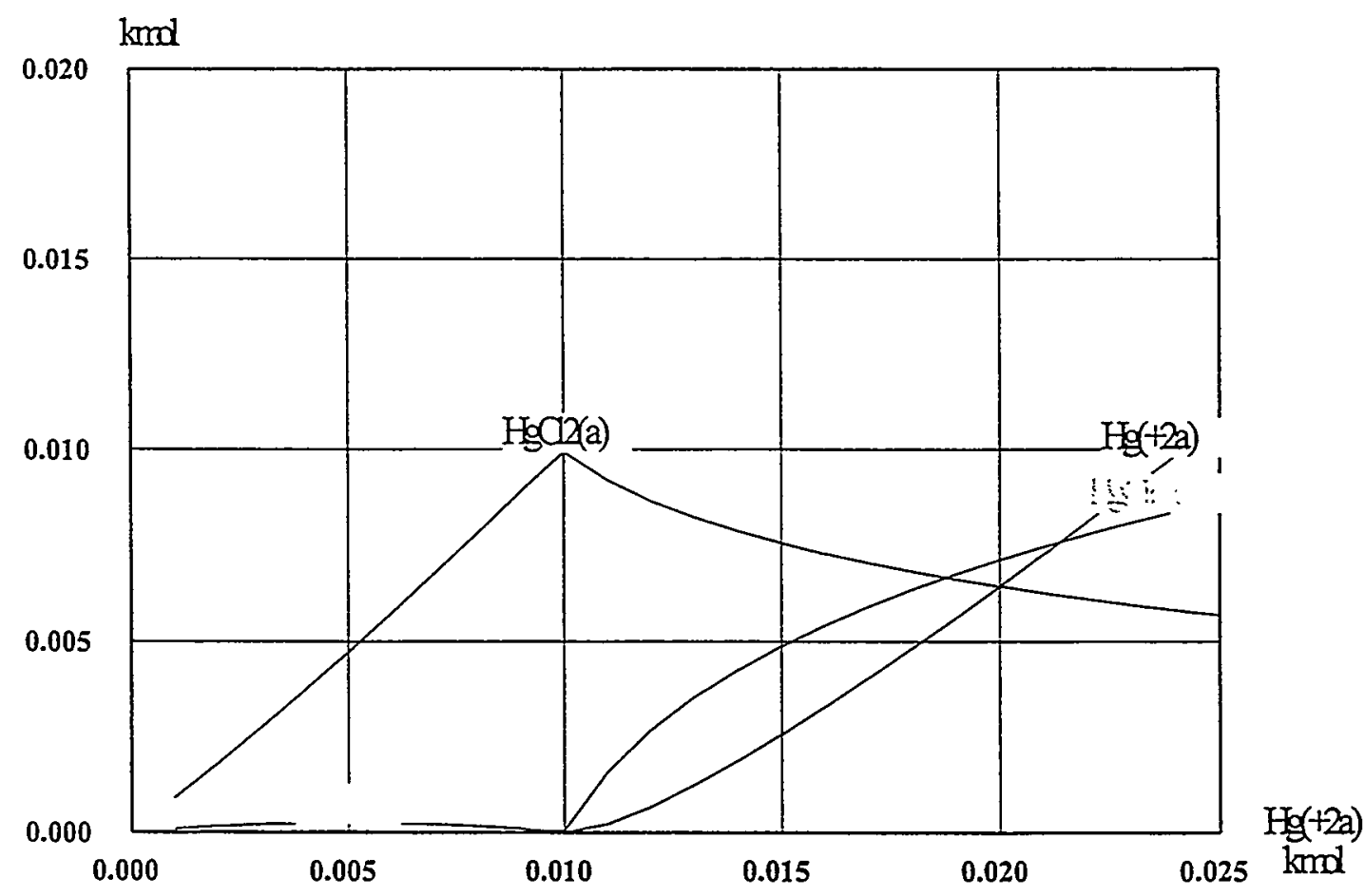

\section{A.3 Gas Phase}

\section{Thermodynamics}

In the gas phase, the temperature and $\mathrm{NO}_{\mathrm{x}}$ composition impacts the speciation of mercury. It is well known that the decomposition temperature of $\mathrm{HgO}$ is close to the calciner operating temperature. The following thermodynamic analysis is used to estimate what will happen to mercury at different temperatures and $\mathrm{NO}_{\mathrm{x}}$ compositions.

$$
\begin{aligned}
& \mathrm{NO}_{2}=\mathrm{NO}+\frac{1}{2} \mathrm{O}_{2} \quad K_{2} \\
& \mathrm{Hg}+\frac{1}{2} \mathrm{O}_{2}=\mathrm{HgO} \quad 1 / K_{1}
\end{aligned}
$$


Figure A-3

\section{[HgO]/[Hg] Ratios vs Temperature}

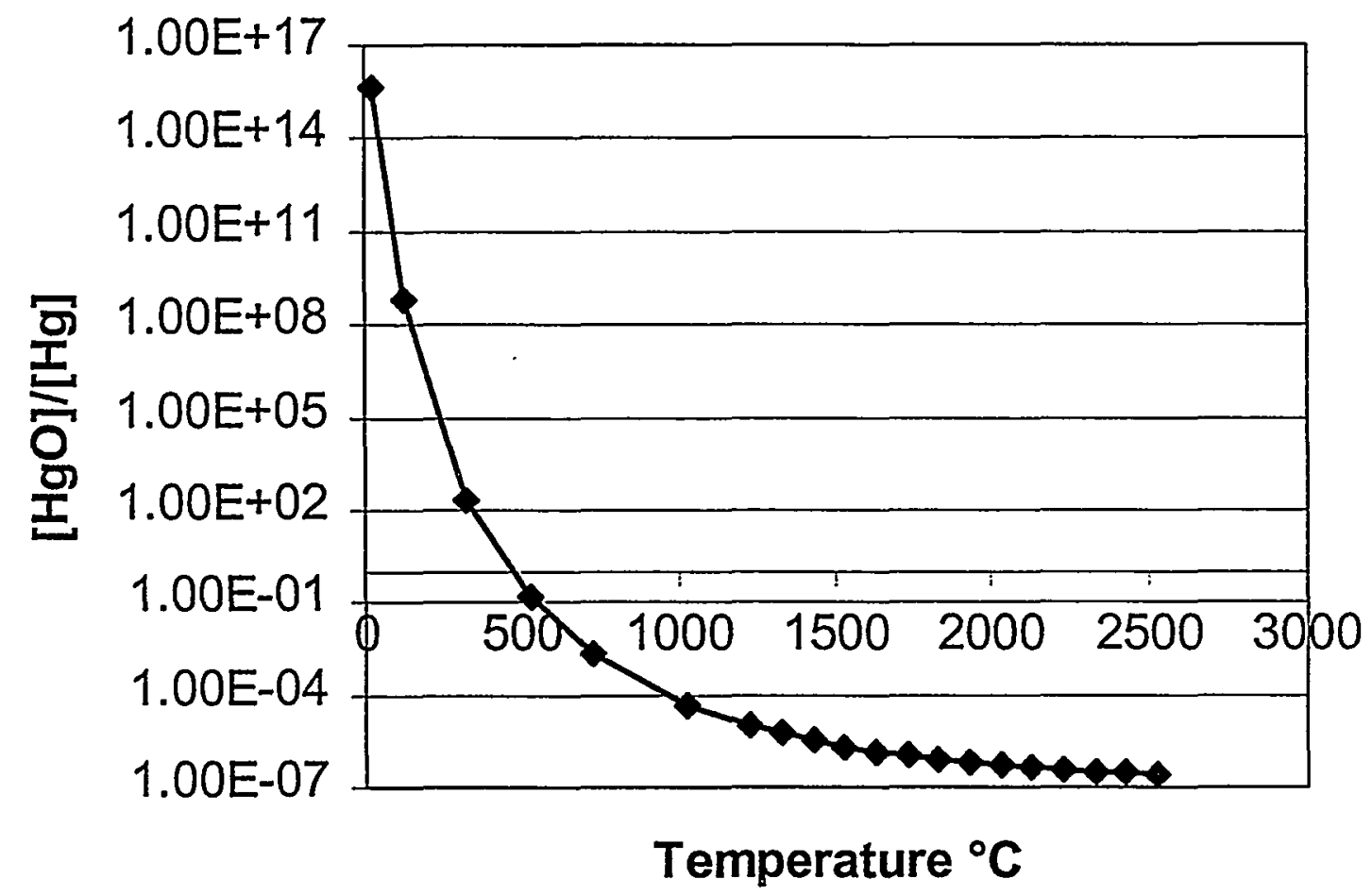


Adding these two together

$$
\begin{aligned}
& \mathrm{NO}_{2}+\mathrm{Hg}=\mathrm{NO}+\mathrm{HgO} \quad \mathrm{K}_{2} / K_{1} \\
& \frac{[\mathrm{HgO}]}{[\mathrm{Hg}]}=\frac{K_{2}}{K_{1}} \frac{\left[\mathrm{NO}_{2}\right]}{[\mathrm{NO}]}
\end{aligned}
$$

The $\mathrm{K}_{1}$ and $\mathrm{K}_{2}$ were determined from published references for free energy as a function of temperature (Lide 1994 and ICT 1930). The results of this indicate that lower temperatures favor the oxide as shown in Figure $\mathrm{A}-3$ as $\mathrm{NO}_{2}$ is oxidizing while $\mathrm{NO}$ is reducing. $\mathrm{A} \mathrm{NO}_{\mathrm{x}}$ idizer is being planned for testing at MSE and subsequent installation at NWCF. This unit will have high temperatures favoring the metallic form of mercury and NO provided non-chloride mercury is even present. However, if the unit is not used, the oxide is favored (based on thermodynamics only) based on the temperature decreases and oxygen partial pressure downstream of the calciner. The mercury speciation depends on the $\left[\mathrm{NO}_{2}\right] /[\mathrm{NO}]$ ratio, but the converse is not true under current calciner conditions (see Figure $\mathrm{A}-4$ ). The $\left[\mathrm{NO}_{2}\right] /[\mathrm{NO}]$ ratio is dependent on the partial pressure of oxygen (estimated at $0.38 \mathrm{~atm}$ for calciner offgas). It has been determined (ADA 1998) that this oxidation is rapid so the indication is that the mercury metal converts to $\mathrm{HgO}$ as it flows through the offgas system. This has also been verified by recent testing of wetted silica gel by INEEL personnel (Siemer 1999).

Figure A-4

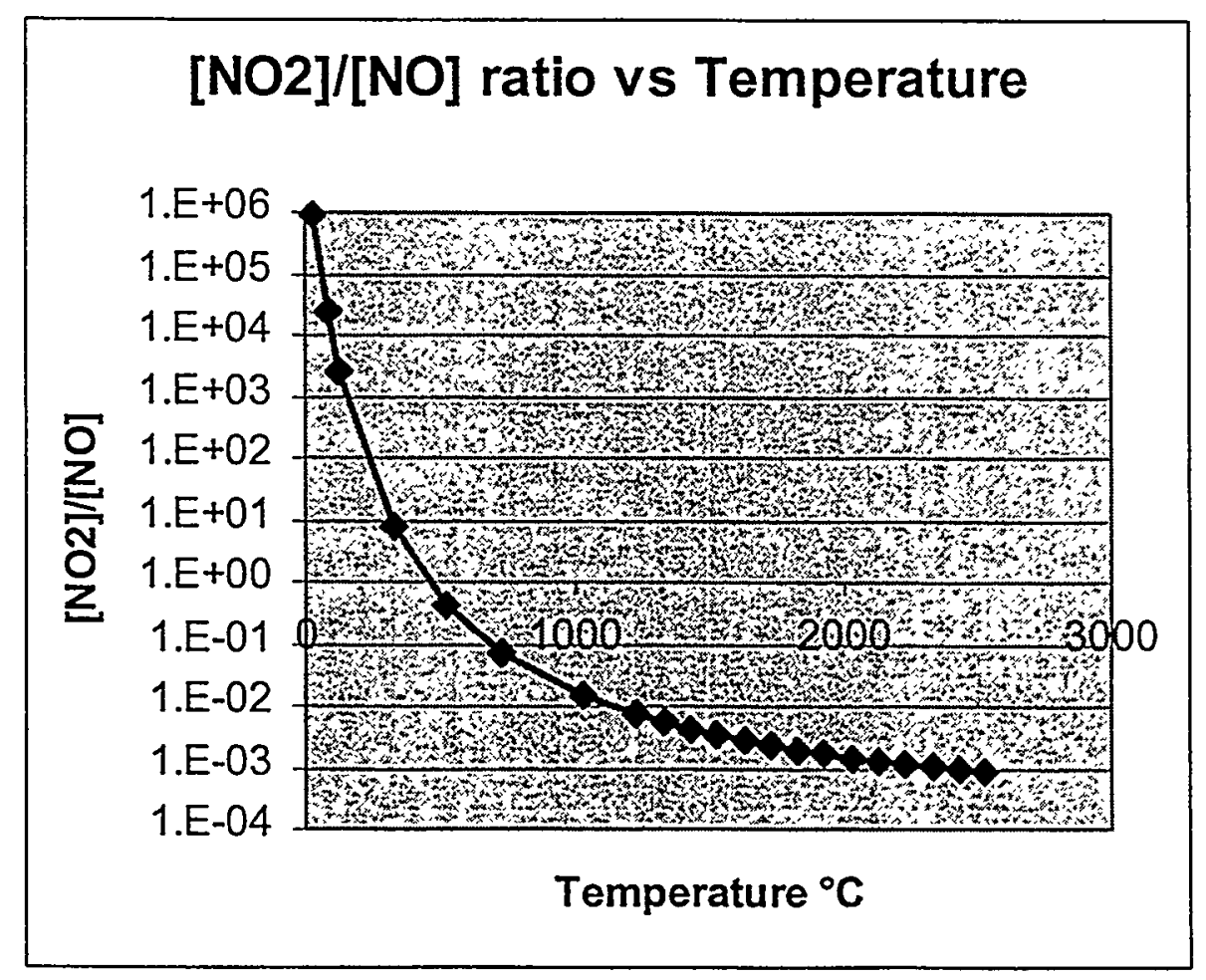


The offgas speciation is predicted to be $\mathrm{HgCl}_{2}$ not removed in the wet processes and $\mathrm{HgO}$ solids that are removed by other equipment. The other species present in the offgas (e.g., $\mathrm{CO}$ ) might also impact gas-phase speciation. HSC Chemistry was used to predict the predominance of $\mathrm{Hg}$ or $\mathrm{HgO}$ in this gas (PFD 1495-CPP-659-F-130) at various temperatures. The results indicate predominance of $\mathrm{HgO}$ at the cooler temperatures downstream of the calciner as shown in Figure A-5.

Figure A-5, HSC Run

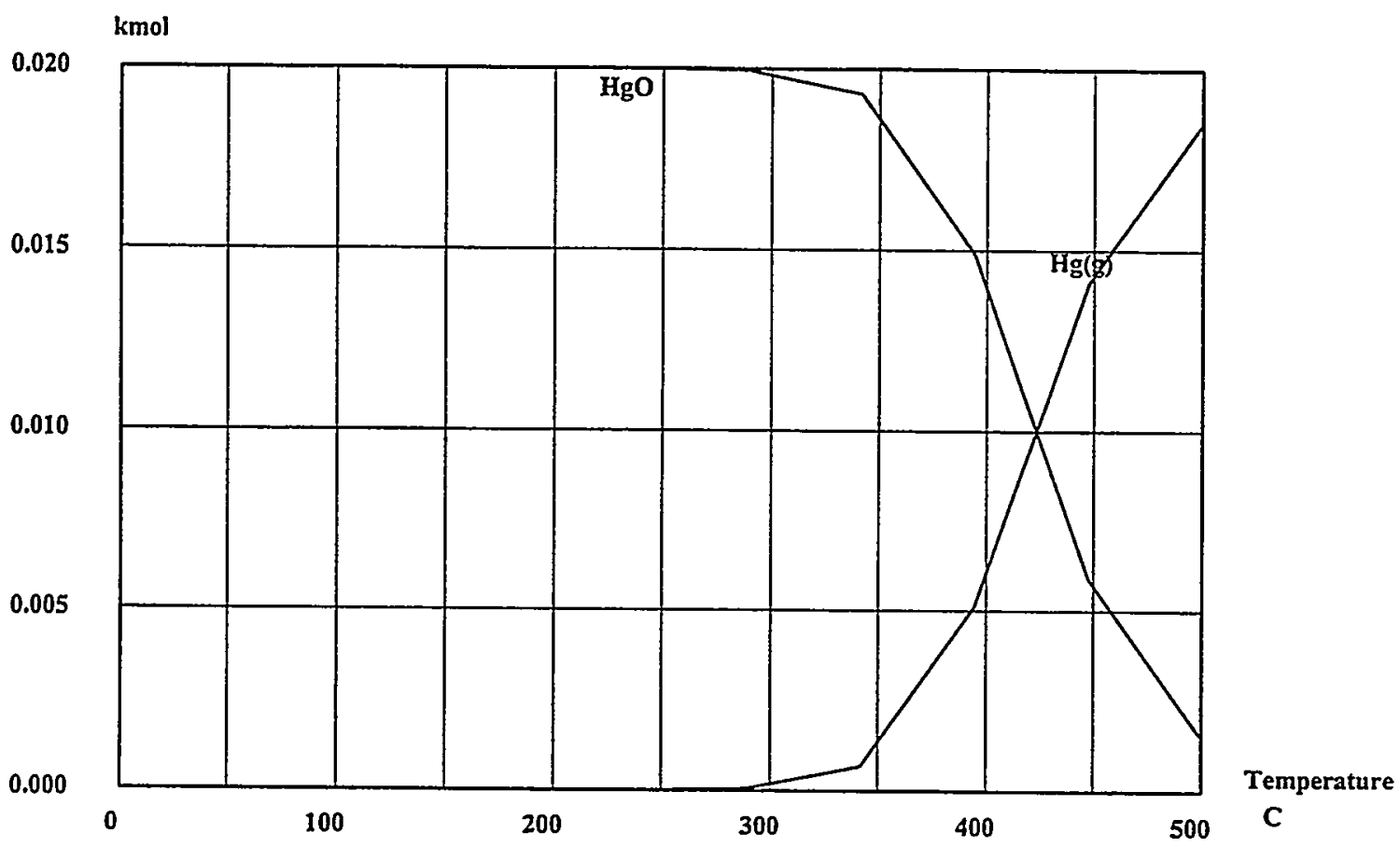


The following equation was evaluated by the HSC reaction equation program to validate the above analysis. The results are shown below in Table A-1 and indicate a large predominance of the oxide at lower temperatures (note that opposite results occur if $\mathrm{HgO}$ is entered as a gas).

Table A-1, HSC Validation

$\begin{array}{rrrrr}\mathrm{Hg}(\mathrm{g})+\mathrm{NO} 2(\mathrm{~g})=\mathrm{HgO}+\mathrm{NO}(\mathrm{g}) & & & \\ \mathbf{T} & \text { deltaH } & \text { deltaS } & \text { deltaG } & \mathrm{K} \\ \mathbf{C} & \text { kcal } & \mathbf{c a l} & \mathbf{k c a l} & \\ 0.000 & -22.775 & -32.324 & -13.945 & 1.442 \mathrm{E}+011 \\ 50.000 & -22.581 & -31.672 & -12.346 & 2.241 \mathrm{E}+008 \\ 100.000 & -22.383 & -31.104 & -10.777 & 2.053 \mathrm{E}+006 \\ 150.000 & -22.180 & -30.594 & -9.235 & 5.887 \mathrm{E}+004 \\ 200.000 & -21.971 & -30.126 & -7.717 & 3.670 \mathrm{E}+003 \\ 250.000 & -21.755 & -29.691 & -6.221 & 3.975 \mathrm{E}+002 \\ 300.000 & -21.532 & -29.286 & -4.747 & 6.461 \mathrm{E}+001 \\ 350.000 & -21.304 & -28.904 & -3.293 & 1.428 \mathrm{E}+001 \\ 400.000 & -21.072 & -28.545 & -1.856 & 4.006 \mathrm{E}+000 \\ 450.000 & -20.835 & -28.206 & -0.438 & 1.356 \mathrm{E}+000 \\ 500.000 & -20.596 & -27.886 & 0.965 & 5.337 \mathrm{E}-001\end{array}$

\section{Kinetics}

The kinetics of the reaction

$$
\mathrm{NO}+\frac{1}{2} \mathrm{O}_{2} \rightarrow \mathrm{NO}_{2}
$$

has the rate equation (Zamecnik 1999) with the rate constant units of $\mathrm{s}^{-1} \mathrm{~atm}^{-2}$ (the back reaction is insignificant at lower temperature).

$$
\log _{10} k=\frac{652.1}{T^{\circ} K}-0.7356
$$

This lends itself to the following kinetic model

$$
-\frac{d C_{N O}}{d t}=k C_{O_{2}}(R T)^{2} C_{N O}^{2}
$$

Using a plug flow model for a vent pipe, the following NO disappearance as a function of residence time was determined. 


$$
C_{N O}(t)=\frac{C_{N O_{1}}}{1+k^{\prime} t_{R} C_{N O_{1}}}
$$

Assuming a constant temperature of $70^{\circ} \mathrm{C}$, the following Figure A-6 was constructed showing disappearance of $\mathrm{NO}$ and conversion to $\mathrm{NO}_{2}$ ( $\mathrm{Hg}$ to $\mathrm{HgO}$ should follow this).

Figure A-6

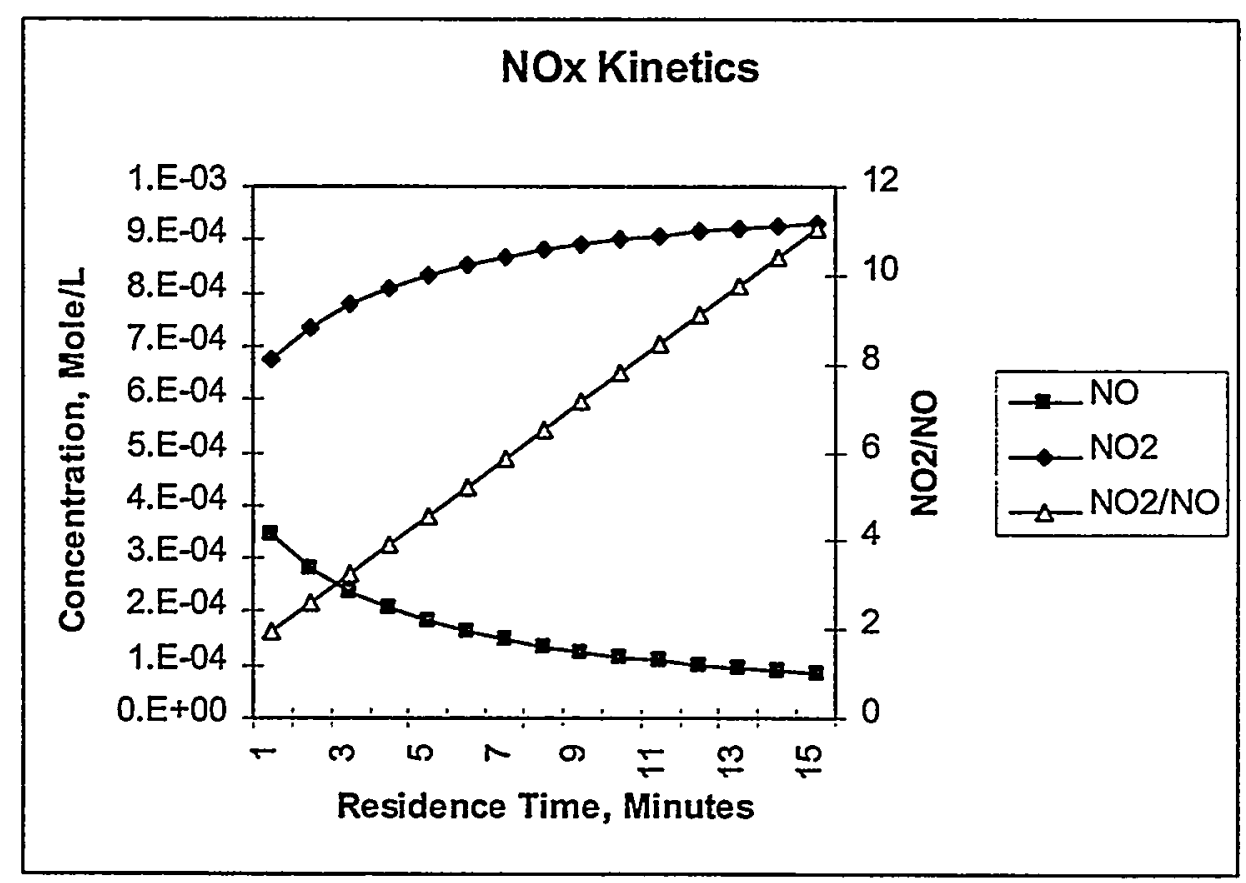

\section{A.4 Properties}

Some of the properties of mercury and applicable compounds are listed below.

\section{A.4.1 HgO}

$\mathrm{HgO}$ does not have a measurable vapor pressure but decomposes as temperature is increased (Chase 1999). It is expected to exist as fine particles in the gas phase.

$$
\mathrm{HgO}=\mathrm{Hg}+\frac{1}{2} \mathrm{O}_{2}
$$

The decomposition temperature is approximately $500^{\circ} \mathrm{C}$ (ICT 1930) where $\mathrm{K}=1$ (it also takes higher temperature to form the $\mathrm{HgO}$ from $\mathrm{Hg}$ in the first place, i.e., it doesn't occur appreciable at ambient conditions).

\section{Solubility}


- Water $2.37 \times 10^{-4} \mathrm{~mol} / \mathrm{dm}^{3} @ 298.2^{\circ} \mathrm{K} \quad 3.47 \times 10^{-4} @ 308.2^{\circ} \mathrm{K}($ IUPAC 1983)

$$
\mathrm{HgO}_{s}+\mathrm{H}_{2} \mathrm{O}=\mathrm{Hg}(\mathrm{OH})_{2} \quad \mathrm{~K}=2.4 \times 10^{-4} \mathrm{~mol} / \mathrm{dm}^{3}
$$

- Acid $\left(298.2{ }^{\circ} \mathrm{K}\right)-\mathrm{HgO}$ is highly soluble in acid but is complicated by the presence of anions, particularly $\mathrm{Cl}^{-}$Also, these reactions take significant time (Smith et al 1999).

$$
\begin{aligned}
& \mathrm{HgO}_{(s)}+\mathrm{H}^{+}=\mathrm{HgOH}^{+} \quad K=0.17 \\
& \mathrm{HgO}_{(s)}+2 \mathrm{H}^{+}=\mathrm{Hg}^{+2}+\mathrm{H}_{2} \mathrm{O} \quad K=53
\end{aligned}
$$

- Base - The solubility is much less than with acid but the following reactions occur under alkalai conditions.

$$
\begin{aligned}
& \mathrm{HgO}_{s}+\mathrm{OH}^{-}=\mathrm{HHgO}_{2}^{-} \\
& \mathrm{HgO}_{s}+2 \mathrm{OH}^{-}=\mathrm{HgO}_{2}^{-2}+\mathrm{H}_{2} \mathrm{O}
\end{aligned}
$$

The solubility chart derived from the solubility of $\mathrm{HgO}$ as a function of acidity-alkalinity from the solubility data series (IUPAC 1983) is shown below in Figure A-7. If chloride is present, it has a major impact on this curve with much more being soluble (as $\mathrm{HgCl}_{2}$ ).

Figure A-7

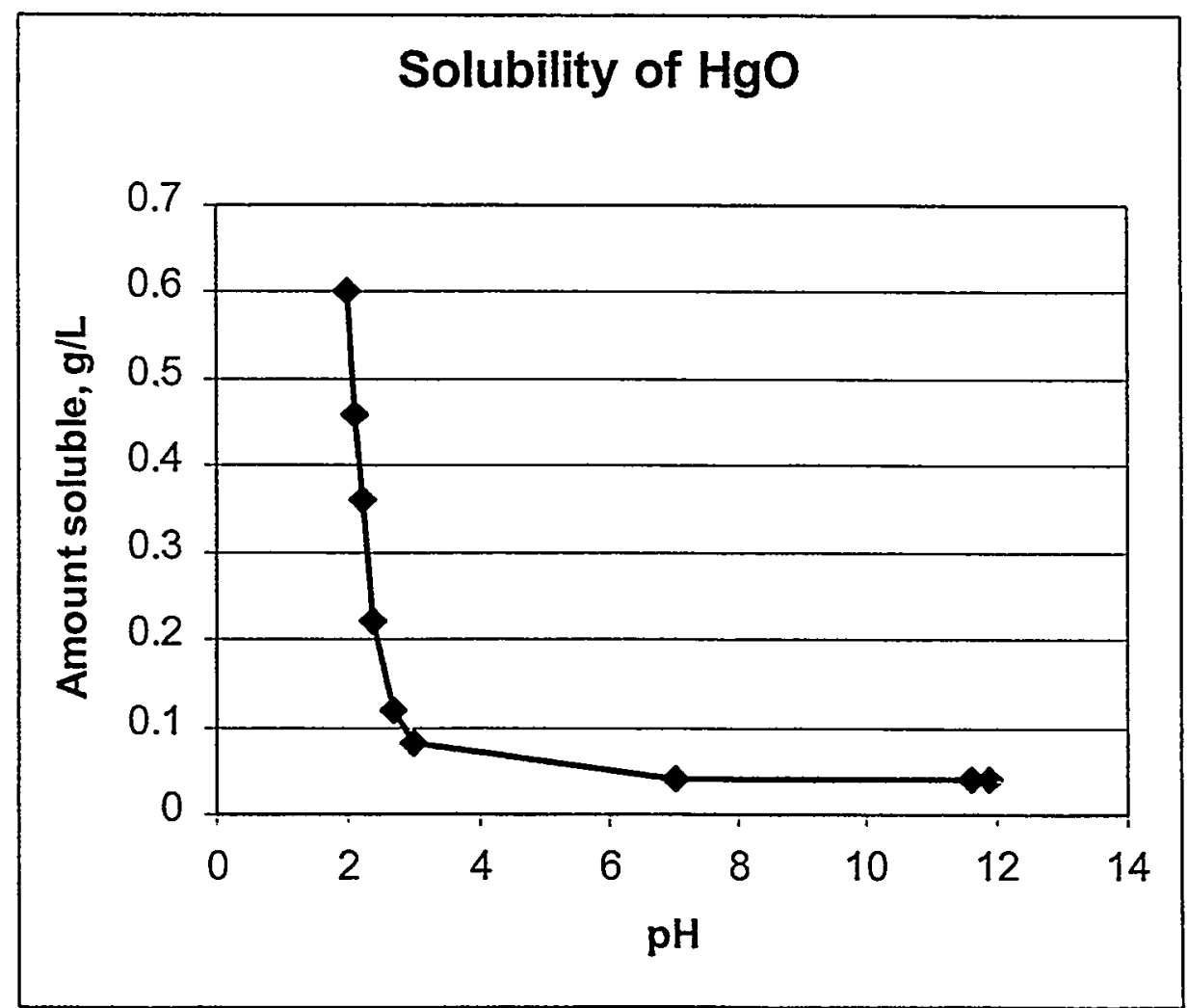




\section{A.4.2 Metallic Mercury}

The metal has low solubility in air-free water as shown in Table A-2 (also includes Henry's Law Constant). However, this solubility increases by a factor of 700 in aerated water (Bailar 1973).

\section{Table A-2, Hg Solubility}

\begin{tabular}{|c|c|c|}
\hline Temperature, ${ }^{\circ} \mathrm{K}$ & Solubility, mole/kg & Henry's Constant, Atm \\
\hline 273.15 & $1.36 \mathrm{E}-07$ & 108 \\
\hline 298.15 & $3.03 \mathrm{E}-07$ & 495 \\
\hline 328.15 & $6.82 \mathrm{E}-07$ & 1980 \\
\hline 358.15 & $1.59 \mathrm{E}-06$ & 5560 \\
\hline 373.15 & $2.40 \mathrm{E}-06$ & 8390 \\
\hline
\end{tabular}

The metal has high vapor pressure. Figure A-8 includes vapor pressure for $\mathrm{Hg}$ and $\mathrm{HgCl}_{2}$.

Figure A-8, Hg Vapor Pressure

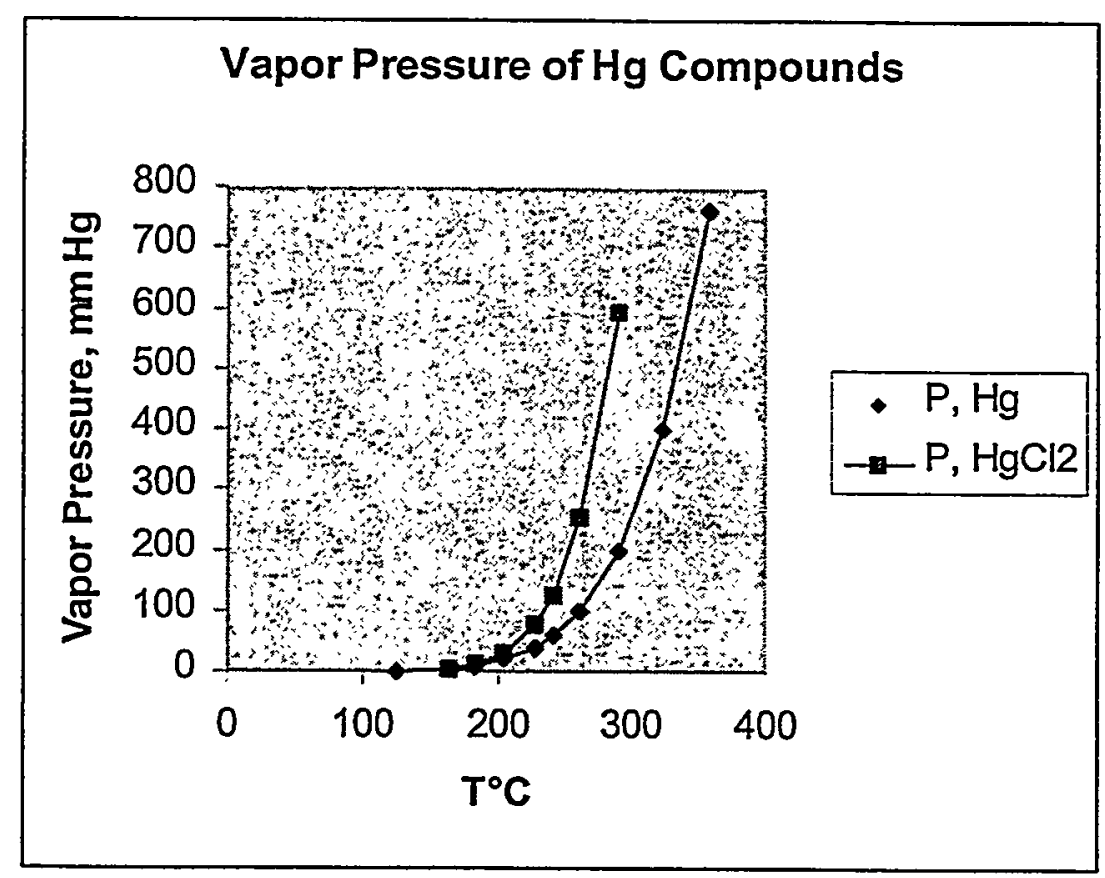

Mercury is slowly oxidized by oxidizing acids (Smith et al 1999) but not reducing acids like $\mathrm{HCl}$. Excess acid as in the scrub liquor ensures mercury as $\mathrm{Hg}^{+2}$ as opposed to the dimer $\mathrm{Hg}_{2}{ }^{+2}$. 


\section{A.4.3 $\mathrm{HgCl}_{2}$}

To extrapolate to lower temperatures for the vapor pressure of $\mathrm{HgCl}_{2}$, an Antoine type equation was used to fit the data and extrapolate.

$$
\ln p=A-\frac{B}{T}
$$

Where $\mathrm{p}=$ vapor pressure, $\mathrm{mm} \mathrm{Hg}$

$\mathrm{T}=$ Temperature $^{\circ} \mathrm{K}$

$\mathrm{A}=10.094$

$\mathrm{B}=4170$

Although the vapor pressure is similar to the metal (Figure A-1), the solubility is far different. The main portion of solubility is as a molecular species (similar to ammonia) as shown below:

$$
\begin{aligned}
& \mathrm{HgCl}_{2}(s)=\mathrm{Hg}^{+2}(a q)+2 \mathrm{Cl}^{-}(a q) \quad K=7.1 \times 10^{-15} \\
& \mathrm{HgCl}_{2}(s)=\mathrm{HgCl}_{2}(a q) \quad \mathrm{K}=0.11
\end{aligned}
$$

The solubility ranges from $0.163 \mathrm{~mole} / \mathrm{kg}$ at $273.15^{\circ} \mathrm{K}$ to 2.128 at $373.15^{\circ} \mathrm{K}$.

\section{Vapor-Liquid}

To estimate the vapor quantities of $\mathrm{HgCl}_{2}$, the activity coefficient is needed. The activity coefficient, $\gamma$, is a function of temperature and composition and for electrolytes, ionic strength and other factors.

$$
\varphi y_{i} P=\gamma x_{i} P^{0}
$$

Assuming the fugacity coefficient is one ( $\varphi=1$, ideal gas assumption), the activity coefficient was determined at 70 and $100^{\circ} \mathrm{C}$ from an ESP run

$$
\begin{aligned}
& \gamma=\frac{y}{x} * \frac{P}{P^{0}}=0.015 * \frac{1}{0.000167}=90 @ 70^{\circ} \mathrm{C} \\
& y=\frac{y}{x} * \frac{P}{P^{0}}=0.02 * \frac{1}{0.000444}=45 @ 100^{\circ} \mathrm{C}
\end{aligned}
$$

If Raoult's Law is assumed, $\gamma=1.0$. This indicates a serious error. However, this particular ESP run provided higher values for Henry's Law constants than Schindler (Schindler 1997c) and the higher, more conservative values are used. 
COGEMA-DOC-001, Rev. 0

Appendix B

Modeling

B-1 


\section{Appendix B Modeling}

\section{B.1 Mercury Absorption and Modifications}

\section{B.1.1 Quench/Venturi Model with Continuous Sidestream}

Overall Material Balance (see Figure B-1)

$$
y_{i} V=L x\left(1-\frac{1}{D F}\right)+y_{\nu} V
$$

Quench Tower Balance

$$
y_{i} V+S_{q} x=y_{q} V+S_{q} x_{q}
$$

Venturi System Balance

$$
y_{q} V+S_{v} x=y_{v} V+S_{v} x_{v}
$$

Scrub Tank

$$
\left(S+L\left(1-\frac{1}{D F}\right)\right) x=S_{q} x_{q}+S_{v} x_{\nu}
$$

Assuming equilibrium between outlets and a Henry's type law ( $\mathrm{H}=$ Henry's constant)

$$
y_{q}=H x_{q}, \quad y_{v}=H x_{v}
$$

Combining all of these

$$
x_{v}=\frac{\left(\frac{H S_{q}}{H V+S_{q}}+S_{v}\right) x+\frac{y_{i} H V}{H V+S_{q}}}{H V+S}
$$

Let

$$
\begin{aligned}
& \alpha=\left(\frac{H S_{q}}{H V+S_{q}}+S_{v}\right) \\
& \beta=\frac{y_{i} H V}{H V+S_{q}}
\end{aligned}
$$




$$
\begin{gathered}
\gamma=H V+S_{v} \\
x_{v}=\frac{\alpha x+\beta}{\gamma} \\
x=\frac{y_{i} V-\frac{\beta H V}{\gamma}}{L(1-1 / D F)+\frac{\alpha H V}{\gamma}} \\
x_{q=} \\
\left(S+L\left(1-\frac{1}{D F}\right)\right) x-S_{v} x_{v} \\
S q
\end{gathered}
$$


Figure B-1, Current Configuration with Sidestream

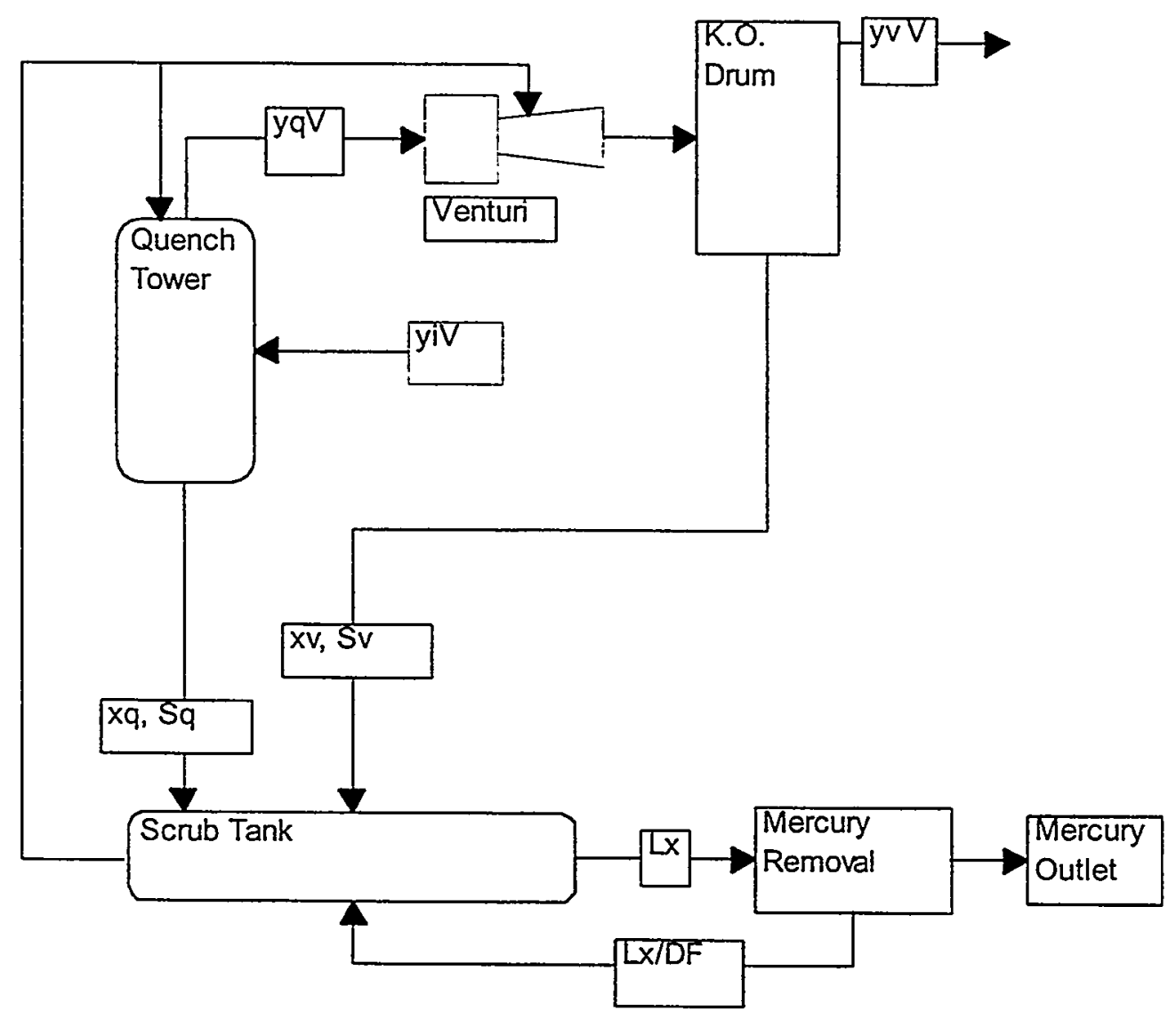




\begin{tabular}{|c|c|c|c|}
\hline $\mathrm{S}_{\mathrm{q}}, \mathrm{gmole} / \mathrm{hr}$ & 552000 & mass in $\mathrm{g} / \mathrm{h}$ & 826.2 \\
\hline$\sqrt{y_{1}, \text { gmole } / \mathrm{hr}}$ & 3.06 & HV & 296.0648 \\
\hline $\mathrm{S}_{\mathrm{v}}$, gmole/hr & 227000 & $(\mathrm{HV}+\mathrm{SV}) \mathrm{N}$ & 3.46 \\
\hline $\mathrm{y}_{1}$, mole fr & $4.66 E-05$ & & \\
\hline Fr HgCl2 & $3.22 \mathrm{E}-07$ & & \\
\hline H, atm (corr) & 4.51E-03 & & \\
\hline V. gmole/hr & 65675 & & \\
\hline s, gmole/hr & 779000 & & \\
\hline$D F$ & 50 & & \\
\hline alpha & $2.27 E+05$ & & \\
\hline beta & $2.50 E-08$ & & \\
\hline gamma & 2.27E+05 & & \\
\hline
\end{tabular}

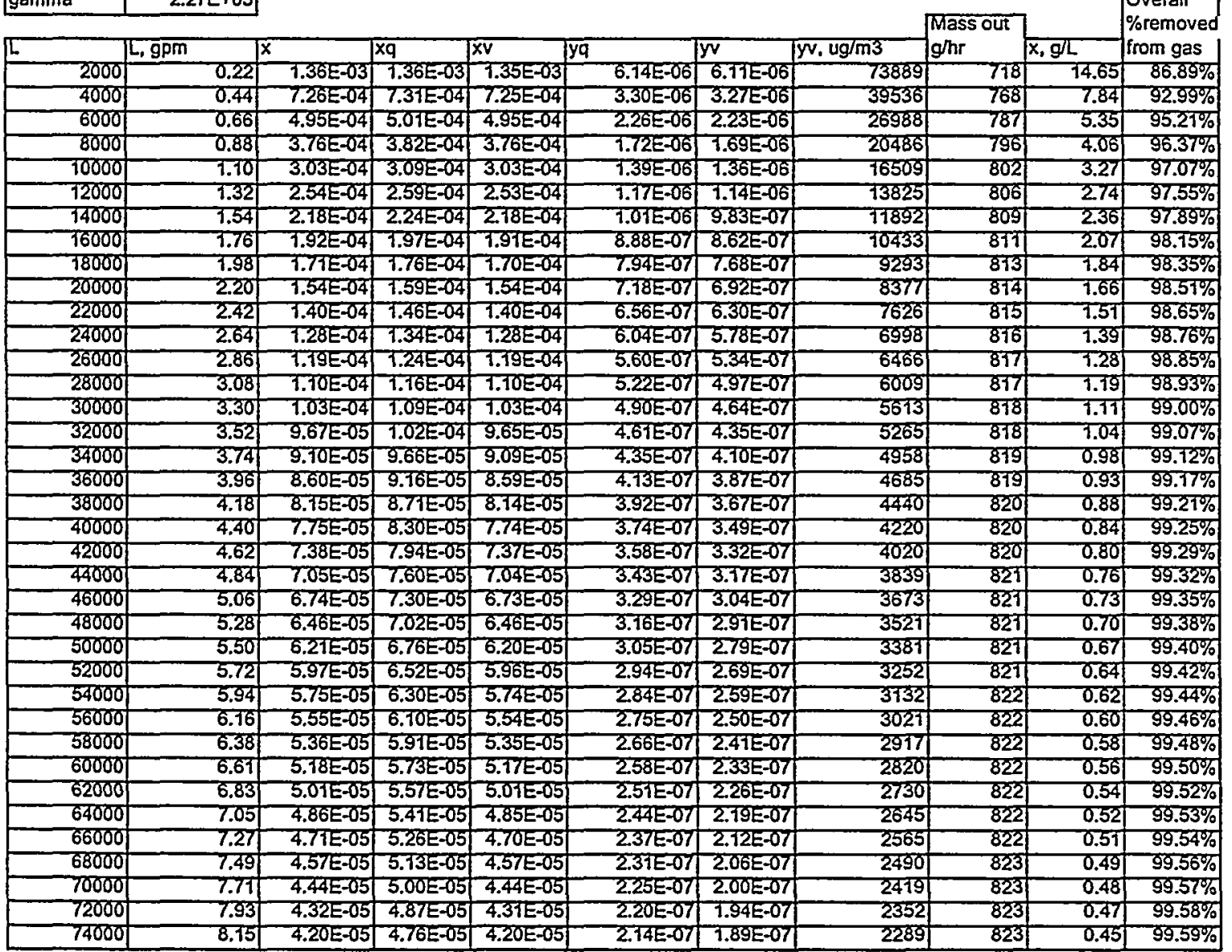

\section{B.1.2 Quench/Venturi Model with Separate Scrubs, Continuous Sidestream}

This is a much simpler case with the quench and venturi assumed to be one equilibrium stage each and each has its own separate scrub solution as shown in Figure B-2. 
Figure B-2, Modified System With Sidestream Treatment

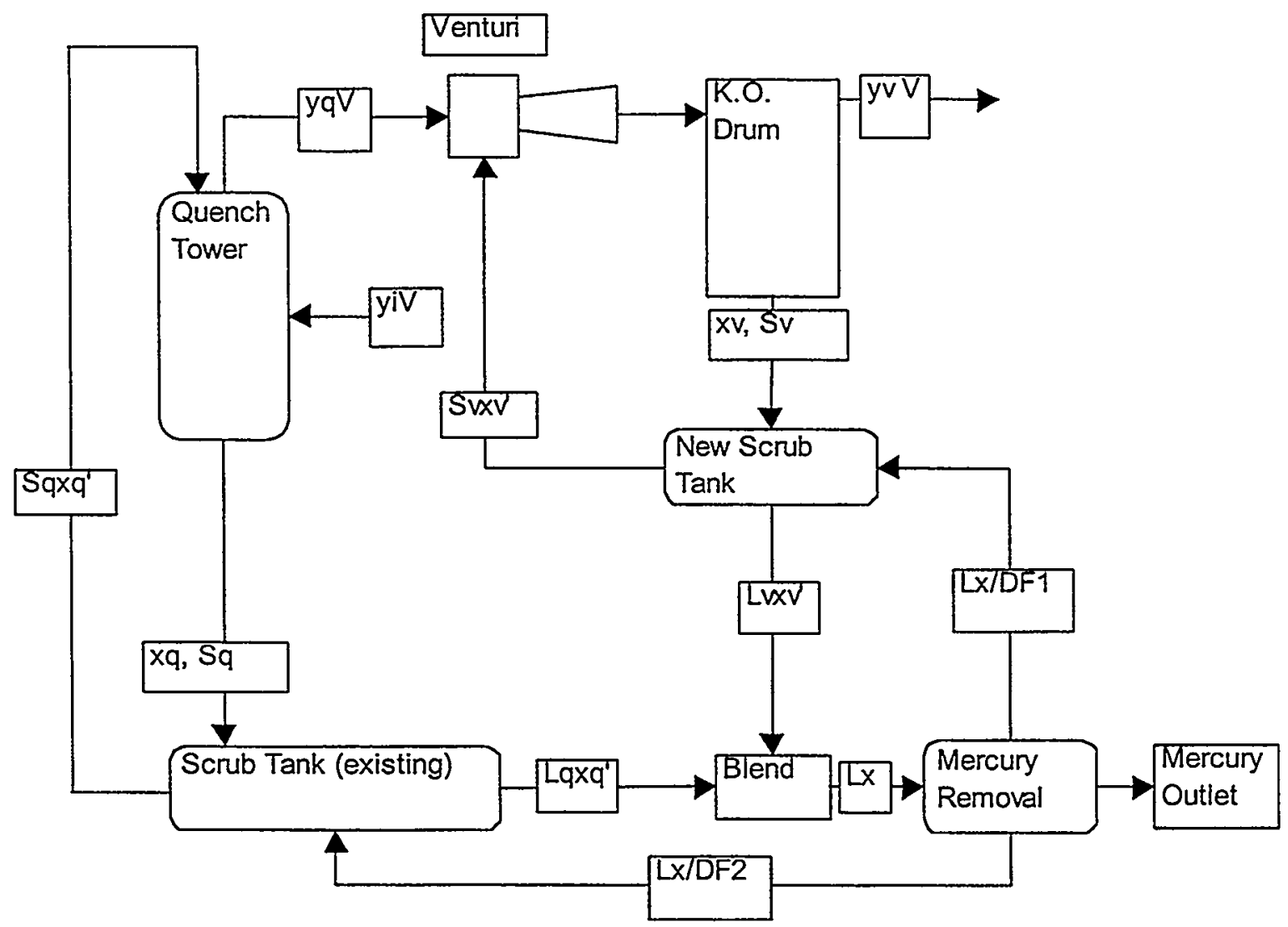

Overall Material Balance (see Figure B-2)

$$
y_{i} V=L x\left(1-\frac{1}{D F_{1}}-\frac{1}{D F_{2}}\right)+y_{\nu} V
$$

Quench System Balance

$$
y_{i} V+\frac{L x}{D F_{2}}=y_{q} V+L_{q} x_{q}
$$

Venturi System Balance

$$
y_{q} V+\frac{L x}{D F_{1}}=y_{v} V+L_{v} x_{v}
$$


Assuming equilibrium between outlets and a Henry's type law ( $\mathrm{H}=$ Henry's constant)

$$
y_{q}=H x_{q}, \quad y_{v}=H x_{v}
$$

The result is

$$
\begin{gathered}
x=\frac{y_{i} V}{\alpha\left(L_{q}+H V\right)+\frac{L}{D F_{2}}} \\
x_{q}^{\prime}=\infty x \\
x_{q}=\frac{y_{i} V+S_{q} x_{q}^{\prime}}{H V+S_{q}} \\
x_{v}^{\prime}=\frac{L x-L_{q} x_{q}^{\prime}}{L_{v}}
\end{gathered}
$$

and

$$
x_{v}=\frac{H x_{q} V}{H V+L_{v}}
$$

Where

$$
\alpha=\frac{\left(\frac{L}{L_{v}}-\frac{L}{D F_{1}\left(H V+L_{v}\right)}\right)}{\left(\frac{L_{q}}{L_{v}}+\frac{H V}{H V+L_{v}}\right)}
$$


COGEMA-DOC-001, Rev. 0

\begin{tabular}{|c|c|c|}
\hline$\sqrt{S_{4} \text { gindent }}$ & 552000 mass in g/h & 826.2 \\
\hline Vy, grndeshs & $3.06 \mathrm{HV}$ & 296.0648 \\
\hline$S_{r}$ Gndehr & $227000 \mid(H V+S V) N$ & 3.46 \\
\hline$y_{r}$ molefr & $4.66 E-05$ & \\
\hline Fr $\mathrm{HgCl}_{2}$ & 0.32 & \\
\hline$A_{1}$ aim (C) & 4.5TE-03 & \\
\hline V. Gmoelir & 55675 & \\
\hline S. çroxent & 7190000 & \\
\hline$\overline{D F} F_{t}$ & 50 & \\
\hline$\overline{\mathrm{DF}_{2}}$ & 50 & \\
\hline
\end{tabular}

\begin{tabular}{|c|c|c|c|c|c|c|c|c|c|c|c|c|c|c|c|}
\hline L. Gndein & La. ginde] & Lv, ginden & $\mathrm{gpm}$ & बढp̆a & $\bar{x}$, mole & & $\overline{x v}$ & $\times 9$ & jya & $X \overline{X Y}$ & Iy & Gintos & $\mathrm{ug} / \mathrm{m}^{3}$ & $\begin{array}{l}\text { mass out } \\
g / h s\end{array}$ & $x, g L$ \\
\hline 3000 & 1500 & 75000 & 0.28 & 1.69 & T.03E-03 & $7.74 E-03$ & $3.21 E-04$ & $7.74 E-03$ & $7.85 E-06$ & $3.23 \mathrm{E}=04$ & 7.45E-O6 & 95045 & 77502 & 800.55 & T.TE+OT \\
\hline 6000 & 3000 & 3000 & 0.55 & 1.80 & $5.26 \mathrm{E} 04$ & $9.48 E-04$ & $1.04 E-04$ & 9.53E-04 & 4.29E-06 & 1.05E-04 & $4.70 \mathrm{E}-07$ & 51951 & 5685 & 877.87 & $5.68 E+\infty 0$ \\
\hline 5000 & 4500 & 4500 & 0.83 & 7.85 & $3.521=04$ & 6.51E04 & 5.3दE-05 & 6.55E04 & 2.55E-06 & $5.42 E-05$ & 2.4FE-07 & 35801 & 291दा & 821.93 & $3.811++00$ \\
\hline 12000 & 6000 & 6000 & 3.10 & 1.87 & 2.65E-04 & 4.95E 04 & $3.34 E=05$ & 5.01E-04 & $2.26 E-06$ & $3.40 \mathrm{E}-05$ & 1.5TE-07 & 27345 & 7823 & 823.53 & $2.80 E+00$ \\
\hline 75000 & 7500 & 7500 & 1.38 & 7.89 & $2.12 E-04$ & 4.01E04 & 2.3दE.05 & 4.05E-04 & $1.83 E=06$ & $2,39 E 05$ & 1.05E-OT & 22142 & 3215 & 824.33 & $2.29 E+\infty$ \\
\hline 78000 & 90001 & 9000 & 7.65 & 7.90 & T.77E-04 & $3.35 E-04$ & $1.75=205$ & 3.47 Eण & $1.54 E-06$ & $7.80=-05$ & $7.91 \mathrm{EN}$ & र8518 & 571 & 824.80 & 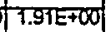 \\
\hline 21000 & T0500 & 10500 & 7.93 & 7.97 & 7.522E-04 & 289E-04 & $1.38=-05$ & 2.SE-04 & T.33E-0\% & T.42E-05 & $6.24 E-08$ & TE्रण4 & 75 aी & 825.09 & $1.64 E+\infty$ \\
\hline 24000 & 12000 & 12000 & 2.20 & 1.91 & $7.33 E=04 \mid$ & 2.5AE-OA & T.13E-05 & 2.59E-04 & T.17E-06 & 7.16E-05 & 5.09E-08 & 34150 & 61क & 825.30 & $1.43 E+\infty 0$ \\
\hline 27000 & $\{3500$ & 13500 & 2.48 & 1.92 & T.18E-04 & 2.26E-04 & $9.48 E=06$ & 232E-04 & T.05E-06 & $9.77 E-06$ & 4.27E-W8 & 72644 & 517 & 825.44 & $3.27 t+\infty 0$ \\
\hline 33000 & 76500 & 76500 & 3.03 & 1.93 & 9.65E-05 & $7.86 E-44$ & $7.07 E-06$ & T.91E-0द्य & 8.63E-Oा। & 7.31E-O5 & 3.T9E-08 & 70440 & 385 & 825.63 & $1.04 E+\infty$ \\
\hline 36000 & 78000 & 18000 & 3.30 & 7.93 & 8.85E-05 & T.7TEO4 & $6.25 E-00$ & $1.765=04$ & $7.94 E-0 T$ & 6.471E-08 & $2.82 \mathrm{E}-0 \mathrm{~S}$ & 9609 & उदा & 825.70 & 9.50Eन-0T \\
\hline 30000 & 79500 & T9500 & 3.58 & 1.93 & $8.57=05$ & $1.581 E=04$ & 5.58E- 06 & T.63E-O4 & $7.35 E-07$ & $5.78 E-08$ & 2.5TE-08 & 8903 & 304 & 825.75 & $8.82 E-07$ \\
\hline 42000 & 21000 & 21000 & 3.85 & 7.93 & 7.59E-05 & 1.47E04 & 5.035 .06 & 1.52E-0दी & $6.80 E 07$ & $5,22 E=0$ का & 2.27E-08 & 8299 & 274 & 825.80 & 8.19E-01 \\
\hline 45000 & 22500 & 22500 & 4.13 & 7.94 & 7.08E-05 & T.37E-04 & 4.57E-06 & 1.42E-04 & 6.42E-07) & 4.75E-00 & $2.06=08$ & 7772 & 250 & 825.83 & 7.55E-01 \\
\hline 48000 & 24000 & 24000 & 4.40 & 1.94 & 6. $.64 E-05$ & $1.29 E-04$ & 4.T9E-DS & 7.34E-04 & $6.04=-07$ & $4.35=-05$ & T.89E-08 & 7310 & 228 & 825.87 & 7.17E-OT \\
\hline 51000 & 25500 & 255000 & 4.58 & 7.94 & 6.25E-05 & 7.21E-04 & $3.86 E-06$ & 1.27ह-णी & 5.71E-07 & $4.02 E-006$ & T.74E-08 & 6003 & 2ग1 & 825.89 & $6.75 \mathrm{E}-01$ \\
\hline 54000 & 27000 & 27000 & 4.35 & 1.94 & $5.90 \mathrm{E}-0 \mathrm{~S}$ & 1.14E-04 & $3.58=-06$ & 1.20E-04 & 5.41E-07 & $3.73 E-05$ & T.57E-08 & 6540 & 795 & 825.91 & 6.37E-01 \\
\hline 57000 & 28500 & 28500 & 5.23 & 7.94 & $5.595-05$ & 1.08E-04 & $3.33 E-06$ & T.14E-C4 & | 5.14E-07| & $3.47 E-05$ & 1.50EDOS & 6215 & 182 & 825.93 & 6.04E-01 \\
\hline
\end{tabular}


B.1.3 Addition of new absorber, multi-staged or packed (Figure B-3) For this case, the Kremser equation is used:

Figure B-3, Multi-Stage System

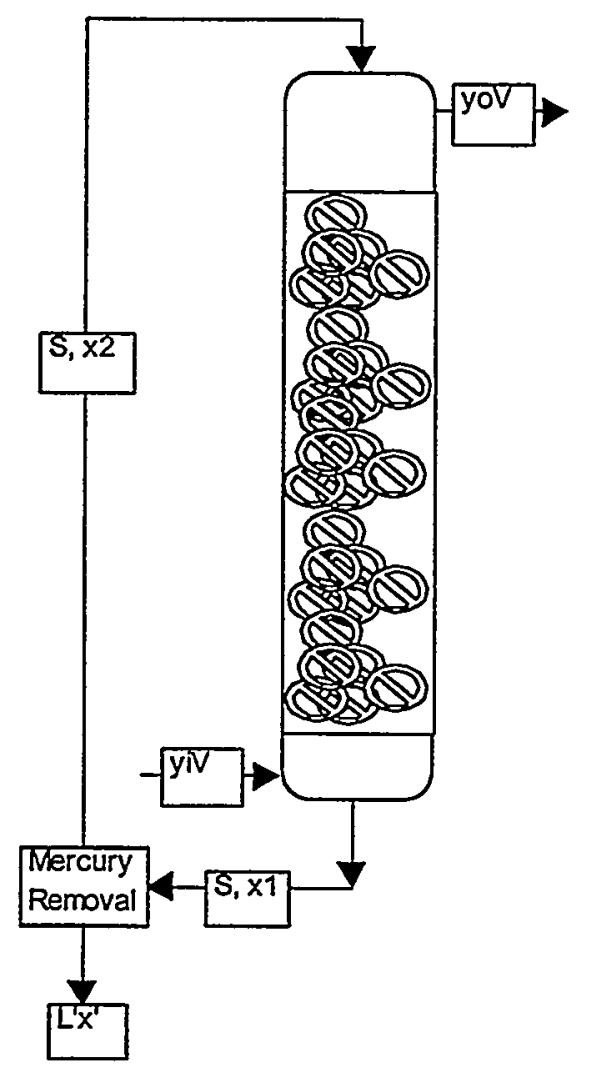

$$
N_{\text {IOG }}=\frac{\ln \left[\frac{y_{i}-H x_{2}}{y_{0}-H x_{2}}\left(1-\frac{1}{A}\right)+\frac{1}{A}\right]}{\left(1-\frac{1}{A}\right)}
$$

Where $1 / \mathrm{A}=$ absorption factor, $\mathrm{L} / \mathrm{HV}$

$\mathrm{H}=$ Henry's Law constant

$\mathrm{L}=\mathrm{Scrub}$ mole rate

$\mathrm{N}_{\mathrm{toG}}=$ The number of transfer units required to make a separation

$\mathrm{x}_{2}=$ the mole fraction of inlet scrub solution (zero if not recirculating)

$\mathrm{V}=$ Vapor mole rate 
COGEMA-DOC-001, Rev. 0

\begin{tabular}{|c|c|c|c|c|}
\hline V, gmole/hr & $6.57 E+04$ & & mole fraction & $\mathrm{ug} / \mathrm{m} 3$ \\
\hline Vyi, gmole/hr & 3.06 & $\overline{y_{i}}$ & $8.22 E-06$ & $9.95 E+04$ \\
\hline$H$, corrected & 0.01358 & $\mathrm{y}_{0}$ & $4.13 E-09$ & 50 \\
\hline fraction $\mathrm{HgCl}_{2}$ & 0.97 & & & \\
\hline Treat Rate, gpm & 2.00 & $x_{n}$ & $3.00 \mathrm{E}-05$ & \\
\hline Absorption Factor & $2.04 E+01$ & $x_{1}$ & $3.00 E-07$ & \\
\hline$\overline{\mathrm{DF}}$ & 100 & & & \\
\hline$x_{1}$ & $3.00 \mathrm{E}-07$ & & & \\
\hline$y_{i}-H x_{1}$ & $8.22 E-06$ & & & \\
\hline $\mathrm{y}_{0}-H x_{1}$ & $5.60 E-11$ & & & \\
\hline$S$ & $1.82 E+04$ & $(2 \mathrm{gpm})$ & & \\
\hline$L x$ & 5.40E-01 & & & \\
\hline L & $9.08 E+02$ & $(0.3 \mathrm{gpm})$ & & \\
\hline$x$ & 5.95E-04 & $(45 \mathrm{~g} / \mathrm{L})$ & & \\
\hline $\mathrm{HV}$ & 892 & & & \\
\hline$A$ & 20 & & & \\
\hline T/A & $5.00 \mathrm{E}-02$ & & & \\
\hline $1-1 / A$ & 9.50E-01 & & & \\
\hline$N_{\text {tOG }}$ & 12 & & & \\
\hline
\end{tabular}


COGEMA-DOC-001, Rev. 0

Figure B=4, DF versus Treatment Rate, Absorber

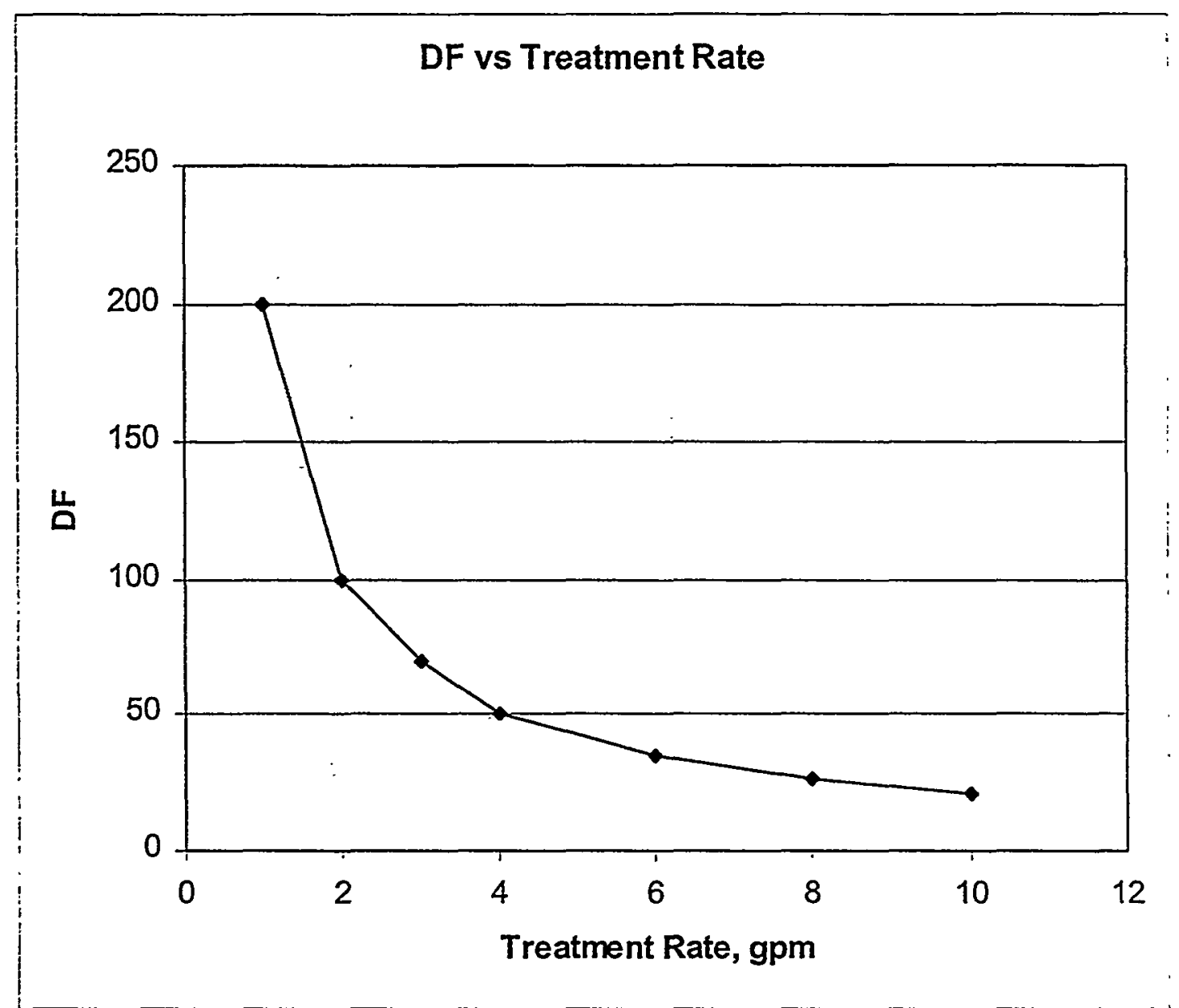

B.2 Sulfide Precipitation

B-11 
The following three reactions are considered to be the main ones:

$$
\begin{aligned}
& H_{2} S \Leftrightarrow H S^{-}+H^{+} \\
& H S^{-} \Leftrightarrow S^{-2}+H^{+} \\
& H g S \Leftrightarrow H g^{+2}+S^{-2}
\end{aligned}
$$

These lead to the following three equations:

$$
\begin{aligned}
& K_{1}=\frac{\left.\left[H^{+}\right] H S^{-}\right]}{\left[H_{2} S\right]} \\
& K_{2}=\frac{\left.\left[H^{+}\right] S^{-2}\right]}{\left[H S^{-}\right]} \\
& K_{s p}=\left[H^{+2}\right] S^{-2}
\end{aligned}
$$

Lastly, either a charge balance or mass balance is required. To simplify, the excess sulfide $\left(\mathrm{S}_{\mathrm{Te}}\right)$ is used as follows:

$$
S_{T e}=\left[H_{2} S\right]+\left[H S^{-}\right]+\left[S^{-2}\right]
$$

Combining all of these shows sulfide works well at even very high acid for precipitating mercury

$$
\left[H g^{+2}\right]=\frac{\frac{K_{s p}\left[H^{+}\right]^{2}}{K_{1} K_{2}} *\left(1+\frac{K_{1}}{\left[H^{+}\right]}\right)+K_{s p}}{S_{T e}}
$$


The chart below (Figure B-5) is a plot of this for 1 molar and 0.5 molar excess sulfide Figure B-5, Sulfide Precipitation

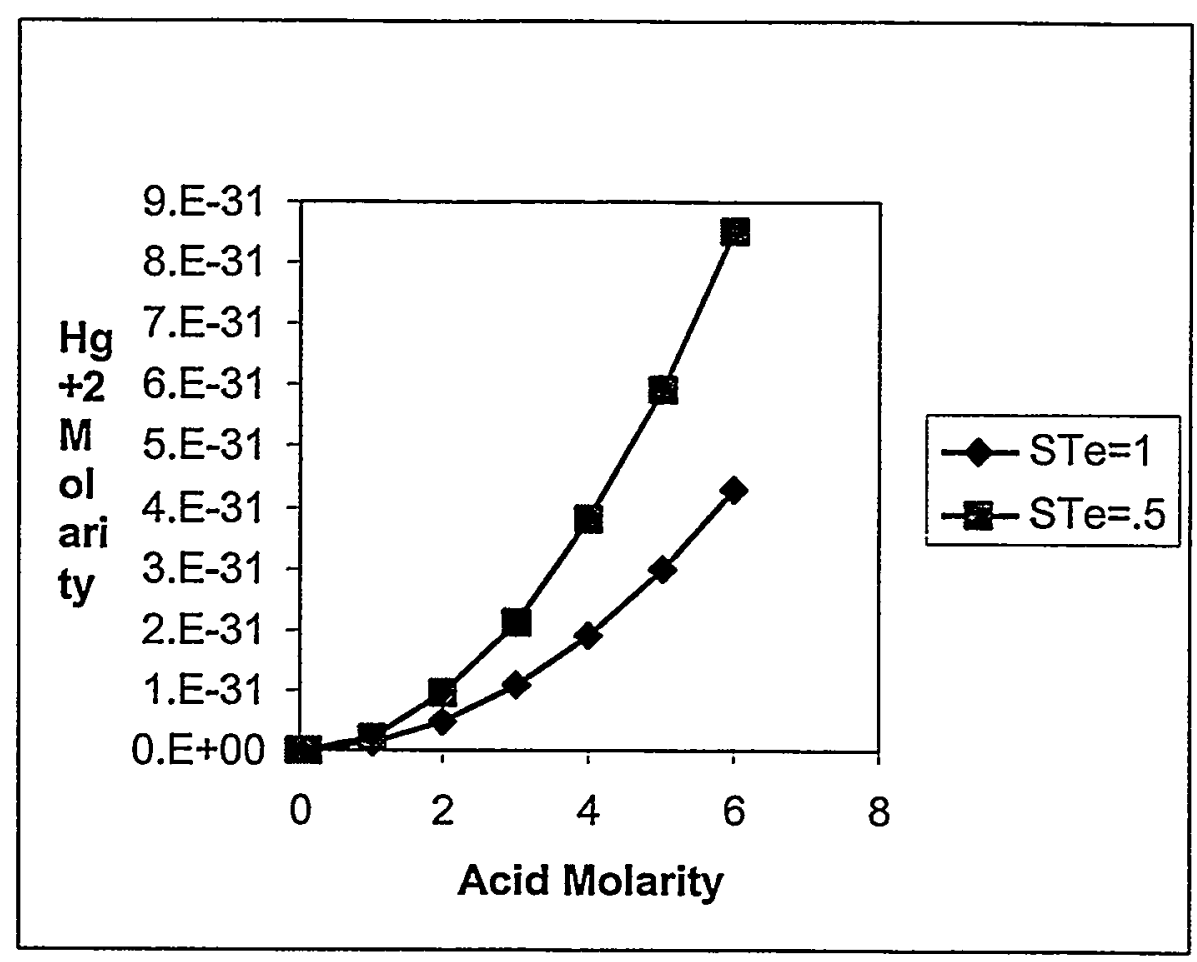


COGEMA-DOC-001, Rev. 0

Appendix C

Electrochemical Modeling and Testing

C-1 


\section{Appendix C..Electrochemical Modeling and Testing}

Determine scale up modeling of the electrochemical, aqueous phase mercury treatment system for batch and flow reactors.

It is assumed that the ionic/molecular diffusion/mass transport of mercury compounds is much smaller than the reaction rate at the cathode. Hence, this becomes a mass transfer problem.

Flow Reactor

\section{Plug Flow Reactor}

This model is a plug flow reactor (PFR) with a rectangular mercury cathode as shown in Figure C-1

Figure C-1

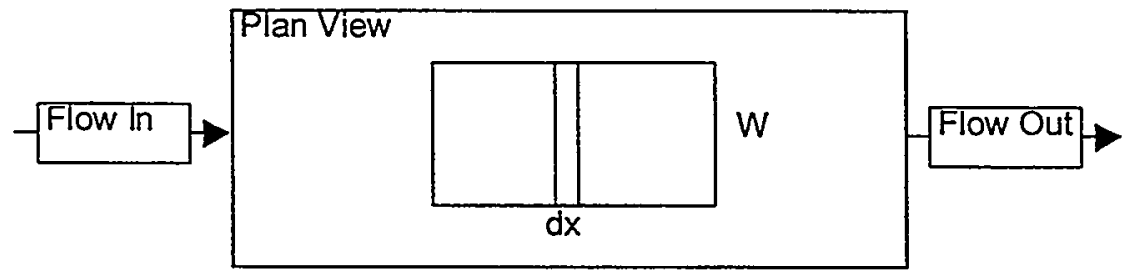

The material balance across $\mathrm{dx}$, assuming mass transfer rate limiting results in

$$
-Q d C-K_{L} W\left(C-C_{s}\right) d x=0
$$

Assuming $\mathrm{C} \gg \mathrm{Cs}$

$$
W x=\text { Area }=\frac{-Q \ln C / C_{0}}{K_{L}}
$$

Where $\mathrm{C}=\mathrm{Hg}$ concentration

$\mathrm{D}=$ Diffusivity, $10^{-5} \mathrm{~cm}^{2} / \mathrm{s}$ (for most ions @2 $25^{\circ} \mathrm{C}$ )

$\mathrm{K}_{\mathrm{L}}=$ Mass Transfer Coefficient $(\sim \mathrm{D} / \delta)$

$\mathrm{Q}=$ Flowrate (2 gpm)

$\mathrm{Wx}=$ Cathode area

$\delta=$ Concentration Boundary layer, $0.05 \mathrm{~cm}$ (stagnant solution)

For the above values, the cathode area required is

$$
W x=\text { Area }=\frac{-2 g p m * 3.785 \mathrm{~L} / \mathrm{gal} \ln \frac{1}{100}}{10^{-5}} * 0.05 * 10^{3} \mathrm{~min} / 60 \mathrm{~s}=291 \mathrm{~m}^{2}
$$


As this indicates, a stagnant film PFR would require too much cathode area to be practical for a $\mathrm{DF}=100$ (if such a reactor could even be assembled).

\section{Stirred Tank}

There is really not a stirred tank reactor (CSTR) for this kind of system. However, a model can be developed with assumptions so that a similar enough expression will apply. Again, it is assumed that the reaction is very fast compared to mass transfer and the cathode surface concentration is low compared to the bulk. The stagnant film is much thinner and mass transfer is accomplished by turbulence. The bulk concentration is uniform throughout.

$$
Q C_{i}-K_{L} A_{c} C=Q C
$$

The cathode area is then

$$
A_{c}=\frac{Q}{K_{L}} *\left(\frac{C_{i}}{C}-1\right)
$$

The mass transfer coefficient, $\mathrm{K}_{\mathrm{L}}$, depends on the turbulent eddies. For baffled, parallel plate, electrochemical reactors, Wragg (Wragg and Leontaritis 1997) found

$$
S h=0.46 \operatorname{Re}^{0.66} S c^{0.33}
$$

From this the mass transfer coefficient is determined

$$
K_{L}=0.46 * \frac{D}{D_{H}} * \operatorname{Re}^{0.66} S c^{0.33}
$$

As shown in Table C-1 below, the flow alone cannot induce enough turbulence to bring the cathode area, A, within practical limitations (it must be able to fit within the box floor). 


\section{Table C-1}

\begin{tabular}{|c|c|c|c|c|c|c|c|c|c|}
\hline$Q, \mathrm{gpm}$ & 2 & $Q, m^{3} / s$ & $1 E-04$ & $D, m^{2} / s$ & $1.00 \mathrm{E}-09$ & & & \multirow{3}{*}{$\begin{array}{l}\mathrm{A}, \mathrm{cm}^{2} \\
\mathrm{DF}=10\end{array}$} & \multirow[b]{3}{*}{$\mathrm{LxW}, \mathrm{cm}^{2}$} \\
\hline Visc, cp & 1 & Dens, $\mathrm{g} / \mathrm{cm}^{3}$ & 1 & Sc & 1000 & & & & \\
\hline$L, m$ & $\mathrm{~W}, \mathrm{~m}$ & $\mathrm{H}, \mathrm{m}$ & $D_{H}, m$ & $\mathrm{v}, \mathrm{m} / \mathrm{s}$ & $\operatorname{Re}$ & $\overline{S h}$ & $\mathrm{~K}, \mathrm{~m} / \mathrm{s}$ & & \\
\hline$T$ & 0.5 & 0.25 & 0.33 & 0.0010 & 336 & 209 & $6.28 \mathrm{E}-07$ & $2 . E+07$ & 5000 \\
\hline 7 & 0.25 & 0.1 & 0.14 & 0.0050 & 721 & 346 & $2.42 E-06$ & $5 . E+06$ & 2500 \\
\hline 1 & 0.1 & 0.1 & 0.10 & 0.0126 & 1262 & 500 & $5.00 E-06$ & $2 . E+06$ & 1000 \\
\hline 7 & 0.1 & 0.05 & 0.07 & 0.0252 & 7682 & 605 & $9.08 E-06$ & 7.E+06 & 1000 \\
\hline 1 & 0.05 & 0.05 & 0.05 & 0.0505 & 2523 & 791 & 1.58E-05 & $7 . E+05$ & 500 \\
\hline
\end{tabular}

Using agitation is required for this type of reactor for a reasonable cathode area. The following is used for agitation (via impeller)

$$
K_{L}=0.592 D^{1 / 2}(\sigma / v)^{1 / 4}
$$

The sigma is the energy dissipation rate

$$
\sigma=\frac{N \rho_{L} N^{3} D_{i m p}^{5}}{M} \phi
$$

The cathode area is determined by the above and shown in Table C-2.

Table C-2

\begin{tabular}{|l|c|l|c|}
\hline Density, $\mathrm{g} / \mathrm{cm}^{3}$ & 1 & Diffusivity,, $\mathrm{cm}^{2} / \mathrm{s}$ & $1.00 \mathrm{E}-05$ \\
\hline Speed, $\mathrm{N}, \mathrm{s}^{+1}$ & 29 & $\mathrm{D}_{\text {imp }}, \mathrm{cm}$ & 30 \\
\hline Viscosity, $\mathrm{cp}$ & 1 & $\mathrm{~Np}$ & 10 \\
\hline Dyn Visc, $\mathrm{cm}^{2} / \mathrm{s}$ & 0.01 & & \\
\hline
\end{tabular}

\begin{tabular}{|c|c|c|c|c|c|c|c|}
\hline $\mathrm{V}, \mathrm{m}^{3}$ & $\mathrm{M}, \mathrm{g}$ & Sigma & $\mathrm{K}, \mathrm{cm} / \mathrm{s}$ & $\mathrm{K}, \mathrm{m} / \mathrm{s}$ & $\mathrm{m}^{2}$ & $\begin{array}{l}\mathrm{A}, \mathrm{m}^{2} \\
(\mathrm{DF}=100)\end{array}$ & $\begin{array}{l}\mathrm{A}, \mathrm{m}^{2} \\
(\mathrm{DF}=10)\end{array}$ \\
\hline 0.5 & $5.0 \mathrm{D}+05$ & $1.2 \mathrm{DF}=07$ & 0.35 & $3.5 \mathrm{E}-03$ & 4 & 0.33 & 0.14 \\
\hline 1 & $1.0 \mathrm{E}+06$ & $6.0 \mathrm{E}+06$ & 0.29 & $2.9 \mathrm{E}-03$ & 4 & 0.39 & 0.17 \\
\hline 1.5 & $1.5 \mathrm{E}+06$ & $4.0 \mathrm{E}+06$ & 0.27 & $2.7 \mathrm{E}-03$ & 5 & 0.43 & 0.19 \\
\hline 2 & $2.0 \mathrm{E}+06$ & $3.0 \mathrm{E}+06$ & 0.25 & $2.5 \mathrm{E}-03$ & 5.06 & 0.46 & 0.20 \\
\hline 2.5 & $2.5 \mathrm{E}+06$ & $2.4 \mathrm{E}+06$ & 0.23 & $2.3 \mathrm{E}-03$ & 5.35 & 0.49 & 0.22 \\
\hline
\end{tabular}

The results indicate rather reasonable cathode areas. It is likely prudent to put two or three in series for practical cathode area application.

\section{Batch Reactor}

The material balance using the same assumptions as previous is 


$$
-K_{L} A_{c} C=V \frac{d C}{d t}
$$

This leads to the cathode area

$$
A_{c}=\frac{V}{K_{L} t} \ln D F
$$

As shown in Table C-3 below, this can also be accomplished reasonably via batch reactors.

\section{Table C-3}

\begin{tabular}{|c|c|c|c|c|c|c|c|c|c|}
\hline & & & & & & & $A, m^{2}$ & $A, m^{2}$ & $A, m^{2}$ \\
\hline$V, m^{3}$ & $\mathrm{t}, \mathrm{hr}$ & $\mathrm{Q}, \mathrm{gpm}$ & $\bar{M}, \mathrm{~g}$ & Sigma & $\mathrm{K}, \mathrm{cm} / \mathrm{s}$ & $\mathrm{K}, \mathrm{m} / \mathrm{s}$ & $(D F=100)$ & $(D F=10)$ & $(D F=5)$ \\
\hline 0.5 & $T$ & 2.20 & $5.0=+05$ & $1.2 E+07$ & 0.35 & 3.5E-03 & 0.18 & 0.09 & 0.06 \\
\hline 7 & 2 & 4.40 & $7.0 E+06$ & $6.0 E+06$ & 0.29 & 2.9E-03 & 0.22 & 0.11 & 0.08 \\
\hline 7.5 & 3 & 6.67 & $1.5 E+06$ & $4.0 E+06$ & 0.27 & 2.7E-03 & 0.24 & 0.12 & 0.08 \\
\hline 2 & 4 & 8.81 & $2.0 E+06$ & $3.0 E+06$ & 0.25 & 2.5E-03 & 0.26 & 0.13 & 0.09 \\
\hline 2.5 & 5 & 77.07 & 2.5E+06 & $2.4 E+06$ & 0.23 & 2.3E-03 & 0.27 & 0.14 & 0.10 \\
\hline
\end{tabular}

\begin{tabular}{|l|c|l|c|}
\hline Density, $\mathrm{g} / \mathrm{cm}^{3}$ & 1 & Diffusivity, D, $\mathrm{cm}^{2} / \mathrm{s}$ & $1.00 \mathrm{E}-05$ \\
\hline Speed, N, s & 29 & $\mathrm{D}_{\text {imp, }} \mathrm{cm}$ & 30 \\
\hline Viscosity, $\mathrm{cp}$ & 1 & $\mathrm{~Np}$ & 10 \\
\hline Dyn Visc, cm $\mathrm{cm}$ & 0.01 & & \\
\hline
\end{tabular}

The use of the $\mathrm{K}_{\mathrm{L}}$ for the above analysis is an estimate. There has been some limited determination of $\mathrm{K}_{\mathrm{L}} \mathrm{s}$ for electrochemical systems, but none were found that match the current system [(Wragg and Leontaritis 1997) (Venkateswarlu et al., 1998) (Taama et al., 1996) (Jiang et al 1996)]. Therefore, $\mathrm{K}_{\mathrm{L}}$ will need to be determined. This can be found experimentally by (Buso et al 1997)

$$
K_{L}=\frac{i_{L}}{n F C}
$$

\section{Mixing}

The stirred continuous and batch reactors are mixed via impellers but gas sparging can probably be implemented as well by ensuring the energy dissipation matches that for an impeller. This can be done using Bernoullis equation. Also, the transfer coefficient used for the impeller is actually based on gas/liquid transfer and liquid phase controlling (hence, the use of $\mathrm{K}_{\mathrm{L}}$ ). This is believed to be overly optimistic and a better correlation is needed.

\section{Design}

The design anticipated will be a multi-cell arrangement similar to the baffled unit in Wragg (Wragg et al 1997). Impellers will be required in each chamber and weirs required to prevent back-mixing. Methods will be required to prevent entrainment via impellers of the liquid mercury cathode.

\section{Scaleup}


The Buckingham $\pi$ method is used to determine some dimensionless numbers for scaling and modeling. The variables will be dependent on the current research so this is an example.

For the CSTR type system, the following is assumed for this exampie

$$
D F=f\left(A_{c}, K_{L}, i, F, Q, t_{R}\right)
$$

for this, $\mathrm{p}=7$ and $\mathrm{m}=4$ so $\mathrm{n}=\mathrm{p}-\mathrm{m}=3$ (see Perry and Green 1984 for nomenclature)

Using the Buckingham method results in three dimensionless numbers

$$
\begin{aligned}
& \pi_{1}=\left(\frac{F W}{i}\right)^{2 / 3} \frac{K_{L}}{Q^{1 / 3}} \\
& \pi_{2}=\frac{i t_{R}}{F W} \\
& \pi_{3}=\left(\frac{i}{F W Q}\right)^{2 / 3} A_{c}
\end{aligned}
$$

Where $A c=$ cathode area

$\mathrm{F}=$ Faradays constant, Coulomb/eq

$\mathrm{i}=$ current, amperes, (Coulomb/s)

$\mathrm{K}_{\mathrm{L}}=$ liquid side mass transfer coefficient

$Q=$ flow rate

$\mathrm{t}_{\mathrm{R}}=$ residence time

$\mathrm{W}=$ amount of $\mathrm{Hg}$, eq 


\section{Appendix B \\ Laboratory Tests of Hg Removal Schemes From Liquid/Gas Phases}




\title{
Appendix B
}

\section{Laboratory Tests of Hg Removal Schemes from Liquid/Gas Phases}

\author{
D.D. Siemer and D.D. Taylor
}

\section{INTRODUCTION}

\section{$1.1 \quad$ Background}

Section 2.2 of the main report discusses potential methods for controlling mercury $(\mathrm{Hg})$ in liquid and gas streams. Some of these methods were recommended for laboratory scale testing to further evaluate their potential application in treatment of high level wastes at the INEEL. This report describes testing that was recommended on the following three such methods:

- Adsorption of gaseous forms of oxidized mercury with silica gel (SG);

- Precipitation of $\mathrm{Hg}$ from acid scrub with TMT;

- Scrubbing of gaseous gaseous forms of oxidized mercury with TMT.

Incident to testing pursuant to this recommendation it was found that high gas phase concentrations of $\mathrm{NO}_{2}$ will rapidly oxidize elemental, gaseous $\mathrm{Hg}$. This phenomenon has also been noted by other researchers ${ }^{1,2}$. Moreover, it is generally accepted that oxidized mercury forms are readily removable with wet scrubbing ${ }^{1}$. This being the case we elected to explore the feasibility of exploiting the high concentration of $\mathrm{NO}_{2}$ expected to be present in the offgas from thermal treatment processes (e.g., calcination) being considered for treatment of INTEC high level waste (HLW) streams. A number of tests were performed with this end in mind.

\subsection{Test Objectives}

The major objectives of the testing described herein were as follows:

- Determine whether or not silica gel, washed with water or nitric acid, is effective in removal of gaseous mercury (oxidized or elemental) from the gas phase;

- Determine whether the commercial complexing agent, TMT $^{2}$ (TriMercapto-s-Triazine) can be used to precipitate mercury from sodium bearing waste (SBW) prior to treatment ${ }^{b}$ by another process (e.g., calcination or cesium ion exchange followed by grouting);

- Determine whether TMT can be used in solution as a secondary scrubbing agent to reduce mercury concentrations gas streams to MACT-compliant levels.

- Manufactured and marketed by Degussa Corporation.

b As noted above, the main report suggests the use of TMT to remove Hg from NWCF scrubbing solution. However, at the request of the HLW projects manager for this task, the focus of this effort was redirected away from NWCF and toward cesium ion exchange treatment of SBW followed by grouting. Therefore, the testing was directed toward removal of $\mathrm{Hg}$ from SBW feed. 
- Determine the extent of oxidation of elemental $\mathrm{Hg}$ by $\mathrm{NO}_{2}$ in a surrogate $\mathrm{NWCF}$ offgas, and measure the scrubbing efficiency of silica gel in removing the $\mathrm{Hg}$ subsequent to oxidation.

\subsection{Acronyms}

The following acronyms and abbreviations have been used throughout this report:

$\begin{array}{ll}\text { AAS } & \text { Atomic Absorption Spectrometer } \\ \text { HLW } & \text { High Level (radioactive) Waste } \\ \text { INTEC } & \text { Idaho Nuclear Technology and Engineering Center } \\ \text { NWCF } & \text { New Waste Calcining Facility } \\ \text { RSD } & \text { Relative Standard Deviation } \\ \text { SG } & \text { Silica Gel } \\ \text { SBW } & \text { Sodium Bearing Waste } \\ \text { SS } & \text { Stainless Steel } \\ \text { TMT } & \text { TriMercaptoTriazine }\end{array}$

\section{TEST SETUP}

\section{$2.1 \quad$ Test Bed}

The testing desribed in this report was performed in TRA-661 during August and September, 1999. We used two test beds to perform the testing. The first test bed was used to investigate the precipitation of $\mathrm{Hg}$ from an aqueous sodium bearing waste surrogate. It consisted of typical lab scale mixing vessels (beakers, test tubes, etc.) in which the surrogate waste was blended with the precipitating agent (TMT). Subsequent to the introduction of TMT, the mixture was shaken (manually and/or mechanically in a rocker) and allowed to react for 10 minutes to 24 hours. The resulting mixture of solids and liquids were then centrifuged and the supernatant liquids decanted and analyzed using the methods described in Section 2.2 .

We used the second test bed to study the Hg scrubbing schemes described above. The basic setup is shown schematically in Figure 1 . The configuration shown was slightly modified in a number of the tests to investigate the effects of different parameters on the scrubbing process. For example, the size of the delay flask for $\mathrm{Hg}$ oxidation was varied to assess the effect of kinetic limitations. The line supplying scrub solution was sometimes removed from the scrub solution flask to determine whether scrubbing can be accomplished directly on a solid surface. The bubbler used to humidify the offgas was sometimes removed completely to assess the impact of moisture on the oxidation and scrubbing processes. Finally, the tubing used to transport the gases through the test bed was varied between tygon, stainless steel (SS), and glass to assess the impacts of the materials with which the offgas has contact.

The portion of the testbed in which the $\mathrm{Hg}$ oxidation and scrubbing processes were investigated were housed in a somewhat modified standard laboratory drying oven. Supply lines for the gases and 
liquids were threaded through holes in the walls of the oven drilled for that purpose. The oven is thermostatically controlled and a standard mercury thermometer was inserted through a hole in the oven roof to monitor temperature. A computer cooling fan was placed inside the oven both to decrease the system's temperature re-equilibration time when the door was opened/closed and reduce spatial temperature variations. It was noted during the testing that the oven thermostat had a fairly large temperature hysteresis resulting in temperature swings as high as $\pm 10^{\circ} \mathrm{C}$ around the setpoint (usually $70^{\circ} \mathrm{C}$ ). (These swings were more typically on the order of $\pm 5^{\circ} \mathrm{C}$.) To reduce the impact of air temperature variations we placed the $\mathrm{Hg}$ and $\mathrm{NO}_{2}$ generators in a water bath inside the oven.

Most flows were controlled using an Ismatec peristaltic pump purchased from Cole-Parmer. This pump was equipped with an 8-channel pumping head, and eight different sizes of tubing, ranging from $0.19-2.79 \mathrm{~mm}$ ID were used to obtain the required flow rates. The pump speed was digitally controlled and could be varied by a factor of 99 . A rotameter was calibrated and used to control the bulk flow rate of the air component of the synthetic offgas. Water to humidify that gas was introduced in most of the tests by bubbling the bulk air flow through liquid water in a bubbler situated within the oven. In those tests it was assumed that the air emerging from the bubbler was saturated (again typically at $70^{\circ} \mathrm{C}$ ). In some tests, however, the air was humidified by metering a small amount of water pump into the SS tube through which the bulk air flow was introduced into the oven. 
Figure 1: Schematic of scrubber test bed.

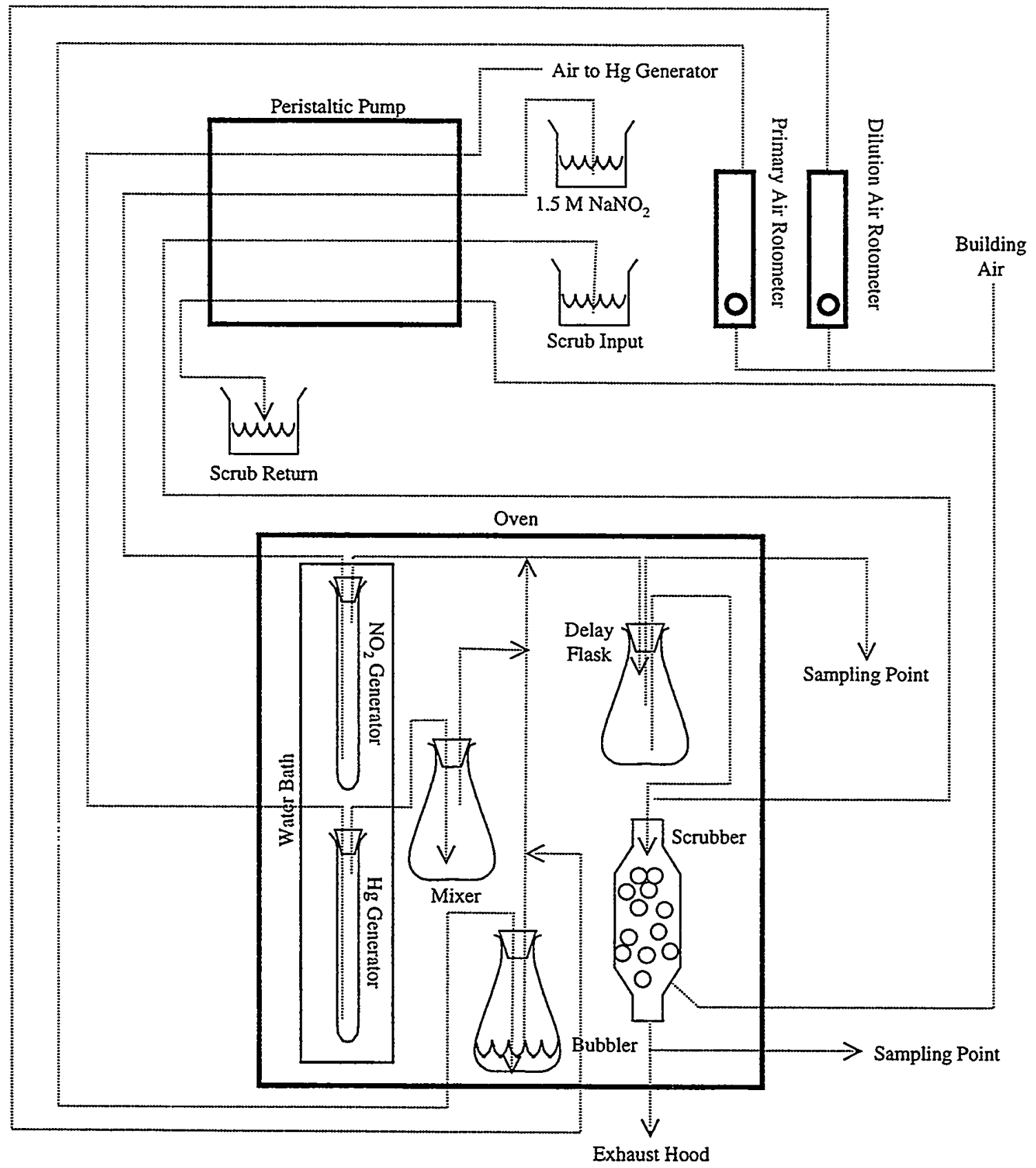

Gaseous forms of $\mathrm{Hg}$ were produced by saturating a prescribed flow rate of air by passing it through either a bed of crystalline mercuric chloride or liquid mercury metal which had been dispersed over glass wool. In both cases we placed a small quantity of glass wool in the bottom of the generator (i.e., test tube) and inserted the bleed air line into that wool, forcing the air to flow upward through the mercuric chloride/mercury metal. This gas (generally a few cc's per minute) was controlled by the peristaltic pump and bled into the bulk moisture-laden air flow to achieve the desired concentration of $\mathrm{Hg}$ in the simulated offgas.

Finally, nitrogen dioxide was added by reaction of nitric oxide with the oxygen of the air. The NO was was generated by pumping a controlled flow rate of $\mathrm{NaNO}_{2}$ (typically a $1.5 \mathrm{M}$ solution) into a 
strong solution of $\mathrm{Fe}_{2}\left(\mathrm{SO}_{4}\right)_{3}$ and dilute $\mathrm{H}_{2} \mathrm{SO}_{4}$. The resulting reaction quantatively reduces $\mathrm{NO}_{2}^{-}$to $\mathrm{NO}$ gas, which immediately disengages from the liquid and flows through a tube to a "tee" in the main gas line.

We sampled the gas stream at two or three locations as shown in the schematic. Small-bore teflon tubes were threaded through the tygon tubing lines or through the rubber stoppers so that gas samples could be drawn from either the mixing flask, the scrubber inlet, or the scrubber outlet with glass syringes. To do a rough speciation of the $\mathrm{Hg}$ we measured both elemental and total $\mathrm{Hg}$ using a cold vapor atomic absorption spectroscopic technique. The concentration of oxidized $\mathrm{Hg}$ was obtained by difference.

\subsection{Analytical Methods}

The analytical system for mercury consisted of a standard Varian Techtron atomic absorption spectrometer (AAS) with a long pathlength quartz-windowed cuvette in the optical path. The cuvette is $17 \mathrm{~cm}$ long with an internal volume of $27 \mathrm{cc}$. Both the inlet and the outlet of this cuvette (located at opposite ends of the tube) are fitted with plugs of glass wool to keep dust and droplets of liquid out of the light path and to slow the diffusion of mercury vapor from the cuvette. A 0.05 " ID hard teflon tube is connected to the inlet end of the cuvette. The other end of the tubing is fitted with a "swinney adaptor", a device to which a standard syringe may be connected.

To use the AAS to determine mercury in a gas sample, we injected a syringe filled with sampled gas (typically $10 \mathrm{cc}$ ) into the cuvette, and read the AAS response. The AAS responds only to elemental mercury vapor and is completely "blind" to any form of oxidized mercury, volatile or otherwise. To detect mercury in a form other than elemental, it must first be reduced to elemental form and stripped out of the phase which contains it (usually gas or aqueous) and into a suitable gas phase (one which is optically transparent and unreactive to mercury vapor--generally air, nitrogen, argon, etc.). If the mercury in question is reasonably labile and is not accompanied by species that form strong complexes with mercury (e.g., iodide, sulfide), the whole sample preparation sequence can be done in the same syringe. This is how we did it in these tests, using roughly $0.3 \mathrm{cc}$ of a $2-3 \mathrm{wt} \% \mathrm{SnCl}_{2} /$ dilute $\mathrm{HCl}$ reducing solution to obtain a measurement of the total mercury concentration (elemental and oxidized) in the gas. Blanks were taken periodically by inspiring room air into the syringe and analyzing its elemental and/or total $\mathrm{Hg}$ content.

To use the AAS to determine mercury in a liquid sample we first treated the sample with an oxidant (potassium permanganate plus nitric acid) to destroy possible interferences from dissolved organics (e.g., TMT) and/or particulates. The sample was then contacted with the same $\mathrm{SnCl}_{2} /$ dilute $\mathrm{HCl}$ reducing solution as was used for the gas analyses to reduce all of the $\mathrm{Hg}$ to the volatile elemental form. As discussed in footnote $\mathrm{c}$, elemental $\mathrm{Hg}$ in an aqueous mixture readily partitions between liquid and gas phases such that roughly $2 / 3$ of the total resides in the liquid and $1 / 3$ in the gas (assuming equal volumes of gas and liquid). Thus, by contacting the liquid sample with a volume of air about thirty times that of the liquid we were able to isolate about $93 \%$ of the initial $\mathrm{Hg}$ in the gas phase. This gas sample was then injected into the AAS to determine the total amount of $\mathrm{Hg}$ originally present in the liquid sample, and thus its concentration.

\subsection{Test Procedures}

\subsubsection{Preliminary Tests}

We performed three different types of test. The first of these were simply preliminary exploratory tests to develop the method to generate a suitable gaseous $\mathrm{Hg}$ stream. The tests were done by 
dissolving reagent grade $\mathrm{HgCl}_{2}$ crystals in water, and pipetting samples of this mixture into stoppered glass bottles placed in the oven. Gas samples were drawn by quickly unstoppering the bottles and drawing headspace samples with a syringe fitted with a long needle. Additional detail on this procedure is provided in Section 3.1.1.

\subsubsection{Aqueous Hg Precipitation Tests}

The second type of experiments measured the degree of precipitation of $\mathrm{Hg}^{+2}$ from aqueous surrogate waste solutions. For these tests we first made a surrogate waste mixture using reagent grade chemicals, distilled water, and concentrated $\mathrm{HNO}_{3}$. To obtain a recipe for this mixture we started with the composition data in Refs. 3 and 4. Reference 3 gives the current (concentrated) composition of SBW in tank WM-180, and Ref. 4 gives projected concentrations from blending and evaporating WM-186 \& WM-181 and WM-184 \& WM-181. These data were used to obtain a volume averaged composite composition for SBW. (Concentrations of $\mathrm{Cd}^{+2}$ and $\mathrm{Pb}^{+2}$, which aren't given in Ref. 4, were calculated from the volume reduction factor [based on the concentrations of aluminum given in Ref. 4] together with the unevaporated concentrations given in Ref. 3.) The resulting composite composition is given in Table 1, below:

\begin{tabular}{|c|c|c|c|c|c|c|c|}
\hline & $\mathrm{MW}$ & units & WM-180 & \multicolumn{2}{|c|}{ WM-186/181|WM-184/181 } & \multicolumn{2}{|c|}{\begin{tabular}{|l|l|l} 
Volume Avg & Max Conc \\
\end{tabular}} \\
\hline & & & & & & & \\
\hline Date & & & $2 / 93$ & $2 / 93,3 / 98$ & $2 / 93,11 / 98$ & & \\
\hline Volume & & $\mathrm{gal}$ & 275900 & 184000 & 233000 & 692900 & \\
\hline SpG. & & & $1.26 E+\infty$ & & & & \\
\hline $\mathrm{H}_{+}$ & 1.008 & $N$ & $1.14 \mathrm{E}+\infty$ & $3.35 E+\infty$ & $287 E+\infty$ & $231 E+00$ & $3.35 E+\infty$ \\
\hline NOB- & 62.0052 & $\mathrm{M}$ & $4.56 \mathrm{E}+\infty$ & $7.80 E+00$ & $7.70 E+\infty 0$ & $6.48 E+\infty$ & $7.80 E+\infty$ \\
\hline a- & 35.453 & $\bar{M}$ & $4.20 \mathrm{E}-02$ & $3.16 \mathrm{E}-02$ & $3.84 E-02$ & $3.80 E-02$ & 4.20E-02 \\
\hline $\mathrm{F}-$ & 19 & $\mathrm{M}$ & $3.10 E-02$ & 1.44E-01 & $8.80 E-02$ & $8.02 E-02$ & $1.44 \mathrm{E}-01$ \\
\hline $\mathrm{A}+3$ & 26.98 & $\mathrm{M}$ & $6.30 \mathrm{E}-01$ & $6.40 \mathrm{E}-01$ & 8.04E-01 & $6.91 \mathrm{E}-01$ & $8.04 E-01$ \\
\hline $\mathrm{Na+1}$ & 229898 & $\overline{\mathrm{M}}$ & $200 E+\infty$ & $221 E+00$ & $226 \mathrm{E}+00$ & $214 E+00$ & $226 E+00$ \\
\hline$K+1$ & 39.102 & $M$ & $1.80 E-01$ & $3.60 \mathrm{E}-01$ & 2.00E-01 & $235 \mathrm{E}-01$ & $3.60 E-01$ \\
\hline $\mathrm{Ca}+2$ & 40.08 & $M$ & $3.40 \mathrm{E}-02$ & $4.60 E-02$ & $4.95 E-02$ & $4.24 E-02$ & $4.95 E-02$ \\
\hline $\mathrm{Fe}+3$ & 55.85 & $M$ & $1.80 \mathrm{E}-02$ & $4.70 E-02$ & $3.14 \mathrm{E}-02$ & $3.02 E-02$ & $4.70 \mathrm{E}-02$ \\
\hline $\mathrm{Cd}+2$ & 1124 & $M$ & $8.01 E-04$ & $1.90 \mathrm{E}-02$ & $1.40 E-02$ & $1.01 \mathrm{E}-02$ & $1.90 E-02$ \\
\hline $\mathrm{a}+7$ & 52 & $M$ & $3.81 E-03$ & $241 E-03$ & $1.80 \mathrm{E}-03$ & $276 E-03$ & $3.81 E-03$ \\
\hline $\mathrm{Hg}+2$ & 200.59 & $\bar{M}$ & $9.72 E-04$ & $1.90 \mathrm{E}-03$ & $1.17 \mathrm{E}-03$ & $1.29 E-03$ & $1.90 E-03$ \\
\hline $\mathrm{Pb}+2$ & 207.19 & $M$ & 1.40E-03 & $1.57 \mathrm{E}-03$ & $1.05 \mathrm{E}-03$ & $1.33 E-03$ & $1.5 / \mathrm{E}-03$ \\
\hline & & & & & & & \\
\hline & & & & & & & \\
\hline Vol redfa & & & & 257 & 1.97 & & \\
\hline A (calcul & ted) & & & 0.641 & 0.804 & & \\
\hline
\end{tabular}

Table 1: Composite composition of SBW.

We made a SBW surrogate based on the maximum concentrations for the three liquid streams (WM-180, WM-186/181, and WM-184/181) listed in column 9 of Table 1. Fluoride, calcium, iron, and chromium were not included in the surrogate because we felt their presence would not materially alter the results. The sodium concentration was increased to represent the combined alkali content $\left(\left[\mathrm{Na}^{+}\right]+\left[\mathrm{K}^{+}\right]\right)$ 
in the last column of Table 1. The resulting composition of the basic SBW surrogate used for the main precipitation tests is given below in Table 2 .

Table 2: Composition of surrogate SBW used in tests.

\begin{tabular}{|l|ll|}
\hline $\mathrm{H}+$ & 2.7 & $\mathrm{M}$ \\
\hline $\mathrm{NO3}-$ & 7.7 & $\mathrm{M}$ \\
\hline $\mathrm{Cl}-$ & 0.043 & $\mathrm{M}$ \\
\hline $\mathrm{F}-$ & 0 & $\mathrm{M}$ \\
\hline $\mathrm{Al}+3$ & 0.8 & $\mathrm{M}$ \\
\hline $\mathrm{Na}+$ & 2.6 & $\mathrm{M}$ \\
\hline $\mathrm{K}+$ & 0 & $\mathrm{M}$ \\
\hline $\mathrm{Ca}+2$ & 0 & $\mathrm{M}$ \\
\hline $\mathrm{Fe}+3$ & 0 & $\mathrm{M}$ \\
\hline $\mathrm{Cd}+2$ & 0.02 & $\mathrm{M}$ \\
\hline $\mathrm{Cr}+7$ & 0 & $\mathrm{M}$ \\
\hline $\mathrm{Hg}+2$ & 0.0017 & $\mathrm{M}$ \\
\hline $\mathrm{Pb}+2$ & 0.0012 & $\mathrm{M}$ \\
\hline $\mathrm{SpG}$ & 1.316 & $\mathrm{M}$ \\
\hline
\end{tabular}

We performed the precipitation tests by mixing small aliquots $(-10 \mathrm{cc})$ of the SBW surrogate with TMT (plus other reagents, e.g., $\mathrm{NaOH}$ for some tests) in a plastic $50 \mathrm{cc}$ centrifuge tube. We shook the mixtures manually to effect mixing, and in other instances placed them in a mechanical "rocker". The mixtures were allowed to react for from several minutes to several hours. We then observed the precipitation behavior, centrifuged down the solids, and decanted sufficient supernate to measure its $\mathrm{Hg}$ concentration. Additional detail for these tests is provided in Section 3.2.1.1.

\subsubsection{Hg Oxidation/Scrubbing Tests}

The third type of test we performed were gaseous $\mathrm{Hg}$ scrubbing tests. In these tests we attempted to make a surrogate offgas which was representative of that emitted from NWCF. The composition was based on 32 slipstream gas samples taken from NWCF in September, 1993 and reported in Reference 3. These measurements are summarized in Table 3, below. The offgas is also known to be nearly saturated with water vapor at a temperature of about $160^{\circ} \mathrm{F}\left(71^{\circ} \mathrm{C}\right)$.

To make the offgas surrogate, we started with a bulk air flow of $250-300 \mathrm{cc} / \mathrm{min}$, measured with a standard rotameter. This air was humidified by bubbling it through liquid water in a stoppered flask at thermal equilibrium inside the drying over. To control condensation of liquid water a second (smaller) bulk air stream was metered through a second rotameter into the humidified air from the bubbler. In some tests an alternative means of humidifying the air was used where water was pumped directly into a $1 / 8$ " SS tube through which the bulk air stream was also routed. The tube was inside the oven and efficient vaporization of the water water into the air stream was obtained.

Mercury was added to the bulk stream by vaporizing elemental $\mathrm{Hg}$ or $\mathrm{HgCl}_{2}$ from a test tube. This tube contained either liquid $\mathrm{Hg}$ or crystalline $\mathrm{HgCl}_{2}$ through which a small stream of air $(-7 \mathrm{cc} / \mathrm{min})$ was pumped. The gas so-produced was essentially saturated with $\mathrm{Hg}$ or $\mathrm{HgCl}_{2}$ at the vapor pressure corresponding to the oven temperature of $70^{\circ} \mathrm{C}$. This gas was then introduced into the humidified air stream. 
We introduced $\mathrm{NO}_{2}$ into the humidified, $\mathrm{Hg}$-containing air by introducing $\mathrm{NO}$ into a separate air stream and allowing it to oxidize. The $\mathrm{NO}$ stream was produced by reducing $\mathrm{NaNO}_{2}$ with $\mathrm{Fe}_{2}\left(\mathrm{SO}_{4}\right)_{3}$ and dilute $\mathrm{H}_{2} \mathrm{SO}_{4}$. This reaction was assumed to be quantitative, with the acididifed ferrous sulfate in excess. Thus, the rate of production of $\mathrm{NO}_{2}$ was dictated by the flow rate of a $1.5 \mathrm{M}$ solution of $\mathrm{NaNO}_{2}$ into a test tube reactor containing the $\mathrm{FeSO}_{4} / \mathrm{H}_{2} \mathrm{SO}_{4}$ solution. This reactor was sealed with a rubber stopper through which the $\mathrm{NaNO}_{2}$ feed tube and and offgas tube were inserted. The flow rate of the nitrite solution was set to attain an total $\mathrm{NO}_{x}$ (mostly $\mathrm{NO}_{2}$ ) concentration of $15,000-25,000 \mathrm{ppm}$ in the surrogate offgas.

We had also planned to introduce $\mathrm{CO}$ into the offgas, to see if it might act as a reducing agent in opposition to the oxidizing $\mathrm{NO}_{2}$. However, testing done at ADA Technologies ${ }^{2}$ under conditions otherwise similar to ours used $\mathrm{CO}$ at concentrations of $7,000 \mathrm{ppm}$ and a temperature of $150^{\circ} \mathrm{C}$. They observed rapid and apparently complete oxidation of elemental mercury by the $\mathrm{NO}_{\mathrm{x}}$ in spite of the presence of $\mathrm{CO}$. Therefore, we assumed that $\mathrm{CO}$ would not materially alter our results, and did not include it in our offgas. Finally, no attempt was made to control $\mathrm{NO}_{x}$ speciation to the exact levels indicated in Table 3. The levels of the various $\mathrm{NO}_{\mathrm{x}}$ species were wholly dictated by the degree of the added NO's reactions with the oxygen (and possibly also with water - to form nitric acid)

The blended offgas containing air, $\mathrm{Hg}$ (or $\mathrm{HgCl}_{2}$ ), $\mathrm{H}_{2} \mathrm{O}$, and $\mathrm{NO} / \mathrm{NO}_{2}$ was generally allowed to react in a closed delay vessel, prior to scrubbing. The volume of the delay vessel was varied (from 0 to $1000 \mathrm{cc}$ ), giving a range of reaction times of less than 1 sec to about 2 min. During this time a distinctive yellow color was noted inside the delay vessel, clearly indicating the presence of $\mathrm{NO}_{2}$. After flowing through the delay vessel the gas was passed through a cylindrical glass scrubber, filled with fine SG (30-60 mesh). The SG was either dry, moist, or continuously washed with pumped liquid (water or $4 \mathrm{M} \mathrm{HNO}_{3}$ ). Gas flow through the SG was cocurrent with the scrub solution.

The effectiveness of the oxidation/scrubbing process was determined by comparing the scrubber inlet and outlet mercury concentrations. These were measured as described in Section 2.2. Generally, we hoped to obtain both the elemental $\mathrm{Hg}$ concentration (injecting the sampled gas directly into the AAS) and the total $\mathrm{Hg}$ concentration (contacting the sampled gas with $\mathrm{SnCl}_{2}$ /dilute $\mathrm{HCl}$ before injecting it into the $\mathrm{AAS}$ ). However, this goal was not accomplished in all the tests.

Table 3: NWCF offgas composition, based on 1993 slipstream measurements.

\begin{tabular}{|l|c|c|c|}
\hline & NO2 & NO & CO \\
\hline Mean & 1.55 & 0.32 & 0.53 \\
\hline Std Dev & 0.42 & 0.09 & 0.15 \\
\hline Max & 24 & 0.56 & 0.92 \\
\hline Mn & 0.68 & 0.12 & 0.375 \\
\hline & & & \\
\hline Mean(ppm) & 15453 & 3213 & 5270 \\
\hline Max(ppm) & 24000 & 5600 & 9200 \\
\hline Mn(ppm) & 6800 & 1200 & 3750 \\
\hline
\end{tabular}




\section{TESTING}

\subsection{Preliminary Tests}

In designing the scrubbing tests we originally assumed that mercury is present in the NWCF offgas as $\mathrm{HgCl}_{2}$. This assumption is based on conversations with INTEC Process Development personnel and others over the past 3-4 years. On the strength of this assumption we attempted to devise a method to produce a surrogate offgas with $\mathrm{HgCl}_{2}$ as the mercury species to be scrubbed. The method originally considered was to dissolve solid $\mathrm{HgCl}_{2}$ in distilled water and then evaporate the solution inside an airpurged container placed in the drying oven. In investigating this procedure a number of observations were made as described below.

\subsubsection{Test Description}

This test was a simple bench top attempt to generate a stable and measurable concentration of $\mathrm{HgCl}_{2}$ in the gas phase. To this end we heated two $300 \mathrm{cc}$ dry glass stoppered Winkler bottles in the drying oven to $70^{\circ} \mathrm{C}$. One bottle had a short length of glass tubing in its bottom and the other had a planchet of SS metal (roughly $3 \mathrm{~cm}^{2}$ and $0.050^{\prime \prime}$ thick). We pipeted $20 \mu \mathrm{L}$ aliquots of a $54 \mu \mathrm{g} / \mathrm{cc}$ mercury-in-water solution $\left(73 \mu \mathrm{g} / \mathrm{g} \mathrm{HgCl}_{2}\right.$ ) into each bottle and quickly replaced the stoppers. The solution in the second bottle was placed on the SS rather than on the glass. After the liquid had completely evaporated in both bottles (neither left a visible spot), the bottles were shaken with the glass tubing/SS planchet inside to mix the gases. The gases were then analyzed by first extracting $10 \mathrm{cc}$ samples via a $0.7 \mathrm{~mm}$ OD, flexible teflon tube attached to a glass syringe and then doing the elemental and total $\mathrm{Hg}$ determination described in Section 2.2. The results were as follows.

- In both cases, the same atomic absorbance response 'was noted ${ }^{\mathrm{c}}$ whether or not the gas was contacted with stannous chloride before injection into the cuvette.

- AAS responses for samples evaporated from the glass surface were much smaller than for those evaporated from SS. The resporises suggested that roughly $10 \%$ and $50 \%$, respectively, of the mercury initially put into the two bottles was in the gas phase and all of it was present as elemental $\mathrm{Hg}$ (rather than $\mathrm{HgCl}_{2}$, as was expected).

- Several $10 \mathrm{cc}$ samples could be taken from the bottles before the AAS responses began to decrease significantly.

- As long as the stopper was kept in place, the concentration of mercury in the gas phase seemed quite stable for at least half an hour after the original droplet of liquid had evaporated.

- When the gas phase in the first bottle (with the glass tubing) had been blown out and the bottle cooled and washed with diluted aqua regia, the resulting liquid was analyzed and found to contain roughly $90 \%$ of the mercury originally added to the bottle.

c Actually the "total $\mathrm{Hg}$ " measurement was slightly lower. This is because the distribution coefficient of $\mathrm{Hg}$ vapor between room temperature air and water solutions is about 0.45 ; i.e., if $\mathrm{Hg}$ vapor is equilibrated between equal volumes of air and water, just over twice as much of it will end up in the water as in the air. In these analyses, we typically used about 30 times as much air as liquid. Thus, $>93 \%$ of the mercury would reside in the gas phase that was injected into the cuvette and measured. 
- $1.5 \mathrm{cc}$ of pure NO was injected into the bottle containing the SS planchet. The bottle was then restoppered and its gas phase elemental mercury concentration monitored several times thereafter. The NO quickly oxidized to $\mathrm{NO}_{2}$ as indicated by a yellowish tinge in the bottle. Two gas analyses done immediately before the NO addition gave elemental $\mathrm{Hg}$ responses of 0.229 and 0.233 absorbance units. Responses at 30 seconds, 1 minute, and two minutes, after the NO addition were $0.141,0.039$, and 0.013 abs units, respectively, indicating rapid decay of the concentration of elemental Hg.

\subsubsection{Discussion of Results}

The above observations suggest that essentially none of the mercury in the gas phases in either bottle was mercuric chloride vapor. Thus, it appears that $\mathrm{HgCl}_{2}$ dissolved in water cannot be evaporated from either steel or glass surfaces into air. Moreover, the fact that elemental mercury was detected in both bottles would indicate that $\mathrm{Hg}^{+2}$ was reduced in some way by the processes in both bottles, with the steel surface having a stronger reducing tendency than the glass surface.

The last test involving the NO injection suggests that mercury vapor is quickly oxidized by $0.5 \%$ $\mathrm{NO}_{2}$ at $70^{\circ} \mathrm{C}$.

\subsubsection{Conclusions}

From these preliminary tests we concluded, first, that the originally-planned approach to generate a surrogate offgas stream containing $\mathrm{HgCl}_{2}$ is not feasible. An alternative scheme whereby a small air stream is bled through a heated bed of $\mathrm{HgCl}_{2}$ and loaded to saturation was tried in its place.

Second, the difficulty experienced in generating $\mathrm{HgCl}_{2}$ vapor suggests that gaseous $\mathrm{HgCl}_{2}$ in contact with steel (or glass) surfaces may be efficiently scavenged. If this conjecture is correct, it may be very easy to extract $\mathrm{HgCl}_{2}$ from the gas phase by suitable contact with a second phase (e.g., silica gel or water).

Third, from these results we reasoned that it may be possible to water-scrub most of the Hg out of any offgas containing a high concentration of $\mathrm{NO}_{2}$, provided an efficient gas/liquid contactor system is used. If this approach were utilized in NWCF, where the scrub solution is recycled, the high $\mathrm{NO}_{2}$ concentration in the offgas would acidify the scrub water. This being the case, all volatile forms of $\mathrm{Hg}$ (elemental $\mathrm{HgCl}_{2}$ ) as well as $\mathrm{Hg}$-bearing particulates could possibly be oxidized, and thus efficiently removed with a secondary wet scrubber. The scrub water could then be recycled back to the NWCF feed (or the main scrub tank). Mercury could be permanently removed from the concentrated scrub liquor (e.g., by electrodeposition).

This approach might also be used in any new waste treatment facility for calcine where denitration of liquid wastes is performed prior to vitrification and/or grouting. In that case, the scub liquor would not be recycled but would be treated to remove mercury and then disposed. This treatment might be effected with the use of a suitable precipitating agent. (However, treatment of the scrubber liquor is beyond the scope of the present study.)

\subsection{Removal of $\mathrm{Hg}^{+2}$ From Aqueous SBW}

As discussed in Section 2.2 of the main report, scoping lab tests by Degussa personnel indicated that at 3.5 $\mathrm{M} \mathrm{HNO}_{3}$, TMT could effectively precipitate $\mathrm{Hg}^{+2}$ out of solution. Our testing was directed at obtaining corroborating data with a more realistic SBW surrogate. 


\subsubsection{Direct Precipitation of $\mathrm{Hg}^{+2}$ from SBW with TMT}

\subsubsection{Test Description}

We started by blending a clear SBW simulant solution as described previously in Section 2.3.2. The TMT solution used to precipitate $\mathrm{Hg}^{+2}$ was obtained from D.R. Haefner, who had used "TMT-15" in mercury precipitation tests earlier this year. (One of Degussa's chemists ${ }^{d}$ had indicated that TMT is stable in solution, so we assumed that Haefner's material was acceptably pure). The TMT-15 was a clear, slightly yellow, aqueous solution. Degussa literature indicates it has a SpG of 1.12, and contains $15 \mathrm{wt} \%$ of TriMercapto-s-Triazine (molecular weight $=243$ ) implying a concentration of $0.69 \mathrm{M}$ of TMT in the TMT-15 solution.

Degussa also indicates that the stoichiometry of TMT's reaction with divalent "heavy" metal cations involves 2 moles of TMT per three moles of metal. Based on this information we added 0.272 gm $(0.243 \mathrm{cc})$ of TMT solution to $10 \mathrm{cc}(13.16 \mathrm{gm})$ of the SBW simulant in a $50 \mathrm{cc}$ plastic centrifuge tube, yielding a 10\% stoichiometric excess of TMT assuming it reacts with all three of the divalent heavy metals $(\mathrm{Hg}, \mathrm{Cd}$, and $\mathrm{Pb})$ in the simulant. A voluminous yellow-white prepititate immediately formed and a sharp sulfur dioxide-like odor was apparent. After capping the tube, we shook it thoroughly and left it to sit at room temperature $\left(-64^{\circ} \mathrm{F}\right)$ for about half an hour. After that time there appeared to be less precipitate than had initially formed and gas bubbles lined the walls of the tube and tended to float the precipitate. The temperature of the solution in the tube was $2^{\circ} \mathrm{F}$ higher than the room, and the tube's headspace gas was distinctly yellow in color-evidence that nitrate was being reduced by the TMT to form $\mathrm{NO}_{2}$. We then centrifuged the precipitate, took a small aliquot of the clear supernate, treated it with potassium permanganate plus nitric acid to destroy possible interferences, and then measured the concentration of mercury using the AAS. The concentration was $0.0017 \mathrm{M}$, identical to that of the original simulant.

\subsubsection{Discussion of Results}

The test suggests that the TMT is not able to precipitate $\mathrm{Hg}^{+2}$ from the surrogate SBW. When we reached this conclusion we contacted Degussa to discuss the apparent conflict between our test results and their earlier reported results using only $3.5 \mathrm{M} \mathrm{HNO}_{3}$ and $\mathrm{Hg}^{+2}$ (see Section 2.2 of the main report). After this discussion we decided to modify the test slightly by (a) reducing the total salt concentration in the SBW surrogate (this would correspond to un-evaporated, blended SBW), and (b) adding sulfamic acid to suppress oxidation of the TMT. We repeated the steps described above with a $10 \mathrm{cc}$ aliquot of the SBW simulant after a 2:1 dilution with distilled water. Since the heavy metal concentration was halved, we also halved the amount of TMT added. The reaction tube was shaken in a mechanical "rocker" for half an hour before the phases were separated. In this case there was no evidence of oxidation of the TMT (no heat, no gas evolution, etc.) but the liquid phase after the precipitation still contained nearly all of the mercury $(-87 \%)$.

We then redid the experiment with undiluted SBW simulant after first adding sulfamic acid. (The acid scavenges the nitrosyl intermediate produced by autocatalytic $\mathrm{HNO}_{3}$ oxidations, thereby preventing redox-type reactions like the TMT oxidation). As before, a significant amount of precipitate was formed but this time with no evidence of oxidation. Measurement of the mercury concentration in the supernate indicated that the liquid phase still contained most of the mercury ( $-65 \%$, initially).

Finally, we repeated the above tests using twice as much TMT. After twenty minutes of shaking, the prepipitates were centrifuged and the supernates analyzed. The results were essentially the same as

d Ernie Haug. 
before--virtually all the mercury remained in solution (85\% of the $\mathrm{Hg}$ in the diluted mixture and $70 \%$ in the undiluted one).

\subsubsection{Conclusions}

Based on the above tests TMT will precipitate only a minor fraction of the $\mathrm{Hg}^{+2}$ in the SBW. Based on the appearance of the precipitates that were formed and the fact that TMT is highly insoluble at $\mathrm{pH}<4.5$ it is likely that the precipitate which formed was the acid form of the TMT reagent, itself. Moreover, unless a "stabilizer" (e.g. urea or sulfamic acid) is added to the solution, the TMT is apparently oxidized by the solution. Based on Degussa's successful precipitation of $\mathrm{Hg}^{+2}$ when only $3.5 \mathrm{M} \mathrm{HNO}_{3}$ and $\mathrm{Hg}^{+2}$ are present, this oxidation may be caused by the high concentration of $\mathrm{NO}_{3}{ }^{-}$in our surrogate, and/or the presence of other potentially catalytic cations $\left(\mathrm{Al}^{+3}, \mathrm{Na}^{+}, \mathrm{Pb}^{+2}\right.$, and $\left.\mathrm{Cd}^{+2}\right)$. Based on discussion of our results with Degussa the reason for poor precipitation of $\mathrm{Hg}^{+2}$ in the surrogate SBW may

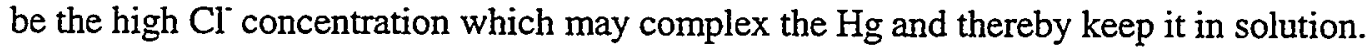

\subsubsection{Precipitation of $\mathrm{Hg}^{+2}$ from SBW with TMT Following Neutralization}

As described in Section 3.2.1, direct precipitation of $\mathrm{Hg}^{+2}$ from SBW simulant with TMT appears to be infeasible. In a discussion with Degussa of our test results it was pointed out that TMT works best above a pH of about 4.5. On this basis we decided to consider partial neutralization of the SBW prior to precipitation with TMT. This option looked potentially attractive as an SBW pretreatment prior to grouting, since some of the grouting recipes under consideration involve neutralization of the liquid waste with $\mathrm{CaO}$ as part of the grouting process. Thus, a test was performed to assess the ability of TMT to remove $\mathrm{Hg}^{+2}$ from partially neutralized SBW simulant.

\subsubsection{Test Description}

As before we started by blending a clear SBW simulant solution. The target composition of the solution for this test was the same as described in Section 2.3.2. The "as mixed" composition is given in Table 4, below.

Table 4: Composition of surrogate SBW used in partial neutralization tests.

\begin{tabular}{|l|ll|}
\hline $\mathrm{H}+$ & 2.5 & $\mathrm{M}$ \\
\hline $\mathrm{NO} 3-$ & 7.5 & $\mathrm{M}$ \\
\hline $\mathrm{Cl}-$ & 0.047 & $\mathrm{M}\left(\right.$ as $\left.\mathrm{CdCl}_{2}\right)$ \\
\hline $\mathrm{F}-$ & 0 & $\mathrm{M}$ \\
\hline $\mathrm{Al}+3$ & 0.81 & $\mathrm{M}$ \\
\hline $\mathrm{Na}+$ & 2.6 & $\mathrm{M}$ \\
\hline $\mathrm{K}+$ & 0 & $\mathrm{M}$ \\
\hline $\mathrm{Ca}+2$ & 0 & $\mathrm{M}$ \\
\hline $\mathrm{Fe}+3$ & 0 & $\mathrm{M}$ \\
\hline $\mathrm{Cd}+2$ & 0.021 & $\mathrm{M}$ (as $\left.\mathrm{CdCl}_{2}\right)$ \\
\hline $\mathrm{Cr}+7$ & 0 & $\mathrm{M}$ \\
\hline $\mathrm{Hg}+2$ & 0.0022 & $\mathrm{M}$ (as $\left.\mathrm{HgCl}_{2}\right)$ \\
\hline $\mathrm{Pb}+2$ & 0.001 & $\mathrm{M}$ (as acetate) \\
\hline $\mathrm{SpG}$ & 1.36 & $\mathrm{M}$ \\
\hline
\end{tabular}


For this test we neutralized part of the acid ${ }^{\mathrm{e}}$ with a $50 \mathrm{wt} \% \mathrm{NaOH}$ solution before adding the TMT. Sufficient caustic was added to neutralize $98 \%$ of the free acid. This step initially produced a significant quantity of precipitate; however, the mixture eventually cleared after about 30 minutes of agitation on a tube rocker. Due to aluminum hydrolysis, this partially neutralized solution was still strongly acidic, with a $\mathrm{pH}$ of -0.15 . We then added sufficient TMT solution for a $12 \%$ excess over the stoichiometric requirement again assuming all three of the heavy metals $(\mathrm{Hg}, \mathrm{Cd}$, and $\mathrm{Pb}$ ) react with it. As before, a creamy yellow precipitate immediately formed. After 15 minutes of agitation we centrifuged the precipitate, took an aliquot of the clear supernatant, treated it with oxidants to destroy possible interferences, and then determined its concentration of mercury as described in Section 2.2. Correcting for dilution from neutralization and TMT addition the $\mathrm{Hg}^{+2}$ concentration in the supernate was $0.0016 \mathrm{M}$. Thus, approximately $86 \%$ of the mercury was not precipitated by the TMT.

As noted in footnote $e$, it would not have been desirable to neutralize all the acid because that would have precipitated large amounts of $\mathrm{Al}(\mathrm{OH})_{3}$. However, if sufficient caustic were added to raise the $\mathrm{pH}$ above 12-13 it may be possible to redissolve all of the aluminum. This requires addition of four moles of hydroxide per mole of aluminum in addition to that required for the free acid. We tried this with three more aliquots of SBW simulant. We then added TMT to one of them and an additional $20 \%$ of the caustic solution to the last one. After about 15 minutes of agitation the reaction tubes were removed, centrifuged, and analyzed for mercury. The results are given in Table 5, below.

Table 5: $\mathrm{Hg}^{+2}$ precipitation test results at high $\mathrm{pH}$.

\begin{tabular}{|c|c|c|c|}
\hline & $\mathrm{NaOH}$ only & $\mathrm{NaOH}+\mathrm{TMT}$ & $\mathrm{NaOH}(120 \%)$ \\
\hline Total final volume, cc & -14.5 & -14.8 & -15 \\
\hline $\mathrm{pH}$ & 13.2 & 13.1 & 13.9 \\
\hline [Hg]aq, M & 0.0016 & 0.00049 & 0.0012 \\
\hline Fraction of $\mathrm{Hg}$ precipitated ${ }^{\mathrm{f}}$ & $0 \%$ & $66 \%$ & $18 \%$ \\
\hline Approximate volume of precipitate, cc & 2 & 2 & 0.5 \\
\hline
\end{tabular}

\subsubsection{Discussion of Results}

Table 5 indicates that in the fully-neutralized solutions, a single precipitation with TMT removed only about $2 / 3$ of the mercury and that hydroxide alone was completely ineffectual. The fact that TMT was able to remove a significant fraction of the mercury is consistent with Degussa's claim that the material performs better in non-acidic solutions. However, the concentration of $\mathrm{Hg}^{+2}$ is still orders of magnitude higher than concentrations attained by Degussa in waste water applications where the ionic

- We neutralized only the free acid moiety. The $\mathrm{pH}$ was not raised further because with real SBW a copious and permanent precipitate of the aluminum would have resulted. This precipitate would be large in volume, would absorb trace fission products, transuranics, and other waste components, and would be combined with any precipitate which might form from reaction of the heavy metals with the TMT. This would result in creation of a large quantity of mixed waste that would be difficult to dispose of and would thus be counterproductive to the purpose doing the $\mathrm{Hg}$ separation in the first place.

$f$ Corrected for dilution from the neutralization step. 
strengths are much lower. We presume that possible catalytic effects of other cations in solution and/or complexation of $\mathrm{Hg}^{+2}$ with the chloride (present in the SBW at roughly 20 times the concentration of $\mathrm{Hg}^{+2}$ ) are the cause of the degraded performance of TMT.

\subsubsection{Conclusions}

It is impractical to fully neutralize the SBW prior to precipitating $\mathrm{Hg}^{+2}$ from solution because of precipitation of $\mathrm{Al}(\mathrm{OH})_{3}$ which occurs between a pH of about 1 and 12 . With partial neutralization the performance of TMT is better than in the straight SBW simulant, but still only about $14 \%$ of the $\mathrm{Hg}^{+2}$ is removed from solution. With full neutralization the performance improves to about $66 \% \mathrm{Hg}^{+2}$ removal. However, these levels are probably not sufficient to ensure that grouted SBW will pass the TCLP test for $\mathrm{Hg}$.

In our opinion sulfide may be a better immobilization agent for mercury. Assuming that SBW will be grouted it would not be necessary to remove $\mathrm{HgS}$ from the pretreated SBW liquid. Mercuric sulfide would easily pass TCLP and would be permanently macroencapsulated by the grout. In addition, the $\mathrm{Hg}$ would be co-disposed with the grout rather than requiring a separate disposal procedure and disposal site.

\subsection{Removal of $\mathrm{Hg}^{+2}$ from the Gas Phase}

\subsubsection{Removal of $\mathrm{HgCl}_{2}$ by Gas Phase Scrubbing with TMT}

As discussed in Section 1.2, one of the objectives of this test program was to examine the use of TMT as a scrubbing agent to reduce $\mathrm{Hg}$ concentrations in present or future INTEC offgase streams to MACT-compliant levels. As noted in Section 3.1, we originally proposed this processing option on the assumption that it is $\mathrm{HgCl}_{2}$ (and not elemental $\mathrm{Hg}$ ) that must be "polished" from the NWCF offgas stream. On the strength of this assumption we attempted to evaluate the performance of TMT in removing $\mathrm{HgCl}_{2}$ from the gas phase. The testing to achieve that objective is described below.

\subsubsection{Test Description}

The test bed used for this test was described in Section 2.1. As discussed in Section 3.1, our early attempts to generate $\mathrm{HgCl}_{2}$ vapor by evaporating a liquid solution of $\mathrm{HgCl}_{2}$ were unsuccessful. We therefore used the $\mathrm{HgCl}_{2}$ vapor generator described in Section 2.1. In this setup we used SS tubing that had been rinsed with aqua regia. Because the vapor pressure for $\mathrm{HgCl}_{2}$ is significantly lower than for elemental $\mathrm{Hg}$ (see Ref. 6) it was necessary to bleed a larger air flow through the $\mathrm{HgCl}_{2}$ generator than for elemental $\mathrm{Hg}$. Even with this adjustment we were unable to obtain $\mathrm{Hg}$ concentrations in the gas phase above about $1,600 \mu \mathrm{g} / \mathrm{m}^{3}$. While this concentration is fairly representative of the $\mathrm{Hg}$ concentrations likely present in NWCF offgas ${ }^{7}$, it is difficult to reliably measure using the AAS method we employed. Moreover, we were unable to obtain stable measurements of elemental and total mercury concentrations at the inlet to the test scrubber setup. Therefore, no measurements were made downstream of the scrubber and no scrubbing efficiency assessment was possible for $\mathrm{HgCl}_{2}$.

\subsubsection{Discussion of Results}

One of the major objectives of the testing program was to evaluate the effectiveness of TMT as a scrubbing agent for $\mathrm{HgCl}_{2}$. That this objective was not realized was therefore disappointing. However, in retrospect it may not be significant. As noted in Section 3.1.3, from the preliminary tests done with 
$\mathrm{HgCl}_{2}$, it is suspected that $\mathrm{HgCl}_{2}$ vapor is readily scavenged by steel, glass, and possibly many other surfaces. This leads us to suspect that it may be very easily scrubbed from the gas phase, even with ordinary water. This is consistent with the accepted notion that scrubbing of oxidized forms of $\mathrm{Hg}$ is readily accomplished in a wet scrubber (see, for example, Ref.. 1). In light of these considerations it may be true that scrubbing of $\mathrm{HgCl}_{2}$ is in fact unavoidable in any reasonable scrubbing system. Therefore, it may be pointless to perform scrubbing tests directed specifically at $\mathrm{HgCl}_{2}$. We hasten to add that (a) this is only conjecture at this point, and not proven by any of our test data, and (b) we do not suggest that scrubbing of all oxidized forms of $\mathrm{Hg}$ is trivial. (In fact, data from testing described in below refutes this.)

\subsubsection{Conclusions}

The only meaningful conclusion from the unsuccessful test is that in order to test the effectiveness TMT (or any other scrubbing agent) for removing $\mathrm{HgCl}_{2}$ from the gas phase it will be necessary to use a more tightly-controlled system than was used in these tests. In addition, in light of the lower vapor pressure of $\mathrm{HgCl}_{2}$, a different analytical technique will likely have to be devised with lower detection limits.

\subsubsection{Removal of $\mathrm{Hg}$ from Gas Phase by $\mathrm{NO}_{2}$ Oxidation and Scrubbing}

We elected to perform the tests described in this section as a result of the third conclusion in Section 3.1.3. This was based on the observation that gaseous, elemental $\mathrm{Hg}$ is readily oxidized by gaseous $\mathrm{NO}_{2}$ when the concentration of the latter in the gas is high. This condition is satisfied in NWCF offgas, and would also likely be satisfied in the offgas from denitration processes contemplated for implementation in the treatment of HLW calcines. Since oxidized $\mathrm{Hg}$ in the gas phase is amenable to wet scrubbing while elemental $\mathrm{Hg}$ is not, we felt that it may be possible to exploit the high $\mathrm{NO}_{2}$ concentrations to facilitate secondary scrubbing of $\mathrm{Hg}$ to achieve MACT compliance. We performed the tests described below to investigate this possibility.

\subsubsection{Test Description}

The test setup and procedure used for these tests was described previously in Sections 2.1 and 2.3, respectively. Our objectives in doing this testing were as follows:

- Measure the extent of oxidation of gaseous elemental $\mathrm{Hg}$ in an offgas stream representative of NWCF offgas;

- Assess the impact of process parameters likely to impact the degree of $\mathrm{Hg}$ oxidation that can be achieved (e.g., reaction time and moisture content of the offgas);

- Determine the extent to which the oxidized form(s) of $\mathrm{Hg}$ produced by the $\mathrm{NO}_{2}$ can be scrubbed using washed SG;

- Evaluate the effectiveness of candidate scrubbing solutions (i.e., water and $4 \mathrm{M} \mathrm{HNO}_{3}$ ).

To achieve these objectives we varied the available inputs to the test setup previously described. The extent of oxidation of $\mathrm{Hg}$ was determined by comparing the inlet and outlet measured concentrations of elemental mercury. For this to be a reliable measure of the degree of oxidation it is necessary that elemental $\mathrm{Hg}$ not be removed to a significant degree in passing through the test bed. That this is, in fact, true was experimentally verified. In determining the extent of oxidation by the method described it is also 
necessary that the inlet $\mathrm{Hg}$ stream be entirely elemental. This condition was satisfied by using only elemental $\mathrm{Hg}$ in generating the surrogate offgas and not adding NO.

The impact of reaction time was assessed by varying the size of the delay flask shown in the test bed schematic (Figure 1). As previously noted, this parameter was varied between less than a second to roughly two minutes in the course of the testing. The effect of moisture in the offgas was assessed by comparing the degree of oxidation for two conditions--with moisture content around $20-30 \%$ and with no moisture content at all.

The effectiveness of the SG scrubber was determined by comparing the oxidized concentrations of $\mathrm{Hg}$ at the scrubber inlet and outlet. We obtained the concentration of oxidized $\mathrm{Hg}$ at a given location by subtracting the concentration of elemental $\mathrm{Hg}$ (which was measured directly) from the total $\mathrm{Hg}$ concentration (measured after contacting the gas sample with the $\mathrm{SnCl}_{2}$ reducting agent, as described in Section 2.2).

The effectiveness of different scrubbing agents was compared by performing the above determinations (a) with no scrubbing solution at all, using only dry SG in the scrubber, (b) applying a single-pass stream of water to the top of the SG bed, and (c) applying a single-pass stream of $4 \mathrm{M} \mathrm{HNO}_{3}$ to the top of the SG bed. In addition, two tests were performed using SG moistened with water and with $\mathrm{HNO}_{3}$ (respectively) but without replenishment of scrub solution in the SG.

\subsubsection{Discussion of Results}

The results from this phase of the testing are summarized in Table 7. Column 1 of the table is a test number assigned to each test. These numbers indicate the chronological order in which we performed the tests. The numbers in column 1 are out of order in the table because the tests have been grouped with tests performed under similar conditions are adjacent in the table. This facilitates comparison of the results. It will be noted that the table contains a number of boxes without entries. This reflects the fact that the test conditions were not ideal. Because of time constraints it was necessary to utilize available equipment and materials at the location where the tests were performed. Also, it was necessary to design, test, and operate the test system in a relatively short period of time. As a result the test conditions achieved were often unstable and probably not steady state (with respect to saturation of the scrubber material). System leaks and other problems were also discovered in the course of a some tests, casting doubt on the accuracy of the measurements and the reliability of the nominal conditions of the test. The resulting quality and completeness of the experimental data is therefore not considered high. However, for the scoping purposes of the study, it is considered adequate. In some cases test conditions were duplicated a number of times to add confidence in the reported results.

The data in the remaining columns of Table 7 summarize the conditions of each test and the objective measurements. Column 2 gives the measured concentration of (elemental) mercury in the mixing flask (labeled "bubbler" in the test bed schematic, Figure 1). Column 4 is the measured concentration of elemental mercury at the scrubber outlet (lower "Sampling Point" in Figure 1). Column 3 is difference between measured elemental and total $\mathrm{Hg}$ concentrations in the outlet gas from the scrubber. Column 5 is the fraction of the inlet elemental $\mathrm{Hg}$ that was oxidized by $\mathrm{NO}_{2}$. Column 6 is the fraction of the total inlet $\mathrm{Hg}$ that was removed by the scrubber. Column 7 is the fraction of the total oxidized $\mathrm{Hg}$ that was removed by the scrubber. Columns 5,6 , and 7 were calculated from the measurements as follows:

$$
\text { Column } 5=\frac{\left[H g_{\text {in }}\right]-\left[H g_{\text {out }}^{\text {elem }}\right]}{\left[H g_{\text {in }}\right]}
$$




$$
\begin{aligned}
& \text { Column } 6=\frac{\left[\mathrm{Hg}_{\text {in }}\right]-\left[\mathrm{Hg}_{\text {out }}{ }^{\text {otal }}\right]}{\left[\mathrm{Hg} g_{\text {in }}\right]} \\
& \text { Column } 7=\frac{\left(\left[\mathrm{Hg} g_{\text {in }}\right]-\left[H g_{\text {out }}^{\text {elem }}\right]\right)-\left[H g_{\text {out }}^{\text {oxid }}\right]}{\left(\left[H g_{\text {in }}\right]-\left[H g_{\text {out }}^{\text {elem }}\right]\right)}
\end{aligned}
$$

In the above equations, [ $\mathrm{Hg}_{\mathrm{in}}$ ] is the total (elemental) concentration of $\mathrm{Hg}$ in the inlet offgas to the scrubber, $\left[\mathrm{Hg}_{\text {out }}{ }^{\text {elem }}\right]$ is the outlet elemental $\mathrm{Hg}$ concentration, and $\left[\mathrm{Hg}_{\text {out }}{ }^{\text {oxid }}\right]$ is the outlet oxidized $\mathrm{Hg}$ concentration. Note that (as previously discussed) the term in large brackets in the third equation was taken as a measure of the portion of the inlet $\mathrm{Hg}$ concentration that was oxidized by $\mathrm{NO}_{2}$ in the test system.

Columns 8,9 , and 10 contain characterizing data for the different test conditions studied. Columns 8 and 9 are the $\mathrm{NO}_{2}$ and $\mathrm{H}_{2} \mathrm{O}$ concentrations, respectively, in the scrubber inlet gas, as calculated from the flows into the system. Column 10 describes the condition of the SG used to effect scrubbing. Finally, column 11 contains salient features we observed in reviewing the test data.

We emphasize that the numbers in the table are nominal values only, and that the error bars on the data are significant. Where it was possible during a test multiple measurements were made of the inlet and outlet $\mathrm{Hg}$ concentrations. Rudimentary statistical analysis of these replicated measurements was performed to give a qualitative idea of the data quality. The results are summarized in Table 6, below.

Table 6: Statistical measures of variability of test conditions.

\begin{tabular}{|l|l|l|l|}
\hline & {$\left[\mathrm{Hg}_{\text {in }}\right]$} & {$\left[\mathrm{Hg}_{\text {out }}^{\text {elem }}\right]$} & {$\left[\mathrm{Hg}_{\text {out }}^{\text {ital }}\right]$} \\
\hline Minimum RSD, all tests & $1 \%$ & $2 \%$ & $2 \%$ \\
\hline Maximum RSD, all tests & $15 \%$ & $197 \%$ & $48 \%$ \\
\hline Average RSD, all tests & $7 \%$ & $65 \%$ & $26 \%$ \\
\hline
\end{tabular}

The data in the table indicate that the inlet $\mathrm{Hg}$ concentration was the most stable of the three measurements made with an average relative standard deviation of only $7 \%$ over all the tests. The other two measurements showed much higher variability with averages of $65 \%$ and $26 \%$. Notwithstanding the poor quality of the experimental data, we made the following observations from the information in Table 7.

Tests 1 and 2 were done with no $\mathrm{NO}_{2}$ in the offgas. In Test 1 the $\mathrm{SG}$ in the scrubber was dry and in Test 2 it was washed with $4 \mathrm{M} \mathrm{HNO}_{3}$. In both cases, without $\mathrm{NO}_{2}$ in the offgas there was probably little or no oxidation of gaseous $\mathrm{Hg}$. The scrubbing efficiency for the dry $\mathrm{SG}$ was less than $1 \%$, and for $\mathrm{HNO}_{3}$ washed SG it was less than $9 \%$. These tests confirmed our expectations that elemental $\mathrm{Hg}$ is not removed in the SG scrubber and indicates that the assumptions underlying the approach used to determine degree of Hg-oxidation (discussed in Section 3.3.2.1) were valid.

Test 3 was the first test with $\mathrm{NO}_{2}$ added to the offgas and with water used as a scrubbing agent. However, the data indicated little or no oxidation of $\mathrm{Hg}$ and only about $17 \%$ removal of mercury in the 
scrubber. For this test no delay flask was used and the only reaction time was the transit time for the offgas in the tubing between the point of introduction of $\mathrm{NO}_{2}$ and the scrubber. We suspected that with more delay time before scrubbing the degree of oxidation and scrubbing efficiency would be increased. Thus in Test 4 we employed a $125 \mathrm{ml}$ delay flask between the point where the $\mathrm{NO}_{2}$ was introduced into the moist $\mathrm{Hg}$-laden offgas. In this case about $68 \%$ of the $\mathrm{Hg}$ was oxidized and $97 \%$ of the oxidized $\mathrm{Hg}$ was scrubbed. Tests 13 and 16 were similar to Test 4 except for the method of scrubbing. For these tests the degree of oxidation was $100 \%$ and $96 \%$, respectively, but the scrubbing efficiency for the oxidized $\mathrm{Hg}$ was lower in Test 16 (it was not determined in Test 13).

In Tests 5 and $6,250 \mathrm{ml}$ and $1000 \mathrm{ml}$ delay flasks were used, respectively. High degrees of oxidation were achieved in both tests ( $87 \%$ and $97 \%$ ), but only about $76 \%$ of the oxidized $\mathrm{Hg}$ was removed by the scrubber in Test 5 . Encouraged by this result we next inserted an 8 "long, $2.3 \mathrm{~mm} \mathrm{ID}$ glass tube as a delay vessel. The volume of the tube was roughly $1 \mathrm{cc}$ and with an offgas flow of $250 \mathrm{cc} / \mathrm{min}$ the residence time in the tube was less than $1 \mathrm{sec}$ but higher than in Test 3 where no delay at all was used. Tests 9, 10, and 14 were done with this configuration, and dry SG was employed as the scrubbing agent. In two of these three tests the degree of $\mathrm{Hg}$ oxidation was more than $97 \%$. Scrubbing efficiency for oxidized $\mathrm{Hg}$ was only determined in one of the three test, and it was lower than $50 \%$.

All the tests described above were done with moist offgas (roughly $22 \% \mathrm{H}_{2} \mathrm{O}$ vapor) and in some of these tests the degree of oxidation of $\mathrm{Hg}$ by $\mathrm{NO}_{2}$ was not high. We suspected that the water vapor may be inhibiting the oxidation and decided to test a dry offgas. Tests $7,12,8$, and 15 were thus done with no water in the offgas. Tests 7 and 12 were done with the $125 \mathrm{ml}$ delay flask and Tests 8 and 15 were done with the 8" glass tube. In all four of these tests we achieved a degree of oxidation of at least $98 \%$ and virtually all of the oxidized $\mathrm{Hg}$ was scrubbed in the three tests where scrubbing efficiency was determined. In two of these three tests dry SG was employed as the scrubbing agent. Thus, this data supports the idea that water in the offgas inhibits the oxidation of the mercury. Moreover, the high degree of scrubbing of the oxidized fraction of the $\mathrm{Hg}$ suggests either that a different oxidized form may be produced in the dry offgas, or that the water vapor somehow inhibits scrubbing of the oxidized form for Hg which was produced.

As we performed different tests we began to suspect that the tygon tubing which we were using in the test bed to convey the offgas may be influencing the oxidation state of the mercury. The upper service limit for tygon is not far above the $70^{\circ} \mathrm{C}$ test condition and we suspected that plasticizers in the tygon may have begun to pyrolyze and emit organic species during the tests. These species could have been responsible for the low degree of oxidation observed in some tests. For this reason we decided to run a series of tests with the tygon tubing removed and replaced with $1 / 8^{\prime \prime}$ OD SS tubing. In the course of performing these tests we discovered that the SS tubing reduced the concentration of elemental $\mathrm{Hg}$ in the offgas by $50-75 \%$. This could have been due to adsorption or amalgamation of $\mathrm{Hg}$ by the SS surfaces. Because of the effect of the SS for the last test with the SS test system we sampled the inlet and outlet $\mathrm{Hg}$ concentrations inside the glass scrubber itself, downstream of the last SS tube seen by the offgas. The results of this test are given as Test 17 in Table 7. The value of $\left[\mathrm{Hg}_{\text {in }}\right]$ in Column 2 is noticeably lower than the corresponding value in the earlier tests with the tygon system and reflects the effect of the SS tubing upstream of the scrubber. The values for $\left[\mathrm{Hg}_{\text {out }}\right.$ (oxid)] and $\left[\mathrm{Hg}_{\text {out }}\right.$ (elem)] are quite low, and result in high calculated values for the degree of oxidation and scrubbing efficiency of the SG (which was moistened, but not washed, with $\mathrm{HNO}_{3}$ ). The result suggests that if nitric acid were used to wash the SG then virtually all of $\mathrm{Hg}$ in the offgas could be scrubbed. However, there was not enough time to re-run this test to establish a statistical basis for this claim. 
Table 7: Scrubber testing results.

\begin{tabular}{|c|c|c|c|c|c|c|c|c|c|c|}
\hline Test & {$[\mathrm{Hg}]_{\ln }$} & $\begin{array}{l}\text { [Hg] out } \\
\text { (oxid) }\end{array}$ & $\begin{array}{l}\text { [Hg] }]_{\text {out }} \\
\text { (elem) }\end{array}$ & $\begin{array}{c}\% \mathrm{Hg} \\
\text { oxidized }\end{array}$ & $\begin{array}{l}\% \mathrm{Hg} \\
\text { rem. }\end{array}$ & $\begin{array}{l}\% \mathrm{Hg}^{\text {oxid }} \\
\text { rem. }\end{array}$ & [NO2] & [H2O] & Scrub & Comments \\
\hline & $\left(\mathrm{ug} / \mathrm{m}^{3}\right)$ & $\left(\mathrm{ug} / \mathrm{m}^{3}\right)$ & $\left(\mathrm{ug} / \mathrm{m}^{3}\right)$ & & & & (ppm) & & & \\
\hline 1 & 6888 & & 6824 & & $0.9 \%$ & & 0 & $22 \%$ & dry SG & $\begin{array}{l}\text { Test scrubbing eff. of SG alone on elem } \mathrm{Hg} \text {. } \\
\text { Very little scrubbing of elemental } \mathrm{Hg} \text {. } \\
\text { [Hg] fairly stable and this is some added text. }\end{array}$ \\
\hline 2 & 7200 & & 6557 & & $8.9 \%$ & & 0 & $22 \%$ & $\begin{array}{c}4 \mathrm{M} \\
\mathrm{HNO3} \\
\text { on SG }\end{array}$ & $\begin{array}{l}\text { Test scrubbing eff. of SG w/ HNO3 on elem Hg. } \\
\text { Very little scrubbing of elemental } \mathrm{Hg}\end{array}$ \\
\hline
\end{tabular}

\begin{tabular}{|c|c|c|c|c|c|c|c|c|c|c|}
\hline 3 & 7144 & & 7184 & $0 \%$ & $16.6 \%$ & & 16912.1 & $22 \%$ & $\begin{array}{l}\text { water } \\
\text { on SG } \mathrm{SG} \text { sec delay time. } \\
\text { Little NO2 oxidation of elem Hg. } \\
\% \mathrm{Hg} \text { removed varied from 0-34\%. }\end{array}$ \\
\hline
\end{tabular}

\begin{tabular}{|c|c|c|c|c|c|c|c|c|c|c|}
\hline 11 & $\begin{array}{c}4899 \\
.\end{array}$ & 4926 & 675 & $86 \%$ & $0.0 \%$ & $0.0 \%$ & 17866.7 & $22 \%$ & $\begin{array}{l}\text { water } \\
\text { on SG }\end{array}$ & $\begin{array}{l}\text { Delay time about } 1 \mathrm{sec} \text {, wet offgas. } \\
\text { Outlet total } \mathrm{Hg} \text { concentration unstable. } \\
\text { About } 85 \% \text { oxidation of } \mathrm{Hg} \text {. } \\
\text { Poor removal of oxidized and total } \mathrm{Hg} \text {. }\end{array}$ \\
\hline
\end{tabular}

\begin{tabular}{|c|c|c|c|c|c|c|c|c|c|l|}
\hline 9 & 6968 & & 1046 & $100 \%$ & & & 17866.7 & $22 \%$ & dry SG & $\begin{array}{l}\text { Delay time about 1 sec, wet offgas. } \\
>85 \% \text { oxidation of Hg. }\end{array}$ \\
\hline 10 & 4464 & & 1795 & $60 \%$ & & & 17866.7 & $22 \%$ & dry SG & $\begin{array}{l}\text { Delay time about 1 sec, wet offgas. } \\
\text { About } 60 \% \text { oxidation of Hg. }\end{array}$ \\
\hline 14 & 6040 & 3292 & 178 & $97 \%$ & $43 \%$ & $44 \%$ & 17158.6 & $22 \%$ & dry SG & $\begin{array}{l}\text { Delay time about 1 sec, wet offgas. } \\
\text { Outlet elemental Hg unstable. } \\
\text { About } 97 \% \text { oxidation of Hg. } \\
\text { About 43\% scubber efficiency. } \\
\text { About 44\% removal of oxidized Hg. }\end{array}$ \\
\hline
\end{tabular}


Table 7 (cont'd):

Table 7: Scrubber testing results (cont'd)

\begin{tabular}{|c|c|c|c|c|c|c|c|c|c|c|}
\hline Test & {$[\mathrm{Hg}]_{\mathrm{In}}$} & $\begin{array}{l}{[\mathrm{Hg}]_{\text {out }}} \\
\text { (oxid) }\end{array}$ & $\begin{array}{l}\mathrm{Hg}]_{\text {out }} \\
\text { (elem) }\end{array}$ & $\begin{array}{c}\% \mathrm{Hg} \\
\text { oxidized }\end{array}$ & $\begin{array}{l}\% \mathrm{Hg} \\
\text { rem. }\end{array}$ & $\begin{array}{c}\% \mathrm{Hg}^{\text {oxid }} \\
\text { rem. }\end{array}$ & [NO2] & {$[\mathrm{H} 2 \mathrm{O}]$} & Scrub & Comments \\
\hline & $\left(\mathrm{ug} / \mathrm{m}^{3}\right)$ & $\left(\mathrm{ug} / \mathrm{m}^{3}\right)$ & $\left(\mathrm{ug} / \mathrm{m}^{3}\right)$ & & & & $(\mathrm{ppm})$ & & & \\
\hline 4 & 6328 & & 2016 & $68 \%$ & $67 \%$ & $97 \%$ & 16912.1 & $22 \%$ & $\begin{array}{l}\text { water } \\
\text { on SG }\end{array}$ & $\begin{array}{l}\text { Delay time about } 17 \text { secs. } \\
\text { About } 70 \% \text { oxidation of } \mathrm{Hg} \text {. } \\
\text { About } 2 / 3 \text { of } \mathrm{Hg} \text { scrubbed. } \\
\text { Unscrubbed } \mathrm{Hg} \text { is elemental. }\end{array}$ \\
\hline 16 & 6120 & 2184 & 240 & $96 \%$ & $60 \%$ & $63 \%$ & 17488.4 & $22 \%$ & $\begin{array}{c}\text { moist } \\
\text { SG }\end{array}$ & $\begin{array}{l}\text { Delay time about } 17 \text { sec, dry offgas. } \\
\text { About } 96 \% \text { oxidation of } \mathrm{Hg} \text {. } \\
60 \% \text { removal of } \mathrm{Hg} \text {. } \\
63 \% \text { removal of oxidized } \mathrm{Hg} \text {. }\end{array}$ \\
\hline 13 & 6883 & & 21 & $100 \%$ & & & 17158.6 & $22 \%$ & dry SG & $\begin{array}{l}\text { Delay time about } 17 \mathrm{sec} \text {, wet offgas. } \\
\text { Nearly } 100 \% \text { oxidation of } \mathrm{Hg} \text {. }\end{array}$ \\
\hline
\end{tabular}

\begin{tabular}{|c|c|c|c|c|c|c|c|c|c|c|}
\hline 5 & 6061 & 680 & 772 & $87 \%$ & $67 \%$ & $76 \%$ & 16912.1 & $22 \%$ & $\begin{array}{l}\text { water } \\
\text { on SG }\end{array}$ & $\begin{array}{l}\text { Delay time about } 35 \text { secs. } \\
\text { About } 85 \% \text { oxidation of } \mathrm{Hg} . \\
\text { About } 67 \% \text { of } \mathrm{Hg} \mathrm{scrubbed.}\end{array}$ \\
\hline 6 & 5157 & & 149 & $97 \%$ & & & 17866.7 & $22 \%$ & $\begin{array}{l}\text { water } \\
\text { on SG }\end{array}$ & $\begin{array}{l}\text { Delay time about } 145 \text { secs. } \\
\text { About } 97 \% \text { oxidation of } \mathrm{Hg} .\end{array}$ \\
\hline
\end{tabular}

\begin{tabular}{|c|c|c|c|c|c|c|c|c|c|c|}
\hline 8 & 5872 & 5827 & 0 & $100 \%$ & $100 \%$ & $100 \%$ & 22907.1 & $0 \%$ & dry SG & $\begin{array}{l}\text { Delay time about } 1 \mathrm{sec} \text {, dry offgas. } \\
\text { Near } 100 \% \text { oxidation of } \mathrm{Hg} \text {. } \\
\text { Near } 100 \% \text { removal of } \mathrm{Hg} \text {. } \\
\text { Near } 100 \% \text { removal of oxidized } \mathrm{Hg} \text {. }\end{array}$ \\
\hline 15 & 7072 & 32 & 40 & $99 \%$ & $99 \%$ & $100 \%$ & 22344 & $0 \%$ & $\begin{array}{c}\text { moist } \\
\text { SG }\end{array}$ & $\begin{array}{l}\text { Delay time about } 1 \mathrm{sec} \text {, dry offgas. } \\
\text { About } 99 \% \text { oxidation of } \mathrm{Hg} \text {. } \\
99 \% \text { removal of } \mathrm{Hg} \text {. } \\
100 \% \text { removal of oxidized } \mathrm{Hg} \text {. }\end{array}$ \\
\hline
\end{tabular}


Table 7 (cont'd):

Table 7: Scrubber testing results (cont'd)

\begin{tabular}{|c|c|c|c|c|c|c|c|c|c|c|}
\hline Test & {$[\mathrm{Hg}]_{\text {in }}$} & $\begin{array}{c}\mathrm{[Hg}]_{\text {out }} \\
\text { (oxid) }\end{array}$ & $\begin{array}{c}{[\mathrm{Hg}]_{\text {out }}} \\
\text { (elem) }\end{array}$ & $\begin{array}{c}\% \mathrm{Hg} \\
\text { oxidized }\end{array}$ & $\begin{array}{c}\% \mathrm{Hg} \\
\mathrm{rem} .\end{array}$ & $\begin{array}{c}\% \mathrm{Hg}^{\text {oxid }} \\
\text { rem. }\end{array}$ & {$[\mathrm{NO} 2]$} & {$[\mathrm{H} 2 \mathrm{O}]$} & Scrub & Comments \\
\hline 7 & $\begin{array}{c}\left(\mathrm{ug} / \mathrm{m}^{3}\right) \\
7013\end{array}$ & $\begin{array}{c}\left(\mathrm{ug} / \mathrm{m}^{3}\right) \\
0\end{array}$ & $\begin{array}{c}\left(\mathrm{ug} / \mathrm{m}^{3}\right) \\
157\end{array}$ & $98 \%$ & $97.8 \%$ & $100.0 \%$ & $\begin{array}{c}(\mathrm{ppm}) \\
22907.1\end{array}$ & $0 \%$ & dry SG & $\begin{array}{l}\text { Delay time about 18 secs, dry offgas. } \\
\text { About } 98 \% \text { oxidation of } \mathrm{Hg} . \\
98 \% \text { removal of } \mathrm{Hg} . \\
100 \% \text { removal of oxidized Hg. }\end{array}$ \\
\hline 12 & 4760 & & 75 & $98 \%$ & & & 21969.1 & $0 \%$ & dry SG & $\begin{array}{l}\text { Delay time about } 22 \text { sec, dry offgas. } \\
\text { About } 98 \% \text { oxidation of } \mathrm{Hg} .\end{array}$ \\
\hline
\end{tabular}

\begin{tabular}{|c|c|c|c|c|c|c|c|c|c|}
\hline 17 & 4965 & 185 & 16 & $99 \%$ & $95.9 \%$ & $96.2 \%$ & 16328.4 & $33 \%$ & $\begin{array}{l}\text { SG } \\
\text { moist } \\
\text { with } \\
\text { HNO3 tygon or SS between sampling points. } \\
\text { Introduce NO2 to offgas in scrubber. } \\
\text { SG moistened with 4 M HNO3. } \\
\text { Delay time about 3 sec, wet offgas. } \\
\text { About 99\% oxidation of } \mathrm{Hg} . \\
96 \% \text { removal of and total Hg. }\end{array}$ \\
\hline
\end{tabular}




\subsubsection{Conclusions}

The data obtained from this test series was not of high quality because of time constraints plus difficulty in maintaining constant and well-controlled conditions. However, taking the nominal data at face value we did draw some tentative conclusions. First, it is clear that concentrations of $\mathrm{NO}_{2}$ above about 10,000-15,000 ppm can completely oxidize concentrations of elemental $\mathrm{Hg}$ has high as 7,000-8,000 $\mu \mathrm{g} / \mathrm{m}^{3}$ in a dry, $70^{\circ} \mathrm{C}$ offgas in less than $1-2 \mathrm{sec}$. This oxidation may also be achievable in a wet gas stream but only if the proper conditions are maintained. Our test conditions were not sufficiently well-characterized to identify the factors which determine the oxidation efficiency in a wet gas stream.

The oxidized form of $\mathrm{Hg}$ initially produced by the reaction of elemental mercury with $\mathrm{NO}_{2}$ in air is not as readily scrubbable as is gaseous $\mathrm{HgCl}_{2}$. Efficient scrubbing of this species with SG pre-wetted with fresh water only was not observed. However, when the same SG was wetted with $4 \mathrm{M} \mathrm{HNO}_{3}$ instead of water, about $96 \%$ removal of the $\mathrm{Hg}$ in the stream was removed (in these, our final, tests, there we imposed no "delay" or "reaction" volume situated between the point where the NO was mixed with the humid, elemental mercury-bearing air stream and the scrubber; additionally, the volume of silica gel relative to the gas flowrate in these tests were such that the gas spent only about two seconds in the "bed").

Finally, stainless steel surfaces appear to extract at least some elemental Hg vapor from these gas mixtures.

\section{SUMMARY}

As a result of work done earlier during FY 1999 in which we assessed a number of potential methods for removing mercury $(\mathrm{Hg})$ from INTEC waste streams, the following tests were proposed:

(1) Determine whether silica gel (SG) can be used to scrub $\mathrm{Hg}$ from offgas.

(2) Determine whether the commercial complexing/precipitating agent, TMT, can be used to remove Hg from surrogate sodium bearing waste (SBW) solutions.

(3) Determine whether TMT can be used in a secondary scrubbing operation to remove $\mathrm{HgCl}_{2}$ from the gas phase to MACT-compliant levels.

A testing program at TRA was conducted to accomplish the above objectives. Testing of SG showed that little or no removal of purely elemental Hg is achieved with either dry SG or with SG scrubbed with $4 \mathrm{M} \mathrm{HNO}_{3}$. SG did remove oxidized $\mathrm{Hg}$ in some tests but was ineffective in others. Wetting it with $4 \mathrm{M}$ nitric acid greatly improved its scrubbing performance for $\mathrm{NO}_{\mathrm{x}}$-oxidized elemental mercury. Some attempts to investigate ways to remove pure $\mathrm{HgCl}_{2}$ vapor were made but stable, measurable concentrations of gaseous $\mathrm{HgCl}_{2}$ could not be generated. Moreover, preliminary tests strongly suggested that $\mathrm{HgCl}_{2}$ is unstable in the presence of liquid water or stainless steel, and appears to be readily reduced to the elemental form. These results suggest that $\mathrm{HgCl}_{2}$ can probably be efficiently scrubbed with ordinary water and that moist SG would remove virtually $100 \%$ of any $\mathrm{HgCl}_{2}$ from the gas phase. 
Testing of TMT with surrogate SBW solutions indicated that the material is essentially useless in highly acidic solutions if chloride is present in concentrations greater than that of the Hg. Similar results were seen when precipitations were attempted after $>90 \%$ of the free acid had been neutralized with caustic. At $\mathrm{pH}>13$, TMT was able to remove about $66 \%$ of the dissolved $\mathrm{Hg}^{+2}$, but a significant fraction of $\mathrm{Al}^{+3}$ remained with the $\mathrm{Hg}$ (probably as a hydrous oxide). Thus it was concluded that TMT is not a suitable precipitating agent for removing $\mathrm{Hg}^{+2}$ from $\mathrm{SBW}$.

Testing of TMT as a scrubbing agent for $\mathrm{Hg}$ from the gas phase was not attempted for the following reasons. First, TMT is totally ineffective in removing elemental $\mathrm{Hg}$. Second, as noted above, $\mathrm{HgCl}_{2}$ can almost certainly be effectively scrubbed with ordinary water, so the only incentive to use TMT would be the possibility of recovering $\mathrm{Hg}$ as a solid precipitate which would pass TCLP (as claimed by the vendor). Since we were unable to generate stable, measurable levels of $\mathrm{HgCl}_{2}$ in our offgas simulants, we were unable to confirm this. Scrubbing of other possible forms of oxidized $\mathrm{Hg}$ (e.g., $\mathrm{HgO}$ ) with pure water may not be effective, so TMT may still have application here. However, we were unable to test this hypothesis due to the limited time available for these experiments.

In addition to the three objectives stated above, experiments were done to examine another option identified during the course of the program. It was discovered that $\mathrm{NO}_{2}$ rapidly oxidizes gaseous, elemental $\mathrm{Hg}$. (This has also been noted by other researchers.) We felt that this could be exploited in INTEC denitration systems where $\mathrm{NO}_{2}$ is present in much higher concentrations than it is in most combustion offgas. Tests were performed to determine (a) the extent to which elemental $\mathrm{Hg}$ can be oxidized in such a stream, and (b) the extent to which the so-oxidized Hg could then be removed by scrubbing through SG. The test bed used in the work was crude and the experimental data obtained was only preliminary. However, the following tentative conclusions can be drawn:

(1) Elemental $\mathrm{Hg}$ is very quickly and very nearly completely oxidized by $\mathrm{NO}_{2}$ at concentrations on the order of the 15,000-20,000 ppm typical of NWCF offgas. This oxidation appears to be more rapid in the absence of water vapor, but high efficiencies were also obtained in tests done with water vapor present at near saturation (20-30 mole/volume \%).

(2) The oxidized form of $\mathrm{Hg}$ so-produced is apparently not as easily scrubbed out as is $\mathrm{HgCl}_{2}$. In some tests, a high fraction of that form of $\mathrm{Hg}$ was removed, but in others (done with either dry or water-wetted) SG, it was not. In a single test involving a two-second contact with SG wetted with $\mathrm{HNO}_{3}, 96 \%$ of the $\mathrm{Hg}$ was removed. The fact that favorable scrubbing efficiencies were achieved in some tests suggests that further testing, with a more stable and better-characterized test setup, would define the conditions necessary to efficiently scrub oxidized $\mathrm{Hg}$ produced in high $\mathrm{NO}_{2}$-bearing offgas streams.

\section{RECOMMENDATIONS}

Based on the testing describing in this report, we submit the following recommendations:

- TMT should not be considered further for removal of $\mathrm{Hg}^{+2}$ from liquid SBW.

- Additional testing should be conducted to characterize the oxidation of $\mathrm{Hg}$ by $\mathrm{NO}_{2}$. This testing should be done in a carefully-designed test bed, capable of maintaining $\pm 1^{\circ} \mathrm{C}$ temperature variation. Testing should be done with an all-glass system, with provision for deliberate insertion of stainless steel (and other materials) to determine their effects on $\mathrm{Hg}$ behavior. Provision should also be made to more rigorously control the concentration of water vapor in the gas phase 
and the residence/reaction times after the $\mathrm{NO}_{\mathrm{x}}$ is injected. A real time $\mathrm{NO}_{\mathrm{x}}$ monitor (at least one of which is available here on site) could/should be used to measure actual concentrations of the various species. Finally, real time monitoring of both elemental and total $\mathrm{Hg}$ is both possible and desirable.

- Additional testing should be conducted to determine the scrubbing efficiency of silica gel for elemental $\mathrm{Hg}$ oxidized with $\mathrm{NO}_{2}$. This testing should be done with both stable inlet and (if possible) stable outlet concentrations of oxidized $\mathrm{Hg}$ in the scrubber, and with more accurately known gas and scrubbing solution flow rates. Pure water, $4 \mathrm{M} \mathrm{HNO3,} \mathrm{and} \mathrm{TMT-15} \mathrm{in} \mathrm{water}$ should all be tested as scrubbing agents. If possible these experiments should be done with both gaseous $\mathrm{HgCl}_{2}$ and elemental $\mathrm{Hg}$.

- NWCF's offgas system and recent qualified gaseous emission data should be analyzed in light of the results from both this and our suggested future test program to evaluate how the operation of that facility might be modified (e.g., occasionally spray the existing SG beds with $4 \mathrm{M}$ nitric acid) to reduce $\mathrm{Hg}$ emissions.

The above tests would provide high quality data on which to base a decision whether $\mathrm{NO}_{2}$ oxidation of gaseous $\mathrm{Hg}$, followed by a secondary, wet scrubber, is a feasible means to control gaseous $\mathrm{Hg}$ to MACT-compliant levels in present or future denitration of HLW at INTEC.

\section{REFERENCES}

1. Livengood, C.D., Marshall, H.M., "Investigation of Modified Speciation for Enhanced Control of Mercury", ANL-ES-CP-96999, July 21-23, 1998.

2. "Investigation on the Removal of Elemental Mercury and Mercuric Chloride from a Highly Oxidizing Gas Stream", white paper prepared for the Federal Energy Technology Center, Morgantown by ADA Technologies, Inc. (Englewood, CO), November, 1998.

3. LMITCO Interdepartmental Communication from R.E. Schindler to B.H. O'Brien, "Compositions of Wastes in Tank Farm", Schi-04-99, dated February 11, 1999.

4. LMITCO Interdepartmental Communication from R.E. Schindler to B.H. O'Brien, "HLLWE Feed Blends for Wastes from WM-186, WM-184, and WM-181", Schi-17-98, dated July 28, 1998.

5. Boardman, R.D., "NWCF Slipstream CO, CO2 concentrations during H-3 Campaign", NWCF Processing Modifications for Sodium Bearing Waste Project Information Routing Sheet, routed to D.D. Taylor (and others) on 3/28/96.

6. Handbook of Chemistry and Physics, 50th Edition (1969), The Chemical Rubber Company, Cleveland, $\mathrm{OH}$.

7. Rawlins, J.K., "Feasibility Study Report for NWCF MACT Compliance Facility", INEEL/INT-97-00992 (Appendix D), November, 1997. 


\section{Appendix C}

Regulatory Considerations in Evaluation of Need for and Method of Mercury Removal in Full Separations Facility 


\title{
Appendix C \\ Regulatory Considerations in Evaluation of Need for and Method of Mercury Removal in Full Separations Facilities
}

\author{
Jim Bosley
}

\section{General Response}

Low Activity Waste (LAW) as defined in the process options for the High-Level Waste (HLW) and Facility Disposition Environmental Impact Statement (EIS) is a low activity fraction separated out of the HLW (Calcine) or Sodium-Bearing Waste (SBW). LAW can either be a Class A or Class C mixed waste depending on the separations techniques employed. High Activity Waste (HAW) is defined as the high activity fraction separated out of $\mathrm{HLW}$ and maybe $\mathrm{SBW}$, which will require geologic isolation. Depending on the techniques used, two or more secondary (new) waste streams containing mercury will be generated and each waste stream will need to be evaluated to determine the appropriate treatment standard for mercury.

The first requirement is to establish the point of generation and the land disposal restriction (LDR) treatment standard at the point of generation. The mercury treatment standard for the LAW depends on several factors. These factors include: (1) Does the LAW exhibit the characteristic of toxicity for mercury based on the TCLP? (2) What is the total concentration of mercury in the waste? (3) Is the LAW a wastewater or a nonwastewater? Based on this information, the appropriate treatment standard can be selected.

A decision chart for LDR treatment of mercury is provided in Figure 1 (page 5) of this report. This decision chart has been specifically developed for the separations option. To use the chart, enter at the top in the rectangle, INTEC WASTE. The definition and treatment standards applicable to mercury are provided in Appendix B and will be referred to in the following questions and answers.

Question 1A. For a facility that will treat SBW and calcine (i.e., the "Full Separations" process), what (if any) are the regulatory requirements for treatment because of the mercury contained in the SBW and calcine? Does the form of the waste (SBW as liquid, calcine in solid form), concentration of the mercury in the waste $(100-2,100 \mathrm{mg} / \mathrm{L}$ for SBW; $10-20,000 \mathrm{ppm}$ for calcine), or original source of mercury in the waste affect these requirements?

\section{Response 1A.}

The LDR treatment standard for HLW is vitrification (HLVIT, see Appendix B), whether or not it is a liquid or solid (40 CFR 268.40). We know mercury will volatize at the vitrification temperatures of $1,000-1,500^{\circ} \mathrm{C}$ and will need to be removed from the offgas. HLVIT would also apply to the HAW fraction, which contains the isotopes requiring geologic isolation. Calcination can be looked at as a pretreatment step or process that removes the majority of mercury, as well as the nitrates from the HLW. The majority of mercury from past calcination activities was scrubbed out of the offgas and is now in the $S B W$.

It is my opinion that the regulators will require the vitrification process to meet the offgas requirements for incinerators and other thermal treatment units, i.e., Maximum Achievable Control Technology (MACT) emission standards. While the concentration of mercury in the calcine is low, it is sufficiently high that treatment of the offgas from a direct vitrification unit, $H A W$ vitrification unit, and $L A W$ calciner will be required. The offgas treatment residue (acid scrub solution, HEPA filters, and sulfur impregnated 
carbon) will each have to be treated depending on its classifications as a wastewater or nonwastewater and high mercury or low mercury.

The full separation option process chemistry suggests that $30 \%$ of the mercury will traffic with the TRU fraction and $70 \%$ will traffic with the LAW. For calcine, both the HAW and LAW offgas scrub systems may concentrate $\mathrm{Hg}$ to levels considered in the high $\mathrm{Hg}$ category. For SBW, both the HAW and LAW will contain sufficient concentrations of $\mathrm{Hg}$ to be considered in the high $\mathrm{Hg}$ category. This will result in the high Hg waste streams having to meet the RMERC and AMALG standards. We should be able to negotiate with the regulators that treatment of the mercury from calcination and vitrification collected in an offgas scrub, followed by precipitation as a sulfide meets the treatment standards of RMERC followed by $A M A L G$ (see Appendix C2 for definitions).

The number of calcine samples collected and analyzed for mercury are limited and for this discussion we should look at the analytical date collected during the H-4 campaign. The SBW and Calcine samples taken during the H-4 campaign indicate that the mercury levels to be:

\section{Calcine}

TCLP 66 to $144 \mathrm{ug} / \mathrm{L}$ or 0.066 to $0.144 \mathrm{mg} / \mathrm{L}$

Total 11.8 to $23 \mathrm{mg} / \mathrm{kg}$

SBW in WM-185 and WM-188, respectively

Total $660 \mathrm{mg} / \mathrm{L}$ and $1,680 \mathrm{mg} / \mathrm{L}$.

For examples of how the treatment limits might apply to the HAW and LAW for mercury, see Appendix C1. It is assumed that SBW will be processed through the separations process and will generate a HAW fraction similar in character to the HAW for calcine and will require vitrification and geologic isolation.

Question $1 B$. One issue behind the above question is whether SBW is "listed" for mercury besides being characteristic. Is this an issue, and if not, can we document its resolution?

\section{RESPONSE IB}

It is my understanding that this concern is related to broken in-cell instruments containing elemental mercury and the elemental mercury from these instruments was flushed with decontamination solution into the PEW/TFF system. If this is the case, the mercury is a characteristic waste and not a listed waste. The mercury was being used for its intended purpose, as part of a thermometer or manometer. It was not discharged into the PEW-TFF system as an unused or off-spec commercial chemical product (i.e., from a reagent flask of elemental mercury). It is not the intent of $R C R A$ to regulate manufacturing articles (e.g., thermometers) that contain a chemical listed in 40 CFR 261.33(U151 for $\mathrm{Hg}$ ). If someone has first hand knowledge or documentation that reagent mercury from a flask was discharged in to the PEW/PEW system, he should provide the information to Ken Gilbert for evaluation.

Question 2. If mercury is not removed (except from offgas streams), a high percentage of mercury in the waste feeds will end up in the LAW grout. Depending on the feed, the mercury concentration in the grout could be as low as $2 \mathrm{ppm}$ or as high as $2,000 \mathrm{ppm}$. Assuming a grout formulation can be found such that mercury will not leach from the grout, are there any regulations that require treatment of the grout or upstream of grouting to keep the mercury concentration in the grout to a specific limit? Is the concentration of mercury in grout of any concern (again assuming the grout passes a TCLP test for mercury) regarding disposal of the grout? 


\section{RESPONSE 2}

The HLW and SBW were corrosive at the point of origin and unless a case can be made that we have generated a new waste (i.e., calcine), then the final waste form must meet the LDR standards applicable at the point of generation. The treatment standard for HLW is HLVIT and you must demonstrate that the final product is not hazardous for all RCRA constituents. SBW is a corrosive-high mercury waste, therefore: (1) the treatment standard is DEACT for the DOO2 corrosive; (2) precipitation of the mercury;(3) RMERC for the precipitate;(4) AMALG for the radioactively contaminated elemental mercury recovered by RMERC; and (5) and treat the wastewater (water left over after precipitation of the mercury) to the universal treatment standards (UTS) before disposal (see Appendix CI). For Hg this concentration based UTS is $0.025 \mathrm{mg} / \mathrm{L}$ TCLP. This standard is based on chemical precipitation of the mercury and or stabilization (see Appendix C2).

Question 3. In the Full Separations process, calcine is dissolved and all separations are made from liquid streams. The primary candidate streams (besides offgas streams) for treatment of mercury are the TRUEX wash effluent and the LAW denitration scrub solution. As I read the RCRA regulations, I would call either of these two streams wastewaters, for which the BDAT for mercury is sulfide precipitation, regardless of the mercury concentration in the wastewater. Is this interpretation correct? Is there any reason from a regulatory perspective that sulfide precipitation would either be favored or not favored as a treatment method? (The expected mercury concentration in the TRUEX wash is $\sim 7 \mathrm{mg} / \mathrm{L}$ to $\sim 8,400$ $\mathrm{mg} / \mathrm{L}$, and in the LAW scrub solution as high as $50,000 \mathrm{mg} / \mathrm{L}$ ).

We are presently testing sulfide precipitation, which produces a mercury sulfide sludge. Would there be any regulatory hurdles to disposing this waste?

\section{RESPONSE 3}

Wastewaters are liquid streams that contain $\geq 0.2 \mathrm{mg} / \mathrm{L} \mathrm{TCLP}$ and $<260 \mathrm{mg} / \mathrm{kg}$ total mercury. If the waste is $<0.2 \mathrm{mg} / \mathrm{L}$ TCLP mercury the waste is not hazardous for mercury (See Appendix B).

Based on the analysis of the $H-4$ campaign for calcine, neither the HLW nor the LAW streams would be considered a high-mercury waste stream. Assuming that all the mercury is soluble then, they are low $\mathrm{Hg}$ wastes with the HAW subject to the vitrification standard and LAW waste streams to the wastewater or nonwastewater low Hg other source concentration based standard. It should be noted the partial treatment or changing treatability groups to avoid a more strigent standard is not acceptable.

The offgas scrub streams would be newly generated waste and evaluated based on mercury concentration.

The concentration treatment levels were established based on a technology that consistently removes the constituents or renders a constituent nonhazardous. The LDR treatment BDAT for mercury in a wastewater is sulfide precipitation. The treater of a hazardous waste can use any method, technology or process as long as it achieves the same degree of removal or rendering of nonhazardous as the BDAT did in setting of the LDR standard.

The hurdle to be overcome would be related to nonwastewater; a liquid classified as a nonwastewater due to being classified as a high-mercury waste. The treatment standard is RMERC, with elemental mercury collected for reuse and the residue meeting a concentration standard. Our waste will be radioactive and retorting would generate elemental mercury not suitable for reuse because of its radioactivity. The treatment standard for radioactive elemental mercury is AMALG. Treating elemental mercury to produce a mercury sulfide is considered to be amalgamation in the LDR standards. We would 
need to get a treatment variance to go directly from a liquid high mercury waste to the amalgamation process, bypassing the RMERC step. The mercury sulfide would need to pass the TCLP test for a hazardous characteristic waste $(0.2 \mathrm{mg} / \mathrm{L} T C L P)$ and the remaining liquid would need to be below the treatment standard for other mercury wastes $(0.025 \mathrm{mg} / \mathrm{L}$ TCLP).

Question 4. I've heard the opinion expressed that we will need to produce an amalgamated mercury waste if mercury exceeds a concentration of $260 \mathrm{mg} / \mathrm{kg}$. Is this correct? When is amalgamation required? Does the $260 \mathrm{mg} / \mathrm{kg}$ concentration apply to the feed (SBW or calcine), the stream we treat, or the final mercury waste form? Does mercury sulfide qualify as a mercury amalgam?

\section{RESPONSE 4}

If a waste (except HLW) contains Hg in concentrations: (1) $\geq 0.2 \mathrm{mg} / \mathrm{L} \mathrm{TCLP}$ and (2) $\geq 260 \mathrm{mg} / \mathrm{kg}$ total then the waste is considered a nonwastewater, even if in all other aspects it looks like a wastewater. Remember the LDR standards apply at the point of generation and addition standards could apply to the waste (i. e:, DOO2 + meet UTS). If we generate new waste as part of the separation process, then each of these streams would need to be evaluated separate from the HLW and SBW.

The LDR treatment standards apply at the point of generation, which is the TFF for SBW and HLW.

The treatment standard for high $\mathrm{Hg}$ waste is RMERC. Amalgamation is required if you have radioactively contaminated elemental mercury.

Mercury in HLW or calcine does not require RMERC since the designated treatment standard is HLVIT (vitrification).

$S B W$ has not been classified as an HLW or non-HLW by DOE/NRC. If we assume that SBW will be classified as incidental to reprocessing of spent fuel, then SBW is a high $\mathrm{Hg}$ waste and would be a nonwastewater subject to the RMERC treatment standard. Except if it is sent to WIPP. Since RMERC treatment would result in radioactively contaminated elemental mercury, it might be beneficial to bypass this step and go directly to amalgamation (i.e., chemical precipitation).

Yes, mercury sulfide is considered a form of AMALG for complying with the LDR treatment standard for radioactively contaminated mercury.

Question 5. I've also heard it expressed that if mercury in the LAW scrub solution (or NWCF scrub solution) is reduced to elemental mercury, it could be disposed of directly (as elemental mercury, without further treatment). Is this correct?

\section{RESPONSE 5}

No, if the mercury in the scrub is reduced to the elemental form, then two standards apply: RMERC (recovery of mercury for recycle) for non-radioactively contaminated mercury and AMALG (amalgamation) for radioactively contaminated mercury. Disposal of elemental mercury directly is not allowed; it needs to be in a non-leachable form.

Question 6. To meet the MACT emission limit for mercury, we would need to remove it from both LAW and HAW offgas streams. If we use carbon, what regulations apply to disposal of the mercury-laden spent carbon? Does it matter whether the carbon is sulfur-impregnated or not? Will any further treatment be required (retorting, grouting...)? 


\section{RESPONSE 6}

First we need to determine the concentration of mercury on the carbon, both total and TCLP values. See the decision diagram for nonwastewater starting with the High Hg diamond \#7. The treatment standard would be RMERC to recover the Hg for reuse.

This offgas waste stream will contain radioactive constituents that will be trapped on or in the carbon and it may not be desirable to subject this waste to REMERC followed by AMALG. If the sulfurimpregnated carbon causes the mercury to become a sulfide we might meet standard for AMALG and would by pass the RMERC step. I feel that we could negotiate this issue with the regulators.

REMEMBER: Technology standards still require the generator to verify that the waste is not hazardous and all UTS have been met before disposal. 


\section{APPENDIX C1}

This appendix has been include to help the engineer or scientist use the flow chart of Figure 1 (page 5) make decisions related to waste generation and treatment. The following Full Separation option waste stream examples demonstrate how the LDR treatment standards for mercury could be applied to each waste generated by this option. The full separation option could potentially generate the follow waste streams which will need to be evaluated for LDR disposal and the engineer or scientist will need to understand how the concentration of mercury will affect the treatment and disposal options.

The evaluation is based on the following assumptions below.

Dissolution of the calcine in nitric acid (ratio of 1 to 8) followed by removal of the TRU, Cs, and Sr components would not result in additional treatment for mercury, if the mercury traffics with the LAW. If the mercury traffics with the high activity fraction, then it might be possible to concentrate the mercury into the HAW, causing additional treatment to be required. Preliminary studies of the Full Separations option indicated that approximately $70 \%$ of the mercury would traffic with the TRU fraction. (Note: Later studies showed that only $\sim 2 \%$ of the mercury is contained in the HAW.)

During HAW vitrification and LAW calcination, the mercury would be vaporized and collected in the offgas scrub solutions. If the mercury concentration in the scrub solution is less than $260 \mathrm{mg} / \mathrm{L}$, the spent scrub solution would be a wastewater and could be stabilized and disposed. The concentration standard will depend on whether the scrub solution is a wastewater or a nonwastewater. The treatment standard for wastewater is $0.15 \mathrm{mg} / \mathrm{L}$ total mercury and for nonwastewater the treatment standard is $0.025 \mathrm{mg} / \mathrm{L}$ TCLP.

\section{HLW/Calcine}

Analytical result for calcine samples taken during the $\mathrm{H}-4$ campaign indicate that the mercury levels to be:

TCLP 66 to $144 \mathrm{ug} / \mathrm{L}$ or 0.066 to $0.144 \mathrm{mg} / \mathrm{L}$

Total 11.8 to $23 \mathrm{mg} / \mathrm{kg}$

The concentration of mercury in the calcine based on a TCLP extraction and analysis indicates that the mercury is at or near the LDR treatment standards. The concentration of $\mathrm{Hg}$ in the calcine based on a total metal indicates that the concentration is greater than the TC limits but less than $260 \mathrm{mg} / \mathrm{kg}$ limit that requires the waste to be retorted.

\section{SBW}

The SBW analyzed during the H-4 campaign indicate that the mercury levels are $660 \mathrm{mg} / \mathrm{L}$ and $1,680 \mathrm{mg} / \mathrm{L}$ in WM-185 and WM-188, respectively. The concentration of mercury in these two tanks indicate that SBW is greater than $260 \mathrm{mg} / \mathrm{Hg}$ and would be considered a nonwastewater for purposes of the LDR standards. Each waste generated from the treatment of SBW would have to be evaluated to determine the concentration of $\mathrm{Hg}$ and the LDR standard that apply.

*HAW (see example below)

*Vitrification offgas scrubber solution (see example below) 
*Vitrification product form (see example below)

Vitrification debris

Spent organic waste form TRUEX and SREX

Spent organic incinerator ash

Spent organic scrub water

Spent organic HEPA filters

Spent organic offgas

Spent CsIX resin

Spent CsIX wash solution to HAW

$\mathrm{Hg}$ wash solution

Hg sulfide precipitate

Hg spent precipitation solution containing Technetium to HAW

SREX wash solution $\mathrm{Sr} /$ some $\mathrm{Tc}$ metal to HAW

LAW evaporator bottoms to LAW Calcine

LAW evaporator offgas

*LAW calcine (see example below)

LAW scrub solution/Hg

LAW Hg precipitate

LAW Hg spent precipitation solution

LAW HEPA filters

LAW offgas

LAW grouted calcine waste

The following examples indicate how the mercury standards might apply to waste streams generated from HLW and SBW during separations.

The following waste streams examples are associated with Full Separations have been used as examples of how the chart (Figure 1, page 5) works. These examples should help identify the potential $\mathrm{Hg}$ classifications and $\mathrm{Hg}$ treatment and limits [see decision chart's numbered decision points (DP)].

EXAMPLE 1

*HAW =TRUEX + CsIX +SREX/some TC metals

Treatment standard is HLVIT (DP-1).

High level vitrification (HLVIT) is the treatment standard for HLW. It is expected that a LAW stream will be generated from treatment of the offgas. Mercury will be volatilized and collected in a scrub solution, on HEPA filters, and/or sulfur impregnated carbon. Each of these potential waste streams needs to be evaluated, based on the TCLP toxic characteristic for mercury $(0.2 \mathrm{mg} / \mathrm{L})$ and the total concentration of mercury $(\geq 260 \mathrm{mg} / \mathrm{kg})$. 
EXAMPLE 2

*Vitrification offgas scrubber solution.

These waste stream maybe a wastewater (ww) or nonwastewater (nww) depending on the concentration of $\mathrm{Hg}$ (DP-4).

$\mathrm{WW}$, is the waste corrosive? (DP-5a)

NO, proceed to (DP-5b)

Is waste characteristically hazardous for $\mathrm{Hg}$ ?

$\mathrm{NO}$, not a hazardous waste for $\mathrm{Hg}$.

YES, treat to WW std $0.2 \mathrm{mg} / \mathrm{L}$ total $\mathrm{Hg}$

YES, then deactivate DOO2 and treat to the UTS for all constituents.

Is $\mathrm{Hg}$ precipitation required to meet the UTS standard (DP-5c)?

NO, treat ww UTS $0.025 \mathrm{mg} / \mathrm{L}$ TCLP, by stabilization.

YES, precipitate $\mathrm{Hg}$ and treat ww to UTS $0.025 \mathrm{mg} / \mathrm{L}$ TCLP, by stabilization.

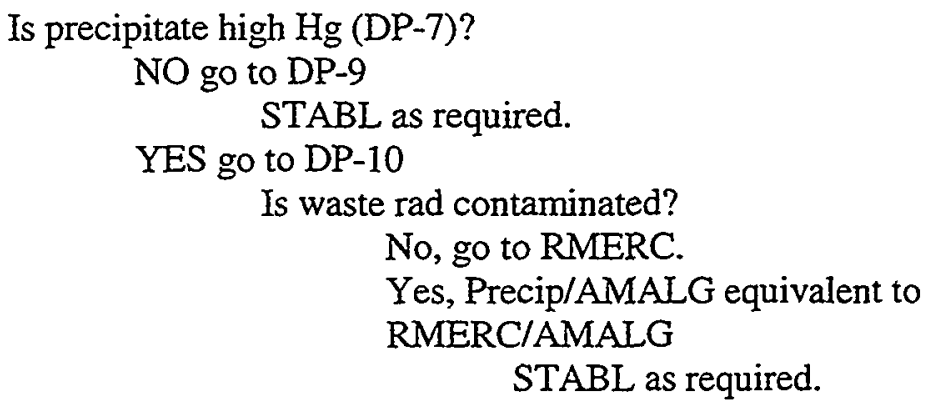

Is waste a high $\mathrm{Hg}(\mathrm{DP}-4)$ ?

YES, waste is a nonwastewater

Go to DP-10

Is waste rad contaminated?

No, go to RMERC.

Yes, Precip/AMALG equivalent to RMERC/AMALG

STABL as required.

\section{EXAMPLE 3}

*Vitrification product form

Meets the RCRA LDR technology standard and RW acceptance criteria if:

1. Radioisotopes verify that product meets the product consistency test criteria

2. TCLP extraction and analysis verify that waste is not hazardous, TC limits.

\section{EXAMPLE 4}

*LAW calcine

This example assumes that the proposed calciner would produce a product similar to the calcine from campaign $\mathrm{H}-4$. Therefore, it would be a low $\mathrm{Hg}$ waste and we can start with DP-9.

Is the waste a low $\mathrm{Hg}$ other source waste?

$\mathrm{NO}$, this waste is not hazardous for mercury

YES, treat mercury to $0.025 \mathrm{mg} / \mathrm{L}$ TCLP

STABL as required. 


\section{APPENDIX C2}

This appendix has been include to help the reader understand how RCRA applies to the waste and how the EPA definitions and treatment standards related to mercury.

\section{RCRA DEFINITIONS}

Wastewaters are wastes that contain less than $1 \%$ by weight total organic carbon (TOC) and less than $1 \%$ by total suspended solids (TSS).

Nonwastewaters are wastes that do not meet the criteria for wastewaters.

NOTE: According to EPA any wastes that contain greater than $260 \mathrm{mg} / \mathrm{L}$ of total mercury, but otherwise appear to meet the definition of wastewaters, are, in fact, classified as nonwastewaters that must be recovered.

Elemental mercury contaminated with radioactive materials (Note: This subcategory consists of nonwastewater only.)

\section{TREATMENT STANDARDS}

Where treatment standards are given in terms of concentration limits, any technology may be used to treat the wastes. However, as it may be difficult to meet the treatment standards without using the same technology that EPA used when developing the standards, it is helpful to know what EPA identified as BDAT for each concentration-based and universal treatment standards. The BDATs for mercury wastes are:

Chemical precipitation for metals/inorganics contained in wastewaters

Roasting or retorting for mercury in nonwastewaters

Amalgamation for elemental mercury with radioactive materials

Incineration for organic-mercury compounds.

Stabilization of technology treatment or wastewater; low mercury treatment residues.

\section{TREATMENT STANDARD - WASTEWATERS CATEGORY}

All mercury wastewater treated to concentration of $0.15 \mathrm{mg} / \mathrm{L}$ and meet 268.48 standards, based on analysis of composite samples.

\section{TREATMENT STANDARD - NONWASTEWATERS CATEGORIES}

Nonwastewaters that exhibit, or are expected to exhibit, the characteristic of toxicity for mercury based on the toxicity characteristic leaching procedure (TCLP) in SW 846; and contain greater than or equal to 260 $\mathrm{mg} / \mathrm{kg}$ total mercury that also contain organics and are not incinerator residues. (High Mercury-Organic Subcategory.) The treatment standard for this subcategory is IMERC or RMERC.

Nonwastewaters that exhibit, or are expected to exhibit, the characteristic of toxicity for mercury based on the TCLP in SW 846; and contain greater than or equal to $260 \mathrm{mg} / \mathrm{kg}$ total mercury that are inorganic, 
including incinerator residues and residue from RMERC. (High Mercury-Inorganic Subcategory.) The treatment standard for this subcategory is RMERC.

Nonwastewaters that exhibit, or are expected to exhibit, the characteristic of toxicity for mercury based on the TCLP in SW 846; and contain less than $260 \mathrm{mg} / \mathrm{kg}$ total mercury and that are residues from RMERC. (Low Mercury Subcategory.) The treatment standard for this subcategory is $0.20 \mathrm{mg} / \mathrm{L}$ TCLP and meet 268.48 standard for UHC

All other nonwastewaters that exhibit, or are expected to exhibit, the characteristic of toxicity for mercury based on the TCLP in SW 846; and contain less than $260 \mathrm{mg} / \mathrm{kg}$ total mercury and that are not residues from RMERC. (Low Mercury Subcategory.) The treatment standard for this subcategory is $0.025 \mathrm{mg} / \mathrm{L}$ TCLP and meet 268.48 standard for UHC.

\section{TECHNOLOGY TREATMENT STANDARDS}

AMLGM - amalgamation of liquid, elemental mercury contaminated with radioactive materials using inorganic reagents such as copper, zinc, nickel, gold, and sulfur that results in a nonliquid, semisolid amalgam and thereby reducing potential emissions of elemental mercury vapors to the air.

DEACT - Deactivation to remove the hazardous characteristics of a waste due to its ignitability, corrosivity, and/or reactivity.

HLVIT - Vitrification of high level mixed radioactive wastes in units in compliance with all applicable radioactive protection requirements under control of the NRC.

IMERC - Incineration of wastes containing organics and mercury in units operated in accordance with the technical operating requirements of 40 CFR Part 264 Subpart $O$ and Part 265 subpart $O$. All wastewater and nonwastewater residues derived from this process must then comply with the corresponding treatment standards per waste code with consideration of any subcategories (e.g., High or Low Mercury subcategories).

RMERC - Retorting or roasting in a thermal processing unit capable of volatilizing mercury and subsequently condensing the volatilized mercury for recovery. The retorting or roasting unit (or facility must be subject to one or more of the following: (a) a National Emissions Standard for Hazardous Air Pollutants (NESHAP) for mercury; (b) a Best Available Control Technology (BACT) or a lowest Achievable Emission Rate (LEAR) standard for mercury imposed pursuant to a Prevention of Significant Deterioration (PSD) permit; or (c) a state permit that establishes emission limitations (within meaning of Section 302 of the Clean air Act) for mercury. All wastewater and nonwastewater residues derived from this process must then comply with the corresponding treatment standards per waste code with consideration of any applicable subcategories (e.g., High or Low Mercury Subcategories).

STABL - Stabilization with the following reagents or (waste reagents) or combinations of reagents: (1) Portland cement; or (2) lime/pozzolans (e.g., fly ash and cement kiln dust) - This does not preclude the addition of reagents (e.g., iron salts, silicates, and clays) designed to enhance the set/cure time and/or compressive strength, or to overall reduce the leachability of the metal or inorganic. 


\section{Appendix D \\ Mercury Precipitation Scoping Study}


Project File Number SPR-HG-001

Project/Task Mercury, Chloride, and Technetium Studies

Subtask Mercury Precipitation Scoping Study

\begin{tabular}{|c|c|c|c|c|c|}
\hline \multicolumn{6}{|c|}{ Mercury Precipitation from Carbonate Wash Solution } \\
\hline \multicolumn{6}{|l|}{ Summary: } \\
\hline \multicolumn{6}{|c|}{$\begin{array}{l}\text { TRUEX processing of dissolved calcine and sodium-bearing waste could generate a } \\
\text { carbonate wash effluent containing mercury in excess of } 100 \mathrm{mg} / \mathrm{L} \text {. One option for } \\
\text { treating this wash water is to precipitate and remove the mercury. Laboratory tests were } \\
\text { conducted on carbonate wash simulants to identify a suitable precipitating agent, } \\
\text { determine the residual mercury in the treated effluent, and to assess characteristics of the } \\
\text { resultant suspension or sludge. Calcium sulfide was preferred over sodium sulfide and a } \\
\text { mercaptan-based precipitant as it produced relatively large, dense flocs of mercuric } \\
\text { sulfide and resulted in low residual mercury levels in the treated water. Solids readily } \\
\text { settled from solution and separation was accomplished by simple decanting. Effluent } \\
\text { concentrations in the treated wash were as low as } 0.1 \mathrm{mg} / \mathrm{L} \mathrm{Hg} \text {; this from a feed } \\
\text { containing mercury at } 400 \mathrm{mg} / \mathrm{L} \text {. Control of excess sulfide, to less than about } 25 \% \text {, is } \\
\text { critical in maintaining low mercury levels as it was found that increased sulfide levels was } \\
\text { accompanied by increased residual mercury. }\end{array}$} \\
\hline \multicolumn{6}{|c|}{$\begin{array}{l}\text { Distribution (complete package): R. S. Herbst, J. D. Law, A. L. Olson, T. A. Todd } \\
\text { Distribution (summary package only): }\end{array}$} \\
\hline $\begin{array}{l}\text { Author Sign.: } \\
\text { A. Heyfoue }\end{array}$ & $\begin{array}{l}\text { Dept. } \\
4170\end{array}$ & $\mid \begin{array}{l}\text { Reviewed: } \\
\text { e m Burne }\end{array}$ & $\begin{array}{l}\text { Date } \\
4 / 15 / 99\end{array}$ & $\begin{array}{l}\text { Approved: } \\
\text { :/Lflecolisen }\end{array}$ & $\begin{array}{l}\text { Date } \\
4-19-99\end{array}$ \\
\hline $\begin{array}{l}\text { Author: } \\
\text { D. R. Haefner }\end{array}$ & & $\begin{array}{l}\text { LMITCO } \\
\text { Reviewer: } \\
\text { C. M. Barnes }\end{array}$ & & $\begin{array}{l}\text { LMFCO } \\
\text { Approval } \\
\text { V. L. Jacobson }\end{array}$ & \\
\hline
\end{tabular}




\subsection{INTRODUCTION}

Sodium-bearing waste (SBW) is generated as a result of operations at the Idaho Nuclear Technology and Engineering Center (INTEC). SBW is an aqueous waste containing moderate levels of actinides and fission products as well as non-radioactive metals. One potentially troublesome non-radioactive metal is mercury, which is regulated by the EPA and may be present beyond $1000 \mathrm{mg} / \mathrm{L}$ in sodium-bearing wastes. Approximately $4000 \mathrm{~m}^{3}$ of calcine has been generated at INTEC over the last 30 years. Aluminum based calcine from the Waste Calcine Facility is known to contain high levels of mercury and dissolution of this calcine will result in a solution laden with mercury. Various treatment alternatives are being evaluated for treatment of dissolved calcine and SBW. One such treatment, termed the "Full Separations" option, involves a Transuranic Extraction (TRUEX) process, wherein an organic solvent is used to extract actinides from the dissolved calcine and SBW. However, it has been found that mercury is also extracted along with the actinides into the organic phase. Subsequent washing of the spent TRUEX solvent with a sodium carbonate solution strips mercury from the solvent. When processing SBW or aluminum calcine, mercury levels in this carbonate wash will likely exceed $260 \mathrm{mg} / \mathrm{L}$, invoking treatment as specified by RCRA regulations.

Successful development of the TRUEX process requires that a suitable means of treating the mercury-laden carbonate wash be found. One concept is to precipitate and remove the mercury, and then recycle the water or combine it with another stream such as the low activity waste. To more fully understand how mercury precipitation might be implemented, laboratory studies were undertaken to determine: (1) a suitable precipitating agent, (2) the residual mercury levels expected after precipitation, and (3) the characteristics of the precipitants and the ability to filter and/or decant them. The results of these studies are detailed in this document.

\subsection{EXPERIMENTAL APPROACH AND RESULTS}

Mercuric sulfide is one of the least soluble compounds known and is typically found in geologic deposits as a red crystalline material called cinnabar. When precipitated from solutions with sulfide, black amorphous mercuric sulfide is produced; however, even this amorphous form has an extremely low solubility with a $\mathrm{K}_{\text {sp }}$ approaching $10^{-53}$. Mercuric sulfide is impervious to most acids and $\mathrm{pH}$ control of the precipitated material is not as critical as with other compounds such as hydroxides or phosphates. For these reasons sulfide precipitation is an attractive means of removing mercury from waste solutions. ${ }^{1,2}$

Sulfide precipitation does suffer a few disadvantages not encountered with other precipitants. One is the potential generation of toxic $\mathrm{H}_{2} \mathrm{~S}$ fumes, however this problem can be mitigated by ensuring that the target solution has a $\mathrm{pH}$ above 8 . Sulfide precipitation is also known to produce very fine particles and can form stable colloidal suspensions. Flocculants are then required to break the suspension and allow separation of precipitated material. 
Two series of tests were performed in the laboratory experiments. The first series used a "clean" test solution composed of $0.25 \mathrm{M}$ sodium carbonate to which $\mathrm{HgCl}_{2}$ was added. Three chemical agents were used to precipitate mercury and the performance of the three were compared. The preferred agent from Series ${ }^{\#} 1$ was then used in Series ${ }^{\#} 2$, where the test solution was a carbonate wash resulting from the TRUEX demonstration experiment.

\subsection{Experimental Method}

A consistent procedure was followed throughout the precipitation studies so that an unbiased comparison between precipitants could be made. All precipitation tests were carried out in $250 \mathrm{ml}$ beakers into which $100 \mathrm{ml}$ of test solution was charged. A magnetic stirrer, operated at slow/medium setting, provided constant well-mixed conditions. $\mathrm{Na}_{2} \mathrm{~S}$ and $\mathrm{CaS}$ were preweighed and added as solid reagents, whereas the TMT-15 is a liquid and was added by pipetting into the test solution. After precipitant was added, the test solution was stirred for 20 minutes. All tests were conducted at ambient conditions.

\subsection{Series ${ }^{\#} 1$ Tests}

Several objectives were outlined as being of interest in the first series, one of which was to determine the saturation loading of mercury in carbonate solution. Mercuric chloride, a white powder, was added to a stock solution of $0.25 \mathrm{M}$ sodium carbonate. Immediately after adding $\mathrm{HgCl}_{2}$, an orange/rust colored precipitate formed - this was most likely a mercury oxide compound. The filtered supernate was analyzed and found to contain mercury at $94 \mathrm{mg} / \mathrm{L}$. This supernate was used throughout the Series ${ }^{\#} 1$ tests.

The primary objective of the first series was to evaluate various precipitating agents and their potential use in an operating system. Sodium sulfide and calcium sulfide were the two sources of sulfide used in the Series ${ }^{\#} 1$ tests. Although both will result in $\mathrm{HgS}$ formation, it was thought that calcium might be better suited for this application since it will form insoluble calcium carbonate, which when co-precipitated with $\mathrm{HgS}$, may promote larger floc formation. In addition to sulfide compounds, a proprietary mercaptan-based precipitant, TMT-15 from Degussa Corporation, was also tested.

Test results for Series " 1 are given in Table 1. Dosages are expressed as "\% Excess" and were based on a feed concentration of $94 \mathrm{mg} / \mathrm{L} \mathrm{Hg}$. Calcium sulfide, at $50 \%$ excess, resulted in the lowest residual mercury concentration. Both sodium and calcium sulfide produced the expected black $\mathrm{HgS}$ precipitates and resulted in relatively large and well-formed flocs. These flocs were formed during the first 5 minutes after adding the chemical agents. Separation of the HgS sludge was easily accomplished by simply decanting the supernate about 15 minutes after mixing was halted. TMT-15 produced a relatively non-dense, cream colored precipitate that required several hours to settle. Calcium sulfide was the preferred precipitant since it produced the lowest residual mercury level and formed a dense sludge easy to separate form the treated liquid. 
Table 1. Analytical data for the Series ${ }^{\#} 1$ precipitation studies using a wash simulant of $0.25 \mathrm{M}$ $\mathrm{Na}_{2} \mathrm{CO}_{3}$ with mercuric chloride.

\begin{tabular}{|c|c|c|c|}
\hline Sample ID & Precipitant & $\begin{array}{c}\text { \% Excess } \\
\text { precipitant }\end{array}$ & $\begin{array}{c}\text { Mercury conc. } \\
\text { (mg/L) }\end{array}$ \\
\hline Raw Feed & - & - & 94 \\
\hline $\mathrm{Na}$ & Sodium sulfide & $46 \%^{2}$ & 0.74 \\
\hline $\mathrm{Ca}$ & Calcium sulfide & $50 \%$ & 0.054 \\
\hline $\mathrm{Ca} 2$ & Calcium sulfide & $128 \%$ & 0.51 \\
\hline $\mathrm{TMT}$ & TMT-15 & $26 \%$ & 0.12 \\
\hline
\end{tabular}

Notes:

$a$ - The source of sodium sulfide was $\mathrm{Na}_{2} \mathrm{~S} \cdot 9 \mathrm{H}_{2} \mathrm{O}$; however, the material received from the storeroom was old and had freestanding liquid in the container. Crystalline material was chipped from the container and used as $\mathrm{Na}_{2} \mathrm{~S} \cdot 9 \mathrm{H}_{2} \mathrm{O}$, however, the accuracy of the calculated sulfide dose is highly questionable.

b- TMT-15 is Degussa Corporation's tradename for a 15 wt\% solution of trisodium trimercapto-s-triazine.

\subsection{Series ${ }^{\#} 2$ Tests}

The second series of tests used a carbonate wash generated from the TRUEX process demonstration on surrogate sodium-bearing waste. The resulting carbonate wash had a mercury level of about $400 \mathrm{mg} / \mathrm{L}$, which is significantly higher than the solution prepared in Series ${ }^{\#}$. The higher levels might have been due to the formation of stable mercury chloride complexes. This conjecture is supported by the high chloride levels in the demonstration carbonate wash. Another possibility is that mercury is bound as an organic complex (maybe with the TRUEX solvent or a component in the solvent) and migrating into the carbonate wash.

Regardless of the mercury speciation, precipitation tests were undertaken with $\mathrm{CaS}$ to determine the level of mercury removal by the sulfide. Dosages were varied in six precipitation experiments and the corresponding analytical results are given in Table 2 . The results show that sulfide is highly effective at scavenging mercury in a single precipitation step, reducing the level from about 400 to $0.1 \mathrm{mg} / \mathrm{L}$. This is $99.975 \%$ removal of the mercury. The data also indicates that excessive sulfide, say beyond $25 \%$, is actually detrimental to performance. This trend is clearly shown in Table 2 where residual mercury steadily increases as the excess sulfide is increased.

Another aspect of these studies was to determine the general character of the precipitated material and the ease of separating $\mathrm{HgS}$. Similar to Series \#1 tests, the flocs produced were fairly large and well-formed. Previous experience has shown that sulfide addition can result in very fine precipitates. In this study, sulfide was added as a solid which may be beneficial in forming larger flocs since the amount of free sulfide is limited by the dissolution rate of CaS. Approximately 15 minutes after stirring was halted, all precipitated material had settled out of solution and the resulting supernate was clear and free of any visable HgS. Samples of the sludge were analyzed for particle size distribution. The graphical display of the data and a corresponding statistical analysis (mean and median particle sizes, accumulated size distribution, etc.) are given in the Attachment. 
Table 2. Analytical results for precipitation studies on the carbonate wash from the TRUEX demonstration experiment.

\begin{tabular}{|c|c|c|}
\hline Sample ID & $\begin{array}{c}\text { \% Excess } \\
\text { sulfide }^{\mathbf{a}}\end{array}$ & $\begin{array}{c}\text { Mercury } \\
\text { conc. }^{\text {(mg/L) }}\end{array}$ \\
\hline Carbonate wash $^{\mathrm{b}}$ & --- & 450 \\
\hline Carbonate wash $^{\mathrm{b}}$ & ---- & 350 \\
\hline $\mathrm{CaS}-1$ & $-7.6^{\mathrm{c}}$ & 0.92 \\
\hline $\mathrm{CaS}-2$ & 17 & 0.10 \\
\hline $\mathrm{CaS}-3$ & 25 & 0.16 \\
\hline $\mathrm{CaS}-4$ & 48 & 0.64 \\
\hline $\mathrm{CaS}-5$ & 68 & 0.84 \\
\hline $\mathrm{CaS}-6$ & 125 & 2.9 \\
\hline
\end{tabular}

Notes:

a-Stoichiometric calcium sulfide dose was based on a carbonate feed of $400 \mathrm{mg} / \mathrm{L} \mathrm{Hg}$.

$b-T$ wo carbonate wash samples were prepared and provided to the analytical lab on two different occasions.

$c-A$ negative value indicates a substoichiometric charge of sulfide.

\subsection{CONCLUDING COMMENTS}

Experimental scoping studies were conducted to determine the suitability of using precipitation to remove mercury from carbonate water. This information is pertinent to TRUEX process development where the carbonate wash will probably contain mercury in excess of 100 $\mathrm{mg} / \mathrm{L}$. Of the three precipitants evaluated, calcium sulfide was preferred. It is a fine, freeflowing white powder that's easy to weigh and dispense. When added as a solid, $\mathrm{CaS}$ dissolves slow enough that $\mathrm{HgS}$ forms relatively large flocs. Floc formation may also have been promoted by $\mathrm{CaCO}_{3}$, which also precipitates as calcium becomes available. Separation of the sludge from the supernate was accomplished by simply decanting - filtration was unnecessary.

Analytical results show that mercury effluent levels of about $0.1 \mathrm{mg} / \mathrm{L}$ are attainable in a single precipitation stage. These results were achieved on a carbonate feed stream containing $400 \mathrm{mg} / \mathrm{L} \mathrm{Hg}$, where the mercury was presumably complexed with chloride and/or organics. Sulfide dosage was identified as an important process control parameter as a large excess (greater than 50\%) will cause solubilization of the HgS.

\subsection{REFERENCES}

1. W. M. Latimer and J. H. Hildebrand, Reference Book of Inorganic Chemistry, The Macmillan Comp., 1951.

2. D. R. Lide, editor, $C R C$ Handbook of Chemistry and Physics, $72^{\text {nd }}$ Edition, The Chemical Rubber Comp, 1991. 


\begin{abstract}
Attachment
Precipitation samples were analyzed for particle sizing. The following pages are a copy of the report summarizing the findings. Samples included "CWS2" and "CWS3" from $\mathrm{CaS}$ precipitation, "MSNA1" from $\mathrm{Na}_{2} \mathrm{~S}$, and "MSDG1" from TMT-15. The distributions from $\mathrm{Na}_{2} \mathrm{~S}$ and TMT-15 show a single distinct peak, whereas the distribution from $\mathrm{CaS}$ shows one prominent peak at about $20 \mu \mathrm{m}$ and another less distinctive one at about 60 to 80 . Presumably the largest peak is due to $\mathrm{HgS}$, while the other is likely from $\mathrm{CaCO}_{3}$.
\end{abstract}




\section{LS Particle Size Analyzer}

File name: $\quad$ cws2.\$01

Sample ID: $\quad$ CWS2

Jperator: $\quad$ TAB

Comments: D. Haefner Separations Precipitation sample CWS.2

Optical model: Fraunhofer PIDS included

LS $230 \quad$ Hazardous Fluids Module

Start time: $\quad 8: 2018 \mathrm{Mar} 1999$

Pump speed: $\quad 20$

Obscuration: $\quad 8 \%$

PIDS Obscur: $\quad 55 \%$

Fluid: Water

Software: $\quad 2.11$

File name: $\quad$ cws2.\$O2

Sample ID: $\quad$ CWS2

Operator: $\quad \mathrm{TAB}$

Comments: D. Haefner Separations Precipatation sample CWS,2

Optical model: Fraunhofer PIDS included

LS 230

Start time:

Pump speed:

Obscuration:

PIDS Obscur:

Fluid:

Software:
Hazardous Fluids Module

11:27 18 Mar 1999 Run length: 65 Seconds

25

$10 \%$

$54 \%$

Water

2.11

Firmware: $\quad 2.022 .02$
Run length: 66 Seconds

Firmware: $\quad 2.022 .02$
Run number: 1

Group ID: $\quad$ CWS2

Run number: 2

Group ID: CWS2

\section{CWS2 Samples}

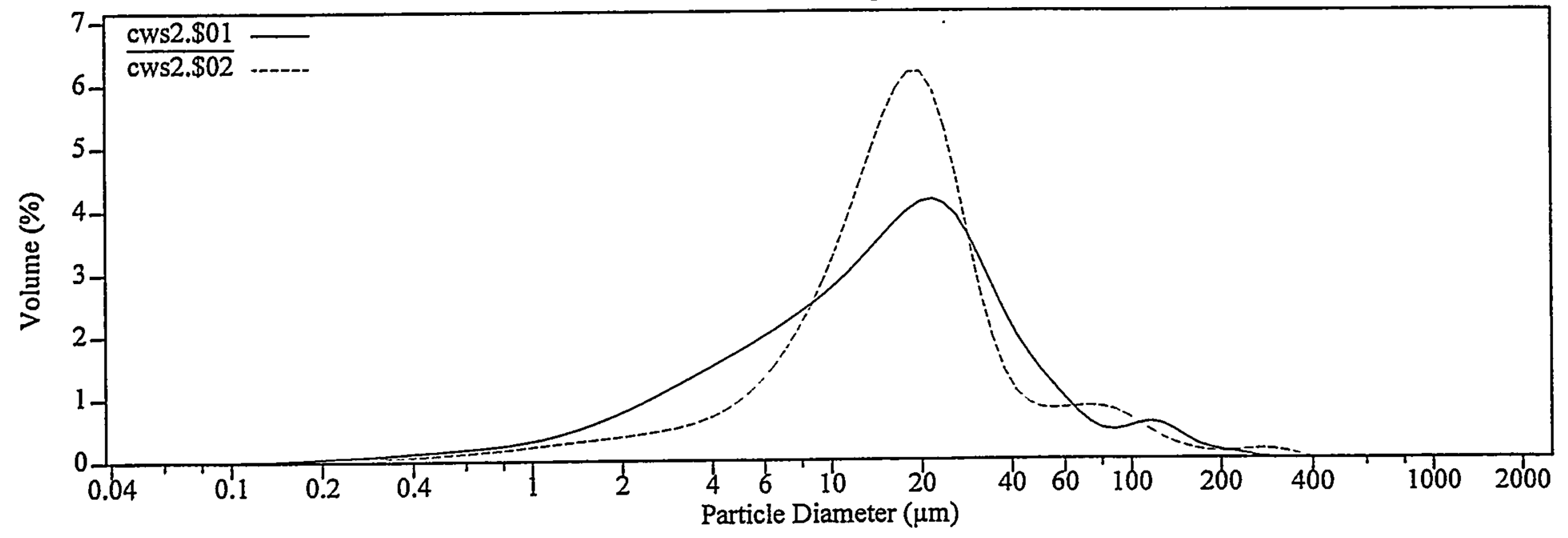




\section{LS Particle Size Analyzer}

Volume Statistics (Geometric) cws2.\$01

Calculations from $0.040 \mu \mathrm{m}$ to $2000 \mu \mathrm{m}$

$\begin{array}{llll}\text { Volume } & 100.0 \% & & \\ \text { Mean: } & 13.00 \mu \mathrm{m} & 95 \% \text { Conf. Limits: } & 1.346-125.6 \mu \mathrm{m} \\ \text { Median: } & 15.32 \mu \mathrm{m} & \text { S.D.: } & 3.180 \\ \text { Mean/Median Ratio: } & 0.849 & \text { Variance: } & 10.11 \\ \text { Mode: } & 21.69 \mu \mathrm{m} & \text { Skewness: } & -0.612 \text { Left skewed } \\ & & \text { Kurtosis: } & 0.818 \text { Leptokurtic }\end{array}$

$\begin{array}{llllll}\%> & 10 & 25 & 50 & 75 & 90 \\ \text { Size } \mu \mathrm{m} & 46.70 & 27.43 & 15.32 & 6.698 & 2.800\end{array}$

Volume Statistics (Geometric) cws2.\$02

Calculations from $0.040 \mu \mathrm{m}$ to $2000 \mu \mathrm{m}$

$\begin{array}{llll}\text { Volume } & 100.0 \% & & \\ \text { Mean: } & 15.58 \mu \mathrm{m} & 95 \% \text { Conf. Limits: } & 2.274-106.8 \mu \mathrm{m} \\ \text { Median: } & 16.91 \mu \mathrm{m} & \text { S.D.: } & 2.670 \\ \text { Mean/Median Ratio: } & 0.922 & \text { Variance: } & 7.126 \\ \text { Mode: } & 19.76 \mu \mathrm{m} & \text { Skewness: } & -0.646 \text { Left skewed } \\ & & \text { Kurtosis: } & \text { 2.422 Leptokurtic }\end{array}$

$\begin{array}{llllll}\%> & 10 & 25 & 50 & 75 & 90\end{array}$

$\begin{array}{llllll}\text { Size } \mu \mathrm{m} & 44.67 & 25.16 & 16.91 & 10.38 & 5.108\end{array}$


File name: cws3.\$01 Group ID: CWS3

Sample ID: $\quad$ CWS3

Operator: $\quad \mathrm{TAB}$

Run number: 1

Comments: $\quad$ D. Haefner Separations Precipitation sample CWS.3

Optical model: Fraunhofer PIDS included

LS 230 Hazardous Fluids Module

Start time: $\quad 8: 4318$ Mar $1999 \quad$ Run length: 64 Seconds

Pump speed: $\quad 20$

Obscuration: $\quad 7 \%$

PIDS Obscur: $\quad 45 \%$

Fluid: $\quad$ Water

Software: $\quad 2.11$

Firmware: $\quad 2.022 .02$

File name: cws3.\$02 Group ID: CWS3

Sample ID: $\quad$ CWS3

Operator: $\quad \mathrm{TAB}$

Run number: 2

Comments: D. Haefner Separations Precipatation sample CWS.3

Optical model: Fraunhofer PIDS included

LS $230 \quad$ Hazardous Fluids Module

Start time: $\quad 10: 3918$ Mar $1999 \quad$ Run length: 66 Seconds

Pump speed: $\quad 25$

Obscuration: $\quad 7 \%$

PIDS Obscur: $\quad 46 \%$

Fluid: $\quad$ Water

$\begin{array}{llll}\text { Software: } & 2.11 & \text { Firmware: } & 2.022 .02\end{array}$

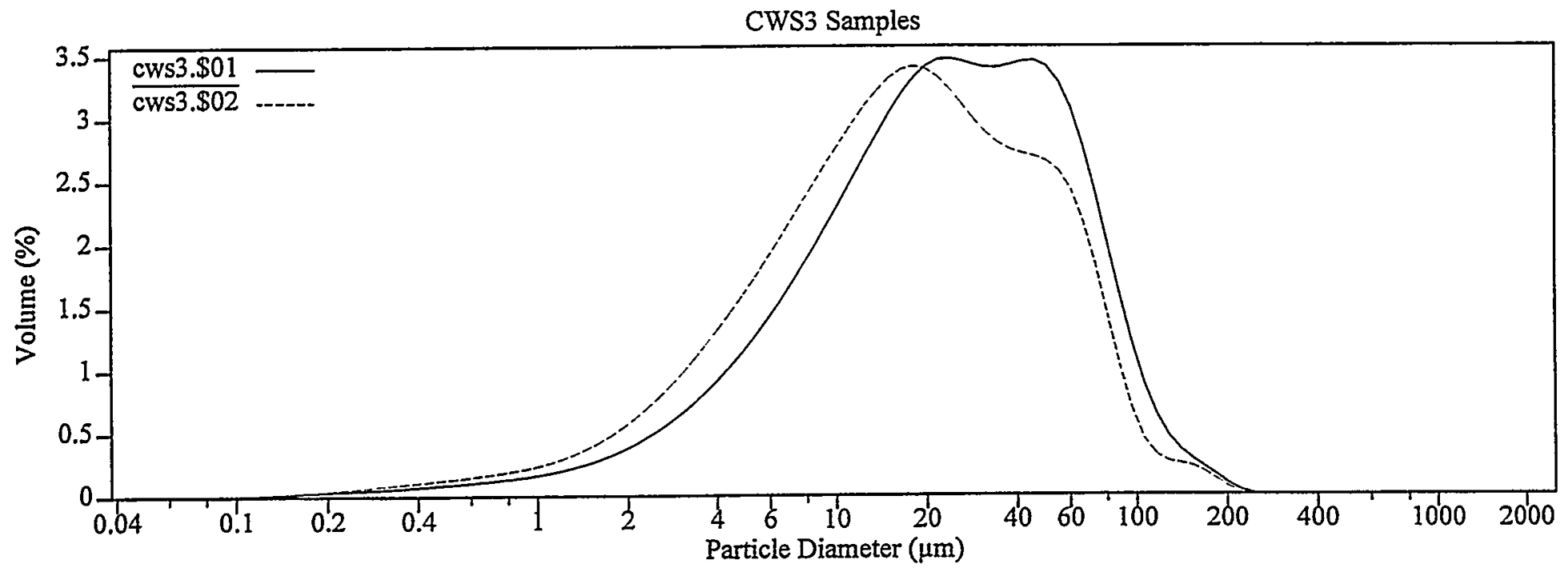




\section{LS Particle Size Analyzer}

\section{$P ;$}

Volume Statistics (Geometric)

cws3.\$01

Calculations from $0.040 \mu \mathrm{m}$ to $2000 \mu \mathrm{m}$

Volume

Mean:

Median:

Mean/Median Ratio

Mode:

$100.0 \%$

$20.02 \mu \mathrm{m}$

$22.97 \mu \mathrm{m}$

0.872

$23.81 \mu \mathrm{m}$

$\%>\quad 10$

Size $\mu \mathrm{m} \quad 70.59$

$$
25
$$

45.33

50

22.97
95\% Conf. Limits:

S.D.:

Variance:

Skewness: $\quad-0.895$ Left skewed

Kurtosis: $\quad 1.298$ Leptokurtic

Volume Statistics (Geometric)

cws3.\$02

Calculations from $0.040 \mu \mathrm{m}$ to $2000 \mu \mathrm{m}$

$\begin{array}{ll}\text { Volume } & 100.0 \% \\ \text { Mean: } & 15.42 \mu \mathrm{m} \\ \text { Median: } & 17.19 \mu \mathrm{m} \\ \text { Mean/Median Ratio: } & 0.897 \\ \text { Mode: } & 18.00 \mu \mathrm{m}\end{array}$

$\%>$

10

Size $\mu \mathrm{m}$
61.17

$$
\begin{aligned}
& 100.0 \% \\
& 15.42 \mu \mathrm{m} \\
& 17.19 \mu \mathrm{m} \\
& 0.897 \\
& 18.00 \mu \mathrm{m}
\end{aligned}
$$

$\begin{array}{llllll}\%> & 10 & 25 & 50 & 75 & 90 \\ \text { Size } \mu \mathrm{m} & 61.17 & 36.08 & 17.19 & 7.832 & 3.461\end{array}$

$\begin{array}{lc}\text { 95\% Conf. Limits: } & 1.613-147.3 \mu \mathrm{m} \\ \text { S.D.: } & 3.163 \\ \text { Variance: } & 10.01 \\ \text { Skewness: } & -0.709 \text { Left skewed } \\ \text { Kurtosis: } & \text { 0.752 Leptokurtic }\end{array}$

3.461 
File name: msdg1.\$01 Group ID: MSDG1

Sample ID: $\quad$ MSDG1

Jperator: $\quad \mathrm{TAB} \quad$ Run number: 1

Comments: D. Haefner Separations Precipitation sample MS.DG1

A fairly "white-ish" precipatate (by visual inspection)

Optical model: Fraunhofer PDS included

LS $230 \quad$ Hazardous Fluids Module

Start time: 7:29 18 Mar $1999 \quad$ Run length: 66 Seconds

Pump speed: $\quad 20$

Obscuration: $\quad 0 \%$

PIDS Obscur: $\quad 17 \%$

Fluid: $\quad$ Water

Software: $\quad 2.11$

Firmware: $\quad 2.022 .02$

File name: $\quad$ msdg1.\$02 Group ID: MSDG1

Sample ID: $\quad$ MSDG1

Operator: $\quad T A B$

Run number: 2

Comments: D. Haefner Separations Precipatation sample MS.DGI

"white-ish" precipatate; all others black; pump speed to $25 \%$

Optical model: Fraunhofer PIDS included

LS 230 Hazardous Fluids Module

Start time: $\quad 9: 3218 \mathrm{Mar} 1999 \quad$ Run length: 78 Seconds

Pump speed: $\quad 25$

Obscuration: $\quad 2 \%$

PIDS Obscur: $\quad 43 \%$

Fluid: Water

$\begin{array}{llll}\text { Software: } & 2.11 & \text { Firmware: } & 2.022 .02\end{array}$

MSDG1 Samples

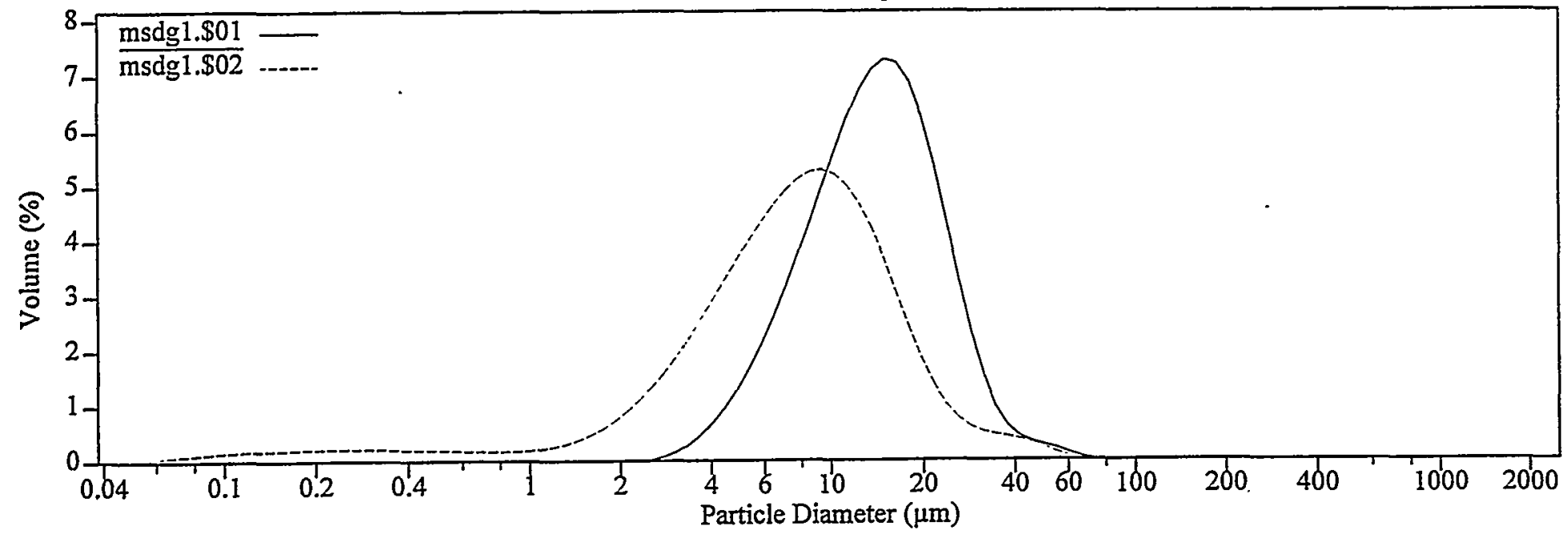




\section{LS Particle Size Analyzer}

$\mathrm{Pa}$.

Volume Statistics (Geometric) msdg1.\$01

Calculations from $0.040 \mu \mathrm{m}$ to $2000 \mu \mathrm{m}$

$\begin{array}{llll}\text { Volume } & 100.0 \% & & \\ \text { Mean: } & 13.42 \mu \mathrm{m} & 95 \% \text { Conf. Limits: } & 4.879-36.92 \mu \mathrm{m} \\ \text { Median: } & 13.86 \mu \mathrm{m} & \text { S.D.: } & 1.676 \\ \text { Mean/Median Ratio: } & 0.969 & \text { Variance: } & 2.808 \\ \text { Mode: } & 14.94 \mu \mathrm{m} & \text { Skewness: } & -0.173 \text { Left skewed } \\ & & \text { Kurtosis: } & -0.075 \text { Platykurtic }\end{array}$

$\begin{array}{llllll}\%> & 10 & 25 & 50 & 75 & 90 \\ \text { Size } \mu \mathrm{m} & 25.18 & 19.26 & 13.86 & 9.545 & 6.692\end{array}$

Volume Statistics (Geometric) msdg1.\$02

Calculations from $0.040 \mu \mathrm{m}$ to $2000 \mu \mathrm{m}$

$\begin{array}{ll}\text { Volume } & 100.0 \% \\ \text { Mean: } & 6.516 \mu \mathrm{m} \\ \text { Median: } & 7.723 \mu \mathrm{m} \\ \text { Mean/Median Ratio: } & 0.844 \\ \text { Mode: } & 9.371 \mu \mathrm{m}\end{array}$

$\%>$

$$
10
$$

Size $\mu \mathrm{m} \quad 17.58$

\begin{abstract}
25
\end{abstract}

12.13

$95 \%$ Conf. Limits:

S.D.:

Variance:

Skewness: $\quad-1.678$ Left skewed

Kurtosis: $\quad 4.300$ Leptokurtic
$0.857-49.56 \mu \mathrm{m}$
2.816

90

$\begin{array}{lll}50 & 75 & 90 \\ 7.723 & 4.500 & 2.337\end{array}$




\begin{tabular}{|c|c|c|c|}
\hline File name: & msna1.\$01 & Group ID: & MSNa1 \\
\hline jample ID: & MSNal & & \\
\hline Jperator: & TAB & Run number: & 1 \\
\hline Jomments: & D. Haefner Separations Preci & pitation sample I & MS.Na.1 \\
\hline Jptical model: & Fraunhofer PDS included & & \\
\hline$S 230$ & Hazardous Fluids Module & & \\
\hline 3tart time: & $7: 55 \quad 18 \mathrm{Mar} 1999$ & Run length: & 65 Seconds \\
\hline 'ump speed: & 20 & & \\
\hline Jbscuration: & $3 \%$ & & \\
\hline गIDS Obscur: & $22 \%$ & & \\
\hline id. & Wate & & \\
\hline
\end{tabular}

joftware: $\quad 2.11$

Firmware: $\quad 2.022 .02$

iile name: msnal.\$02 Group ID: MSNa1

jample ID: $\quad$ MSNa1

Jperator: $\quad \mathrm{TAB} \quad$ Run number: 2

Jomments: $\quad$ D. Haefner Separations Precipatation sample MS.Na.1

Iptical model: Fraunhofer PIDS included

s $230 \quad$ Hazardous Fluids Module

itart time: $\quad 11: 0618$ Mar $1999 \quad$ Run length: 65 Seconds

'ump speed: 25

Jbscuration: $\quad 5 \%$

'IDS Obscur: $\quad 26 \%$

iluid: Water

Software: $\quad 2.11 \quad$ Firmware: 2.022 .02

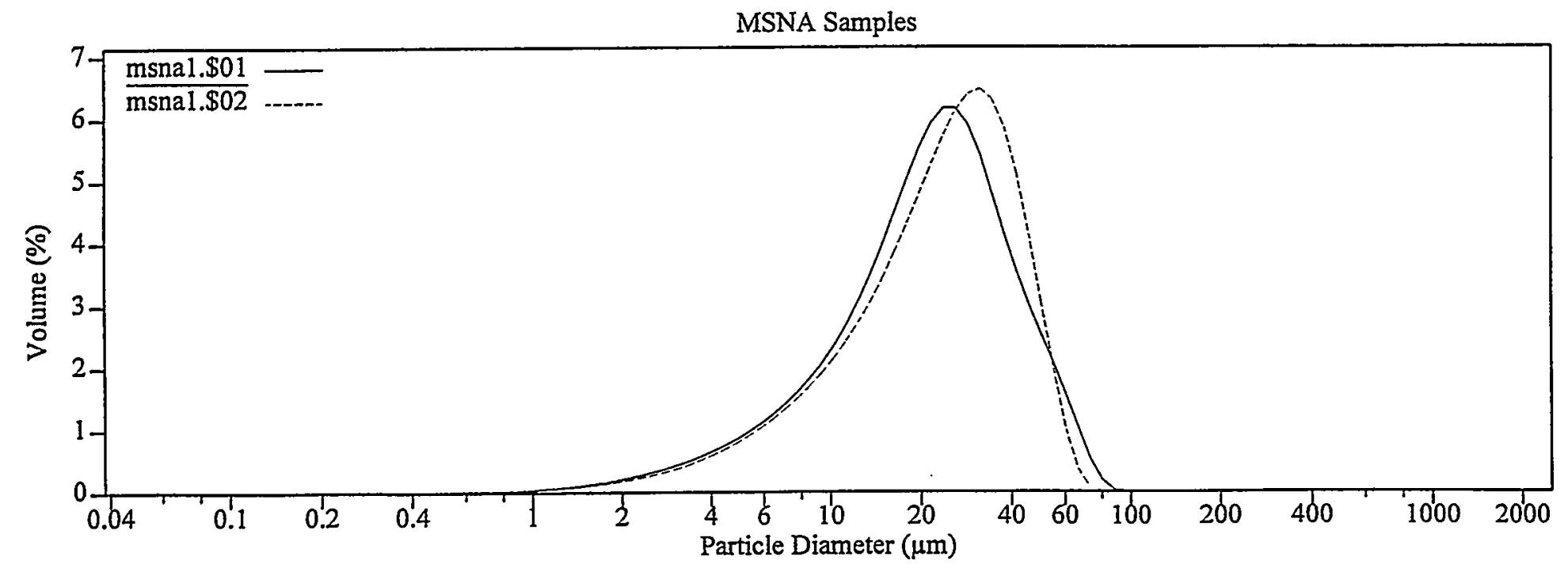




\section{LS Particle Size Analyzer}

Volume Statistics (Geometric) msnal $\$ 01$

Calculations from $0.040 \mu \mathrm{m}$ to $2000 \mu \mathrm{m}$

$\begin{array}{ll}\text { Volume } & 100.0 \% \\ \text { Mean: } & 19.43 \mu \mathrm{m} \\ \text { Median: } & 21.80 \mu \mathrm{m} \\ \text { Mean/Median Ratio: } & 0.892 \\ \text { Mode: } & 23.81 \mu \mathrm{m}\end{array}$

$\begin{array}{lc}\text { 95\% Conf. Limits: } & 4.604-82.03 \mu \mathrm{m} \\ \text { S.D.: } & 2.085 \\ \text { Variance: } & 4.347 \\ \text { Skewness: } & -0.901 \text { Left skewed } \\ \text { Kurtosis: } & \text { 1.029 Leptokurtic }\end{array}$

$\begin{array}{llllll}\%> & 10 & 25 & 50 & 75 & 90 \\ \text { Size } \mu \mathrm{m} & 45.12 & 32.23 & 21.80 & 13.29 & 7.155\end{array}$

Volume Statistics (Geometric) msnal.\$02

Calculations from $0.040 \mu \mathrm{m}$ to $2000 \mu \mathrm{m}$

$\begin{array}{llll}\text { Volume } & 100.0 \% & & \\ \text { Mean: } & 20.20 \mu \mathrm{m} & 95 \% \text { Conf. Limits: } & 4.625-88.18 \mu \mathrm{m} \\ \text { Median: } & 23.75 \mu \mathrm{m} & \text { S.D.: } & 2.121 \\ \text { Mean/Median Ratio: } & 0.850 & \text { Variance: } & 4.500 \\ \text { Mode: } & 31.50 \mu \mathrm{m} & \text { Skewness: } & -1.419 \text { Left skewed } \\ & & \text { Kurtosis: } & 3.533 \text { Leptokurtic }\end{array}$

$\begin{array}{llllll}\%> & 10 & 25 & 50 & 75 & 90\end{array}$

$\begin{array}{llllll}\text { Size } \mu \mathrm{m} & 44.28 & 34.49 & 23.75 & 14.02 & 7.390\end{array}$




\section{Appendix E \\ Mercury Sensitivity Study}


Project File Number 01102

Project/Task Mercury, Chloride and Technetium Removal Studies

Subtask Mercury Sensitivity Study

Title: $\quad$ Sensitivity of Mercury Flowrates and Concentrations in the Full

Separations Material Balance to Changes in Process Parameters and

Process Schemes

Summary: Mercury is present in sodium bearing waste (SBW), alumina calcine, and in trace amounts in other calcines, all of which are feeds to the Full Separations treatment process. The Maximum Achievable Control Technology (MACD) regulations limit mercury releases from the stack, and the mercury concentrations in the final solid waste streams from Full Separations are limited because of upstream high temperature processes. Thus either a process step is needed to specifically remove mercury in the Full Separations process, which would result in a separate mercury waste, or offgas scrub solutions containing mercury will require grouting, either in combination with the denitration solids or as a separate waste. If not removed as a separate waste, mercury concentrations in the LAW grout will be approximately $2 \mathrm{ppm}$ when processing zirconia calcine, about $60 \mathrm{ppm}$ for a well blended calcine, $170 \mathrm{ppm}$ when processing an "average" SBW, and up to 2000 ppm when alumina calcine is processed.

Five schemes for removal of mercury were evaluated:

1. Grouting LAW scrub purge in combination with LAW denitration solids

2. Grouting LAW scrub purge to form a separate Hg-containing grouted waste

3. Removal of mercury from the TRUEX carbonate wash

4. Removal of mercury from the LAW scrub purge

5. Recycle of the LAW scrub purge to the LAW evaporator without treatment.

Schemes 1 and 2 do not meet RCRA regulations except for zirconia calcine. Scheme 3 is recommended for the baseline flowsheet for all feed cases, although tests are needed to demonstrate several parts of this scheme. These tests and studies include:

1. Demonstration of methods for selective removal of mercury and technetium

2. Determination of the limiting feedstock case for processing alumina calcine

3. TRUEX and SREX tests with the limiting mercury and technetium concentration

4. Demonstration of mercury removal from offgas streams.

Distribution (complete package): C. M. Barnes, MS 3625; V. L. Jacobson, MS 3211 Distribution (summary package only): J. J. McCarthy

\begin{tabular}{|l|l|l|l|l|l|}
\hline Author & Dept. & Reviewed & Date & Approved & Date \\
C.M. Barnes & Chemical & & & V. L. Jacobson & \\
EmBum & Envir. & & & \\
$3-2.99$ & Eng. & & & & \\
\hline
\end{tabular}




\section{Sensitivity of Mercury Flowrates in the Full Separations Material Balance to Changes in Process Parameters and Process Schemes}

\section{Contents}

INTRODUCTION

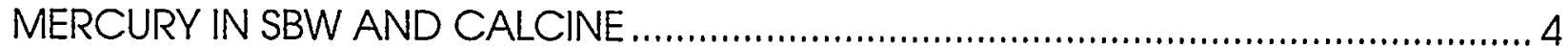

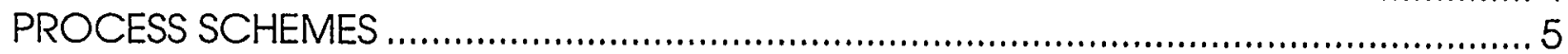

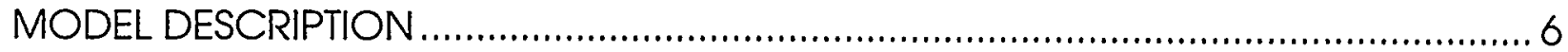

GROUTING LAW SCRUB PURGE WITH DENITRATION SOLIDS …............................. 7

GROUTING SCRUB PURGE SEPARATELY .......................................................... 9

REMOVAL OF MERCURY FROM TRUEX CARBONATE WASH EFFLUENT ................... 10

Results for Sodium Bearing Waste Feed ................................................................ 10

Effect of Mercury Partitioning in TRUEX ......................................................... 12

Effect of Mercury Partitioning in SREX .............................................................. 13

Sensitivity to Carbonate Wash Mercury Removal Efficiency .......................... 14

Effect of LAW Variables..................................................................................... 16

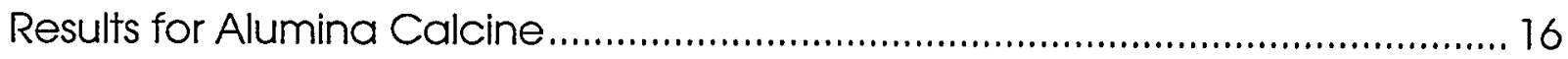

Effect of Mercury Partitioning in TRUEX................................................................ 17

Mercury Build Up in SREX Solvent ............................................................... 18

LAW and HAW Offgas Treatment ............................................................. 18

Results for Zirconia Calcine ................................................................................. 18

REMOVAL OF MERCURY FROM LAW DENITRATOR OFFGAS SCRUB PURGE ........... 19

Model Results for SBW ....................................................................................... 19

Model Results for Calcine .................................................................................... 20

COMPARISON AND EVALUATION OF PROCESS SCHEMES ................................ 20

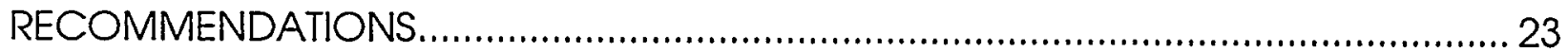

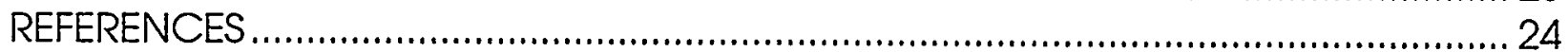

Figures

Appendices

Appendix A: Tables of Model Results 


\section{INTRODUCTION}

The purpose of this study is to determine the sensitivity of mercury distribution among waste products and concentrations in streams throughout the Full Separations process to changes in process parameters, in order to better evaluate alternative schemes of mercury removal or processing. The results of this study are intended to help guide development activities for the Full Separations Process. A previous study' evaluated specific technologies for mercury removal. This study does not repeat these technology evaluations, but seeks to provide guidance as to (a) if and when mercury removal is required, (b) which streams should be considered for mercury removal, and (c) what development activities are needed to ensure technical feasibility of mercury removal and regulatory compliance the resulting mercury wastes.

In the Full Separations treatment process, Sodium Bearing Waste (SBW) or calcine is processed to produce a high activity glass and a low activity grout. Both of these products involve high temperature unit operations, namely a glass melter for the high activity waste (HAW) and a denitration unit upstream of the low activity waste (LAW) grouting operation. Mercury present in the SBW and calcine distributes in separations unit operations between high and low activity effluents, and then vaporizes to a large extent in the HAW melter and the LAW denitrator. Only very small or negligible quantities are retained in the glass and denitration solids. The Maximum Achievable Control Technology (MACT) regulations impose a stringent limit, $40 \mu \mathrm{g} / \mathrm{dscm}$, on mercury released to the atmosphere. Thus the solid and gaseous wastes from the Full Separations treatment process can not contain but a small fraction of the mercury in the feed SBW or calcine. The process must therefore either be designed to produce a separate mercury waste (or more than one) or the high-mercury wastes from LAW denitrator offgas treatment must be recombined with the denitration solids prior to grouting.

An review of RCRA regulations applied to mercury-containing streams and wastes of the WTF is included as an Appendix to this report. LAW as defined in the process options for the HLW and Facility Disposition EIS is a low activity fraction separated out of the HLW (calcine) or SBW. LAW can either be a Class A or Class $C$ mixed waste depending on the separations techniques employed. HAW is defined as the high activity fraction separated out of HLW and maybe SBW. Depending on the techniques used, two or more secondary (new) waste streams containing mercury will be generated and each waste stream will need to be evaluated to determine the appropriate treatment standard for mercury.

\footnotetext{
'C. M. Barnes, "Mercury Material Balance and Evaluation of Mercury Removal Processes," Engineering Design File EDF-WTFO-002, containing in Waste Treatment Facilities Optimization Study Report, INEEL/EXT-01064, November, 1998.
} 
The first requirement is to establish the point of generation and the LDR treatment standard at the point of generation. The mercury treatment standard for the low-activity waste (LAW) depends on several factors. These factors include:

1. Does the LAW exhibit the characteristic of toxicity for mercury based on the TCLP?

2. What is the total concentration of mercury in the waste?

3. is the LAW a wastewater or a nonwastewater?

Based on this information the appropriate treatment standard can be selected.

\section{MERCURY IN SBW AND CALCINE}

The amount of mercury present in SBW is shown in Table 1. An additional $160 \mathrm{~kg}$ of mercury is present in heels of tanks WM-182, WM-183, WM-187 and WM-188.

Table 1. Mercury Present in SBW.

\begin{tabular}{|l|c|c|c|}
\hline Tank & $\begin{array}{c}\text { Volume, gallons } \\
\left(^{\text {Nov. 30, 1998) }}\right.\end{array}$ & $\begin{array}{c}\text { Hg Concentration, } \\
\text { mol/liter }^{\mathrm{b}}\end{array}$ & Hg Inventory, kg \\
\hline WM-180 & 278,600 & $1.02 \mathrm{E}-03$ & 216 \\
\hline WM-181 & 275,900 & $4.70 \mathrm{E}-04$ & 98 \\
\hline WM-184 & 262,600 & $1.58 \mathrm{E}-03$ & 315 \\
\hline WM-185 & 74,800 & $4.11 \mathrm{E}-03$ & 233 \\
\hline WM-186 & 281,500 & $1.14 \mathrm{E}-03^{\mathrm{c}}$ & 244 \\
\hline WM-189 & 146,100 & $1.06 \mathrm{E}-02$ & $\underline{1176}$ \\
\hline Total & $1,319,500$ & & 2282 \\
\hline
\end{tabular}

${ }^{\circ}$ From http://wab08/nichtt/im/tankdata/Tankmap.htm

'From web pages accessible from the above URL

' $\mathrm{No} \mathrm{Hg}$ analysis available for $\mathrm{WM}-186$, concentration shown is the average of the other tanks

Table 1 shows that the mercury concentration in SBW varies widely, from less than $100 \mathrm{mg} /$ liter in WM-181 to over $2100 \mathrm{mg} /$ liter in Tank WM-189. Waste in some of the tanks is expected to be concentrated in the HLLWE before treatment, which will increase the mercury concentration. The material balances calculated in this study use a SBW volume of 3.79 million liters and an average mercury concentration of $0.00149 \mathrm{~mol} /$ liter, values taken from the Full Separations SBW material balance.

The amount of mercury present in calcine is shown in Table 2. 
Table 2. Estimated Mercury Quantities and Concentrations in Calcine.

\begin{tabular}{|c|c|c|c|}
\hline Bin Set & $\begin{array}{c}\text { Calcine } \\
\text { Volume, } \mathrm{m}^{3}\end{array}$ & $\mathrm{Hg}, \mathrm{kg}^{\mathrm{a}}$ & $\mathrm{Hg}, \mathrm{ppm}$ \\
\hline 1 & 217 & 3,430 & 19,000 \\
\hline 2 & 856 & 127 & 120 \\
\hline 3 & 1092 & 27 & 19 \\
\hline 4 & 488 & 10 & 15 \\
\hline 5 & 992 & 29 & 21 \\
\hline 6 & 491 & 25 & 39 \\
\hline Total & 4136 & 3,648 & 680 (ave) \\
\hline
\end{tabular}

'Data from Dan Staiger, MDS-02-99, January 25, 1999 and MDS-03-99, February 25, 1999.

The quantities of mercury shown in Table 2 were calculated based on Waste Calcining Facility (WCF) and NWCF feed analysis and very limited data on calcine mercury retention. Thus the uncertainty in these values may be large.

Analysis of a few samples of calcine $e^{2}$ from Bin Set 2 performed in 1979 shows mercury concentrations of 1.6-1.9 wt\% for alumina calcine and 0.02-0.05 wt\% for zirconia calcine. The data in Table 2 for Bin Set 1, containing only alumina calcine, is in agreement with the higher value for alumina calcine, but is much lower than the zirconia calcine 1979 analyses. More recent analyses, of NWCF $\mathrm{H}-4$ calcine, has shown mercury concentrations of $12-57 \mathrm{ppm},{ }^{3}$ consistent with the values above for Bin Sets 4-6. The mercury concentrations shown in Table 2 were used in the material balances done for this study.

\section{PROCESS SCHEMES}

Mercury can conceivably be removed at several different points in the Full Separations process. In the Waste Treatment Facilities (WTF) Feasibility Study ${ }^{4}$ design, mercury is removed from TRUEX and SREX carbonate wash effluent. Based on the present configuration of SREX, treatment of the SREX carbonate wash is unnecessary, as essentially no mercury will be present in this stream. Testing is ongoing to find a means of removing mercury from the SREX solvent.

\footnotetext{
${ }^{2}$ B. S. Staples, G. S. Pomiak, E. L. Wade, Properties of Radioactive Calcine Retrieved from the Second Calcined Solids Storage Facility, ICP-1189, March, 1979, p. 9.

${ }^{3}$ INEEL/INT-98-00931, Analysis of the HLW Calcined During the NWCF Campaign H-4 contains data for 3 samples, which show Hg concentrations of 11-23 ppm. R. S. Herbst, "Mercury and Chloride Analyses in Calcines Produced in NWCF Campaign H-4," RSH-07-98, reports data for an additional 3 samples, which show Hg concentrations of $<18-57 \mathrm{ppm}$.

${ }^{4}$ Fluor Daniel, Inc.. Idaho Chemical Processing Plant Waste Treatment Facilities Feasibility Study Report, DOE/ID/13206, December, 1997.
} 
Figures 1 and 2 show the Full Separations scheme with mercury removal from the TRUEX carbonate wash.

If not removed from the carbonate wash, a high percentage of the mercury in the Full Separations process will be contained in LAW streams, which, after concentration by evaporation, are fed to the LAW denitrator. In the denitrator, most of the mercury will volatilize and then be captured by and build up in the offgas scrub liquid. Blow-down or purge of the LAW scrub liquid could be:

1. Treated to remove mercury

2. Recycled to the LAW evaporator

3. Sent to grouting to be grouted with the denitrator solids, or

4. Grouted separately from the denitrator solids.

A sketch of the first option, treatment of the scrub liquid blow-down, is shown in Figure 3. If recycled to the LAW evaporator, a scheme shown in Figure 4, mercury will build up in the scrub liquid to the point that the flowrate of mercury in the denitator offgas downstream of the demister will equal the net feed rate of mercury to the denitrator (total feed minus the scrub recycle). Mercury in the LAW offgas will be absorbed on activated carbon beds (or a different sorbant), and this spent sorbant will become the mercury waste product.

Alternatively, the scrub liquid could be grouted either along with or separate from the denitration solids. Sketches of these options are shown in Figures 5 and 6.

Table 3 shows gives a comparison of the different process schemes for removing mercury. Other schemes for removing mercury in the full separations process, such as removal of mercury directly from SBW or dissolved calcine prior to radionuclide separations, or retorting calcine to remove mercury, will not be considered in this study. These processes would likely require more development or higher costs than those that will be discussed.

\section{MODEL DESCRIPTION}

Mercuny material balances were calculated for the different alternative process schemes and for various cases of the schemes using an Excel spreadsheet model. The model used constants, specific to a given feed case; and variables, specific to a given alternative. Constants are shown in Table 4. Variables are given in the discussion of the results from the different alternative process schemes. The variables were expressed as the amount of mercury in a given stream divided by the amount of mercury in the feed to the unit operation that 
produces that stream. Thus the model is a set of linear equations that, for any given set of variable values, have a unique solution.

Table 3. Comparison of Alternative Schemes for Treatment of Mercury in Full Separations.

\begin{tabular}{|c|c|c|c|c|c|}
\hline Scheme & $\begin{array}{l}\text { Stream Treated } \\
\text { for Mercury } \\
\text {. }\end{array}$ & $\begin{array}{l}\text { Mercury } \\
\text { Treatment }\end{array}$ & $\begin{array}{l}\text { Mercury } \\
\text { Final Form }\end{array}$ & $\begin{array}{l}\text { Relative } \\
\text { Concentration } \\
\text { of } \mathrm{Hg} \text { in Final } \\
\text { Form }\end{array}$ & $\begin{array}{l}\text { LAW Scrub } \\
\text { purge sent } \\
\text { to }\end{array}$ \\
\hline 1 (Fig. $1 \& 2)$ & $\begin{array}{l}\text { TRUEX } \\
\text { carbonate } \\
\text { wash effi. }\end{array}$ & Removal $^{\circ}$ & $\begin{array}{l}\text { Mercury } \\
\text { Sulfide } \\
\text { Sludge }^{c}\end{array}$ & High $^{c}$ & $\begin{array}{l}\text { Upstream of } \\
\text { TRUEX }\end{array}$ \\
\hline 2 (Figure 3) & $\begin{array}{l}\text { LAW scrub } \\
\text { purge }\end{array}$ & $\begin{array}{l}\text { Removal \& } \\
\text { Amalgamation } \\
b\end{array}$ & Amalgam & High & Hg recovery \\
\hline 3 (Figure 4) & LAW offgas & $\begin{array}{l}\text { Removal by } \\
\text { sorbant }\end{array}$ & $\begin{array}{l}\text { Spent } \\
\text { Carbon }\end{array}$ & Low & $\begin{array}{l}\text { LAW } \\
\text { Evaporator }\end{array}$ \\
\hline 4 (Figure 5) & $\begin{array}{l}\text { LAW scrub } \\
\text { purge } \\
\text { combined with } \\
\text { denitrator } \\
\text { solids }\end{array}$ & Stabilization & LAW Grout & Low & $\begin{array}{l}\text { LAW } \\
\text { Grouting }\end{array}$ \\
\hline 5 (Figure 6) & $\begin{array}{l}\text { LAW scrub } \\
\text { purge }\end{array}$ & Stabilization & $\begin{array}{l}\text { High } \mathrm{Hg} \\
\text { Grout }\end{array}$ & Medium & $\begin{array}{l}\text { Separate } \\
\text { grouting unit }\end{array}$ \\
\hline
\end{tabular}

"Removal methods include precipitation, electrolytic reduction, adsorption, absorption and chemical reduction. For a discussion and evaluation of these methods, see "Mercury Material Balance and Evaluation of Mercury Removal Processes," EDF-WTFO-002, containing in Appendix B of Waste Treatment Facilities Optimization Study Report, INEEL/EXT-98-0164, November, 1998. 'Removal by electrolytic reduction followed by amalgamation of elemental mercury. 'Sulfide precipitation assumed as the removal process.

\section{GROUTING LAW SCRUB PURGE WITH DENITRATION SOLIDS}

The benefits of the alternative in which the LAW scrub purge is combined with the denitrated solids and grouted are (1) lower capital costs than other alternatives (2) no separate mercuny waste stream, and (3) no recycle of LAW scrub solution. The only equipment unique to this alternative are a hold tank for the scrub blow-down and a pump to transfer the scrub solution from the hold tank to the LAW grout mixing tank water inlet line. Assuming the scrub blowdown is fed into the grout mix tank at a constant rate, the expected concentrations of mercury in the grout are:

Zirconia calcine feed Average SBW feed

Average calcine feed Alumina calcine feed $\sim 2 \mathrm{ppm}$

$170 \mathrm{ppm}$

$60 \mathrm{ppm}$

$1900 \mathrm{ppm}$. 
This scheme is not acceptable from a RCRA perspective for any feed except zirconia calcine. For all but zirconia feed, the mercury concentration in the LAW scrub solution will exceed $260 \mathrm{mg} / \mathrm{liter}$, meeting the "high mercury" criteria and hence be categorized as a nonwastewater. The treatment standard for high mercury wastewaters is RMERC (retorting) plus AMLGM (amalgamation) of the recovered mercury. Thus the scrub solution would require treatment.

Table 4. Constants Used in the Mercury Material Balances.

\begin{tabular}{|c|c|c|c|}
\hline & $\begin{array}{l}\text { Sodium Bearing } \\
\text { Waste }\end{array}$ & $\begin{array}{l}\text { Calcine Bin Set } 1 \\
\text { (Alumina) }\end{array}$ & $\begin{array}{l}\text { Calcine Bin Set } 4 \\
\text { (Zirconia) }\end{array}$ \\
\hline Total $\mathrm{Hg}$ in feed, $\mathrm{kq}^{(0)}$ & 1133 & 3430 & 10 \\
\hline $\begin{array}{l}\text { Processing time, } \mathrm{yr}^{(\mathrm{o})} \\
(200 \mathrm{~d} / \mathrm{yr}, 24 \mathrm{hr} / \mathrm{d})\end{array}$ & 1.0 & 0.37 & 1.22 \\
\hline $\begin{array}{l}\text { HAW offgas rafe, } \\
\mathrm{mol} / \mathrm{hr}, \text { dry }\end{array}$ & 868 & 1341 & 1341 \\
\hline $\begin{array}{l}\text { LAW offgas rate, }{ }^{(c)} \\
\mathrm{mol} / \mathrm{hr} \text {, dry }\end{array}$ & 18760 & 18760 & 18760 \\
\hline $\begin{array}{l}\text { Hg loading on } \\
\text { carbon, }{ }^{(0)} \text { wt } \%\end{array}$ & 18 & 18 & 18 \\
\hline $\begin{array}{l}\text { Carbon density, } \\
\text { lb/gal }{ }^{(\omega)}\end{array}$ & 4.0 & 4.0 & 4.0 \\
\hline
\end{tabular}

(a) From Full Separations material balances, drafts as of late December, 1998 and contained in "Controlled Material Balances" folder on FROGG server.

(0) From Fluor Daniel, Inc., ICPP WTF Feasibility Study Report, DOE/ID/13206, December, 1997, stream 1040 in Table 17 (SBW) and Table 18 (calcine) of Appendix E.

(c) Based on "Material Balance for the Rotary Kin Denitrator," EDF-WTFO-003, contained in WTF Optimization Study Report, INEEL/EXT-98-01064, November, 1998. The value shown above was prorated from the material balance in EDF-WTFO-003 by the ratio of denitration solids flow rates (although this ratio varied from 1.31-1.36 for the different feed cases, a value .of 1.35 was used as the proration factor for all feed cases)

(o) From "Mercury Control Process Evaluation," Appendix F, Feasibility Study Report for NWCF MACT Compliance Facility, INEEL/INT-97-00992, November, 1997.

Even when processing zirconia calcine, mercury will build up in the LAW scrub solution and require frequent purging to keep the mercury level below 260 $\mathrm{mg} /$ liter. If purged at a mercury concentration of $200 \mathrm{mg} / \mathrm{liter}$, the scrub purge will amount to about $6 \%$ of the total water needed for LAW grouting. If this option is pursued, a neutral or alkaline scrub solution should be used to avoid high nitrate levels in the LAW grout.

The Mixed Waste Focus Area, working with the EPA, is presently conducting grouting tests of high mercury wastes. The results of these tests may result in regulatory changes such that LAW scrub from processing SBW or some calcine blends could also be used as part of the water needed in grouting. However, 
with higher mercury and salt concentrations, the effects of substitution of scrub liquid for grout makeup water are unknown. The long-term effects of mercury on the grout is also unknown. Mercury is typically stabilized in grout waste forms as a sulfur compound, using either additives or sulfur-containing make-up constituents as flyash. However, sulfites and sulfides oxidize slowly in grout to sulfates. ${ }^{5}$ Conversion to sulfate causes expansion due to an increase in crystal size, and stress can cause the cracking or spalling in the grout. In addition, conversion of mercury sulfide to sulfate results in a water-soluble mercury compound in the grout.

\section{GROUTING SCRUB PURGE SEPARATELY}

Assuming the LAW scrub liquid is purged at a mercury concentration of about 30 $\mathrm{g} /$ liter, the total scrub purge from processing the full inventory of calcine would be approximately $32,000 \mathrm{gal}$, with another 20,000 gal from processing SBW. Using a $15 \%$ loading, about $580 \mathrm{~m}^{3}$ of high mercury grout from calcine and 360 $\mathrm{m}^{3}$ high mercury grout from SBW would be produced. The mercury concentration in the grout would be about $1600 \mathrm{ppm}$.

This alternative would require:

(1) Changes to RCRA regulations such that grouting a high mercury waste is acceptable

(2) Development of a grout formuation for high mercury waste ${ }^{7}$

(3) Grouting equipment, including dry material bins, a scrub purge hold tank and pump, a grout mixing tank, a decontamination system, and a grout packaging system.

(4) Space in the LAW Treatment Facility to hold the above equipment

(5) Finding a disposal site for the high-mercury grout.

Table 5 shows a summary of information from the material balances for this alternative. A more complete material balance including all input values is given in Appendix A, Tables A1 and A2.

\footnotetext{
${ }^{5}$ C. H. Mattus, T. M. Gilliam, A Literature Review of Mixed Waste Components: Sensitivities and Effects Upon Solidification/Stabilization in Cement-Based Matrices, ORNL/TM-12656, March, 1994. ${ }^{6}$ The $15 \%$ loading is based on (1) direct grouting of SBW tests which achieved a $30 \%$ waste loading (see A. K. Herbst, D. W. Marshall, J. A. McCray, Idaho Chemical Processing Plant LowActivity Waste Grout Stabilization Development Program FY-97 Status Report, INEEL/EXT-98-00116, February, 1998 and (2) an assumed scrub purge composition approximately twice as concentrated as the simulant used in the SBW direct grout tests.

${ }^{7}$ Formulations for direct grouting of SBW would be a starting point for this development, as well as FY-99 testing of commercial grouts with very high mercury-content wastes.
} 
Although the mercury feed rate and the distribution factors for mercury in SREX are quite different for zirconia and alumina calcine (See Table A1, Appendix A), the fractions of mercury in the final waste products are very similar for the two feed cases.

Table 5. Summary Material Balance Information for Separate Grouting of LAW Scrub Purge.

\begin{tabular}{|l|l|l|}
\hline & Zr Calcine & Al Calcine \\
\hline$\%$ of Hg in the feed contained in: & & \\
\hline LAW grout & 0.30 & 0.30 \\
\hline LAW carbon & 2.69 & 2.99 \\
\hline LAW stack release & 0.30 & 0.001 \\
\hline Hg grout & 96.67 & 96.67 \\
\hline HAW carbon & 0.03 & 0.04 \\
\hline HAW stack release & 0.01 & 0.00004 \\
\hline & & \\
\hline $\mathrm{kg} / \mathrm{hr}$ Hg in TRUEX Feed & 0.0058 & 2.03 \\
\hline $\mathrm{kg} / \mathrm{hr}$ in total LAW Feed & 0.0057 & 1.99 \\
\hline
\end{tabular}

\section{REMOVAL OF MERCURY FROM TRUEX CARBONATE WASH EFFLUENT}

The sensitivity of mercury flowrates in a full separations material balance in which mercury is removed from the TRUEX carbonate wash was determined for SBW, alumina calcine and zirconia calcine. In this process scheme, shown in Figures 1 and 2, LAW and HAW offgas treatment blowdown and nitric acid are recycled upstream of TRUEX. The results for SBW are discussed first and for the most cases. Because of the insensitivity of the material balance to most variables, only a small set of cases was run for the calcine feeds.

\section{Results for Sodium Bearing Waste Feed}

For the process scheme in which mercury is removed from the carbonate wash, the material balance model contains thirty variables, shown in Table 6. Table 6 also shows the "low," "normal," and "high" values used for each of the variables. The basis or reference for many of the values used is discussed below. Material balances were not calculated for all combinations of the variable values, but only for a set selected to determine the sensitivity of the material balance to different key parameters. The model calculates mercury rates and concentrations for sixty-seven streams throughout the full separations process, as well as twelve other response parameters, such as the required mercury removal efficiency by a carbon bed to clean offgas to the MACT limit. For the cases that were run, complete results are given in Appendix $A$, and only a summary of the results in the discussion below. 
Table 6. Variables of the Mercury Sensitivity Model.

\begin{tabular}{|c|c|c|c|}
\hline Variable (Note 1) & Normal & Low & High \\
\hline 1. Fraction $\mathrm{Hg}$ removed by ion exchange sorbant & 0 & 0 & 0.1 \\
\hline 2. Fraction $\mathrm{Hg}$ in TRUEX strip & 0.02 & 0 & 0.04 \\
\hline 3. Fraction $\mathrm{Hg}$ in TRUEX carbonate wash & 0.8 & 0.6 & 0.97 \\
\hline 4. Fraction $\mathrm{Hg}$ in TRUEX acid rinse & to & 0 & 0.02 \\
\hline 5. Fraction $\mathrm{Hg}$ in TRUEX raffinate (2) & 0.18 & 0.02 & 0.37 \\
\hline 6. Fraction $\mathrm{Hg}$ retained in TRUEX solvent & 0 & 0 & 0.01 \\
\hline 7. Fraction $\mathrm{Hg}$ in SREX strip & 0.004 & 0 & 0.05 \\
\hline 8. Fraction $\mathrm{Hg}$ in SREX carbonate wash & 0.002 & 0 & 0.01 \\
\hline 9. Fraction $\mathrm{Hg}$ in SREX acid rinse & 0.043 & 0 & 0.1 \\
\hline 10. Fraction $\mathrm{Hg}$ in SREX raffinate & 0.95 & 0.09 & 0.95 \\
\hline 11. Fraction $\mathrm{Hg}$ retained in SREX solvent (2) & 0.001 & 0.001 & 0.906 \\
\hline 12. Fraction $\mathrm{Hg}$ removed from TRUEX carbonate wash & 0.99 & 0.9 & 0.999 \\
\hline 13. Fraction $\mathrm{Hg}$ in $\mathrm{HAW}$ evaporator overhead & 0.025 & 0.01 & 0.05 \\
\hline 14. Fraction $\mathrm{Hg}$ retained in glass & 0.09 & 0 & 0.09 \\
\hline 15. Fraction $\mathrm{Hg}$ removed by HAW offgas dust scrubber & 0.5 & 0.5 & 0.6 \\
\hline 16. Fraction $\mathrm{Hg}$ removed by HAW offgas condenser & 0.5 & 0.5 & 0.9 \\
\hline 17. Fraction $\mathrm{Hg}$ removed by HAW offgas NOx column & 0.5 & 0.5 & 0.9 \\
\hline 18. Fraction $\mathrm{Hg}$ removed by HAW offgas wash column & 0.92 & 0.92 & 0.99 \\
\hline 19. Fraction $\mathrm{Hg}$ removed by HAW offgas cold trap & To & 0 & 0.5 \\
\hline 20. Fraction $\mathrm{Hg}$ removed by HAW offgas demister & 0 & 0 & 0.5 \\
\hline 21. Fraction $\mathrm{Hg}$ retained by $\mathrm{HAW}$ offgas HEPA filters & 0 & 0 & 0.01 \\
\hline 22. Fraction $\mathrm{Hg}$ retained by HAW SCR reactors & 10 & 0 & 0.01 \\
\hline 23. Fraction $\mathrm{Hg}$ in $\mathrm{LAW}$ evaporator overhead & 0.025 & 0.01 & 0.05 \\
\hline 24. Fraction $\mathrm{Hg}$ recycled from $\mathrm{HNO} 3$ fractionator & 1 & 0.98 & 1 \\
\hline 25. Fraction $\mathrm{Hg}$ retained by denitrator solids & 0.003 & 0 & 0.1 \\
\hline 26. Fraction $\mathrm{Hg}$ retained in the grout & 1 & 0.999 & 1 \\
\hline $\begin{array}{l}\text { 27. Fraction } \mathrm{Hg} \text { removed by LAW offgas quench } \\
\text { column }\end{array}$ & 0.9 & 0.9 & 0.99 \\
\hline 28. Fraction $\mathrm{Hg}$ removed by LAW offgas venturi & 0.7 & 0.7 & 0.9 \\
\hline 29. Fraction $\mathrm{Hg}$ removed by LAW offgas demister & 0 & 0 & 0.5 \\
\hline 30. Fraction $\mathrm{Hg}$ retained by LAW offgas HEPA prefilter & 0 & 0 & 0.01 \\
\hline 31. Fraction $\mathrm{Hg}$ retained by LAW offgas HEPA filters & to & 0 & 0.01 \\
\hline 32. Fraction $\mathrm{Hg}$ retained by LAW SCR reactors & 0 & 0 & 0.01 \\
\hline 33. Fraction $\mathrm{Hg}$ in $\mathrm{HNO} 3$ Fractionator Condensate & 0.001 & 0 & 0.01 \\
\hline 34. Fraction $\mathrm{Hg}$ in $\mathrm{HNO} 3$ Fractionator Bottoms ${ }^{(2)}$ & 0.99899 & 0.9899 & 1 \\
\hline 35. Fraction $\mathrm{Hg}$ in $\mathrm{HNO} 3$ Fractionator Vent gas & 0.00001 & 0 & 0.0001 \\
\hline 36. Fraction $\mathrm{Hg}$ removed by HAW carbon bed & Calculated & Calculated & Calculated \\
\hline 37. Fraction $\mathrm{Hg}$ removed by LAW carbon bed & Calculated & Calculated & Calculated \\
\hline
\end{tabular}

(1) Fractions expressed as weight fraction of the mercury in the feed to the given unit operation

(2) Calculated by material balance 


\section{Effect of Mercury Partitioning in TRUEX}

Four cases of mercury partitioning in TRUEX were run. The first or "base" case used partitioning fractions based on the latest TRUEX distribution coefficients, documented in Reference 1. A "low wash" case used 60\% partitioning of mercury to the carbonate wash, based on unnormalized data from TRUEX tests documented in Reference 2. A "high wash" case utilized 97\% partitioning of mercury to the carbonate wash, based on TRUEX test data given in Reference 3.

Table 7 shows both the input variable values and some of the model results.

Table 7. Cases and Results of Various Hg Partitioning Combinations in TRUEX. Variables (Input) (as fraction of $\mathrm{Hg}$ in TRUEX feed)

Fraction mercury partitioned to TRUEX strip Base Low Wash High Wash High Strip Fraction mercury partitioned to TRUEX carbonate wash Fraction mercury partitioned to TRUEX acid rinse Fraction mercury partitioned to TRUEX raffinate Fraction mercury retained in TRUEX solvent

0.02

0.8

0.18

0.18

0

125.2

99.2

0.0

0.050

0.069

0.67
0.01

0.6

0.02

0.37

0.01

164.7

97.8

0.0

0.037

0.190

1.89
0.01

0.97

0

0.02

0

104.0

99.9

0.0

0.020

0.009

0.08
0.04

0.94

0

0.02

0

Mercury in grout

Mercury retained in LAW offgas carbon bed

The results show that a high percentage of the mercury in the SBW, $97.8 \%$ to $99.9 \%$, can be recovered from the carbonate wash effluent, and that the recovery is reasonably insensitive to mercury partitioning to the carbonate wash in TRUEX. The amount of carbon needed to remove mercury from the LAW offgas is small for all cases; even the "low wash" case requires only about $9 \mathrm{ft}^{3}$ or $65 \mathrm{gal}$ of carbon, based on a mercury loading of $18 \mathrm{wt} \%$.

Response parameters that do show significant changes with changes in TRUEX mercury partitioning factors are (a) the required efficiency of the LAW carbon bed, (b) the TRUEX mercury feed rate, and (c) the concentration of mercury in the LAW grout.

For the "low wash" case, in which $60 \%$ of the mercury in the TRUEX feed is partitioned to the carbonate wash, the required LAW carbon bed removal efficiency is $99.6 \%$, compared with $88 \%$ removal efficiency for $97 \%$ partitioning to the carbonate wash. An efficiency of $99.6 \%$ may require a much larger carbon bed $\left(-160 \mathrm{ff}^{3}\right.$ based on a 10 -second residence time). Additional discussion of the required carbon volume, efficiency and offgas treatment design 
alternatives is given in sections "Effect of HAW Variables" and "Effect of LAW Variables" below.

The concentration of mercury in grout is also sensitive to the amount of mercury partitioned to the carbonate wash in TRUEX, varying from about $11 \mathrm{mg} / \mathrm{kg}$ for the base case to $32 \mathrm{mg} / \mathrm{kg}$ for the "low wash" case to about $2 \mathrm{mg} / \mathrm{kg}$ for the "high wash" case.

The lower the fraction of mercury partitioned to the carbonate wash in TRUEX, the higher the rate of mercury recycled to the TRUEX feed tank from either or both the LAW and HAW scrub systems. Although the mercury rate in these recycles, and hence the total mercury in the TRUEX feed, is very sensitive to TRUEX mercury partitioning, the increase in the TRUEX feed flowrate is relatively insensitive because the LAW scrub purge will be highly concentrated in mercury. For the base case; the recycles are expected to add less than $1 \%$ to the TRUEX feed rate, even though they add $25 \%$ to the mercury in the total TRUEX feed. Since the recycle streams add negligibly to the total feed rate, they will not significantly affect equipment sizes and hence capital costs.

\section{Effect of Mercury Partitioning in SREX}

The SREX solvent has been shown to be effective in extracting mercury from acidic wastes, but an effective means of stripping mercury from the SREX solvent has not been found. ${ }^{8}$ Since high concentrations of mercury in the SREX solvent will affect its ability to extract strontium, a means of stripping mercury from the SREX solvent must be found.

Three cases of mercury partitioning in SREX were run in the mercury sensitivity model. The base case was based on distribution coefficients as documented in Reference 1. A "high strip" case was based on the amount of mercury that partitioned to the first strip in test results given in Reference 4, and "high strip" TRUEX partitioning values were also used in this case. And a "solvent retention" case was run to determine the approximate mercury concentration in the solvent if a means of stripping mercury from the solvent is not found.

Increasing the mercury in the SREX \#1 strip by a factor of 12 , from $0.4 \%$ to $5 \%$ increases the mercury retained in the HAW offgas carbon bed by a factor of 1.03 , and increases the required removal efficiency of the HAW carbon bed from $99.2 \%$ to $99.6 \%$.

${ }^{B}$ D. J. Wood, T. D. Law, T. G. Garn, R. D. Tillotson, P. A. Tullock, T. A. Todd, Development of the SREX Process for the Treatment of ICPP Liquid Wastes, INEEL/EXT-97-00831, December, 1997. Also phone conversation with Don Wood, January, 1999. 
If mercury is not removed from the SREX solvent, the mercury concentration will build up to about $6 \mathrm{~g} / \mathrm{liter}$, based on a 24 -hr volume of solvent and processing all SBW in one year.

\section{Sensitivity to Carbonate Wash Mercury Removal Efficiency}

As the efficiency of mercury removal from the carbonate wash increases, mercury concentrations drop in streams and effluents throughout the separations processes. Table 8 shows a comparison of $90 \%, 99 \%$ and $99.9 \%$ removal efficiencies.

Table 8. Sensitivity of Mercury Flowrates to Carbonate Wash Mercury Removal Efficiency.

Results (as percentage of $\mathrm{Hg}$ in SBW feed)

Mercury in TRUEX feed

Mercury recovered from TRUEX carbonate wash effluent

Mercury in glass

Mercury retained in HAW offgas carbon bed

Mercury in grout

Mercury retained in LAW offgas carbon bed

\begin{tabular}{|c|c|c|}
\hline $\begin{array}{l}0 \% \mathrm{Hg} \\
\text { emoval }\end{array}$ & $\begin{array}{l}99 \% \mathrm{Hg} \\
\text { Removal }\end{array}$ & $\begin{array}{l}99.9 \% \mathrm{Hg} \\
\text { Removal }\end{array}$ \\
\hline 137.2 & 125.2 & 124 \\
\hline 98.8 & 99.2 & 99 \\
\hline
\end{tabular}

Mercury in TRUEX Carbonate Wash Effluent, $\mathrm{mg} / \mathrm{l}$

$\mathrm{mg} / \mathrm{kg} \mathrm{Hg}$ in LAW grout

Required HAW Carbon Bed Removal Efficiency, \%

Required LAW Carbon Bed Removal Efficiency, \%

Minimum HAW carbon, $\mathrm{ft}^{3}$

Minimum LAW carbon, $\mathrm{ft}^{3}$

$\begin{array}{rrr}0.0 & 0.0 & 0.0 \\ 0.055 & 0.050 & 0.049 \\ 0.104 & 0.069 & 0.066 \\ 1.03 & 0.67 & 0.64 \\ & & \\ 770 & 710 & 700 \\ 0.2 & 0.1 & 0.1 \\ 98.8 & 98.7 & 98.7 \\ 99.0 & 98.5 & 98.4 \\ 0.3 & 0.2 & 0.2 \\ 4.8 & 3.1 & 3.0\end{array}$

Table 9 shows that there is no significant incentive to achieve a $99.9 \%$ removal efficiency of mercury from carbonate wash. The incentive to achieve $99 \%$, as opposed to $90-95 \%$ is small as well. Although the required removal efficiency of mercury from LAW offgas in the carbon bed is higher for lower carbonate wash removal efficiencies, an achievable efficiency range for the carbon bed can be more easily obtained by adding additional carbon or changing the design of other equipment in the LAW offgas treatment system.

\section{Effect of HAW Variables}

HAW variables include the fraction of mercury carried over to the overhead of the HAW evaporator, the fraction of mercury in the glass product, and removal efficiencies for mercury in HAW offgas treatment equipment. 
The range for mercury in the HAW evaporator overhead was based on data and simulations for the INTEC High Level Liquid Waste Evaporator (HLLWE). ${ }^{9}$ With this value being small (1-5\%) and the amount of mercury partitioned to the HAW streams being small, the effects of changing this variable are negligibly small.

The base case assumes no retention of mercury in the glass, based on a discussion with Bruce Staples. ${ }^{10}$ The maximum value of $9 \%$ is based on data from the PAMELA melter as documented in Reference 5. Reference 5 contains data for other melters in which mercury retention was higher than the PAMELA melter, however the conditions for these melters is less similar to what would be expected in the WTF melter.

If $9 \%$ of the mercury in the melter feed is retained in the glass, then the mercury concentration in the glass would be about $62 \mathrm{mg} / \mathrm{kg}$, assuming a $30 \%$ waste loading for the glass. The mercury in the glass is equivalent to $0.4 \%$ of the mercury in the SBW feed. Apart from reducing the amount of mercury recovered by the mercury removal system by an amount equivalent to that retained in the glass and a small decrease in the amount of mercury removed by carbon from the HAW offgas, the case of retention of a mercury in glass has no significant effect on the material balance.

Mercury removal efficiencies for HAW offgas equipment were also taken from Reference 5. As these variables change, the only response parameters affected are the amount of carbon required and the required carbon bed removal efficiency. For the base case, which uses $50 \% \mathrm{Hg}$ removal in the dust scrubber, $70 \%$ removal in the condenser, $70 \%$ removal in the $\mathrm{NO}_{\mathrm{x}}$ absorber, and $92 \%$ removal in the wash column, only a small amount of carbon, $0.2 \mathrm{ft}^{3}$, is needed. A removal efficiency, calculated as the amount of mercury absorbed divided by the amount in the carbon bed feed, of $98.7 \%$, is needed to reduce the mercury concentration in the offgas to the MACT limit.

The model calculates the amount of required carbon by dividing the total amount of mercury absorbed on the carbon by a loading factor, $0.18 \mathrm{~g} \mathrm{Hg} / \mathrm{g}$ carbon. More realistically, the carbon bed volume would be determined by a residence time to achieve the required outlet concentration. Based on a residence time of 10 seconds, which will remove "virtually all mercury", "a volume of about $4 \mathrm{ft}^{3}$ will be required.

\footnotetext{
${ }^{9}$ R. E. Schindler, B. H. O'Brien, "HLLWE Feed Blends for Wastes From WM-186, WM-184, and WM181." LMITCO Interdepartimental Communication, Schi-17-98, July 28, 1998.

${ }^{10}$ Phone conversation with Bruce Staples, November 16, 1998.

"Nucon, International, Inc., "Design and Performance Characteristics of MERSORB® Mercury Adsorbents in Liquids and Gases," Nucon 11B28, August, 1995.
} 
Elimination of the carbon bed is possible if the condenser and $\mathrm{NO}_{\mathrm{x}}$ absorber are designed with mercury removal efficiencies greater than $90 \%$ and a wash column efficiency greater than $99 \%$.

\section{Effect of LAW Variables}

LAW variables include (1) the fraction of mercury carried over from the LAW evaporator feed to the overhead, (2) the fraction of mercury in the acid fractionator feed released in the fractionator overhead condenser offgas, (3) the fraction of mercury in the denitrator feed retained in the solids, (4) the fraction of mercury released in the grout operation, and (5) removal efficiencies for mercury in LAW offgas treatment equipment. Variables (2) and (4) may be of importance in determining overall emissions from the WTF, but have negligible effect on the overall mercury material balance.

The split of mercury in the LAW evaporator also has a negligible affect on the mercury material balance.

The value of mercury in denitrator solids for the base case, $0.3 \%$, was derived from mercury analyses of NWCF H-4 calcine. ${ }^{12}$ If mercury retention in denitrator solids is higher than this value, the mercury concentration in the grout product increases proportionately. Mercury concentrations in LAW offgas, and hence the amount of LAW carbon, decrease.

For the base case, a mercury removal efficiency of $90 \%$ was used for the LAW quench column and $70 \%$ for the vernturi scrubber. These values were based on a recent calculation of mercury emissions from the NWCF. ${ }^{13}$ Using these values, and assuming no mercury removal by the demister or HEPA filters, about $2.5 \mathrm{ft}^{3}$ of carbon and a removal efficiency in the carbon bed of $98.5 \%$ are required. As discussed for the HAW offgas, the carbon bed would likely be designed for a larger volume to achieve adequate gas-carbon contact to meet the emission limit. To eliminate the carbon bed, an overall removal (quench column, venturi and demister) greater than $99.95 \%$ would be required.

\section{$\underline{\text { Results for Alumina Calcine }}$}

Aluminia calcine represents the design case for mercury removal, as mercury concentrations are higher than SBW and much higher than other calcine types.

\footnotetext{
${ }^{12}$ HLW Program Office, Analysis of the HLW Calcined During the NWCF Campaign H-4, INEEL/INT98-00931, September, 1998.

${ }^{13}$ R. E. Schindler, "Revised Calculation of NWCF Atmospheric Mercury Emission," LMITCO Interdepantmental Communication, Schi-08-98, April 27, 1998.
} 
The TRUEX feed concentration for alumina calcine is about 6 times the average concentration for SBW, and more than 1000 times the concentration for zirconia calcine.

\section{Effect of Mercury Partitioning in TRUEX}

Table 10 gives a summary of the effects of TRUEX variables on the mercury material balance. The trends are the same as for SBW, although the mercury concentrations are higher: At the expected (base case) TRUEX distribution coefficients, $99.5 \%$ of the mercury in the calcine can be recovered from the TRUEX carbonate wash, and the recovery of mercury is very insensitive to changes in TRUEX distribution coefficients. About $8 \mathrm{ft}^{3}$ of carbon would be required to remove mercury from the LAW offgas from processing Bin Set 1 calcine, based on a mercury loading on carbon. However, because of the high removal efficiency requirement, the carbon beds will need to be sized based on residence time. Based on a 10-second residence time in the carbon bed, $82 \mathrm{ft}^{3}$ is required for the LAW offgas and $6 \mathrm{ft}^{3}$ for HAW offgas. Since these volumes are based on gas flowrate and vessel residence time, they are the same for all cases shown in Table 10.

Table 10. Cases and Results of Various Hg Partitioning Combinations in TRUEX, Alumina Calcine Feed.

Variables (Input) (as fraction of $\mathrm{Hg}$ in TRUEX feed)

Fraction mercury partitioned to TRUEX strip

Fraction mercury partitioned to TRUEX carbonate wash

Fraction mercury partitioned to TRUEX acid rinse

Fraction mercury partitioned to TRUEX raffinate

Fraction mercury retained in TRUEX solvent

Results (as percentage of $\mathrm{Hg}$ in SBW feed)

Mercury in TRUEX feed

Mercury recovered from TRUEX carbonate wash effluent

Mercury in glass

Mercury retained in HAW offgas carbon bed

Mercury in grout

Mercury retained in LAW offgas carbon bed

Required removal fraction of $\mathrm{Hg}$ from LAW offgas

Required removal fraction of $\mathrm{Hg}$ from HAW offgas

LAW Carbon required, $\mathrm{ft}^{3}$ (minimum - see discussion)

HAW Carbon required, $\mathrm{ft}^{3}$ (minimum - see discussion)

$\mathrm{Hg}$ concentration in LAW Grout, $\mathrm{mg} / \mathrm{kg}$

\begin{tabular}{rrrr} 
Base & Low Wash & High Wash & High Strip \\
\hline 0.02 & 0.01 & 0.01 & 0.04 \\
0.86 & 0.7 & 0.99 & 0.86 \\
0.02 & 0.02 & 0 & 0.02 \\
0.1 & 0.27 & 0 & 0.08 \\
0 & 0 & 0 & 0
\end{tabular}

$\begin{array}{rrrr}116.8 & 142.3 & 102.0 & 116.9 \\ 99.5 & 98.6 & 99.9 & 99.5 \\ 0.00 & 0.00 & 0.00 & 0.00 \\ 0.05 & 0.03 & 0.02 & 0.09 \\ 0.04 & 0.12 & 0.00 & 0.04 \\ 0.44 & 1.23 & 0.03 & 0.37\end{array}$

$\begin{array}{rrrr}0.999 & 0.9996 & 0.983 & 0.999 \\ 0.999 & 0.999 & 0.998 & 0.9996 \\ 8.2 & 23 & 0.6 & 7 \\ 0.9 & 0.6 & 0.4 & 1.7 \\ 0.8 & 2.3 & 0.1 & 0.7\end{array}$




\section{Mercury Build Up in SREX Solvent}

If $96 \%$ of the mercury in the SREX feed is retained in the solvent, then the concentration of mercury in the solvent will increase by $2.9 \mathrm{~g} /$ liter per month, based on the "Base Case" values of all other variables. However, if TRUEX parameters can be altered to achieve $99 \%$ removal of mercury in TRUEX, the build up in the SREX solvent can be reduced to $0.28 \mathrm{~g} /$ liters per month. Assuming no SREX solvent replacement, the mercury concentration in the SREX solvent would be about $1.2 \mathrm{~g} / \mathrm{liter}$ at the end of processing Bin Set 1 calcine.

\section{LAW and HAW Offgas Treatment}

As discussed above, for the base case variables $82 \mathrm{ft}^{3}$ of carbon would be required to remove mercury from LAW offgas along with a removal efficiency of 99.9\% to meet the MACT emission limit. If the LAW offgas treatment equipment was designed for higher mercury removal efficiencies than the base case (quench column efficiency increased from 0.9 to 0.99 , venturi scrubber from 0.7 to 0.9 and demister from 0 to 0.5 ), then the required removal efficiency in the carbon bed drops from $99.9 \%$ to $92.9 \%$. The concentration of mercury in the carbon bed feed is about $560 \mu \mathrm{g} / \mathrm{dscm}$, about 14 times the MACT limit. Elimination of the carbon bed is likely not feasible, as overall mercury removal efficiency would need to be greater than $99.995 \%$ (compared to $97 \%$ for the base case).

To eliminate the HAW offgas carbon bed, the overall mercury removal efficiency from HAW offgas would need to increase from the base case value of $98 \%$ to a value of $99.998 \%$. This efficiency would be achieved if all HAW offgas treatment variables were increased to their maximum value. However, since the HAW offgas requires a smaller volume of carbon, about $6 \mathrm{ft}^{3}$ for the base case, it is doubtful that elimination of the carbon bed would be economic. Some enhanced mercury removal upstream of the carbon bed may be needed to ensure that the MACT emission limit is met. The base case requires a 99.92\% removal of mercury in the carbon bed; to reduce this efficiency to $98 \%$ would require increasing the condenser and $\mathrm{NO}_{\mathrm{x}}$ column mercury removal efficiencies from $50 \%$ to $85 \%$ and the wash column efficiency from $92 \%$ to $96 \%$.

\section{Results for Zirconia Calcine}

A comparison of results for zirconia calcine feed for several cases of TRUEX partitioning and mercury removal efficiencies is given in Table 11. Because the concentration of mercury in zirconia calcine is very low $(-2 \mathrm{ppm})$, the concentration of mercury in the TRUEX carbonate wash effluent will be low $(\sim 10$ 
$\mathrm{mg} /$ liter), as well as in streams throughout the process. As seen in Table 11, if high removal efficiencies are achieved, removal of $\mathrm{Hg}$ is not required from one or both of the offgas streams. However, because the quantity of mercury in the offgas streams is so low, very little carbon is required, and hence the cost savings from eliminating an offgas removal system will be low. To process calcine from Bin Sets 3-6, even at $60 \%$ mercury removal, less than on cubic foot of is required.

\begin{tabular}{|c|c|c|c|c|c|c|}
\hline Hg Removal Efficiency & $60 \%$ & $90 \%$ & $99 \%$ & $99 \%$ & $99 \%$ & $99 \%$ \\
\hline $\begin{array}{l}\text { TRUEX } \mathrm{Hg} \text { Partitioning: fraction in } \\
\text { raffinate/strip/wash/rinse }\end{array}$ & $\begin{array}{c}0.06 / 0.02 / \\
0.92 / 0\end{array}$ & $\begin{array}{l}0.06 / 0.02 / \\
0.92 / 0\end{array}$ & $\begin{array}{l}0.06 / 0.02 / \\
0.92 / 0\end{array}$ & $\begin{array}{l}0.27 / 0.01 / \\
0.7 / 0.02\end{array}$ & $\begin{array}{l}0 / 0.01 / \\
0.99 / 0\end{array}$ & $\begin{array}{c}0.04 / 0.04 \\
/ 0.92 / 0\end{array}$ \\
\hline \multicolumn{7}{|l|}{ Relative amount of $\mathrm{Hg}$} \\
\hline to TRUEX & 177 & 120 & 110 & 142 & 102 & 110 \\
\hline recovered from TRUEX Carbonate Wash & 97.5 & 99.4 & 99.7 & 98.6 & 99.9 & 99.7 \\
\hline in Grout & 0.02 & 0.05 & 0.02 & 0.12 & 0.003 & 0.02 \\
\hline retained in LAW offgas carbon bed & 1.9 & 0.23 & Not req'd & 0.92 & Not req'd & Not req'd \\
\hline retained in HAW offgas carbon bed & 0.05 & 0.03 & 0.02 & 0.01 & Not req'd & 0.07 \\
\hline Required LAW Offgas $\mathrm{Hg}$ removal efficiency & 86 & 43 & 0 & 75 & 0 & 0 \\
\hline Required HAW Offgas $\mathrm{Hg}$ removal efficiency & 70 & 55 & 51 & 39 & 0 & 75 \\
\hline $\begin{array}{l}\text { Concentration in Carbonate Wash Effluent, } \\
\mathrm{mg} / \text { liter }\end{array}$ & 11.5 & $7.8^{-}$ & 7.1 & 7.0 & 7.1 & 7.1 \\
\hline Concentration in grout, $\mathrm{mg} / \mathrm{kg}$ & 0.3 & 0.08 & 0.03 & 0.2 & 0.004 & 0.02 \\
\hline
\end{tabular}

\section{REMOVAL OF MERCURY FROM LAW DENITRATOR OFFGAS SCRUB PURGE}

The scheme for removal of mercury from the LAW denitrator offgas scrub purge is shown in Figure 3. Either a slip stream from the LAW scrub liquid is continually processed to remove mercury or mercury is allowed to build up in the LAW scrub liquid and the scrub system is periodically purged and treated. The scrub purge is treated by a process such as electrolytic reduction or ion exchange, with the liquid effluent from the treatment process recycled to the LAW evaporator feed tank.

\section{Model Results for SBW}

Table 12 shows a summary of results for various cases for this scheme.

As seen in Table 12, the mercury material balance is very insensitive to most variables (additional cases are shown in the Appendix). The amount of mercury retained in the HAW carbon shows variations from case to case, but is so low for all cases that the variations have little significance in terms of process design or cost. The amount of mercury in the final LAW grout is very low and very insensitive to process variables, even efficiency of the the mercury removal 
system. Over a removal efficiency range of $80-99.9 \%$, the mercury concentration varies only between 0.6-0.4 ppm. As expected, the amount of mercury retained on the LAW and HAW carbon is sensitive to mercury removal efficiencies in each respective offgas system. It does not appear likely that the carbon bed on either the LAW or HAW offgas stream could be eliminated by more efficient design of upstream offgas removal equipment.

Table 12. Summary of Results for SBW Feed and LAW Scrub Treatment Scheme

\begin{tabular}{|l|c|c|c|c|c|c|c|}
\hline & \multicolumn{3}{|c|}{ Expressed as Percentage of $\mathrm{Hg}$ in SBW } & \multicolumn{2}{c|}{ Percentage } \\
\hline $\begin{array}{l}\text { Case (See Appendix A } \\
\text { for input variables for } \\
\text { each case) }\end{array}$ & $\begin{array}{c}\mathrm{Hg} \text { to } \\
\text { TRUEX }\end{array}$ & $\begin{array}{c}\mathrm{Hg} \\
\text { Recovered } \\
\text { from LAW } \\
\text { Scrub }\end{array}$ & $\begin{array}{c}\mathrm{Hg} \\
\text { Retained } \\
\text { in Grout }\end{array}$ & $\begin{array}{c}\mathrm{Hg} \\
\text { Retained } \\
\text { in LAW } \\
\text { Carbon }\end{array}$ & $\begin{array}{c}\mathrm{Hg} \\
\text { Retained } \\
\text { in HAW } \\
\text { Carbon }\end{array}$ & $\begin{array}{c}\text { Req'd } \\
\text { LAW } \\
\text { Carbon } \\
\text { Eff. }\end{array}$ & $\begin{array}{l}\text { Req'd HAW } \\
\text { Carbon Eff. }\end{array}$ \\
\hline Base & 104.7 & 96.6 & 0.30 & 3.0 & 0.04 & 99.8 & 99.2 \\
\hline Low TRUEXW Wash & 103.7 & 96.6 & 0.30 & 3.0 & 0.02 & 99.8 & 98.6 \\
\hline High TRUEX Wash & 103.6 & 96.7 & 0.30 & 3.0 & 0.02 & 99.8 & 98.4 \\
\hline High TRUEX Strip & 106.7 & 96.6 & 0.30 & 3.0 & 0.08 & 99.8 & 99.6 \\
\hline Low Hg Removal Eff. & 104.9 & 96.3 & 0.33 & 3.3 & 0.04 & 99.8 & 99.2 \\
\hline High Hg Removal Eff. & 104.6 & 96.6 & 0.30 & 3.0 & 0.04 & 99.8 & 99.2 \\
\hline Hg in Glass & 104.3 & 96.3 & 0.30 & 3.0 & 0.03 & 99.8 & 99.1 \\
\hline $\begin{array}{l}\text { High LAW Offgas } \\
\text { Removal (upstream of } \\
\text { Carbon bed) }\end{array}$ & 104.7 & 99.6 & 0.30 & 0.04 & 0.04 & 85.8 & 99.2 \\
\hline $\begin{array}{l}\text { High HAW Offgas } \\
\text { Removal (upstream of } \\
\text { carbon bed) }\end{array}$ & 104.7 & 96.7 & 0.30 & 3.0 & 0.002 & 99.8 & 82.7 \\
\hline
\end{tabular}

\section{Model Results for Calcine}

The material balance results for calcine feeds are very similar to those for SBW. Mercury concentrations in process streams will be higher for alumina calcine than for SBW, and will be lower for zirconia calcine than SBW, but the overall distribution of mercury into the product streams is very similar. Also the effects of changes of variables for calcine is similar to the same variable changes for SBW. Model results for some cases of alumina and zirconia calcine feed are given in Appendix A.

\section{COMPARISON AND EVALUATION OF PROCESS SCHEMES}

The process schemes considered in this study include:

1. Grouting LAW scrub purge in combination with LAW denitration solids 2. Grouting LAW scrub purge to form a separate Hg-containing grouted waste

3. Removal of mercury from the TRUEX carbonate wash 
4. Removal of mercury from the LAW scrub purge

5. Recycle of the LAW scrub purge to the LAW evaporator without treatment.

For Scheme 5, removal of mercury from the LAW offgas is the primary means of mercury removal. Unless offgas quench, wash and scrubbing systems are designed for very high mercury removal, all the process schemes will also require secondary mercury removal from HAW offgas, and Schemes 1-4 will require secondary mercury removal from the LAW offgas.

The advantages of Scheme 1, grouting the LAW scrub purge with denitrator solids include:

1. No additional treatment of a liquid stream for mercury

2. Very minimal additional equipment

3. No additional waste product.

However, Scheme 1 would not meet RCRA regulations for any feed except zirconia calcine. For this reason it is not recommended, except as a backup scheme for zirconia calcine.

Scheme 2, grouting the LAW scrub purge separately, also does meet RCRA regulations, and is therefore not recommended. Schemes 1 and 2 were included in the evaluation because they would require no modifications to the separations processes and because of the possibility the grouting becomes an acceptable RCRA treatment for high mercury wastes. Should this happen, these schemes should be reevaluated.

A comparison of material balance results for the other three schemes, for alumina calcine feed, is given in Table 13.

Table 13. Material Balance Summary Comparison for Alumina Calcine Feed (Bin Set 1) Mercury Recovered From:

Carbonate LAW Scrub LAW Wash Purge Offgas Expressed as a percentage of $\mathrm{Hg}$ in the feed

$\mathrm{Hg}$ to TRUEX

$\mathrm{Hg}$ to LAW Evaporator

$\mathrm{Hg}$ Recovered from carbonate wash or LAW scrub

$\mathrm{Hg}$ retained in HAW offgas

117

15

99.5

0.05

0.04

0.44

$\mathrm{Hg}$ retained in LAW offgas

$\mathrm{Hg}$ Concentration in LAW grout, $\mathrm{mg} / \mathrm{kg}$

Required $\mathrm{Hg}$ removal eff. in HAW carbon bed
0.8

99.92
105

111

96.3

0.04

0.33

3.31

6.2

99.92
181

3036

0

0.07

9.1

90.8 
Required $\mathrm{Hg}$ removal eff. in LAW carbon bed Cubic feet carbon needed for HAW offgas

Table 13 shows that if mercury is not removed from a liquid stream, the concentration will build up in the LAW evaporator feed by a factor of 30 times the net rate of mercury in the calcine feed. The mercury concentration in the grout is also higher for the offgas only removal scheme, about 27 times higher than for the scheme in which mercury is removed from the LAW scrub solution purge and more than 200 times higher than the carbonate wash scheme.

Comparing the two liquid removal cases, removal from the carbonate wash shows a higher overall recovery of mercury, a lower concentration in the grout, and a lower volume of carbon required. Removal from carbonate wash has several additional advantages as well. The TRUEX carbonate wash stream contains negligible concentrations of species other than mercury, sodium, carbonate, chloride and technetium whereas the LAW scrub solution will contain all species that are in denitrator offgas, whether by solids carryover or specie volatility. Removal of mercury from a stream with fewer potentially competing species will likely be easier. Also, because the carbonate wash has a high $\mathrm{pH}$, several methods commonly used for mercury removal, such as precipitation and ion exchange are possible. The LAW scrub solution may be acidic. Fewer and less developed alternatives exist for removal of mercury from acidic wastes.

Because of these advantages, removal from the TRUEX carbonate wash is the recommended scheme for mercury removal, for all feed cases. Partial substitution of grout water with LAW offgas scrub solution can be considered a backup scheme for zirconia calcine feed. Treatment of the LAW scrub solution can be backup schemes for any of the feeds.

The presence of technetium in both the carbonate wash and the LAW offgais scrub solution may present a complication for mercury removal technologies, as most technologies that remove mercury may also remove technetium. Significant concentrations of ${ }^{99} \mathrm{Tc}$ in the mercury waste could preclude its disposal. This issue is covered in more detail in EDF-004, "Preliminary Evaluation of Technetium Removal from INTEC Wastes." 


\section{DEVELOPMENT RECOMMENDATIONS}

1. Develop, test and demonstrate methods of selective removal of technetium and mercury.

The first step in this study will be to analyze solutions from recent mercury sulfide precipitation tests to see if rhenium, a technetium surrogate, is removed with mercury from the TRUEX carbonate by sulfide precipitation. If technetium is not removed, sulfide precipitation can be used on the TRUEX carbonate wash and other demonstrated technologies for technetium removal can be used to treat the precipitation effluent. If technetium does precipitate with mercury, different technetium extraction schemes and other methods to selectively remove technetium and mercury from the TRUEX carbonate wash should be tested. Additional testing is needed as well to find a means of removing mercury from the SREX solvent.

2. Determine the limiting feed case in regard to mercury.

Alumina calcine presents the "worst case" in having both the highest mercury and technetium concentrations. Thus a study is needed to determine if alumina calcine should be processed separately or mixed with other calcine, and if mixed, what the maximum expected concentrations of mercury and other key species will be.

\section{Perform TRUEX and SREX tests with the limiting feed cases.}

Data from TRUEX and SREX tests are needed to verify assumed distributions for processing alumina calcine, whether by itself or blended with other calcines. For example, the present alumina calcine material balance shows a mercury concentration of over $7 \mathrm{~g} /$ /iter in the TRUEX carbonate wash effluent, a value more than an order of magnitude greater that the solubility of mercury chloride in a sodium carbonate solution. Since the mercury concentration in alumina calcine is greater that that of zirconia calcine by a factor of as much as three orders of magnitude, mercury distributions in the solvent extraction process with the maximum alumina calcine feed is needed.

\section{Obtain data for mercury removal from LAW and HAW offgas}

The material balances for many cases of process schemes and variables showed that, to achieve the MACT emission limit for mercury, very high removal efficiencies are needed. Testing of systems to remove mercury from offgas is recommended to (1) demonstrate that the MACT emission limit can be met, (2) determine the effect of offgas temperature on mercury removal (3) determine 
the effect of gas inlet mercury concentration on mercury removal (4) determine the required residence time and its relation to feed temperature and composition, and (5) determine the quantity and characteristics of the mercurywaste to be diposed of. Although a carbon bed was assumed as the method of mercury removal from offgas streams for this study, it is recognized that at present, this system has not been demonstrated. The mercury removal offgas testing should include representative compositions for both the LAW and HAW offgas streams. The tests should recognize that mercury speciation in the offgas streams, which is largely unknown, may be an important factor in test results, and provide an adequate basis for an assumed range of speciation.

Depending on the results of the offgas mercury removal tests, upstream systems may need to be modified from the WTF design to achieve higher removal efficiencies for mercury.

\section{REFERENCES}

1. J. D. Law, "Update of Assumptions and Distribution Coefficients for Generation of a SBW Flowsheet," LMITCO Interdepartimental Communication, JLAW-03-98, September 3, 1998.

2. J. D. Law, K. N. Brewer, R. S. Herbst, T. A. Todd, Demonstration of the TRUEX Process for Partitioning of Actinides from Actual ICPP Tank Waste Using Centrifugal Contactors in a Shielded Cell Facility, INEL-96/0353, September, 1996.

3. J. D. Law. R. S. Herbst, TRUEX Flowsheet Development as Applied to ICPP Sodium-Bearing Waste Using Centrifugal Contactors, INEL-95/0130, February, 1995.

4. J. D. Law, D. J. Wood, Development and Testing of a SREX Flowsheet for the Partitioning of Strontium and Lead from Simulated ICPP Sodium-Bearing Waste, INEL-96/0437, November, 1996.

5. G. E. Stegen, Melter Offgas and Treatment System Performance Data, DS197GES-024, Attachment 1, June, 1997. 


\section{APPENDIX A - MATERIAL BALANCE TABLES}

Table Al. Input Values for Material Balance in which LAW Scrub Purge is Grouted as a Separate Waste Product.

Variable

All values are expressed as the $\mathrm{Hg}$ in the given stream divided by the $\mathrm{Hg}$ in the feed to the unit operation resulting in that stream

1. Fraction mercury removed by ion exchange sorbant

2. Fraction mercury in TRUEX strip

3. Fraction mercury in TRUEX carbonate wash

4. Fraction mercury in TRUEX acid rinse

5. Fraction mercury in TRUEX raffinate

6. Fraction mercury retained in TRUEX solvent

7. Fraction mercury in SREX strip

8. Fraction mercury in SREX carbonate wash

9. Fraction mercury in SREX acid rinse

10. Fraction mercury in SREX raffinate

11. Fraction mercury retained in SREX solvent

13. Fraction of $\mathrm{Hg}$ in $\mathrm{HAW}$ evaporator overhead

14. Fraction mercury retained in glass

15. Fraction $\mathrm{Hg}$ removed by HAW offgas dust scrubber

16. Fraction $\mathrm{Hg}$ removed by HAW offgas condenser

17. Fraction $\mathrm{Hg}$ removed by $\mathrm{HAW}$ offgas NOx column

18. Fraction $\mathrm{Hg}$ removed by HAW offgas wash column

19. Fraction $\mathrm{Hg}$ removed by HAW offgas cold trap

20. Fraction $\mathrm{Hg}$ removed by HAW offgas demister

21. Fraction $\mathrm{Hg}$ retained by HAW offgas HEPA filters

22. Fraction $\mathrm{Hg}$ retained by HAW SCR reactors

23. Fraction of mercury in LAW evaporator overhead

24. Fraction of mercury recycled from $\mathrm{HNO} 3$ fractionator

25. Fraction of mercury retained by denitrator solids

26. Fraction of mercury retained in the grout

27. Fraction of mercury removed by LAW offgas scrubber

28. Fraction of mercury removed by LAW offgas venturi

29. Fraction $\mathrm{Hg}$ removed by LAW offgas demister

30. Fraction $\mathrm{Hg}$ retained by LAW offgas HEPA prefilter

31. Fraction $\mathrm{Hg}$ retained by LAW offgas HEPA filters

32. Fraction $\mathrm{Hg}$ retained by LAW SCR reactors

33. Fraction $\mathrm{Hg}$ in $\mathrm{HNO} 3$ Fractionator Condensate

34. Fraction $\mathrm{Hg}$ in $\mathrm{HNO} 3$ Fractionator Bottoms

35. Fraction $\mathrm{Hg}$ in $\mathrm{HNO} 3$ Fractionator Vent gas
Al Calcine $\quad$ Zr Calcine

$\begin{array}{rr}0 & 0 \\ 0.02 & 0.02 \\ 0.86 & 0.92 \\ 0.02 & 0 \\ 0.1 & 0.06 \\ 0 & 0 \\ 0.003 & 0.79 \\ 0.029 & 0 \\ 0.611 & 0 \\ 0.357 & 0.21 \\ 0 & 0 \\ 0.025 & 0.025 \\ 0 & 0 \\ 0.5 & 0.5 \\ 0.5 & 0.5 \\ 0.5 & 0.5 \\ 0.92 & 0.92 \\ 0 & 0 \\ 0 & 0 \\ 0 & 0 \\ 0 & 0 \\ 0.025 & 0.025 \\ 1 & 1 \\ 0.003 & 0.003 \\ 1 & 1 \\ 0.9 & 0.9 \\ 0.7 & 0.7 \\ 0 & 0 \\ 0 & 0 \\ 0 & 0 \\ 0 & 0 \\ 0.001 & 0.001 \\ 0.99899 & 0.99899 \\ 0.00001 & 0.00001\end{array}$


Table A2. Material Balance Results for Grouting LAW Scrub Purge as a Separate Waste.

\begin{tabular}{|c|c|c|c|c|}
\hline & $\begin{array}{c}\text { Bin Set } 1 \\
\text { Al Feed } \\
\mathrm{kg} / \mathrm{hr}\end{array}$ & $\begin{array}{c}\text { Bin Set } 4 \\
\text { Zr Feed } \\
\mathrm{kg} / \mathrm{hr}\end{array}$ & $\begin{array}{l}\text { Bin Set } 1 \\
\text { Al Feed } \\
\text { as fraction of } \\
\text { calcine }\end{array}$ & $\begin{array}{l}\text { Bin Set } 4 \\
\mathrm{Zr} \text { Feed } \\
\text { f Hg in the } \\
\text { feed }\end{array}$ \\
\hline $\mathrm{Hg}$ in SBW Feed & 1.94 & $5.6 \mathrm{E}-03$ & 100 & 100.0 \\
\hline $\mathrm{Hg}$ in Total Dissolver Feed & 2.03 & $5.8 E-03$ & 104.6 & 104.6 \\
\hline $\mathrm{Hg}$ retained by cesium IX sorbant & 0.00 & 0 & 0 & 0.0 \\
\hline $\mathrm{Hg}$ in TRUEX feed & 2.03 & $5.8 E-03$ & 104.6 & 104.6 \\
\hline $\mathrm{Hg}$ in TRUEX strip effluent & 0.041 & $1.2 \mathrm{E}-04$ & 2.1 & 2.1 \\
\hline $\mathrm{Hg}$ in TRUEX wash effluent & 1.74 & 5.4E-03 & 89.9 & 96.3 \\
\hline $\mathrm{Hg}$ in TRUEX rinse effluent & 0.041 & 0 & 2.1 & 0.0 \\
\hline $\mathrm{Hg}$ in TRUEX raffinate & 0.20 & $3.5 \mathrm{E}-04$ & 10.5 & 6.3 \\
\hline $\mathrm{Hg}$ in TRUEX solvent & 0.00 & 0 & 0 & 0.0 \\
\hline $\mathrm{Hg}$ in SREX strip effluent & 0.0006 & $3.5 E-06$ & 0.03 & 0.1 \\
\hline $\mathrm{Hg}$ in SREX wash effluent & 0.0059 & $1.8 \mathrm{E}-05$ & 0.3 & 0.3 \\
\hline $\mathrm{Hg}$ in SREX rinse effluent & 0.12 & 8.1E-05 & 6.4 & 1.4 \\
\hline $\mathrm{Hg}$ in SREX raffinate & 0.072 & $2.5 E-04$ & 3.7 & 4.5 \\
\hline $\mathrm{Hg}$ retained in SREX solvent & 0.00 & 0 & 0 & 0.0 \\
\hline $\mathrm{Hg}$ in HAW evaporator feed & 0.041 & $1.2 E-04$ & 2.1 & 2.2 \\
\hline $\mathrm{Hg}$ in HAW evaporator bottoms & 0.040 & $1.2 \mathrm{E}-04$ & 2.1 & 2.1 \\
\hline $\mathrm{Hg}$ in melter feed & 0.080 & 2.3E-04 & 4.1 & 4.2 \\
\hline $\mathrm{Hg}$ in glass & 0.00 & 0 & 0 & 0.0 \\
\hline $\mathrm{Hg}$ in melter offgas & 0.080 & 2.3E-04 & 4.1 & 4.2 \\
\hline $\mathrm{Hg}$ in dust scrubber offgas & 0.040 & $1.2 E-04$ & 2.1 & 2.1 \\
\hline $\mathrm{Hg}$ in dust scrubber recycle & 0.040 & $1.2 E-04$ & 2.1 & 2.1 \\
\hline $\mathrm{Hg}$ in HAW condenser liquid & 0.020 & 5.9E-05 & 1.0 & 1.1 \\
\hline $\mathrm{Hg}$ in HAW condenser offgas & 0.020 & $5.9 E-05$ & 1.0 & 1.1 \\
\hline $\mathrm{Hg}$ in NOx Absorber liquid & 0.010 & $2.9 E-05$ & 0.5 & 0.5 \\
\hline $\mathrm{Hg}$ in NOx Absorber offgas & 0.010 & $2.9 E-05$ & 0.5 & 0.5 \\
\hline $\mathrm{Hg}$ in wash column liquid & 0.009 & 2.7E-05 & 0.5 & 0.5 \\
\hline $\mathrm{Hg}$ in wash column offgas & 0.0008 & 2.3E-06 & 0.04 & 0.0 \\
\hline $\mathrm{Hg}$ in cold trap liquid & 0.00 & 0 & 0 & 0.0 \\
\hline $\mathrm{Hg}$ in cold trap offgas & 0.0008 & 2.3E-06 & 0.04 & 0.0 \\
\hline $\mathrm{Hg}$ in demister liquid & 0.00 & 0 & 0 & 0.0 \\
\hline $\mathrm{Hg}$ in demister offgas & 0.0008 & 2.3E-06 & 0.04 & 0.0 \\
\hline $\mathrm{Hg}$ retained in HEPA filters & 0.00 & 0 & 0 & 0.0 \\
\hline $\mathrm{Hg}$ in HEPA filter offgas & 0.0008 & 2.3E-06 & 0.04 & 0.0 \\
\hline Hg retained in HAW SCR reactor & 0.00 & 0 & 0 & 0.0 \\
\hline $\mathrm{Hg}$ in SCR reactor effluent & 0.0008 & 2.3E-06 & 0.04 & 0.0 \\
\hline $\mathrm{Hg}$ retained in HAW carbon bed & 0.0008 & $1.6 \mathrm{E}-06$ & 0.04 & 0.0 \\
\hline Hg from HAW offgas to stack & $7.8 \mathrm{E}-07$ & $7.8 E-07$ & 4.0E-05 & 0.0 \\
\hline HAW liquid recycle to dissolution & 0.039 & $1.2 E-04$ & 2.0 & 2.1 \\
\hline $\mathrm{Hg}$ in HAW evaporator condensate & 0.0010 & $3.0 E-06$ & 0.05 & 0.1 \\
\hline $\mathrm{Hg}$ in LAW feed & 1.99 & 5.7E-03 & 102.5 & 102.5 \\
\hline $\mathrm{Hg}$ in LAW condensate & 0.050 & 1.4E-04 & 2.6 & 2.6 \\
\hline $\mathrm{Hg}$ in denitrator feed & 1.94 & 5.6E-03 & 100.0 & 100.0 \\
\hline $\mathrm{Hg}$ in $\mathrm{HNO} 3$ fractionator condensate & 5.0E-05 & $1.4 \mathrm{E}-07$ & 2.56E-03 & 0.0 \\
\hline $\mathrm{Hg}$ in $\mathrm{HNO} 3$ fractionator bottoms & 0.050 & $1.4 \mathrm{E}-04$ & 2.6 & 2.6 \\
\hline
\end{tabular}


Hg emissions from acid fractionator

$\mathrm{Hg}$ in acid and water recycle

$\mathrm{Hg}$ in denitrator offgas

$\mathrm{Hg}$ in denitrator solids

$\mathrm{Hg}$ in grout

$\mathrm{Hg}$ emissions from grouting

$\mathrm{Hg}$ in offgas from LAW scrubber

$\mathrm{Hg}$ in liquid from LAW scrubber

$\mathrm{Hg}$ in offgas from venturi scrubber

$\mathrm{Hg}$ in liquid from venturi scrubber

$\mathrm{Hg}$ in offgas from demister

$\mathrm{Hg}$ in liquid from demister

$\mathrm{Hg}$ in LAW scrub liquid

$\mathrm{Hg}$ retained in LAW HEPA prefilter

$\mathrm{Hg}$ in LAW HEPA prefilter effluent

$\mathrm{Hg}$ retained in LAW HEPA filters

$\mathrm{Hg}$ in LAW HEPA filter effluent

$\mathrm{Hg}$ retained in LAW SCR

$\mathrm{Hg}$ in LAW SCR effluent

$\mathrm{Hg}$ retained in LAW Carbon bed

$\mathrm{Hg}$ in LAW offgas to stack

$\mathrm{Hg}$ in HAW offgas, ug/dscm

kg carbon - HAW

gal carbon - HAW

$\mathrm{kg}$ carbon - LAW

gal carbon - LAW
5.0E-07

0.050

1.93

0.006

0.006

0.00

0.19

1.74

0.058

0.14

0.06

0.00

1.88

0.00

0.06

0.00

0.06

0.00

0.06

0.06

1.7E-05
1.4E-09

1.4E-04

5.6E-03

1.7E-05

1.7E-05

0

5.6E-04

5.0E-03

1.7E-04

3.9E-04

1.7E-04

5.4E-03

0

1.7E-04

0

1.7E-04

$17 \mathrm{E}-04$

1.5E-04

1.7E-05
0.0

2.6

99.7

0.3

0.3

0

10.0

89.7

3.0

7.0

3.0

0

96.7

0

3.0

0

3.0

0

3.0

3.0

5.21E-04

40

7.9

3.5

570

250
0.0

2.6

99.7

0.3

0.3

0.0

10.0

89.7

3.0

7.0

3.0

0.0

96.7

0.0

3.0

0.0

3.0

0.0

3.0

2.7

0.3

40

0.02

0.01

1.5

0.7

Table A3. Key to Tables A4-A7.

Line Input Variable

1 Fraction mercury removed by ion exchange sorbant

2 Fraction mercury in TRUEX strip

3 Fraction mercury in TRUEX carbonate wash

4 Fraction mercury in TRUEX acid rinse

5 Fraction mercury in TRUEX raffinate

6 Fraction mercury retained in TRUEX solvent

7 Fraction mercury in SREX strip

8 Fraction mercury in SREX carbonate wash

9 Fraction mercury in SREX acid rinse

10 Fraction mercury in SREX raffinate (+ Strip \#2)

11 Fraction mercury retained in SREX solvent

12 Fraction $\mathrm{Hg}$ removed from TRUEX carbonate wash

13 Fraction of $\mathrm{Hg}$ in HAW evaporator overhead

14 Fraction mercury retained in glass

15 Fraction $\mathrm{Hg}$ removed by HAW offgas dust scrubber

16 Fraction $\mathrm{Hg}$ removed by HAW offgas condenser

17 Fraction $\mathrm{Hg}$ removed by HAW offgas NOx column 
18 Fraction $\mathrm{Hg}$ removed by HAW offgas wash column

19 Fraction $\mathrm{Hg}$ removed by HAW offgas cold trap

20 Fraction $\mathrm{Hg}$ removed by HAW offgas demister

21 Fraction $\mathrm{Hg}$ retained by HAW offgas HEPA filters

22 Fraction $\mathrm{Hg}$ retained by HAW SCR reactors

23 Fraction of mercury in LAW evaporator overhead

24 Fraction of mercury recycled from $\mathrm{HNO} 3$ fractionator

25 Fraction of mercury retained by denitrator solids

26 Fraction of mercury retained in the grout

27 Fraction of mercury removed by LAW offgas scrubber

28 Fraction of mercury removed by LAW offgas venturi

29 Fraction $\mathrm{Hg}$ removed by LAW offgas demister

30 Fraction $\mathrm{Hg}$ retained by LAW offgas HEPA prefilter

31 Fraction $\mathrm{Hg}$ retained by LAW offgas HEPA filters

32 Fraction $\mathrm{Hg}$ retained by LAW SCR reactors

33 Fraction $\mathrm{Hg}$ in $\mathrm{HNO} 3$ Fractionator Condensate

34 Fraction $\mathrm{Hg}$ in $\mathrm{HNO} 3$ Fractionator Bottoms

35 Fraction $\mathrm{Hg}$ in $\mathrm{HNO} 3$ Fractionator Vent gas

\section{Line Material Balance Model Results}

36 Fraction $\mathrm{Hg}$ removed by HAW carbon bed

37 Fraction $\mathrm{Hg}$ removed by LAW carbon bed

38 Mercury in SBW

39 Mercury in Total Dissolver Feed

40 Mercury retained by cesium IX sorbant

41 Mercury in TRUEX feed

41 Mercury in TRUEX strip effluent

43 Mercury in TRUEX wash effluent

44 Mercury in TRUEX rinse effluent

45 Mercury in TRUEX raffinate

46 Mercury in TRUEX solvent

47 Mercury recovered from wash effluent

$48 \mathrm{Mercury}$ in $\mathrm{Hg}$ recovery waste

49 Mercury in SREX strip effluent

50 Mercury in SREX wash effluent

51 Mercury in SREX rinse effluent

52 Mercury in SREX raffinate

53 Mercury retained in SREX solvent

54 Mercury in HAW evaporator feed

55 Mercury in HAW evaporator bottoms .

56 Mercury in melter feed

57 Mercury in glass

58 Mercury in melter offgas

59 Mercury in dust scrubber offgas

60 Mercury in dust scrubber recycle

61 Mercury in HAW condenser liquid

62 Mercury in HAW condenser offgas

63 Mercury in NOx Absorber liquid 
64 Mercury in NOx Absorber offgas

65 Mercury in wash column liquid

66 Mercury in wash column offgas

67 Mercury in cold trap liquid

68 Mercury in cold trap offgas

69 Mercury in demister liquid

70 Mercury in demister offgas

71 Mercury retained in HEPA filters

72 Mercury in HEPA filter offgas

73 Mercury retained in HAW SCR reactor

74 Mercury in SCR reactor effluent

75 Mercury retained in HAW carbon bed

76 Mercury from HAW offgas to stack

77 HAW liquid recycle to dissolution

78 Mercury in HAW evaporator condensate

79 Mercury in LAW feed

80 Mercury in LAW condensate

81 Mercury in denitrator feed

82 Mercury in $\mathrm{HNO} 3$ fractionator condensate

83 Mercury in $\mathrm{HNO} 3$ fractionator bottoms

84 Mercury emissions from acid fractionator 85 Mercury in acid and water recycle

86 Mercury in denitrator offgas

87 Mercury in denitrator solids

88 Mercury in grout

89 Mercury emissions from grouting

90 Mercury in offgas from LAW scrubber

91 Mercury in liquid from LAW scrubber

92 Mercury in offgas from venturi scrubber

93 Mercury in liquid from venturi scrubber

94 Mercury in offgas from demister

95 Mercury in liquid from demister

96 Mercury in LAW scrub liquid recycle

97 Mercury retained in LAW HEPA prefilter

98 Mercury in LAW HEPA prefilter effluent

99 Mercury retained in LAW HEPA filters

100 Mercury in LAW HEPA filter effluent

101 Mercury retained in LAW SCR

102 Mercury in LAW SCR effluent

103 Mercury retained in LAW Carbon bed

104 Mercury in LAW offgas to stack

105 Mercury in HAW offgas, ug/dscm

$106 \mathrm{~kg}$ carbon - HAW

107 gal carbon - HAW

$108 \mathrm{~kg}$ carbon - LAW

109 gal carbon - LAW 
Table A4. SBW Feed, Mercury Removal From Cabonate Wash, Part 1. (See Table A3 for Key).

\begin{tabular}{|c|c|c|c|c|c|c|}
\hline Line & Base Case & $\begin{array}{l}\text { Truex A } \\
\text { Low Wash } \\
\text { Removal }\end{array}$ & $\begin{array}{l}\text { Truex B } \\
\text { High Wash } \\
\text { Removal }\end{array}$ & $\begin{array}{l}\text { Truex C } \\
\text { High } \mathrm{Hg} \text { in } \\
\text { Strip }\end{array}$ & $\begin{array}{l}90 \% \mathrm{Hg} \\
\text { Removal }\end{array}$ & $\begin{array}{c}99.9 \% \mathrm{Hg} \\
\text { Removal }\end{array}$ \\
\hline 1 & 0 & 0 & 0 & 0 & 0 & 0 \\
\hline 2 & 0.02 & 0.01 & 0.01 & 0.04 & 0.02 & 0.02 \\
\hline 3 & 0.80 & 0.60 & 0.97 & 0.94 & 0.80 & 0.80 \\
\hline 4 & 0 & 0 & 0 & 0 & 0 & 0 \\
\hline 5 & 0.18 & 0.37 & 0.02 & 0.02 & 0.18 & 0.18 \\
\hline 6 & 0 & 0 & 0 & 0 & 0 & $\overline{0}$ \\
\hline 7 & 0.004 & 0.004 & 0.004 & 0.004 & 0.004 & 0.004 \\
\hline 8 & 0.002 & 0.002 & 0.002 & 0.002 & 0.002 & 0.002 \\
\hline 9 & 0.043 & 0.043 & 0.043 & 0.043 & 0.043 & 0.043 \\
\hline 10 & 0.95 & 0.95 & 0.95 & 0.95 & 0.95 & 0.95 \\
\hline 11 & 0.001 & 0.001 & 0.001 & 0.001 & 0.001 & 0.001 \\
\hline 12 & 0.99 & 0.99 & 0.99 & 0.99 & 0.90 & 1.00 \\
\hline 13 & 0.025 & 0.025 & 0.025 & 0.025 & 0.025 & 0.025 \\
\hline 14 & 0 & 0 & 0 & 0 & 0 & 0 \\
\hline 15 & 0.5 & 0.5 & 0.5 & 0.5 & 0.5 & 0.5 \\
\hline 16 & 0.5 & 0.5 & 0.5 & 0.5 & 0.5 & 0.5 \\
\hline 17 & 0.5 & 0.5 & 0.5 & 0.5 & 0.5 & $\overline{0.5}$ \\
\hline 18 & 0.92 & 0.92 & 0.92 & 0.92 & 0.92 & 0.92 \\
\hline 19 & 0 & 0 & 0 & 0 & 0 & $\overline{0}$ \\
\hline 20 & 0 & 0 & 0 & 0 & 0 & 0 \\
\hline 21 & o & 0 & 0 & 0 & 0 & 0 \\
\hline 22 & 0 & 0 & 0 & 0 & 0 & 0 \\
\hline 23 & 0.025 & 0.025 & 0.025 & 0.025 & 0.025 & 0.025 \\
\hline 24 & 1 & 1 & 1 & 1 & 1 & 1 \\
\hline 25 & 0.003 & 0.003 & 0.003 & 0.003 & 0.003 & 0.003 \\
\hline 26 & 1 & 1 & 1 & 1 & 1 & 1 \\
\hline 27 & 0.9 & 0.9 & 0.9 & 0.9 & 0.9 & 0.9 \\
\hline 28 & 0.7 & 0.7 & 0.7 & 0.7 & 0.7 & 0.7 \\
\hline 29 & 0 & 0 & 0 & 0 & 0 & 0 \\
\hline 30 & 0 & 0 & 0 & 0 & 0 & 0 \\
\hline 31 & 0 & 0 & 0 & 0 & 0 & 0 \\
\hline 32 & 이 & 0 & 요 & 0 & 0 & 0 \\
\hline 33 & 0.001 & 0.001 & 0.001 & 0.001 & 0.001 & 0.001 \\
\hline 34 & 0.99899 & 0.99899 & 0.99899 & 0.99899 & 0.99899 & 0.99899 \\
\hline \multirow[t]{3}{*}{35} & 0.00001 & 0.00001 & 0.00001 & 0.00001 & 0.00001 & 0.00001 \\
\hline & & & : & & & \\
\hline & \multicolumn{6}{|c|}{ Results in Lines 38-104 are expressed as a fraction of the mercury in the SBW feed } \\
\hline 36 & 0.9870 & 0.9911 & 0.9678 & 0.9921 & 0.9881 & 0.9869 \\
\hline 37 & 0.9846 & 0.9962 & 0.8834 & 0.8886 & 0.9898 & 0.9838 \\
\hline 38 & 100.00 & 100.00 & 100.00 & 100.00 & 100.00 & 100.00 \\
\hline 39 & 125.22 & 164.68 & 104.01 & 107.25 & 137.19 & 124.14 \\
\hline 40 & 0.00 & 0.00 & 0.00 & 0.00 & 0.00 & 0.00 \\
\hline 41 & 125.22 & 164.68 & 104.01 & 107.25 & 137.19 & 124.14 \\
\hline
\end{tabular}




\begin{tabular}{|c|c|c|c|c|c|c|}
\hline 41 & 2.50 & 1.65 & 1.04 & 4.29 & 2.74 & 2.48 \\
\hline 43 & 100.17 & 98.81 & 100.89 & 100.82 & 109.75 & 99.31 \\
\hline$\overline{44}$ & 0.00 & 3.29 & 0.00 & 0.00 & 0.00 & 0.00 \\
\hline 45 & 22.54 & 60.93 & 2.08 & 2.15 & 24.69 & 22.34 \\
\hline 46 & 0.00 & 1.65 & 0.00 & 0.00 & 0.00 & 0.00 \\
\hline 47 & 99.17 & 97.82 & 99.88 & 99.81 & 98.78 & 99.21 \\
\hline 48 & 1.00 & 0.99 & 1.01 & 1.01 & 10.98 & 0.10 \\
\hline 49 & 0.090 & 0.244 & 0.008 & 0.009 & 0.099 & 0.089 \\
\hline 50 & 0.045 & 0.122 & 0.004 & 0.004 & 0.049 & 0.045 \\
\hline 51 & \begin{tabular}{l|l}
0.969 \\
\end{tabular} & 2.620 & 0.089 & 0.092 & 1.062 & 0.961 \\
\hline 52 & 21.41 & 57.88 & 1.98 & 2.04 & 23.46 & 21.23 \\
\hline 53 & 0.023 & 0.061 & 0.002 & 0.002 & 0.025 & 0.022 \\
\hline 54 & 2.59 & 1.89 & 1.05 & 4.30 & 2.84 & 2.57 \\
\hline 55 & 2.53 & 1.84 & 1.02 & 4.19 & 2.77 & 2.51 \\
\hline 56 & 5.06 & 3.69 & 2.04 & 8.38 & 5.54 & 5.02 \\
\hline 57 & 0 & 0 & 0 & 0 & 0 & 0 \\
\hline 58 & 5.06 & 3.69 & 2.04 & 8.38 & 5.54 & 5.02 \\
\hline 59 & 2.53 & 1.84 & 1.02 & 4.19 & 2.77 & 2.51 \\
\hline 60 & 2.53 & 1.84 & 1.02 & 4.19 & 2.77 & 2.51 \\
\hline 61 & 1.26 & \begin{tabular}{l|}
0.92 \\
\end{tabular} & 0.51 & 2.10 & 1.39 & 1.25 \\
\hline 62 & 1.26 & 0.92 & 0.51 & 2.10 & 1.39 & 1.25 \\
\hline 63 & 0.63 & 0.46 & 0.26 & 1.05 & 0.69 & 0.63 \\
\hline 64 & 0.63 & 0.46 & 0.26 & 1.05 & 0.69 & 0.63 \\
\hline 65 & 0.58 & 0.42 & 0.24 & 0.96 & 0.64 & 0.58 \\
\hline 66 & 0.05 & .0 .04 & 0.02 & 0.08 & 0.06 & 0.05 \\
\hline 67 & 0 & 0 & 0 & 0 & 0 & 0 \\
\hline 68 & 0.0506 & 0.0369 & 0.0204 & 0.0838 & 0.0554 & 0.0502 \\
\hline 69 & 0 & 0 & 0 & 0 & 0 & 0 \\
\hline 70 & 0.0506 & 0.0369 & 0.0204 & 0.0838 & 0.0554 & 0.0502 \\
\hline 71 & 0 & 0 & 0 & 0) & 0 & 0 \\
\hline 72 & \begin{tabular}{l|l}
0.0506 \\
\end{tabular} & 0.0369 & 0.0204 & 0.0838 & 0.0554 & 0.0502 \\
\hline 73 & 0 & 0 & 0 & 0 & 0 & 0 \\
\hline 74 & 0.0506 & 0.0369 & 0.0204 & 0.0838 & 0.0554 & 0.0502 \\
\hline 75 & 0.0499 & 0.0365 & 0.0198 & 0.0832 & 0.0548 & 0.0495 \\
\hline 76 & 0.0007 & 0.0003 & 0.0007 & 0.0007 & 0.0007 & 0.0007 \\
\hline 77 & 2.48 & 1.81 & 1.00 & 4.11 & 2.72 & 2.46 \\
\hline 78 & 0.0649 & 0.0473 & 0.0262 & 0.1075 & 0.0711 & 0.0643 \\
\hline 79 & 23.49 & 64.95 & 3.10 & 3.25 & 35.62 & 22.40 \\
\hline 80 & 0.59 & 1.62 & 0.08 & 0.08 & 0.89 & 0.56 \\
\hline 81 & 22.91 & 63.33 & 3.03 & 3.17 & 34.73 & 21.84 \\
\hline 82 & 0.0006 & 0.0016 & 0.0001 & 0.0001 & 0.0009 & 0.0006 \\
\hline 83 & 0.59 & 1.62 & 0.08 & 0.08 & 0.89 & 0.559 \\
\hline 84 & 5.87E-06 & 1.62E-05 & 7.76E-07 & $8.12 \mathrm{E}-07$ & $8.90 E-06$ & $5.60 \mathrm{E}-06$ \\
\hline 85 & 0.59 & 1.62 & 0.08 & 0.08 & 0.89 & 0.56 \\
\hline 86 & 22.84 & 63.14 & 3.02 & 3.16 & 34.62 & 21.77 \\
\hline 87 & 0.0687 & 0.1900 & 0.0091 & 0.0095 & 0.1042 & 0.0655 \\
\hline
\end{tabular}




\begin{tabular}{|r|r|r|r|r|r|r|}
\hline 88 & 0.0687 & 0.1900 & 0.0091 & 0.0095 & 0.1042 & 0.0655 \\
\hline 89 & 0 & 0 & 0 & 0 & 0 & 0 \\
\hline 90 & 2.28 & 6.31 & 0.30 & 0.32 & 3.46 & 2.18 \\
\hline 91 & 20.55 & 56.83 & 2.72 & 2.84 & 31.16 & 19.59 \\
\hline 92 & 0.69 & 1.89 & 0.09 & 0.09 & 1.04 & 0.65 \\
\hline 93 & 1.60 & 4.42 & 0.21 & 0.22 & 2.42 & 1.52 \\
\hline 94 & 0.69 & 1.89 & 0.09 & 0.09 & 1.04 & 0.65 \\
\hline 95 & 0 & 0 & 0 & 0 & 0 & 0 \\
\hline 96 & 22.15 & 61.25 & 2.93 & 3.06 & 33.58 & 21.12 \\
\hline 97 & 0 & 0 & 0 & 0 & 0 & 0 \\
\hline 98 & 0.685 & 1.894 & 0.091 & 0.095 & 1.039 & 0.653 \\
\hline 99 & 0 & 0 & 0 & 0 & 0 & 0 \\
\hline 100 & 0.685 & 1.894 & 0.091 & 0.095 & 1.039 & 0.653 \\
\hline 101 & 0 & 0 & 0 & 0 & 0 & 0 \\
\hline 102 & 0.69 & 1.89 & 0.09 & 0.09 & 1.04 & 0.65 \\
\hline 103 & 0.67 & 1.89 & 0.08 & 0.08 & 1.03 & 0.64 \\
\hline 104 & 0.011 & 0.007 & 0.011 & 0.011 & 0.011 & 0.011 \\
\hline 105 & 40 & 40 & 40 & 40 & 40 & 40 \\
\hline 106 & 3.1 & 2.3 & 1.2 & 5.2 & 3.4 & 3.1 \\
\hline 107 & 1.4 & 1.0 & 0.5 & 2.3 & 1.5 & 1.4 \\
\hline 108 & 42.4 & 118.7 & 5.0 & 5.3 & 64.7 & 40.4 \\
\hline 109 & 18.7 & 52.4 & 2.2 & 2.3 & 28.5 & 17.8 \\
\hline & & & & & & \\
\hline
\end{tabular}

Table A5. SBW Feed, Mercury Removal From Cabonate Wash, Part 2. (See Table A3 for Key).

\begin{tabular}{|r|r|r|r|r|r|r|r|r|r|}
\hline & $\begin{array}{l}\text { No Hg Liq } \\
\text { Treatment }\end{array}$ & $\begin{array}{l}\text { High } \\
\text { HAW }\end{array}$ & $\begin{array}{l}\text { Hg } \\
\text { Retained } \\
\text { in SREX } \\
\text { Solvent }\end{array}$ & $\begin{array}{l}\text { Hg in } \\
\text { Glass }\end{array}$ & $\begin{array}{l}\text { Low Hg in } \\
\text { HAW } \\
\text { evap ovhd }\end{array}$ & $\begin{array}{l}\text { High } \text { ing } \\
\text { HAW } \\
\text { evap ovhd }\end{array}$ & $\begin{array}{l}\text { Int. HAW } \\
\text { Offgas } \\
\text { Removal } \\
\text { Efficiency }\end{array}$ & $\begin{array}{l}\text { Int-2 HAW } \\
\text { Offgas } \\
\text { Removal } \\
\text { Efficiency }\end{array}$ & $\begin{array}{l}\text { Add HAW } \\
\text { Offgas } \\
\text { Removal }\end{array}$ \\
\hline 1 & 0 & 0 & 0 & 0 & 0 & 0 & 0 & 0 & 0 \\
\hline 2 & 0.02 & 0.04 & 0.02 & 0.02 & 0.02 & 0.02 & 0.02 & 0.02 & 0.02 \\
\hline 3 & 0.8 & 0.94 & 0.8 & 0.8 & 0.8 & 0.8 & 0.8 & 0.8 & 0.8 \\
\hline 4 & 0 & 0 & 0 & 0 & 0 & 0 & 0 & 0 & 0 \\
\hline 5 & 0.18 & 0.02 & 0.18 & 0.18 & 0.18 & 0.18 & 0.18 & 0.18 & 0.18 \\
\hline 6 & 0 & 0 & 0 & 0 & 0 & 0 & 0 & 0 & 0 \\
\hline 7 & 0.004 & 0.05 & 0.004 & 0.004 & 0.004 & 0.004 & 0.004 & 0.004 & 0.004 \\
\hline 8 & 0.002 & 0.01 & 0 & 0.002 & 0.002 & 0.002 & 0.002 & 0.002 & 0.002 \\
\hline 9 & 0.043 & 0.1 & 0 & 0.043 & 0.043 & 0.043 & 0.043 & 0.043 & 0.043 \\
\hline 10 & 0.95 & 0.8 & 0.09 & 0.95 & 0.95 & 0.95 & 0.95 & 0.95 & 0.95 \\
\hline 11 & 0.001 & 0.04 & 0.906 & 0.001 & 0.001 & 0.001 & 0.001 & 0.001 & 0.001 \\
\hline 12 & 0 & 0.99 & 0.99 & 0.99 & 0.99 & 0.99 & 0.99 & 0.99 & 0.99 \\
\hline 13 & 0.025 & 0.025 & 0.025 & 0.025 & 0.01 & 0.05 & 0.025 & 0.025 & 0.025 \\
\hline 14 & 0 & 0 & 0 & 0.09 & 0.09 & 0.09 & 0.09 & 0.09 & 0.09 \\
\hline 15 & 0.5 & 0.5 & 0.5 & 0.5 & 0.5 & 0.5 & 0.5 & 0.5 & 0.5 \\
\hline 16 & 0.5 & 0.5 & 0.5 & 0.5 & 0.5 & 0.5 & 0.7 & 0.9 & 0.5 \\
\hline 17 & 0.5 & 0.5 & 0.5 & 0.5 & 0.5 & 0.5 & 0.7 & 0.9 & 0.5 \\
\hline 18 & 0.92 & 0.92 & 0.92 & 0.92 & 0.92 & 0.92 & 0.95 & 0.95 & 0.92 \\
\hline 19 & 0 & 0 & 0 & 0 & 0 & 0 & 0 & 0 & 0.5 \\
\hline
\end{tabular}




\begin{tabular}{|c|c|c|c|c|c|c|c|c|c|}
\hline 20 & 0) & 0 & 0 & 이 & 0] & 0 & 0 & 이 & 0.5 \\
\hline 21 & 0 & 0 & 0 & 0 & 0 & 0 & 0 & 0 & 0.01 \\
\hline 22 & 0 & 0 & 0 & 0 & 0 & 0 & 0 & 0 & 0.01 \\
\hline 23 & 0.025 & 0.025 & 0.025 & 0.025 & 0.025 & 0.025 & 0.025 & 0.025 & 0.025 \\
\hline 24 & 1 & 1 & 1 & 1 & 1 & 1 & 1 & 1 & 1 \\
\hline 25 & 0.003 & 0.003 & 0.003 & 0.003 & 0.003 & 0.003 & 0.003 & |0.003 & 0.003 \\
\hline 26 & 1 & 1 & 1 & 1 & 1 & 1 & 1 & 1 & 1 \\
\hline 27 & 0.9 & 0.9 & 0.9 & 0.9 & 0.9 & 0.9 & 0.9 & 0.9 & 0.9 \\
\hline 28 & 0.7 & 0.7 & 0.7 & 0.7 & 0.7 & 0.7 & 0.7 & 0.7 & 0.7 \\
\hline 29 & 0 & 0 & 요 & 0 & 0 & 요 & 0 & 0 & 0 \\
\hline 30 & 0 & 0 & 0 & 0 & 0 & 0 & 0 & 0 & 0 \\
\hline 31 & 0 & 0) & 0 & 0 & 0 & 0 & 요 & 0 & 0 \\
\hline 32 & 0 & 0 & 0 & 0 & 0 & 0 & 0 & 0 & 0 \\
\hline 33 & 0.01 & 0.001 & 0.001 & 0.001 & 0.001 & 0.001 & 0.001 & 0.001 & 0.001 \\
\hline 34 & 0.9899 & 0.99899 & 0.99899 & 0.99899 & 0.99899 & 0.99899 & 0.99899 & 0.99899 & 0.99899 \\
\hline 35 & 0.0001 & 0.00001 & 0.00001 & 0.00001 & 0.00001 & 0.00001 & 0.00001 & 0.00001 & 0.00001 \\
\hline & & & & & & & & & \\
\hline \multicolumn{10}{|c|}{ Results in Lines 38-104 are expressed as a fraction of the mercury in the SBW feed } \\
\hline 36 & 0.9997 & 0.9962 & 0.9922 & 0.9843 & 0.9846 & 0.9839 & 0.9304 & 0.3735 & 0.9361 \\
\hline 37 & 0.9999 & 0.9204 & 0.9055 & 0.9845 & 0.9845 & 0.9846 & 0.9845 & 0.9845 & 0.9845 \\
\hline 38 & 100 & 100 & 100 & 100 & 100 & 100 & 100 & 100 & 100 \\
\hline 39 & 3123.29 & 107.17 & 104.57 & 124.71 & 124.70 & 124.72 & 124.75 & 124.76 & 124.75 \\
\hline 40 & 0 & 0 & 0 & 0 & 0 & 0 & 0 & 0 & 0 \\
\hline 41 & 3123.29 & 107.17 & 104.57 & 124.71 & 124.70 & 124.72 & 124.75 & 124.76 & 124.75 \\
\hline 41 & 62.47 & 4.29 & 2.09 & 2.49 & 2.49 & 2.49 & 2.49 & 2.50 & 2.49 \\
\hline 43 & 2498.63 & 100.74 & 83.66 & 99.77 & 99.76 & 99.78 & 99.80 & 99.81 & 99.80 \\
\hline 44 & 0 & 0 & 0 & 0 & 0 & o & 이 & 0 & 이 \\
\hline 45 & 562.19 & 2.14 & 18.82 & 22.45 & 22.45 & 22.45 & 22.45 & 22.46 & 22.45 \\
\hline 46 & 0 & 0 & 0 & 이 & 0 & 0 & 이 & 0 & 0 \\
\hline 47 & 요 & 99.73 & 82.82 & 98.77 & 98.76 & 98.78 & 98.80 & 98.81 & 98.80 \\
\hline 48 & 2498.63 & 1.01 & 0.84 & 1.00 & 1.00 & 1.00 & 1.00 & 1.00 & 1.00 \\
\hline 49 & 2.25 & 0.11 & 0.08 & 0.09 & 0.09 & 0.09 & 0.09 & 0.09 & 0.09 \\
\hline 50 & 1.12 & 0.02 & 0 & 0.04 & 0.04 & 0.04 & 0.04 & 0.04 & 0.04 \\
\hline 51 & 24.17 & 0.21 & 0 & 0.97 & 0.97 & 0.97 & 0.97 & 0.97 & 0.97 \\
\hline 52 & 534.08 & 1.71 & 1.69 & 21.33 & 21.32 & 21.33 & 21.33 & 21.33 & 21.33 \\
\hline 53 & 0.56 & 0.09 & 17.05 & 0.02 & 0.02 & 0.02 & 0.02 & 0.02 & 0.02 \\
\hline 54 & 64.71 & 4.39 & 2.17 & 2.58 & 2.58 & 2.58 & 2.58 & 2.59 & 2.58 \\
\hline 55 & 63.10 & 4.28 & 2.11 & 2.52 & 2.56 & 2.45 & 2.52 & 2.52 & 2.52 \\
\hline 56 & 126.19 & 8.57 & 4.23 & 4.62 & 4.69 & 4.50 & 4.62 & \begin{tabular}{ll|}
4.62 \\
\end{tabular} & 4.62 \\
\hline 57 & 0 & 0 & 0 & 0.42 & 0.42 & 0.41 & 0.42 & \begin{tabular}{l|l}
0.42 \\
\end{tabular} & 0.42 \\
\hline 58 & 126.19 & 8.57 & 4.23 & 4.21 & 4.27 & 4.10 & \begin{tabular}{ll|}
4.21 \\
\end{tabular} & 4.21 & 4.21 \\
\hline 59 & 63.10 & 4.28 & 2.11 & 2.10 & 2.14 & 2.05 & 2.10 & 2.10 & 2.10 \\
\hline 60 & 63.10 & 4.28 & 2.11 & 2.10 & 2.14 & 2.05 & 2.10 & 2.10 & 2.10 \\
\hline 61 & 31.55 & 2.14 & 1.06 & 1.05 & 1.07 & 1.02 & 1.47 & 1.89 & 1.05 \\
\hline 62 & 31.55 & 2.14 & 1.06 & 1.05 & 1.07 & 1.02 & 0.63 & 0.21 & 1.05 \\
\hline 63 & 15.77 & 1.07 & 0.53 & 0.53 & 0.53 & 0.51 & 0.44 & 0.19 & 0.53 \\
\hline
\end{tabular}




\begin{tabular}{|c|c|c|c|c|c|c|c|c|c|}
\hline 64 & 15.77 & 1.07 & 0.53 & 0.53 & 0.53 & 0.51 & 0.19 & 0.02 & 0.53 \\
\hline 65 & 14.51 & 0.99 & 0.49 & 0.48 & 0.49 & 0.47 & 0.18 & 0.02 & 0.48 \\
\hline 66 & 1.262 & 0.086 & 0.042 & 0.042 & 0.043 & 0.041 & 0.009 & 0.001 & 0.042 \\
\hline 67 & 0 & 0 & 0 & 0 & 0 & 0 & 0 & 0 & 0.0210 \\
\hline 68 & 1.262 & 0.086 & 0.042 & 0.042 & 0.043 & 0.041 & 0.0095 & 0.0011 & 0.0210 \\
\hline 69 & 0 & 0 & 0 & 0 & 0 & 0 & 0 & 0 & 0.0105 \\
\hline 70 & 1.262 & 0.086 & 0.042 & 0.042 & 0.043 & 0.041 & 0.0095 & 0.0011 & 0.0105 \\
\hline 71 & 0 & 이 & 0 & 0 & 0 & 0 & 0 & 0 & 0.0001 \\
\hline 72 & 1.2619 & 0.0857 & 0.0423 & 0.0421 & 0.0427 & 0.0410 & 0.0095 & 0.0011 & 0.0104 \\
\hline 73 & 0 & 이 & 0 & 0 & 0 & 이 & 0 & 0 & 0.0001 \\
\hline 74 & 1.262 & 0.086 & 0.042 & 0.042 & 0.043 & 0.041 & 0.009 & 0.0011 & 0.0103 \\
\hline 75 & 1.262 & 0.085 & 0.042 & 0.041 & 0.042 & 0.040 & 0.009 & 0.0004 & 0.0097 \\
\hline 76 & 0.00033 & 0.00033 & 0.00033 & 0.00066 & 0.00066 & 0.00066 & 0.00066 & 0.00066 & 0.0007 \\
\hline 77 & 61.83 & 4.20 & 2.07 & 2.06 & 2.09 & 2.01 & 2.09 & 2.10 & 2.09 \\
\hline 78 & 1.62 & 0.11 & 0.05 & 0.06 & 0.03 & 0.13 & 0.06 & 0.06 & 0.065 \\
\hline 79 & 3059.63 & 3.07 & 2.58 & 23.40 & 23.36 & 23.46 & 23.41 & 23.41 & 23.405 \\
\hline 80 & 76.49 & 0.08 & 0.06 & 0.58 & 0.58 & 0.59 & 0.59 & 0.59 & 0.59 \\
\hline 81 & 2983.14 & 2.99 & 2.52 & 22.81 & 22.77 & 22.88 & 22.82 & 22.82 & 22.82 \\
\hline 82 & 0.76 & 7.7E-05 & $6.46 E-05$ & $5.8 E-04$ & $5.84 \mathrm{E}-04$ & 5.87E-04 & $5.85 E-04$ & $5.85 E-04$ & $5.85 E-04$ \\
\hline 83 & 75.72 & 0.08 & 0.06 & 0.58 & 0.58 & 0.59 & 0.58 & 0.58 & 0.58 \\
\hline 84 & $7.65 \mathrm{E}-03$ & 7.7E-07 & $6.46 \mathrm{E}-07$ & 5.8E-06 & 5.84E-06 & 5.87E-06 & 5.85E-06 & 5.85E-06 & 5.85E-06 \\
\hline 85 & 76.48 & 0.08 & 0.06 & 0.58 & 0.58 & 0.59 & 0.59 & 0.59 & 0.59 \\
\hline 86 & 2974.19 & 2.98 & 2.51 & 22.74 & 22.71 & 22.81 & 22.75 & 22.75 & 22.75 \\
\hline 87 & 8.95 & 0.01 & 0.01 & 0.07 & 0.07 & 0.07 & 0.07 & 0.07 & 0.07 \\
\hline 88 & 8.95 & 0.01 & 0.01 & 0.07 & 0.07 & 0.07 & 0.07 & 0.07 & 0.07 \\
\hline 89 & 0 & 0 & 0 & 0 & 0 & 0 & 0 & 0 & 0 \\
\hline 90 & 297.42 & 0.30 & 0.25 & 2.27 & 2.27 & 2.28 & 2.28 & 2.28 & 2.28 \\
\hline 91 & 2676.77 & 2.68 & 2.26 & 20.47 & 20.43 & 20.53 & 20.48 & 20.48 & 20.48 \\
\hline 92 & 89.23 & 0.09 & 0.08 & 0.68 & 0.68 & 0.68 & 0.68 & 0.68 & 0.68 \\
\hline 93 & 208.19 & 0.21 & 0.18 & 1.59 & 1.59 & 1.60 & 1.59 & 1.59 & 1.59 \\
\hline 94 & 89.23 & 0.09 & 0.08 & 0.68 & 0.68 & 0.68 & 0.68 & 0.68 & 0.68 \\
\hline 95 & 0 & 0 & 0 & 0 & 0 & 0 & 0 & 0 & 0 \\
\hline 96 & 2884.96 & 2.89 & 2.44 & 22.06 & 22.02 & 22.12 & 22.07 & 22.07 & 22.07 \\
\hline 97 & 0 & 0 & 0 & 0 & 0 & 0 & 0 & 0 & 0 \\
\hline 98 & 89.23 & 0.09 & 0.08 & 0.68 & 0.68 & 0.68 & 0.68 & 0.68 & 0.68 \\
\hline 99 & 0 & 0 & 이 & 0 & 0 & 0 & 0 & 0 & 0 \\
\hline 100 & 89.23 & 0.09 & 0.08 & 0.68 & 0.68 & 0.68 & 0.68 & 0.68 & 0.68 \\
\hline 101 & 0 & 0 & 0 & 0 & 0 & 0 & 0 & 0 & 0 \\
\hline 102 & 89.23 & 0.09 & 0.08 & 0.68 & 0.68 & 0.68 & 0.68 & 0.68 & 0.68 \\
\hline 103 & 89.22 & 0.08 & 0.07 & 0.67 & 0.67 & 0.67 & 0.67 & 0.67 & 0.67 \\
\hline 104 & 0.007 & 0.007 & 0.007 & 0.011 & 0.011 & 0.011 & 0.011 & 0.011 & 0.011 \\
\hline 105 & 40 & 40 & 40 & & & & 40 & 40 & 40 \\
\hline 106 & 79.38 & 5.37 & 2.64 & 2.61 & 2.65 & 2.54 & 0.55 & 0.02 & 0.61 \\
\hline 107 & 35.00 & 2.37 & 1.16 & 1.15 & 1.17 & 1.12 & 0.24 & 0.01 & 0.27 \\
\hline 108 & 5613.81 & 5.18 & 4.29 & 42.27 & 42.20 & 42.39 & 42.28 & 42.29 & 42.28 \\
\hline 109 & 2475.24 & 2.28 & 1.89 & 18.64 & 18.60 & 18.69 & 18.64 & 18.64 & 18.64 \\
\hline
\end{tabular}


Table A6. Alumina Calcine Feed, Mercury Removal From Cabonate Wash. (See Table A3 for Key, Table A7 for additional cases of alumina calcine feed).

\begin{tabular}{|c|c|c|c|c|c|c|c|c|c|}
\hline & $\begin{array}{l}\text { Base } \\
\text { Case }\end{array}$ & $\begin{array}{l}\text { Truex A } \\
\text { Low Wash } \\
\text { Removal }\end{array}$ & $\begin{array}{l}\text { Truex } \mathrm{B} \\
\text { High Wash } \\
\text { Removal }\end{array}$ & $\begin{array}{l}\text { Truex C } \\
\text { High Strip }\end{array}$ & $\begin{array}{l}\mathrm{Hg} \\
\text { Retained } \\
\text { in SREX } \\
\text { Solvent }\end{array}$ & $\begin{array}{l}\text { Hg retn in } \\
\text { SREX } \\
\text { solv \& high } \\
\text { TRUEX } \\
\text { removal } \\
\end{array}$ & $\begin{array}{l}90 \% \mathrm{Hg} \\
\text { Removal }\end{array}$ & $\begin{array}{l}99.9 \% \\
\mathrm{Hg} \\
\text { Removal }\end{array}$ & $\begin{array}{l}60 \% \mathrm{Hg} \\
\text { Removal }\end{array}$ \\
\hline 1 & 0 & 0 & 0 & 0 & 0 & 0 & 0 & 0 & \\
\hline 2 & 0.02 & 0.01 & 0.01 & 0.04 & 0.02 & 0.02 & 0.02 & 0.02 & 0.02 \\
\hline 3 & 0.86 & 0.7 & 0.99 & 0.86 & 0.86 & 0.97 & 0.86 & 0.86 & 0.86 \\
\hline 4 & 0.02 & 0.02 & 이 & \begin{tabular}{l|}
0.02 \\
\end{tabular} & 0.02 & 0 & 0.02 & 0.02 & 0.02 \\
\hline 5 & 0.1 & 0.27 & 0 & 0.08 & 0.1 & 0.01 & 0.1 & 0.1 & 0.1 \\
\hline 6 & 0 & 0 & 0 & 0 & 0 & 0 & 0 & 0 & $\overline{0}$ \\
\hline 7 & 0.003 & 0.003 & 0.003 & 0.003 & 0.003 & 0.003 & 0.003 & 0.003 & 0.003 \\
\hline 8 & 0.029 & 0.029 & 0.029 & 0.029 & 0 & 0 & 0.029 & 0.029 & 0.029 \\
\hline 9 & 0.611 & 0.611 & 0.611 & 0.611 & 0 & 0 & 0.611 & 0.611 & 0.611 \\
\hline 10 & 0.357 & 0.357 & 0.357 & 0.357 & 0.037 & 0.037 & 0.357 & 0.357 & 0.357 \\
\hline 11 & 0 & 0 & 0 & 0 & 0.96 & 0.96 & 0 & 0 & - \\
\hline 12 & 0.99 & 0.99 & 0.99 & 0.99 & 0.99 & 0.99 & 0.9 & 0.999 & 0.6 \\
\hline 13 & 0.025 & 0.025 & 0.025 & 0.025 & 0.025 & 0.025 & 0.025 & 0.025 & 0.025 \\
\hline 14 & 0 & 0 & 0 & 0) & o & 0 & 0 & 0 & 0 \\
\hline 15 & 0.5 & 0.5 & 0.5 & 0.5 & 0.5 & 0.5 & 0.5 & 0.5 & $\overline{0.5}$ \\
\hline 16 & 0.5 & 0.5 & 0.5 & 0.5 & 0.5 & 0.5 & 0.5 & 0.5 & 0.5 \\
\hline 17 & 0.5 & 0.5 & 0.5 & 0.5 & 0.5 & 0.5 & 0.5 & 0.5 & 0.5 \\
\hline 18 & 0.92 & 0.92 & 0.92 & 0.92 & 0.92 & 0.92 & 0.92 & 0.92 & 0.92 \\
\hline 19 & 0 & 0 & 0 & 0 & 0 & 0 & 0 & 0 & 0 \\
\hline 20 & 0 & 0 & 이 & 0 & 0 & 이 & 0 & 0 & 0 \\
\hline 21 & 0 & 0 & 0 & 0 & 0 & 0 & 0 & 0 & 0 \\
\hline 22 & 0 & 0 & 0 & 0 & 0 & 0 & 0 & 0 & 0 \\
\hline 23 & 0.025 & 0.025 & 0.025 & 0.025 & 0.025 & 0.025 & 0.025 & 0.025 & 0.025 \\
\hline 24 & 1 & 1 & 1 & 1 & 1 & 1 & 1 & 1 & 1 \\
\hline 25 & 0.003 & 0.003 & 0.003 & 0.003 & 0.003 & 0.003 & 0.003 & 0.003 & 0.003 \\
\hline 26 & 1 & 1 & 1 & 1 & 1 & 1 & 1 & 1 & 1 \\
\hline 27 & 0.9 & 0.9 & 0.9 & 0.9 & 0.9 & 0.9 & 0.9 & 0.9 & 0.9 \\
\hline 28 & 0.7 & 0.7 & 0.7 & 0.7 & 0.7 & 0.7 & 0.7 & 0.7 & 0.7 \\
\hline 29 & 0 & 0 & 0 & 0 & 0 & o & 0) & 0 & 0 \\
\hline 30 & 0 & 0 & 0 & 0 & 0 & 0 & 0 & 0 & 0 \\
\hline 31 & 0 & 0 & 0 & 0 & 0 & 0 & 0 & 0 & 0 \\
\hline 32 & 0 & 0 & 0 & 0] & 0 & o & 0 & 0 & 0 \\
\hline 33 & 0.001 & 0.001 & 0.001 & 0.001 & 0.001 & 0.001 & 0.001 & 0.001 & 0.001 \\
\hline 34 & 0.99899 & 0.99899 & 0.99899 & 0.99899 & 0.99899 & 0.99899 & 0.99899 & 0.99899 & 0.99899 \\
\hline 35 & 0.00001 & 0.00001 & 0.00001 & 0.00001 & 0.00001 & 0.00001 & 0.00001 & 0.00001 & 0.00001 \\
\hline & \multicolumn{9}{|c|}{ Results in Lines 38-104 are expressed as a fraction of the mercury in the calcine feed } \\
\hline 36 & 0.9987 & 0.9979 & 0.9969 & 0.9993 & 0.9985 & 0.9985 & 0.9988 & 0.9986 & 0.9992 \\
\hline 37 & 0.9980 & 0.9993 & 0.9713 & 0.9977 & 0.9914 & 0.9727 & 0.9989 & 0.9979 & 0.9997 \\
\hline 38 & 100 & 100 & 100 & 100 & 100 & 100 & 100 & 100 & 100 \\
\hline
\end{tabular}




\begin{tabular}{|c|c|c|c|c|c|c|c|c|c|}
\hline 39 & 116.83 & 142.30 & 101.98 & 116.86 & 105.39 & 103.03 & 128.04 & 115.82 & 188.22 \\
\hline 40 & 0 & 0 & 0 & o & 이 & 0 & 0 & 0 & 0 \\
\hline 41 & 116.83 & 142.30 & 101.98 & 116.86 & 105.39 & 103.03 & 128.04 & 115.82 & 188.22 \\
\hline 41 & 2.34 & 1.42 & 1.02 & 4.67 & 2.11 & 2.06 & 2.56 & 2.32 & 3.76 \\
\hline 43 & 100.48 & 99.61 & 100.96 & 100.50 & 90.64 & 99.94 & 110.11 & 99.60 & 161.87 \\
\hline 44 & 2.34 & 2.85 & 0.00 & 2.34 & 2.11 & 0.00 & 2.56 & 2.32 & 3.76 \\
\hline 45 & 11.68 & \begin{tabular}{l|}
38.42 \\
\end{tabular} & 0.00 & 9.35 & 10.54 & 1.03 & 12.80 & 11.58 & 18.82 \\
\hline 46 & 0 & 0 & 이 & 0 & 0 & 0 & 0 & 0 & 0 \\
\hline 47 & 99.47 & 98.62 & 99.95 & 99.50 & 89.73 & 98.94 & 99.10 & 99.50 & 97.12 \\
\hline 48 & 1.00 & 1.00 & 1.01 & 1.01 & 0.91 & 1.00 & 11.01 & 0.10 & 64.75 \\
\hline 49 & 0.04 & 0.12 & 0 & 0.03 & 0.032 & 0.003 & 0.038 & 0.035 & 0.056 \\
\hline 50 & 0.34 & 1.11 & 0 & 0.27 & 0 & 0 & 0.371 & 0.336 & 0.546 \\
\hline 51 & 7.14 & 23.48 & 0 & 5.71 & o & 0 & 7.823 & 7.077 & 11.500 \\
\hline 52 & 4.17 & 13.72 & 0 & 3.34 & 0.39 & 0.04 & 4.571 & 4.135 & 6.719 \\
\hline 53 & o & 0 & 이 & 0 & 10.12 & 0.99 & 0 & 0 & 0 \\
\hline 54 & 2.37 & 1.54 & 1.02 & 4.70 & 2.14 & 2.06 & 2.60 & 2.35 & 3.82 \\
\hline 55 & 2.31 & 1.50 & 0.99 & 4.59 & 2.09 & 2.01 & 2.53 & 2.29 & 3.73 \\
\hline 56 & 4.62 & 3.00 & 1.99 & 9.17 & 4.17 & 4.02 & 5.07 & 4.58 & 7.45 \\
\hline 57 & 0 & 0 & 0 & 0 & 0 & 0 & 0 & 0 & 0 \\
\hline 58 & 4.62 & 3.00 & 1.99 & 9.17 & 4.17 & 4.02 & 5.07 & 4.58 & 7.45 \\
\hline 59 & 2.31 & 1.50 & 0.99 & 4.59 & 2.09 & 2.01 & 2.53 & 2.29 & 3.73 \\
\hline 60 & 2.31 & 1.50 & 0.99 & 4.59 & 2.09 & 2.01 & 2.53 & 2.29 & 3.73 \\
\hline 61 & 1.16 & 0.75 & 0.50 & 2.29 & 1.04 & 1.01 & 1.27 & 1.15 & 1.86 \\
\hline 62 & 1.16 & 0.75 & 0.50 & 2.29 & 1.04 & 1.01 & 1.27 & 1.15 & 1.86 \\
\hline 63 & 0.58 & 0.37 & 0.25 & 1.15 & 0.52 & 0.50 & 0.63 & 0.57 & 0.93 \\
\hline 64 & 0.58 & 0.37 & 0.25 & 1.15 & 0.52 & 0.50 & 0.63 & 0.57 & 0.93 \\
\hline 65 & 0.53 & 0.34 & 0.23 & 1.05 & 0.48 & 0.46 & 0.58 & 0.53 & 0.86 \\
\hline 66 & 0.05 & 0.03 & 0.02 & 0.09 & 0.04 & 0.04 & 0.05 & 0.05 & 0.07 \\
\hline 67 & 0 & 0 & 0 & 0 & 0 & 0 & 0 & 0 & 0 \\
\hline 68 & 0.046 & 0.030 & 0.020 & 0.092 & 0.042 & 0.040 & 0.051 & 0.046 & 0.075 \\
\hline 69 & 0 & 0 & 이 & 0 & 0 & 0 & 0 & 0 & 0 \\
\hline 70 & 0.046 & 0.030 & 0.020 & 0.092 & 0.042 & 0.040 & 0.051 & 0.046 & 0.075 \\
\hline 71 & 0 & 0 & 0 & 0 & 0 & 0 & 0 & 0 & 0 \\
\hline 72 & 0.046 & 0.030 & 0.020 & 0.092 & 0.042 & 0.040 & 0.051 & 0.046 & 0.075 \\
\hline 73 & 0 & 0 & 0 & 0 & 0 & 0 & 0 & 0 & 0 \\
\hline 74 & 0.046 & 0.030 & 0.020 & 0.092 & 0.042 & 0.040 & 0.051 & 0.046 & 0.075 \\
\hline 75 & 0.046 & 0.030 & 0.020 & 0.092 & 0.042 & 0.040 & 0.051 & 0.046 & 0.074 \\
\hline 76 & $6.19 \mathrm{E}-05$ & $6.19 \mathrm{E}-05$ & $6.19 \mathrm{E}-05$ & $6.19 \mathrm{E}-05$ & $6.19 \mathrm{E}-05$ & $6.19 \mathrm{E}-05$ & $6.19 \mathrm{E}-05$ & $6.19 E-05$ & 6.19E-05 \\
\hline 77 & 2.27 & 1.47 & 0.97 & 4.49 & 2.04 & 1.97 & 2.48 & 2.25 & 3.65 \\
\hline 78 & 0.059 & 0.038 & 0.025 & 0.118 & 0.053 & 0.052 & 0.065 & 0.059 & 0.096 \\
\hline 79 & 15.05 & 42.19 & 1.04 & 12.78 & 3.46 & 1.09 & 26.40 & 14.02 & 87.37 \\
\hline 80 & 0.38 & 1.05 & 0.03 & 0.32 & 0.09 & 0.03 & 0.66 & 0.35 & 2.18 \\
\hline 81 & 14.67 & 41.13 & 1.01 & 12.46 & 3.37 & 1.06 & 25.74 & 13.67 & 85.19 \\
\hline 82 & $3.76 \mathrm{E}-04$ & $1.05 E-03$ & $2.59 \mathrm{E}-05$ & $3.20 \mathrm{E}-04$ & $8.64 \mathrm{E}-05$ & $2.72 \mathrm{E}-05$ & $6.60 \mathrm{E}-04$ & $3.51 \mathrm{E}-04$ & $2.18 \mathrm{E}-03$ \\
\hline 83 & 0.38 & 1.05 & 0.03 & 0.32 & 0.09 & 0.03 & 0.66 & 0.35 & 2.18 \\
\hline 84 & $3.76 \mathrm{E}-06$ & $1.05 E-05$ & $2.59 E-07$ & $3.20 E-06$ & 8.64E-07 & $2.72 E-07$ & $6.60 \mathrm{E}-06$ & $3.51 E-06$ & $2.18 \mathrm{E}-05$ \\
\hline
\end{tabular}




\begin{tabular}{|r|r|r|r|r|r|r|r|r|r|}
\hline 85 & 0.38 & 1.05 & 0.03 & 0.32 & 0.09 & 0.03 & 0.66 & 0.35 & 2.18 \\
\hline 86 & 14.63 & 41.01 & 1.01 & 12.42 & 3.36 & 1.06 & 25.67 & 13.63 & 84.93 \\
\hline 87 & 0.044 & 0.123 & 0.003 & 0.037 & 0.010 & 0.003 & 0.077 & 0.041 & 0.256 \\
\hline 88 & 0.044 & 0.123 & 0.003 & 0.037 & 0.010 & 0.003 & 0.077 & 0.041 & 0.256 \\
\hline 89 & 0 & 0 & 0 & 0 & 0 & 0 & 0 & 0 & 0 \\
\hline 90 & 1.46 & 4.10 & 0.10 & 1.24 & 0.34 & 0.11 & 2.57 & 1.36 & 8.49 \\
\hline 91 & 13.17 & 36.91 & 0.91 & 11.18 & 3.02 & 0.95 & 23.10 & 12.27 & 76.44 \\
\hline 92 & 0.44 & 1.23 & 0.03 & 0.37 & 0.10 & 0.03 & 0.77 & 0.41 & 2.55 \\
\hline 93 & 1.02 & 2.87 & 0.07 & 0.87 & 0.24 & 0.07 & 1.80 & 0.95 & 5.95 \\
\hline 94 & 0.44 & 1.23 & 0.03 & 0.37 & 0.10 & 0.03 & 0.77 & 0.41 & 2.55 \\
\hline 95 & 0 & 0 & 0 & 0 & 0 & 0 & 0 & 0 & 0 \\
\hline 96 & 14.19 & 39.78 & 0.98 & 12.05 & 3.26 & 1.03 & 24.90 & 13.22 & 82.39 \\
\hline 97 & 0 & 0 & 0 & 0 & 0 & 0 & 0 & 0 & 0 \\
\hline 98 & 0.44 & 1.23 & 0.03 & 0.37 & 0.10 & 0.03 & 0.77 & 0.41 & 2.55 \\
\hline 99 & 0 & 0 & 0 & 0 & 0 & 0 & 0 & 0 & 0 \\
\hline 100 & 0.44 & 1.23 & 0.03 & 0.37 & 0.10 & 0.03 & 0.77 & 0.41 & 2.55 \\
\hline 101 & 0 & 0 & 0 & 0 & 0 & 0 & 0 & 0 & 0 \\
\hline 102 & 0.44 & 1.23 & 0.03 & 0.37 & 0.10 & 0.03 & 0.77 & 0.41 & 2.55 \\
\hline 103 & 0.44 & 1.23 & 0.03 & 0.37 & 0.10 & 0.03 & 0.77 & 0.41 & 2.55 \\
\hline 104 & $8.7 \mathrm{E}-04$ & $8.7 \mathrm{E}-04$ & $8.7 \mathrm{E}-04$ & $8.7 \mathrm{E}-04$ & $8.7 \mathrm{E}-04$ & $8.7 \mathrm{E}-04$ & $8.7 \mathrm{E}-04$ & $8.7 \mathrm{E}-04$ & $8.7 \mathrm{E}-04$ \\
\hline 105 & 40 & 40 & 40 & 40 & 40 & 40 & 40 & 40 & 40 \\
\hline 106 & 8.80 & 5.70 & 3.78 & 17.46 & 7.94 & 7.66 & 9.65 & 8.72 & 14.19 \\
\hline 107 & 3.88 & 2.52 & 1.67 & 7.70 & 3.50 & 3.38 & 4.25 & 3.85 & 6.25 \\
\hline 108 & 83.46 & 234.27 & 5.59 & 70.86 & 19.05 & 5.89 & 146.55 & 77.75 & 485.37 \\
\hline 109 & 36.80 & 103.29 & 2.46 & 31.24 & 8.40 & 2.60 & 64.62 & 34.28 & 214.01 \\
\hline & & & & & & & & 0.03 \\
\hline
\end{tabular}

Table A7. Calcine Feeds, Mercury Removal From Cabonate Wash. (See Table A3 for Key, Table A6 for additional cases of alumina calcine feed).

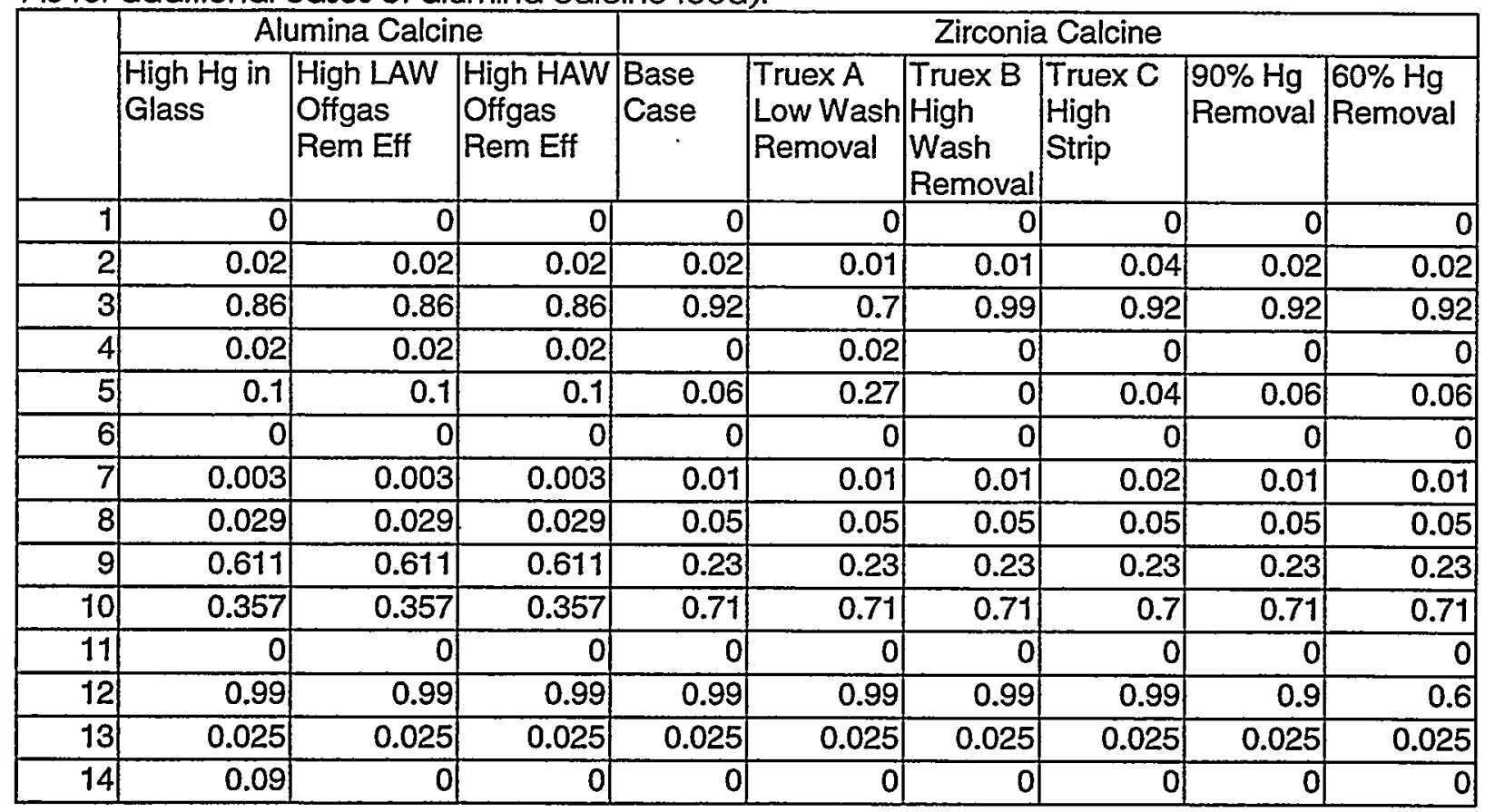




\begin{tabular}{|c|c|c|c|c|c|c|c|c|c|}
\hline 15 & 0.5 & 0.5 & 0.6 & 0.5 & 0.5 & 0.5 & 0.5 & 0.5 & 0.5 \\
\hline 16 & 0.5 & 0.5 & 0.9 & 0.5 & 0.5 & 0.5 & 0.5 & 0.5 & 0.5 \\
\hline 17 & 0.5 & 0.5 & 0.9 & 0.5 & 0.5 & 0.5 & 0.5 & 0.5 & 0.5 \\
\hline 18 & 0.92 & 0.92 & 0.99 & 0.92 & 0.92 & 0.92 & 0.92 & 0.92 & 0.92 \\
\hline 19 & 0 & 0 & 0.5 & 0 & 0 & 0 & 0 & 0 & 0 \\
\hline 20 & 0 & 0 & 0.5 & 0 & 0 & 0 & 0 & 0 & 0 \\
\hline 21 & 0 & o & 0 & 0 & 0 & 0 & 0 & 0 & 0 \\
\hline 22 & 0 & 0 & 0 & 0 & 0 & 0 & 0 & 0 & 0 \\
\hline 23 & 0.025 & 0.025 & 0.025 & 0.025 & 0.025 & 0.025 & 0.025 & 0.025 & 0.025 \\
\hline 24 & 1 & 1 & 1 & 1 & 1 & 1 & 1 & 1 & 1 \\
\hline 25 & 0.003 & 0.003 & 0.003 & 0.003 & 0.003 & 0.003 & 0.003 & 0.003 & 0.003 \\
\hline 26 & 1 & 1 & 1 & 1 & 1 & 1 & 1 & 1 & 1 \\
\hline 27 & 0.9 & 0.99 & 0.9 & 0.9 & 0.9 & 0.9 & 0.9 & 0.9 & 0.9 \\
\hline 28 & 0.7 & 0.9 & 0.7 & \begin{tabular}{l|}
0.7 \\
\end{tabular} & 0.7 & 0.7 & 0.7 & \begin{tabular}{l|}
0.7 \\
\end{tabular} & 0.7 \\
\hline 29 & 0 & 0.5 & 0 & 0 & 0 & 0 & 0 & 0 & 0 \\
\hline 30 & 0 & 0 & 0 & 0 & 0 & 0 & 0 & 아 & 0 \\
\hline 31 & 0 & 0 & 0 & 0 & 0 & 0 & 0 & 0 & 0 \\
\hline 32 & 0 & 0 & 0 & o & 0 & 0 & 0 & 0 & 0 \\
\hline 33 & 0.001 & 0.001 & 0.001 & 0.001 & 0.001 & 0.001 & 0.001 & 0.001 & 0.001 \\
\hline 34 & 0.99899 & 0.99899 & 0.99899 & 0.99899 & 0.99899 & 0.99899 & 0.99899 & 0.99899 & 0.99899 \\
\hline \multirow[t]{3}{*}{35} & 0.00001 & 0.00001 & 0.00001 & 0.00001 & 0.00001 & 0.00001 & 0.00001 & 0.00001 & 0.00001 \\
\hline & & & & & & & & & \\
\hline & \multicolumn{9}{|c|}{ Results in Lines 38-104 are expressed as a fraction of the mercury in the calcine feed } \\
\hline 36 & 0.9984 & 0.9987 & -0.0710 & 0.5110 & 0.3898 & -0.0815 & 0.7532 & 0.5539 & 0.6969 \\
\hline 37 & 0.9980 & 0.8820 & 0.9980 & -0.3635 & 0.7539 & -8.9674 & -0.9063 & 0.4341 & 0.8635 \\
\hline 38 & 100 & 100 & 100 & 100 & 100 & 100 & 100 & 100 & 100 \\
\hline 39 & 116.40 & 117.34 & 116.89 & 109.48 & 142.31 & 101.98 & 109.51 & 120.01 & 176.64 \\
\hline 40 & of & 0 & 0 & of & 0 & 0 & 0 & 0 & 0 \\
\hline 41 & 116.40 & 117.34 & 116.89 & 109.48 & 142.31 & 101.98 & 109.51 & 120.01 & 176.64 \\
\hline 41 & 2.33 & 2.35 & 2.34 & 2.19 & 1.42 & 1.02 & 4.38 & 2.40 & 3.53 \\
\hline 43 & 100.10 & 100.91 & 100.52 & 100.72 & 99.62 & 100.96 & 100.75 & 110.41 & 162.51 \\
\hline 44 & 2.33 & 2.35 & 2.34 & 0 & 2.846 & 0 & 0 & 0 & 0 \\
\hline 45 & 11.64 & 11.73 & 11.69 & 6.57 & 38.42 & 0 & 4.38 & 7.20 & 10.60 \\
\hline 46 & 0 & 0 & 0 & 0) & 0 & 0 & 0 & 0 & 0 \\
\hline 47 & 99.10 & 99.90 & 99.52 & 99.71 & 98.62 & 99.95 & 99.74 & 99.37 & 97.50 \\
\hline 48 & 1.00 & 1.01 & 1.01 & 1.01 & 1.00 & 1.01 & 1.01 & 11.04 & 65.00 \\
\hline 49 & 0.03 & 0.04 & 0.04 & 0.07 & 0.38 & 0 & 0.09 & 0.07 & $\overline{0.11}$ \\
\hline 50 & 0.34 & 0.34 & 0.34 & 0.33 & 1.92 & 0 & 0.22 & 0.36 & 0.53 \\
\hline 51 & 7.11 & 7.17 & 7.14 & 1.51 & 8.84 & 0 & 1.01 & 1.66 & 2.44 \\
\hline 52 & 4.16 & 4.19 & 4.17 & 4.66 & 27.28 & 0 & 3.07 & 5.11 & 7.52 \\
\hline 53 & 0 & 0 & 0 & 이 & 0 & 0 & 0 & 0 & 0 \\
\hline 54 & 2.36 & 2.38 & 2.37 & 2.26 & 1.81 & 1.02 & 4.47 & 2.47 & 3.64 \\
\hline 55 & 2.30 & 2.32 & 2.31 & 2.20 & 1.76 & 0.99 & 4.36 & 2.41 & 3.55 \\
\hline 56 & 4.23 & 4.64 & 4.63 & 4.40 & 3.52 & 1.99 & 8.71 & 4.82 & 7.10 \\
\hline 57 & 0.38 & 이 & 0 & 0 & 0 & 0 & 0 & 0 & 0 \\
\hline 58 & 3.85 & 4.64 & 4.63 & 4.40 & 3.52 & 1.99 & 8.71 & \begin{tabular}{l|}
4.82 \\
\end{tabular} & 7.10 \\
\hline
\end{tabular}




\begin{tabular}{|c|c|c|c|c|c|c|c|c|c|}
\hline 59 & 1.92 & 2.32 & 2.31 & 2.20 & 1.76 & 0.99 & 4.36 & 2.41 & 3.55 \\
\hline 60 & 1.92 & 2.32 & 2.31 & 2.20 & 1.76 & 0.99 & 4.36 & 2.41 & 3.55 \\
\hline 61 & 0.96 & 1.16 & 2.08 & 1.10 & 0.88 & 0.50 & 2.18 & 1.21 & 1.77 \\
\hline 62 & 0.96 & 1.16 & 0.23 & 1.10 & 0.88 & 0.50 & 2.18 & 1.21 & 1.77 \\
\hline 63 & 0.48 & 0.58 & 0.21 & 0.55 & 0.44 & 0.25 & 1.09 & 0.60 & 0.89 \\
\hline 64 & 0.48 & 0.58 & 0.02 & 0.55 & 0.44 & 0.25 & 1.09 & 0.60 & 0.89 \\
\hline 65 & 0.44 & 0.53 & 0.02 & 0.51 & 0.41 & 0.23 & 1.00 & 0.55 & 0.82 \\
\hline 66 & 0.038 & 0.046 & 0.000 & 0.044 & 0.035 & 0.020 & 0.087 & 0.048 & 0.071 \\
\hline 67 & 0 & 이 & $1.2 \mathrm{E}-04$ & 이 & 0 & 0 & 0 & 0 & \\
\hline 68 & 0.038 & 0.046 & $1.2 \mathrm{E}-04$ & 0.044 & 0.035 & 0.020 & 0.087 & 0.048 & 0.071 \\
\hline 69 & 0 & 0 & $5.8 \mathrm{E}-05$ & 0 & 0 & 0 & 0 & 0 & \\
\hline 70 & 0.038 & 0.046 & $5.8 \mathrm{E}-05$ & 0.044 & 0.035 & 0.020 & 0.087 & 0.048 & 0.071 \\
\hline 71 & 0 & 0 & 0 & 0 & 0 & 0 & 0 & 0 & 0 \\
\hline 72 & 0.038 & 0.046 & $5.8 \mathrm{E}-05$ & 0.044 & 0.035 & 0.020 & 0.087 & 0.048 & 0.071 \\
\hline 73 & 0 & o & 0 & 0 & 0 & 0 & 0 & 0 & 0 \\
\hline 74 & 0.038 & 0.046 & $5.8 E-05$ & 0.044 & 0.035 & 0.020 & 0.087 & 0.048 & 0.071 \\
\hline 75 & 0.038 & 0.046 & $-4.1 E-06$ & 0.022 & 0.014 & -0.002 & 0.066 & 0.027 & 0.049 \\
\hline 76 & 6.2E-05 & $6.2 \mathrm{E}-05$ & $6.2 \mathrm{E}-05$ & $2.2 \mathrm{E}-02$ & $2.2 \mathrm{E}-02$ & $2.2 \mathrm{E}-02$ & $2.2 E-02$ & $2.2 \mathrm{E}-02$ & $2.2 \mathrm{E}-02$ \\
\hline 77 & 1.88 & 2.28 & 2.31 & 2.15 & 1.73 & 0.97 & 4.27 & 2.36 & 3.48 \\
\hline 78 & 0.059 & 0.060 & 0.059 & 0.056 & 0.045 & 0.025 & 0.112 & 0.062 & 0.091 \\
\hline 79 & 14.99 & 15.11 & 15.06 & 7.57 & 41.93 & 1.04 & 5.41 & 18.23 & 75.59 \\
\hline 80 & 0.37 & 0.38 & 0.38 & 0.19 & 1.05 & 0.03 & 0.14 & 0.46 & 1.89 \\
\hline 81 & 14.62 & 14.74 & 14.68 & 7.38 & 40.88 & 1.01 & 5.28 & 17.78 & 73.70 \\
\hline 82 & 3.7E-04 & $3.8 \mathrm{E}-04$ & $3.8 \mathrm{E}-04$ & $1.9 \mathrm{E}-04$ & 1.0E-03 & $2.6 \mathrm{E}-05$ & 1.4E-04 & $4.6 E-04$ & 1.9E-03 \\
\hline 83 & 0.37 & 0.38 & 0.38 & 0.19 & 1.05 & 0.03 & 0.14 & 0.46 & 1.89 \\
\hline 84 & 0.00 & 0.00 & 0.00 & 0.00 & 0.00 & 0.00 & 0.00 & 0.00 & 0.00 \\
\hline 85 & 0.37 & 0.38 & 0.38 & 0.19 & 1.05 & 0.03 & 0.14 & 0.46 & 1.89 \\
\hline 86 & 14.57 & 14.69 & 14.64 & 7.36 & 40.76 & 1.01 & 5.26 & 17.72 & 73.47 \\
\hline 87 & 0.044 & 0.044 & 0.044 & 0.022 & 0.123 & 0.003 & 0.016 & 0.053 & 0.221 \\
\hline 88 & 0.044 & 0.044 & 0.044 & 0.022 & 0.123 & 0.003 & 0.016 & 0.053 & 0.221 \\
\hline 89 & 0 & 0 & 이 & 0 & 0 & 0 & 0 & 0 & 0 \\
\hline 90 & 1.46 & 0.15 & 1.46 & 0.74 & 4.08 & 0.10 & 0.53 & 1.77 & 7.35 \\
\hline 91 & 13.12 & 14.55 & 13.17 & 6.62 & 36.68 & 0.91 & 4.73 & 15.95 & 66.13 \\
\hline 92 & 0.44 & 0.01 & 0.44 & 0.22 & 1.22 & 0.03 & 0.16 & 0.53 & 2.20 \\
\hline 93 & 1.02 & 0.13 & 1.02 & 0.51 & 2.85 & 0.07 & 0.37 & 1.24 & 5.14 \\
\hline 94 & 0.44 & 0.01 & 0.44 & 0.22 & 1.22 & 0.03 & 0.16 & 0.53 & 2.20 \\
\hline 95 & 0 & 0.0073 & 0 & 0 & 0 & .0 & 0 & 0 & 0 \\
\hline 96 & 14.14 & 14.68 & 14.20 & 7.13 & 39.53 & 0.98 & 5.10 & 17.19 & 71.27 \\
\hline 97 & 0 & of & 0 & 0 & 0 & 0 & 0 & 0 & 0 \\
\hline 98 & 0.44 & 0.01 & 0.44 & 0.22 & 1.22 & 0.03 & 0.16 & 0.53 & 2.20 \\
\hline 99 & 0 & 0 & 0) & 0 & 0 & 0 & 0 & 0 & 0 \\
\hline 100 & 0.44 & 0.01 & 0.44 & 0.22 & 1.22 & 0.03 & 0.16 & 0.53 & 2.20 \\
\hline 101 & 0 & 0 & 0 & 0 & 0 & o & 0 & 0 & 0 \\
\hline 102 & 0.44 & 0.01 & 0.44 & 0.22 & 1.22 & 0.03 & 0.16 & 0.53 & 2.20 \\
\hline 103 & 0.44 & 0.01 & 0.44 & -0.08 & 0.92 & -0.27 & -0.14 & 0.23 & 1.90 \\
\hline 104 & 8.7E-04 & $8.7 E-04$ & 8.7E-04 & $3.0 \mathrm{E}-01$ & 3.0E-01 & $3.0 \mathrm{E}-01$ & $3.0 \mathrm{E}-01$ & 3.0E-01 & 3.0E-01 \\
\hline
\end{tabular}




\begin{tabular}{|r|r|r|r|r|r|r|r|r|r|}
\hline 105 & 40 & 40 & 40 & 40 & 40 & 40 & 40 & 40 & 40 \\
\hline 106 & 7.32 & 8.84 & 0.00 & 0.012 & 0.008 & -0.001 & 0.036 & 0.015 & 0.027 \\
\hline 107 & 3.23 & 3.90 & 0.00 & 0.005 & 0.003 & 0.000 & 0.016 & 0.006 & 0.012 \\
\hline 108 & 83.15 & 1.23 & 83.50 & -0.04 & 0.51 & -0.15 & -0.08 & 0.13 & 1.04 \\
\hline 109 & 36.66 & 0.54 & 36.82 & -0.02 & 0.22 & -0.07 & -0.03 & 0.06 & 0.46 \\
\hline
\end{tabular}

Table A8. Key to Tables A9-A11.

Line Input Variable

1 Fraction mercury removed by ion exchange sorbant

2 Fraction mercury in TRUEX strip

3 Fraction mercury in TRUEX carbonate wash

4 Fraction mercury in TRUEX acid rinse

5 Fraction mercury in TRUEX raffinate

6 Fraction mercury retained in TRUEX solvent

7 Fraction mercury in SREX strip

8 Fraction mercury in SREX carbonate wash

9 Fraction mercury in SREX acid rinse

10 Fraction mercury in SREX raffinate (\& strip \#2 for SBW)

11 Fraction mercury retained in SREX solvent

12 Fraction $\mathrm{Hg}$ removed from TRUEX carbonate wash

13 Fraction of $\mathrm{Hg}$ in HAW evaporator overhead

14 Fraction mercury retained in glass

15 Fraction $\mathrm{Hg}$ removed by HAW offgas dust scrubber

16 Fraction $\mathrm{Hg}$ removed by HAW offgas condenser

17 Fraction $\mathrm{Hg}$ removed by HAW offgas NOx column

18 Fraction $\mathrm{Hg}$ removed by HAW offgas wash column

19 Fraction $\mathrm{Hg}$ removed by HAW offgas cold trap

20 Fraction $\mathrm{Hg}$ removed by HAW offgas demister

21 Fraction $\mathrm{Hg}$ retained by HAW offgas HEPA filters

22 Fraction $\mathrm{Hg}$ retained by HAW SCR reactors

23 Fraction of mercury in LAW evaporator overhead

24 Fraction of mercury recycled from $\mathrm{HNO} 3$ fractionator

25 Fraction of mercury retained by denitrator solids

26 Fraction of mercury retained in the grout

27 Fraction of mercury removed by LAW offgas scrubber

28 Fraction of mercury removed by LAW offgas venturi

29 Fraction $\mathrm{Hg}$ removed by LAW offgas demister

30 Fraction $\mathrm{Hg}$ retained by LAW offgas HEPA prefilter

31 Fraction $\mathrm{Hg}$ retained by LAW offgas HEPA filters

32 Fraction $\mathrm{Hg}$ retained by LAW SCR reactors

33 Fraction $\mathrm{Hg}$ in $\mathrm{HNO} 3$ Fractionator Condensate

34 Fraction $\mathrm{Hg}$ in $\mathrm{HNO} 3$ Fractionator Bottoms

35 Fraction $\mathrm{Hg}$ in $\mathrm{HNO} 3$ Fractionator Vent gas

\section{Line Material Balance Model Results}

36 Fraction $\mathrm{Hg}$ removed by HAW carbon bed

37 Fraction $\mathrm{Hg}$ removed by LAW carbon bed

38 Mercury in SBW Feed 
39 Mercury in Total Dissolver Feed

40 Mercury retained by cesium IX sorbant

41 Mercury in TRUEX feed

41 Mercury in TRUEX strip effluent

43 Mercury in TRUEX wash effluent

44 Mercury in TRUEX rinse effluent

45 Mercury in TRUEX raffinate

46 Mercury in TRUEX solvent

47 Mercury in SREX strip effluent

48 Mercury in SREX wash effluent

49 Mercury in SREX rinse effluent

50 Mercury in SREX raffinate

51 Mercury retained in SREX solvent

52 Mercury in HAW evaporator feed

53 Mercury in HAW evaporator bottoms

54 Mercury in melter feed

55 Mercury in glass

56 Mercury in melter offgas

57 Mercury in dust scrubber offgas

58 Mercury in dust scrubber recycle

59 Mercury in HAW condenser liquid

60 Mercury in HAW condenser offgas

61 Mercury in NOx Absorber liquid

62 Mercury in NOx Absorber offgas

63 Mercury in wash column liquid

64 Mercury in wash column offgas

65 Mercury in cold trap liquid

66 Mercury in cold trap offgas

67 Mercury in demister liquid

68 Mercury in demister offgas

69 Mercury retained in HEPA filters

70 Mercury in HEPA filter offgas

71 Mercury retained in HAW SCR reactor

72 Mercury in SCR reactor effluent

73 Mercury retained in HAW carbon bed

74 Mercury from HAW offgas to stack

75 HAW liquid recycle to dissolution

76 Mercury in HAW evaporator condensate

77 Mercury in LAW feed

78 Mercury in LAW condensate

79 Mercury in denitrator feed

80 Mercury in $\mathrm{HNO} 3$ fractionator condensate

81 Mercury in $\mathrm{HNO} 3$ fractionator bottoms

82 Mercury emissions from acid fractionator

83 Mercury in acid and water recycle

84 Mercury in denitrator offgas

85 Mercury in denitrator solids

86 Mercury in grout 
87 Mercury emissions from grouting

88 Mercury in offgas from LAW scrubber

89 Mercury in liquid from LAW scrubber

90 Mercury in offgas from venturi scrubber

91 Mercury in liquid from venturi scrubber

92 Mercury in offgas from demister

93 Mercury in liquid from demister

94 Mercury in LAW scrub liquid ( $\mathrm{Hg}$ removal feed)

95 Mercury in LAW scrub liquid recycle

96 Recovered $\mathrm{Hg}$

97 Mercury retained in LAW HEPA prefilter

98 Mercury in LAW HEPA prefilter effluent

99 Mercury retained in LAW HEPA filters

100 Mercury in LAW HEPA filter effluent

101 Mercury retained in LAW SCR

102 Mercury in LAW SCR effluent

103 Mercury retained in LAW Carbon bed

104 Mercury in LAW offgas to stack

105 Mercury in HAW offgas, ug/dscm

$106 \mathrm{~kg}$ carbon - HAW

107 gal carbon - HAW

$108 \mathrm{~kg}$ carbon - LAW

109 gal carbon - LAW

Table A9. SBW Feed, Mercury Recovery from LAW Scrub Liquid (See Table A8 for key, Table A10 for additional results for SBW.)

\begin{tabular}{|r|r|r|r|r|r|r|r|r|r|}
\hline Line & Base & & Truex A & Truex B & Truex C & $\begin{array}{l}\text { SREX } \\
\text { solvent } \\
\text { retention }\end{array}$ & $\begin{array}{l}\text { Lower } \\
\text { Removal } \\
\text { Efficiency }\end{array}$ & $\begin{array}{l}\text { Low } \\
\text { Removal } \\
\text { Efficiency }\end{array}$ & $\begin{array}{l}\text { High } \\
\text { Removal } \\
\text { Efficiency }\end{array}$ \\
\hline 1 & 0 & 0 & 0 & 0 & 0 & 0 & 0 & 0 & $\begin{array}{l}\text { Gg in } \\
\text { Glass }\end{array}$ \\
\hline 2 & 0.02 & 0.01 & 0.01 & 0.04 & 0.02 & 0.02 & 0.02 & 0.02 & 0.02 \\
\hline 3 & 0.8 & 0.6 & 0.97 & 0.94 & 0.8 & 0.8 & 0.8 & 0.8 & 0.8 \\
\hline 4 & 0 & 0.02 & 0 & 0 & 0 & 0 & 0 & 0 & 0 \\
\hline 5 & 0.18 & 0.37 & 0.02 & 0.02 & 0.18 & 0.18 & 0.18 & 0.18 & 0.18 \\
\hline 6 & 0 & 0 & 0 & 0 & 0 & 0 & 0 & 0 & 0 \\
\hline 7 & 0.004 & 0.004 & 0.004 & 0.004 & 0.004 & 0.004 & 0.004 & 0.004 & 0.004 \\
\hline 8 & 0.002 & 0.002 & 0.002 & 0.002 & 0.002 & 0.002 & 0.002 & 0.002 & 0.002 \\
\hline 9 & 0.043 & 0.043 & 0.043 & 0.043 & 0.004 & 0.043 & 0.043 & 0.043 & 0.043 \\
\hline 10 & 0.95 & 0.95 & 0.95 & 0.95 & 0.09 & 0.95 & 0.95 & 0.95 & 0.95 \\
\hline 11 & 0.001 & 0.001 & 0.001 & 0.001 & 0.9 & 0.001 & 0.001 & 0.001 & 0.001 \\
\hline 12 & 0.99 & 0.99 & 0.99 & 0.99 & 0.99 & 0.8 & 0.9 & 0.999 & 0.99 \\
\hline 13 & 0.025 & 0.025 & 0.025 & 0.025 & 0.025 & 0.025 & 0.025 & 0.025 & 0.025 \\
\hline 14 & 0 & 0 & 0 & 0 & 0 & 0 & 0 & 0 & 0.09 \\
\hline 15 & 0.5 & 0.5 & 0.5 & 0.5 & 0.5 & 0.5 & 0.5 & 0.5 & 0.5 \\
\hline 16 & 0.5 & 0.5 & 0.5 & 0.5 & 0.5 & 0.5 & 0.5 & 0.5 & 0.5 \\
\hline 17 & 0.5 & 0.5 & 0.5 & 0.5 & 0.5 & 0.5 & 0.5 & 0.5 & 0.5 \\
\hline 18 & 0.92 & 0.92 & 0.92 & 0.92 & 0.92 & 0.92 & 0.92 & 0.92 & 0.92 \\
\hline
\end{tabular}




\begin{tabular}{|c|c|c|c|c|c|c|c|c|c|}
\hline 19 & 0 & 이 & 이 & 0 & 0 & 0 & 0) & 0 & 0 \\
\hline 20 & 0 & 0 & 0 & 0 & 0 & 0 & 0 & 0 & 0 \\
\hline 21 & 0 & 0 & 0 & 0 & 0 & 0 & 0 & 0 & 0 \\
\hline 22 & 0 & 0 & 0 & 0 & 0 & 0 & 0 & 0 & 0 \\
\hline 23 & 0.025 & 0.025 & 0.025 & 0.025 & 0.025 & 0.025 & 0.025 & 0.025 & 0.025 \\
\hline 24 & 1 & 1 & 1 & 1 & 1 & 1 & 1 & 1 & 1 \\
\hline 25 & 0.003 & 0.003 & 0.003 & 0.003 & 0.003 & 0.003 & 0.003 & 0.003 & 0.003 \\
\hline 26 & 1 & 1 & $1)$ & 1 & 1 & 1 & 1 & 1) & 1 \\
\hline 27 & 0.9 & 0.9 & 0.9 & 0.9 & 0.9 & 0.9 & 0.9 & 0.9 & 0.9 \\
\hline 28 & 0.7 & 0.7 & 0.7 & 0.7 & 0.7 & 0.7 & 0.7 & $\overline{0.7}$ & 0.7 \\
\hline 29 & 0 & 0 & 0 & 0 & 0 & 0 & 0 & 0 & 0 \\
\hline 30 & 0 & 0 & 0 & 0 & 0 & 0 & 0 & 0 & 이 \\
\hline 31 & 0 & 0 & 0 & 0 & 0 & 0 & 0 & 0 & 0 \\
\hline 32 & 0 & 0 & 0 & 0 & 0 & 0) & 0 & 0 & 0 \\
\hline 33 & 0.001 & 0.001 & 0.001 & 0.001 & 0.001 & 0.001 & 0.001 & 0.001 & 0.001 \\
\hline 34 & 0.99899 & 0.99899 & 0.99899 & 0.99899 & 0.99899 & 0.99899 & 0.99899 & 0.99899 & 0.99899 \\
\hline 35 & 0.00001 & 0.00001 & 0.00001 & 0.00001 & 0.00001 & 0.00001 & 0.00001 & 0.00001 & 0.00001 \\
\hline & \multicolumn{9}{|c|}{ Results in Lines 38-104 are expressed as a fraction of the mercury in the SBW feed } \\
\hline 36 & 0.9922 & 0.9858 & 0.9838 & 0.9960 & 0.9922 & 0.9923 & 0.9922 & 0.9922 & 0.9906 \\
\hline 37 & 0.9976 & 0.9976 & 0.9976 & 0.9976 & 0.9972 & 0.9981 & 0.9978 & 0.9976 & 0.9976 \\
\hline 38 & 100 & 100 & 100 & 100 & 100 & 100 & 100 & 100 & 100 \\
\hline 39 & 104.66 & 103.73 & 103.59 & 106.67 & 104.21 & 105.26 & 104.91 & 104.64 & 104.30 \\
\hline 40 & of & 0 & 0 & 0| & 0 & 0 & 0 & 0 & 0 \\
\hline 41 & 104.66 & 103.73 & 103.59 & 106.67 & 104.21 & 105.26 & $104.91 \mid$ & 104.64 & 104.30 \\
\hline 41 & 2.09 & 1.04 & 1.04 & 4.27 & 2.08 & 2.11 & 2.10 & 2.09 & 2.09 \\
\hline 43 & 83.73 & 62.24 & 100.48 & 100.27 & 83.37 & 84.21 & 83.93 & 83.71 & 83.44 \\
\hline 44 & 0 & 2.07 & 0 & 이 & 0 & 0 & 0 & 0 & 0 \\
\hline 45 & 18.84 & 38.38 & 2.07 & 2.13 & 18.76 & 18.95 & 18.88 & 18.83 & 18.77 \\
\hline 46 & 0 & 0 & 0 & 0 & 0 & 0 & 0 & 0 & 0 \\
\hline 47 & 0.075 & 0.154 & 0.008 & 0.009 & 0.075 & \begin{tabular}{l|l|}
0.076 \\
\end{tabular} & 0.076 & 0.075 & 0.075 \\
\hline 48 & 0.038 & 0.077 & 0.004 & 0.004 & 0.038 & 0.038 & 0.038 & 0.038 & 0.038 \\
\hline 49 & 0.81 & 1.65 & 0.09 & 0.09 & 0.08 & 0.81 & 0.81 & 0.81 & 0.81 \\
\hline 50 & 17.90 & 36.46 & 1.97 & 2.03 & 1.69 & 18.00 & 17.94 & 17.89 & 17.84 \\
\hline 51 & \begin{tabular}{l|l}
0.019 \\
\end{tabular} & 0.038 & 0.0021 & 0.0021 & 16.883 & 0.019 & 0.019 & 0.019 & 0.019 \\
\hline 52 & 2.17 & 1.19 & 1.04 & 4.28 & 2.16 & 2.18 & 2.17 & 2.17 & 2.16 \\
\hline 53 & 2.11 & 1.16 & 1.02 & 4.17 & 2.11 & 2.13 & 2.12 & 2.11 & 2.11 \\
\hline 54 & 4.23 & 2.32 & 2.04 & 8.34 & 4.21 & 4.25 & 4.24 & 4.23 & 3.87 \\
\hline 55 & 0 & 0 & 0 & 0 & 0 & 0 & 0 & 0 & 0.35 \\
\hline 56 & 4.23 & 2.32 & 2.04 & 8.34 & 4.21 & 4.25 & 4.24 & 4.23 & 3.52 \\
\hline 57 & 2.11 & 1.16 & 1.02 & 4.17 & 2.11 & 2.13 & 2.12 & 2.11 & 1.76 \\
\hline 58 & 2.11 & 1.16 & 1.02 & \begin{tabular}{|l|}
4.17 \\
\end{tabular} & 2.11 & 2.13 & 2.12 & 2.11 & 1.76 \\
\hline 59 & 1.06 & 0.58 & 0.51 & 2.08 & 1.05 & 1.06 & 1.06 & 1.06 & 0.88 \\
\hline 60 & 1.06 & 0.58 & 0.51 & 2.08 & 1.05 & 1.06 & 1.06 & 1.06 & 0.88 \\
\hline 61 & 0.53 & 0.29 & 0.25 & 1.04 & 0.53 & 0.53 & 0.53 & 0.53 & 0.44 \\
\hline 62 & 0.53 & 0.29 & 0.25 & 1.04 & $\begin{array}{ll}0.53 \\
\end{array}$ & 0.53 & \begin{tabular}{l|l}
0.53 \\
\end{tabular} & 0.53 & 0.44 \\
\hline 63 & 0.49 & 0.27 & 0.23 & 0.96 & \begin{tabular}{l|}
0.48 \\
\end{tabular} & 0.49 & 0.49 & 0.49 & 0.40 \\
\hline
\end{tabular}




\begin{tabular}{|c|c|c|c|c|c|c|c|c|c|}
\hline 64 & 0.042 & 0.023 & 0.020 & 0.083 & 0.042 & 0.043 & 0.042 & 0.042 & 0.035 \\
\hline 65 & 0 & 0 & 아 & 0 & 0 & 0 & 0 & 0 & $\overline{0}$ \\
\hline 66 & 0.042 & 0.023 & 0.020 & 0.083 & 0.042 & 0.043 & 0.042 & 0.042 & 0.035 \\
\hline 67 & 0 & 0 & 0 & 0 & 요 & 0 & 0 & 0 & 0 \\
\hline 68 & 0.042 & 0.023 & 0.020 & 0.083 & 0.042 & 0.043 & 0.042 & 0.042 & 0.035 \\
\hline 69 & 0 & 0 & 이 & 0 & 0 & 0 & 0 & 0 & 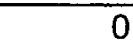 \\
\hline 70 & 0.042 & 0.023 & 0.020 & 0.083 & 0.042 & 0.043 & 0.042 & 0.042 & 0.035 \\
\hline 71 & 0 & 0 & 이 & 0 & 0 & 0 & 0 & 0 & 0 \\
\hline 72 & 0.042 & 0.023 & 0.020 & 0.083 & 0.042 & 0.043 & 0.042 & 0.042 & 0.035 \\
\hline 73 & 0.042 & 0.023 & 0.020 & 0.083 & 0.042 & 0.042 & 0.042 & 0.042 & 0.035 \\
\hline 74 & $3.3 E-04$ & 3.3E-04 & 3.3E-04 & 3.3E-04 & 3.3E-04 & 3.3E-04 & 3.3E-04 & 3.3E-04 & $3.3 \mathrm{E}-04$ \\
\hline 75 & 2.07 & 1.14 & 1.00 & 4.09 & 2.06 & 2.08 & 2.08 & 2.07 & 1.72 \\
\hline 76 & 0.054 & 0.030 & 0.026 & 0.107 & 0.054 & 0.055 & 0.054 & 0.054 & 0.054 \\
\hline 77 & 103.50 & 103.50 & 103.54 & 103.48 & 86.04 & 127.08 & 113.48 & 102.60 & 103.15 \\
\hline 78 & 2.59 & 2.59 & 2.59 & 2.59 & 2.15 & 3.18 & 2.84 & 2.57 & 2.58 \\
\hline 79 & 100.91 & 100.91 & 100.95 & 100.89 & 83.89 & 123.90 & 110.64 & 100.04 & 100.57 \\
\hline 80 & 0.0026 & 0.0026 & 0.0026 & 0.0026 & 0.0022 & 0.0032 & 0.0028 & 0.0026 & 0.0026 \\
\hline 81 & 2.58 & 2.58 & 2.59 & 2.58 & 2.15 & 3.17 & 2.83 & 2.56 & 2.58 \\
\hline 82 & 0.00 & 0.00 & 0.00 & 0.00 & 0.00 & 0.00 & 0.00 & 0.00 & 0.00 \\
\hline 83 & 2.59 & 2.59 & 2.59 & 2.59 & 2.15 & 3.18 & 2.84 & 2.56 & 2.58 \\
\hline 84 & 100.61 & 100.61 & 100.65 & 100.59 & 83.63 & 123.53 & 110.31 & 99.74 & 100.27 \\
\hline 85 & 0.30 & 0.30 & 0.30 & 0.30 & 0.25 & 0.37 & 0.33 & 0.30 & 0.30 \\
\hline 86 & 0.30 & 0.30 & 0.30 & 0.30 & 0.25 & 0.37 & 0.33 & 0.30 & 0.30 \\
\hline 87 & 0 & 0 & 0 & 0 & 0 & 0 & 0 & 0 & 0 \\
\hline 88 & 10.06 & 10.06 & 10.07 & 10.06 & 8.36 & 12.35 & 11.03 & 9.97 & 10.03 \\
\hline 89 & 90.55 & 90.55 & 90.59 & 90.53 & 75.27 & 111.18 & 99.28 & 89.76 & 90.24 \\
\hline 90 & 3.02 & 3.02 & 3.02 & 3.02 & 2.51 & $\overline{3.71}$ & 3.31 & 2.99 & 3.01 \\
\hline 91 & 7.04 & 7.04 & 7.05 & 7.04 & 5.85 & 8.65 & 7.72 & 6.98 & 7.02 \\
\hline 92 & 3.02 & 3.02 & 3.02 & 3.02 & 2.51 & 3.71 & 3.31 & 2.99 & 3.01 \\
\hline 93 & 0 & 0 & 0 & 0 & 0 & 0 & o & 0 & 0 \\
\hline 94 & 97.59 & 97.59 & 97.63 & 97.57 & 81.13 & 119.83 & 107.00 & 96.74 & 97.26 \\
\hline 95 & 0.98 & 0.98 & 0.98 & 0.98 & 0.81 & 23.97 & 10.70 & 0.10 & 0.97 \\
\hline 96 & 96.62 & 96.62 & 96.66 & 96.59 & 80.31 & 95.86 & 96.30 & 96.65 & 96.29 \\
\hline 97 & 0 & 0 & 0 & 0 & 0 & 0 & 0 & 0 & 0 \\
\hline 98 & 3.02 & 3.02 & 3.02 & 3.02 & 2.51 & 3.71 & 3.31 & 2.99 & 3.01 \\
\hline 99 & 0 & 0 & 0 & 0 & 0 & 0 & 인 & 0 & 0 \\
\hline 100 & 3.02 & 3.02 & 3.02 & 3.02 & 2.51 & 3.71 & 3.31 & 2.99 & 3.01 \\
\hline 101 & 0 & 0 & 0 & 0 & 0 & 0 & 0 & 0 & 0 \\
\hline 102 & 3.02 & 3.02 & 3.02 & 3.02 & 2.51 & $\overline{3.71}$ & 3.31 & 2.99 & 3.01 \\
\hline 103 & 3.01 & 3.01 & 3.01 & 3.01 & 2.50 & 3.70 & 3.30 & 2.98 & 3.00 \\
\hline 104 & 0.0071 & 0.0071 & 0.0071 & 0.0071 & 0.0071 & 0.0071 & 0.0071 & 0.0071 & 0.0071 \\
\hline 105 & 40 & 40 & 40 & 40 & 40 & 40 & 40 & 40 & 40 \\
\hline 106 & 2.64 & 1.44 & 1.26 & 5.23 & 2.63 & 2.66 & 2.65 & 2.64 & 2.19 \\
\hline 107 & 1.16 & 0.64 & 0.56 & 2.30 & 1.16 & 1.17 & 1.17 & 1.16 & 0.97 \\
\hline 108 & 189.47 & 189.47 & 189.55 & 189.43 & 157.43 & 232.74 & 207.77 & 187.82 & 188.83 \\
\hline 109 & 83.54 & 83.54 & 83.57 & 83.52 & 69.41 & 102.62 & 91.61 & 82.81 & 83.26 \\
\hline
\end{tabular}


Table A10. SBW and Zirconia Calcine Feeds, Mercury Recovery from LAW Scrub Liquid (See Table A8 for key, Table A9 for additional results for SBW.)

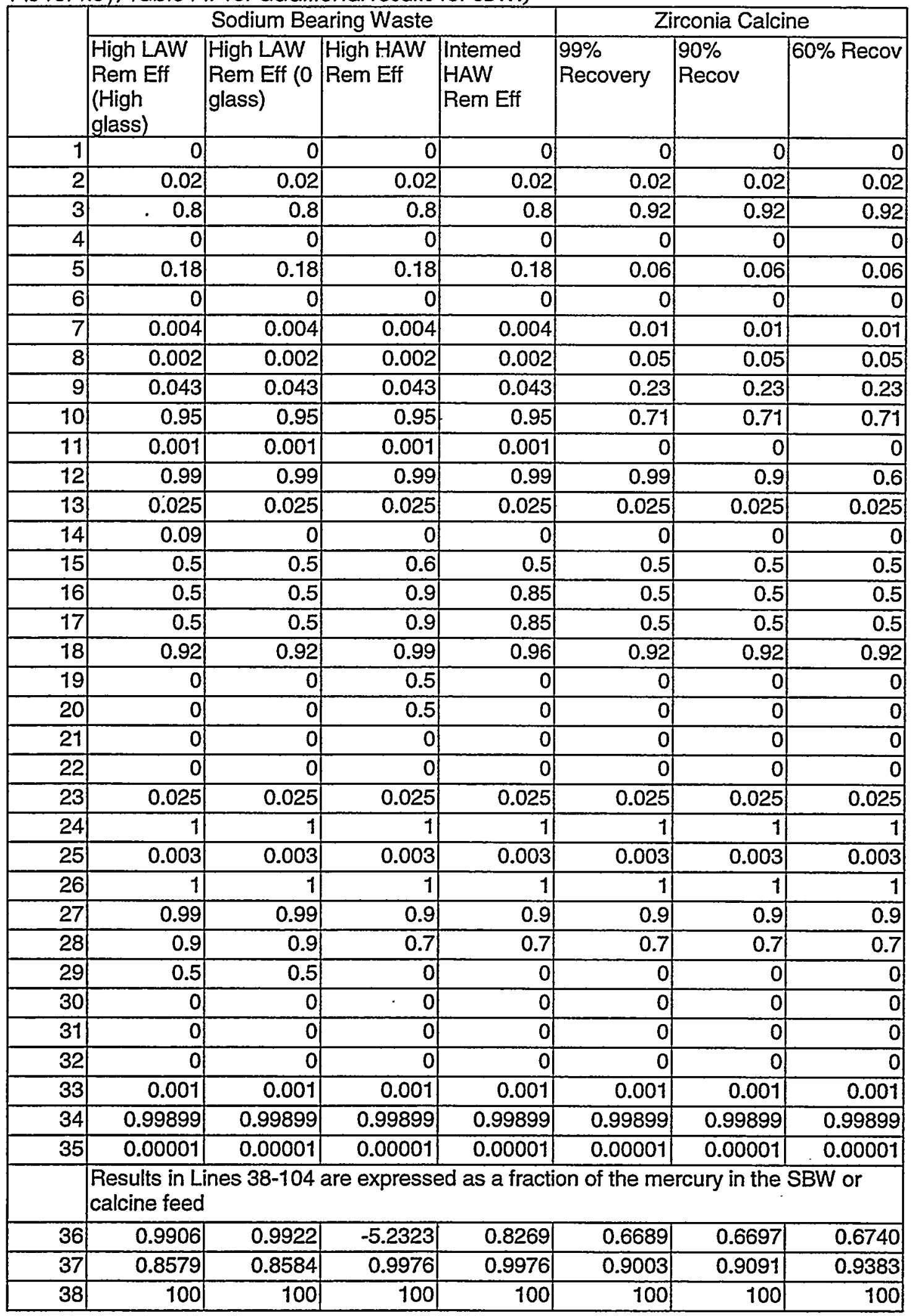




\begin{tabular}{|c|c|c|c|c|c|c|c|}
\hline 39 & 104.30 & \begin{tabular}{l|l|}
104.66 \\
\end{tabular} & 104.70 & 104.70 & 104.65 & 104.90 & 106.27 \\
\hline 40 & 0 & 0 & 0 & 0 & 0 & 0 & 0 \\
\hline 41 & 104.30 & 104.66 & 104.70 & 104.70 & 104.65 & 104.90 & 106.27 \\
\hline 41 & 2.09 & 2.09 & 2.09 & 2.09 & 2.09 & 2.10 & 2.13 \\
\hline 43 & 83.44 & 83.73 & 83.76 & 83.76 & 96.28 & 96.51 & 97.77 \\
\hline 44 & 0 & 0 & 0 & 0 & 0 & 0 & $\overline{0}$ \\
\hline 45 & 18.77 & 18.84 & 18.85 & 18.85 & 6.28 & 6.29 & 6.38 \\
\hline 46 & 0 & 0 & 0 & 0 & 0 & 0 & 0 \\
\hline 47 & 0.075 & 0.075 & 0.075 & 0.075 & 0.063 & 0.063 & 0.064 \\
\hline 48 & 0.038 & 0.038 & 0.038 & 0.038 & 0.314 & 0.315 & 0.319 \\
\hline 49 & 0.807 & 0.810 & 0.810 & 0.810 & 1.444 & 1.448 & 1.467 \\
\hline 50 & 17.836 & 17.897| & 17.904 & 17.904 & 4.458 & 4.469 & 4.527 \\
\hline 51 & 0.0188 & 0.0188 & 0.0188 & 0.0188 & 0 & 0 & 0 \\
\hline 52 & 2.16 & 2.17 & 2.17 & 2.17 & 2.16 & 2.16 & 2.19 \\
\hline 53 & 2.11 & 2.11 & 2.12 & 2.12 & 2.10 & 2.11 & 2.13 \\
\hline 54 & 3.87 & 4.23 & 4.23 & 4.23 & 4.20 & 4.21 & 4.27 \\
\hline 55 & 0.35 & 0 & 0 & 0 & 0 & 0 & 0 \\
\hline 56 & 3.52 & 4.23 & 4.23 & 4.23 & 4.20 & 4.21 & 4.27 \\
\hline 57 & 1.76 & 2.11 & 2.12 & 2.12 & 2.10 & 2.11 & 2.13 \\
\hline 58 & 1.76 & 2.11 & 2.12 & 2.12 & 2.10 & 2.11 & 2.13 \\
\hline 59 & 0.88 & 1.06 & 1.90 & 1.80 & 1.05 & 1.05 & 1.07 \\
\hline 60 & 0.88 & 1.06 & 0.21 & 0.32 & 1.05 & 1.05 & 1.07 \\
\hline 61 & 0.44 & 0.53 & 0.19 & 0.27 & 0.53 & 0.53 & 0.53 \\
\hline 62 & 0.44 & 0.53 & 0.02 & 0.05 & 0.53 & 0.53 & 0.53 \\
\hline 63 & 0.40 & 0.49 & 0.02 & 0.05 & 0.48 & 0.48 & 0.49 \\
\hline 64 & $3.5 E-02$ & $4.2 \mathrm{E}-02$ & $2.1 \mathrm{E}-04$ & $1.9 \mathrm{E}-03$ & $4.2 \mathrm{E}-02$ & $4.2 \mathrm{E}-02$ & $4.3 \mathrm{E}-02$ \\
\hline 65 & 0 & 0 & $1.1 E-04$ & 0 & 0 & 0 & 0 \\
\hline 66 & 0.035 & 0.042 & $1.1 E-04$ & 0.0019 & 0.042 & 0.042 & 0.043 \\
\hline 67 & 0 & 0 & 5.3E-05 & 0 & 0 & 0 & 0 \\
\hline 68 & 0.035 & 0.042 & $5.3 \mathrm{E}-05$ & 0.0019 & 0.042 & 0.042 & 0.043 \\
\hline 69 & 0 & 0 & $0.0 \mathrm{E}+00$ & 0 & $\overline{0}$ & 0 & 0 \\
\hline 70 & 0.035 & 0.042 & 5.3E-05 & 0.0019 & 0.042 & 0.042 & 0.043 \\
\hline 71 & 이 & 0 & $0.0 \mathrm{E}+00$ & 0 & 0 & 요 & 0 \\
\hline 72 & 0.035 & 0.042 & $5.3 \mathrm{E}-05$ & 0.0019 & 0.042 & 0.042 & 0.043 \\
\hline 73 & 0.035 & 0.042 & $-2.8 E-04$ & 0.0016 & 0.028 & 0.028 & 0.029 \\
\hline 74 & $3.3 E-04$ & $3.3 E-04$ & $3.3 \mathrm{E}-04$ & $3.3 E-04$ & $1.4 \mathrm{E}-02$ & $1.4 \mathrm{E}-02$ & 1.4E-02 \\
\hline 75 & 1.72 & 2.07 & 2.12 & 2.11 & 2.06 & 2.06 & 2.09 \\
\hline 76 & 0.05 & 0.05 & 0.05 & 0.05 & 0.05 & 0.05 & 0.05 \\
\hline 77 & 103.18 & 103.53 & 103.55 & 103.54 & 103.52 & 113.50 & 167.20 \\
\hline 78 & 2.58 & 2.59 & 2.59 & 2.59 & 2.59 & 2.84 & 4.18 \\
\hline 79 & 100.60 & 100.94 & 100.96 & 100.96 & 100.93 & 110.66 & 163.02 \\
\hline 80 & 0.00 & 0.00 & 0.00 & 0.00 & 0.00 & 0.00 & 0.00 \\
\hline 81 & 2.58 & 2.59 & 2.59 & 2.59 & 2.59 & 2.83 & 4.18 \\
\hline 82 & 0.00 & 0.00 & 0.00 & 0.00 & 0.00 & 0.00 & 0.00 \\
\hline 83 & 2.58 & 2.59 & 2.59 & 2.59 & 2.59 & 2.84 & 4.18 \\
\hline 84 & 100.30 & 100.64 & 100.65 & 100.65 & 100.63 & 110.33 & 162.53 \\
\hline
\end{tabular}




\begin{tabular}{|r|r|r|r|r|r|r|r|}
\hline 85 & 0.30 & 0.30 & 0.30 & 0.30 & 0.30 & 0.33 & 0.49 \\
\hline 86 & 0.30 & 0.30 & 0.30 & 0.30 & 0.30 & 0.33 & 0.49 \\
\hline 87 & 0 & 0 & 0 & 0 & 0 & 0 & 0 \\
\hline 88 & 1.00 & 1.01 & 10.07 & 10.07 & 10.06 & 11.03 & 16.25 \\
\hline 89 & 99.30 & 99.64 & 90.59 & 90.59 & 90.57 & 99.29 & 146.28 \\
\hline 90 & 0.10 & 0.10 & 3.02 & 3.02 & 3.02 & 3.31 & 4.88 \\
\hline 91 & 0.90 & 0.91 & 7.05 & 7.05 & 7.04 & 7.72 & 11.38 \\
\hline 92 & 0.05 & 0.05 & 3.02 & 3.02 & 3.02 & 3.31 & 4.88 \\
\hline 93 & 0.050 & 0.050 & 0 & 0 & 0 & 0 & 0 \\
\hline 94 & 100.25 & 100.59 & 97.63 & 97.63 & 97.61 & 107.02 & 157.65 \\
\hline 95 & 1.00 & 1.01 & 0.98 & 0.98 & 0.98 & 10.70 & 63.06 \\
\hline 96 & 99.25 & 99.59 & 96.66 & 96.66 & 96.64 & 96.32 & 94.59 \\
\hline 97 & 0 & 0 & 0 & 0 & 0 & 0 & 0 \\
\hline 98 & 0.05 & 0.05 & 3.02 & 3.02 & 3.02 & 3.31 & 4.88 \\
\hline 99 & 0 & 0 & 0 & 0 & 0 & 0 & 0 \\
\hline 100 & 0.05 & 0.05 & 3.02 & 3.02 & 3.02 & 3.31 & 4.88 \\
\hline 101 & 0 & 0 & 0 & 0 & 0 & 0 & 0 \\
\hline 102 & 0.05 & 0.05 & 3.02 & 3.02 & 3.02 & 3.31 & 4.88 \\
\hline 103 & 0.04 & 0.04 & 3.01 & 3.01 & 2.72 & 3.01 & 4.58 \\
\hline 104 & 0.007 & 0.007 & 0.007 & 0.007 & 0.301 & 0.301 & 0.301 \\
\hline 105 & 40 & 40 & 40 & 40 & 40 & 40 & 40 \\
\hline 106 & 2.19 & 2.64 & -0.02 & 0.10 & 0.02 & 0.02 & 0.02 \\
\hline 107 & 0.97 & 1.16 & -0.01 & 0.04 & 0.007 & 0.007 & 0.007 \\
\hline 108 & 2.71 & 2.72 & 189.55 & 189.55 & 1.49 & 1.65 & 2.51 \\
\hline 109 & 1.19 & 1.20 & 83.58 & 83.58 & 0.66 & 0.73 & 1.11 \\
\hline
\end{tabular}

Table A11. Alumina Calcine Feed, Mercury Recovery from LAW Scrub Liquid (See Table A8 for key.)

\begin{tabular}{|r|r|r|r|r|r|r|r|}
\hline $\begin{array}{l}\text { Base (90\% } \\
\text { removal) }\end{array}$ & $\begin{array}{l}99 \% \mathrm{Hg} \\
\text { removal }\end{array}$ & $\begin{array}{l}80 \% \mathrm{Hg} \\
\text { removal }\end{array}$ & $\begin{array}{l}\text { l\% Hg } \\
\text { removal }\end{array}$ & $\begin{array}{l}\text { Low } \\
\text { TRUEX }\end{array}$ & $\begin{array}{l}\text { High Hg } \\
\text { recovery in } \\
\text { LAW } \\
\text { offgas }\end{array}$ & $\begin{array}{l}\text { High HAW } \\
\text { recovery }\end{array}$ \\
\hline 1 & 0 & 0 & 0 & 0 & 0 & 0 & 0 \\
\hline 2 & 0.02 & 0.02 & 0.02 & 0.02 & 0.01 & 0.02 & 0.02 \\
\hline 3 & 0.86 & 0.86 & 0.86 & 0.86 & 0.7 & 0.86 & 0.86 \\
\hline 4 & 0.02 & 0.02 & 0.02 & 0.02 & 0.02 & 0.02 & 0.02 \\
\hline 5 & 0.1 & 0.1 & 0.1 & 0.1 & 0.27 & 0.1 & 0.1 \\
\hline 6 & 0 & 0 & 0 & 0 & 0 & 0 & 0 \\
\hline 7 & 0.003 & 0.003 & 0.003 & 0.003 & 0.003 & 0.003 & 0.003 \\
\hline 8 & 0.029 & 0.029 & 0.029 & 0.029 & 0.029 & 0.029 & 0.029 \\
\hline 9 & 0.611 & 0.611 & 0.611 & 0.611 & 0.611 & 0.611 & 0.611 \\
\hline 10 & 0.357 & 0.357 & 0.357 & 0.357 & 0.357 & 0.357 & 0.357 \\
\hline 11 & 0 & 0 & 0 & 0 & 0 & 0 & 0 \\
\hline 12 & 0.9 & 0.99 & 0.8 & 0 & 0.9 & 0.9 & 0.9 \\
\hline 13 & 0.025 & 0.025 & 0.025 & 0.025 & 0.025 & 0.025 & 0.025 \\
\hline 14 & 0 & 0 & 0 & 0 & 0 & 0 & 0 \\
\hline 15 & 0.5 & 0.5 & 0.5 & 0.5 & 0.5 & 0.5 & 0.5 \\
\hline
\end{tabular}




\begin{tabular}{|c|c|c|c|c|c|c|c|}
\hline 16 & 0.5 & 0.5 & 0.5 & 0.5 & 0.5 & 0.5 & 0.5 \\
\hline 17 & 0.5 & 0.5 & 0.5 & 0.5 & 0.5 & 0.5 & 0.5 \\
\hline 18 & 0.92 & 0.92 & 0.92 & 0.92 & 0.92 & 0.92 & 0.975 \\
\hline 19 & 0 & 이 & 0 & 이 & 0 & 0 & 0 \\
\hline 20 & 0 & 이 & 0 & 이 & 0 & 0 & 0 \\
\hline 21 & 0 & 0 & 0 & 0 & 0 & 0 & 0 \\
\hline 22 & .0 & 이 & 0 & 이 & 0 & of & 0 \\
\hline 23 & 0.025 & 0.025 & 0.025 & 0.025 & 0.025 & 0.025 & 0.025 \\
\hline 24 & 1 & 1 & 1 & 11 & 1 & 1 & 1 \\
\hline 25 & 0.003 & 0.003 & 0.003 & 0.003 & 0.003 & 0.003 & 0.003 \\
\hline 26 & 1 & 1 & 1 & 1 & 1 & 1 & 1 \\
\hline 27 & 0.9 & 0.9 & 0.9 & 0.9 & 0.9 & 0.96 & $\overline{0.9}$ \\
\hline 28 & 0.7 & 0.7 & 0.7 & 0.7 & 0.7 & 0.8 & 0.7 \\
\hline 29 & 0 & 0] & 0 & 0 & 0 & 0 & 0 \\
\hline 30 & 0 & 0 & 0 & 이 & 0 & 0 & 0 \\
\hline 31 & 0 & 0 & 0 & 0 & 0 & 0 & 0 \\
\hline 32 & 이 & 0 & 0 & 0 & 0 & 0) & 0 \\
\hline 33 & 0.001 & 0.001 & 0.001 & 0.001 & 0.001 & 0.001 & 0.001 \\
\hline 34 & 0.99899 & 0.99899 & 0.99899 & 0.99899 & 0.99899 & 0.99899 & 0.99899 \\
\hline 35 & 0.00001 & 0.00001 & 0.00001 & 0.00001 & 0.00001 & 0.00001 & 0.00001 \\
\hline & \multicolumn{7}{|c|}{$\begin{array}{l}\text { Results in Lines 38-104 are expressed as a fraction of the mercury in the calcine } \\
\text { feed }\end{array}$} \\
\hline 36 & 0.9990 & 0.9990 & 0.9990 & 0.9994 & 0.9982 & 0.9990 & 0.9969 \\
\hline 37 & 0.9997 & 0.9997 & 0.9998 & 1.0000 & 0.9997 & 0.9990 & 0.9997 \\
\hline 38 & 100 & 100 & 100 & 100 & 100 & 100 & 100 \\
\hline 39 & 104.87 & 104.62 & 105.22 & 181.38 & 103.91 & 104.88 & 104.90 \\
\hline 40 & 0 & 0 & 0 & 이 & 0 & 이 & 0 \\
\hline 41 & 104.87 & 104.62 & 105.22 & 181.38 & 103.91 & 104.88 & 104.90 \\
\hline 41 & 2.10 & 2.09 & 2.10 & 3.63 & 1.04 & 2.10 & 2.10 \\
\hline 43 & 90.19 & 89.97 & \begin{tabular}{|c|}
90.49 \\
\end{tabular} & 155.98 & \begin{tabular}{|l|}
72.74 \\
\end{tabular} & 90.20 & 90.22 \\
\hline 44 & 2.10 & 2.09 & 2.10 & 3.63 & 2.08 & 2.10 & 2.10 \\
\hline 45 & 10.49 & 10.46 & 10.52 & 18.14 & 28.06 & 10.49 & 10.49 \\
\hline 46 & 0 & 0 & 0 & 0 & 0 & 0 & 0 \\
\hline 47 & 0.031 & 0.031 & 0.032 & 0.054 & 0.084 & 0.031 & 0.031 \\
\hline 48 & 0.30 & 0.30 & 0.31 & 0.53 & 0.81 & 0.30 & 0.30 \\
\hline 49 & 6.41 & 6.39 & 6.43 & 11.08 & 17.14 & 6.41 & 6.41 \\
\hline 50 & 3.74 & 3.73 & 3.76 & 6.48 & 10.02 & 3.74 & 3.74 \\
\hline 51 & 0 & 0 & 0 & 0 & 0 & 0) & 0 \\
\hline 52 & 2.13 & 2.12 & 2.14 & 3.68 & 1.12 & 2.13 & 2.13 \\
\hline 53 & 2.08 & 2.07 & 2.08 & 3.59 & 1.10 & 2.08 & 2.08 \\
\hline 54 & 4.15 & 4.14 & 4.17 & 7.18 & 2.19 & 4.15 & 4.15 \\
\hline 55 & 0 & 0 & 0 & 0 & 0 & 0 & 0 \\
\hline 56 & 4.15 & 4.14 & 4.17 & 7.18 & 2.19 & 4.15 & 4.15 \\
\hline 57 & 2.08 & 2.07 & 2.08 & 3.59 & 1.10 & 2.08 & 2.08 \\
\hline 58 & 2.08 & 2.07 & 2.08 & 3.59 & 1.10 & 2.08 & 2.08 \\
\hline 59 & 1.04 & 1.04 & 1.04 & 1.79 & 0.55 & 1.04 & 1.04 \\
\hline 60 & 1.04 & 1.04 & 1.04 & 1.79 & 0.55 & 1.04 & 1.04 \\
\hline
\end{tabular}




\begin{tabular}{|c|c|c|c|c|c|c|c|}
\hline 61 & 0.52 & 0.52 & 0.52 & 0.90 & 0.27 & 0.52 & 0.52 \\
\hline 62 & 0.52 & 0.52 & 0.52 & 0.90 & 0.27 & $\begin{array}{ll}0.52 \\
\end{array}$ & 0.52 \\
\hline 63 & 0.48 & 0.48 & 0.48 & 0.83 & 0.25 & 0.48 & 0.51 \\
\hline 64 & 0.042 & 0.041 & 0.042 & 0.072 & 0.022 & 0.042 & 0.013 \\
\hline 65 & 0 & 0 & 0 & 0 & 0 & 0 & 0 \\
\hline 66 & 0.042 & 0.041 & 0.042 & 0.072 & 0.022 & 0.042 & 0.013 \\
\hline 67) & 0 & 0 & 0 & 0 & 0 & 0) & 0 \\
\hline 68 & 0.042 & 0.041 & 0.042 & 0.072 & 0.022 & \begin{tabular}{l|}
0.042 \\
\end{tabular} & 0.013 \\
\hline 69 & 0 & 0 & o & 아 & 0 & 0 & 0 \\
\hline 70 & 0.042 & 0.041 & 0.042 & 0.072 & 0.022 & 0.042 & 0.013 \\
\hline 71 & 0 & 0 & 이 & 0 & 0 & o & 0 \\
\hline 72 & 0.042 & 0.041 & 0.042 & 0.072 & 0.022 & 0.042 & 0.013 \\
\hline 73 & 0.041 & 0.041 & 0.042 & 0.072 & 0.022 & 0.041 & 0.013 \\
\hline 74 & $4.0 \mathrm{E}-05$ & $4.0 \mathrm{E}-05$ & $4.0 \mathrm{E}-05$ & $4.0 \mathrm{E}-05$ & $4.0 \mathrm{E}-05$ & $4.0 \mathrm{E}-05$ & $4.0 \mathrm{E}-05$ \\
\hline 75 & 2.03 & 2.03 & 2.04 & 3.52 & 1.07 & 2.03 & 2.06 \\
\hline 76 & 0.053 & 0.053 & 0.053 & 0.092 & 0.028 & 0.053 & 0.053 \\
\hline 77 & 113.50 & 103.52 & 127.11 & 3114.33 & 113.52 & 113.77 & 113.53 \\
\hline 78 & 2.84 & 2.59 & 3.18 & 77.86 & 2.84 & 2.84 & 2.84 \\
\hline 79 & 110.66 & 100.93 & 123.93 & 3036.47 & 110.68 & 110.93 & 110.69 \\
\hline 80 & $2.8 \mathrm{E}-03$ & $2.6 \mathrm{E}-03$ & $3.2 E-03$ & $7.8 \mathrm{E}-02$ & $2.8 \mathrm{E}-03$ & $2.8 \mathrm{E}-03$ & $2.8 \mathrm{E}-03$ \\
\hline 81 & 2.83 & 2.59 & 3.17 & 77.78 & 2.84 & 2.84 & 2.84 \\
\hline 82 & 0.00 & 0.00 & 0.00 & 0.00 & 0.00 & 0.00 & 0.00 \\
\hline 83 & 2.84 & 2.59 & 3.18 & 77.86 & 2.84 & 2.84 & 2.84 \\
\hline 84 & 110.33 & 100.63 & 123.56 & 3027.36 & 110.35 & 110.60 & 110.36 \\
\hline 85 & 0.33 & 0.30 & 0.37 & 9.11 & 0.33 & 0.33 & 0.33 \\
\hline 86 & 0.33 & 0.30 & 0.37 & 9.11 & 0.33 & 0.33 & 0.33 \\
\hline 87 & 아 & 0 & 0 & 0 & 0 & 0 & 0 \\
\hline 88 & 11.03 & 10.06 & 12.36 & 302.74 & 11.03 & 4.42 & 11.04 \\
\hline 89 & 99.30 & 90.57 & 111.20 & 2724.63 & 99.31 & 106.17 & 99.32 \\
\hline 90 & 3.31 & 3.02 & 3.71 & 90.82 & 3.31 & 0.88 & 3.31 \\
\hline 91 & 7.72 & 7.04 & 8.65 & 211.92 & 7.72 & 3.54 & 7.73 \\
\hline 92 & 3.31 & 3.02 & 3.71 & 90.82 & 3.31 & 0.88 & 3.31 \\
\hline 93 & 0 & 0 & 0 & 0 & 0 & 0 & 0 \\
\hline 94 & 107.02 & 97.61 & 119.85 & 2936.54 & 107.04 & 109.71 & 107.05 \\
\hline 95 & 10.70 & 0.98 & 23.97 & 2936.54 & 10.70 & 10.97 & 10.70 \\
\hline 96 & 96.32 & 96.64 & 95.88 & 0 & 96.34 & 98.74 & 96.34 \\
\hline 97 & 0 & 0 & 0 & 0 & 어 & 0 & 0 \\
\hline 98 & 3.31 & 3.02 & 3.71 & 90.82 & 3.31 & 0.88 & 3.31 \\
\hline 99 & 0 & 0 & 0 & 0 & 0 & 0 & 0 \\
\hline 100 & 3.31 & 3.02 & 3.71 & 90.82 & 3.31 & 0.88 & 3.31 \\
\hline 101 & 0 & 0 & 0 & o & 0 & 0 & 0 \\
\hline 102 & 3.31 & 3.02 & 3.71 & 90.82 & 3.31 & 0.88 & 3.31 \\
\hline 103 & 3.31 & 3.02 & 3.71 & 90.82 & 3.31 & 0.88 & 3.31 \\
\hline 104 & 8.7E-04 & 8.7E-04 & 8.7E-04 & 8.7E-04 & 8.7E-04 & 8.7E-04 & 8.7E-04 \\
\hline 105 & 40 & 40 & 40 & 40 & 40 & 40 & 40 \\
\hline 106 & 7.90 & 7.88 & 7.93 & 13.67 & 4.17 & \begin{tabular}{l|l}
7.90 \\
\end{tabular} & 2.47 \\
\hline
\end{tabular}




\begin{tabular}{|r|r|r|r|r|r|r|r|}
\hline 107 & 3.48 & 3.48 & 3.50 & 6.03 & 1.84 & 3.48 & 1.09 \\
\hline 108 & 630.55 & 575.11 & 706.17 & 17306.26 & 630.67 & 168.43 & 630.73 \\
\hline 109 & 278.02 & 253.58 & 311.36 & 7630.68 & 278.07 & 74.27 & 278.10 \\
\hline
\end{tabular}


Figure 1. Flow Scheme for Mercury Removal from TRUEX Carbonate Wash, Sodium Bearing Waste Feed.

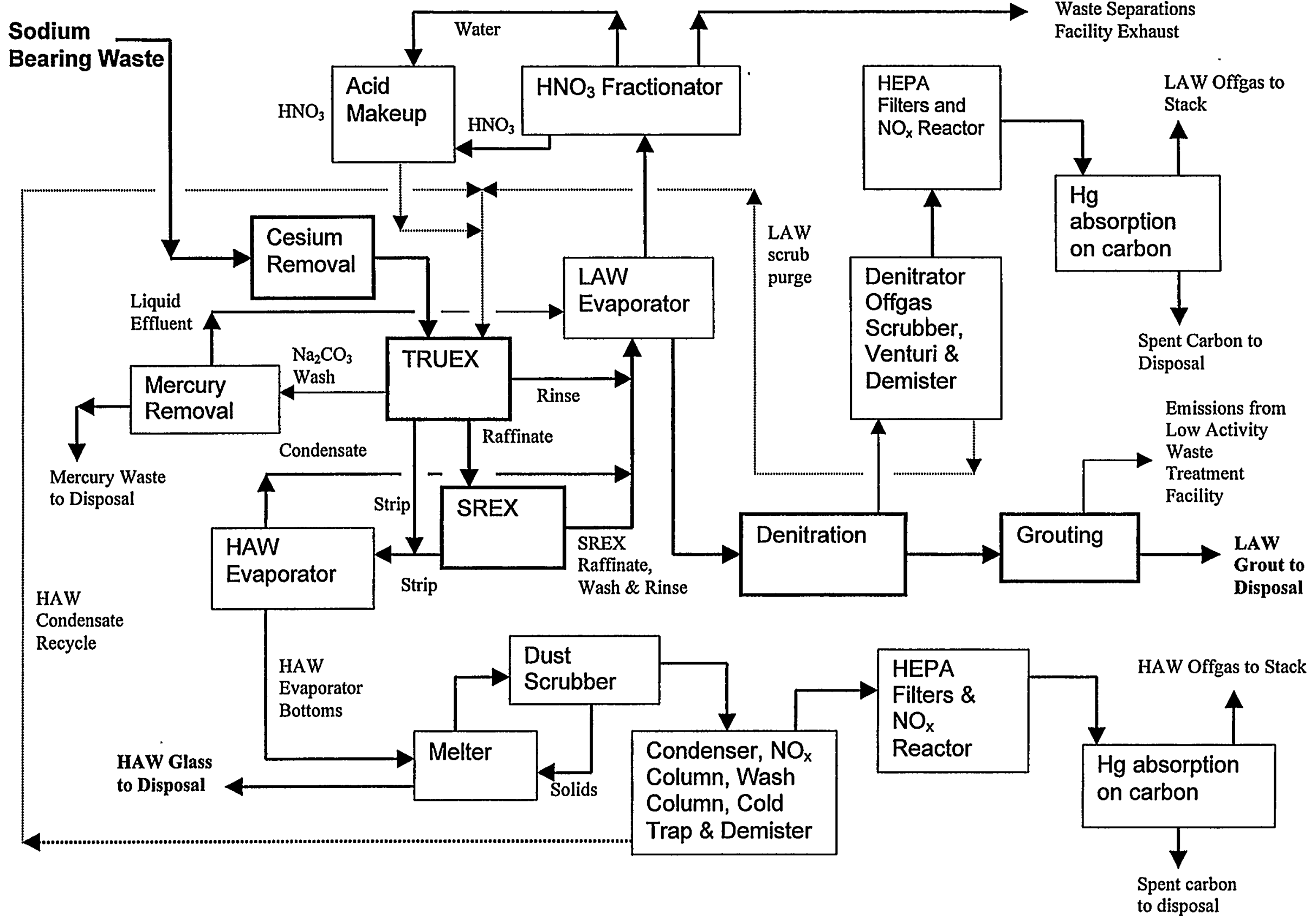




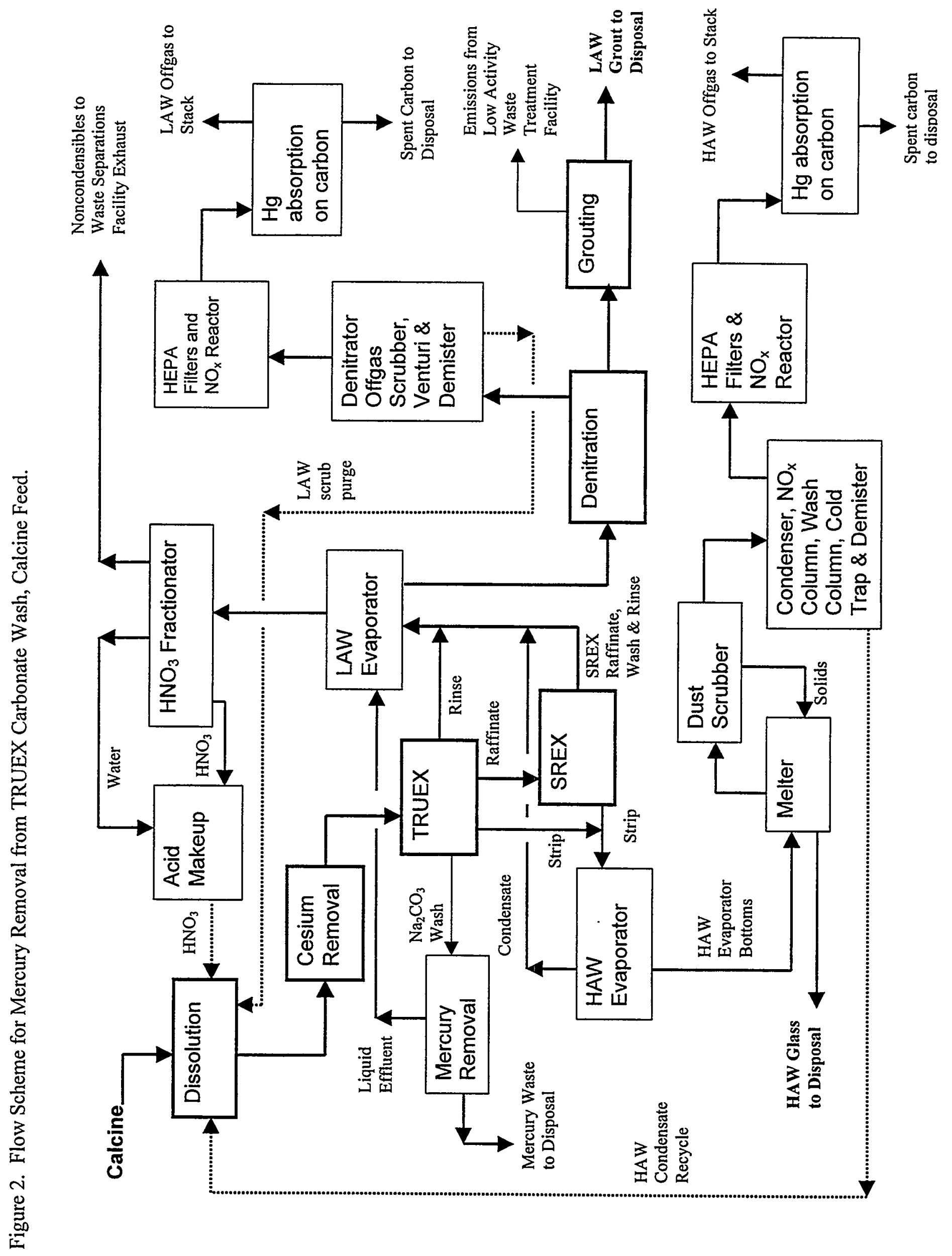


Figure 3. Flow Scheme of Full Separations with Mercury Removal from LAW Denitration Offgas Scrub Blowdown.

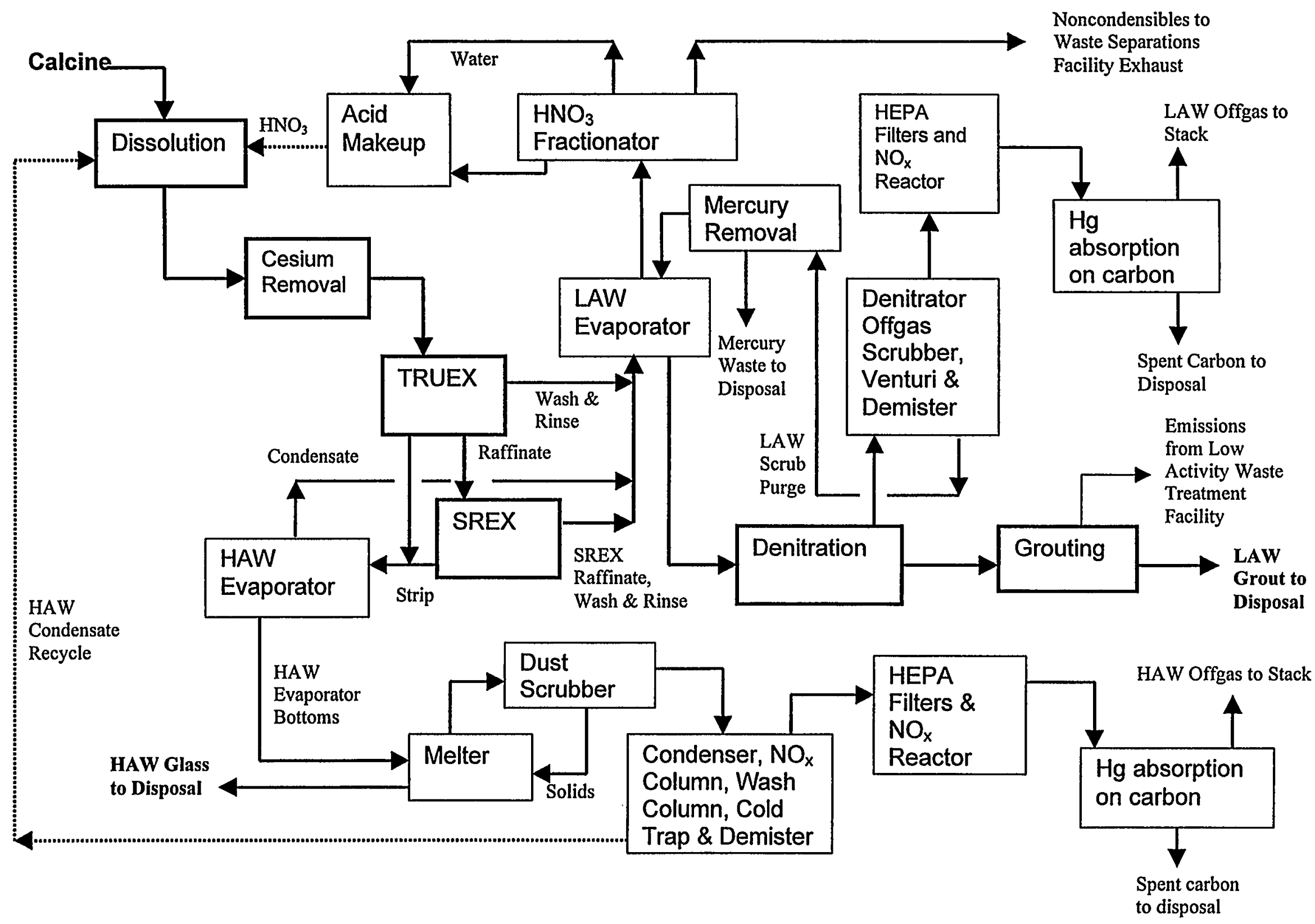




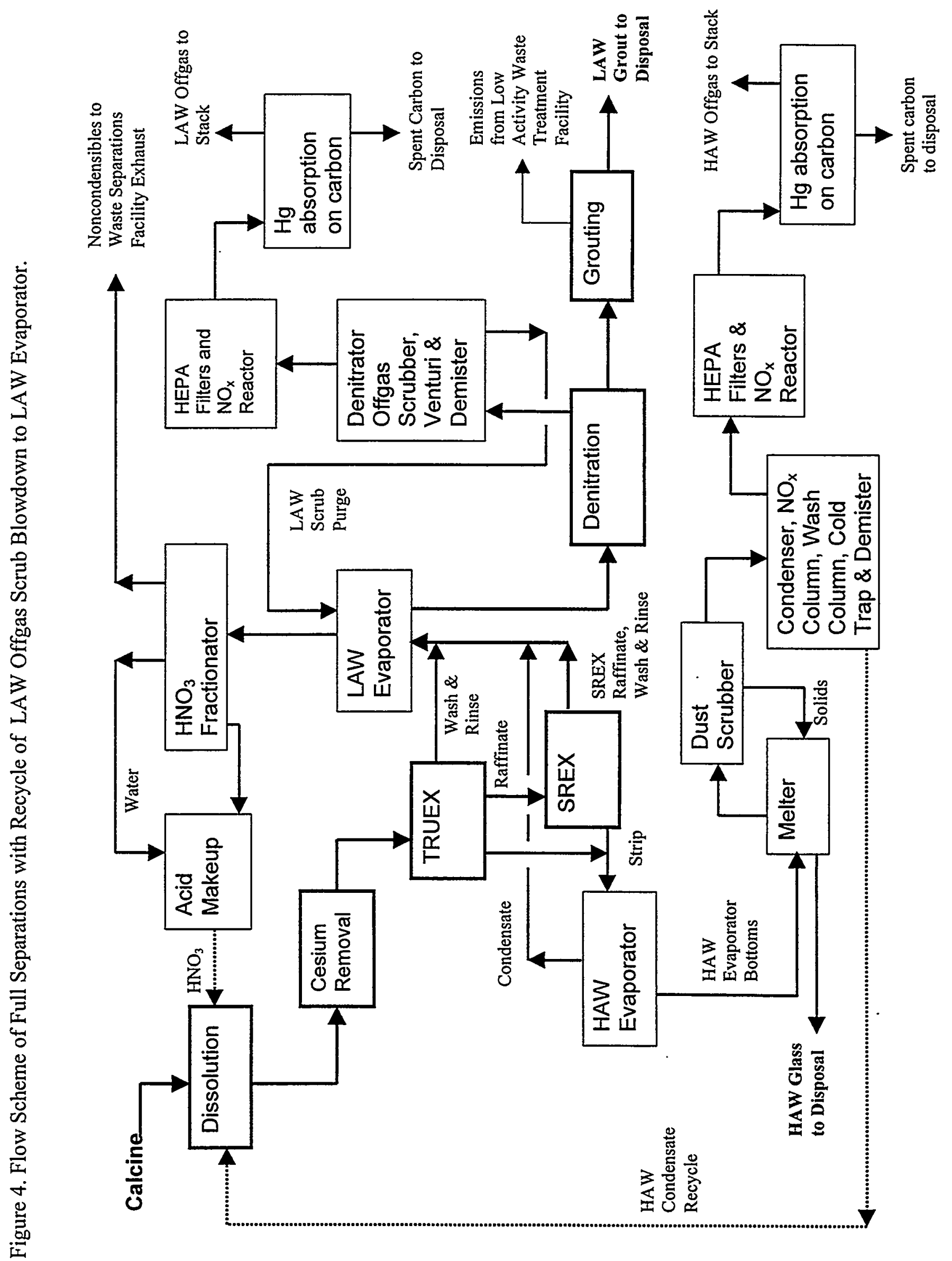


Figure 5. Flow Scheme for Full Separations with Stabilization of Mercury in LAW Grout

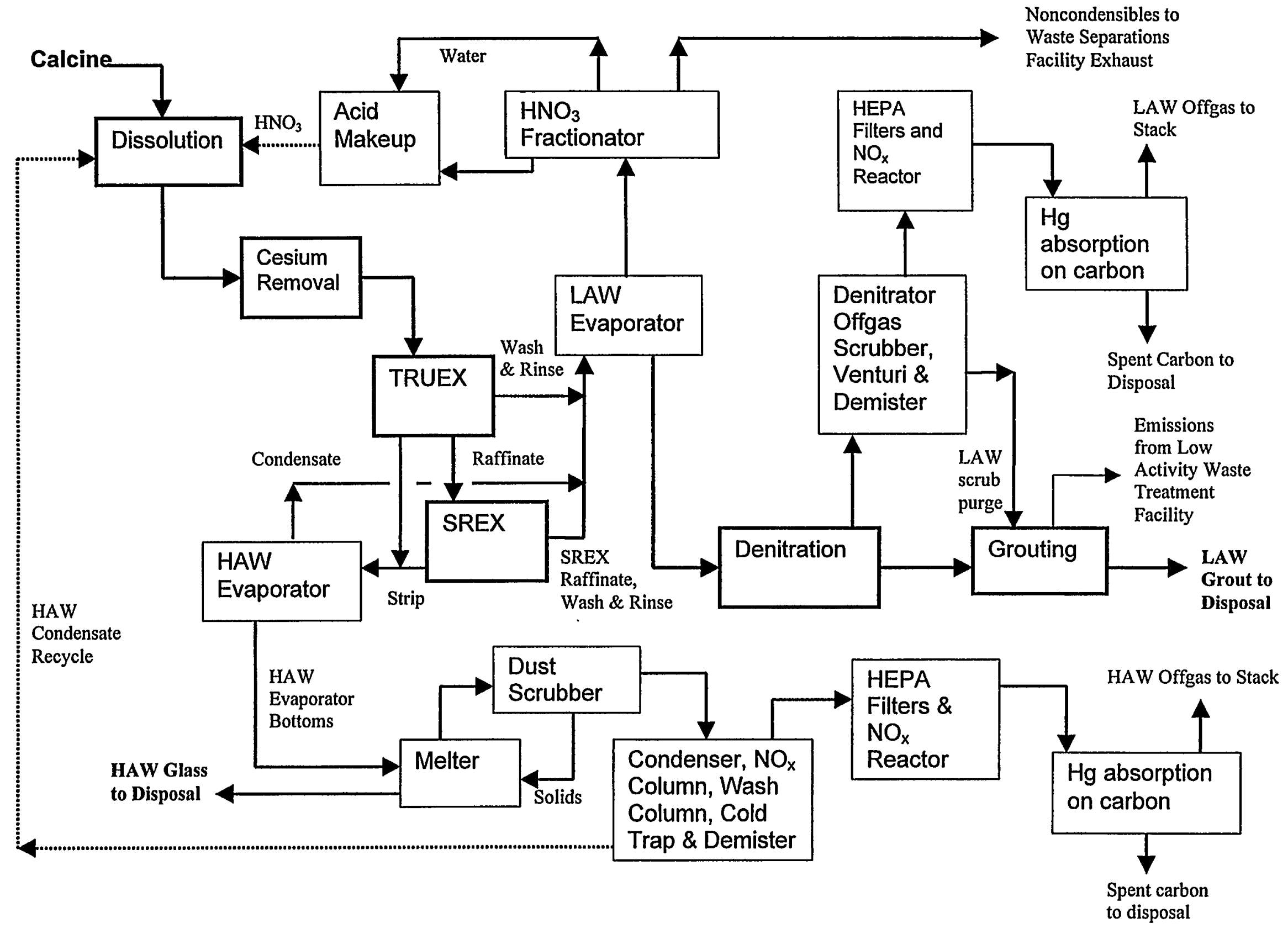




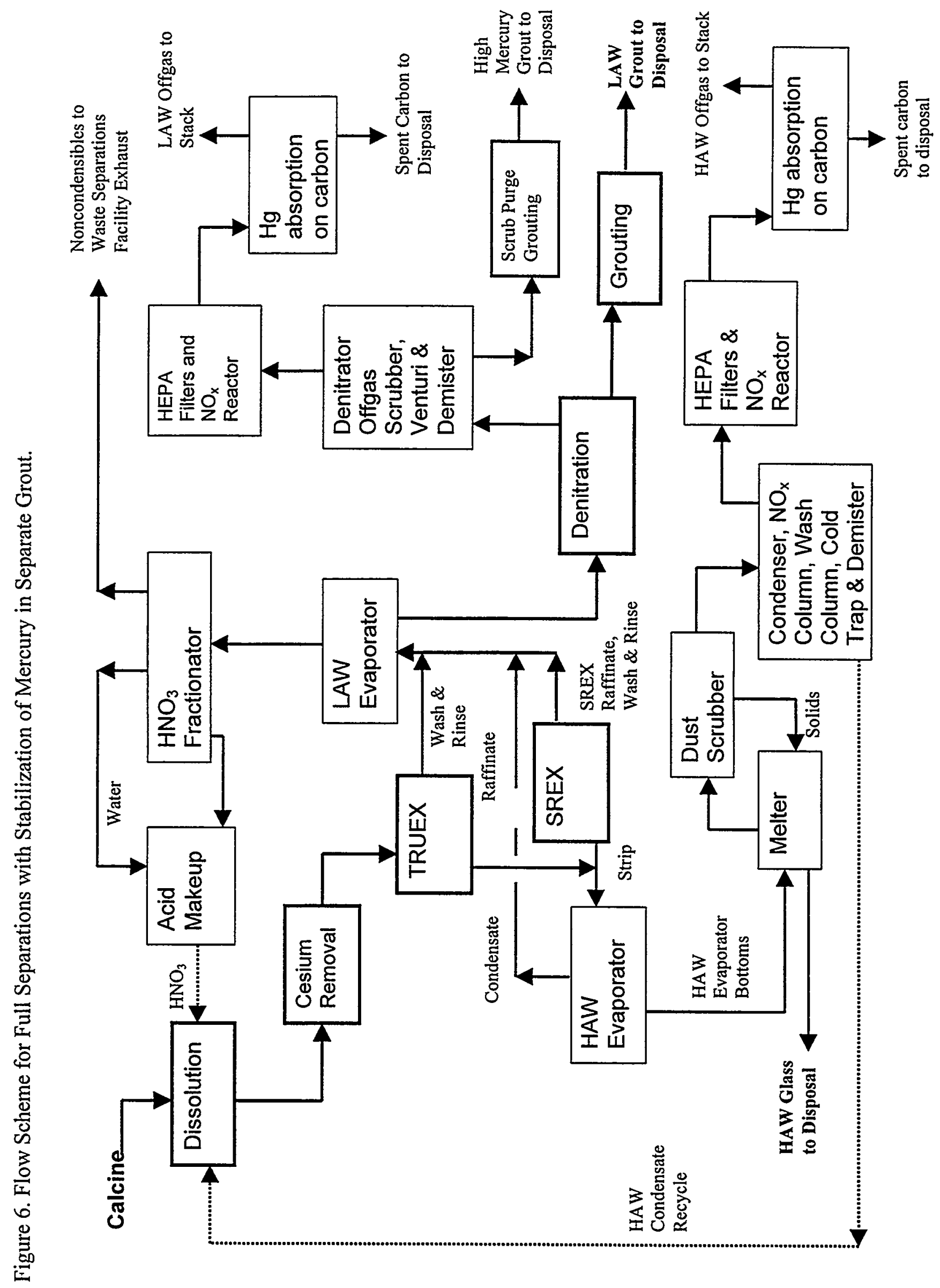




\section{Appendix F \\ Update of Chloride Concentrations in NWCF Scrub Solution and Offgas}


Project File Number 01102

Project/Task Mercury, Chloride and Technetium Removal Studies

\section{Subtask Update of Evaluation of Need for Chloride Removal}

\section{Title: Evaluation of Chloride Concentrations in NWCF Scrub Solution and Offgas}

Summary: Several options being evaluated in the Environmental Impact Statement for INEEL High Level Waste include calcination in the New Waste Calcining Facility (NWCF) of liquid waste presently stored in tanks at the Idaho Nuclear Technology Engineering Center (INTEC). Chloride present in the feed to the calciner partially volatilizes, and is captured in part in the NWCF scrub solution. The concern has been raised that chloride could build up in the scrub solution and cause increased corrosion in scrub system piping or components, $\mathrm{HCl}$ emissions exceeding the MACT limit, or an unworkable frequency of scrub solution recycle to the Tank Farm.

The potential for unacceptable buildup of chlorides in NWCF scub solution and offgas was evaluated using (1) data from FY98 runs in the $10-\mathrm{cm}$ and $15-\mathrm{cm}$ calciners, (2) data from the NWCF H-4 campaign, (3) a spreadsheet material balance model, and (4) results from ASPEN PLUS simulations of the NWCF scrub and offgas treatment system.

Data from pilot calciner runs show that calcine solids retain a high percentage, $50-90 \%$, of the chlorides in the feed and that runs at higher temperatures do not show lower retention of chlorides in calcine. The average chloride carry over factor, defined as the fraction of chloride in the calciner feed that is captured in the scrub solution, for five pilot runs at $600^{\circ} \mathrm{C}$ was 0.32 and the range $0.28-0.43$.

Data from three periods of the NWCF H-4 campaign show chloride carry-over factors in the range $0.15-0.34$. Because the mercury to chloride ratio is higher, and the sodium to chloride ratio the same or lower for the $\mathrm{H}-4$ feeds than remaining SBW, higher chloride carry over factors are not expected when processing SBW in the NWCF. For the H-4 campaign, scrub solution was transferred to.sump tanks upon reaching a chloride concentration of $5000 \mathrm{mg} / \mathrm{liter}$. Based on a chloride carry over factor of 0.34 , chlorides are not expected to build up to concentrations above $5000 \mathrm{mg} /$ liter and recycle of scrub solution to the tank farm will not be required. (Although recycle will not be required because of chloride, it may be required because of the build up of mercury.)

ASPEN PLUS vapor-liquid equilibrium calculations indicate that $\mathrm{HCl}$ emissions will be $<50 \%$ of the MACT limit.

Distribution (complete package): C. M. Barnes, MS 3625; V. L. Jacobson, MS 3211 Distribution (summary package only): J. J. McCarthy

\begin{tabular}{|c|c|c|c|c|c|}
\hline $\begin{array}{l}\text { Author } \\
\text { C.M. Barnes }\end{array}$ & $\begin{array}{l}\text { Dept. } \\
\text { Chemical \& } \\
\text { Envir. Eng. }\end{array}$ & $\begin{array}{l}\text { Reviewed } \\
\text { D. D. Taylor } \\
\text { D. D. jay / } 2\end{array}$ & Date & $\begin{array}{l}\text { Approved } \\
\text { V. L.Jacobson } \\
\text { i/J Jacolien. }\end{array}$ & $\begin{array}{l}\text { Date } \\
1 / \operatorname{Tan} 99\end{array}$ \\
\hline emBane- & $1-11.99$ & $1-11-99$ & & 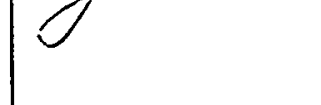 & \\
\hline
\end{tabular}




\section{INTRODUCTION}

Several options being evaluated in the Environmental Impact Statement for INEEL High Level Waste include calcination in the New Waste Calcining Facility (NWCF) of liquid waste presently stored in the Idaho Nuclear Technology Engineering Center (INTEC). These include the Continued Current Operation Alternative, the Direct Cement Option (DCO), and the Hot Isotatic Press Waste Option (HWO). Chloride present in the feed to the calciner partially volatilizes, is captured in part in the NWCF scrub liquid, and hence, if spent scrub liquid is recycled to the tank farm, could build up in tank farm waste. This chloride build up could potentially cause increased corrosion in scrub system piping or components, $\mathrm{HCl}$ emissions exceeding the MACT limit, or a unworkable frequency of scrub solution recycle to the tank farm.

Table 1 shows the present concentrations in Tank Farm waste. The concentrations shown in Table 1 were taken from the HLW Systems Engineering web pages, last updated in December, 1997. Besides chloride concentrations, Table 1 shows the ratio of the concentration of chloride for each tank compared to the chloride concentration of WM-188 and WM-185, the tanks from which feed was taken for the $\mathrm{H}-4$ calciner campaign.

Table 1. Tank Farm Chloride Concentrations (as of December, 1997).

\begin{tabular}{|c|c|c|c|c|c|}
\hline Tank & $\begin{array}{c}\text { Chloride } \\
\text { concentration, } \\
\text { Mol/liter }\end{array}$ & $\begin{array}{l}\text { Chloride, } \\
\text { ratio to WM- } \\
188\end{array}$ & $\begin{array}{c}\text { Chloride, } \\
\text { ratio to WM- } \\
185\end{array}$ & $\begin{array}{c}\text { Volume, } \\
\text { gal }\end{array}$ & $\begin{array}{c}\text { Chloride, } \\
\text { kg }\end{array}$ \\
\hline \multicolumn{6}{|c|}{ Full or Partially Full Tanks } \\
\hline WM-180 & $\overline{0.0326}$ & 2.1 & 1.0 & 278,600 & 1219 \\
\hline WM-181 & 0.0126 & 0.8 & 0.4 & 276,900 & 466 \\
\hline WM-184 & 0.0453 & 2.9 & 1.4 & 262,600 & 1596 \\
\hline WM-185 & 0.0316 & 2.1 & 1.0 & 74,800 & 317 \\
\hline WM-186 & 0.0211 & 1.4 & 0.7 & 281,500 & 797 \\
\hline WM-189 & 0.022 & 1.4 & 0.7 & 148,000 & 437 \\
\hline \multicolumn{2}{|l|}{ Total } & & & & 4832 \\
\hline \multicolumn{6}{|l|}{ Heels } \\
\hline WM-182 & 0.027 & 1.2 & 0.9 & 10,300 & 37 \\
\hline WM-183 & 0.0116 & 0.8 & 0.4 & 23,300 & 36 \\
\hline WM-187 & 0.0022 & 0.14 & 0.07 & 24,100 & 7 \\
\hline WM-188 & 0.0154 & 1.0 & 0.5 & 13,400 & 28 \\
\hline
\end{tabular}

Liquids in Tanks WM-181 and -184 are expected to be blended and concentrated in the High Level Liquid Waste Evaporator (HLLWE) prior to calcination; likewise liquid in Tank WM-186 is expected to be concentrated in the HLLWE. After concentration, the liquid from WM-181 and WM-184 is expected to have a chloride concentration of about 0.052 $\mathrm{mol} / \mathrm{liter}$, and the liquid from WM-186 a concentration of about $0.042 \mathrm{~mol} / \mathrm{liter}$.

Chloride build-up in the scrub solution poses four potential problems - corrosion of components in the offgas and scrub system, emissions exceeding the MACT limit, transfers of scrub solution liquid into and out of the deep recycle tanks at a frequency beyond the present capability of the system, and chloride buildup in the Tank Farm due to 
deep recycles to a concentration which would prevent calcination of the waste in the final tank. The last problem is really a result on one or more of the others. If the chloride concentration in the tank farm increased to above the threshold for corrosion, emissions or unworkable transfers, operation of the calciner would be threatened.

An evaluation of chloride buildup in the calciner feed was performed for the NWCF Process Modification Sodium-Bearing Waste Project Conceptual Design.' This analysis was based on a SBW chloride concentration of $1270 \mathrm{mg} / \mathrm{liter}$ or $0.0358 \mathrm{~mol} / \mathrm{liter}$ and used a chloride carry-over factor of 0.4-0.45. The chloride carry-over factor was defined in this study as the fraction of chloride in the blended calciner feed that is carried over from the calciner to the scrub solution, and the range used, 0.4-0.45, was based on data from one run of the $10-\mathrm{cm}$ pilot calciner at $600^{\circ} \mathrm{C}$. Using a model described in the report, the chloride concentration in the scrub solution was expected to build up to a constant concentration of $1340-1640 \mathrm{mg} /$ liter. This concentration is well below the level of concern for corrosion in scrub solution equipment. However, the report recommended both additional pilot calciner runs to verify this chloride carry-over factor value and data from the NWCF to determine what effects scale has on chloride volatility. Additional data has been generated since the NWCF Modification Conceptual Design relevant to chloride volatility and build up, and includes data from additional pilot calciner runs, NWCF scrub solution concentrations during the $\mathrm{H}-4$ campaign, and measurements of chloride in $\mathrm{H}-4$ calcine samples.

\section{Review of Pilot Calciner Data}

Runs in both the $10-\mathrm{cm}$ and $15-\mathrm{cm}$ pilot calciners were made in FY-98, ${ }^{2}$ and chloride distribution data from these runs are shown in Table 2. The chloride distribution values shown in Table 2 are the percentages of chloride in the feed that partition to a given product. The data in Table 2 are normalized; Table A1 in Appendix A shows the same data as reported ${ }^{2}$ and not normalized.

Table 3 shows data from FY-97 pilot runs as well as averages of both FY-97 and FY-98 data for runs at $500^{\circ} \mathrm{C}$ (two runs) and at $600^{\circ} \mathrm{C}$ (five runs). It should be noted that the FY97 pilot data has been reported in two different ways. In the previous evaluation of chloride build up, ${ }^{9}$ the amounts of chloride in each calciner product are reported based only on the analyses of the corresponding samples. In the report of the pilot runs, ${ }^{3}$ calculations were made to separate the amount of chloride volatilized from the amount of chloride carried over into the scrub due to fines carryover. Both sets of data are shown in Appendix A; the values in Table 3 are taken from the latter source. While these two methods result in slightly different chloride distributions, they do not change the conclusions drawn from the pilot calciner data.

\footnotetext{
${ }^{1} \mathrm{H}$. Welland, NWCF Process Modification Sodium-Bearing Waste Project Conceptual Design, INEL/INT-00075, April, 1997, Appendix B8, "Evaluation of Chloride Build Up in Scrub Solution and Deep Recycle Tanks.

${ }^{2}$ D. R. Marshall, J. A. Nenni, Calcination of WM-185 Waste, September, 1998.

3 J. A. Nenni, L. J. Young, Status Report for Alternative Calcination Scoping Tests, April, 1997. contained in R. D. Boardman, Transmittal of Status Report on Alternative Calcination Development Accomplishments and Results, BDMN-01-97, April 30, 1997.
} 
Table 2. FY-98 Pilot Plant Calciner Chloride Volatility Data.

\begin{tabular}{|c|c|c|c|c|c|c|}
\hline Run ID & EC15-8 & SBW-HT-8 & SBW-HT-7 & SBW-HT-10 & SBW-HT-11 & SBW-HT-12 \\
\hline Year & FY-98 & FY-98 & FY-98 & FY-98 & FY-98 & FY-98 \\
\hline Calciner & $15-\mathrm{cm}$ & $10-\mathrm{cm}$ & $10-\mathrm{cm}$ & $15-\mathrm{cm}$ & $15-\mathrm{cm}$ & $15-\mathrm{cm}$ \\
\hline Temperature, C & 500 & 550 & 600 & 600 & 600 & 600 \\
\hline Al to $\mathrm{Na}+\mathrm{K}$ Ratio & 3.2 & 2.7 & 1.45 & 1.86 & 1.58 & 1.38 \\
\hline \multicolumn{7}{|c|}{ Percent of $\mathrm{Cl}$ in feed contained in: } \\
\hline Calcine solids & 49.9 & 92.4 & 57.1 & 66.8 & 72.5 & 76.2 \\
\hline Product & 40.5 & 87.0 & 51.6 & 35.3 & 37.1 & 57.9 \\
\hline Fines & 9.4 & 5.4 & 5.5 & 31.5 & 35.4 & 18.3 \\
\hline Acid Scrub & 40.5 & \multirow{2}{*}{7.6} & \multirow{2}{*}{42.9} & 30.5 & 14.0 & 14.7 \\
\hline Condensate & 9.6 & & & 2.7 & 13.5 & 9.1 \\
\hline $\begin{array}{l}\text { Scrub Plus } \\
\text { Condensate }\end{array}$ & 50.1 & 7.6 & 42.9 & 33.5 & 27.5 & 23.8 \\
\hline $\begin{array}{l}\text { Scrub, Cond. \& } \\
10 \% \text { Fines }\end{array}$ & 51.0 & 8.1 & 43.5 & 36.6 & 31.0 & 25.6 \\
\hline
\end{tabular}

Table 3. FY-97 Pilot Plant Calciner Chloride Volatility Data.

\begin{tabular}{|l|c|c|c|c|c|c|}
\hline Run ID & SBW-BL-1 & SBW-HT-2 & SBW-HT-1 & & $\begin{array}{c}\text { Average for } \\
500^{\circ} \text { Runs }\end{array}$ & $\begin{array}{c}\text { Average for } \\
600^{\circ} \text { Runs }\end{array}$ \\
\hline Year & FY-97 & FY-97 & FY-97 & & & \\
\hline Calciner & $10-\mathrm{cm}$ & $10-\mathrm{cm}$ & $10-\mathrm{cm}$ & & & \\
\hline Temperature, C & 500 & 600 & 650 & & 500 & 600 \\
\hline Al to Na+K Ratio & 3.5 & 1.5 & 1.0 & & & \\
\hline \multicolumn{7}{|c|}{ Percent of Cl in feed contained in: } \\
\hline Calcine solids & 53.6 & 69.6 & 66.9 & & 51.3 & 66.6 \\
\hline $\begin{array}{l}\text { Scrub, Cond. \& } \\
\text { Fines Carryover }\end{array}$ & 46.4 & 30.4 & 33.1 & & 48.6 & 33.4 \\
\hline
\end{tabular}

The data in Table 2 show:

1. Calcine solids retain a high percentage of the chlorides in the feed waste.

1a. For all runs, the percentage retained in the solids is in the range $50-92 \%$.

1b. For the runs at $600^{\circ} \mathrm{C}$, the average retained is $67 \%$, and the range is $57-76 \%$.

2. Runs at higher temperatures do not show lower retention of chlorides in calcine.

2a. Retention of $\mathrm{Cl}$ for each of the five $600^{\circ} \mathrm{C}$ runs is higher than either of the two runs at $500^{\circ} \mathrm{C}$.

2b. Retention of $\mathrm{Cl}$ in calcine at $650^{\circ} \mathrm{F}$ is within the range of the values for $600^{\circ} \mathrm{C}$ and higher than the runs at $500^{\circ} \mathrm{C}$. 
3. The FY-98 data show that the chloride carry-over factor was, at worst, about 0.43 and more likely is less than this value.

3a. The value of 0.43 is based on run SWB-HT-7 (which showed the lowest retention of chlorides in the calcine) and assumes all $\mathrm{Cl}$ not retained in calcine will be captured by the scrub solution.

$3 \mathrm{~b}$. Using the average of the five $600^{\circ} \mathrm{C}$ runs, the chloride carry over factor would be less about 0.33 . (The value of 0.33 assumes all chloride not retained in calcine is captured by the scrub solution. A small amount of chloride will escape in the offgas. It also assumes $10 \%$ of the fines are carried over to the scrub solution.)

3c. Thus the FY-98 data confirm that the carry over factors used in the previous evaluation, 0.4 and 0.45 , are reasonable upper bounds.

Thus the $10-\mathrm{cm}$ and $15-\mathrm{cm}$ pilot plant data confirm that chlorides will not build up in calciner scrub solution to a concentration approaching the corrosion limit. Based on a feed concentration of $1830 \mathrm{mg} / \mathrm{liter}$ (the expected concentration of WM-181 and WM-184 after waste in these tanks is concentrated in the HLLWE) and a chloride carry-over factor of 0.45 , chlorides would build up to only $2400 \mathrm{mg} / \mathrm{liter}$ in the scrub solution.

However, data from NWCF calcination, discussed below, are still needed to confirm this chloride carry-over factor, as the difference in scale could result in differences in chloride behavior.

\section{Analysis of NWCF H-4 Scrub Solution Data}

Figure 1 shows the chloride concentration in the scrub solution during the NWCF one period in the $\mathrm{H}-4$ campaign. A similar plot for the remainder of the $\mathrm{H}-4$ campaign is shown in Appendix B.

Chloride carry-over factors for NWCF calcination were estimated by seeking to match scrub solution concentrations, calculated as shown below, with $\mathrm{H}-4$ data.

Scrub solution $\mathrm{Cl}$ concentration $=$ Mass $\mathrm{Cl}$ in scub/volume of scrub solution

(Mass $\mathrm{Cl}$ in scrub) $)_{\text {Day } i}=$ (Mass $\mathrm{Cl}$ in scrub) Day $i-1+\mathrm{V}_{\mathrm{F}} \mathrm{C}_{\mathrm{F}} \mathrm{C}_{\mathrm{O}}$

$V_{F}=$ Volume of tank farm waste fed to the calciner per day

$\mathrm{C}_{\mathrm{F}}=$ Chloride concentration in the tank farm waste

$\mathrm{C}_{\mathrm{o}}=$ Fraction of chloride carried over from the feed to the scrub

$(\text { Volume of scrub })_{\text {Day } i}=(\text { Volume of scrub })_{\text {Day } i-1}+(\text { Scrub additions })_{\text {Day } i}-($ Scrub solution recycled to deep tanks) Day $i$ 
Figure 1. Scrub Solution Concentration During NWCF H-4 Campaign.

\section{NWCF Scrub Solution Chloride Concentration, June 20-Sept 25, 1997}

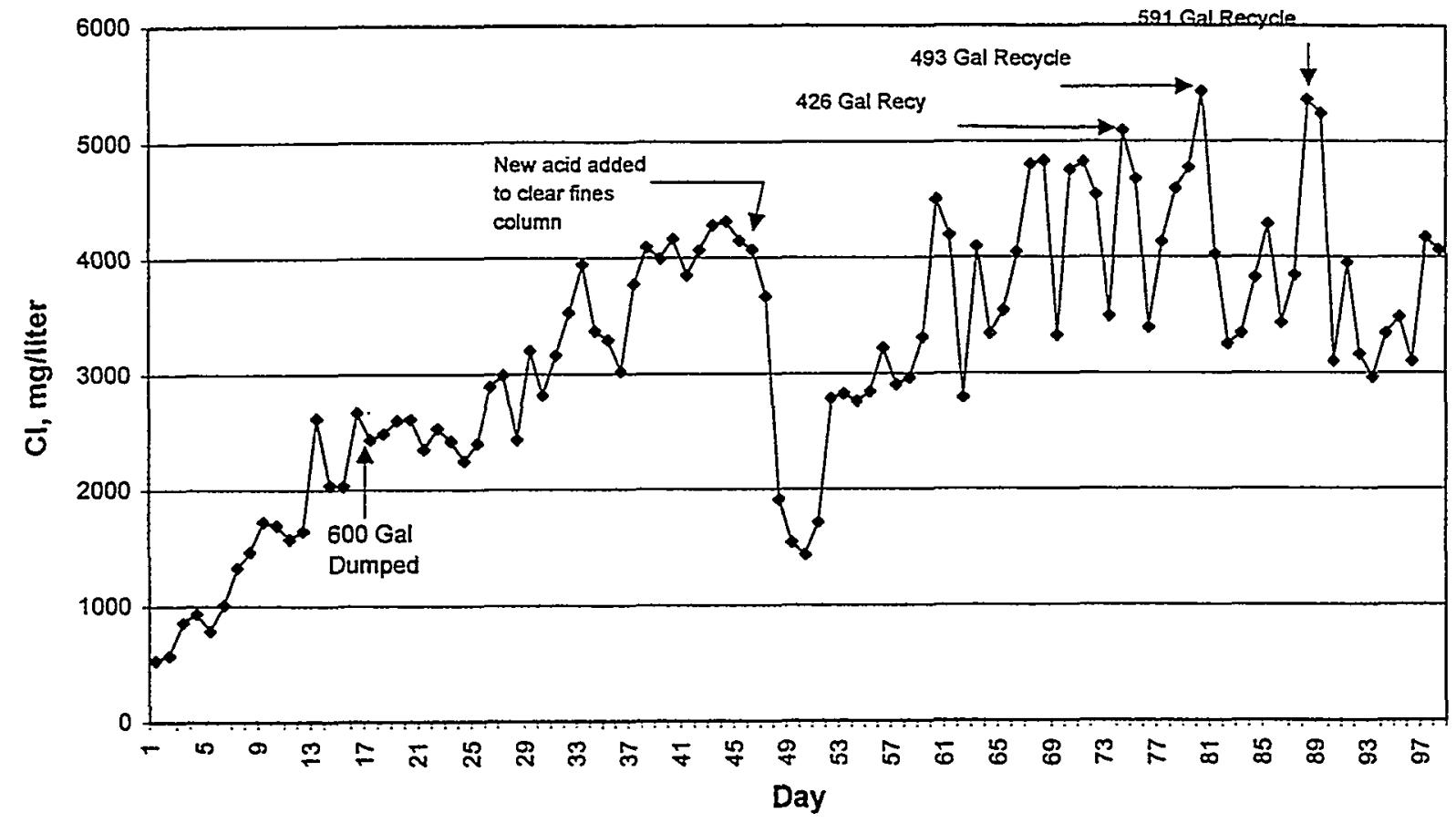

Figures 2, 3, and 4 show scrub concentrations during three separate periods of the H-4 campaign, along with calculated concentrations. Parameters used in the calculations are shown in Table 4.

Figure 2. Estimation of Chloride Carry-Over Factor, Period 1.

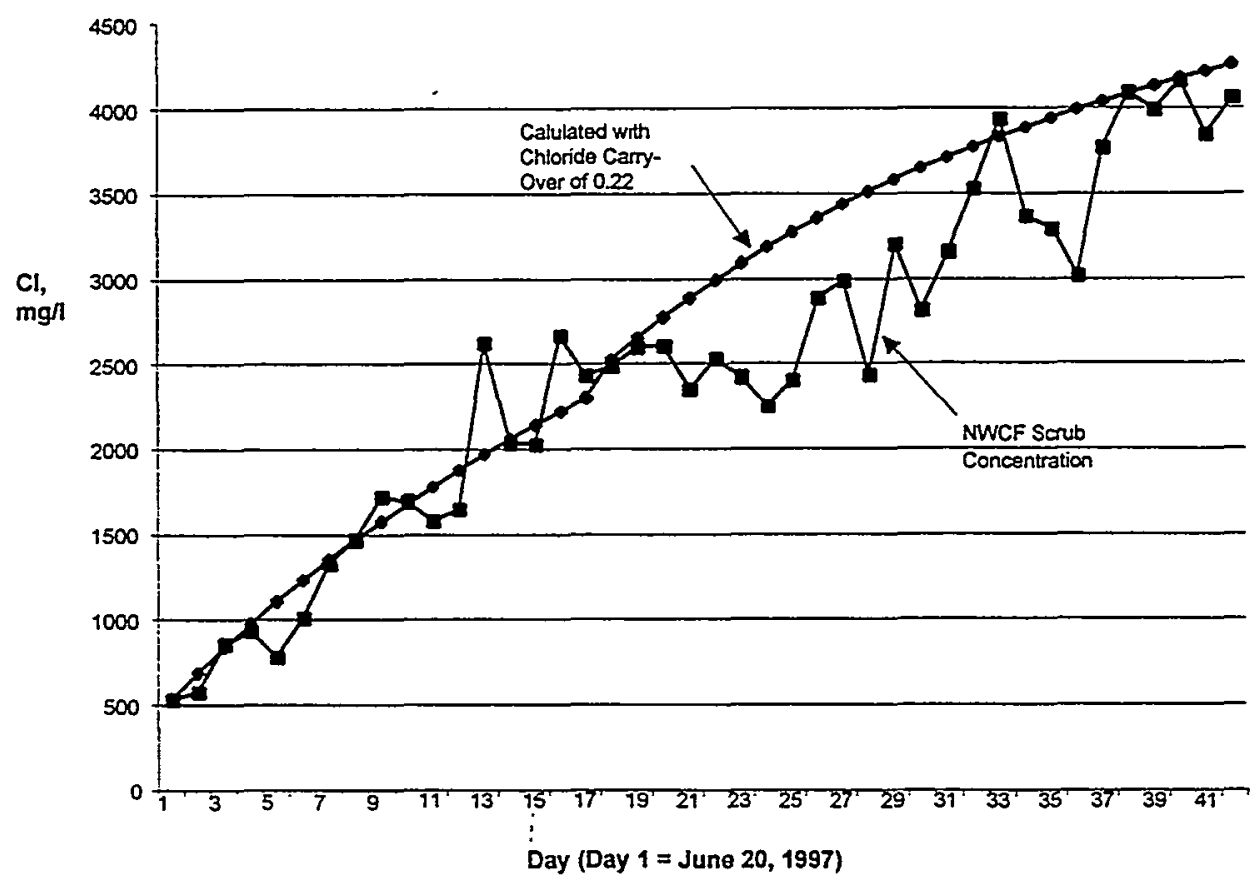


Figure 3. Estimation of Chloride Carry-Over Factor, Period 2.

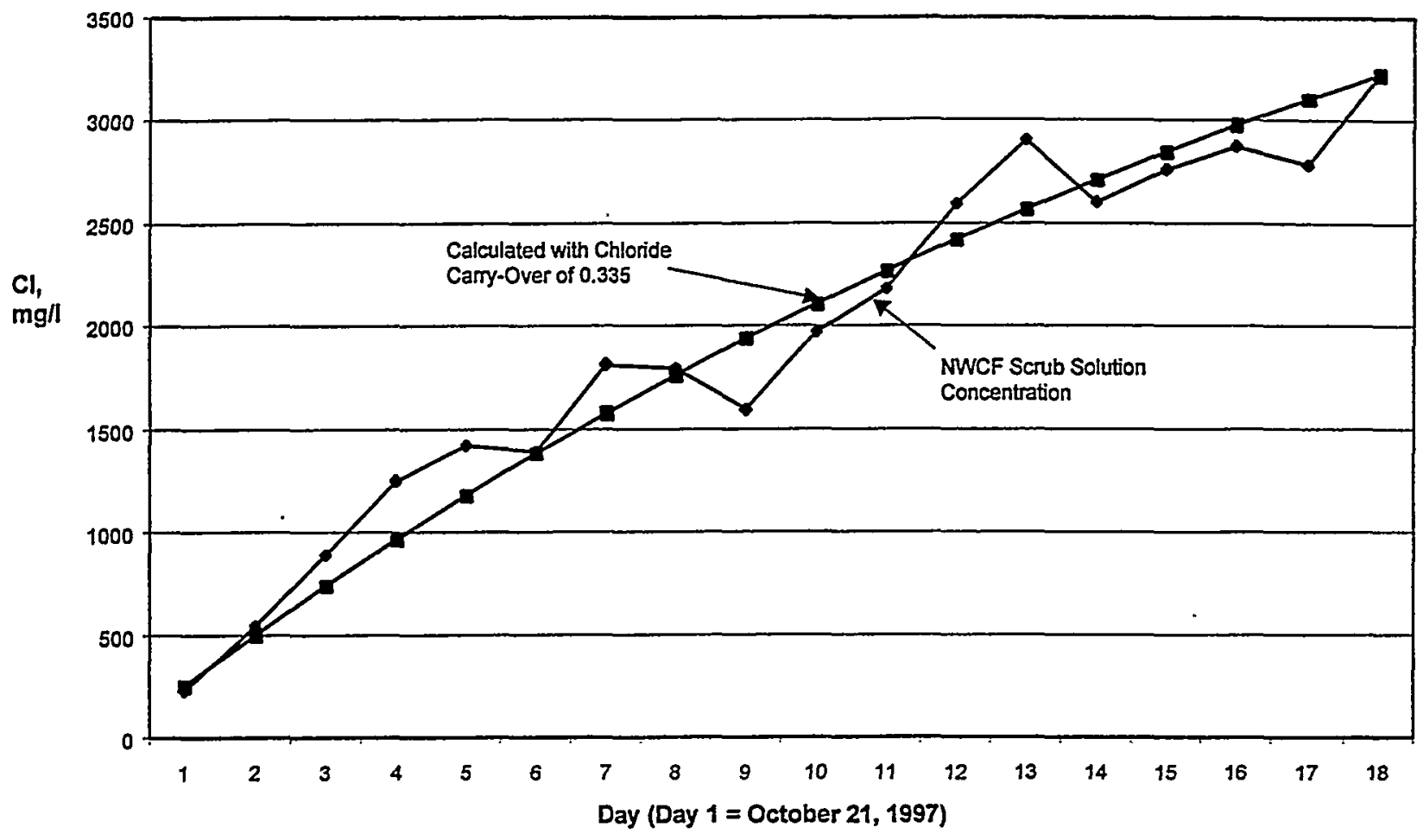

Figure 4. Estimation of Chloride Carry-Over Factor, Period 3.

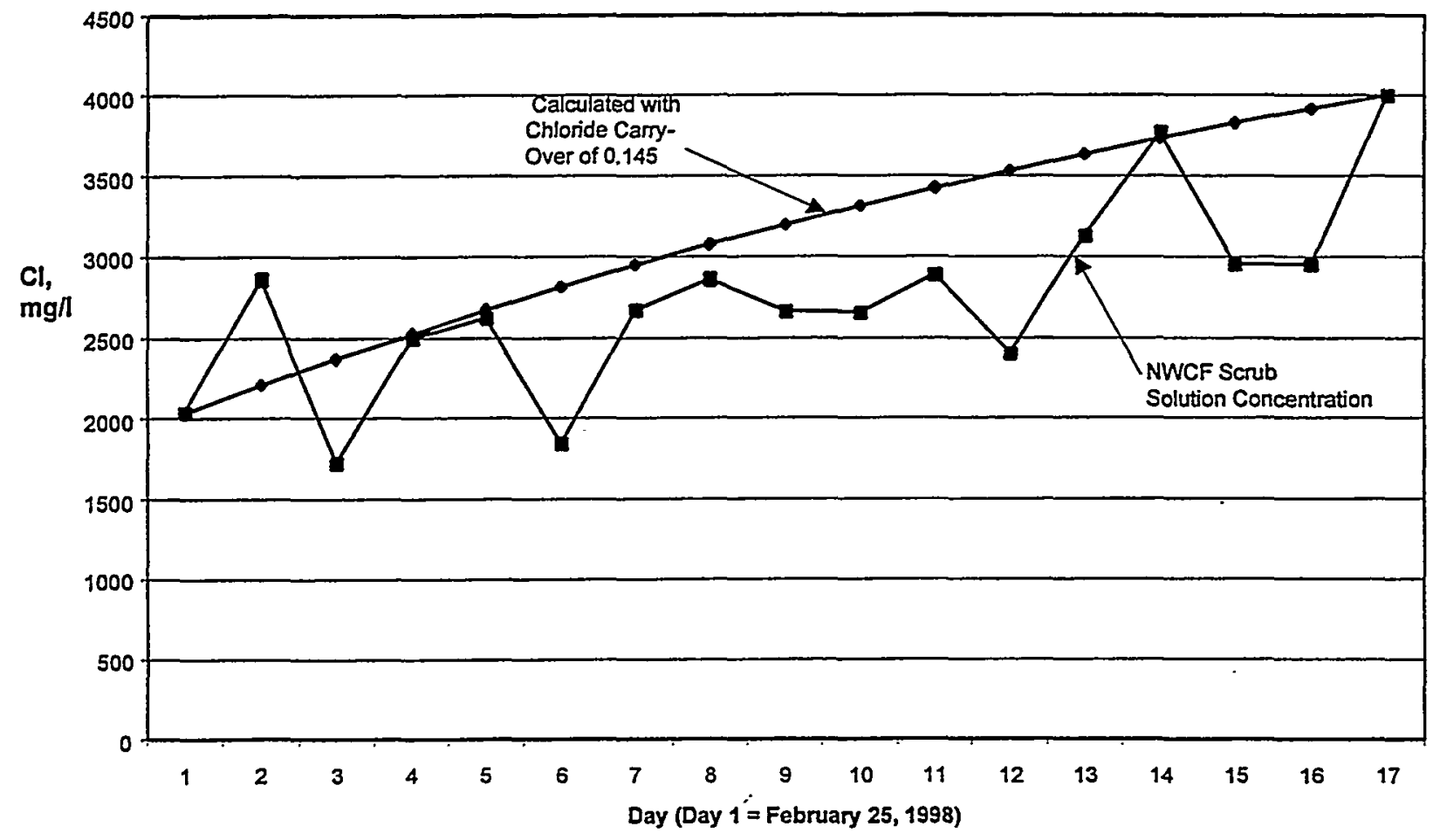


Table 4. Parameters Used in Choride Carry-Over Estimations.

\begin{tabular}{|l|c|c|c|}
\hline & Period 1 & Period 2 & Period 3 \\
\hline Feed & WM-188 & WM-188 & WM-185 \\
\hline Feed Cl concentration, mg/l & 546 & 546 & 1120 \\
\hline Feed volume, gal/day & 1300 & 1300 & 1300 \\
\hline Day O scrub Cl conc., mg/l & 594 & 0 & 1796 \\
\hline Initial scrub volume, gal & 900 & 900 & 900 \\
\hline Scrub additions, gal/day & 25 & 25 & 25 \\
\hline Scrub recycle during period & $\begin{array}{c}1 \text { on Day 18, } \\
600 \text { gal }\end{array}$ & None & None \\
\hline Final scrub volume, gal & 1300 & 1375 & 1300 \\
\hline $\begin{array}{l}\text { Estimated chloride carry- } \\
\text { over factor }\end{array}$ & 0.22 & 0.335 & 0.145 \\
\hline
\end{tabular}

Further analysis of $\mathrm{H}-4$ data could be done in an attempt to explain why chloride carry-over factors estimated for Periods 1 and 2 were different, or to refine the calculations so that scrub concentrations more closely match secondary trends in the data. However, the $\mathrm{H}-4$ data would suggest that (a) the chloride carry over factor for the NWCF does not appear to be greater that that seen in the pilot calciner for the same feed and (b) the chloride carryover factor is relatively low, $\leq 0.34$.

\section{Effect of Feed Chemistry on Chioride Carry-Over}

The chloride carry-over to the scrub can be expected to vary with feed chemistry. A higher mercury to chloride ratio or a lower sodium to chloride ratio in the total calciner feed could result in a higher chloride carry over factor. Table 5 shows the ratios of $\mathrm{Hg}$ to $\mathrm{Cl}$ and $\mathrm{Na}$ to $\mathrm{Cl}$ for some of the waste tanks. Since the SBW tanks (WM-180, -181, -184 and 186) have lower mercury to chloride ratios than the waste processed during the $\mathrm{H}-4$ campaign (from (WM-185 and WM-188), and similar if not higher sodium to chloride ratios, chloride carry-over factors when processing SBW are not expected to be higher than were seen in the $\mathrm{H}-4$ campaign.

Table 5. Waste Chemistry Comparison.

\begin{tabular}{|l|c|c|}
\hline Waste Tank & Mercury to chloride molar ratio & Sodium to chloride molar ratio \\
\hline WM-188 & 0.50 & 51 \\
\hline WM-185 & 0.13 & 47 \\
\hline WM-180 & 0.03 & 65 \\
\hline $\begin{array}{l}\text { WM-181/4 (blended and } \\
\text { evaporated }\end{array}$ & 0.04 & 57 \\
\hline WM-186 (evaporated) & 0.06 & 48 \\
\hline
\end{tabular}

Because essentially all of the mercury in the feed is captured in the scrub solution, the total calciner feed mercury concentration will be dominated by the scrub recycle. Assuming a mercury concentration in the scrub recycle of $25,000 \mathrm{mg} /$ liter for each case, the total calciner feed for waste from WM-181/4 would have a mercury concentration of $93 \%$ of that for WM-188 or $96 \%$ of that for WM-185. For reference, mercury concentrations in the scrub solution in the NWCF H-4 campaign are given in Appendix C. 


\section{Review of the Need for Scrub Recycle to Tank Farm}

When scrub solution reaches the chloride concentration limit, a portion is transferred from the Scrub Hold Tank, VES-NCC-108, to the Fluoride Hot Sump Tank, VES-NCC-119. From there it is recycled to the Blend Tank, VES-NCC-101, to be blended with Tank Farm waste and chemical additives before being fed to the calciner. For the high temperature case in the NWCF Modifications for Sodium Bearing Waste Conceptual Design, the feed to the calciner included $20 \%$ scrub recycle, or $864 \mathrm{gpd}$. For the sake of chloride only, transfer of any scrub solution to the Tank Farm would be needed only if more than $864 \mathrm{gal} /$ day of scrub solution had to be removed from the scrub inventory to keep chloride concentrations below the limit.

In order to check that all tank farm waste could be processed without excessive chloride build-up in the scrub solution (necessitating recycle to the Tank Farm), a processing scenario was developed and chloride material balance calculations performed. The goal of these calculations was not to optimize processing or to try to match all present NWCF operating parameters or procedures, but to determine chloride build-up, if any, for one reasonable scenario for processing the remaining Tank Farm waste. The scenario assumed processing waste in WM-185 first, and then processing tanks in order of decreasing chloride concentration. Fresh acid was added at a rate of $25 \mathrm{gal} / \mathrm{day}$ to the scrub system. The rate of Tank Farm waste fed to the calciner and the rate of removal of scrub solution were adjusted to keep the chloride concentration below $5000 \mathrm{mg} / \mathrm{liter}$.

A portion of the scrub solution was assumed transferred to VES-NCC-119 every ten days to either maintain the chloride concentration below $5000 \mathrm{mg} / \mathrm{liter}$ or to avoid excessive volume of liquid in the scrub system due to the daily addition rate. The frequency and rate of transfer of this scrub solution is somewhat arbitrary. Scrub recycle collected in VESNCC-119 during processing of one Tank Farm tank or, in the case of full tanks, a onemonth batch of feed, was assumed fed to the next campaign or month of processing. A chloride carry-over factor of 0.34 was used in the analysis, based on $\mathrm{H}-4$ and pilot calciner data discussed above. The results of these calcualtions are shown in Table 6.

Table 6. Scenario for processing remaining tank farm liquid based on a chloride carry over factor of 0.34 .

\begin{tabular}{|c|c|c|c|c|c|c|c|}
\hline $\begin{array}{l}\text { Waste } \\
\text { Sequence }\end{array}$ & $\begin{array}{l}\text { Process } \\
\text { Time, } \\
\text { months }\end{array}$ & $\begin{array}{c}\text { Cl in } \\
\text { Feed, } \\
\text { mg/liter }\end{array}$ & $\begin{array}{c}\text { Gallons } \\
\text { Feed } \\
\text { Processed }\end{array}$ & $\begin{array}{c}\text { Gallons } \\
\text { Recycle } \\
\text { Processed }\end{array}$ & $\begin{array}{c}\text { Gallons } \\
\text { Recycled to } \\
\text { VES-119 }\end{array}$ & $\begin{array}{l}\mathrm{Cl} \text { in } \\
\text { Recycle, } \\
\text { mg/liter }\end{array}$ & $\begin{array}{l}\text { Recycle } \\
\text { Rate, per } \\
10 \text { days }\end{array}$ \\
\hline WM-185 & 1.7 & 1120 & 80,000 & 0 & 3,000 & 5000 & $600 \mathrm{gal}$ \\
\hline WM-181/4 & 11 & 1680 & 300,000 & 21,000 & 20,400 & 5000 & $600 \mathrm{gal}$ \\
\hline WM-186 & 4 & 1480 & 120,000 & 7,200 & 7,200 & 5000 & $600 \mathrm{gal}$ \\
\hline WM-180 & 7 & 1160 & 280,000 & 12,600 & 12,600 & 5000 & $600 \mathrm{gal}$ \\
\hline WM-189 & 3.5 & 780 & 150,000 & 3,100 & 3,100 & -3400 & $250 \mathrm{gal}$ \\
\hline Tank Heels & 2 & 400 & 80,000 & 2,800 & 1,500 & -1700 & $250 \mathrm{gal}$ \\
\hline Total & 29.2 & & $1,010,000$ & 47,800 & 47,800 & & \\
\hline
\end{tabular}

The analysis showed that recycle of scrub solution to the tank farm will not be required. Scrub solution could be recycled to the 6420-gal Fluoride Hot Sump Tank, VES-NCC-119 and from there to the Blend Tank, VES-NCC-101. 
It should be noted that although recycle to the Tank Farm was not required to purge the scrub system of chlorides, it may be required to avoid excessive build-up of mercury. In the NWCF H-4 campaign, the concentration of mercury in the scrub solution reached maximum concentrations of 50,000-60,000 mg/liter (see Appendix C). Analyses of waste presently in the Tank Farm indicate a total mercury inventory of about $2100 \mathrm{~kg}$. If $100 \%$ of the mercury in the NWCF feed is captured in the scrub solution, and allowed to build up to $50,000 \mathrm{mg} / \mathrm{liter}$, all of the mercury in the waste could be contained in 11,000 gallons. Thus mercury removal will likely be required on a relatively small amount of scrub solution.

\section{Review of H-4 Calcine Chloride Analysis}

Analysis for chlorides was performed on three samples of $\mathrm{H}-4$ calcine, and the results are shown in Table 7.

Table 7. H-4 Calcine Chloride Analysis Results.

\begin{tabular}{|c|l|c|}
\hline Log Number & \multicolumn{1}{|c|}{ Calcine Type } & $\begin{array}{c}\text { Chloride content of dissolved } \\
\text { calcine, mg/ml }\end{array}$ \\
\hline $98-06092$ & H-4 from WM-188 & $<24.38$ \\
\hline $98-11303$ & H-4 from WM-185 & $\begin{array}{c}44 \pm 12 \\
51 \pm 12\end{array}$ \\
\hline $98-05214$ & $\begin{array}{l}\text { WM-188 calcine \& WM- } \\
\text { 185 calcine mixed }\end{array}$ & 283 \\
\hline
\end{tabular}

From the above analyses, the percentage of chloride in the calciner feed (WM-185 and WM-188 liquid) was estimated using the following additional data or assumptions:

1. For samples $98-060092$ and $98-05214,10 \mathrm{ml}$ of acid was used per gram of calcine in the dissolution.

2. For sample $98-11303,20.18 \mathrm{~g}$ calcine were dissolved in $201 \mathrm{ml}$ of acid.

3. Sample $98-05214$ consisted of $106.9 \mathrm{~g}$ of calcine from WM-188 plus $59 \mathrm{~g}$ of calcine from WM-185

4. It was assumed all chlorides in the calcine dissoived (for sample 98-11303, an estimated $90 \%$ of the calcine dissolved).

5. The $\mathrm{Cl}$ concentration of WM-188 liquid was 0.0154 moles/liter.

6. The $\mathrm{Cl}$ concentration of WM-185 liquid was 0.316 moles/liter.

7. An estimated $279 \mathrm{~g}$ of calcine is produced from 1 liter of $\mathrm{WM}-188$ liquid.

8. An estimated $466 \mathrm{~g}$ of calcine is produced from 1 liter of WM-185 liquid.

The estimated percentages of chloride retained in the calcine based on the three $\mathrm{H}-4$ chloride analyses and the above data and assumptions are shown in Table 8.

Table 8. Estimated H-4 Calcine Chloride Retention from Calcine $\mathrm{Cl}$ Analyses

\begin{tabular}{|c|l|c|}
\hline Sample & \multicolumn{1}{|c|}{ Calcine Type } & $\begin{array}{c}\text { Estimated percentage of } \\
\text { chloride retained in the calcine }\end{array}$ \\
\hline $98-06092$ & H-4 from WM-188 & $21 \pm 7$ \\
\hline $98-11303$ & H-4 from WM-185 & 143 \\
\hline $98-05214$ & $\begin{array}{l}\text { WM-188 calcine \& WM- } \\
185 \text { calcine mixed }\end{array}$ & \\
\hline
\end{tabular}


The range of the above estimates, from $<13 \%$ to $143 \%$, prevents using this data to either confirm the high chloride retention seen in calcine solids from pilot runs, or to forcibly argue against the conclusions drawn regarding chloride carry-over from the $\mathrm{H}-4$ scrub solution data and the pilot data.

The high chloride seen in sample $98-05314$ is not unreasonable considering the fact that chlorides in the scrub recycle account for a significant percentage of the total chlorides in the calciner feed. The analysis of sample $98-05314$ would indicate about $40 \%$ of the chlorides in the total calcine feed (Tank Farm waste plus scrub recycle) were retained in the calcine. Speculating, the low chloride levels seen in the other two samples could potentially be a result of a high percentage of the chlorides in the solid calcine being present in the fines rather than the bulk calcine. All of the $\mathrm{H}-4$ samples analyzed were of bulk material and did not contain fines. However, additional data are required to better explain the high.variability seen in chloride analyses of $\mathrm{H}-4$ calcine.

\section{Review of Chloride Emission Rate}

The MACT limit for $\mathrm{HCl}$ and $\mathrm{Cl}_{2}$ is 75 ppmv. This concentration, for a NWCF offgas flowrate of $1400 \mathrm{SCFM}^{4}$ is equivalent to $275 \mathrm{~g} / \mathrm{hr} \mathrm{HCl}$ emission. Based on a feed rate of SBW to the calciner of $56.8 \mathrm{gph}^{5}$ the allowable chloride feed concentration, if all chloride in the feed is released to the stack, is $1279 \mathrm{mg} / \mathrm{liter}$ or $0.036 \mathrm{~mol} / \mathrm{liter}$. However, if $50 \%$ of the chloride in the feed is retained in the calcine, the allowable chloride limit in the feed before exceeding the MACT limit would be about $2560 \mathrm{mg} / \mathrm{liter}$, a concentration greater than any of the waste tanks, even after further concentration. Based on the analysis shown in Table 6, the maximum chloride rate in the total feed (tank farm waste plus scrub recycle) is $300 \mathrm{~g} / \mathrm{hr}$ (as $\mathrm{HCl}$ ). Thus chloride emissions would meet the MACT limit as long as retention of chloride in the calcine was greater than about $9 \%$.

As an additional check on chloride emissions, vapor-liquid equilibrium calculations were made using the process simulation program ASPEN PLUS. The ASPEN PLUS simulations included the quench tower, venturi scrubber/separator, mist eliminator and scrub tank. Input parameters are shown in Table 9. The simulations used the "ELECNRTL" property option set. To my knowledge, no NWCF offgas data are available to verify the vapor-liquid equilibrium models used by ASPEN PLUS.

Results from the ASPEN simulation using parameters as given in Table 9 show the concentration of chloride in the offgas from the mist eliminator to be $35 \mathrm{ppmv}$, or about $46 \%$ of the MACT limit. This baseline case assumed a chloride concentration in the scrub solution of $5000 \mathrm{mg} / \mathrm{l}$, the maximum concentration used for the $\mathrm{H}-4$ campaign. It also assumed that all $\mathrm{Cl}$ in the calciner feed volatilized to $\mathrm{HCl}$. If the scrub chloride concentration increased to $10,000 \mathrm{mg} / \mathrm{l}$, the ASPEN model predicts the concentration of chloride in the offgas would increase to $77 \mathrm{ppmv}$, slightly above the MACT limit of 75 ppmv.

\footnotetext{
${ }^{4}$ From Drawing 453438, contained in INEEL/INT-97-00992.

${ }^{5}$ From H. Welland, NWCF Process Modification for Sodium-Bearing Waste Project Conceptual Design, INEL/INT-97-00075, p.33.
} 
Table 8. Input parameters for ASPEN simulations of NWCF offgas system.

\begin{tabular}{|c|c|c|c|c|c|c|}
\hline & \multicolumn{2}{|c|}{$\begin{array}{l}\text { Feed rate and } \\
\text { Composition }\end{array}$} & $T,{ }^{\circ} \mathrm{F}$ & P, psia & $\begin{array}{l}\text { Entrainment, } \\
\text { mole fraction }\end{array}$ & Duty, Btu/hr \\
\hline \multicolumn{7}{|l|}{ Feeds } \\
\hline Offgas & $\begin{array}{l}\mathrm{O}_{2} \\
\mathrm{~N}_{2} \\
\mathrm{CO} \\
\mathrm{CO}_{2} \\
\mathrm{SO}_{2} \\
\mathrm{NO} \\
\mathrm{NO}_{2} \\
\mathrm{H}_{2} \mathrm{O} \\
\mathrm{HCl}\end{array}$ & $\begin{array}{c}\text { SCFM } \\
169 \\
415 \\
14.2 \\
68.6 \\
0.13 \\
4.47 \\
40.3 \\
686 \\
0.34\end{array}$ & $\begin{array}{r}1112 \\
(600 \\
\left.{ }^{\circ} \mathrm{C}\right)\end{array}$ & 11.0 & - & - \\
\hline Scrub to quench & $\begin{array}{l}\mathrm{H}^{+} \\
\mathrm{NO}_{3} \\
\mathrm{Al}^{+3} \\
\mathrm{Hg}^{+2} \\
\mathrm{Cl}^{-}\end{array}$ & $\begin{array}{l}88 \mathrm{gpm} \\
3.2 \mathrm{~mol} / \mathrm{l} \\
6.2 \mathrm{~mol} / \mathrm{l} \\
0.87 \mathrm{~mol} / \mathrm{l} \\
0.25 \mathrm{~mol} / \mathrm{l} \\
0.14 \mathrm{~mol} / \mathrm{l} \\
\end{array}$ & 147 & 50 & - & - \\
\hline Scrub to venturi & $\begin{array}{l}\text { Comp } \\
\text { as scl }\end{array}$ & $\begin{array}{l}29 \mathrm{gpm} \\
\text { sition same } \\
\text { b to quench }\end{array}$ & 147 & 50 & - & - \\
\hline Acid to mist eliminator & & $\begin{array}{r}9 \mathrm{gph} \\
0 \mathrm{wt} \% \mathrm{HNO}_{3}\end{array}$ & 86 & 15 & - & - \\
\hline \multicolumn{7}{|l|}{ Steps } \\
\hline Quench tower & & - & Calc'd & 10.6 & 0.002 & 0 \\
\hline Venturi & & - & Calc'd & 8.4 & 0.0036 & 0 \\
\hline Mist eliminator & & - & Calc'd & 8.2 & 0.025 & 12,000 \\
\hline Scrub tank & & - & Calc'd & 10.6 & - & 0 \\
\hline
\end{tabular}

Sources for input values:

(a) Offgas feed rate and composition and scrub flowrates: Drawing 453438, contained in INEEL/INT97-00992

(b) Pressures, entrainment fractions, duty of mist eliminator, and acid feed rate: R. E. Schindler, ASPEN Model of NWCF Scrub System, Schi-30-97, Dec. 8, 1997.

(c) Scrub compostions: Acid, nitrate and aluminum are averages from NWCF H-4 campaign, chloride and mercury are maximum values.

Additional runs were made to determine the sensitivity of the offgas chloride concentration to other parameters. Changing the rate of acid to the mist eliminator, over a range of 0 to $18 \mathrm{gph}$, had a negligible effect on chloride in the offgas. Decreasing the rates of scrub solution to the Quench Tower and Venturi Scrubber by $20 \%$ from the base case rates increased the chloride in the offgas to $40 \mathrm{ppmv}$. Increasing the rate of scrub solution to the Quench Tower and Verturi Scrubber decreased the chloride in the offgas. Reducing the amount of chlorides in the calciner offgas, even by a factor of 10 , had a negligible effect on the chloride concentration in the offgas. 


\section{Conclusions}

1. Scrub solution chloride concentrations can be maintained below a concentration of 5000 $\mathrm{mg} /$ liter when processing SBW in the NWCF

2. Chloride volatility at a calcination temperature of $600^{\circ} \mathrm{C}$ does not appear to be significantly greater than at $500^{\circ} \mathrm{C}$.

3. Minimal, if any, recycle of scrub solution to the tank farm will be required during processing of SBW in the NWCF because of chloride buildup. Recycle may be required because of mercury build-up.

4. Removal of chloride from the NWCF feed or scrub solution is not needed.

5. Chloride emissions will be well below the MACT limit during processing of SBW in the NWCF. 


\section{Appendix A. FY-97 \& -98 Pilot Calciner Chloride Volatility Data}

Table A1. FY-98 Pilot Calciner Chloride Volatility Results (from D. R. Marshall \& J. A.

Nenni, Calcination of WM-185 Waste, September, 1998, Table 16, p. 38).

\begin{tabular}{|c|c|c|c|c|c|c|}
\hline$\% \mathrm{Cl}$ of feed in: & $\begin{array}{c}\text { SBW-HT-7 } \\
\left(600^{\circ} \mathrm{C}\right)\end{array}$ & $\begin{array}{c}\text { SBW-HT-8 } \\
\left(550^{\circ} \mathrm{C}\right)\end{array}$ & $\begin{array}{l}E C 15-8 \\
\left(500^{\circ} \mathrm{C}\right)\end{array}$ & $\begin{array}{c}\text { SBW-HT-10 } \\
\left(600^{\circ} \mathrm{C}\right)\end{array}$ & $\begin{array}{c}\text { SBW-HT-11 } \\
\left(600^{\circ} \mathrm{C}\right)\end{array}$ & $\begin{array}{c}\text { SBW-HT-12 } \\
\left(600^{\circ} \mathrm{C}\right)\end{array}$ \\
\hline Calcined solids & 85.9 & 159.7 & 50.1 & 69.5 & 62.8 & 56.0 \\
\hline Product & 77.6 & 150.3 & 40.7 & 36.7 & 32.1 & 42.6 \\
\hline Fines & 8.3 & 9.4 & 9.4 & 32.8 & 30.6 & 13.4 \\
\hline Acid Scrub & \multirow{2}{*}{64.4} & \multirow{2}{*}{13.2} & 40.7 & 31.7 & 12.1 & 10.8 \\
\hline Condensate & & & 9.7 & 2.8 & 11.7 & 6.7 \\
\hline Recovered & 150.3 & 172.9 & 107.9 & 104.0 & 86.6 & 73.4 \\
\hline
\end{tabular}

Table A2. FY-97 Pilot Calciner Chloride Volatility Data (from J. A. Nenni and L. J. Young, Status Report for Alternative Calcination Scoping Tests, April, 1997, Table 14, p. 33)

\begin{tabular}{|l|c|c|c|c|}
\hline \multicolumn{1}{|c|}{$\%$ Cl of feed in: } & $\begin{array}{c}\text { SBW-BL-1 } \\
\left(500^{\circ} \mathrm{C}\right)\end{array}$ & $\begin{array}{c}\text { SBW-HT-1 } \\
\left(650^{\circ} \mathrm{C}\right)\end{array}$ & $\begin{array}{c}\text { SBW-HT-2 } \\
\left(600^{\circ} \mathrm{C}\right)\end{array}$ & $\begin{array}{c}\text { SBW-SA-1 } \\
\left(500^{\circ} \mathrm{C}, \text { sugar }\right)\end{array}$ \\
\hline Solids & 40.9 & 32.6 & 55.8 & 78.6 \\
\hline Solids not collected & 12.7 & 34.3 & 13.8 & 10.3 \\
\hline Fines carryover & 8.4 & 21.9 & 25.3 & 11.1 \\
\hline Volatilized & 38.0 & 11.2 & 5.1 & 0 \\
\hline
\end{tabular}

Table A3. FY-97 10-cm Calciner Pilot Plant Chloride Data as reported in H. Welland, NWCF Process Modification Sodium-Bearing Waste Project Conceptual Design, INEL/INT00075, April, 1997, Appendix B8, "Evaluation of Chloride Build Up in Scrub Solution and Deep Recycle Tanks.

\begin{tabular}{|c|c|c|c|c|}
\hline & SBW-BL-1 & SBW-HT-1 & SBW-HT-2 & SBW-SA-1 \\
\hline Temperature, oC & 500 & 650 & 600 & 500 \\
\hline Percent of total Cl from: & & & & \\
\hline Feed & 99 & 99.6 & 99.6 & 99.6 \\
\hline Starting bed & 1 & 0.4 & 0.4 & 0.4 \\
\hline Percent of total Cl in: & & & & \\
\hline Product & 13.1 & 15.6 & 41.7 & 26.7 \\
\hline Fines & 22.8 & 4.8 & 4.8 & 29.7 \\
\hline Cut zero product and \\
fines & 0.2 & 0.1 & 0.1 & 0 \\
\hline Final bed & 9.5 & 19.5 & 35.3 & 29.2 \\
\hline Total solids & $(45.6)$ & $(40.0)$ & $(81.9)$ & $(85.6)$ \\
\hline Acid scrub & 37.7 & $54.1 \mathrm{a}$ & 39.9 & 3.0 \\
\hline Condensate & 13.5 & 5.9 & 4.8 & 4.4 \\
\hline Total recovered & $96.8^{\circ}$ & $100.0^{\circ}$ & $126.6^{\circ}$ & $93.0^{\circ}$ \\
\hline
\end{tabular}

${ }^{a}$ Analysis for acid scrub not available, balance of $\mathrm{Cl}$ assumed in acid scrub

- Chloride distribution values are based on analytical results and were not normalized nor adjusted due to lack of material balance. 


\section{Appendix B. NWCF H-4 Campaign Scrub Solution Chloride Data}

NWCF Scrub Solution Concentration, 10/27/97-4/7/98

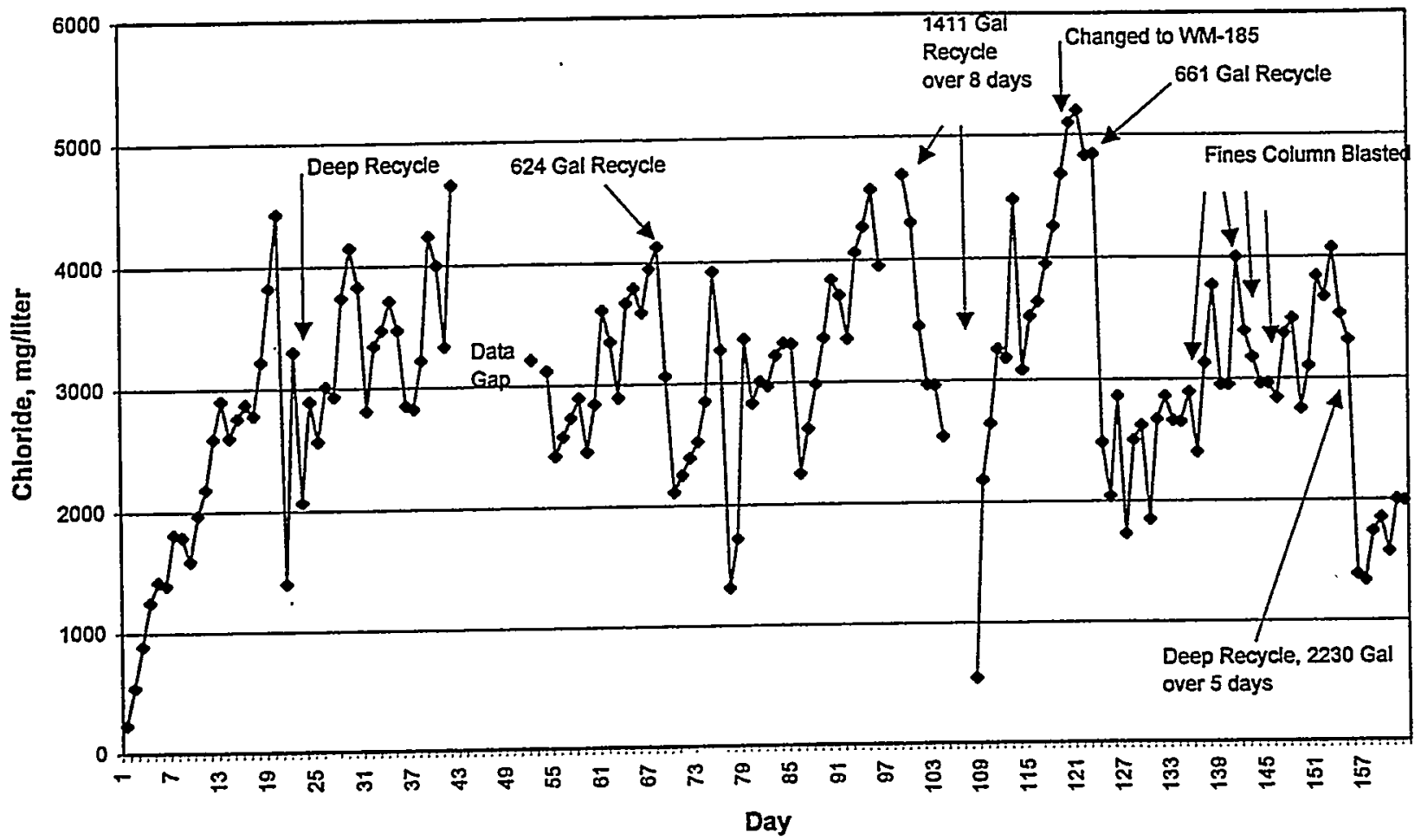




\section{Appendix C. NWCF H-4 Campaign Scrub Solution Mercury Data}

Hg Concentration in Scrub Solution, NWCF H-4 Campaign

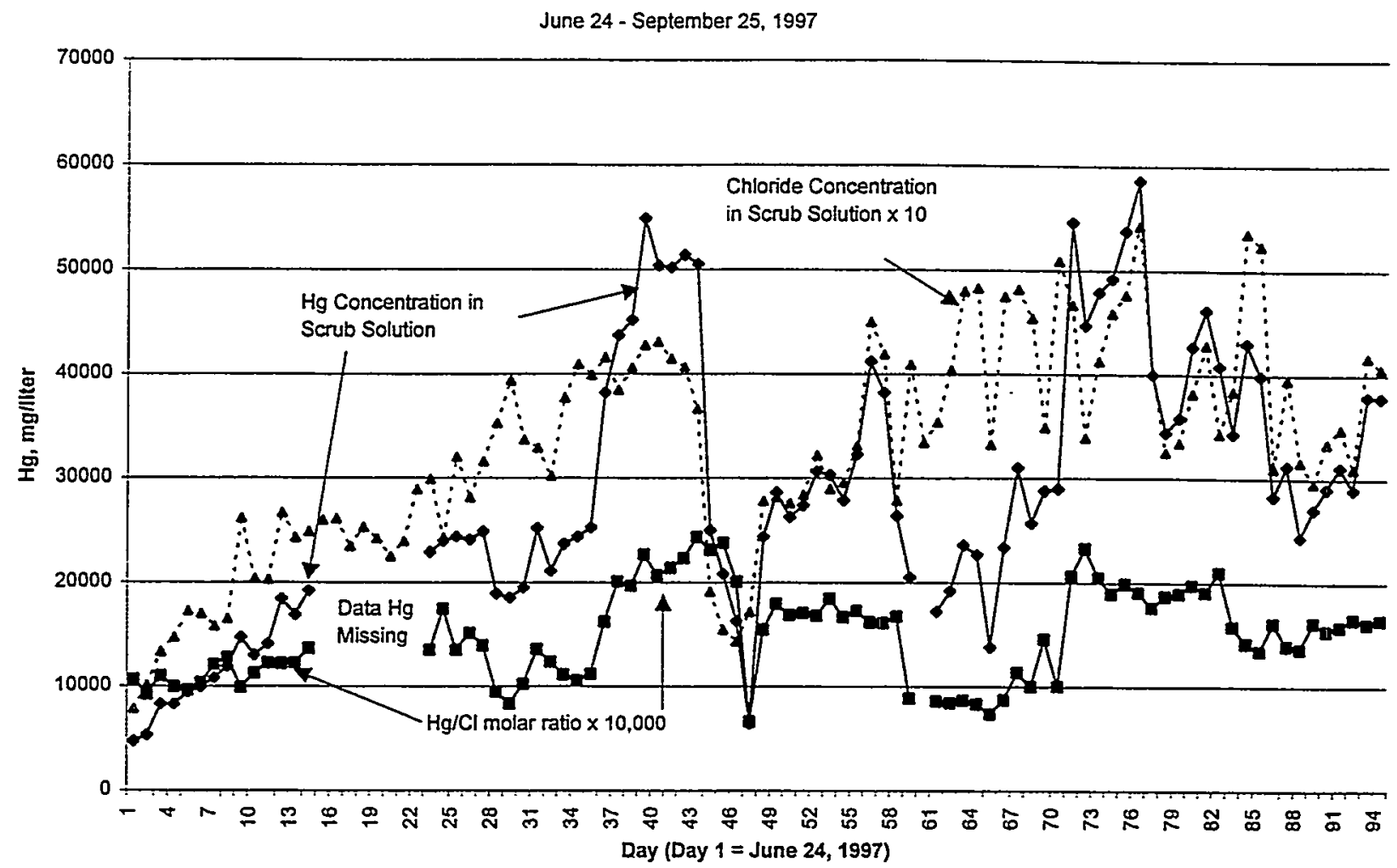

Hg Concentration in Scrub Solution, NWCF H-4 Campaign

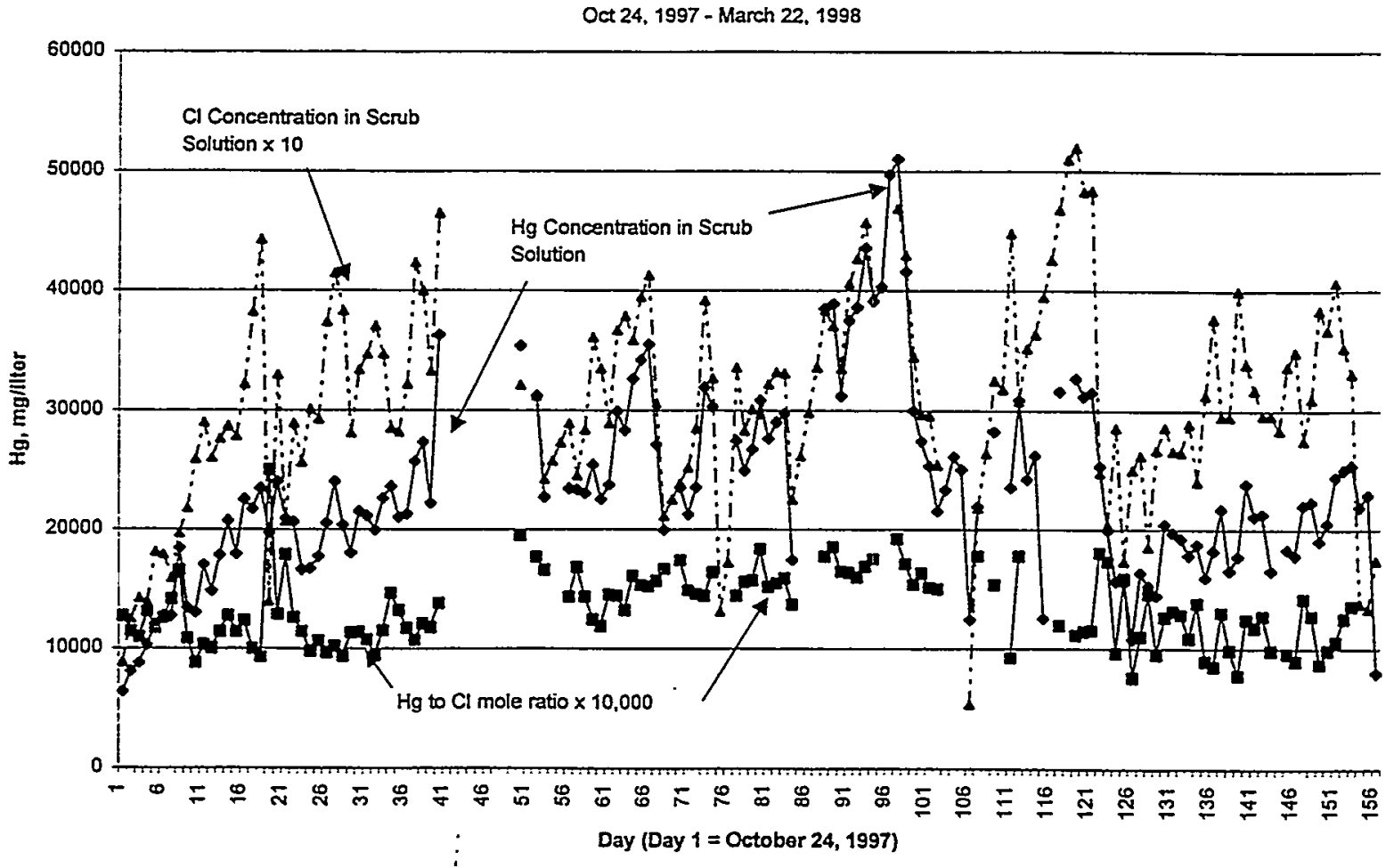

